TIAGO LOURENÇO DE LIMA TORQUATO

\title{
JERK COMO INDICADOR DE CONSISTÊNCIA GEOMÉTRICA PARA RODOVIAS
}

Tese apresentada à Escola de Engenharia de São Carlos da Universidade de São Paulo, como parte dos requisitos para a obtenção do título de Doutor em Ciências no Programa de Pós-Graduação em Engenharia de Transportes.

Área de concentração: Infraestrutura de Transportes.

Orientadora: Professora Associada Ana Paula Camargo Larocca

SÃO CARLOS

2019

EXEMPLAR DEFINITIVO (CORRIGIDO). EXEMPLAR ORIGINAL DISPONÍVEL NA CPG DA EESC-USP.

RESOLUÇÃO COPGR № 6018 
AUTORIZO A REPRODUÇÃO TOTAL OU PARCIAL DESTE TRABALHO, POR QUALQUER MEIO CONVENCIONAL OU ELETRÔNICO, PARA FINS DE ESTUDO E PESQUISA, DESDE QUE CITADA A FONTE.

Ficha catalográfica elaborada pela Biblioteca Prof. Dr. Sérgio Rodrigues Fontes da EESC/USP com os dados inseridos pelo(a) autor(a).

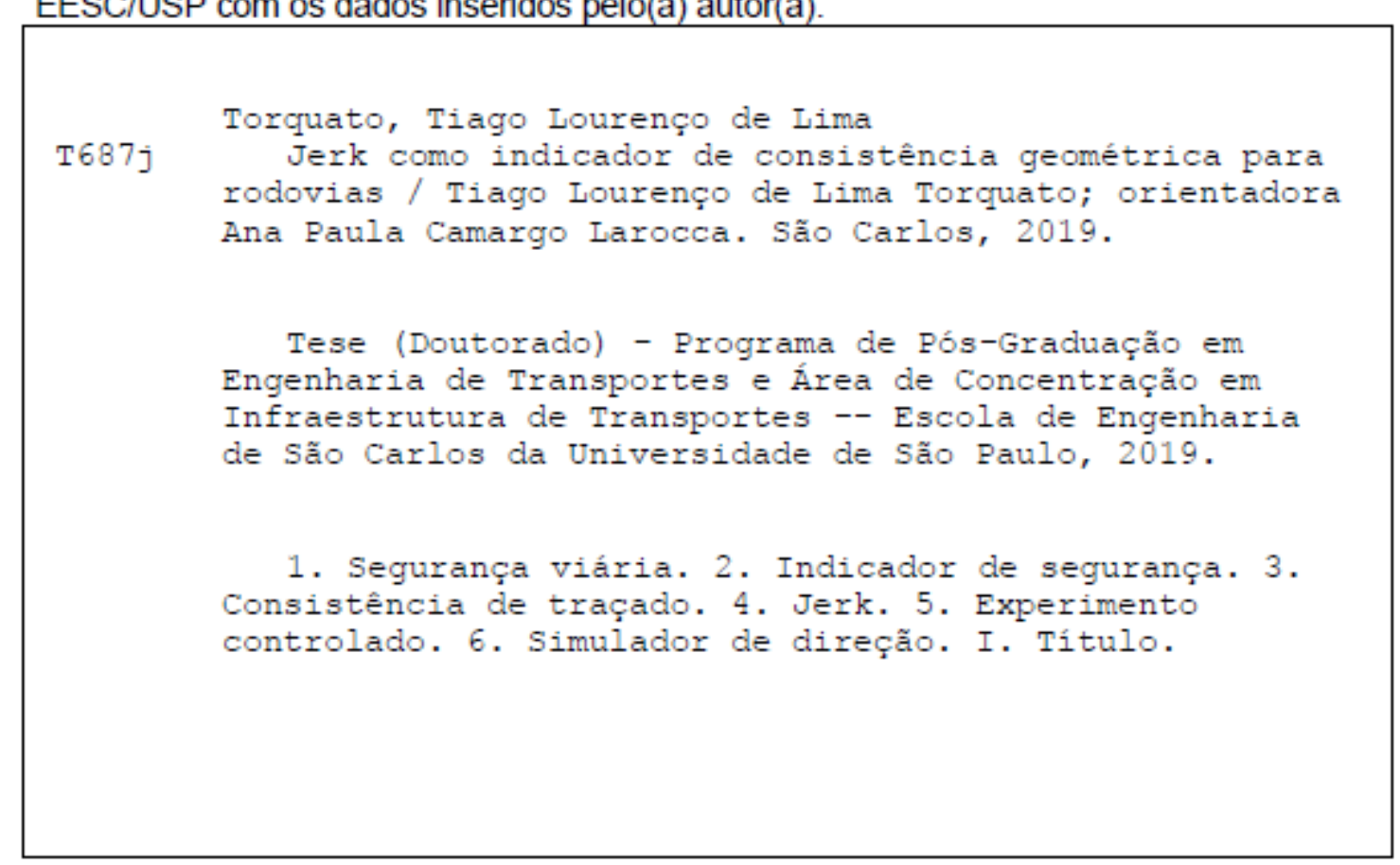

Eduardo Graziosi Silva - CRB - 8/8907 


\section{FOLHA DE JULGAMENTO}

Candidato: Engenheiro TIAGO LOURENÇO DE LIMA TORQUATO.

Título da tese: "Jerk como indicador de consistência geométrica para rodovias".

Data da defesa: 05/04/2019.

Comissão julgadora:

Resultado:

Profa. Associada Ana Paula Camargo Larocca (Orientadora)

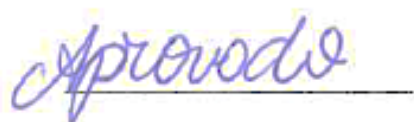

(Escola de Engenharia de São Carlos/EESC)

Prof. Dr. Daniel Sergio Presta Garcia

APROVA DO

(Universidade Federal do Rio Grande do Sul/UFRGS)

Prof. Dr. Felipe Issa Kabbach Junior

(Escola Politécnica/EP-USP)

Prof. Dr. Flávio José Craveiro Cunto

(Universidade Federal do Ceará/UFC)

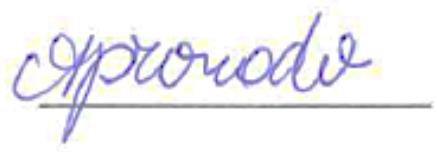

Prof. Dr. Jose Weissmann

(University of Texas)

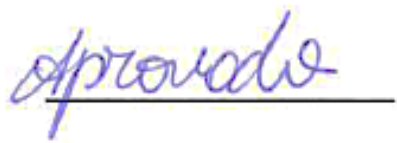

Coordenadora do Programa de Pós-Graduação em Engenharia de Transportes:

Profa. Associada Ana Paula Camargo Larocca

Presidente da Comissão de Pós-Graduação:

Prof. Titular Murilo Araujo Romero 

Este trabalho é dedicado ao amigo Vitor Hugo Rossi Faria de Souza (头 23/10/1987- † 22/08/2010) que teve sua rota encurtada por uma curva do caminho, assim como tantos outros brasileiros. 

Gostaria de agradecer a todos que possibilitaram essa experiência fabulosa de vida. A escrita científica não é famosa pelas adjetivações, porém adianto que esta sessão não se furtará de usálas de acordo com os sentimentos do pesquisador.

Primeiramente, gostaria de agradecer à minha orientadora Ana Paula. Mulher forte que, com sua coragem, acreditou no meu projeto, o que possibilitou chegarmos ao hoje.

Dando sequência às mulheres fortes que influenciaram minha vida. Obrigado, mãe Beranice. Sua força e perseverança fomentaram toda a minha formação. Gostaria de agradecer meu pai Mário, minha irmã Mariana, minha avó Belanizia e meu avô Orides. Mesmo sendo difícil explicar o trabalho acadêmico, vocês confiaram em mim.

Já que falei em academia, esse é o momento de agradecer aos docentes que me deram exemplos de integridade, consistência, alegria, interesse, dedicação, trabalho, paz, respeito, coração, comunhão e conhecimento. Lições de vida. Meu obrigado aos professores: Antônio Nelson, André, Cira, Manoel, Setti, Faxina, Furlan, Glauco, Leomar, Segantine e Irineu.

Mesmo que a pipoca tenha sido compartilhada menos vezes do que poderia ser, os funcionários nunca seriam esquecidos. Muito obrigado pelas conversas não tão somente acadêmicas: Paulo, João, Paulinho, Toco, Gigante, Benê, Ana, Sabrina, Beth, Heloísa, Samira e Sueli.

Finalmente, gostaria de agradecer aos amigos e colegas que facilitaram minha vida nesse período. Afinal, alguns passaram longas horas do dia comigo, com direito a almoço, jantar e muito mais. A fila começa com a terceira mulher forte dessa jornada, minha amiga Aurenice. Muito obrigado pelo engrandecimento proporcionado na minha vida. Gostaria de agradecer os amigos de sala: Bel, Fábio, Felipe, Gustavo, Luiz, Miguel, Paulo, Renaude e Zé Venâncio. Ainda aos "parças" do departamento: Alisson, Anthony, Elaine, Francisco, Sérgio, Piva e Thaís. E todos os outros amigos que esse período me proporcionou.

Finalmente, agradeço à quarta grande mulher dessa jornada, Daniela. Quem me deu a força que faltava para terminar esse trabalho. 

"Felicidade é a certeza de que a nossa vida não está se passando inutilmente."

(VERÍSSIMO, 2005, p. 230) 



\section{RESUMO}

TORQUATO, T. L. L. Jerk como Indicador de Consistência Geométrica para Rodovias. 2019. 243p. Tese (Doutorado). Escola de Engenharia de São Carlos, Universidade de São Paulo, São Carlos, 2019.

As ocorrências de trânsito são grandes causadoras de mortes tanto em países desenvolvidos como nos em desenvolvimento. Tradicionalmente, atribuiu-se aos condutores a maior parte da responsabilidade por esses registros, porém a repetição dos casos em regiões específicas nutriria a hipótese da existência de locais com maior risco. Entende-se que a identicação desses trechos teria importância fundamental na tentativa de mitigar esse problema grave. Já que essa possibilitaria maior eficiência na aplicação de medidas de segurança para reduzir as probabilidades, ou até a gravidade, das ocorrências. Essa tese teve o objetivo de investigar o uso da variável jerk (primeira derivada da aceleração no tempo) como indicadora de locais de risco de saídas de pista ocasionadas por falta de consistência geométrica entre as tangentes de aproximação e as curvas horizontais subsequentes. Para tanto, realizou-se um experimento controlado em simulador de direção de base fixa. Os resultados do trabalho mostraram que houve efeito significativo da variação das características geométricas no valor do jerk mínimo médio aplicado. Ainda houve correlação forte do indicador proposto com dois métodos tradicionais. Fomenta-se a continuação do desenvolvimento do uso do jerk mínimo como indicador de consistência geométrica para rodovias. Em tempos de Big Data e sensores espalhados pela população, o uso de uma variável de obtenção, aparentemente, simplificada possibilitaria o levantamento em tempo real de problemas de infraestrutura, como a inconsistência geométrica nas rodovias, com a contribuição dos próprios usuários.

Palavras-chave: Consistência de Traçado. Jerk. Experimento Controlado. Simulador de Direção. 



\begin{abstract}
TORQUATO, T. L. L. Jerk as a Road Geometric Consistency Indicator. 2019. 243p. Thesis (Ph.D.). São Carlos School of Engineering, University of São Paulo, São Carlos, 2019.

Traffic crashes are a major cause of death in both developed and developing countries. Traditionally, most of the responsibility for such records was attributed to drivers, but the repetition of the cases in specific regions would support the hypothesis of the existence of higher risk locations. In a general understanding, this identification would have a fundamental importance in attempting to mitigate this serious problem. Since this would allow greater efficiency in the application of safety measures to reduce the probabilities, or even the severity, of the occurrences. The aim of this thesis was to investigate the use of the jerk (the first derivative of acceleration in time) as an indicator of run-off-road risk locations caused by lack of geometric consistency between the approach tangents and the subsequent horizontal curves. For this purpose, a controlled experiment was carried out in a fixed-base driving simulator. The results of the research showed that there was a significant effect of the variation of the geometric characteristics in the value of the applied average minimum jerk. There was still a strong correlation between the proposed indicator with two traditional methods. The results would encourage the further development of the use of the minimum jerk as an indicator of geometric consistency for highways. In times of Big Data and sensors spread out throughout the population, the use of a seemingly simplified obtainable variable would allow the real-time survey of infrastructure problems, such as the geometric inconsistency of the roads, with the contribution of the users themselves.
\end{abstract}

Keywords: Geometric Consistency. Jerk. Controlled Experiment. Driving Simulator. 

Figura 1 - Evolução temporal das mortes e da mortalidade em rodovias federais brasileiras ..3

Figura 2 - Trecho estudado da BR-116. .4

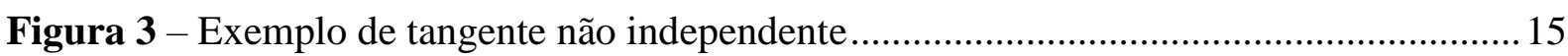

Figura 4 - Comparação dos métodos tradicionais...............................................................22

Figura 5 - Esquema dos jerks longitudinais, laterais e resultantes em um veículo em curva. 25

Figura 6 - Esquema da interface com o usuário do simulador utilizado na pesquisa ..............43

Figura 7 - Imagens do simulador utilizado na pesquisa.......................................................4

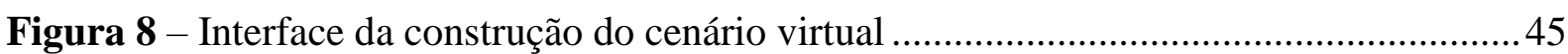

Figura 9 - Distribuição das ocorrências em função dos tipos e do traçado ...............................47

Figura 10 - Relações existentes entre os raios das curvas e as taxas de ocorrências................50

Figura 11 - Fluxograma da realização do experimento ..........................................................54

Figura 12 - Trecho do arquivo com formato pré-definido para entrada no programa ROD ..58

Figura 13 - Eixo da rodovia de acordo com as sequências de tratamentos .............................59

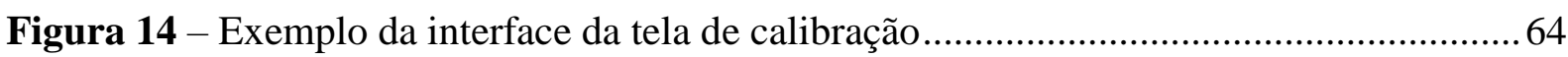

Figura 15 - Ambiente da simulação de direção de um condutor ................................................65

Figura 16 - Trecho de um arquivo exportado pelo VTD ........................................................66

Figura 17 - Dados de jerk, da energia da Wavelet, da velocidade do motor e detalhe............72

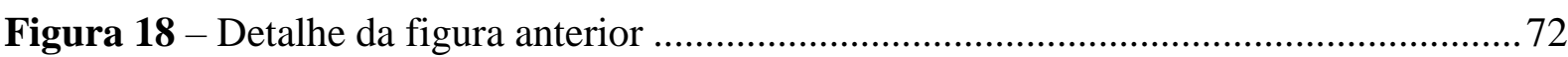

Figura 19 - Exemplo de respostas do experimento do condutor 3 no tratamento 6 …............73

Figura 20 - Exemplo de respostas do experimento do condutor 2 no tratamento 6 ................74

Figura 21 - Exemplo de respostas do experimento do condutor 26 no tratamento 6 ..............75

Figura 22 - Distribuição dos jerks mínimos encontrados ........................................................77

Figura 23 - Distribuição dos dos jerks mínimos encontrados.....................................................78

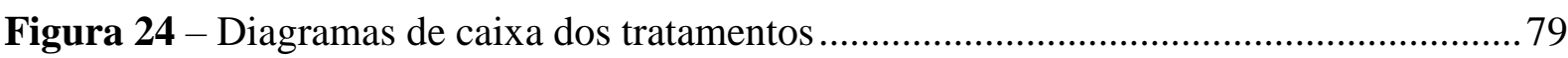

Figura 25 - Diagrama de barras de erros para os diferentes níveis da variável Raio................81

Figura 26 - Diagrama de barras de erros para os diferentes níveis da variável Tangente ........82

Figura 27 - Jerk médio para os diferentes níveis da combinação das variáveis estudadas..... 82

Figura 28 - Perfis de velocidades dos condutores no tratamento 1 ......................................... 84

Figura 29 - Perfis de velocidades dos condutores no tratamento 2 ......................................... 85

Figura 30 - Perfis de velocidades dos condutores no tratamento 3 ........................................... 85

Figura 31 - Perfis de velocidades dos condutores no tratamento 4 .......................................... 86

Figura 32 - Perfis de velocidades dos condutores no tratamento 5 ........................................... 86

Figura 33 - Perfis de velocidades dos condutores no tratamento 6 ........................................... 87 


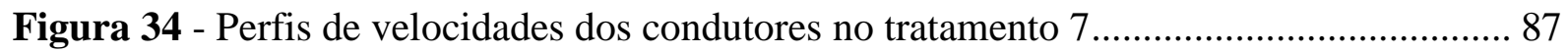

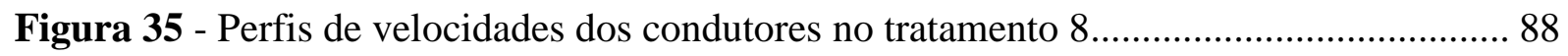

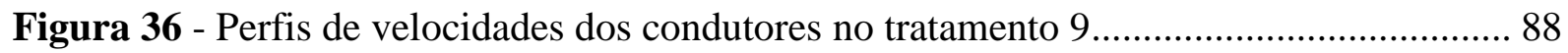

Figura 37 - Distribuição dos valores encontrados para a abordagem 85MSR..................... 101

Figura 38 - Distribuição dos valores encontrados para a abordagem 85MSR 60 ................... 102

Figura 39 - Dispersão dos pontos entre as respostas da abordagem 85MSR e da tese ........ 103

Figura 40 - Dispersão dos pontos por tratamento entre as abordagens 85MSR e da tese.... 104

Figura 41 - Dispersão dos pontos entre as respostas da abordagem 85MSR 60 e da tese ...... 104

Figura 42 - Dispersão dos pontos por tratamento entre as abordagens $85 \mathrm{MSR}_{60}$ e da tese.. 105

Figura 43 - Função de distribuição empírica cumulativa do jerk mínimo 85 ....................... 106

Figura 44 - Função de distribuição empírica cumulativa do 85MSR .................................. 107

Figura 45 - Função de distribuição empírica cumulativa do 85MSR60 ................................ 107

Figura 46 - Função de distribuição empírica cumulativa do $\Delta \mathrm{V}_{85}$ para o meio da curva ..... 108

Figura 47 - Função de distribuição empírica cumulativa do $\Delta \mathrm{V}_{85}$ para o meio da tangente 108

Figura 48 - Dispersão dos pontos entre as respostas da abordagem $\Delta \mathrm{V}_{85}$ e da tese ............ 111

Figura 49 - Dispersão dos pontos entre as respostas da abordagem $\Delta \mathrm{V}_{85}$ e da tese ............. 111 
Tabela 1 - Representatividade do transporte como causa de mortes no Brasil (em milhares) .2

Tabela 2 - Estimativa anual de mortos por distância percorrida. ... 4

Tabela 3 - Caracterização das ocorrências e mortes ocorridas no trecho ............................... 5

Tabela 4 - Distribuição geográfica das ocorrências ............................................................5

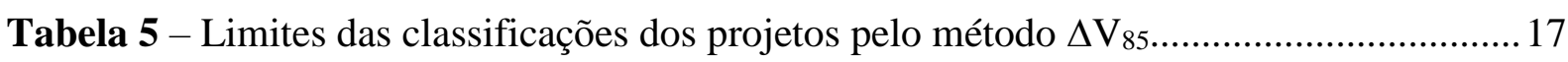

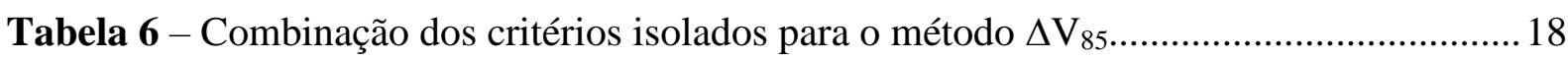

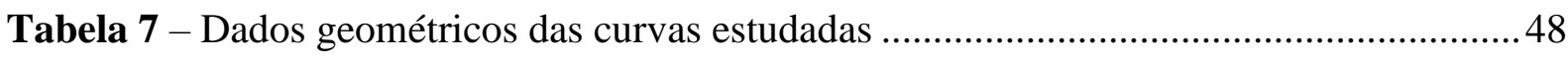

Tabela 8 - Distribuição das ocorrências em função da curva e do ano de registro ................. 49

Tabela 9 - Definição dos níveis dos fatores adotados .........................................................50

Tabela 10 - Definição dos tratamentos apresentados aos condutores ....................................51

Tabela 11 - Amostra em função do tamanho de efeito .........................................................53

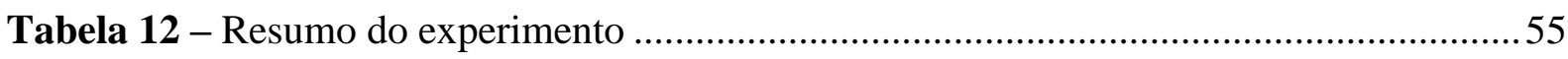

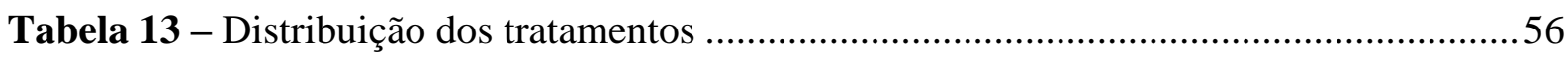

Tabela 14 - Características geométricas das curvas construídas...........................................56

Tabela 15 - Pontos de interesse exportados pelo AutoCAD Civil 3d...................................57

Tabela 16 - Atrito transversal disponível e solicitado no simulador.....................................59

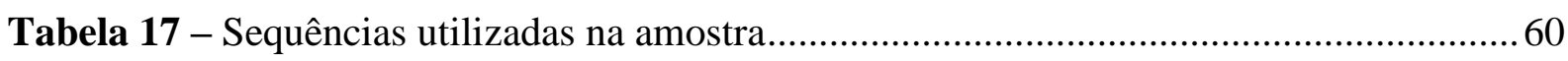

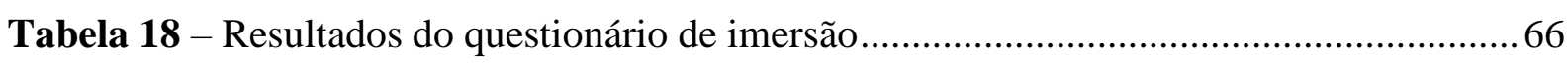

Tabela 19 - Arquivo adicional utilizado para a identificação dos tratamentos ....................... 70

Tabela 20 - Exemplo de cálculo dos valores de aceleração e de jerk ..................................... 71

Tabela 21 - Valores do jerk mínimo encontrados nos tratamentos ....................................... 76

Tabela 22 - Estatísticas descritivas e teste de normalidade do jerk para cada tratamento ...... 79

Tabela 23 - Diferenças de velocidade registradas no tratamento 1 ....................................... 90

Tabela 24 - Diferenças de velocidade registradas no tratamento 2 .................................... 91

Tabela 25 - Diferenças de velocidade registradas no tratamento 3 ...................................... 92

Tabela 26 - Diferenças de velocidade registradas no tratamento 4 ..................................... 93

Tabela 27 - Diferenças de velocidade registradas no tratamento 5 ...................................... 94

Tabela 28 - Diferenças de velocidade registradas no tratamento 6 .......................................95

Tabela 29 - Diferenças de velocidade registradas no tratamento 7 ...................................... 96

Tabela 30 - Diferenças de velocidade registradas no tratamento 8 ..................................... 97

Tabela 31 - Diferenças de velocidade registradas no tratamento 9 ....................................... 98

Tabela 32 - Diferenças de velocidade registradas nos tratamentos 1,2 e 3 .......................... 99

Tabela 33 - Diferenças de velocidade registradas nos tratamentos restantes ....................... 100 
Tabela 34 - Teste de normalidade para cada método em função do tratamento 102

Tabela 35 - Comparação dos valores encontrados 109

Tabela 36 - Correlações entre os métodos 110 


\section{SUMÁRIO}

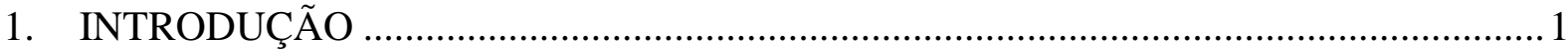

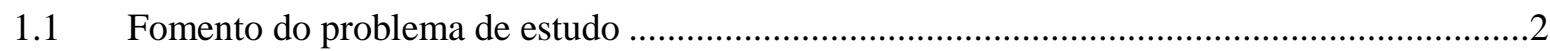

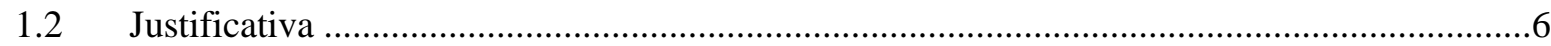

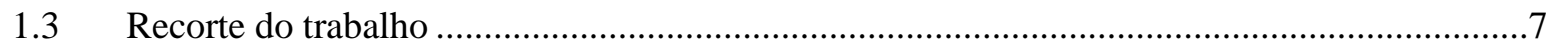

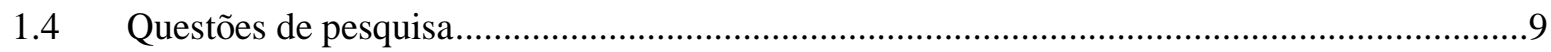

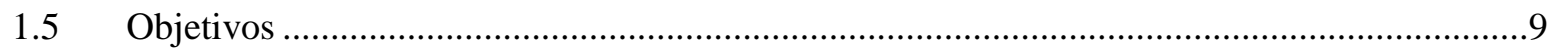

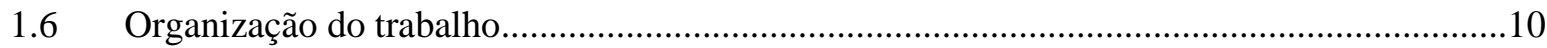

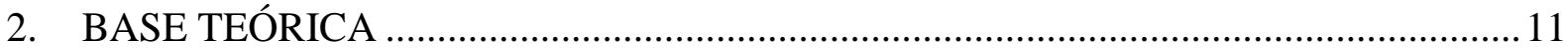

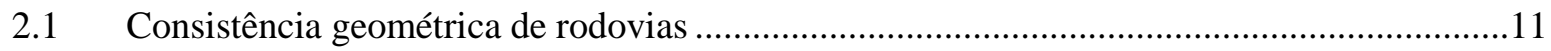

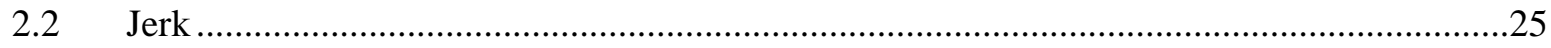

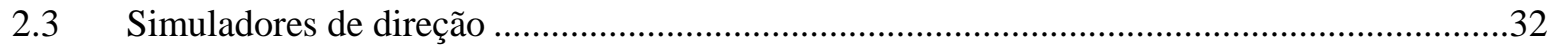

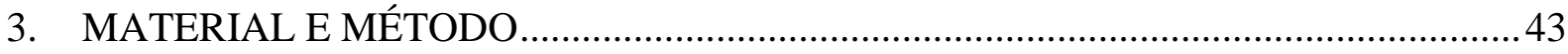

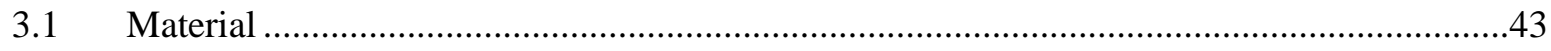

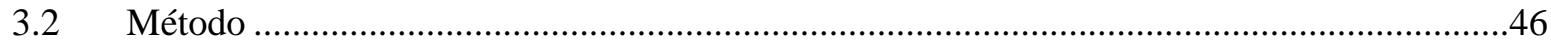

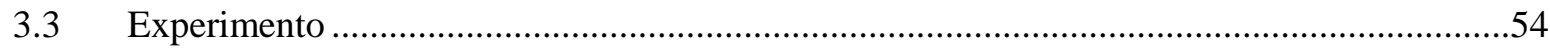

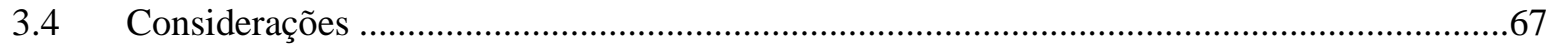

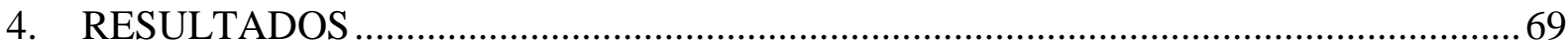

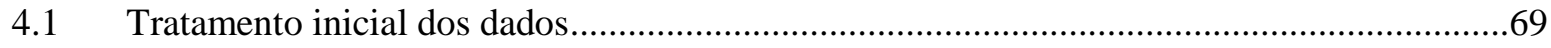

4.2 Avaliar a influência de características geométricas no jerk ..................................................77

4.3 Comparar as respostas do indicador proposto com métodos tradicionais ...............................84

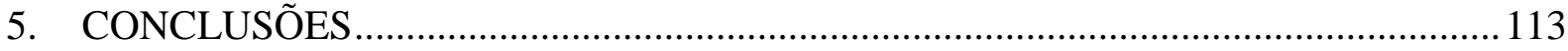

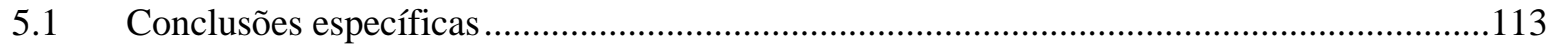

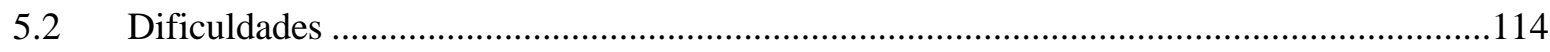

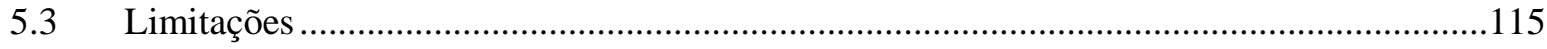

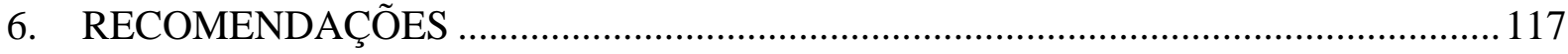

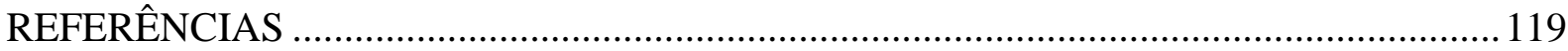

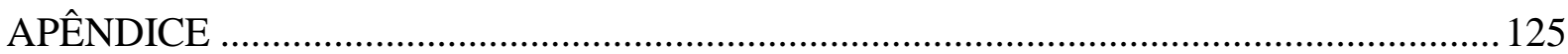

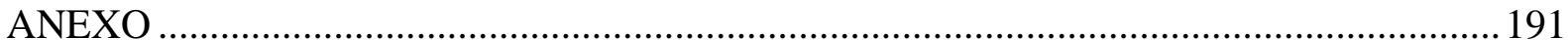





\section{INTRODUÇÃO}

A geração de conhecimento é um produto esperado de uma tese de doutorado.

"§ $2^{\circ}$ - Considera-se tese de Doutorado o texto resultante de trabalho supervisionado de investigação científica, tecnológica ou artística que represente contribuição original em pesquisa e inovação, visando desenvolvimento acadêmico ou profissional, de acordo com a natureza da área e os objetivos do curso" (FUNARO et al., 2016, p. 23).

Adjacente à pretensão científica da ampliação do conhecimento pelo conhecimento, coexiste a ambição de encontrar respostas para problemas cotidianos da sociedade. Porém, as tentativas em resolvê-los geram, naturalmente, mais questionamentos do que certezas. Uma experiência, que busque uma solução, poderá ser considerada de natureza científica se as alternativas levantadas puderem ser testadas e refutadas. Sempre com o esforço de se evitar "distorções convencionalistas", as quais podem surgir pelo apego às ideias iniciais (POPPER, 1980).

O propósito desse trabalho era contribuir com a segurança viária, área do conhecimento usualmente associada à Engenharia de Transportes, mas que permeia o cotidiano da população humana, seja em regiões mais desenvolvidas ou menos. A partir do desenvolvimento desse trabalho esperava-se colaborar, mais precisamente, com a identificação de regiões de transição entre tangentes de aproximação e curvas horizontais de rodovias rurais cujas combinações de características geométricas fomentassem o emprego de velocidades inadequadas pelos condutores que aumentariam a probabilidade do registro de ocorrências.

Neste texto, o termo "acidente" será substituído por "ocorrência". Essa sugestão de Honorato (2011) teria a finalidade de diminuir a tolerância que o termo tradicional daria para a remição da responsabilização pelos fatos. De maneira similar, na língua inglesa, foi aconselhada a substituição do termo "accident" por "crash" com o intuito de diminuir a noção de imprevisibilidade do evento e aumentar a busca por prevenção (SHINAR, 2017).

Para apontar essa falta de consistência geométrica entre elementos, optou-se por investigar o uso da variável jerk longitudinal (primeira derivada da aceleração pelo tempo no sentido da rodagem dos veículos). Para tanto, imaginou-se realizar um experimento controlado em simulador de direção estático. 


\subsection{Fomento do problema de estudo}

No ano 2000, as ocorrências de trânsito foram listadas como a décima primeira causa de mortes no planeta, com estimativas maiores que 1 milhão de casos. Em 2012, essa causa subiu duas posições no ranking geral, em função dos mais de 1,2 milhões de registros feitos no período (WHO, 2014). Se nenhuma medida efetiva fosse tomada, projetava-se que em 2030, os falecimentos decorrentes do trânsito subissem para a quinta posição da lista (WHO, 2015).

As ocorrências fatais causadas pelo trânsito são problemas enfrentados pela sociedade moderna, tanto em países ricos como nas regiões em desenvolvimento. Nos Estados Unidos, elas são consideradas como uma das maiores questões de segurança nacional. Os últimos anos apresentaram tendência de queda nos registros, mesmo assim, esses continuam a ultrapassar a barreira dos 30.000 casos anualmente. Para mudar essa realidade, a American Association of State Highway and Transportation Officials (AASTHO) adotou a Visão Zero em seus planos para, assim, tentar reduzir as fatalidades pela metade até 2030 (FHWA, 2013).

No Brasil, entre 2001 e 2010, as ocorrências devidas ao transporte terrestre foram responsáveis por 360,000 dos 10,374,096 óbitos registrados no Sistema de Informações sobre Mortalidade do departamento de informática do Sistema Único de Saúde do Brasil (DATASUS, 2018). A breve comparação do dados do DATASUS com os do World Health Organization (2014), permite pressupor que na realidade brasileira, as mortes resultantes do trânsito têm representatividade ligeiramente maior que no resto do mundo, $3.5 \%$ ante $2.3 \%$. A Tabela 1 apresenta a evolução temporal dos registros apresentados pelo DATASUS e a relação existente entre o número total de mortes e os causados pelo transporte terrestre, em milhares.

Tabela 1 - Representatividade do transporte como causa de mortes no Brasil (em milhares)

\begin{tabular}{lrrrrrrrrrrr}
\hline Mortes & $\mathbf{2 0 0 1}$ & $\mathbf{2 0 0 2}$ & $\mathbf{2 0 0 3}$ & $\mathbf{2 0 0 4}$ & $\mathbf{2 0 0 5}$ & $\mathbf{2 0 0 6}$ & $\mathbf{2 0 0 7}$ & $\mathbf{2 0 0 8}$ & $\mathbf{2 0 0 9}$ & $\mathbf{2 0 1 0}$ & Total \\
\hline Transporte (1) & 31 & 33 & 33 & 35 & 36 & 36 & 37 & 38 & 38 & 43 & 360 \\
Total (2) & 961 & 983 & 1002 & 1024 & 1007 & 1032 & 1048 & 1077 & 1103 & 1137 & 10374 \\
$(1) \div(2)$ & $3.2 \%$ & $3.3 \%$ & $3.3 \%$ & $3.4 \%$ & $3.6 \%$ & $3.5 \%$ & $3.6 \%$ & $3.6 \%$ & $3.4 \%$ & $3.8 \%$ & $3.5 \%$ \\
\hline
\end{tabular}

Fonte: (DATASUS, 2018)

Houve crescimento da representatividade do transporte no número total de mortes para o período apresentado. Ademais, imagina-se que os dados relativos ao transporte, retratavam apenas uma parcela do fenômeno, o que poderia aumentar sua representatividade como causa. 
Apenas nas rodovias federais brasileiras, registraram-se 82.561 mortes devidas às ocorrências de trânsito entre janeiro de 2007 e novembro de 2017. Houve, a partir de 2012, uma queda no número absoluto de falecimentos, porém, a taxa de mortalidade aumentou, como mostra a Figura 1. Essas ocorrências foram registradas com maior frequência em ambiente rural e nos trechos em tangente. Todavia, as curvas tiveram maiores taxas de mortalidade, 58 mortes a cada 1,000 ocorrências, em comparação com os trechos de reta, 51 mortes a cada 1,000 ocorrências (DPRF, 2018).

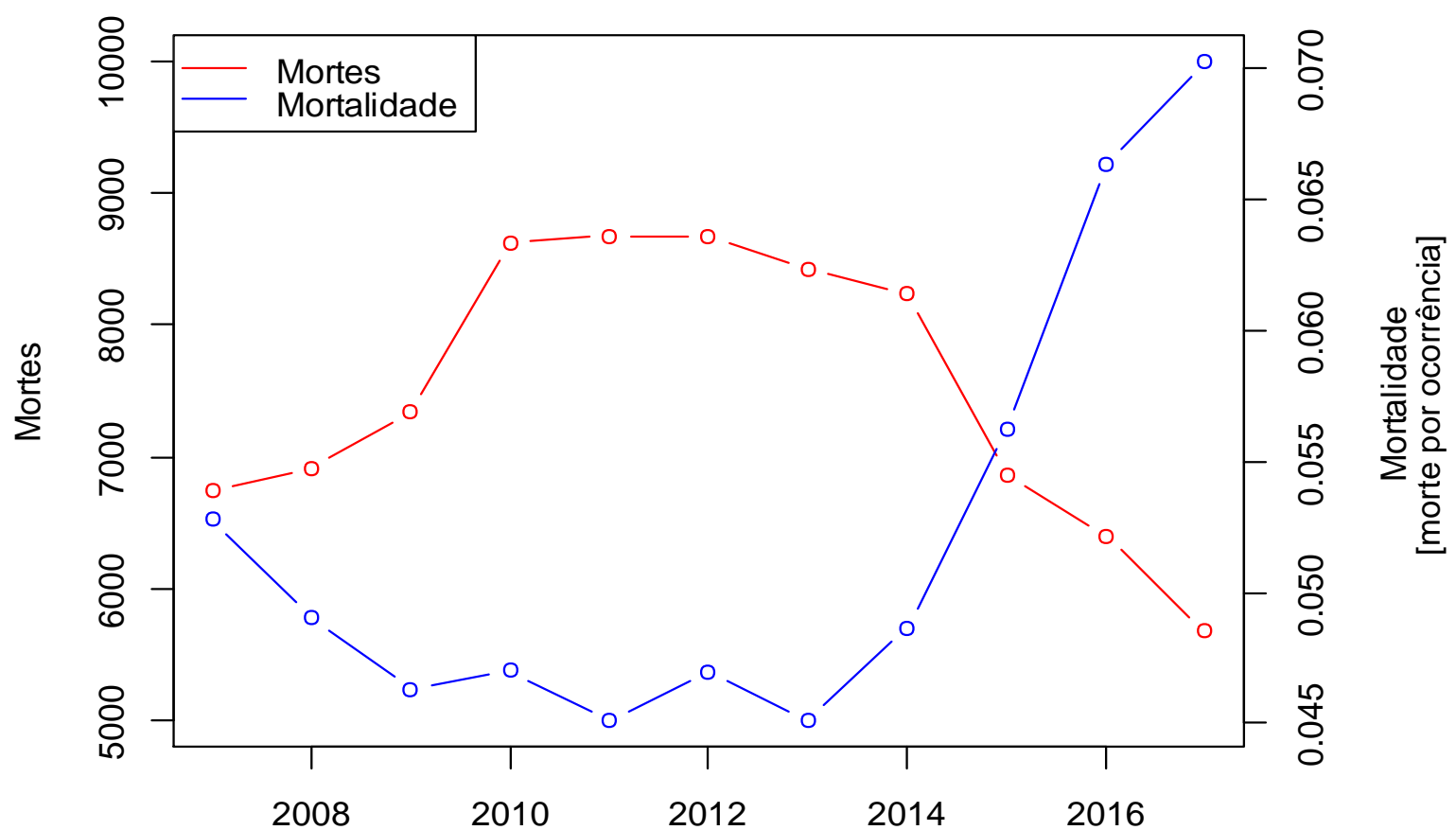

Figura 1 - Evolução temporal das mortes e da mortalidade em rodovias federais brasileiras Fonte: (DPRF, 2018)

Dentre as rodovias federais, a BR-116 é uma importante ligação que cruza o Brasil verticalmente. Ela passa pelos estados de São Paulo, Paraná e Santa Catarina, e tem extensão total de 496 quilômetros. Como registra muitas ocorrências graves, essa também é conhecida como "Rodovia da Morte".

O trecho dessa rodovia compreendido entre o $\mathrm{km} 500$ e o $\mathrm{km} 540$, entre agosto de 2008 e julho de 2016, registrou 5.412 ocorrências, que acabou por provocar 95 mortes. Essa região, Figura 2, faz parte da conexão existente entre São Paulo - população estimada de 12.1 milhões de habitantes - e Curitiba - população estimada de 1.9 milhões de habitantes (Instituto Brasileiro De Geografia E Estatística, 2017). 


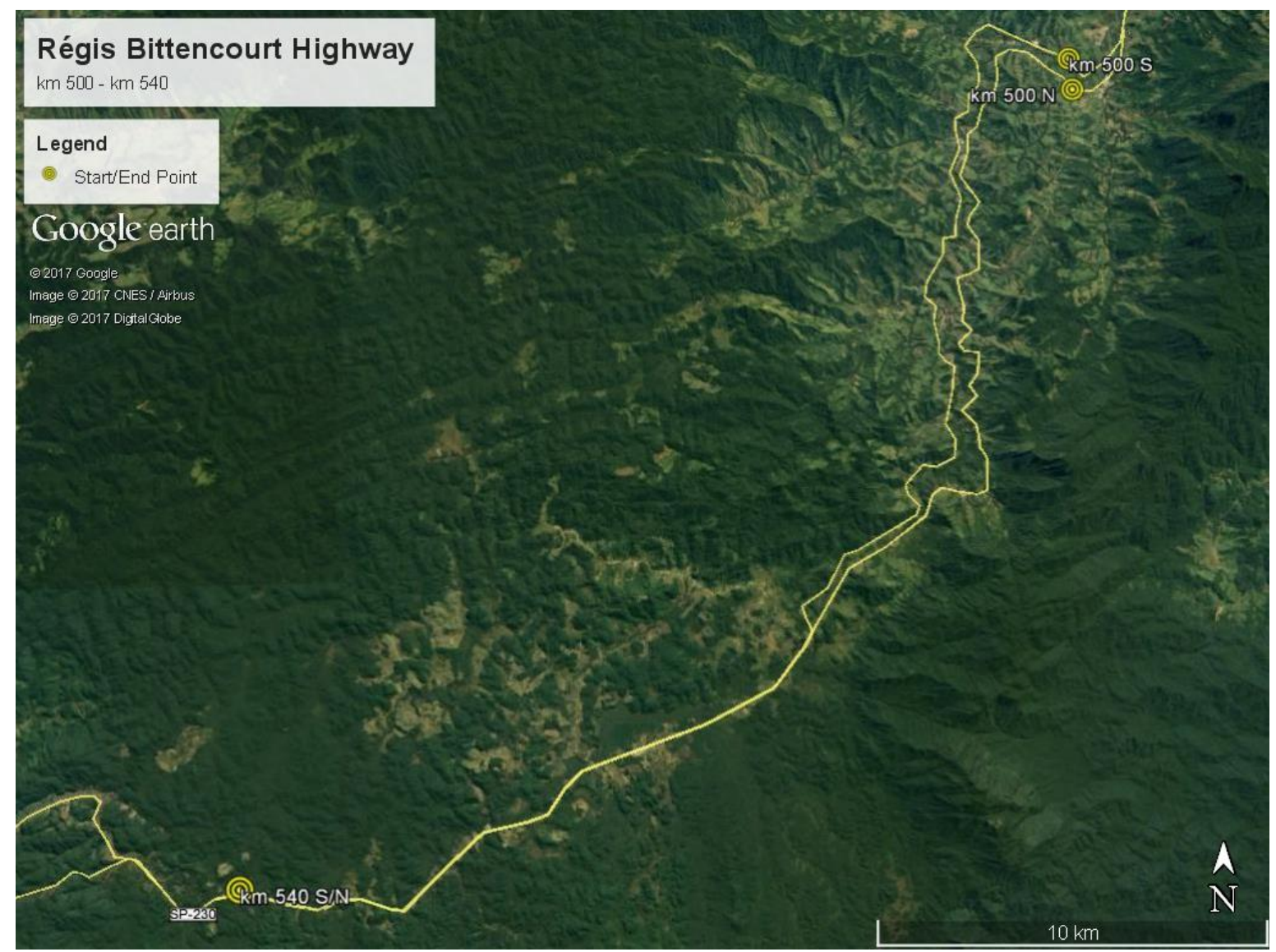

Figura 2 - Trecho estudado da BR-116

Fonte: (GOOGLE, 2017)

A Tabela 2 apresenta uma estimativa do número de ocorrências e de mortes por veículoquilômetro rodado (SHINAR, 2017) desse trecho. A coluna "Veículos" apresenta o total de veículos que passaram, em ambas direções, pelo pedágio mais próximo do trecho, localizado no quilômetro 485.7 (ANTT, 2017). Com a adoção da distância de 40 quilômetros por veículo, a "Distância Total” viajada, em bilhões de quilômetros por ano, foi estimada.

Tabela 2 - Estimativa anual de mortos por distância percorrida

\begin{tabular}{|c|c|c|c|c|c|c|}
\hline \multirow{2}{*}{ Ano } & \multirow{2}{*}{ Veículos } & \multirow{2}{*}{$\begin{array}{c}\text { Distância } \\
{\left[10^{9} \mathrm{~km}\right]} \\
\end{array}$} & \multirow{2}{*}{ Mortes } & \multirow{2}{*}{ Ocorrências } & \multirow{2}{*}{$\begin{array}{c}\text { Ocorrências por distância } \\
\left.\text { [ocorrências } / 10^{6} \mathrm{~km}\right]\end{array}$} & \multirow{2}{*}{$\frac{\text { Mortes por distância }}{\left[\text { mortes } / 10^{9} \mathrm{~km}\right]}$} \\
\hline & & & & & & \\
\hline 2009 & $6,940,632$ & 0.278 & 14 & 801 & 2.89 & 50 \\
\hline 2010 & $7,702,650$ & 0.308 & 16 & 896 & 2.91 & 52 \\
\hline 2011 & $7,996,657$ & 0.320 & 11 & 875 & 2.73 & 34 \\
\hline 2012 & $8,253,314$ & 0.330 & 17 & 730 & 2.21 & 51 \\
\hline 2013 & $8,490,129$ & 0.340 & 14 & 613 & 1.80 & 41 \\
\hline
\end{tabular}

Com pelo menos 34 mortes por bilhão de quilômetros viajado por ano, a segurança desse segmento poderia ser considerada pobre, muito pior que a não boa taxa média de 7 mortes por bilhão de quilômetros viajados observada nos Estados Unidos em 2015 (NHTSA, 2017). 
O número de ocorrências por milhão de quilômetros viajados por ano ficou, na maioria dos anos, acima do valor estipulado por Choueiri et al. (1994), que propuseram um limite de 2 ocorrências por milhão de quilômetros viajado como ponto de separação entre a segurança e a insegurança de tráfego.

Na região, apesar de grande parte das mortes serem consequência de tombamentos (Tabela 3), a maioria das ocorrências foram do tipo saída de pista. Ademais, 907 dessas saídas foram identificadas como veículos leves que escaparam em curvas fechadas.

Tabela 3 - Caracterização das ocorrências e mortes ocorridas no trecho

\begin{tabular}{lrrrr}
\hline \multicolumn{1}{c}{ Tipo } & Ocorrências [1] & \% de [1] & Ocorrências fatais [2] & \% de [2] \\
\hline Colisão com objeto fixo & 916 & $17 \%$ & 6 & $6 \%$ \\
Queda de motocicleta & 97 & $2 \%$ & 3 & $3 \%$ \\
Outro & 600 & $10 \%$ & 17 & $18 \%$ \\
Atropelamento & 24 & $0 \%$ & 15 & $16 \%$ \\
Colisão traseira & 467 & $9 \%$ & 10 & $11 \%$ \\
Capotamento & 718 & $13 \%$ & 11 & $12 \%$ \\
Saída de pista & 1,738 & $\mathbf{3 2 \%}$ & 8 & $8 \%$ \\
Tombamento & 647 & $12 \%$ & 25 & $\mathbf{2 6 \%}$ \\
\hline
\end{tabular}

A Tabela 4 apresenta, em segmentos de 10 quilômetros, as características geométricas, as ocorrências e mortes registradas nessa localidade no mesmo período mencionado anteriormente; essa caracterização segue o método proposto por Haynes et al. (2008). Pelo método sugerido, a densidade de curvas foi calculada a partir da divisão do número de curvas pela extensão do trecho; e o ângulo médio resultou da soma de todas as deflexões das curvas divididida pelo total de curvas.

Tabela 4 - Distribuição geográfica das ocorrências

\begin{tabular}{clrrrrrrrr}
\hline \multirow{2}{*}{ Segmento } & \multirow{2}{*}{ Direção } & \multirow{2}{*}{ Ocorrências } & \multirow{2}{*}{ Mortes } & \multicolumn{2}{c}{ Extensão } & \multirow{2}{*}{ Curvas } & \multicolumn{2}{c}{$\begin{array}{c}\text { Densidade } \\
\text { de curvas }\end{array}$} & \multicolumn{2}{c}{ Angulo médio } \\
\hline \multirow{2}{*}{$500-509$} & Norte & 366 & 11 & 9,056 & 14 & 0.0015 & 55 \\
& Sul & 542 & 10 & 9,759 & 18 & 0.0018 & 60 \\
\hline \multirow{2}{*}{$\mathbf{5 1 0}-\mathbf{5 1 9}$} & Norte & $\mathbf{2 , 2 1 8}$ & $\mathbf{4 2}$ & 10,161 & 26 & $\mathbf{0 . 0 0 2 6}$ & $\mathbf{6 4}$ \\
& Sul & $\mathbf{7 9 1}$ & $\mathbf{6}$ & 9,698 & 20 & $\mathbf{0 . 0 0 2 1}$ & $\mathbf{5 3}$ \\
\hline \multirow{2}{*}{$520-529$} & Norte & 169 & 9 & 9,128 & 7 & 0.0008 & 24 \\
& Sul & 583 & 8 & 9,662 & 8 & 0.0008 & 46 \\
\hline \multirow{2}{*}{$530-539$} & Norte & 183 & 4 & 9,682 & 8 & 0.0008 & 45 \\
& Sul & 560 & 5 & 9,666 & 10 & 0.0010 & 33 \\
\hline
\end{tabular}


O segmento "510 - 519", o qual obteve os maiores valores tanto de densidade de curvas como de ângulos médios, registrou também a maior parte das ocorrências e mortes. A diferença entre as duas direções era a inclinação do greide. Condutores que transitavam na direção norte experimentavam trechos em declive, enquanto que os que trafegavam para o sul experimentavam aclives.

Nesse setor as vias tinham três faixas de rodagem em cada sentido, com total separação de fluxos. Ainda assim, o limite de velocidade apresentado em sinalizações verticais era de $80 \mathrm{~km} / \mathrm{h}$. A explicação para essa discordância poderia ser o caráter montanhoso do trecho e a pequena dimensão dos raios das curvas, as quais partiam de 125 metros de comprimento.

Essa divergência entre o número de faixas e a velocidade limite afixada poderia colaborar para a menor segurança do trecho. Características de projetos mais elevados, como faixas mais largas, menor tráfego, entre outros, fomentariam o emprego de velocidades maiores, o que resultaria em uma maior probabilidade de ocorrências (CHOUEIRI et al., 1994).

Um trecho como o apresentado, impulsionaria os registros ao unir a impressão sugerida pela seção transversal diferente da limitação imposta pelo projeto horizontal, um exemplo de inconsistência. Esse fenômeno poderia ser a consequência de um melhoramento na seção transversal, sem a melhoria do alinhamento horizontal. A seção transversal seria mais aparente ao condutor, assim, uma mensagem errada poderia ser emitida, o que fomentaria velocidades operacionais maiores do que as de projeto (LAMM; SMITH, 1994).

\subsection{Justificativa}

Para melhorar a segurança de tráfego no Brasil, que agrega expressivos números de ocorrências de trânsito, se faz necessária a melhoria na catalogação dos registros. Essa deveria ser realizada de modo mais contínuo, mais preciso e mais transparente para a população. Assim, o investimento em infraestrutura, em educação e em fiscalização poderia ter sua efetividade potencializada.

Tão importante quanto o registro das ocorrências, seria o rastreamento prévio de pontos de maior risco. A rede rodoviária brasileira é extensa e a espera por ações governamentais poderia agravar a situação atual. 
A proliferação dos smartphones e de seus sensores, pela população, teria potencial para alimentar uma base alternativa. Esperava-se que até o final de 2017, o Brasil alcançasse a marca de um aparelho por pessoa (CAPELAS, 2017). Evidentemente, essa média não significaria a abrangência total da população, mas poderia indicar o aumento do acesso. O emprego desses sistemas possibilitaria a contribuição popular para levantar defeitos existentes em rodovias e, principalmente, daria suporte para manifestações por melhorias. $\mathrm{O}$ efeito da sensação de pertencimento poderia ainda fomentar mudanças de comportamento na condução.

Porém, a depender do método escolhido para efetuar esses registros, as informações colaborativas criariam bancos de dados de tamanho significativo, que além de utilizar grande parte do desempenho dos aparelhos dos usuários, também aumentaria o tempo da análise posterior. Para não incorrer nessas dificuldades seria necessário adotar um indicador que, com o menor número de registros possível, conseguisse levantar potenciais locais de risco. Sempre com o interesse em minimizar falsas indicações positivas.

Justifica-se assim a investigação do uso de um indicador que fosse capaz de identificar pontos rodoviários com inconsistência geométrica a partir de uma variável que pudesse ser obtida por dispositivos móveis a fim de aumentar o poder de previsão das ocorrências de trânsito e contribuir com a segurança viária.

\subsection{Recorte do trabalho}

Existiriam variados tipos de ocorrências de trânsito e possibilidades de indicadores. Uma tentativa de desenvolver um método que generalizasse todas as soluções pareceria improvável ou singela. Para tanto, optou-se por estudar um tipo de ocorrência e um indicador.

Com relação ao tipo de ocorrência, elegeram-se as saídas de pista de rodovias rurais como o fenômeno de estudo, haja visto a grande representatividade dessas na região estudada inicialmente (apresentada no item anterior). Com ênfase naquelas ocasionadas, provavelmente, por velocidades inadequadas na transição de trechos de tangente para curvas (inconsistência geométrica).

As curvas são elementos cruciais para a segurança das rodovias, esses elementos registram muitas ocorrências de trânsito. Esses eventos não têm tratamento trivial, eles seguem uma distribuição rara, nem sempre são bem registrados, têm alta mortalidade e não são novos. 
Glennon, Neuman e Leisch (1983) faziam essas ressalvas desde a década de 1980. Eles apontavam ainda o maior risco existente nas curvas em comparação com as tangentes e clamavam por maior enfoque na análise das ocorrências do tipo saídas de pista.

Tradicionalmente, as ocorrências se agrupavam perto das curvas, principalmente das mais acentuadas. Quando essas surgiam após tangentes longas, as saídas de pista se tornavam mais frequentes. Ademais, a sinergia da sucessão dessas mudanças no alinhamento também teria efeitos na segurança. Uma curva isolada, com raio pequeno, poderia ser mais perigosa que uma sequência de curvas com raios mais compatíveis (CHOUEIRI et al., 1994).

Em 2002, 76\% das ocorrências fatais americanas, que aconteceram em curvas, foram identificadas como saídas de pista. Usualmente, essas mortes eram decorrência do escape de um veículo leve isolado que, ao ultrapassar os limites da faixa de rolagem, colidiam com objetos fixos ou capotavam. Muitas estratégias para mitigar esse tipo de ocorrência estavam relacionadas com tratamentos para curvas horizontais (TORBIC et al., 2004).

A Federal Highway Administration (FHWA) desenvolveu um plano estratégico voltado para a redução das saídas de pista, as quais representavam mais da metade das ocorrências de trânsito americanas com morte entre 2004 e 2009 (FHWA, 2013). Outra pesquisa estadunidense National Motor Vehicle Crash Causation Survey (NMVCCS) - mostrou que, entre 2005 e 2007, os erros de decisão, como a velocidade inadequada de entrada nas curvas, representariam $25.4 \%$ dos eventos que antecediam as saídas de pista (LIU; YE, 2011).

Parte desses erros poderia ser aliviado se a geometria da via tivesse mais consistência, se as escolhas de comprimentos de tangentes e de raios promovessem traçados com mudanças menos bruscas (LAMM; SMITH, 1994), os quais não causariam surpresas na condução. As curvas horizontais que obrigariam os condutores a fazerem maiores reduções de velocidade provavelmente registrariam maiores taxas de ocorrências (ANDERSON et al., 1999).

Já com relação ao indicador, optou-se por estudar o uso da varíavel jerk longitudinal. Tal medida física representaria a variação da aceleração no tempo (terceira derivada da posição com relação ao tempo). Tradicionalmente, como o capítulo de revisão abordará, utilizou-se as diferenças de velocidade para quantificar problemas de consistência no traçado. Esses métodos demandavam registros contínuos de dados e pós-processamento para levantar pontos críticos. 
A hipótese principal de trabalho era de que o uso da varíavel jerk longitudinal possibilitaria exprimir, com menos dados coletados e instantaneamente, as mudanças de comportamento dos condutores com relação quando esses passavam de trechos de tangente para as curvas horizontais. Essa variável já fora avaliada para outras situações de estudo (estudos naturalísticos para levantamento de comportamentos de direção, os quais serão apresentados no próximo capítulo). Os resultados desses trabalhos mostraram melhores taxa de acerto a partir do uso dessa variável do que o uso das desacelerações por si só, por exemplo.

\subsection{Questões de pesquisa}

Diante do recorte do problema feito, algumas questões foram levantadas a fim de investigar o uso do jerk como indicador de consistência geométrica:

- O valor médio do jerk longitunal aplicado por uma amostra de condutores sofreria influência de diferentes combinações geométricas? Ou seja, os valores encontrados estariam relacionados com as características geométricas da via ou representariam uma resposta aleatória.

- Como o valor registrado do jerk longitudinal se compararia com os métodos tradicionais para avaliar a consistência geométrica de trechos? Eles apontariam os mesmos resultados ou apontariam de forma diferente trechos consistentes ou inconsistentes.

Com o intuito de responder essas perguntas, elencou-se um conjunto de objetivos para a realização desse trabalho.

\subsection{Objetivos}

O objetivo geral deste estudo era investigar o uso da variável jerk como indicadora da consistência geométrica de rodovias. Para atingir o objetivo geral desse trabalho, um experimento em simulador de direção foi desenvolvido. Para tanto, objetivos específicos foram determinados na tentativa de otimizar a separação de tarefas para a apresentação do trabalho:

- Avaliar a influência de características geométricas no jerk longitudinal;

- Comparar as respostas do indicador proposto com métodos tradicionais. 


\subsection{Organização do trabalho}

$\mathrm{O}$ trabalho está dividido em seis capítulos. O primeiro recortou o tema estudado. O segundo apresenta a revisão bibliográfica que serviu de base para o desenvolvimento do mesmo. $\mathrm{O}$ terceiro capítulo traz os materiais e métodos adotados. Os resultados estão apresentados no quarto capítulo. O capítulo cinco relaciona as conclusões suportadas pelos resultados apresentados, bem como os limites e dificuldades encontrados na realização do trabalho. E, o último capítulo apresenta sugestões de trabalhos futuros. No final, estão apresentadas as referências, apêndices e anexos. 


\section{BASE TEÓRICA}

Essa revisão foi construída a fim de melhor conceituar os assuntos necessários para o desenvolvimento do método utilizado, para assim, possibilitar uma análise adequada dos resultados e permitir tecer conclusões razoáveis a cerca dos objetivos propostos.

O objetivo desse trabalho é investigar o uso da variável jerk como indicadora da consistência geométrica de rodovias. Além disso, optou-se pela utilização de um simulador de direção estático como ferramenta para essa finalidade. Afinal, uma das finalidades dessa ferramenta seria estimar parâmetros para propor novos dispositivos ou métodos (DAWSON, 2011). Assim, os estudos melhor aprofundados nesse capítulo versarão sobre: consistência geométrica de rodovias, o uso da variável jerk e simuladores de direção.

\subsection{Consistência geométrica de rodovias}

Tradicionalmente, ao se projetar uma rodovia, adotar-se-ia uma velocidade de projeto, a qual garantiria a estabilidade dinâmica dos veículos (CHOUEIRI et al., 1994). Essa determinação guiaria a escolha de outras características da via, como os raios mínimos das curvas horizontais, as taxas máximas de superelevação e as distâncias de visibilidade (LAMM; CHOUEIRI, 1987; DER-SP, 2005). Depois de aberta ao tráfego, essa rodovia registraria, em função de especificidades locais, diferentes velocidades de operação, as quais não deveriam superar os limites máximos regulamentados. Essas três grandezas poderiam ser melhor definidas como:

- Velocidade de projeto $\left(\mathrm{V}_{\mathrm{d}}\right)$ : valor utilizado para projetar as características da rodovia a fim de permitir segurança e conforto para os usuários;

- Velocidade de operação $\left(\mathrm{V}_{85}\right)$ : reflexo da utilização pelo público, sua determinação partiria do pressuposto que essa não deveria ser superada por $85 \%$ dos condutores em um trecho da rodovia;

- Velocidade máxima permitida: valor limite regulamentado para um trecho da rodovia.

Esse procedimento de projeto, adotado desde 1930, subestimaria a possibilidade de as velocidades operacionais serem maiores que as de projeto. O risco dessa omissão, bem como a adição da análise do comportamento dos condutores na avaliação dos projetos, foram aventadas a partir de 1970 (SHINAR; ROCKWELL; MALECKI, 1980; LAMM; CHOUEIRI, 1987). 
Leisch e Leisch (1977) pregavam que quanto maior fosse a diferença entre as velocidades de projeto e de operação, maior seria a segurança de tráfego. As características geométricas adotadas dariam maior margem de segurança à negociação com as curvas horizontais.

Eles salientaram que as velocidades de projeto adotadas, por vezes, eram inferiores às expectativas dos condutores, o que fomentava desacelerações nas curvas e acelerações nas tangentes. A diminuição das velocidades nas curvas seria natural, porém algumas características das tangentes favoreciam comportamentos menos seguros nessa transição. As variações nos alinhamentos, principalmente horizontais no caso dos veículos leves, surtiriam reflexos nas velocidades operacionais. O problema era ainda maior em rodovias de classes inferiores, onde as velocidades de projeto eram menores que $100 \mathrm{~km} / \mathrm{h}$.

As velocidades escolhidas para a negociação com as curvas teriam importância fundamental na operação das rodovias. Seu efeito refletiria diretamente na aceleração lateral dos veículos nesses elementos. Curvas mal projetadas poderiam ser mal interpretadas, o que gerariam expectativas equivocadas nos condutores. Assim, eles poderiam transpor esses trechos com velocidades inadequadas o que aumentaria a probabilidade da perda de controle dos veículos (GLENNON; NEUMAN; LEISCH, 1983; LAMM; HAYWARD; CARGIN, 1986).

O primeiro passo para a melhoria do alinhamento horizontal seria o desenvolvimento de um método conveniente para localizar regiões com traçado inconsistente (LAMM; HAYWARD; CARGIN, 1986). Traçado inconsistente poderia ser entendido como aquele que não propiciaria ao condutor a possibilidade de trafegar com segurança por toda uma rodovia a partir de uma velocidade desejada (LAMM et al., 1996).

Um projeto inconsistente provocaria mudanças bruscas nas velocidades em curtos período de tempo (HIRSH, 1987). Assim, se o traçado não causasse surpresas para os condutores, a geometria desse poderia ser considerada consistente. Consistência, entre diversos significados, pode ser entendida como a qualidade de um ente que é estável (MICHAELIS, 2015).

Nas últimas décadas, algumas abordagens foram sugeridas com o intuito de sistematizar a avaliação da consistência dos alinhamentos. Na sequência, os trabalhos cujas propostas de identificação de trechos inconsistentes foram, bibliograficamente, mais citadas serão melhores aprofundados. 


\subsubsection{Regra dos $15 \mathrm{~km} / \mathrm{h}$}

Leisch e Leisch (1977) salientaram dois problemas, classificados pelos mesmos como, de consistência operacional, que o procedimento corrente à época - uso da velocidade de projeto sem a observância dos efeitos sistemáticos impostos pelo tráfego - causava: a variação contínua de velocidade pelos condutores nas rodovias e as diferenças existentes entre as velocidades dos veículos leves e dos pesados.

A solução apontada pelos autores era uniformizar as velocidades operacionais. Para tanto, esses propuseram a regra dos $15 \mathrm{~km} / \mathrm{h}$. Esse valor foi sugerido em função da presunção da habilidade que os condutores teriam em lidar com essa variação de velocidade. Vale ressaltar que os pesquisadores concordavam com reduções maiores na velocidade de projeto, desde que essas fossem psicologicamente aceitáveis para os condutores, como variações aparentes de relevo.

Com a regra sugerida, os projetistas deveriam desencorajar, a partir de modificações físicas do alinhamento, três situações: modificações de velocidade de projeto entre trechos contíguos acima de $15 \mathrm{~km} / \mathrm{h}$; variações da velocidade dos veículos leves acima de $15 \mathrm{~km} / \mathrm{h}$ em relação à velocidade de projeto; e diferenças entre as velocidades médias dos veículos leves e pesados acima de $15 \mathrm{~km} / \mathrm{h}$.

Para aplicar esse método, o fluxo livre deveria ser observado, pois era sob essa condição que se observaria influências mais significativas do alinhamento nas velocidades. Além disso, esperava-se por condições favoráveis como luz do dia e bom tempo, entre outros pressupostos.

Essa técnica se baseava na análise dos perfis de velocidade dos elementos (speed-profile technique). Ela deveria ser utilizada para rodovias novas, porém, teria utilidade para identificar medidas mitigatórias em trechos existentes. $\mathrm{O}$ intuito dos autores era melhorar o atendimento das expectativas dos condutores e, por consequência, o seu conforto e segurança durante a rodagem.

Lamm, Hayward e Cargin (1986) fizeram uma comparação dessa abordagem com os métodos empregados na Suíça e na Alemanha para um trecho existente de rodovia. Eles chegaram à conclusão que, apesar de pequenas variações entre as respostas das abordagens, os trechos com menor consistência eram identificados da mesma forma. Os três métodos seguiam a identificação de diferenças nas velocidades de operação encontradas entre trechos. 
Porém, o método germânico, ao utilizar o cruzamento da taxa de mudança de curvatura (Curvature change rate - CCR) com modelos de velocidade operacional (calibrados para diferentes larguras de pista), acabou por fomentar o desenvolvimento de uma abordagem que, diferente de Leisch e Leisch (1977), pudesse ser mais conveniente na indicação de inconsistências no alinhamento horizontal em trechos mais extensos de rodovia. Esse método seria conhecido posteriormente como $\Delta \mathrm{V}_{85}$.

\subsection{2 $\Delta \mathrm{V}_{85}$}

Lamm e Choueiri (1987) adaptaram a abordagem alemã para a realidade americana a partir de um estudo no estado de Nova Iorque. Esse trabalho tinha o intuito de favorecer a detecção e correção de deficiências geométricas das rodovias americanas.

Primeiro, eles estabeleceram relações entre as taxas de mudança de curvatura (CCR) e os graus de curvatura (Degree of Curve - DC), a partir das velocidades operacionais de 261 trechos de rodovias desse estado. Posteriomente, calibraram modelos dessas velocidades a partir da regressão dos graus de curvatura, das larguras das faixas, das larguras dos acostamentos e dos volumes diários médios anuais. Finalmente, a partir dos valores sugeridos pelos métodos Suíço e Alemão, eles encontraram os limites para qualificar os projetos, a partir das diferenças nos graus de curvatura e nas velocidades operacionais.

Os melhores parâmetros para explicar a variação das velocidades de operação, e das taxas de ocorrências, foram o grau de curvatura e os limites de velocidade existentes. Quanto maiores os graus de curvatura, maiores seriam as taxas de ocorrências e menores seriam as velocidades operacionais. Essas relações formaram a base do procedimento sugerido por Lamm et al. (1988).

Para prever a consistência dos alinhamentos, a partir das velocidades operacionais, essa abordagem sugeria o cumprimento de uma sequência de seis passos: 1. dividir as rodovias em trechos de CCR semelhante; 2. determinar os graus de curvatura e os comprimentos das tangentes; 3. determinar os valores esperados das velocidades operacionais (de acordo com os graus de curvatura e da largura das faixas); 4. avaliar a independência das tangentes; 5. calcular as variações dos graus de curvatura e das velocidades operacionais entre elementos (de acordo com a interação presente, tangente-curva ou curva-curva); 6. qualificar as variações de acordo com os limites impostos para projetos bons, razoáveis e fracos. 
A fim de balancear as características da rodovia com o comportamento dos condutores e dos veículos, os autores também aventaram a possibilidade de avaliar a diferença entre as velocidades operacionais e de projeto de cada um dos elementos dos trechos. Nessa publicação, a independência das tangentes foi brevemente abordada.

Esse conceito foi mais aprofundado em Lamm, Choueiri e Hayward (1988). Nesse trabalho, um procedimento foi sugerido para avaliar como as tangentes deveriam ser consideradas na avaliação da qualidade dos projetos.

A partir da comparação do comprimento dessas com os valores limites impostos pela velocidade de operação da curva adjacente com maior grau de curvatura, consideraria-se esses elementos como independentes ou não.

Se o comprimento da tangente fosse menor que o valor tabelado, essa seria considerada nãoindependente e, por consequência, seria desconsiderada na análise. Seriam considerados os valores das velocidades operacionais das duas curvas adjacentes a ela. Porém, se fossem maiores, suas velocidades operacionais seriam observadas. Elas seriam consideradas independentes. Com essa designação, durante a condução, era esperado um comportamento de aceleração completo até uma velocidade operacional máxima modelada e uma desaceleração completa até a entrada na curva, o que não ocorreria em tangentes não-independentes (Figura 3).

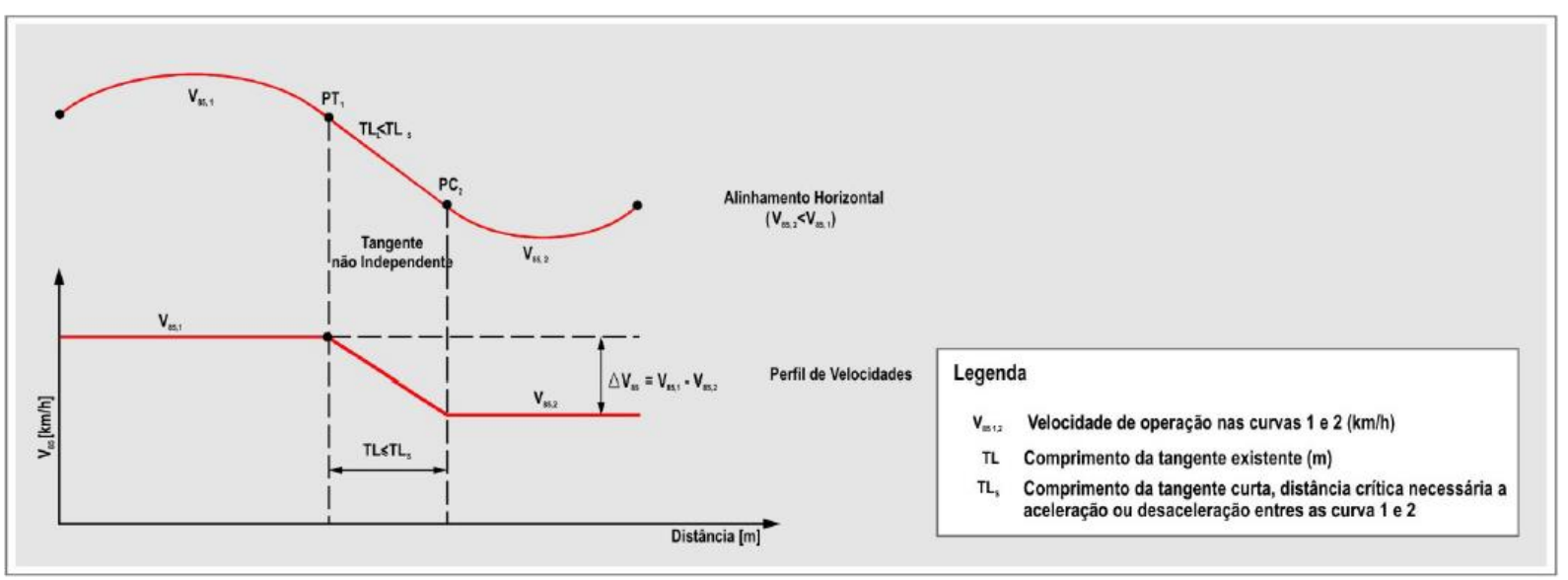

Figura 3 - Exemplo de tangente não independente Fonte: (TRENTIN, 2007, p. 40) 
Depois de avaliar as consistências entre a geometria dos elementos horizontais e entre as velocidades de projeto e de operação, Lamm, Choueri e Mailaender (1991) apontaram ainda a discrepância existente entre os coeficientes de atrito transversais demandados na operação e assumidos em projeto (segurança dinâmica).

Para tanto, esses, a partir da relação existente entre velocidade, raio de curvatura, superelevação e atrito transversal, investigaram 197 seções de curvas de rodovias. A partir da superelevação e do grau de curvatura levantados em campo, e da velocidade de projeto relativa a norma vigente, estipularam-se os coeficientes de atrito transversais assumidos em projeto. E, a partir da substituição das velocidades de projeto pelas velocidades operacionais, calibradas em campo, eles estimaram os valores demandados na operação.

Ao calibrar modelos dessas respostas a partir dos graus de curvatura, das velocidades operacionais e das ocorrências, os pesquisadores encontraram três relações: conforme aumentava o grau de curvatura, a partir de $6.5^{\circ}$; conforme aumentava a taxa de ocorrências, a partir de 6 ocorrências a cada milhão de veículos-milhas viajados; e conforme diminuia a velocidade de operação, a partir de 50 milhas por hora, o valor de atrito transversal demandado era maior que o assumido.

Esse trabalho fortaleceu a hipótese de que os valores vigentes à época poderiam ser inadequados. Principalmente, em rodovias de menor classe, onde as restrições geométricas eram mais brandas, assim, existiria maior risco que os valores demandados fossem superiores aos assumidos, o que aumentaria o risco de ocorrências. Assim, eles aventaram o terceiro critério para a análise de consistência das rodovias, com base na segurança dinâmica dos veículos.

Concomitantemente, Lamm e Smith (1994) ainda sugeriram a adoção de uma abordagem de projeto curvilínea, onde buscar-se-iam propor tangentes com comprimentos menores e curvas maiores. Para tanto, os elementos não deveriam ser projetados de maneira isolada. Deveria ser considerada a sinergia existente entre eles, a fim de fomentar a consistência do traçado e a segurança no tráfego. Esse seria chamado de projeto relacional (relation design). Todavia, dever-se-ia observar o aumento no risco das ultrapassagens causado por essa proposta (LAMM; STEFFEN; GUENTHER, 1994). 
Com a união dos trabalhos desenvolvidos, Lamm, Steffen e Guenther (1994) apresentaram uma proposta de avaliação do alinhamento horizontal de pista simples a partir dos três critérios salientados anteriormente.

Sinteticamente: o critério I - consistência da velocidade operacional - avaliava as diferenças entre as velocidades operacionais de elementos adjacentes; o critério II - consistência de projeto - avaliava a harmonia entre as velocidades operacionais e as de projeto de cada curva circular; e o critério III - segurança dinâmica dos veículos - avaliava a discrepância entre os coeficientes de atrito adotados em projeto e os demandados na operação. Esses valores seriam classificados em bom, razoável e fraco, de acordo com os limites apresentados na Tabela 5. Nessa tabela, "V85" representa a velocidade operacional no elemento; " $\mathrm{V}_{\mathrm{d}}$ " representa a velocidade de projeto do elemento; " $f_{R A}$ " representa o coeficiente de atrito assumido; $e$ " $f_{R D}$ " representa o coeficiente de atrito demandado.

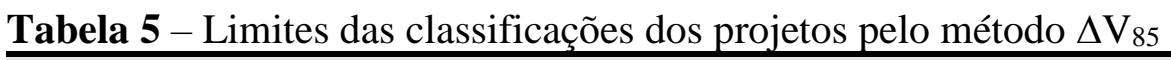

\begin{tabular}{clll}
\hline \multirow{2}{*}{ Critério } & \multicolumn{3}{c}{ Classificação do projeto } \\
\cline { 2 - 4 } & \multicolumn{1}{c}{ Bom } & \multicolumn{1}{c}{ Razoável } & \multicolumn{1}{c}{ Fraco } \\
\hline I & $\left|\mathrm{V}_{85 \mathrm{i}}-\mathrm{V}_{85 \mathrm{i}+1}\right| \leq 10 \mathrm{~km} / \mathrm{h}$ & $10 \mathrm{~km} / \mathrm{h}<\left|\mathrm{V}_{85 \mathrm{i}}-\mathrm{V}_{85 \mathrm{i}+1}\right| \leq 20 \mathrm{~km} / \mathrm{h}$ & $20 \mathrm{~km} / \mathrm{h}<\left|\mathrm{V}_{85 \mathrm{i}}-\mathrm{V}_{85 \mathrm{i}+1}\right|$ \\
II & $\left|\mathrm{V}_{85}-\mathrm{V}_{\mathrm{d}}\right| \leq 10 \mathrm{~km} / \mathrm{h}$ & $10 \mathrm{~km} / \mathrm{h}<\left|\mathrm{V}_{85}-\mathrm{V}_{\mathrm{d}}\right| \leq 20 \mathrm{~km} / \mathrm{h}$ & $20 \mathrm{~km} / \mathrm{h}<\left|\mathrm{V}_{85}-\mathrm{V}_{\mathrm{d}}\right|$ \\
III & $0 \leq \mathrm{f}_{\mathrm{RA}}-\mathrm{f}_{\mathrm{RD}}$ & $-0.02 \leq \mathrm{f}_{\mathrm{RA}}-\mathrm{f}_{\mathrm{RD}}<0$ & $\mathrm{f}_{\mathrm{RA}}-\mathrm{f}_{\mathrm{RD}}<-0.02$ \\
\hline
\end{tabular}

Uma aplicação para CAD foi aventada para auxiliar o emprego dessa abordagem. Seu uso possibilitaria identificar erros em projetos novos ou falhas em rodovias existentes. Cada um dos três critérios deveria ser avaliado de maneira isolada. Se um ou mais desses não fosse satisfeito, alternativas de projeto deveriam ser analisadas até se encontrar um alinhamento satisfatório.

Nesse trabalho, um exemplo de trecho de rodovia alemã com problemas de consistência foi exposto. Soluções provisórias foram apresentadas com o objetivo de chegar a um nível razoável de projeto, com a manutenção dos custos de reconstrução em cifras mais baixas. Sobretudo, por razões de segurança, o próprio autor recomendara que um projeto bom deveria ser sempre fomentado. Como esses critérios, de maneira isolada, poderiam das respostas diferentes com relação a qualidade de projeto para um mesmo trecho, Lamm, Guenther e Choueiri (1995) propuseram um módulo de segurança que combinasse essas repostas em um valor geral. Essas combinações seguiriam a Tabela 6: 
Tabela 6 - Combinação dos critérios isolados para o método $\Delta \mathrm{V}_{85}$

\begin{tabular}{lc}
\hline & Classificação \\
\hline Critérios de I, II e III & Módulo de Segurança \\
\hline 3 Bons & Projeto Bom \\
2 Bons e 1 Razoável & \\
2 Bons e 1 Fraco & \\
\hline 3 Razoáveis & Projeto Razoável \\
2 Razoáveis e 1 Bom & \\
2 Razoáveis e 1 Fraco & \\
1 Bom, 1 Razoável e 1 Fraco & Projeto Fraco \\
\hline 3 Fracos & \\
2 Fracos e 1 Bom & \\
\hline Fracos e 1 Razoável &
\end{tabular}

As respostas desse módulo foram comparadas com 3 anos de ocorrências registradas em rodovias alemãs. Essa classificação teve boa previsão das taxas de ocorrências para a maioria dos trechos, ou pelo menos, o valor previsto era menos seguro do que o observado. Nesse artigo os autores propuseram o uso de um sistema de informações geográficas (SIG) para avaliar essas combinações. A utilização de cores, para discriminar a qualidade de projeto dos trechos, facilitaria o trabalho do projetista em reconhecer as falhas de cada um dos critérios para a rede rodoviária como um todo.

Para rodovias de pista dupla, não havia relação estatisticamente significativa conhecida entre as velocidades de operação e as taxas de mudança de curvatura ou os graus de curvatura, provavelmente por causa do alinhamento mais generoso existente nas classes de projeto que utilizavam um número maior de faixas. Portanto, não se considerou na época relevante a análise do critério I para essas rodovias. Porém considerou-se analisar o critério II para o processo de projeto dessas, em busca do aumento da segurança de tráfego (LAMM et al., 1996).

Os critérios observados até então, principalmente com relação aos indicadores que avaliavam as variações de velocidade entre elementos consecutivos, pressupunham a avaliação de diferenças entre duas posições das distribuições dos dados, os percentis 85 . Ou seja, modelavam-se velocidades operacionais para cada um dos elementos - tangentes e curvas - e encontravam-se as diferenças entre esses valores. 
Todavia, Hirsh (1987) salientava que essa abordagem poderia qualificar trechos inconsistentes como consistentes, ou seja, ela poderia subestimar as diferenças existentes. $\mathrm{O}$ autor partia do pressuposto que, provavelmente, o condutor real que registrava a velocidade operacional da tangente não era o mesmo da curva. Assim, a diferença entre os dois percentis 85 não representaria as variações experimentadas por um condutor naquela transição, ela simbolizaria uma diferença hipotética. $\mathrm{O}$ autor propunha que se avaliasse as diferenças reais experimentadas pelos condutores na análise dos trechos, já que cada motorista teria uma aceitação diferente das acelerações laterais impostas pelas curvas.

Assim, o indicador não deveria avaliar a diferença entre a velocidade de operação da curva com a da tangente $\left(\Delta \mathrm{V}_{85}\right)$. Ele deveria avaliar o percentil 85 das diferenças de cada condutor $\left(\Delta_{85} \mathrm{~V}\right)$. MCFadden e Elefteriadou (2000) ratificaram essa abordagem. Eles a nomearam como percentil 85 da máxima redução de velocidade (85th percentile maximum reduction in speed - 85MSR).

\subsubsection{MSR}

Adimitia-se a existência de uma relação entre a taxa de ocorrências e a variação de velocidade entre elementos sussessivos. No entanto, usar a diferença entre as velocidades operacionais deles poderia não representar a real redução experimentada pelos condutores nesses trechos. Como fora proposto por Hirsh, essa abordagem subestimaria a verdadeira redução experimentada pelos condutores individualmente.

Para avaliar essa sugestão de mudança de abordagem, McFadden e Elefteriadou (2000) estudaram 21 curvas estadunidenses. A partir das velocidades, de carros de passeio em fluxo livre, coletadas com radares (lidar) os autores compararam três abordagens: $\Delta \mathrm{V}_{85}$ (com dados coletados em dois pontos), $\Delta \mathrm{V}_{85}$ (com dados coletados em nove pontos) e $85 \mathrm{MSR}$.

Isso porquê a abordagem $\Delta \mathrm{V}_{85}$ previa a variação de velocidades entre o ponto médio das tangentes de aproximação e o ponto médio das curvas horizontais, ou seja, as diferenças eram calculadas a partir de dois pontos. O 85MSR representava a posição 85 da distribuição de frequência acumulada das reduções de velocidade experimentadas pelos condutores a partir de 200 metros antes do início das curvas. 
$\mathrm{O}$ método $\Delta \mathrm{V}_{85}$ (com dados coletados em dois pontos) teve as menores reduções em comparação com os outros métodos. 85MSR teve a maior, aproximadamente 2 vezes maior que o método anterior. Os autores ainda calibraram dois modelos para representar a redução de velocidade encontrada a partir da abordagem proposta. $\mathrm{O}$ primeiro, a partir da velocidade operacional de aproximação, 200 metros antes da curva, do comprimento da tangente de aproximação e do comprimento do raio. Como era pouco provável que as velocidades operacionais de aproximação fossem disponíveis, o segundo modelo foi calibrado sem essa variável dependente (Equação 1).

$85 \mathrm{MSR}=-0.812+\frac{998.19}{R}+0.017 \times L A P T$

(Equação 1)

Nessa equação, "R" representaria o comprimento dos raios, em metros, "LAPT" representaria o comprimento das tangentes de aproximação, em metros, e "85MSR" representaria o percentil 85 das reduções experimentadas pelos condutores, em quilômetros por hora.

Misaghi e Hassan (2005) apontaram que essa abordagem poderia falhar em dois pontos, com relação ao método de coleta: o uso do radar de mão poderia influenciar no comportamento dos condutores e o ângulo desses poderia gerar erros nas velocidades registradas (erro do cosseno). Um método menos intrusivo poderia revelar velocidades diferentes dos motoristas. Para tanto, esses pesquisadores buscaram relacionar, em campo, as diferenças operacionais de velocidades $\left(\Delta_{85} \mathrm{~V}\right)$ entre o centro de 35 curvas circulares e as tangentes de aproximação.

Eles observaram fortes relações entre essas diferenças e os raios de curvatura experimentados pelos condutores. Os dados foram coletados em áreas rurais, com baixo volume de tráfego, com faixas de rolagem de largura constante e em curvas cujos comprimentos de raios eram menores que 1200 metros. Utilizaram-se os dados dos veículos de passeio e dos caminhões leves. E, as tangentes com mais de 200 metros foram consideradas independentes.

Assim como fora hipotetizado, quando foi utilizado o radar de mão, percebeu-se a redução das velocidades pelos condutores assim que esses perceberiam a presença dos membros da coleta de pé ou andando perto dos locais de coleta. 
Contudo, esse trabalho corroborou com a hipótese teórica de Hirsh (1987) e com o trabalho de McFadden e Elefteriadou (2000), de que o método $\Delta \mathrm{V}_{85}$ poderia subestimar as diferenças de velocidade observadas em cada elemento e de que as distribuições de velocidades entre elementos sucessivos seriam semelhantes. Um modelo de regressão calibrado para a comparação das duas abordagens, mostrou que a abordagem $\Delta \mathrm{V}_{85}$ registrava, aproximadamente, diferenças $7.55 \mathrm{~km} / \mathrm{h}$ menores que a $\Delta_{85} \mathrm{~V}\left(\mathrm{R}^{2}=0.721\right)$.

Mesmo com esse desvio, os autores ainda consideravam, dentre os métodos para avaliar a consistência de projeto, a abordagem das diferenças entre as velocidades de operação como a métrica mais eficiente e mais quantificável.

Afinal, os condutores escolheriam suas velocidades de acordo com a sua percepção da via $\left(\mathrm{V}_{85}\right)$, o que poderia não ter concordância com o limite sugerido pelos projetistas $\left(\mathrm{V}_{\mathrm{d}}\right)$. O nível de conforto e de aderência dos pneus com o pavimento teriam mais influência que os limites apresentados nas sinalizações (MISAGHI; HASSAN, 2005).

\subsubsection{Comparação dos métodos tradicionais}

A produção científica adjacente à época, que tinha como tema relacionado a identificação de trechos com inconsistência geométrica, dedicou enfoque adicional: no emprego de índices com características geométricas da curvas horizontais (ANDERSON et al., 1999); na incorporação da consideração do alinhamento vertical (FITZPATRICK; COLLINS, 2000); na calibração de modelos de velocidade de operação para realidades diferentes (GARCÍA, 2008); na verificação, e calibração, de taxas de aceleração e desaceleração na negociação com as curvas (FIGUEROA MEDINA; TARKO, 2007); na comparação das diferentes abordagens existentes (TRENTIN, 2007); no emprego dos simuladores de direção como ferramenta de investigação (BELLA, 2008); e, mais recentemente, no uso de dados de sistemas de posicionamento global (Global Positioning System - GPS) para a coleta de dados (PÉREZ-ZURIAGA; CAMACHOTORREGROSA; GARCÍA, 2013; LLOPIS-CASTELLÓ et al., 2018)

Porém, os dois métodos aprofundados anteriormente ( $\Delta \mathrm{V}_{85}$ e $\left.85 \mathrm{MSR}\right)$ foram mais salientados. As diferenças de velocidades desses estão esquematizadas na Figura 4. O gráfico apresenta um perfil de velocidade hipotético, típico para situações de negociação de condutores quando transitavam entre tangentes e curvas. 
Nessa representação, "PT" representaria o ponto de tangente, "PC" o ponto de curva, "LT" o comprimento da tangente, " $D_{C}$ " o desenvolvimento da curva, " $\Delta \mathrm{V}$ " a diferença de velocidades da posição central dos elementos e "MSR" a máxima diferença de velocidades experimentada entre elementos.

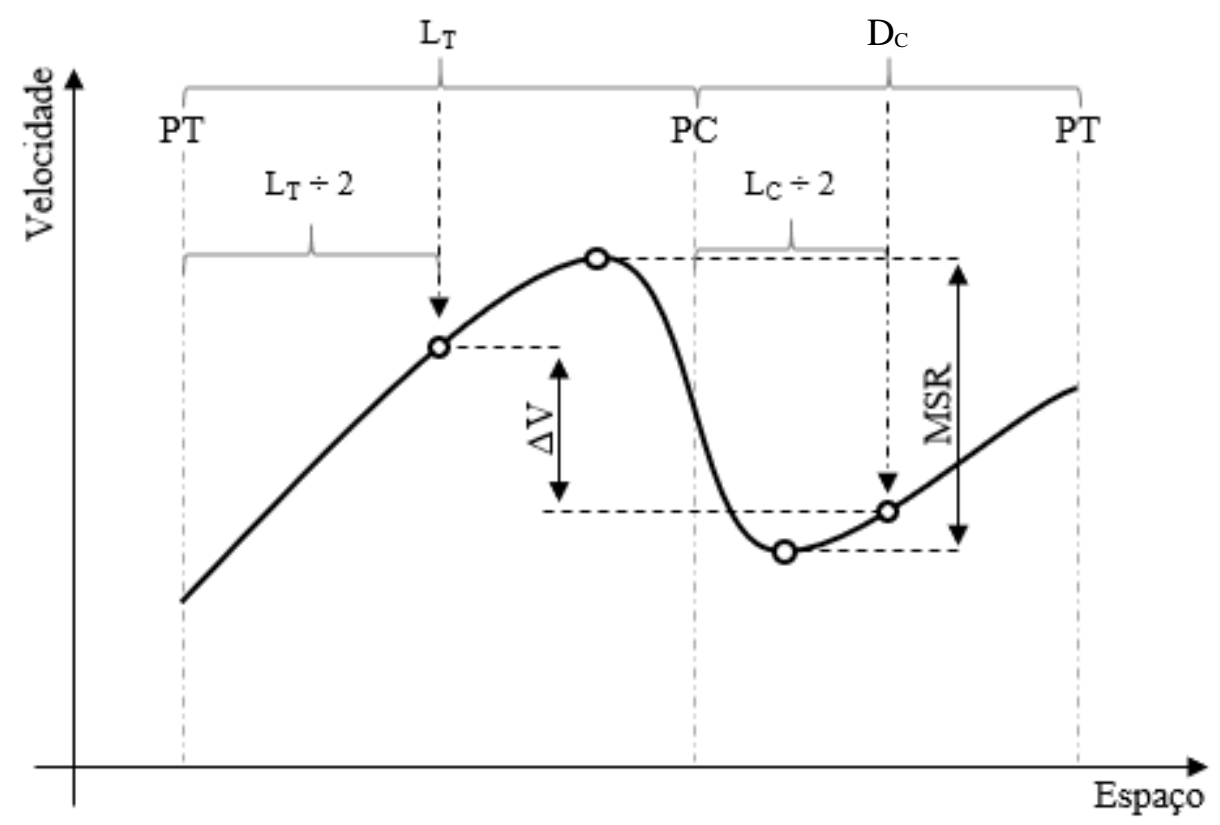

Figura 4 - Comparação dos métodos tradicionais

Para encontrar as diferenças de velocidade operacional entre elementos $\left(\Delta \mathrm{V}_{85}\right)$, LAMM et al. (1990) relataram que as velocidades nas curvas eram calculadas, indiretamente, a partir da observação do tempo necessário para os veículos percorrerem uma distância de 150 pés $(\approx 45.72$ metros) até o meio daquele elemento. Os tempos eram registrados manualmente por pesquisadores localizados no bordo da pista a partir de cronômetros.

Todavia, ao comparar sua proposta (MSR) com a corrente à época, McFadden e Elefteriadou (2000) avaliaram as velocidades pontuais no centro dos elementos a partir de radares de mão para encontrar a diferença entre as velocidades operacionais dos elementos $\left(\Delta \mathrm{V}_{85}\right)$.

Para comparar esses dois métodos (85MSR $\left.v s \Delta_{85} \mathrm{~V}\right)$, um simulador de direção fora utilizado por Bella (2008). O trabalho utilizou um equipamento de base fixa para avaliar qual dos métodos refletiria melhor as reduções experimentadas - diferenças de velocidade encontradas na interação entre tangentes e curvas - por 30 condutores em 16 combinações geométricas diferentes. Outro objetivo era calibrar novos modelos de estimativa de redução de velocidades operacionais de acordo com as características geométricas dos trechos. 
Para tanto, o autor considerou o 85MSR como o percentil 85 das máximas reduções experimentadas pelos condutores a partir das velocidades registradas nas tangentes antes de 200 metros do ponto de curva, a cada 50 metros, e das velocidades registradas em quatro pontos das curvas subsequentes (primeiro quarto da curva, meio da curva, terceiro quarto da curva e ponto de tangente). $\Delta_{85} \mathrm{~V}$ fora considerado como o percentil 85 das reduções experimentadas pelos condutores entre dois pontos fixos, um nas tangentes (100 metros antes do ponto de curva) e um no meio das curvas.

A diferença básica dos dois métodos estaria relacionada com a disponibilidade de dados. $\mathrm{O}$ primeiro método era considerado de antemão como o que melhor representaria o fenômeno. Os autores aventavam que o segundo não garantiria que a diferença calculada refletiria o máximo experimentado pelos condutores.

Para a realização do experimento construíram-se, virtualmente, 16 configurações de alinhamento. Nessas, os comprimentos das tangentes de aproximação, dos raios das curvas e das espirais de entrada e de saída eram variados.

O experimento fora realizado em pista simples, com pavimento seco, em bom estado de manutenção e com fluxo livre na faixa de rodagem experimentada pelos condutores. As idades dos condutores variavam entre 24 e 52 anos. Eles foram selecionados de acordo com alguns critérios: ausência de experiência prévia com o simulador; pelo menos 5 anos de experiência em direção; e rodagem anual em rodovias de pista simples de no mínimo 3,000 km.

Os resultados do trabalho demostraram que as diferenças encontradas pela abordagem $85 \mathrm{MSR}$ foram, em média, mais altas que pela $\Delta_{85} \mathrm{~V}$, para um nível de significância de 0.001 . Isso fomentou a conclusão de que o uso do $\Delta_{85} \mathrm{~V}$ subestimaria as diferenças experimentadas, em relação ao 85MSR.

Ainda, os autores calcularam o 85MSR para cada 5 metros das tangentes e das curvas. Essa abordagem revelou diferenças ainda maiores. Para prever esses valores, calibraram-se modelos a partir dos comprimentos das tangentes de aproximação, dos comprimentos dos raios das curvas e das velocidades operacionais a 200 metros do ponto de curva. O modelo que considerava apenas as características geométricas da via (Equação 2) teve coeficiente de determinação de 0.497 . 
$85 M S R_{5 m}=-0.198+0.037 \times L_{m}+\frac{7929.37}{R}$

(Equação 2)

Nessa equação, "R" representaria o comprimento dos raios, em metros, " $\mathrm{L}_{\mathrm{m}}$ " representaria o comprimento das tangentes de aproximação, em metros, e " $85 \mathrm{MSR}_{5 \mathrm{~m}}$ " representaria o percentil 85 das reduções experimentadas pelos condutores, em quilômetros por hora.

Quando comparado com o trabalho de campo feito por McFadden e Elefteriadou (2000) os resultados do simulador registraram diferenças maiores. Isso já era esperado pelos autores em função do ambiente simulado. Ainda assim, eles estimularam o uso dos simuladores de direção para a análise dos efeitos das modificações nos alinhamentos no comportamento dos condutores.

A análise das acelerações também já fora utilizada como forma de análise da consistência dos traçados (ZURIAGA et al., 2010), porém, o uso da variável jerk longitudinal não fora identificada em nenhum estudo relacionado.

Utilizar somente a desaceleração como método para a separação de reduções de velocidade normais para frenagens em conflitos mais sérios seria insuficiente. Os perfis de aceleração nessas situações seria similar, contanto seria necessário o uso de um indicador complementar de conflitos (BAGDADI; VÁRHELYI, 2011).

Ademais, altos valores de desaceleração não seriam necessariamente um indicador de problemas de segurança na rodagem, porém desacelerações abruptas poderiam ser. Esse fenômento poderia ser investigado a partir do estudo da variável jerk (KULMALA; LUOMA; NYGÅRD, 2000).

Estudos sobre essa variável serão melhor aprofundados na sequência. Esperava-se que o uso dela possibilitasse a identificação de trechos com traçados inconsistentes de maneira mais automática, ou seja, sem a demanda de coleta pontual e pós-processamento como era o caso dos métodos apresentados anteriormente. 


\subsection{Jerk}

Eager, Pendrill e Reistad (2016) apontaram que as aulas de mecânica clássica de corpos rígidos, raramente, abordavam as derivadas mais altas do movimento em relação ao tempo. Apesar das sensações cotidianas causadas pelos efeitos dessas. Matematicamente, a terceira derivada do movimento no tempo poderia ser nomeada como jerk. Em movimento, os corpos não sentiriam os efeitos da velocidade, somente das variações dela - as acelerações. Como essas não seriam constantes, provavelmente, o que o corpo perceberia era a influência do jerk.

A velocidade não muda repentinamente, ela precisa de uma aceleração para sair do zero. Da mesma forma, a aceleração precisa de um jerk aplicado para mudar de valor. Esse seria o fator causador da variação, crescente ou decrescente, das forças atuantes nos corpos. Tais variações poderiam causar sensações biomecânicas pouco prazerosas para o corpo humano, por isso, elas deveriam ser evitadas, por exemplo, em sistemas de transportes. Os efeitos da velocidade, da aceleração e do jerk poderiam ser percebidos na condução de um veículo, por exemplo.

Um condutor mais experiente aceleraria mais suavemente em relação a um inexperiente. O uso de clotóides na transição entre trechos retos e curvos seria outro exemplo da tentativa de diminuir os efeitos das variações bruscas dos valores de jerk, a fim de aumentar o conforto e diminuir o risco no tráfego (EAGER; PENDRILL; REISTAD, 2016). Nesse trabalho, como apresentado anteriormente, o jerk estudado será o longitudinal (seta contínua preta), no sentido de rodagem dos veículos, principalmente o sofrido em frenagens, não o lateral (seta pontilhada verde), sofrido em mudanças de direção ao disterçar o volante dos veículos, e nem o resultante (seta pontilhada vermelha), como esquematizado na Figura 5.

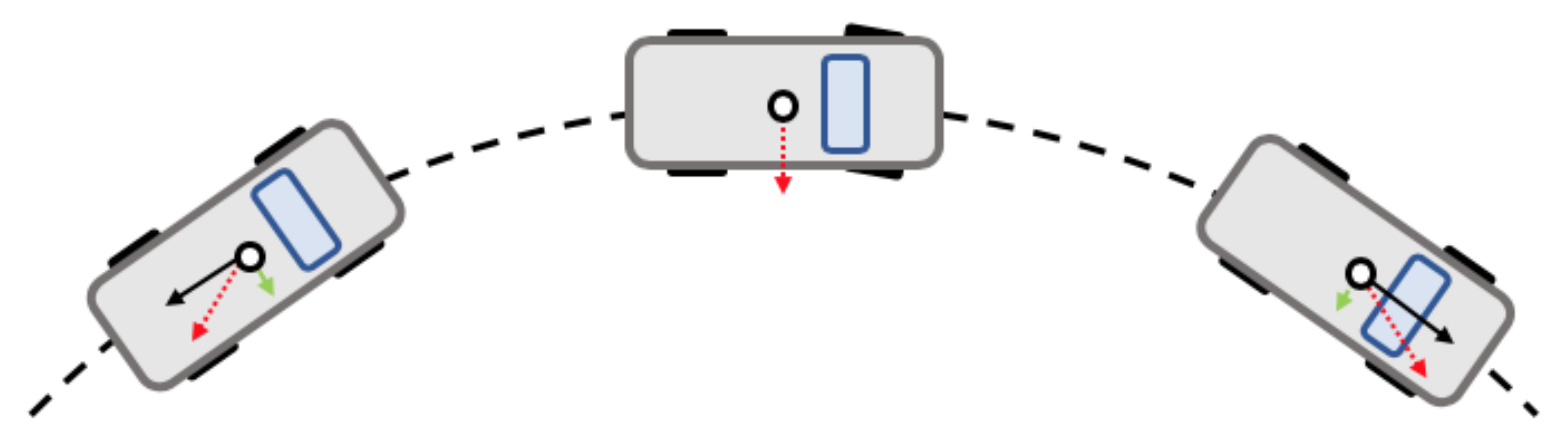

Figura 5 - Esquema dos jerks longitudinais, laterais e resultantes em um veículo em curva 


\subsubsection{Uso da variável jerk em estudos sobre segurança de tráfego}

As pesquisas sobre segurança, tradicionalmente, se concentravam em analisar ocorrências. Porém, o baixo número de registros, dificultaria a tentativa de realizar avanços nessa área. Estudar os conflitos - situações onde manobras evasivas seriam necessárias até 1.5 segundos antes de uma provável colisão - possibilitaria a realização de maiores coletas em menores períodos de tempo. Isso poderia dar melhores pistas sobre a interação dos usuários com a rodovia (NYGÅRD, 1999). A dificuldade dessa abordagem seria a baixa automatização dos estudos de campo. Medições automáticas seriam uma forma muito mais prática de coletar esses dados. Com esse objetivo, Nygård (1999) desenvolveu um trabalho cujo intuito era desenvolver um método para identificar conflitos de tráfego a partir dos perfis de velocidade dos carros. $\mathrm{O}$ foco principal era definir as características das frenagens típicas ocorridas nesses eventos a partir de valores limites de desaceleração e de jerk.

A velocidade adotada por cada condutor fora considerada como a principal ferramenta para a análise da adaptação comportamental ao tráfego. Ela seria um importante meio de comunição entre os usuários. Os instrumentos pelos quais se realizariam essas interações seriam os pedais de freio e de aceleração. A frenagem era dada como o tipo mais comum de manobra evasiva em quase todos os conflitos. Já que uma abrupta desaceleração, oriunda dessa, indicaria um comportamento crítico no tráfego.

Para tanto, o pesquisador realizou um estudo de campo com veículos instrumentados. Setenta condutores, acompanhados por um observador treinado, tiveram seus dados registrados em uma rota de $50 \mathrm{~km}$. Esse acompanhante tinha a tarefa de identificar os conflitos: potenciais (condutores conseguiam ajustar suas velocidades, porém a situação terminava em conflito); sérios (manobra evasiva não controlada); ou situações de frenagem normal. Foram identificados 6 conflitos potenciais, 5 conflitos sérios e 1400 situações de frenagem normal.

Apesar do pequeno número de conflitos registrados, o autor concluiu que o padrão de desacelerações, entre condutores, foi consideravelmente diferente, portanto um valor limite para identificar conflitos sérios, a partir dessa variável, não poderia ser definido. Algumas pessoas, em situações de frenagem normal, aplicavam desacelerações maiores que as aplicadas por outras, em conflitos potenciais. Ademais, não houve diferença clara entre as desacelerações de conflitos potenciais e as de frenagens normais. 
No entanto, o jerk registrado em conflitos sérios se diferenciou dos valores encontrados em frenagens normais ou em conflitos potenciais. Essa diferença foi maior que a variação registrada entre pessoas. O que mostra que o jerk foi menos dependente dos condutores do que a desaceleração. Porém, não houve diferença clara entre conflitos potenciais e frenagens normais. Uma característica típica para frenagens em conflitos sérios foi encontrada, elas iniciavam abruptamente. Isso foi observado a partir dos grandes valores de jerk registrados. Assim, o pesquisador considerou a variável jerk como uma medida relevante para a identificação de conflitos. O pesquisador apontou que um jerk típico para frenagens normais seria de $-3.6 \mathrm{~m} / \mathrm{s}^{3}$, esse valor poderia chegar até $-8.0 \mathrm{~m} / \mathrm{s}^{3}$, enquanto que os valores que identificariam os conflitos variavam entre $-9.9 \mathrm{~m} / \mathrm{s}^{3} \mathrm{e}-12.6 \mathrm{~m} / \mathrm{s}^{3}$.

Em outro estudo, o jerk foi uma das variáveis respostas utilizadas para investigar os efeitos do uso de um sistema de transporte inteligente (Intelligent Traffic System - ITS), o qual recebia mensagens de tráfego por rádio (Radio Data System - Traffic Message Channel - RDS-TMC), no comportamento de condutores (KULMALA; LUOMA; NYGÅRD, 2000). Esse estudo mostrou que o uso do equipamento não causou efeitos estatisticamente significantes no valor dos jerks encontrados. Nas conversões, houve redução das velocidades acompanhada de fortes frenagens e jerks mais inseguros (maior frequência de valores menores que $-10 \mathrm{~m} / \mathrm{s}^{3}$ ).

Othman et al. (2008) propuseram um método para detectar e classificar comportamentos de direção anormais baseados na análise estatística de dados de condução. Os pesquisadores se fundamentavam no pressuposto de que entender o compotamento humano seria uma das chaves para mitigar o problema das mortes causadas no trânsito. Para tanto seria importante identificar e classificar comportamentos normais e anormais. O comportamento normal seria o resultante de uma condução segura, prazerosa e confortável. Os anormais resultariam de muitas causas possíves, as quais seriam difíceis de medir e avaliar. As ocorrências aconteceriam quando o comportamento dos conduotres se desviasse do padrão esperado de performance. Pesquisas focadas em detectar desvios de comportamentos eram pouco exploradas. Para fazer essa classificação, eles relacionaram o estado interior de 11 condutores (a partir de questionários sobre os níveis de estresse) com os níveis de jerk aplicados no início e no final de 13 cenários de um experimento em simulador de direção estático. O valor do jerk era estimado indiretamente a partir das acelerações registradas pelo simulador. Os comportamentos eram diferentes entre os condutores, porém essas diferenças eram proporcionais entre cenários. 
As condições internas dos condutores tiveram relação linear com os valores de jerk encontrados. Quanto menos relaxados (ou mais estressados) os condutores eram classificados, maiores os valores de jerk aplicados por eles. Encontrou-se o limite de $7.0 \mathrm{~m} / \mathrm{s}^{3}$ para classificar um condutor como estressado no início da condução e $6.5 \mathrm{~m} / \mathrm{s}^{3}$ no final.

Um estudo naturalístico, realizado a partir do registro contínuo de dados de 166 veículos leves, teve o objetivo de comparar os valores de jerk, em situações de condução cotidianas, com os registros de envolvimento em ocorrências reportados pelos próprios condutores (BAGDADI; VÁRHELYI, 2011).

A hipótese dos pesquisadores era de que a análise do jerk possibilitaria identificar a propensão dos condutores em se envolver em ocorrências. Também seria útil para desenvolver medidas de segurança e sistemas de auxílio à condução (Advanced Driver Assistance Systems - ADAS).

Os autores utilizaram o valor limite sugerido por Nygård (1999) - jerks menores que $-9.9 \mathrm{~m} / \mathrm{s}^{3}$ - para identificar comportamentos críticos para segurança. Assim, os resultados mostraram que quanto maior o número de jerks críticos empregados pelos condutores, maior seria o número reportado de ocorrências sofridas. Ou seja, maior o risco associado ao seu estilo de condução.

Esse estudo reforçou o potencial do uso da variável jerk como métrica para identificar condutores com comportamento de risco. Apesar da probabilidade de se envolver em uma ocorrência ser dependente de muitas outras variáveis, identificar esses comportamentos, ao invés de estudar ocorrências sofridas, pareceria melhor para o desenvolvimento de medidas de segurança.

Além do enfoque nos condutores, o jerk fora utilizado para a identificar locais inseguros (hazardous road locations - HRL). Tradicionalmente, para realizar essa tarefa, utilizavam-se os registros de ocorrência das forças legais, os quais seriam as estatísticas principais em muitos países. O uso desses, porém, poderia subestimar a realidade e essa identificação seria retrospectiva - para localizar um local de risco, se fazia necessário o registro de ocorrências e de mortes. Na tentativa de substituir esse método, Agerholm e Lahrmann (2012) sugeriram o emprego de uma abordagem baseada em valores limites de jerk registrados a partir de veículos em movimento (Floating Car Data - FCD). 
A hipótese desse trabalho era de que existiria conexão entre fortes jerks e as ocorrências registrados em uma mesma região. Para tanto, coletou-se os dados de seis condutores por seis meses. Registraram-se as velocidades a partir de um sistema de GPS e as acelerações e jerks, a partir de acelerômetros. As conclusões do trabalho corroboraram com os resultados de Nygård (1999), o qual indicava que a variável jerk seria confiável para a análise de conflitos, mesmo que alguns falsos positivos (como o registro da condução por ondulações verticais) tenham sido encontrados.

Para melhorar a precisão dessa abordagem, sugeriu-se o emprego da análise dos valores de jerk entre picos (peak-to-peak - P2P). Discutiu-se também sobre o período esperado para a recorrência de grandes jerks. Estimava-se registrar valor elevados em longas distâncias. Um condutor típico necessitaria dirigir muitos quilômetros para esses conflitos surgirem. Períodos maiores que seis meses seriam preferíveis.

O uso do jerk entre picos fora aventado por outro estudo de identificação de comportamentos de risco (BAGDADI; VÁRHELYI, 2013). Inicialmente, propôs-se utilizar os valores de jerk negativos para diferenciar frenagens críticas de potencialmente críticas. Porém, esses valores, e nem as desacelerações, cumpriram essa tarefa com significância estatística. Somente o valor do jerk de pico-a-pico teve esse efeito.

Os autores consideravam que as frenagens fariam parte da tarefa cotidiana de dirigir. Essas representariam desde ações de reduções de marcha até frenagens mais agudas. A motivação deles era identificar o grau de controle entre elas, se eram planejadas ou não. Esses eventos precisariam ser diferenciados para reduzir a possibilidade de falsos positivos na detecção de situações de risco.

Para tanto foi realizado um estudo em duas etapas. Primeiro, tentou-se calibrar limites para as varíaveis respostas em um estudo de campo piloto - a partir de registros de acelerômetros e receptores GPS - com dois condutores de experiência semelhante. Posteriormente, esses limites seriam comparados com os registros de um estudo naturalístico. 
Na primeira etapa, o pesquisador acompanhava os condutores em trechos de rodovia rurais, com dois limites de velocidade diferentes, e dava dois tipos de ordem a eles: "sair da pista e parar o veículo o mais rápido possível" (situação potencialmente crítica); ou "parar o veículo imediatamente" (situação crítica).

Nesse teste, as acelerações e os valores negativos do jerks não foram significativamente diferentes nas duas situações, enquanto que o valor do jerk de pico-a-pico foi. Um valor registrado maior que $1.50 \mathrm{~m} / \mathrm{s}^{3}$ diferenciaria uma situação crítica de uma potencialmente crítica. Esse limite foi ratificado pelos resultados do estudo naturalístico utilizado para a comparação.

Zaki, Sayed e Shaaban (2014) utilizaram a análise automática computacional de vídeos, de duas cidades (Vancouver-CA e cidade do Kuwait-KW), com o objetivo de ratificar a hipótese de que o valor do jerk poderia ser utilizado como métrica para identificar conflitos e as desacelerações por si só não.

Essa análise computacional possibilitou a extração das posições dos veículos e suas interações. Essas foram categorizadas em críticas ou normais de acordo com o tempo para colisão entre eles (time-to-collision - TTC). Nesse estudo, TTCs menores que 4s foram considerados como indicadores de situações críticas. Com a derivação das posições dos veículos no tempo, encontraram-se os valores de velocidade, aceleração e jerk.

Nesse trabalho, uma amostra com 178 conflitos de tráfego, do tipo colisão traseira, foi manualmente identificada a partir dos vídeos por um observador perito em segurança de tráfego. A mesma amostra passou por uma seleção automática com os limites de TTC (menores que 4s) e de jerk mínimo (menores que $-8,00 \mathrm{~m} / \mathrm{s}^{3}$ ) sugeridos. 150 eventos foram identificados pelo limite do TTC e 45 foram identificados pelo limite do jerk, 15 não foram identificados por nenhum dos métodos, e nem pela interação deles. Isso mostrou que não houve uma associação orbrigatória entre as duas variáveis. O que é interessante notar é que a adição da variável jerk, ao TTC, aumentou a acurácia da detecção de conflitos.

Depois, identificaram-se dois grupos de condutores em função da presença de conflitos em sua condução ou não. Os grupos com conflito tiveram valores de jerk estatisticamente menores do que os que se envolveram somente em interações normais. Isso não ocorreu com as desacelerações. 
A maioria dos veículos em conflitos registraram jerks mínimos negativos entre $-8 \mathrm{~m} / \mathrm{s}^{3} \mathrm{e}-10$ $\mathrm{m} / \mathrm{s}^{3}$. Como os vídeos representavam uma realidade para interações urbanas, os autores esperavam valores mais altos para usuários em rodovias. $\mathrm{O}$ estudo reiterou os benefícios de se incorporar os valores mínimos de jerk como indicador de conflitos. Ademais, um comportamento agressivo de direção, identificado a partir dos valores de jerk elevados, seria associado positivamente com o registro de conflitos.

A fim de melhorar o registro dos locais das ocorrências de trânsito, um método que utilizava valores limites de jerk associado ao uso de sistemas de navegação global por satelite (Global Navigation Satellite Systems - GNSS) e unidades de medida inerciais (Inertial Measurement Units - IMU) foi sugerido por Navidi e Landry (2017). Um dos objetivos do trabalho era identificar a posição de uma ocorrência a partir de um algoritmo de detecção baseado nos valores de jerk. Considerou-se que valores de jerk maiores que $20.00 \mathrm{~m} / \mathrm{s}^{3}$, ou menores que $20.00 \mathrm{~m} / \mathrm{s}^{3}$, indicariam uma ocorrência.

\subsubsection{Considerações sobre o uso da variável jerk}

A partir dos resultados dos estudos publicados, observa-se que existe forte tendência em se utilizar a variável jerk como indicadora de risco no tráfego, tanto com relação ao comportamento dos condutores como na indicação de locais menos seguros. Observou-se que os simuladores de direção foram pouco utilizados para esse fim.

Esse fato pode ter explicação na limitação existente nos sistemas de base fixa, realidade da maioria dos simuladores existentes. Sem a sensação de movimento, o estudo dessa variável pareceria inviável. Porém, poder-se-ia utilizá-la como medida indireta da variação dos perfis de velocidade, ou para caracterizar a intensidade com a qual os condutores utilizavam o pedal de freio.

Os simuladores de direção serão o tema abordado no próximo item desse capítulo. 


\subsection{Simuladores de direção}

Dirigir é uma das tarefas mais comuns entre os seres humanos, ao mesmo tempo ela também é uma das mais perigosas e complicadas. Essa ação faz uso de diversas funções corporais sensoriais, perceptuais, congnitivas e motoras - e é afetada por difererentes singularidades do comportamento do condutor - estado emocional e experiência (ALLEN; ROSENTHAL; COOK, 2011).

Mesmo que, no futuro, o desenvolvimento de veículos autônomos consiga diminuir os efeitos das falhas humanas nessa tarefa, a compreensão do comportamento dos motoristas ainda teria forte influência no avanço dos estudos para a segurança do tráfego. Para entender esse comportamento, se faz necessário o desenvolvimento de diferentes tipos de pesquisa, as quais conteriam variadas complexidades para sua execução. Essas incluiriam desde observações mais simplificadas do comportamento humano até análises mais difusas, como a observação do tráfego e suas interações. Entre esses extremos se posicionariam as pesquisas com simuladores de direção (SHINAR, 2017). Esses se situariam entre estudos naturalísticos e análises de registros de ocorrências (KONSTANTOPOULOS; CHAPMAN; CRUNDALL, 2010).

Nos estudos com simuladores de direção, os pesquisadores se deparariam com resultados que sofreriam tanto menos com a falta de controle de um experimento de campo, como com a dificuldade de generalização que um estudo laboratorial muito controlado afixaria. Porém as diferenças com tais tipos de pesquisas seriam estreitas (KANTOWITZ, 2011).

O emprego dos simuladores de direção requereria prolongado treinamento por parte dos pesquisadores. Porém, seu uso teria fundamental importância para testar, por exemplo: a eficácia de medidas mitigatórias na mudança de comportamento dos condutores; a capacidade de direção de motoristas idosos ou de pessoas que sofreram alterações e traumas neurológicos; o efeito de medicamentos; o impacto de modificações nos sistemas de controle de tráfego; e o uso de sistemas de auxílio à condução (FISHER et al., 2011).

O uso dos simuladores de direção seria fomentado quando os condutores experimentassem situações de risco. O uso dessa ferramenta permitiria não comprometer a segurança dos condutores e dos outros usuários da via. Ademais, ele facilitaria a obtenção de informações, como comportamentos de antecipação de riscos, os quais não teriam simplicidade de obtenção em campo (FISHER et al., 2007). 
As principais qualidades dessa ferramenta seriam: a segurança física proporcionada à amostra; a possibilidade de criar, e repetir, inúmeros fenômenos que poderiam não ocorrer durante uma condução típica; e o baixo custo para avaliar os efeitos das mais diversas propostas de medidas de segurança. A análise das respostas dessa ferramenta, em sinergia com outros métodos, favoreceria o progresso da segurança de tráfego. Afinal, o uso exclusivo dela limitaria a capacidade de extrapolação dos resultados para a realidade (SHINAR, 2017).

A alta segurança imposta ao condutor, fomentada pela diminuição da responsabilidade da tarefa de dirigir no ambiente simulado, promoveria comportamentos menos seguros, ou mais agressivos. Consequentemente, ao mesmo tempo que o comportamento dos condutores sofresse a influência da ausência das consequências de uma experiência real mais arriscada, seria possível experimentar, ou até tecer conclusões, sobre eventos mais raros, como ocorrências, com menor tempo e sem grandes prejuízos físicos à amostra (CAIRD; HORREY, 2011).

Os simuladores de direção diminuiriam os custos, aumentariam o controle das situações e reduziriam os riscos que um estudo de campo apresentaria. Os elementos principais de um simulador englobariam (ALLEN; ROSENTHAL; COOK, 2011):

- Sistemas sensoriais;

- Modelo do veículo;

- Computadores e sistemas eletrônicos;

- Cabines e controles;

- Algoritmos de registro;

- Armazenamento e análise de dados.

Esses sistemas sensoriais forneceriam aos condutores estímulos: visuais (imagens projetadas); auditivos (sons do ambiente); proprioceptivos (respostas dos sistemas de direção, pedais e mudanças de marcha); e de movimento (dinâmica do sistema).

Durante sua evolução, os pesquisadores se dedicaram em aumentar a representatividade do ambiente de direção simulado para os condutores. Isso envolveria a fidelidade dessas respostas sensoriais, do controle do veículo e nas tarefas de direção (ALLEN; ROSENTHAL; COOK, 2011). 


\subsubsection{Validade de uma simulação}

Fidelidade em simulação poderia ser definida sob duas óticas: 1. fidelidade física - seria o grau de proximidade que as características físicas de um simulador corresponderiam à de um veículo real; 2. fidelidade funcional - seria o grau de proximidade psicológica que as tarefas da simulação teriam com a vivência real da aplicação estudada. A habilidade de replicar as respostas encontradas nos experimentos, ou validade do mesmo, estaria mais relacionada com a tarefa estudada do que com o equipamento utilizado. Por isso seria incorreto, nessa área, tecer conclusões sobre a validade de um simulador. $\mathrm{O}$ mais correto seria avaliar a validade de uma simulação (FISHER et al., 2011).

A validação de um experimento poderia ser considerada: absoluta se os resultados dele fossem idênticos ao que ocorreria na realidade; ou relativa se os efeitos na simulação fossem correlacionados com a realidade. A segunda hipótese seria a mais provável de acontecer e ainda teria utilidade (KANTOWITZ, 2011).

Estabelecer a fidelidade e a validade de uma simulação seria um problema multidisciplinar. Existiriam três métodos típicos para esse fim: 1. a validação absoluta dos componentes desse sistema; 2. a comparação das respostas do simulador com as de veículos reais em experimentos controlados; 3. a comparação da variação dos comportamentos no simulador com observações reais não-controlados (ALLEN; ROSENTHAL; COOK, 2011).

Se a simulação reproduzisse com qualidade a memória da experiência de dirigir, ela poderia ser classificada como de alta fidelidade, senão seria de baixa fidelidade. Essa classificação dependeria do propósito do trabalho, uma mesma simulação poderia ter uma avaliação alta para um evento e baixa para outro. Seria importante definir um modo para avaliar o nível de relevância que essas falhas teriam nos resultados (GREENBERG; BLOMMER, 2011).

Tradicionalmente, os comportamentos registrados no simulador não seriam idênticos aos do campo, porém esses se correlacionariam. Uma alternativa de validação da associação desses ambientes seria a comparação entre as performances obtidas na simulação com comportamentos já identificados em campo, essa seria chamada de validação ecológica. Por exemplo, condutores homens seriam mais agressivos que mulheres. Desse modo as simulações teriam padrões de comportamentos validados sem medidas diretas de performance em campo (MULLEN et al., 2011). 
Os simuladores seriam ferramentas ideais para o desenvolvimento de projetos para rodovias. Várias possibilidades de sinalização, tanto horizontal como vertical, e geometria poderiam ser desenvolvidas com um custo excessivamente menor que se fossem avaliados, inicialmente, em trechos reais (KANTOWITZ, 2011). Alguns exemplos de experimentos relacionados estão apresentados no próximo item.

\subsubsection{Exemplos de trabalhos realizados a partir de simuladores de direção}

Um simulador de direção foi utilizado por Ariën et al. (2013) para analisar o efeito da construção de um pórtico na variação da velocidade empregada por condutores. O estudo registrou o comportamento de 46 motoristas que dirigiram por um cenário que simulava a transição entre um ambiente rural e um urbano.

O pórtico reduziu a velocidade média, porém o impacto foi somente local, próximo da estrutura. A estrutura interrompeu a homogeneidade do volume de tráfego e aumentou a variação da posição lateral dos veículos nas faixas.

Com o intuito de mostrar que o treinamento seria uma ferramenta importante para a mitigação das ocorrências de trânsito, Freeman et al. (2015) realizaram um experimento em simulador de direção para avaliar as reações dos condutores em situações de saída de pista, antes e depois de um treinamento por vídeo.

A amostra foi dividida, a fim de se obter um grupo de controle para o qual seria passado um vídeo placebo. Foram montados três cenários para as saídas de pista: uma pista dupla, uma curva horizontal e uma pista simples. Depois dos testes, a hipótese da pesquisa foi comprovada, o treinamento obteve influência positiva na reação em situações de saída de pista. As curvas horizontais foram os trechos mais desafiadores para os condutores.

Com enfoque nas curvas horizontais, Comte e Jamson (2000) avaliaram a eficácia de quatro métodos para a melhoria da segurança na negociação com essas. Eles testaram uma sinalização vertical, uma horizontal e dois sistemas inteligentes de transportes, um ativo e um passivo.

O ITS ativo, que restringia a velocidade do veículo de acordo com o trecho da via, teve as menores variações na velocidade e na posição dos veículos, porém esse teve as piores notas de aceitabilidade pelos condutores. 
Na mesma linha, Charlton (2007) examinou o papel de diversos tipos de medidas para alertar os condutores sobre os riscos associados às curvas a jusante. Para tanto, o mesmo realizou dois experimentos.

No primeiro, comparou quatro tipos de sinalizações verticais e quatro tipos de marcações horizontais com as medidas típicas utilizadas para avisar sobre o risco de uma curva à frente. No segundo, combinou a sinalização vertical e a marcação horizontal mais eficientes, do primeiro experimento, e avaliou a mudança na velocidade adotada pelos condutores.

As faixas com sonorizadores tiveram o melhor desempenho na redução da velocidade, porém os herringbones tiveram um grande efeito na posição dos veículos. Isso reiterou o potencial do uso do estreitamento da via para um melhor controle dos motoristas.

Para reduzir a velocidade empregada, realizou-se, na Bélgica, um estudo, em simulador de direção e em trecho real, para avaliar os efeitos de dois novos tipos de marcações horizontais. A primeira consistia em faixas brancas paralelas à borda externa da pista, com meio metro de comprimento, repetidas a cada 50 metros. A segunda era feita a partir da pintura de um caractere “7”, na mesma posição do anterior, a fim de repetir o alerta sobre o limite de velocidade.

Cada voluntário passou por três cenários: um com a primeira marcação; um com a segunda; e um sem nenhuma delas. As marcações novas não surtiram efeito quanto à velocidade, porém essas melhoraram a posição lateral dos veículos em relação ao eixo da via (DANIELS et al., 2010).

Calvi (2015) realizou um experimento fatorial, do tipo $3^{2} \times 2^{3}$, com 30 estudantes do departamento de engenharia da Universidade de Roma, também em simulador de direção, para avaliar as características do design das vias e suas relações com o comportamento dos condutores nas curvas horizontais. Para tanto, foram criados três cenários com características de três classes de projeto diferentes (pista simples sem acostamento, pista simples com acostamento e pista dupla com acostamento e canteiro central), porém com geometria idêntica (24 curvas horizontais criadas em função de três tamanhos de raios, duas direções, duas condições de visibilidade e a presença ou ausência de curvas de transição). 
Desse trabalho, concluiu-se que os condutores empregaram velocidades maiores nas pistas duplas, com maiores raios, visibilidade irrestrita e presença de curvas de transição. Com relação à trajetória, essa ficou mais comprometida nas pistas mais largas, em situações de visibilidade livre e na ausência de curvas de transição. Ou seja, nesse estudo, os condutores foram mais agressivos em condições mais seguras e mais cautelosos em condições de desconforto.

Apesar do grande potencial de utilização, é necessário entender os problemas e limitações que essas ferramentas têm (CAIRD; HORREY, 2011). Alguns dos problemas enfrentados pelo seu emprego seriam: a dificuldade em estudar a direção noturna; a retroreflectância nas sinalizações verticais; e as respostas dos condutores em car-following (FISHER et al., 2011).

\subsubsection{Limitações dos simuladores de direção}

Todos os trabalhos apresentados anteriomente utilizaram para sua realização, simuladores com base fixa, ou seja, seus sistemas não forneciam sensações de movimentações físicas aos condutores.

Esse tipo de simulador fora muito empregado para estudos de distração, fadiga e sinalização, porém esse não era indicado para trabalhos que necessitassem de sensações corporais de desaceleração. Para tanto, seria fomentado o uso de simuladores de base móvel, apesar do seu alto custo e da baixa capacidade desses em recriar as sensações reais de campo (HANCOCK; SHERIDAN, 2011).

Siegler et al. (2001) avaliaram a contribuição da adição de uma base móvel à execução de frenagens e conversões em um simulador de direção. Para tanto, esses realizaram um experimento em um simulador de base móvel para avaliar a frenagem de 11 condutores.

Esses eram convidados a alcançar a velocidade de $80 \mathrm{~km} / \mathrm{h}$ e frear até que o veículo parasse. Isso fora repetido por 16 vezes com cada motorista - metade da amostra realizou essa tarefa 8 vezes seguidas com a base móvel desligada e 8 seguidas com ela ligada e a outra metade fez o oposto. Nesse estudo, avaliou-se os três primeiros segundos seguintes a cada frenagem e o jerk fora calculado a partir da média dos valores para a primeira metade desse intervalo. Os resultados sugeriram que a aplicação da base móvel reduziria o valor das desacelerações e do jerk aplicados, os quais se aproximariam mais de valores de experimentos reais. As velocidades não tiveram diferenças significativas entre métodos. 
Houve também uma maior adaptação do comportamento de frenagem na base estática. Desse modo a cada teste, os condutores aumentavam a pressão nos freios, enquanto que na base móvel, esse comportamento não ocorria. Concluiu-se que os condutores teriam comportamentos mais abruptos com a plataforma estática em função da diminuição do número de pistas sobre o fenômeno experimentado. Se além das sensações visuais e auditivas, o condutor tivesse o estímulo do movimento, o comportamento de frenagem seria menos extremo, pois existiriam mais pistas sobre o risco da situação. Na base estática, a frenagem viria desacompanhada da sensação do movimento. Esse conflito seria uma das maiores causas de enjôos em simulações. Porém, a movimentação real seria difícil, ou até considerado impossível, de ser recriada por bases móveis, em função das limitações das amplitudes das desacelerações e dos movimentos possibilitados por elas.

A tarefa de direção é orientada pelas sensações das forças de aceleração, frenagens e mudanças de direção. Essas informações aumentariam o controle dos veículos. As experiências de um condutor em uma simulação seriam propiciadas por encenações de sensações reais. Cada uma dessas representações induziria a uma distribuição de erros ou distorções. Nenhum sistema estaria livre desses. Seria importante deixá-los claros para uma melhor interpretação dos resultados (GREENBERG; BLOMMER, 2011).

Além do uso da base fixa, outro fator que potencializaria o risco de enjôos seria o tamanho do campo de visão das telas projetadas. Um grande campo potencializaria uma maior estimulação periférica da visão, esse fato fomentaria a impressão de movimento mesmo com o condutor parado. Essa contradição induziria a uma maior probabilidade de mal-estar (ANDERSEN, 2011).

Outro dilema dos simuladores é que essas ferramentas mediriam, primordialmente, a performance da condução, ou seja, eles registrariam quão bem um condutor teria a capacidade de realizar uma tarefa. No entanto, os estudos sobre segurança estariam mais interessados no comportamento dos condutores, ou seja, nas escolhas que eles fariam e, principalmente, nas interações dessas. Por exemplo, um condutor de 20 anos provavelmente registraria performances superiores a um motorista de 50 anos no simulador, porém o mais experiente poderia ter um risco muito menor de provocar ocorrências na condução real (CAIRD; HORREY, 2011). 
Esses problemas fazem com que as respostas dos experimentos com simuladores de direção sejam questionadas por pesquisadores em função da presunção da falta de realismo dos experimentos. Mesmo que a fidelidade fosse aumentada, não necessariamente a fidelidade psicológica cresceria conjuntamente. Essa seria muito influenciada pelo engajamento da amostra. Mesmo os simuladores mais modernos teriam dificuldades em atingir uma característica muito importante das viagens, o seu propósito. A variação da motivação na vida real já tem efeito na direção. Um mesmo condutor em viagem rotineira à trabalho, provavelmente, teria performances e comportamentos diferentes de um deslocamento por lazer. Um dos métodos sugeridos para contornar essa influência em ambiente simulado seria a gratificação monetária por boa performance. Mesmo assim, o efeito dessa abordagem ainda seria discutível (RANNEY, 2011).

Mesmo assim, os experimentos com simuladores de direção poderiam ser entendidos como um primeiro passo para o desenvolvimento, e validação, de equipamentos e tarefas adicionadas à condução de veículos. Testes em campo seriam os passos finais para a confirmação das conclusões encontradas. Para tanto, a simulação deveria emular as condições esperadas no ambiente real. Suas respostas permitiriam a economia de recursos em função da filtragem das muitas possibilidades existentes na fase de protótipo (ANGELL, 2011).

Ao mesmo tempo que os simuladores tem a vantagem ética de oferecer menos risco aos condutores, essa vantagem acaba por modificar a motivação deles. O que induziria a um comportamento de maior risco (JAMSON, 2011).

As pequisas com simulador de direção acabam por trocar o realismo pelo controle experimental (RANNEY, 2011). Essas ferramentas teriam um grande custo-benefício em replicar as mesmas condições experimentais com um menor risco associado. $\mathrm{O}$ uso desse equipamento seria uma boa fonte de evidências sobre comportamentos e níveis de performance (FISHER et al., 2011).

\subsubsection{Simuladores como ferramenta de estudo}

Os trabalhos com simuladores de direção tiveram seus primeiros registros no começo da década de 1930. Eles, inicialmente, foram imaginados como ambiente para testes compulsórios de possíveis condutores. A finalidade dessa medida era diminuir a aversão existente na população pelo grande número de mortes e machucados causados por ocorrências de trânsito da época (CAIRD; HORREY, 2011). 
A base dos procedimentos das pesquisas com simuladores de direção, fundalmentalmente, incluiria o desenvolvimento de cenários, a partir de variáveis independentes (eventos, características geométricas), dos quais se registrariam as variáveis dependentes (comportamentos, performances) de interesse (ALLEN; ROSENTHAL; COOK, 2011).

O cenário definiria as configurações e condições da simulação, ele englobaria tanto a estrutura estática do ambiente - rodovia, terreno - como as condições dinâmicas - tráfego, eventos críticos (KEARNEY; GRECHKIN, 2011). Ele deveria conter elementos que fomentassem os comportamentos relevantes desejados pelo trabalho (ALLEN; ROSENTHAL; COOK, 2011).

O desenvolvimento de cerários teria como principal objetivo criar uma experiência que pudesse ser replicada para cada condutor da amostra, a fim de possibilitar a comparação entre eles. Mesmo assim, um mesmo condutor poderia apresentar variações de performance em função de mudanças de humor ou sensações de urgência, por exemplo. Essa natureza metamórfica da condução tornaria cada simulação única. Para garantir a consistência entre experimentos, o pesquisador deveria identificar, e controlar, os fatores que influenciariam o comportamento dos condutores a fim de replicar somente as circunstâncias fundamentais para o objetivo do trabalho. Interações não previstas, com características estranhas do ambiente, poderiam gerar conflitos que interfeririam nas performances dos condutores (KEARNEY; GRECHKIN, 2011).

Como forma de diagnóstico da influência dessas variáveis nas respostas dos condutores, comumente utilizou-se em experimentos com simulador de direção a análise de variância de medidas repetidas (Repeated Measures Analysis of Variance - ANOVA RM). Ademais, aplicou-se a correção de Bonferroni para as comparações múltiplas (MILLOY; CAIRD, 2011).

A identificação do método de análise estatística seria essencial para o sucesso do experimento, essa deveria ser incorporada desde o início e necessitaria se estender por todas as etapas restantes da pesquisa. Uma das vangentes dos estudos de medidas repetidas seria o fato de que cada condutor serviria como seu controle, assim o poder estatístico do experimento aumentaria. O problema dessa abordagem era o efeito do aprendizado - uma condição experimental poderia influenciar a próxima. Para tanto seria fundamental a aleatorização dos tratamentos pelos condutores. Ainda, se as respostas não se aproximassem de uma distribuição normal, seria conveniente transformar numericamente os dados (DAWSON, 2011). 
A escolha das variáveis dependentes estaria sujeita às questões estudadas. Dentre as possibilidades existentes se destacariam os registros relacionados ao controle longitudinal dos veículos, ao tempo de reação dos condutores, ao número de infrações, ao controle lateral do veículo, aos movimentos dos olhos e à carga mental associada à tarefa (CAIRD; HORREY, 2011). O uso de métricas de performance permitiria quantificar com maior objetividade tanto os comportamentos dos condutores como o sistema (KEARNEY; GRECHKIN, 2011).

Apesar da improbabilidade em se reproduzir a fidelidade visual do mundo real, o objetivo primordial das pesquisas com simuladores se baseava na análise das respostas que os condutores dariam à diferentes informações visuais projetadas na tela. Ao conduzir um veículo, por exemplo, as informações visuais extraídas do entorno seriam utilizadas pelos condutores para melhorar a performance na realização de tarefas, inclusive nas frenagens (ANDERSEN, 2011).

\subsubsection{Considerações sobre o uso dos simuladores de direção}

Os simuladores de direção são uma das ferramentas utilizadas para o desenvolvimento da área de segurança de tráfego. Suas respostas devem ser encaradas como indícios para propostas de mudança. Portanto, deve-se replicar os métodos em outros ambientes para uma maior generalização das conclusões obtidas.

A segurança imposta por essa ferramenta aos condutores induziria comportamentos menos seguros, como o emprego de velocidades maiores. Esse desvio poderia ser tomado, naturalmente, como uma desvantagem, porém o fomento de performances menos seguras, desde que distribuído de forma similar pela amostra, possibilitaria o estudo de eventos mais raros.

Deve-se tentar validar os resultados dos experimentos. Uma das abordagens empregadas para esse fim seria a validação ecológica. Por ela, os comportamentos registrados no simulador seriam comparados com resultados já densificados no estado da arte do objetivo proposto. Apesar da indicação do uso da base móvel para experimentos que investigassem efeitos de modificações de aceleração nas conduções, o seu uso implicaria em um alto custo de incorporação, sem a garantia de comprovação de sua eficácia. A característica visual que a tarefa de direção primordialmente tem incentivaria o desenvolvimento de estudos iniciais desse tipo mesmo sem a presença dessa tecnologia. 



\section{MATERIAL E MÉTODO}

Para a realização dos objetivos prospostos, com base nas referências e no problema específico estudado, optou-se pela realização de um experimento controlado do tipo fatorial relacionado (método) a partir de um simulador de direção estático (material). Esses itens serão apresentados na sequência. No final do capítulo, o experimento empreendido será detalhado.

\subsection{Material}

Para a realização do trabalho pretendido, adotou-se como ferramenta o simulador de direção estático do Departamento de Engenharia de Transportes, da Escola de Engenharia de São Carlos da Universidade de São Paulo. Para melhor caracterização, esse sistema poderia ser dividido em duas partes: o equipamento (hardware) e o programa (software).

\subsubsection{Equipamento}

O simulador era composto por um cockpit de base fixa equipado com um sistema de direção Logitech $\mathrm{G} 27$ e uma tela plana $(1,425 \mathrm{~mm}$ x $800 \mathrm{~mm}$ ) com imagens retroprojetadas (projetor DepthQ HDs3D2 com 1080 p de resolução e $60 \mathrm{~Hz}$ de taxa de atualização, campo de visão horizontal de $120^{\circ}$ e vertical de $50^{\circ}$ ). A Figura 6 apresenta um esquema da interface utilizada.

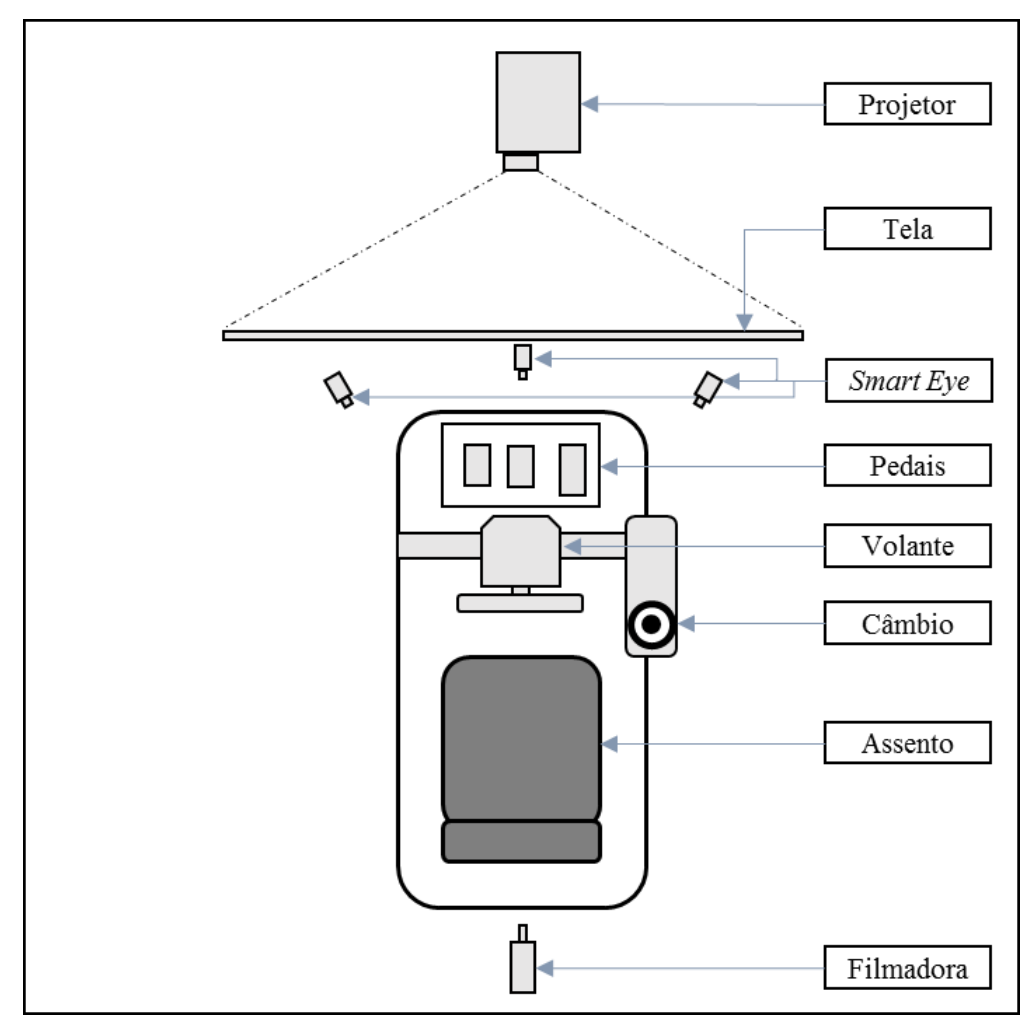

Figura 6 - Esquema da interface com o usuário do simulador utilizado na pesquisa 
Apesar da disponibilidade da manopla de câmbio e do pedal da embreagem, esses não foram utilizados. Os condutores utilizaram um sistema de trocas semi-automático, onde era necessária a utilização de borboletas atrás do volante para fazer as mudanças de marchas. Essa limitação foi causada pela incompatibilidade do software que controlava o veículo virtual com o sistema de direção.

Existia ainda no simulador um sistema de captura do olhar (Smart-Eye $\left.{ }^{\circledR}\right)$, o qual registrava a partir de 4 câmeras ( 3 frontais e 1 traseira) a posição para onde os condutores fixavam sua visão durante a simulação.

A Figura 7 apresenta algumas imagens do simulador utilizado na pesquisa. Nela é possível notar a câmera traseira, os computadores pelos quais o pesquisador monitorava a simulação, os comandos utilizados pelo condutor e as câmeras frontais.

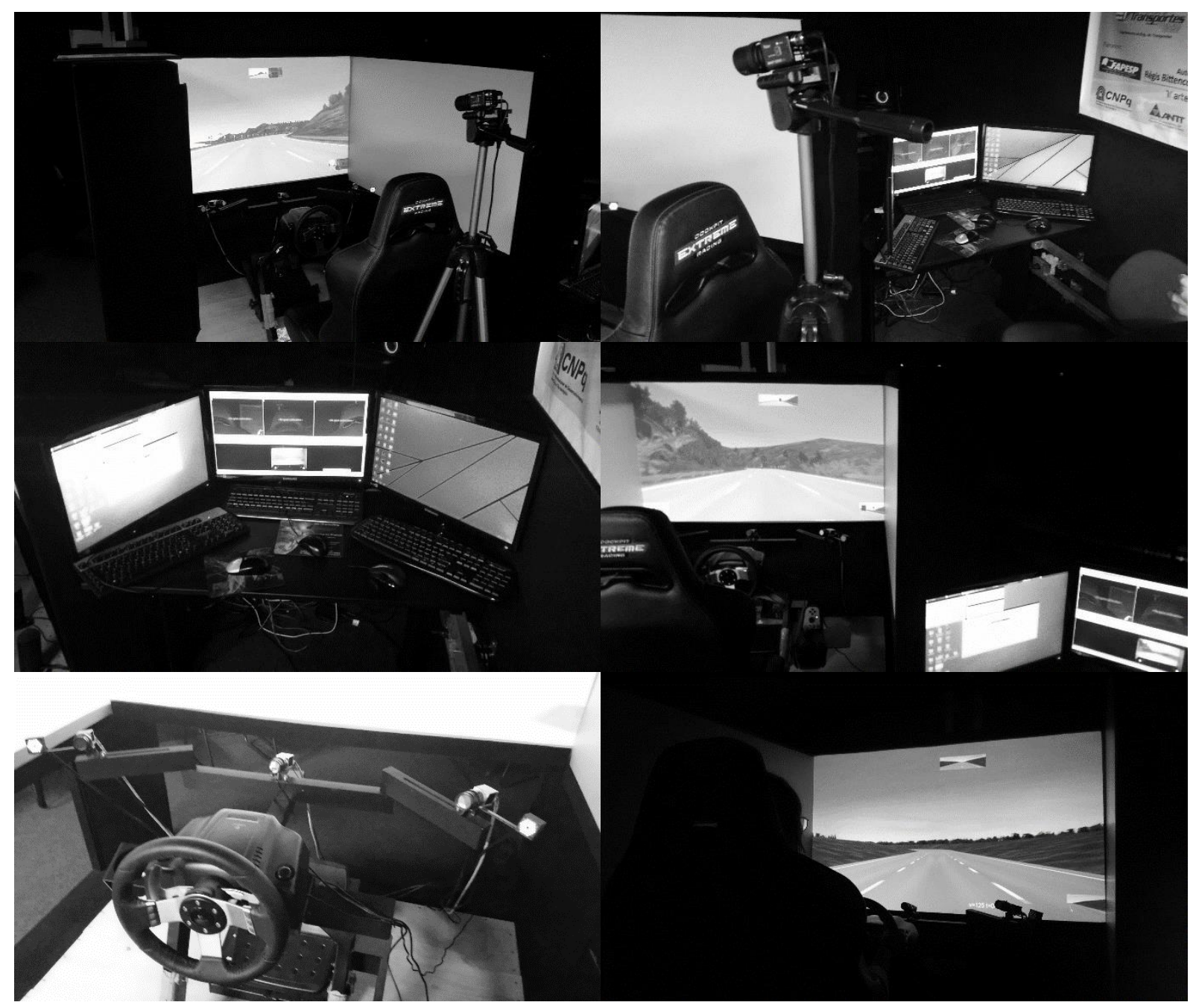

Figura 7 - Imagens do simulador utilizado na pesquisa 


\subsubsection{Programa}

A simulação foi possibilitada a partir do uso de três softwares: (1) Vires Virtual Test Drive programa que possibilitou a construção da rodovia, a pré-configuração do ambiente experimentado e a emulação do cenário virtual final; (2) VI-Grade VI-CarRealTime 16 programa que gerenciou a simulação do veículo (Citroen C3); e (3) Smart Eye Recorder programa que registrava o rastreio do olhar dos condutores.

A Figura 8 apresenta uma tela de um dos pacotes do primeiro software citado. Ela exemplifica o processo de construção de um cenário virtual utilizado nessa pesquisa (o desenvolvimento desse será melhor abordado no item 3.3). A porção esquerda do topo da imagem apresenta o eixo da via, a porção direita apresenta uma projeção do cenário virtual futuro (delimitado pela caixa preta) e a porção inferior apresenta a distribuição da superelevação durante o percurso.

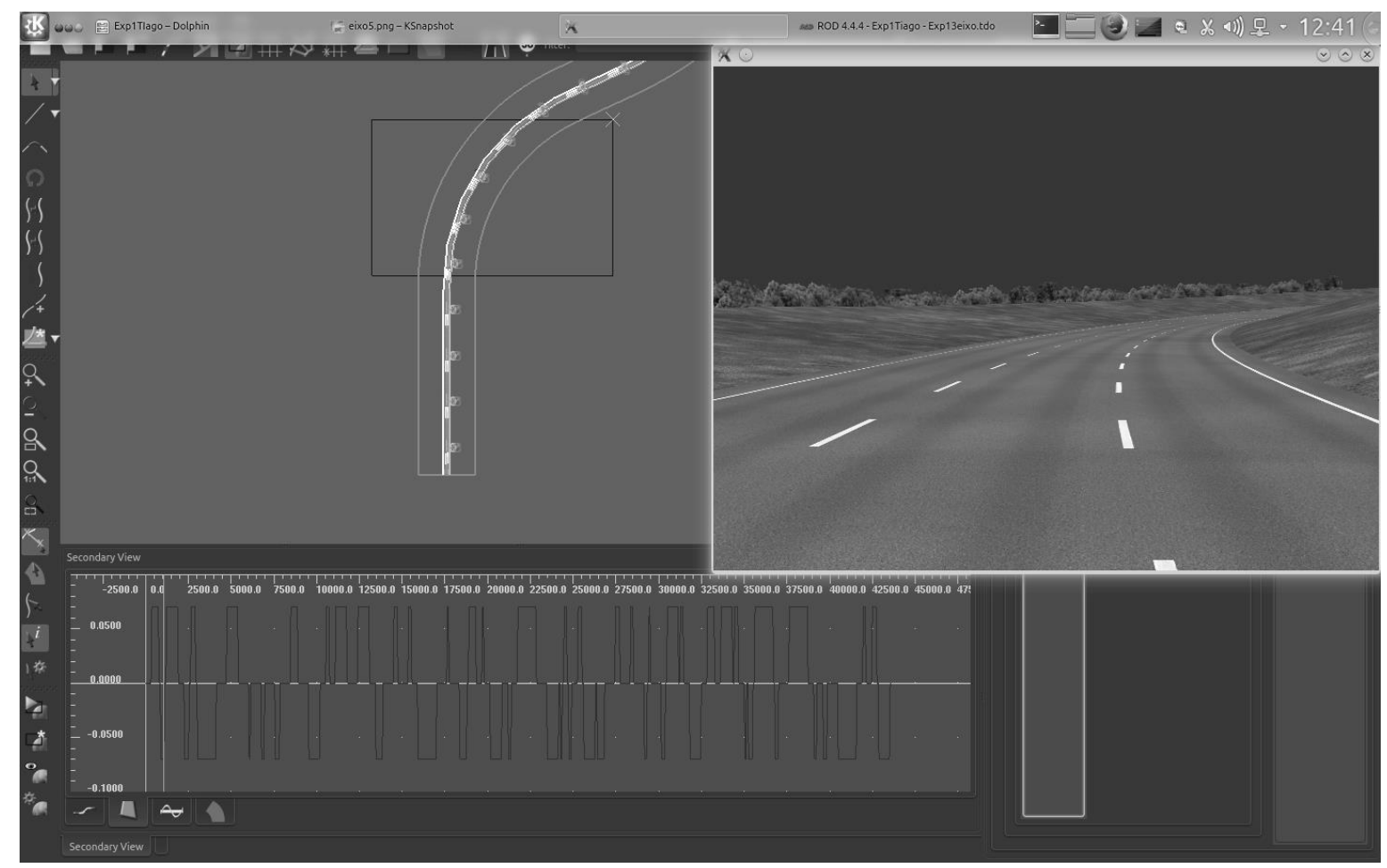

Figura 8 - Interface da construção do cenário virtual

O modelo multicorpo do veículo utilizado foi cedido, e calibrado, pela PSA Peugeot Citroën do Brasil. Esse representava as características de um veículo compacto Citroën C3. O trabalho intitulado "Conceito, configuração e aplicação de um simulador de direção no Brasil - Estudo de caso" (DOS SANTOS et al., 2017) descreveu com mais detalhes a ferramenta utilizada. Esse simulador já fora adotado como ferramenta por outros pesquisadores do grupo (VIEIRA, 2016; VIEIRA; LAROCCA, 2017). 


\subsection{Método}

Como enunciado, para responder às perguntas feitas, um experimento controlado, do tipo fatorial relacionado, fora desenvolvido com condutores reais em ambiente de direção simulada.

O experimento controlado é um dos métodos utilizados nas pesquisas explicativas. Nele o pesquisador estabeleceria fatores experimentais, que seriam aplicados a uma amostra geralmente limitada. Nesse tipo de pesquisa é incomum a utilização da amostragem aleatória. Esse fato tornaria a relevância dos resultados crítica, pois os sujeitos seriam definidos em função da disponibilidade da população objetivo. Ainda assim esse experimento teria eficiência no controle das características explanatórias. Para diminuir o erro da pesquisa, seriam importantes o controle e a aleatorização da atribuição dos tratamentos à amostra. O intuito dessas medidas seria reduzir a tendenciosidade e aumentar o controle de características estranhas que diminuiriam a validade da pesquisa (SILVA, 2007).

Em experimentos fatoriais relacionados, as variáveis dependentes são mensuradas a partir da experimentação da combinação dos níveis de mais de uma variável independente - tratamentos - pelas mesmas pessoas (FIELD, 2009). Essa prática é comum em pesquisas realizadas a partir de simuladores de direção.

Para a delineação final do experimento fora necessário definir: as variáveis dependentes; as variáveis independentes; as variáveis de controle; as variáveis moderadoras; as variáveis estranhas; a análise estatística; e o tamanho da amostra.

\subsubsection{Variável dependente}

A variável dependente é a saída do experimento, a resposta que depende dos tratamentos experimentados. Para o desenvolvimento do primeiro objetivo específico, o jerk mínimo adotado pelos condutores entre o ponto médio das tangentes de aproximação e o ponto médio das curvas foi registrado como variável dependente. Essa restrição espacial foi tomada para seguir as abordagens tradicionais e evitar a influência das curvas adjacentes ao tratamento analisado. Glennon, Neuman e Leisch (1983) observaram, em estudos de campo, que os condutores ajustavam suas velocidades a menos de 90 metros antes do ponto de curva (PC). Em curvas mais fechadas, as reduções ocorriam após esse ponto. Condutores mais agressivos, não ajustavam suas velocidades até que a curva fosse iminente. Provavelmente, a maior parte da redução de velocidade ocorreria nas tangentes de aproximação (ANDERSON et al., 1999). 
Além disso, para o desenvolvimento do segundo objetivo específico, registraram-se as diferenças de velocidade adotadas nas abordagens tradicionais, com as quais se desejava fazer comparações ( $\triangle \mathrm{V}$ e MSR).

\subsubsection{Variáveis independentes}

As variáveis independentes são as entradas do experimento. São os fatores dos quais se deseja entender o efeito de suas variações nas respostas. Para a definição dessas, o experimento proposto neste trabalho adotou como base um trecho real de 10 quilômetro, o mesmo fora melhor apresentado no capítulo de introdução dessa tese. Esse foi escolhido pois fora objeto de estudo de outros trabalhos do grupo de pesquisa e tinha características geométricas e parâmetros de projeto que propiciavam o registro de um número elevado de saídas de pista.

Apesar da direção Norte desse segmento $(510 \mathrm{~km}$ ao $519 \mathrm{~km})$ conter a maioria dos registros, provavelmente influenciado pelo greide, optou-se por melhor investigar as ocorrências da direção Sul, a fim de dar continuidade com os estudos do grupo de pesquisas. Entre setembro de 2008 e junho de 2015 foram registradas 876 ocorrências com 1.602 ilesos, 193 vítimas leves, 33 moderadas, 4 graves e 3 fatais. As ocorrências foram majoritariamente registradas em curvas acentuadas. Foram principalmente do tipo saída de pista, 291 casos. A Figura 9 apresenta os registros divididos pelo traçado da pista e o tipo de ocorrência.

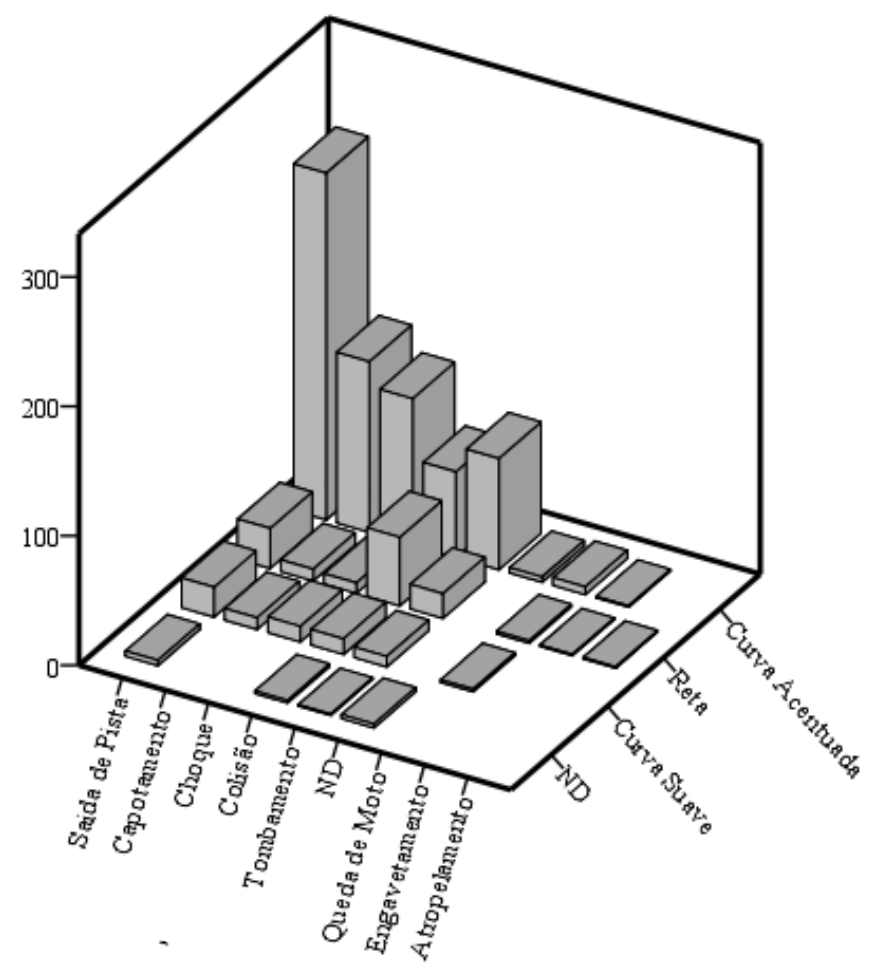

Figura 9 - Distribuição das ocorrências em função dos tipos e do traçado 
Observa-se do gráfico a grande representatividade das saídas de pista em curvas acentuadas que foram registradas nesse trecho. Esse trecho era formado por 20 curvas horizontais e suas tangentes de ligação. Suas características geométricas estão apresentadas na Tabela 7. A tabela tem suas linhas organizadas de acordo com a ordem natural de aparição das curvas para os condutores no sentido do tráfego.

Tabela 7 - Dados geométricos das curvas estudadas

\begin{tabular}{|c|c|c|c|c|c|}
\hline \multirow{2}{*}{ Curva } & $\begin{array}{c}\text { Comprimento } \\
\text { do raio }\end{array}$ & $\begin{array}{c}\text { Comprimento } \\
\text { da curva }\end{array}$ & $\begin{array}{l}\text { Deflexão } \\
\text { da curva }\end{array}$ & $\begin{array}{c}\text { Comprimento } \\
\text { da tangente }\end{array}$ & \multirow{2}{*}{$\begin{array}{l}\text { Direção } \\
\text { da curva }\end{array}$} \\
\hline & {$[\mathrm{m}]$} & {$[\mathrm{m}]$} & {$\left[^{\circ}\right]$} & {$[\mathrm{m}]$} & \\
\hline 01 & 130 & 347 & 82,4 & 50 & Direita \\
\hline 02 & 130 & 338 & 96,1 & 65 & Esquerda \\
\hline 03 & 130 & 174 & 23,8 & 40 & Direita \\
\hline 04 & 615 & 142 & 13,2 & 235 & Direita \\
\hline 05 & 190 & 166 & 1,8 & 310 & Esquerda \\
\hline 06 & 130 & 261 & 44,4 & 275 & Esquerda \\
\hline 07 & 180 & 341 & 70,2 & 50 & Direita \\
\hline 08 & 230 & 263 & 20,6 & 65 & Esquerda \\
\hline 09 & 615 & 345 & 32,1 & 245 & Direita \\
\hline 10 & 190 & 369 & 57,0 & 115 & Esquerda \\
\hline 11 & 190 & 352 & 51,7 & 50 & Direita \\
\hline 12 & 230 & 162 & 0,5 & 300 & Direita \\
\hline 13 & 605 & 170 & 16,0 & 50 & Esquerda \\
\hline 14 & 130 & 205 & 19,7 & 570 & Esquerda \\
\hline 15 & 230 & 270 & 22,3 & 185 & Direita \\
\hline 16 & 190 & 288 & 32,5 & 215 & Direita \\
\hline 17 & 155 & 217 & 21,0 & 330 & Direita \\
\hline 18 & 215 & 342 & 43,3 & 45 & Esquerda \\
\hline 19 & 285 & 564 & 73,1 & 395 & Esquerda \\
\hline 20 & 185 & 424 & 81,7 & 168 & Direita \\
\hline
\end{tabular}

Observa-se que no trecho existia grande variação nas características geométricas das curvas: elementos com pequenos raios (130 metros), elementos com ângulos centrais grandes $\left(96,1^{\circ}\right) \mathrm{e}$ elementos com tangentes de aproximação compridas (570 m). Para buscar relações existentes, a Tabela 8 apresenta o valor das correlações entre as saídas de pista registradas em diversos períodos e as características geométricas das curvas. 
Tabela 8 - Distribuição das ocorrências em função da curva e do ano de registro

\begin{tabular}{|c|c|c|c|c|c|c|c|c|c|c|}
\hline Saídas de Pist & & 08 15 & 2008 & 2009 & 2010 & 2011 & 2012 & 2013 & 2014 & 2015 \\
\hline \multirow{2}{*}{$\begin{array}{l}\text { Comprimento } \\
\text { do raio }\end{array}$} & $\mathbf{R}$ & $-0,227$ & 0,193 & $-0,265$ & $-0,189$ & $-0,239$ & $-0,182$ & $-0,113$ & $-0,043$ & $-0,476$ \\
\hline & s & 0,336 & 0,416 & 0,259 & 0,426 & 0,309 & 0,443 & 0,634 & 0,857 & $\mathbf{0 , 0 3 4}$ \\
\hline \multirow{2}{*}{$\begin{array}{l}\text { Comprimento } \\
\text { da curva }\end{array}$} & $\mathbf{R}$ & $-0,113$ & $-0,080$ & $-0,032$ & $-0,088$ & $-0,090$ & $-0,147$ & $-0,214$ & $-0,185$ & 0,315 \\
\hline & $\mathbf{s}$ & 0,637 & 0,737 & 0,895 & 0,713 & 0,705 & 0,536 & 0,365 & 0,434 & 0,177 \\
\hline \multirow{2}{*}{$\begin{array}{l}\text { Deflexão } \\
\text { da curva }\end{array}$} & $\mathbf{R}$ & 0,083 & 0,029 & 0,193 & 0,116 & 0,126 & $-0,074$ & $-0,149$ & $-0,053$ & $\mathbf{0 , 5 9 1}$ \\
\hline & $\mathbf{s}$ & 0,728 & 0,905 & 0,416 & 0,626 & 0,597 & 0,755 & 0,531 & 0,824 & 0,006 \\
\hline \multirow{2}{*}{$\begin{array}{l}\text { Comprimento } \\
\text { da tangente }\end{array}$} & $\mathbf{R}$ & 0,272 & $-0,347$ & 0,093 & 0,149 & 0,194 & 0,483 & 0,529 & 0,174 & $-0,113$ \\
\hline & $\mathbf{s}$ & 0,246 & 0,134 & 0,698 & 0,529 & 0,412 & 0,031 & 0,016 & 0,462 & 0,635 \\
\hline
\end{tabular}

Não existiu correlação significativa para o período todo de análise (08 15). Entretanto, para o ano de 2015 é possível pressupor que o comprimento do raio teve correlação moderada negativa nas saídas de pista. Quanto maior a dimensão, menor o número de ocorrências. A deflexão da curva, para o mesmo ano, e o comprimento das tangentes de aproximação, para os anos de 2012 e 2013, tiveram correlações positivas com as ocorrências. Quanto maior o valor desses, maior a chance de uma ocorrência desse tipo ser registrada.

Como indicado, a significância não foi forte na maioria dos casos, e a conclusão não poderia ser tomada para todos os anos registrados, apenas para alguns de maneira isolada. É importante salientar que o comprimento total das curvas não teve correlação significativa em nenhum dos períodos estudados. Em decorrência desses resultados, os fatores identificados para o experimento seriam as características geométricas: comprimento do raio de curvatura, ângulo de deflexão da curva e comprimento da tangente de aproximação.

Porém, para esse estudo, optou-se por não investigar a influência da variação dos ângulos de deflexão das curvas nas respostas. Isso porque, as abordagens com as quais se desejava comparar o método proposto não utilizavam essa variável em seus modelos de previsão $(\Delta \mathrm{V}$ e MSR) e existiria maior dificuldade na identificação dos efeitos dos contrastes com um maior número de fatores e, por consequência, de tratamentos.

Para definir os níveis dos dois fatores restantes (Tabela 9), optou-se por trabalhar com os extremos, inferiores e superiores, existentes nas curvas do trecho real e com um valor equidistante desses. Para facilitar a construção do nível intermediário do fator "comprimento do raio da curva", optou-se por diminuir o nível inferior em cinco metros. 
Tabela 9 - Definição dos níveis dos fatores adotados

\begin{tabular}{cccr}
\hline \multirow{2}{*}{ Níveis } & \multicolumn{2}{c}{ Comprimento do raio da curva } & \multicolumn{2}{c}{ Comprimento da tangente de aproximação } \\
\cline { 2 - 4 } & {$[\mathrm{m}]$} & & {$[\mathrm{m}]$} \\
\hline Inferior & 125 & 50 \\
Intermediário & 370 & 310 \\
Superior & 615 & 570 \\
\hline
\end{tabular}

Os valores adotados para os raios das curvas representariam bem as relações existentes na literatura desses com as ocorrências (Figura 10). O valor inferior, 125 metros, estaria próximo das taxas mais altas (assíntota vertical); o intermediário, 370 metros, estaria próximo da inflexão; e o superior, 615 metros, estaria próximo da região estabilizada (assíntota horizontal).

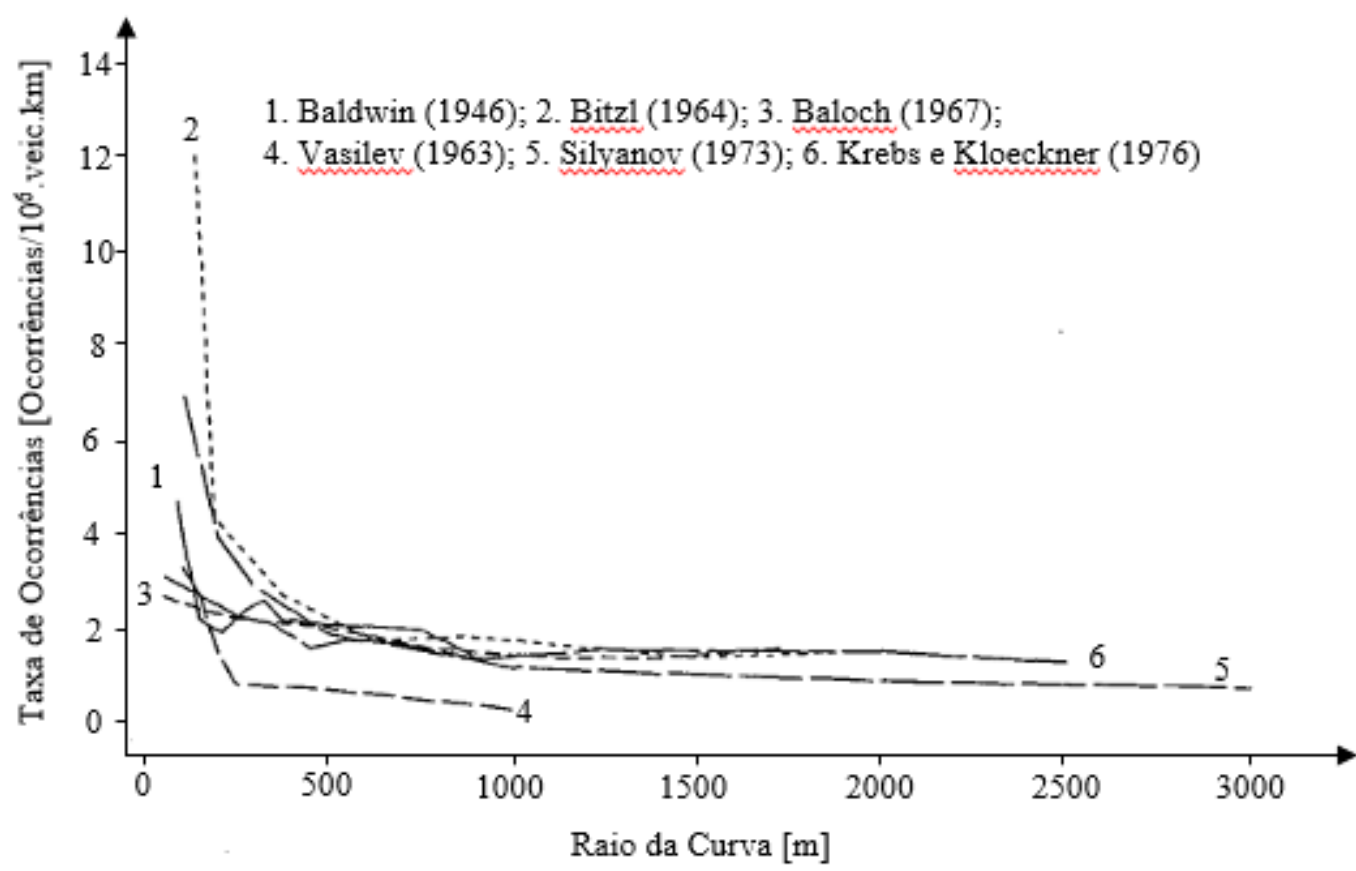

Figura 10 - Relações existentes entre os raios das curvas e as taxas de ocorrências Fonte: Adaptado de CHOUEIRI et al. (1994, p. 36)

A combinação dos três níveis dos dois fatores resultou em nove diferentes tratamentos. Para dividir os cenários, um tratamento adicional foi criado com dimensões duas vezes maiores que os níveis superiores da Tabela 9. A Tabela 10 apresenta os tratamentos resultantes. 
Tabela 10 - Definição dos tratamentos apresentados aos condutores

\begin{tabular}{|c|c|c|c|c|}
\hline \multirow{2}{*}{ ID } & \multirow{2}{*}{ Nome } & Comprimento do raio da curva & Comprimento da tangente de aproximação & \multirow{2}{*}{ Direção } \\
\hline & & {$[\mathrm{m}]$} & {$[\mathrm{m}]$} & \\
\hline 1 & $\mathrm{Rp}-\mathrm{Tp}$ & 125 & 50 & Esquerda \\
\hline 2 & Rp-Tm & 125 & 310 & Esquerda \\
\hline 3 & $\mathrm{Rp}-\mathrm{Tg}$ & 125 & 570 & Direita \\
\hline 4 & $\mathrm{Rm}-\mathrm{Tp}$ & 370 & 50 & Esquerda \\
\hline 5 & $\mathrm{Rm}-\mathrm{Tm}$ & 370 & 310 & Esquerda \\
\hline 6 & $\mathrm{Rm}-\mathrm{Tg}$ & 370 & 570 & Esquerda \\
\hline 7 & $\operatorname{Rg}-\mathrm{Tp}$ & 615 & 50 & Direita \\
\hline 8 & $\mathrm{Rg}-\mathrm{Tm}$ & 615 & 310 & Direita \\
\hline 9 & $\mathrm{Rg}-\mathrm{Tg}$ & 615 & 570 & Direita \\
\hline 0 & - & 1,230 & 1,140 & Esquerda \\
\hline
\end{tabular}

\subsubsection{Variáveis de controle}

As variáveis de controle são parâmetros constantes que tem a finalidade de diminuir a possibilidade de aumentar as variações não planejadas no experimento (SHINAR, 2017). Para o desenvolvimento desse experimento, além da tentativa da padronização do procedimento de coleta, algumas características do cenário foram mantidas fixas: o ângulo de deflexão das curvas, a direção das curvas, a declividade longitudinal e o tráfego.

A deflexão adotada para as curvas foi de $56^{\circ}$, esse era o valor equidistante dos extremos inferiores e superiores das características geométricas encontradas no trecho real, com a desconsideração de deflexões próximas de $0^{\circ}$. Como o trecho estudado não conteria fluxo oposto, ou seja, não existiria a possibilidade de ultrapassagens, considerou-se que a direção das curvas não influenciaria o comportamento dos condutores. Para tanto, definiu-se para cada tratamento uma única direção, apenas com a restrição de se evitar a sobreposição de trechos durante o processo de construção do cenário.

A fim de diminuir a possibilidade de enjôos e desconfortos durante as simulações, o greide do cenário experimentado pelos condutores fora definido como plano. Consequentemente, a inclinação da rodovia não fora pressuposta como variável explicativa para esse estudo. Essa era uma medida de prevenção tomada tipicamente em simuladores de base fixa, reforçada por pesquisadores da área, em visitas realizadas nos laboratórios de simulador de direção da Faculdade de Engenharia da Universidade do Porto - FEUP e do Instituto Francês de Ciências e Tecnologias de Transportes, Planejamento e Redes (Institut français des sciences et Technologies des transports, de l'aménagement et des réseaux - IFFSTAR). 
Uma das conclusões encontradas por Glennon, Neuman e Leisch (1983) foi que a proporção de saídas de pista de um veículo isolado aumentava substancialmente ao passo que o tráfego diminuía. Ademais, como o fenômeno estudado foi entendido inicialmente, como de distribuição similar a um evento raro, optou-se por excluir o tráfego de veículos, o que fomentaria comportamentos mais agressivos. Esperava-se que o fluxo livre induzisse comportamentos mais agressivos por todos os condutores. Para não se sentir só no cenário, e modificar a motivação no experimento, um veículo fora posicionado no início de cada experimento.

\subsubsection{Variáveis moderadoras}

Esperava-se que uma pessoa, após algum período de prática, aumentasse sua capacidade de realizar uma tarefa. Essa adaptação comportamental é presumida em experimentos com simulador de direção. Por outro lado, o tempo utilizado nessa prática poderia gerar cansaço, tédio ou náuseas, o que poderia propiciaria efeitos contrários à performance normal dos condutores. Para diminuir esse tipo de influência no experimento, empregaram-se variáveis moderadoras. Essas foram impostas à amostra a fim de diminuir os efeitos aleatórios nos resultados observados.

Além dos efeitos aleatórios citados, aprendizado e tédio, existiria ainda o efeito da mudança de marcha diferente do típico para a realidade brasileira e a falta de familiaridade com o uso do simulador de direção. A fim de diminuir esses, respectivamente, planejou-se aleatorizar os tratamentos apresentados aos condutores, restringir o tempo de condução a quinze minutos, repetir o ensaio duas vezes por pessoa com a pós-analize apenas da segunda volta e fazer um treinamento em cenário alternativo com a amostra antes do experimento.

\subsubsection{Variáveis estranhas}

Variáveis estranhas, ou de confundimento, são características do experimento que acarretam variações não-sistemáticas. Essas influenciariam as respostas a partir de diferenças não explicadas dentro da amostra (FIELD, 2009).

Mesmo com a tentativa de se diminuir a sua influência, deve-se ressaltar que possivelmente as limitações do simulador, tanto físicas como comportamentais, a homogeneidade da amostra (alunos do departamento de pós-graduação), a redução do número de variáveis explicativas e outros, poderiam influenciar as respostas. 
Porém, vale lembrar que o simulador de direção é tão somente uma das ferramentas para estudos de segurança. Esse deveria servir de indício para alguma proposta. A ratificação dos seus resultados em outros ambientes deveria ser incentivada para a tomada de decisão.

\subsubsection{Análise estatística}

Para cumprir com os objetivos específicos propostos, anteriormente à realização do experimento, imaginou-se como método de análise dos resultados fazer:

- uma análise de variância fatorial de medidas repetidas com duas variáveis independentes para cumprir com o primeiro objetivo;

- uma análise de correlação para cumprir com o segundo objetivo.

\subsubsection{Amostra}

Contou-se com a colaboração dos alunos do próprio departamento de pós-graduação em Engenharia de Transportes para a realização do experimento. Essa amostragem não foi aleatória, seguiu a conveniência. Porém, nenhum dos participantes tinha contato prévio com a pesquisa realizada.

Uma previsão inicial do número de medições necessárias sugerida por Montgomery (2013), aconselhava registrar duas medições para cada combinação de fatores. Como existiam nesse trabalho nove tratamentos, dezoito condutores pelo menos deveriam ter seus dados registrados.

Porém, com intenção de estimar o tamanho da amostra para diferentes tamanhos de efeito, ou seja, para avaliar o tamanho necessário para inferir diferentes importâncias de efeitos na população (FIELD, 2009), estimaram-se essas, a partir do software G*Power 3.1 (FAUL et al., 2007). Para esse cálculo, utilizou-se uma probabilidade de 5\% ( $\alpha$ ) de se incorrer em um erro do tipo I, 20\% em um erro do tipo II ( $\beta$ ) e com a hipótese da esfericidade assumida Tabela 11.

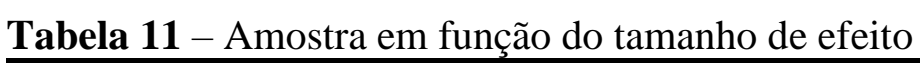

\begin{tabular}{llrrrr}
\hline \multicolumn{1}{c}{ Efeito } & $\boldsymbol{r}$ & Confiança $(\boldsymbol{\alpha})$ & Poder (1- $\boldsymbol{\beta})$ & Correção da Esfericidade & \multicolumn{1}{c}{ Amostra } \\
\hline Pequeno & 0.1 & 0.05 & 0.80 & 1 & 483 \\
Médio & 0.3 & 0.05 & 0.80 & 1 & 60 \\
Grande & 0.5 & 0.05 & 0.80 & 1 & 24 \\
\hline
\end{tabular}


Optou-se então por trabalhar com a detecção de um efeito grande, assim a amostra mínima necessária objetivada foi de pelo menos 24 condutores. Para dar margem para a aparição de conduções incompletas ou perda de dados, adotou-se inicialmente um valor de 30 condutores.

\subsection{Experimento}

Findada a etapa de delineamento do experimento, partiu-se para a realização do mesmo. A Figura 11 apresenta o fluxograma de sua realização. Essa pode ser dividida em três etapas: $1^{\text {a }}$ Etapa - preparativos; $2^{\text {a }}$ Etapa - coleta; e $3^{\text {a }}$ Etapa - análise. Cada tarefa está melhor detalhada na sequência.

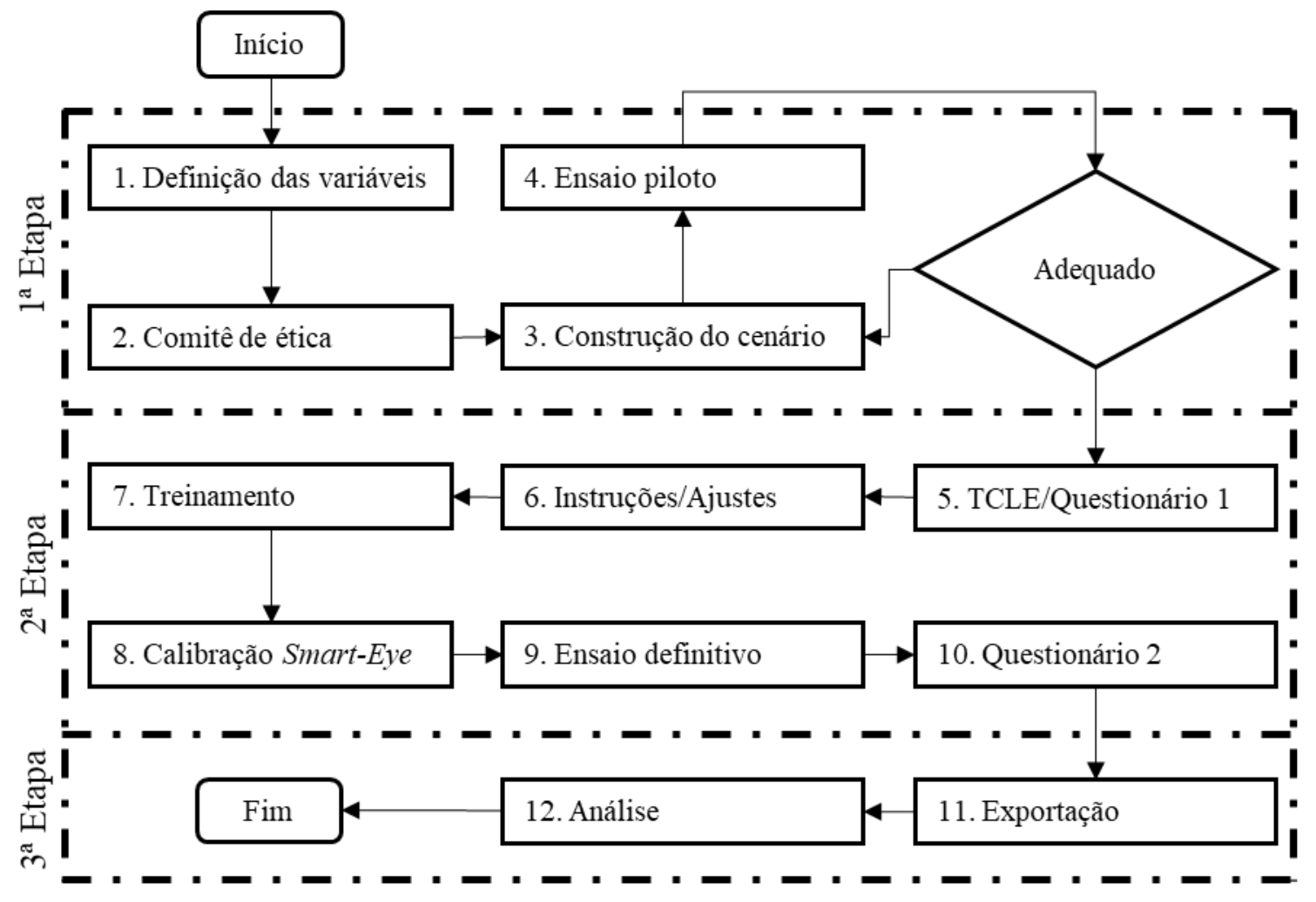

Figura 11 - Fluxograma da realização do experimento

\subsubsection{Definição das variáveis}

As variáveis utilizadas para o delineamento do experimento, definidas no item anterior, estão resumidas na Tabela 12. Essa apresenta as características principais do estudo. Outras definições não foram relacionadas nessa tabela, como as variáveis de controle, moderadoras e estranhas. 
Tabela 12 - Resumo do experimento

\begin{tabular}{cccc}
\hline Tipo & Variáveis independentes & Amostra & Variáveis dependentes \\
\hline $3^{2}$ & $\begin{array}{c}\text { Comprimento do raio da curva (3) } \\
\text { Comprimento da tangente de aproximação (3) }\end{array}$ & 30 & $\begin{array}{c}\text { Jerk mínimo } \\
\text { Diferenças de velocidade }\end{array}$ \\
\hline
\end{tabular}

\subsubsection{Comitê de ética}

Como o experimento necessitou de respostas de condutores reais, foi necessário o cumprimento, antes das coletas, de um processo no comitê de ética da Plataforma Brasil. Essa é uma base nacional para cadastro de pesquisas que envolvessem seres humanos em sua realização. Os documentos exigidos para a avaliação do trabalho foram:

- Folha de rosto do projeto: documento que identificava o projeto, o pesquisador responsável e a instituição proponente;

- Projeto detalhado: documento mais detalhado sobre o experimento;

- Autorização da instituição: documento que ratificava a ciência da instituição (EESCUSP) sobre a realização do experimento;

- Termo de consentimento livre e esclarecido (TCLE): documento que apresentava a cada pessoa da amostra os benefícios e prejuízos que aquele experimento poderia surtir em sua vida, bem como demostrava o consentimento na participação;

- Questionários: cópias dos questionários utilizados no experimento.

Depois de correções sugeridas no TCLE, a proposta foi deferida. O tempo necessário para o desdobramento do processo foi de dois meses. A primeira entrada no sistema da Plataforma Brasil foi realizada em 23 de maio de 2017 e o parecer final de aprovação foi emitido em 24 de julho de 2017 pelo Comitê de Ética em Pesquisa da Universidade Federal de São Carlos.

Número do parecer: 2184786. Endereço de contato do comitê: cephumanos@ufscar.br. Alguns dos documentos citados podem ser encontrados nos anexos desse trabalho. O projeto detalhado não está contido nessa seção para evitar repetições. 


\subsubsection{Construção do cenário}

Com as variáveis definidas, partiu-se para a construção do cenário virtual utilizado nessa pesquisa. Para reduzir os efeitos do aprendizado e do tédio, como tratado no 3.2.4, utilizou-se do método SUDOKU (SABA; SINHA, 2014; SARKAR; SINHA, 2015) para a atribuição dos tratamentos aos condutores. O método SUDOKU, assim como o jogo de lógica propõe, apresenta um ordenamento no qual os tratamentos se tornam ortogonais. Tanto as linhas como colunas não apresentam repetição de valores. Assim, construíram-se nove sequências possíveis, como apresenta a Tabela 13.

Tabela 13 - Distribuição dos tratamentos

\begin{tabular}{c|llllllllll}
\hline \multirow{2}{*}{ Cenário } & \multicolumn{10}{c}{ Ordem de apresentação dos tratamentos } \\
\cline { 2 - 9 }$y$ & 1 & 2 & 3 & 4 & 5 & 6 & 7 & 8 & 9 \\
\hline 1 & 2 & 1 & 5 & 8 & 7 & 6 & 9 & 4 & 3 \\
2 & 4 & 9 & 7 & 2 & 3 & 1 & 8 & 5 & 6 \\
3 & 8 & 6 & 3 & 5 & 9 & 4 & 1 & 2 & 7 \\
4 & 7 & 4 & 6 & 9 & 5 & 3 & 2 & 1 & 8 \\
5 & 5 & 2 & 8 & 1 & 4 & 7 & 6 & 3 & 9 \\
6 & 1 & 3 & 9 & 6 & 2 & 8 & 4 & 7 & 5 \\
7 & 6 & 8 & 4 & 3 & 1 & 5 & 7 & 9 & 2 \\
8 & 3 & 7 & 2 & 4 & 6 & 9 & 5 & 8 & 1 \\
\hline
\end{tabular}

A fim de facilitar a seleção da sequência no procedimento da simulação, construiu-se um cenário único com as nove sequências, com um trecho de transição entre as sequências. A direção das curvas foi sorteada, iterativamente, até que não houvesse a sobreposição dos trechos. Contudo, para um mesmo tratamento, as curvas tiveram a mesma direção, como mostrou a Tabela 10. Como o objeto de estudo continha curvas de transição de 60 metros de comprimento (Ls), adotou-se esse valor para o cálculo da geometria dos elementos do cenário. A Tabela 14 serviu de apoio para a contrução desse.

Tabela 14 - Características geométricas das curvas construídas

\begin{tabular}{rcccccccccccc}
\hline $\mathbf{R}$ & $\mathbf{L s}$ & $\boldsymbol{\theta s}$ & $\mathbf{X s}$ & $\mathbf{Y s}$ & $\mathbf{Q}$ & $\mathbf{p}$ & \multicolumn{2}{c}{ Deflexão } & $\mathbf{T T}$ & $\boldsymbol{\theta c}$ & $\mathbf{D}$ & $\mathbf{L}$ \\
\hline$[\mathrm{m}]$ & {$[\mathrm{m}]$} & {$[\mathrm{rad}]$} & {$[\mathrm{m}]$} & {$[\mathrm{m}]$} & {$[\mathrm{m}]$} & {$[\mathrm{m}]$} & {$\left[{ }^{\circ}\right]$} & {$[\mathrm{rad}]$} & {$[\mathrm{m}]$} & {$[\mathrm{rad}]$} & {$[\mathrm{m}]$} & {$[\mathrm{m}]$} \\
\hline 125 & 60 & 0.2400 & 59.66 & 4.78 & 29.94 & 1.20 & 56 & 0.9774 & 97.04 & 0.4974 & 62.17 & 182.17 \\
370 & 60 & 0.0811 & 59.96 & 1.62 & 29.99 & 0.41 & 56 & 0.9774 & 226.94 & 0.8152 & 301.63 & 421.63 \\
615 & 60 & 0.0488 & 59.99 & 0.98 & 30.00 & 0.24 & 56 & 0.9774 & 357.13 & 0.8798 & 541.09 & 661.09 \\
1230 & 60 & 0.0244 & 60.00 & 0.49 & 30.00 & 0.12 & 56 & 0.9774 & 684.07 & 0.9286 & 1142.18 & 1262.18 \\
\hline
\end{tabular}


A construção de uma planilha eletrônica permitiu a elaboração de um script que, a partir da função "pline" do AutoCAD Civil 3D, possibilitou a exportação dos pontos de interesse do cenário (Tabela 15). Por ela fez-se a locação das sinalizações verticais. De acordo com as recomendações do Manual de Sinalização Rodoviária do Departamento Nacional de Infraestrutura de Transporte (DNIT, 2010). Adotaram-se sinais de regulamentação de "Velocidade máxima permitida" para $100 \mathrm{~km} / \mathrm{h}$ (R 19-10) no início de cada cenário e os sinais de advertência de "Curva à esquerda" (A-2a), "Curva à direita" (A-2b), "Pista sinuosa à esquerda" (A-3a), "Curva em "S" à esquerda" (A-4a), "Curva em "S" à direita" (A-5b), posicionadas de acordo com os tipos de curvas, as distâncias entre elas e os agrupamentos.

Tabela 15 - Pontos de interesse exportados pelo AutoCAD Civil 3d

\begin{tabular}{crccccc}
\hline \multirow{2}{*}{ Identificação } & \multicolumn{2}{c}{ Comprimento } & \multicolumn{1}{c}{ X Inicial } & Y Inicial & X Final & Y Final \\
\cline { 2 - 7 } & \multicolumn{1}{c}{ Parcial } & Acumulado & {$[\mathrm{m}]$} & {$[\mathrm{m}]$} & {$[\mathrm{m}]$} & {$[\mathrm{m}]$} \\
\hline $001 \mathrm{~T}$ & 1140 & 1140 & -5912.5124 & -3990.9940 & -5912.5124 & -2850.9940 \\
$001 \mathrm{SE}$ & 60 & 1200 & -5912.5124 & -2850.9940 & -5912.0246 & -2790.9975 \\
$001 \mathrm{C}$ & 1142.183 & 2342.183 & -5912.0246 & -2790.9975 & -5394.8618 & -1818.3558 \\
$001 \mathrm{SS}$ & 60 & 2402.183 & -5394.8618 & -1818.3558 & -5345.3953 & -1784.4018 \\
002T & 570 & 2972.183 & -5345.3953 & -1784.4018 & -4872.8439 & -1465.6619 \\
002SE & 60 & 3032.183 & -4872.8439 & -1465.6619 & -4822.5680 & -1432.9269 \\
002C & 541.091 & 3573.274 & -4822.5680 & -1432.9269 & -4301.6302 & -1378.1742 \\
$002 \mathrm{SS}$ & 60 & 3633.274 & -4301.6302 & -1378.1742 & -4245.6470 & -1399.7408 \\
003T & 310 & 3943.274 & -4245.6470 & -1399.7408 & -3958.2201 & -1515.8688 \\
$\vdots$ & $\vdots$ & $\vdots$ & $\vdots$ & $\vdots$ & $\vdots$ & $\vdots$ \\
\hline
\end{tabular}

Com os pontos notáveis definidos, partiu-se para a construção do cenário virtual. O software utilizado para esse fim foi o editor interativo de redes rodoviárias ROD do pacote Vires Virtual Test Drive.

Para otimizar o processo de construção, seguiu-se um formato pré-definido de importação (Figura 12) que a partir da junção dos dados das tangentes contidos na tabela anterior, linhas “FIT_LINE_XY", e as características geométricas das curvas (comprimento do raio da curva e constante positiva da curva de transição), linhas “FIT_CURVE_SYM", construíu-se o eixo final. 
Tabela 16 - Atrito transversal disponível e solicitado no simulador

\begin{tabular}{|c|c|c|c|c|}
\hline \multirow{2}{*}{$\begin{array}{c}\text { Raio } \\
{[\mathrm{m}]}\end{array}$} & \multirow{2}{*}{$\begin{array}{c}\text { Superelevação } \\
{[\mathrm{m} / \mathrm{m}]}\end{array}$} & \multirow{2}{*}{$\begin{array}{c}\text { Velocidade de Projeto } \\
\qquad[\mathrm{km} / \mathrm{h}]\end{array}$} & \multicolumn{2}{|c|}{ Coeficiente de Atrito Transversal } \\
\hline & & & Disponível & Solicitado \\
\hline 125 & 0.04 & 100 & $1.0734 * 0.65=0.69771$ & 0.589921 \\
\hline 370 & 0.04 & 100 & $1.0734 * 0.65=0.69771$ & 0.172811 \\
\hline 615 & 0.04 & 100 & $1.0734 * 0.65=0.69771$ & 0.088033 \\
\hline 1230 & 0.04 & 100 & $1.0734 * 0.65=0.69771$ & 0.024016 \\
\hline
\end{tabular}

Assim, com a adoção de limites fora dos valores estipulados pelas recomendações, esperava-se que os condutores cumprissem a tarefa de negociar com as curvas mesmo que houvesse maior dificuldade no menor raio experimentado. Uma superelevação maior, facilitaria ainda mais a tarefa de condução nesse ambiente, portanto adotou-se esse valor extremo inferior, menos confortável e seguro.

Para o ambiente de condução, foram definidas, a partir do editor de cenários virtuais Scenario Editor do pacote Vires Virtual Test Drive, as posições de onde as conduções começariam nos experimentos. Como dito anteriormente, a fim de reduzir os efeitos da falta de habilidade com o simulador de direção, e, principalmente, com o sistema de mudança de marcha diferentes do usual, optou-se por passar os condutores por duas sequências consecutivas e utilizar apenas os dados registrados na segunda. A Figura 13 apresenta a disposição final do eixo da rodovia, de acordo com as sequências de tratamentos diferentes.

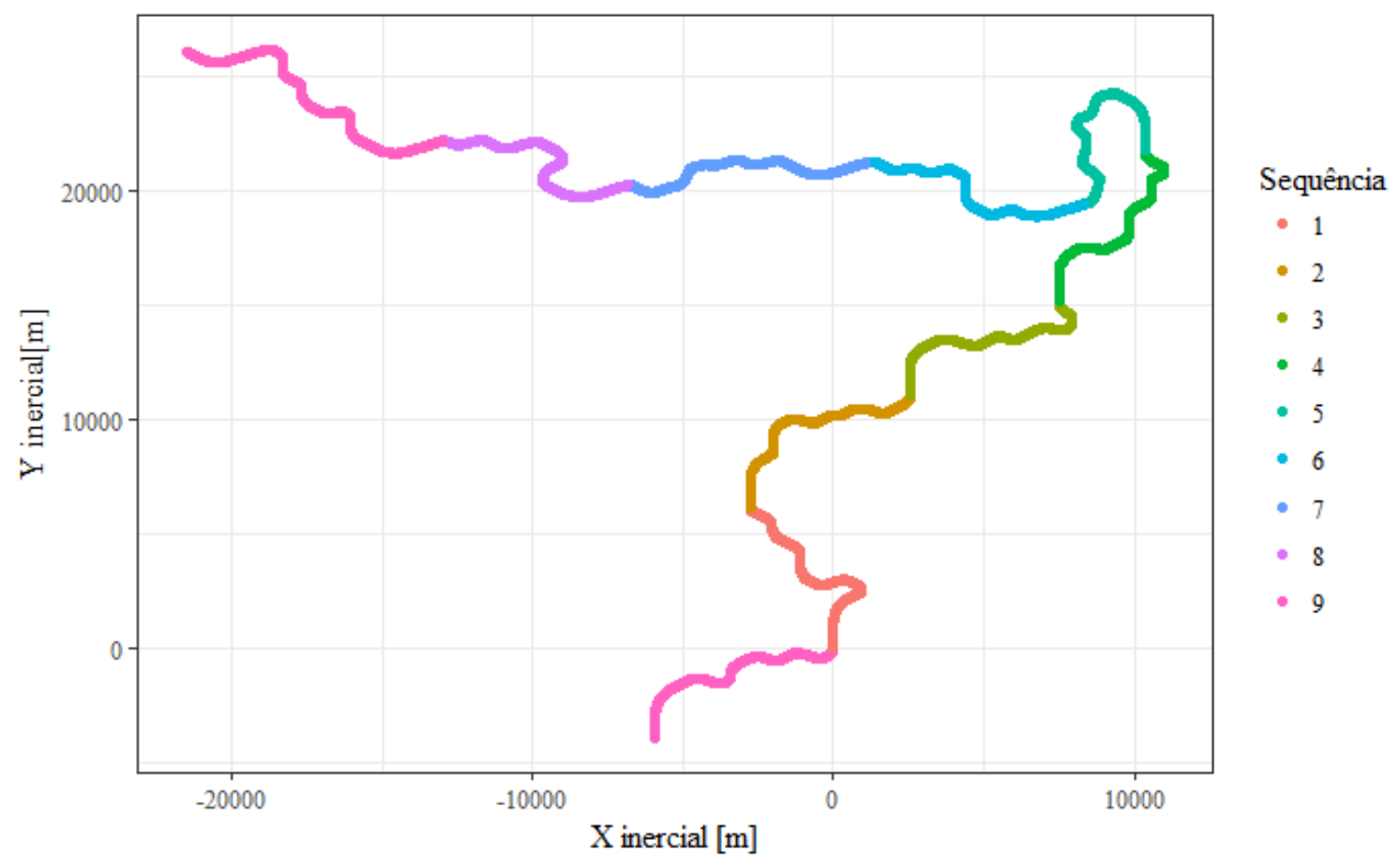

Figura 13 - Eixo da rodovia de acordo com as sequências de tratamentos 
Na tentativa de estruturar os procedimentos de coleta de dados, formulou-se um documento no qual estavam contidos os passos, e até as falas, que o pesquisador deveria seguir durante o experimento. O último item desse documento, que está no final do trabalho, na seção de anexos, apresentava uma tabela (Tabela 17) com o primeiro valor da sequência que deveria ser experimentada pelo condutor do momento.

Tabela 17 - Sequências utilizadas na amostra

\begin{tabular}{cccccc}
\hline \multicolumn{2}{c}{ Primeira rodada } & \multicolumn{2}{c}{ Segunda rodada } & \multicolumn{2}{c}{ Terceira rodada } \\
\hline 0.30 & 5 & 0.22 & 1 & 0.05 & 3 \\
0.31 & 7 & 0.25 & 3 & 0.12 & 4 \\
0.39 & 4 & 0.31 & 6 & 0.14 & 9 \\
0.44 & 6 & 0.31 & 4 & 0.25 & 8 \\
0.47 & 3 & 0.54 & 8 & 0.26 & 2 \\
0.51 & 1 & 0.63 & 7 & 0.34 & 7 \\
0.55 & 2 & 0.76 & 5 & 0.46 & 5 \\
0.67 & 8 & 0.76 & 9 & 0.65 & 6 \\
0.89 & 9 & 0.97 & 2 & 0.71 & 1 \\
\hline
\end{tabular}

Ou seja, na primeira rodada de coletas, a qual cumpriria as 9 possibilidades, o primeiro condutor experimentaria a sequência 5 e, por conseguinte, a sequência 6 de tratamentos. $O$ valor decimal apresentado serviu apenas para o sorteio dentro da planilha eletrônica. Com o desenho do experimento definido, partiu-se para um ensaio piloto.

\subsubsection{Ensaio piloto}

Depois de realizado o processo de construção do cenário, partiu-se para a etapa de ensaio piloto com um voluntário. Essa etapa do processo foi necessária, e importante, para ajustar os procedimentos de coleta e ratificar a escolha das condições da via, do veículo e do tráfego presente. Nessa etapa, definiu-se que não haveria tráfego na via já que se esperava caracterizar o comportamento do condutor em fluxo livre sem restrições, ou seja, o objetivo do pesquisador com o experimento era avaliar as escolhas do motorista apenas com as mudanças percebidas no alinhamento. Medida similar foi tomada por Ben-Bassat e Shinar (2011).

Apenas definiu-se que em todo começo de condução, o veículo do condutor experimentado seria acompanhado na curva inicial por um veículo no mesmo sentido de tráfego, a fim de diminuir a possibilidade de sensação de estar sozinho no cenário. Porém, no restante da experimentação, não haveria outro tráfego. 
A ausência do tráfego já fora tomada por outros trabalhos da mesma área, como Comte e Jamson (2000) e Calvi (2015). Quando testada, a ocorrência de car-following modificou o comportamento do voluntário do ensaio piloto. O motorista só observava o carro à frente no desenvolvimento das curvas e não mais observava as mudanças no alinhamento, diferente do comportamento em fluxo livre.

Também nessa etapa, fez-se um ajuste no limite de velocidade apresentado. Inicialmente, adotaram-se sinalizações verticais de regulamentação de velocidade máxima permitida de 80 $\mathrm{km} / \mathrm{h}$ para seguir o existente no objeto de estudo, porém sua adoção fez com que o voluntário dirigisse com muita cautela, o que ocasionou poucas variações nas velocidades entre tratamentos.

Depois, testou-se a velocidade limite de $110 \mathrm{~km} / \mathrm{h}$, que era um limite típico para uma rodovia com configuração de pistas com três faixas, como era apresentado para o voluntário. Essa adoção fez com que o voluntário sofresse capotamentos sequentes, em função das restrições geométricas.

Por fim, adotou-se um limite de $100 \mathrm{~km} / \mathrm{h}$, o qual não incorreu em nenhuma das duas dificuldades com o volutário. Para cada variação dessas, foi necessária a readequação do cenário, o que fazia voltar para a construção do mesmo.

Vale ressaltar que no objeto de estudo, o design da rodovia, três faixas de rolagem por pista, não condizia com o limite de velocidade imposta, $80 \mathrm{~km} / \mathrm{h}$. Isso poderia explicar o grande número de ocorrências, principalmente do tipo saída de pista. Por isso, a adoção de um limite maior poderia condizer com o comportamento do ambiente real.

\subsubsection{TCLE/Questionário 1}

Depois de terminada a etapa de preparativos do primeiro experimento, partiu-se para a coleta dos dados. Para a realização desse experimento, coletou-se os dados de vinte e oito motoristas. A amostra foi definida por conveniência, os condutores foram selecionados de acordo com a experiência em pistas duplas e o baixo interesse por jogos virtuais de corrida. 
Esse critério foi adotado em função de experimentos anteriores, nos quais a amostra foi selecionada por chamada pública, por e-mail. Esse método acabou por atrair motoristas interessados em jogos virtuais de corrida, os quais dirigiam com o intuito de fazer os menores tempos e praticar as maiores velocidades possíveis, o que acabou por gerar capotamentos desnecessários e velocidades médias muito superiores aos limites apresentados nas sinalizações verticais existentes.

A amostra desta pesquisa foi composta por alunos de graduação e pós-graduação da USP, todos com alguma experiência declarada em pistas dupla e com baixa, ou inexistente, prática de jogos virtuais de corrida. Para cada sujeito, o passo inicial do procedimento de coleta de dados foi ler, consentir e assinar o Termo de consentimento livre e esclarecido (TCLE) e responder um questionário demográfico que versava sobre características de interesse relacionadas com a tarefa da direção. Esses documentos se encontram no final do trabalho.

A amostra foi composta por dezenove homens e nove mulheres. A idade variava de 20 a 38 anos de idade, com média igual a 26.61 anos, com desvio padrão de 4.07 anos. O tempo de habilitação médio era de 7.52 anos, com desvio padrão de 3.97 anos.

Das respostas dos questionários, dez condutores apontaram que dirigiam todos os dias da semana, seis dirigiam de quatro a seis dias, seis dirigiam de um a três dias e seis não dirigiam semanalmente. Treze responderam que dirigiam até trinta minutos por dia típico, oito dirigiam até duas horas, um extrapolava duas horas e seis afirmaram que não conduziam. Vinte e três se considerava experientes e cinco se consideravam inexperientes.

Dezoito se consideravam condutores cautelosos, enquanto nove disseram que eram confiantes e um se disse inseguro. Catorze já receberam multas de trânsito. Dezesseis se envolveram em ocorrências leves de trânsito, dois em ocorrências com vítimas. Catorze afirmaram que raramente praticavam jogos de corrida, dois se entretinham algumas vezes por mês e os outros doze não jogavam. Todos os sujeitos consentiram que seus dados fossem utilizados nessa pesquisa científica. 


\subsubsection{Instruções/Ajustes}

Após o preenchimento do questionário, os condutores eram convidados a se sentar no cockpit utilizado nesse experimento, o qual tinha regulagens para frente e para trás no assento. O sujeito era convidado a ajustar a posição do banco de forma que ficasse o mais confortável possível para a execução da tarefa.

Nessa etapa, os comandos do simulador eram apresentados e algumas informações eram passadas ao voluntário. Esse procedimento está contido na seção de anexos desse trabalho.

\subsubsection{Treinamento}

Na tentativa de diminuir a possibilidade de falta de experiência no simulador, vale ressaltar que antes do ensaio definitivo, os condutores treinaram por até 10 minutos, ou até se sentirem aptos a dirigirem, em um cenário alternativo ao proposto para esse experimento. Esse cenário fora objeto de estudos de outros pesquisadores do grupo de pesquisas e trazia características mais fidedignas com a realidade da rodovia Régis Bittencourt.

Esse passo é importante pois o primeiro contato com o simulador, também conhecido como fase de treinamento, é a etapa onde os condutores estão aprendendo a lidar com o ambiente virtual (BENEDETTO et al., 2002). Um dado registrado ou analisado nessa etapa poderia diferir do comportamento do condutor.

\subsubsection{Calibração Smart-Eye}

Depois do treinamento, o sistema de captura do olhar SmartEye ${ }^{\circledR}$ era calibrado para o condutor. Nesse passo o foco e a abertura das três câmeras frontais eram ajustados e o modelo tridimensional da posição da cabeça do condutor era calibrado com o auxílio de um tabuleiro. A Figura 14 apresenta uma imagem de um processo de calibração. 


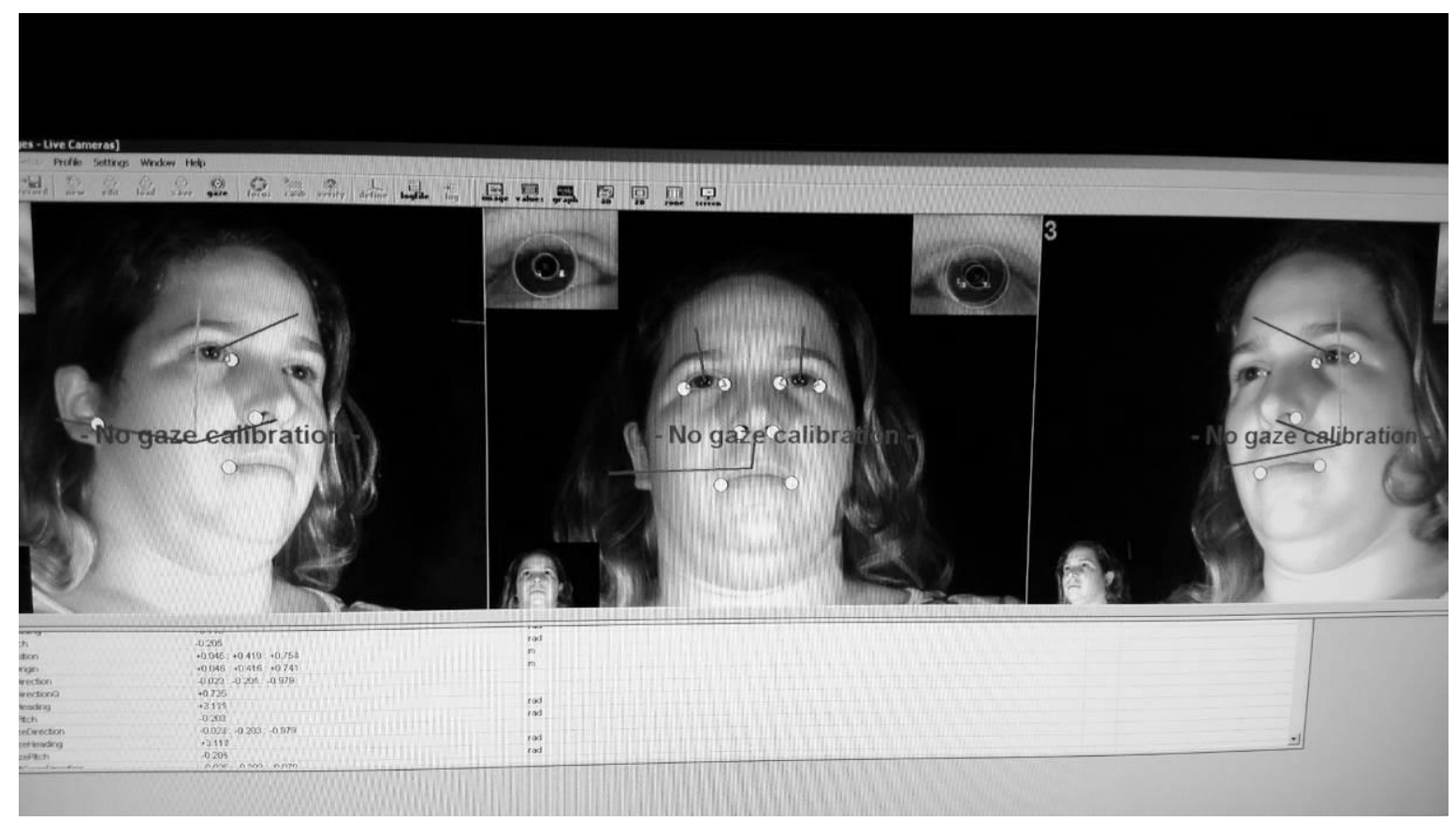

Figura 14 - Exemplo da interface da tela de calibração

\subsubsection{Ensaio definitivo}

Assim que terminava o processo de calibração, os condutores recebiam instruções acerca da simulação que passariam. Era pedido para que os mesmos dirigissem de maneira normal, como fariam em um ambiente real com aquelas características apresentadas. A Figura 15 apresenta um condutor durante a simulação.

Durante a simulação, o pesquisador controlava três máquinas que geravam a simulação, o modelo do veículo e capturavam o olhar dos condutores. O condutor tinha sua velocidade e os espelhos apresentados na tela. Dois condutores capotaram no meio do trecho e tiveram suas voltas repetidas.

A volta completa no circuito tinha 18 quilômetros de extensão. O procedimento do experimento completo, desde a recepção do voluntário até a aplicação do segundo questionário, não superou 1 hora para cada participante. 


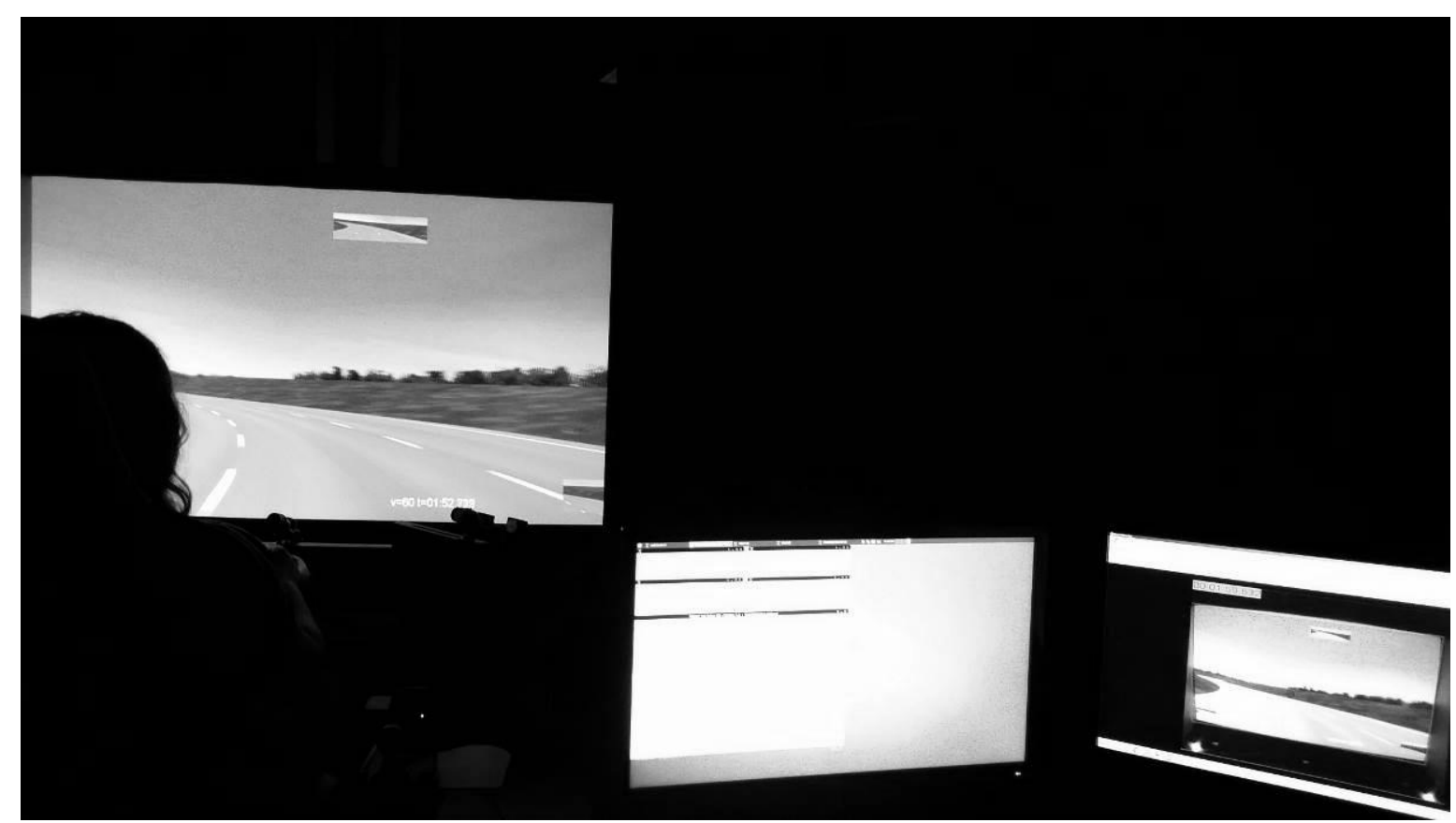

Figura 15 - Ambiente da simulação de direção de um condutor

\subsubsection{Questionário 2}

Depois das coletas, os condutores responderam um questionário de imersão na simulação. $\mathrm{O}$ questionário utilizado para esse fim foi o PQ (Presence Questionnaire), traduzido para o português por integrantes do grupo de pesquisa. Esse utilizava uma escala de sete níveis que qualificava a experiência daquela simulação a partir de 21 perguntas. O mesmo se encontra na seção de anexos, no final do trabalho.

As perguntas do questionário tinham o intuito de levantar a impressão dos condutores com relação as seguintes características da simulação: realismo (questões 3, 4, 5, 6, 7 e 12); possibilidade de controle (questões 1, 2, 8 e 9); qualidade da interface (questões 13, 16 e 17); possibilidade de avaliação (questões 10, 11 e 18); e autoavaliação da performance (questões 14 e 15). A Tabela 18 apresenta o resultado da média das respostas dos vinte oito motoristas de acordo com os agrupamentos indicados anteriormente.

Para efeito de comparação, esses valores foram confrontados com os resultados de um trabalho de validação, de uma tradução para o francês, feito pelo laboratório de cyber-psicologia da Universidade de Québec. Observa-se que os valores foram próximos, ou seja, os respondentes deram notas de imersão proporcionais ao trabalho canadense (ROBILLARD; BOUCHARD; RENAUD, 2002). 
Tabela 18 - Resultados do questionário de imersão

\begin{tabular}{lrrrr} 
& \multirow{2}{*}{ Pontuação } & \multicolumn{2}{c}{ Tese } & \multicolumn{2}{c}{ Valores para comparação } \\
\cline { 2 - 5 } & Média & Desvio-Padrão & Média & Desvio-Padrão \\
\hline Total & 99.39 & 9.52 & 104.39 & 18.99 \\
\hline Realismo & 31.46 & 5.32 & 29.45 & 12.04 \\
\hline Possibilidade de controle & 22.43 & 2.08 & 20.76 & 6.01 \\
\hline Qualidade da interface & 17.79 & 2.36 & 15.37 & 5.15 \\
\hline Possibilidade de avaliação & 16.64 & 1.73 & 15.38 & 4.90 \\
\hline Autoavaliação da performace & 11.07 & 2.19 & 11.00 & 2.87 \\
\hline
\end{tabular}

Quando comparado com o valor proposto pelo autor original do questionário em inglês (WITMER; SINGER, 1998), a pontuação total fica próxima da obtida, média de 98.11 com desvio-padrão de 15.78. Ou seja, os condutores assinalaram escores elevados com relação a sensação de imersão no ambiente virtual apresentado.

Vale ressaltar que a amostra utilizada foi de conveniência, e mesmo com a solicitação da imparcialidade nas respostas, com o encorajamento pela melhoria do equipamento, esses escores podem ter sofrido a influência da relação natural existente entre o pesquisador e os condutores. Existiram dúvidas acerca das perguntas, por isso, esse questionário necessitaria de ajustes de tradução. Como optou-se por utilizar o mesmo questionário utilizado pelas duas últimas pesquisas feitas pelo grupo, e o procedimento já havia começado no trabalho, essa modificação não foi realizada durante esse trabalho.

\subsubsection{Exportação}

Depois de terminadas as coletas, exportou-se os registros tanto da captura do olhar, quanto do sistema que controlava o veículo, pacote Vires Virtual Test Drive - VTD. A Figura 16 apresenta o trecho inicial de um arquivo de saída do VTD.

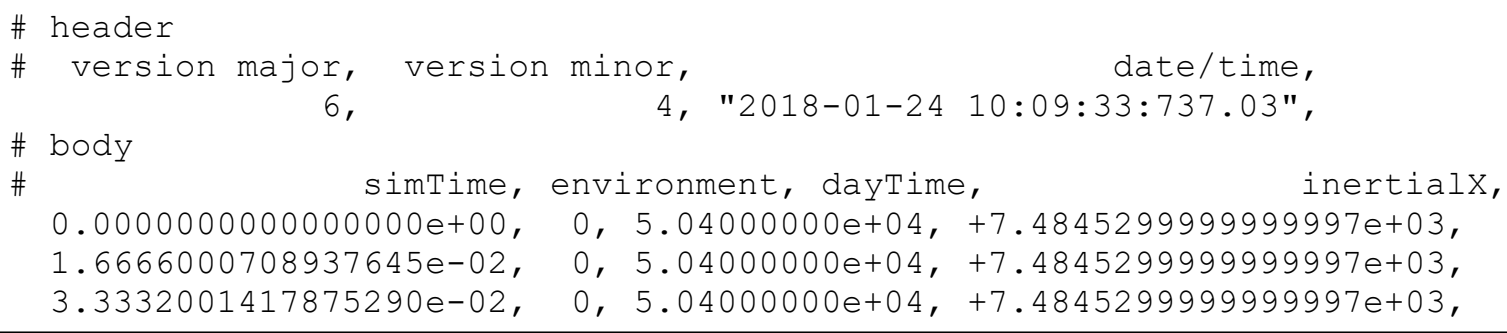

Figura 16 - Trecho de um arquivo exportado pelo VTD 
Como será tratado na seção de resultados, cada arquivo desses continha 70 variáveis, registradas com uma taxa de $60 \mathrm{~Hz}$. Para esse estudo, algumas dessas foram selecionadas e através de um algoritmo escrito a partir da linguagem $\mathrm{R}$, fez-se a análise desejada.

\subsubsection{Análise}

A análise das respostas dos condutores será aprofundada no capítulo 4, o qual versa sobre os resultados do trabalho. Haja dito, essa foi realizada a partir do uso do RStudio, para o desenvolvimento do algoritmo em R, e do SPSS, para as análises estatítiscas.

\subsection{Considerações}

O simulador de direção é uma das ferramentas utilizadas para estudos sobre a condução. Essa pesquisa usará esse material para investigar o uso da variável jerk na identificação de trechos com inconsistência geométrica.

Para tanto delineou-se um experimento do tipo controlado fatorial relacionado. Com as respostas desse experimento, espera-se cumprir com os três objetivos específicos préformulados.

Tanto o uso do simulador como o desenvolvimento de experimentos controlados foram temas novos estudados pelo pesquisador. Por isso, algumas falhas podem ter acontecido durante a realização do trabalho.

Antes do experimento apresentado nesse texto, o próprio pesquisador descartou um experimento similar, cujos resultados foram apresentados na qualificação, por entender posteriormente que haviam falhas irrecuperáveis.

O trâmite existente na Plataforma Brasil também não era esperado no início dessa tese. Apesar de, aparentemente, não ter consumido tempo excessivo ( 2 meses), a passagem por essa plataforma pareceu desnecessária para o pesquisador. Em artigos adjacentes, de trabalhos similares feitos no exterior, observou-se que a ciência de um comitê se restringia à localidade da pesquisa.

Com o trabalho delineado e as coletas feitas, partiu-se para a análise dos resultados, os quais estão apresentados no próximo capítulo. 



\section{RESULTADOS}

Os resultados do trabalho serão apresentados de acordo com a ordem dos objetivos específicos. Porém, para encontrá-los, fez-se necessário um pré-processamento dos registros advindos do experimento supracitado.

\subsection{Tratamento inicial dos dados}

Para tratar os dados, escreveu-se uma rotina na linguagem R (TEAM, 2013) com o intuito de diminuir a possibilidade de erros grosseiros e aumentar a capacidade de análise. A sequência de passos desse algoritmo consistia principalmente em:

1. Ler cada um dos arquivos advindos das conduções;

2. Selecionar as variáveis de interesse;

3. Identificar os tratamentos;

4. Definir os valores de jerk;

5. Filtrar as influências das trocas de marcha com a transformada contínua de Wavelet;

6. Encontrar para cada tratamento os valores de jerk mínimo e as respostas nos métodos tradicionais $(\triangle \mathrm{V}$ e MSR).

\subsubsection{Ler cada um dos arquivos advindos das conduções}

As coletas resultaram em 28 arquivos do tipo ".csv", cada um desses continha 70 variáveis, com taxa de gravação de sessenta dados por segundo $(60 \mathrm{~Hz})$. O que resultava em mais de 40.000 linhas por arquivo.

\subsubsection{Selecionar as variáveis de interesse}

Dentre as possibilidades existentes, selecionaram-se as variáveis que definiam: o tempo de simulação ("X...................simTime" [s]); as coordenadas inerciais do veículo em relação à pista ("inertialX“, "inertalY", e "inertialZ" [m, m, m]); a velocidade instantânea do veículo ("vPlayerX" [m/s]); e a velocidade do motor ("rpm" [1/s]). 


\subsubsection{Identificar os tratamentos}

Para analisar cada tratamento, era necessário identificá-los dentre as diversas linhas dos bancos de dados. Para isso a partir de um arquivo adicional, definiu-se qual eram as coordenadas inerciais iniciais e as coordenadas inerciais finais de cada tratamento. Descobertos esses pontos, o algoritmo repetia o nome daquele tratamento para todos os pontos intermediários. A Tabela 19 apresenta parte do arquivo adicional utilizado.

Tabela 19 - Arquivo adicional utilizado para a identificação dos tratamentos

\begin{tabular}{|c|c|c|c|c|c|c|}
\hline \multirow{2}{*}{ Tratamento } & \multirow{2}{*}{ Elemento } & \multirow{2}{*}{ Identificação } & X.Inicial & Y.Inicial & X.Final & Y.Final \\
\hline & & & {$[\mathrm{m}]$} & {$[\mathrm{m}]$} & {$[\mathrm{m}]$} & {$[\mathrm{m}]$} \\
\hline 0 & Tangente & $001 \mathrm{~T}$ & -5912.512 & -3990.994 & -5912.512 & -2850.994 \\
\hline 0 & Espiral de Entrada & 001SE & -5912.512 & -2850.994 & -5912.025 & -2790.997 \\
\hline 0 & Setor Circular & $001 \mathrm{C}$ & -5912.025 & -2790.997 & -5394.862 & -1818.356 \\
\hline 0 & Espiral de Saída & 001SS & -5394.862 & -1818.356 & -5345.395 & -1784.402 \\
\hline 9 & Tangente & $002 \mathrm{~T}$ & -5345.395 & -1784.402 & -4872.844 & -1465.662 \\
\hline 9 & Espiral de Entrada & 002SE & -4872.844 & -1465.662 & -4822.568 & -1432.927 \\
\hline 9 & Setor Circular & $002 \mathrm{C}$ & -4822.568 & -1432.927 & -4301.63 & -1378.174 \\
\hline 9 & Espiral de Saída & 002SS & -4301.630 & -1378.174 & -4245.647 & -1399.741 \\
\hline$\vdots$ & $\vdots$ & $\vdots$ & $\vdots$ & $\vdots$ & $\vdots$ & $\vdots$ \\
\hline
\end{tabular}

\subsubsection{Definir os valores de jerk}

Para encontrar os valores de jerk, essa tese adotou o mesmo procedimento de Nygård (1999). Esse procedimento foi tomado como base a fim de possibilitar comparações e diminuir os ruídos das variações instantâneas das velocidades.

Primeiro, encontraram-se os valores das acelerações, a partir de diferenciações numéricas de três pontos das velocidades em relação ao tempo (Equação 3), e depois os valores de jerk, a partir da derivação das acelerações pelo método de Euler inverso em relação ao tempo (Equação 4). Um exemplo de cálculo está apresentado na Tabela 20.

$$
\begin{aligned}
& a_{i}=\frac{\left(\frac{v_{i}-v_{i-2}}{t_{i}-t_{i-2}}\right)+\left(\frac{v_{i+1}-v_{i-1}}{t_{i+1}-t_{i-1}}\right)}{2} \\
& J_{i}=\frac{\left(a_{i}-a_{i-1}\right)}{\left(t_{i}-t_{i-1}\right)}
\end{aligned}
$$

Em que: $J_{i}=$ valor do jerk na linha "i"; $a_{i}=$ valor da aceleração na linha "i”"; $v_{i}=$ valor da velocidade instantânea na linha "i"; $t_{i}=$ valor do tempo na linha "i". 
Tabela 20 - Exemplo de cálculo dos valores de aceleração e de jerk

\begin{tabular}{|c|c|c|c|c|c|c|c|c|}
\hline \multicolumn{2}{|c|}{ Tempo [s] } & \multicolumn{2}{|c|}{ Velocidade $[\mathrm{m} / \mathrm{s}]$} & \multicolumn{3}{|c|}{ Aceleração $\left[\mathrm{m} / \mathrm{s}^{2}\right]$} & \multicolumn{2}{|l|}{ Jerk $\left[\mathrm{m} / \mathrm{s}^{3}\right]$} \\
\hline$t_{1}=$ & 227.141 & $v_{1}=$ & 29.550 & & & & & \\
\hline$t_{2}=$ & 227.158 & $v_{2}=$ & 29.554 & & $=-v_{1}$ & & & \\
\hline$t_{3}=$ & 227.174 & $v_{3}=$ & 29.558 & $a_{3}=$ & $\frac{\left(\frac{t_{3}-t_{1}}{t_{3}}\right)+\left(\frac{t_{2}}{t_{4}-t_{2}}\right)}{2}=$ & 0.236 & & \\
\hline$t_{4}=$ & 227.191 & $v_{4}=$ & 29.562 & $a_{4}=$ & $\frac{\left(\frac{v_{4}-v_{2}}{t_{4}-t_{2}}\right)+\left(\frac{v_{5}-v_{3}}{t_{5}-t_{3}}\right)}{2}=$ & 0.222 & $J_{4}=\frac{\left(a_{4}-a_{3}\right)}{\left(t_{4}-t_{3}\right)}=$ & -0.871 \\
\hline$t_{5}=$ & 227.208 & $v_{5}=$ & 29.565 & & & & & \\
\hline
\end{tabular}

\subsubsection{Filtrar as influências das trocas de marcha com a transformada contínua de Wavelet}

O método proposto por essa tese teve como ideia básica relacionar os valores mínimos de jerk encontrados em trechos de rodovias para avaliar a consistência geométrica. Porém, as trocas de marcha geravam valores exorbitantes de jerk, em uma escala diferente do que se era esperado para uma frenagem típica. Esse efeito já fora aventado por Eager, Pendrill e Reistad (2016). Esses pesquisadores salientaram que a mudança manual de marchas poderia gerar variações nos valores do jerk. Para solucionar esse problema foi necessário o desenvolvimento de uma filtragem que retirasse, de maneira automática, esses valores estranhos.

Esse problema já havia sido ressaltado também por Nygård (1999). Sua solução envolvia a adoção de um valor limite de aceleração logo antes dos valores de jerk encontrados, "these cases can be eliminated by using a value of $+1.2 \mathrm{~m} / \mathrm{s}^{2}$ as a limit for the acceleration value just prior to the deceleration derivative value"(NYGÅRD, 1999, p. 44). Essa abordagem não obteve sucesso na filtragem dos dados dessa tese, a explicação pode ser a diferença nas taxas de coleta.

Das opções avaliadas (filtragem pela média móvel, filtragem pela mediana, transformada discreta de Wavelet), obteve-se maior sucesso a partir do uso da transformada contínua de Wavelet. Para tanto, utilizou-se a biblioteca WaveletComp (ROESCH; SCHMIDBAUER, 2014) para encontrar as regiões onde aconteciam as trocas de marchas e, a partir do valor da energia do sinal, fazer a filtragem. A Figura 17 apresenta o resultado da análise feita para uma volta de um condutor, ela apresenta tanto o sinal do jerk original analisado (em preto), como o seu respectivo valor de energia para a Wavelet (em vermelho) e o valor do giro do motor (em verde). $\mathrm{O}$ valor da velocidade do motor seria importante para avaliar onde ocorreram mudanças de marcha. Como a ordem de grandeza das variáveis seria muito diferente (o jerk para mudança de marcha seria muito maior que as demais) montou-se um gráfico elucidativo sem escalas. 


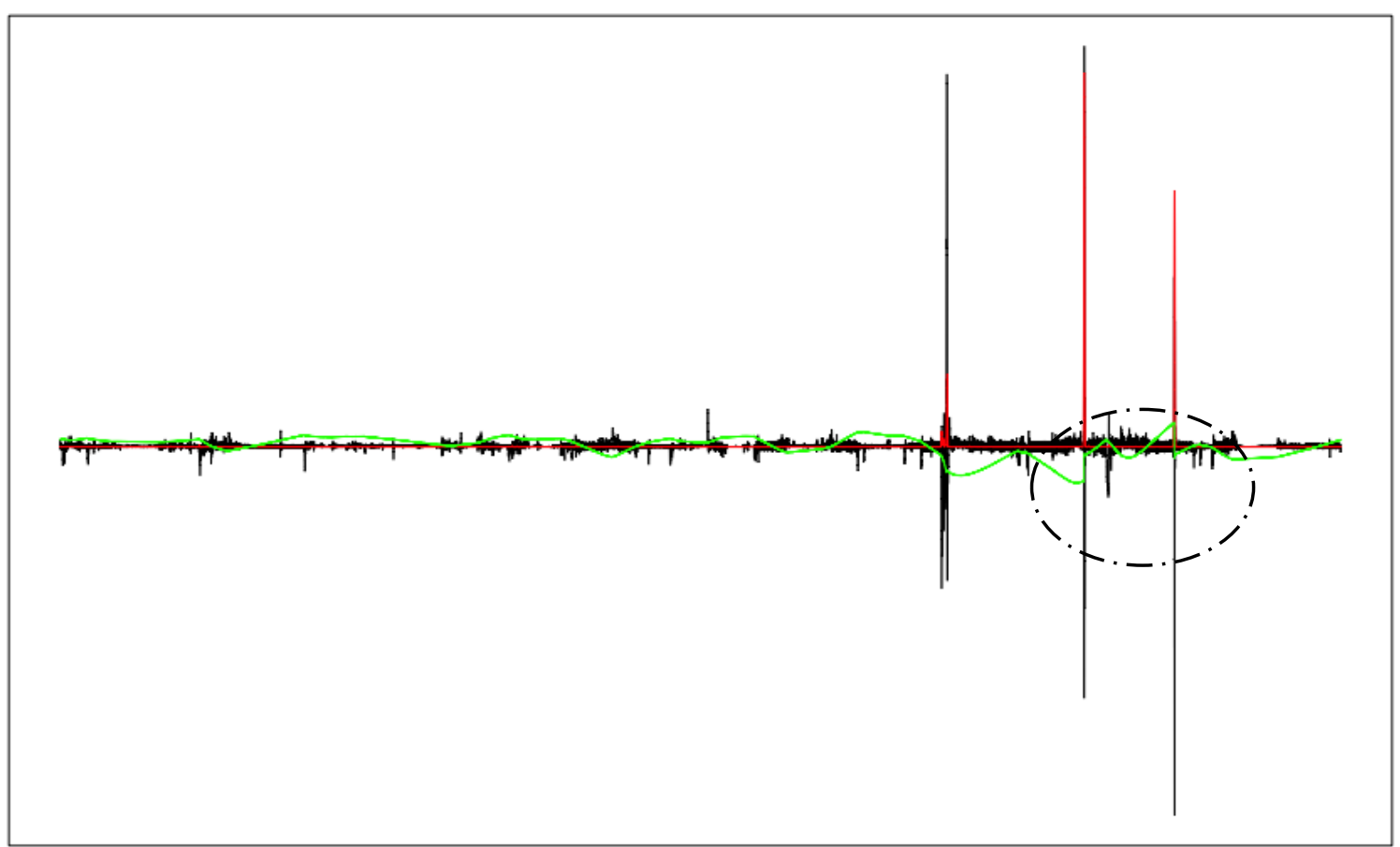

Figura 17 - Dados de jerk, da energia da Wavelet, da velocidade do motor e detalhe

Quando um condutor reduzia uma marcha, o motor repentinamente funcionava com uma maior rotação, o que resultaria em um pico de jerk e, por consequência, um pico no valor da energia da Wavelet. A Figura 18 apresenta o detalhe ressaltado na figura anterior, nela é possível notar que conforme reduziu-se uma marcha (detalhe 1), ou quando se aumentou uma marcha (detalhe 2), houve um pico expressivo tanto na energia da Wavelet como no valor do jerk.

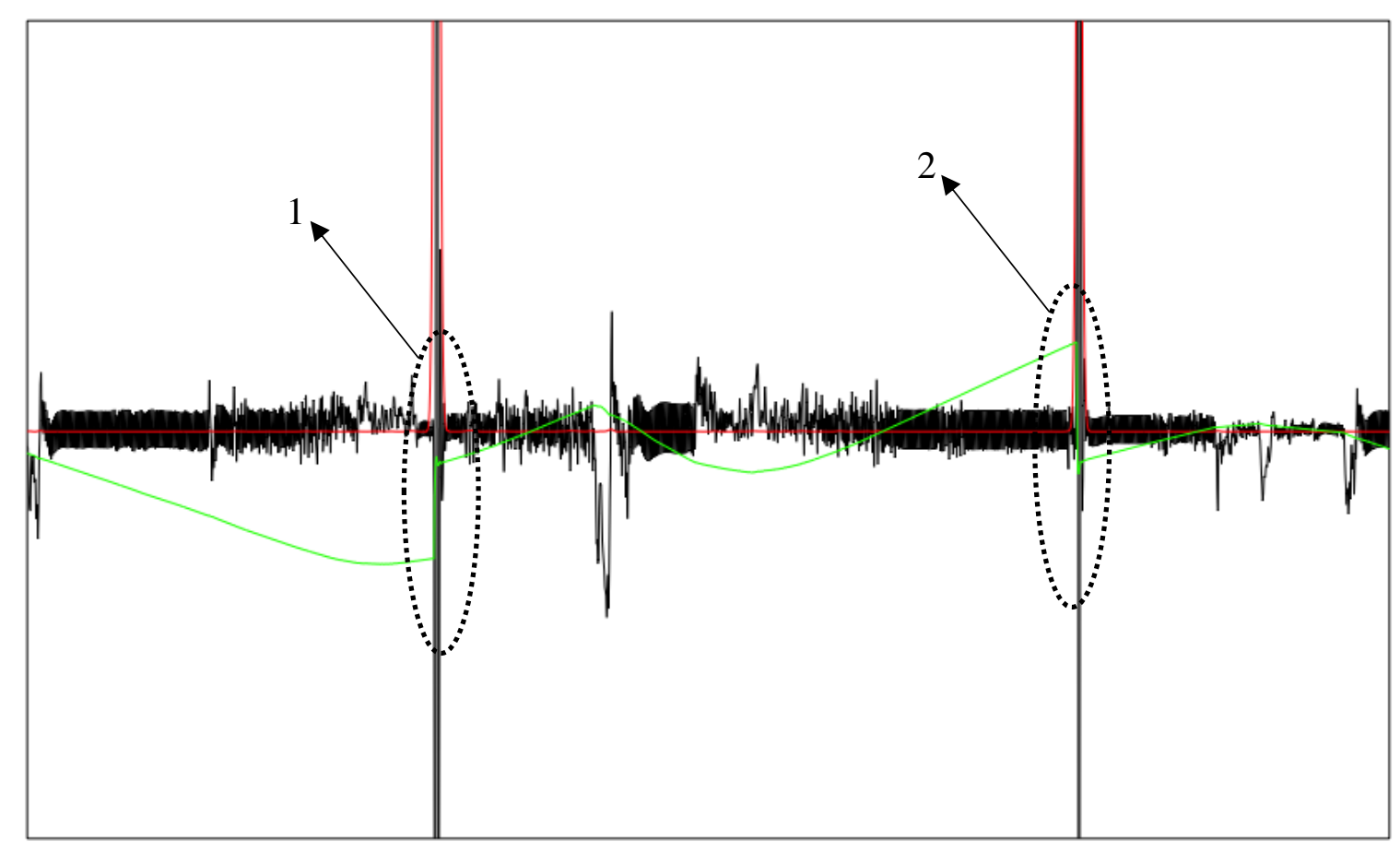

Figura 18 - Detalhe da figura anterior 
O valor de energia para a filtragem desses dados foi encontrado a partir das respostas de cada condutor. Como as mudanças de marcha tinham uma resposta brusca na velocidade do motor, como mostrou a Figura 18 (em verde), identificou-se para cada condutor o valor mínimo de energia para essa quebra de velocidade e esse foi adotado para a filtragem. Os valores de jerk relativos a energias maiores que esses valores foram substituídos pelo valor mediano daquele trecho.

\subsubsection{Encontrar para cada tratamento os valores de jerk mínimo e as respostas nos métodos tradicionais ( $\Delta \mathrm{V}_{85}$ e 85MSR)}

Para cada tratamento experimentado por cada condutor, encontraram-se os valores de jerk mínimo e as respostas dos métodos tradicionais. Construíram-se gráficos para dar suporte a análise de todos os casos. A Figura 19 apresenta um exemplo desses.

O gráfico traz os valores de jerk (em vermelho), da aceleração (em azul), da velocidade do veículo (em preto) e da velocidade do motor (em verde). Ele ainda apresenta os valores mínimos de jerk para cada metade de cada elemento (círculo vazado vermelho), o valor mínimo de jerk no tratamento (círculo amarelo) e os valores de velocidade para os métodos tradicionais $\left(\Delta \mathrm{V}_{85}\right.$ em azul claro e 85MSR em roxo).

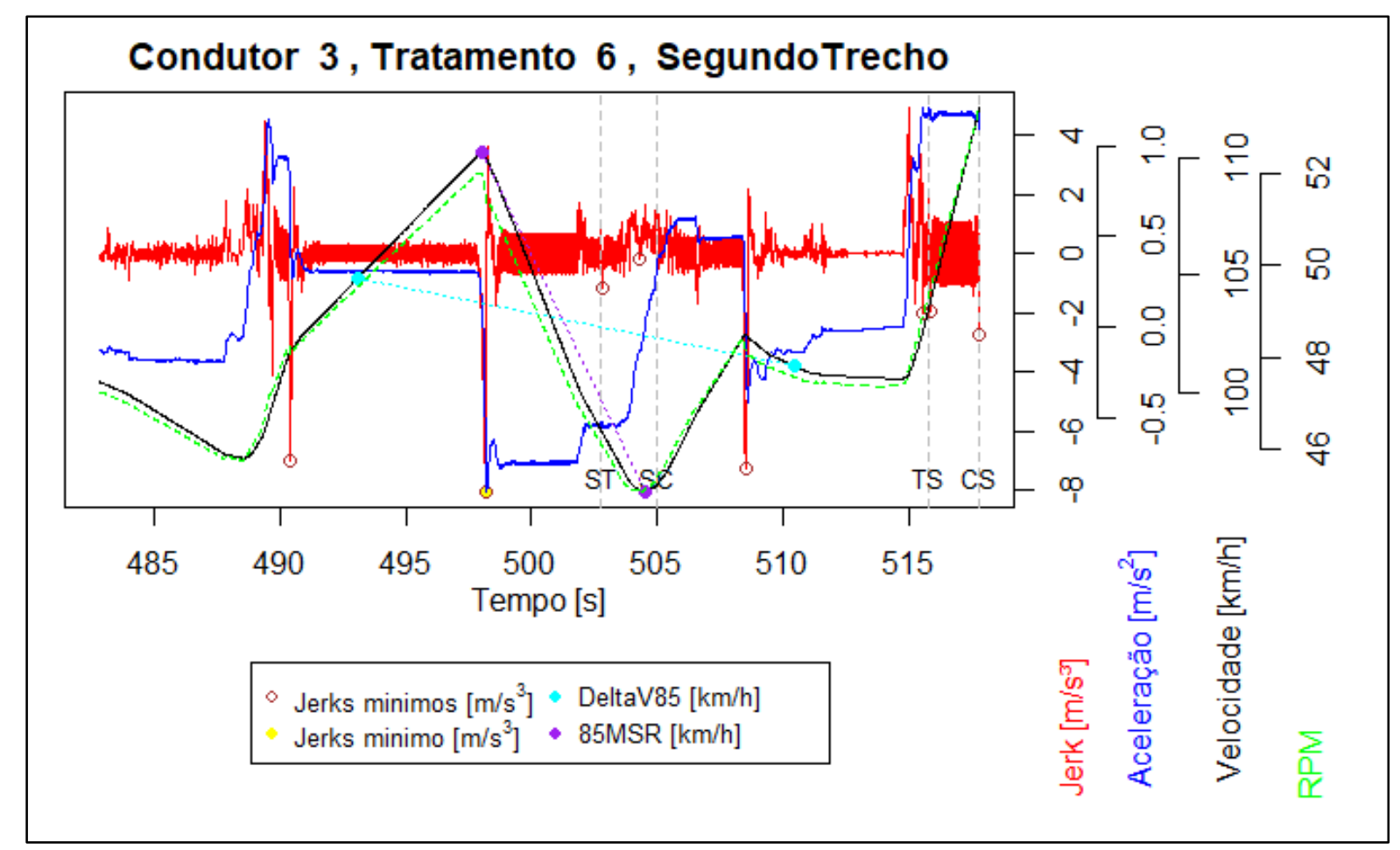

Figura 19 - Exemplo de respostas do experimento do condutor 3 no tratamento 6 
Observa-se nesse exemplo que para o método tradicional $\Delta \mathrm{V}_{85}$ (azul claro), o qual avaliava diferenças de velocidade entre os pontos médios das tangentes e das curvas, não existiu grande variação na velocidade do condutor. Já para o método 85MSR (roxo) essa diferença foi maior, para essa abordagem considerou-se a máxima diferença como a subtração entre a mínima velocidade registrada dentro da curva e a máxima velocidade encontrada até 200 metros antes do ponto de curva. Nesse caso, o jerk mínimo ficou próximo ao ponto de inflexão máximo da velocidade e o pico negativo da aceleração.

Esse pareceria um bom exemplo do uso da variável jerk como indicadora de reduções de velocidade nas curvas, porém esse fenômeno não ocorreu em todos os casos analisados. A Figura 20 apresenta outro exemplo do mesmo tratamento com um condutor diferente.

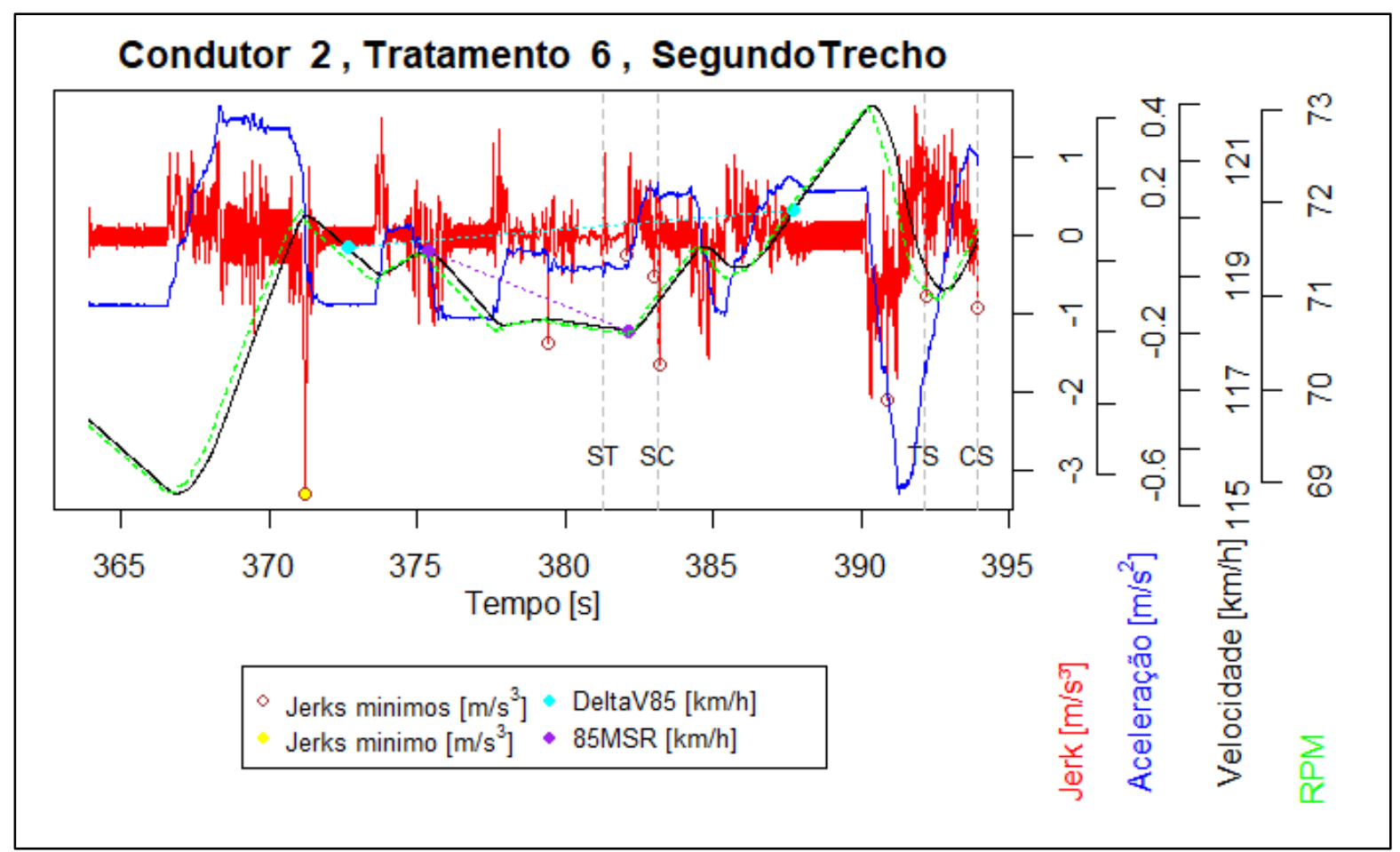

Figura 20 - Exemplo de respostas do experimento do condutor 2 no tratamento 6

Observa-se que as respostas foram diferentes da anterior, inclusive no valor do jerk aplicado. As diferenças do $\Delta \mathrm{V}_{85}$ (azul claro) foram positivas, enquanto as diferenças do 85MSR (roxo) foram negativas. $\mathrm{O}$ valor mínimo do jerk ocorreu na primeira metade da tangente, fora dos limites propostos pelo método. Esse perfil mostra que o condutor reduziu sua velocidade ao entrar na tangente (até 367s), começou uma aceleração forte (até 370s), reduziu bruscamente (371s), manteve a velocidade até entrar na curva e começou a ganhar velocidade novamente. A Figura 21 apresenta mais um perfil de um condutor diferente no mesmo tratamento. 


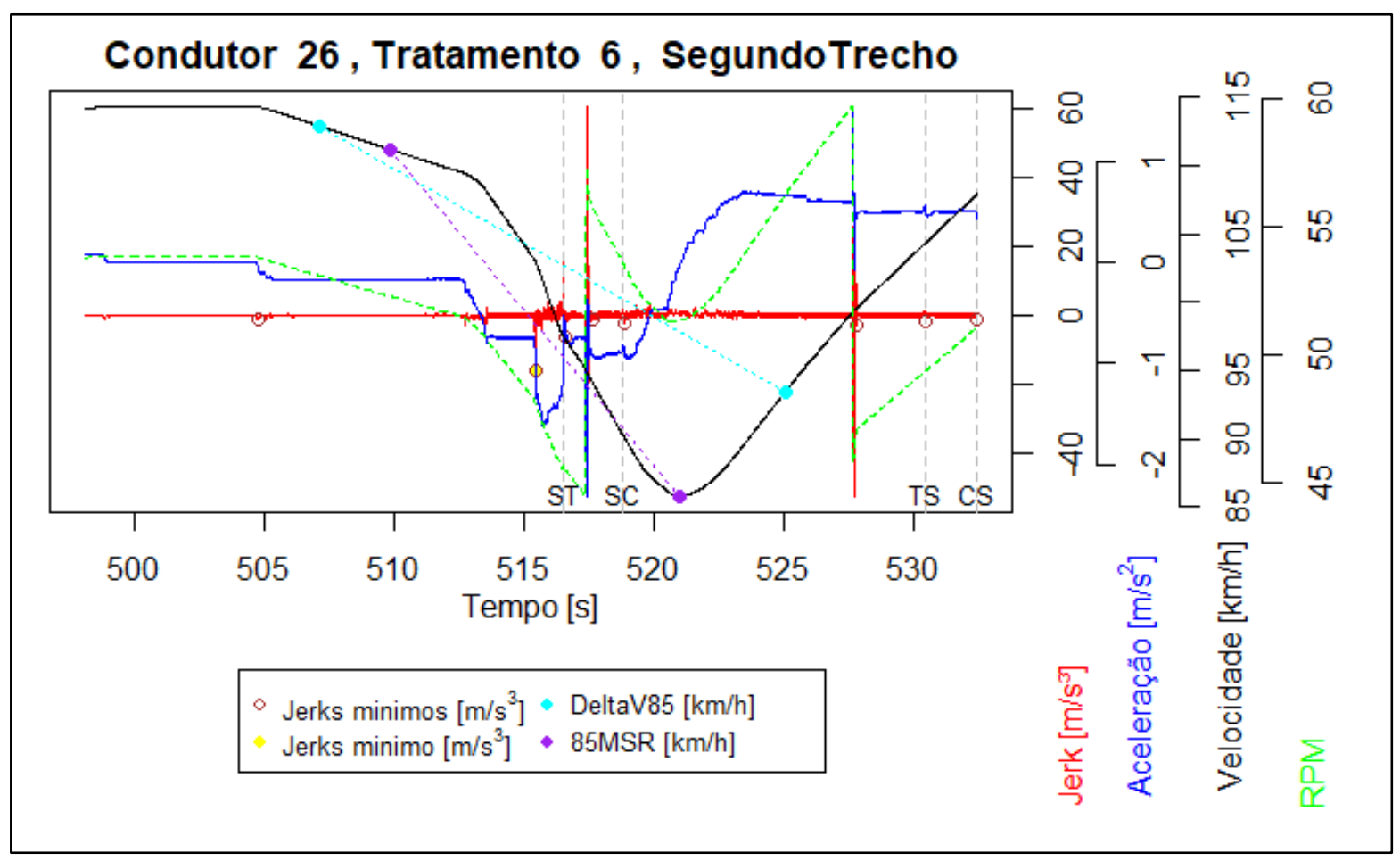

Figura 21 - Exemplo de respostas do experimento do condutor 26 no tratamento 6

Observa-se a influência da troca de marcha próxima do tempo 517.5s e 527.5s. As diferenças de velocidade dos métodos tradicionais foram mais próximas e o valor do jerk adotado não foi o mínimo, porém foi o mínimo do trecho, com a consideração da exclusão automática dos valores exorbitantes ocasionados pelas trocas de marcha.

Todos os perfis dos condutores construídos estão contidos nos apêndices desse trabalho. Depois de tratar os dados coletados, partiu-se para a realização dos objetivos específicos propostos.

A Tabela 21 apresenta os valores mínimos de jerk registrados, entre o ponto médio das tangentes de aproximação e o ponto médio dos trechos circulares das curvas horizontais, pelos 28 condutores da amostra nos 9 tratamentos apresentados (Rp-Tp, Rp-Tm, Rp-Tg, Rm-Tp, RmTm, Rm-Tg, Rg-Tp, Rg-Tm, Rg-Tg). Ela apresenta ainda a média simples desses valores. 
Tabela 21 - Valores do jerk mínimo encontrados nos tratamentos

\begin{tabular}{|c|c|c|c|c|c|c|c|c|c|}
\hline \multirow{3}{*}{ Condutor } & \multicolumn{9}{|c|}{ Jerk mínimo $\left[\mathrm{m} / \mathbf{s}^{3}\right]$} \\
\hline & \multicolumn{3}{|c|}{$\mathrm{Rp}$} & \multicolumn{3}{|c|}{$\mathrm{Rm}$} & \multicolumn{3}{|c|}{$\mathrm{Rg}$} \\
\hline & $\mathrm{Tp}$ & $\mathrm{Tm}$ & $\mathrm{Tg}$ & $\mathrm{Tp}$ & $\mathrm{Tm}$ & $\mathrm{Tg}$ & $\mathrm{Tp}$ & $\mathrm{Tm}$ & $\mathrm{Tg}$ \\
\hline 1 & -28.83 & -25.01 & -17.99 & -1.12 & -6.55 & -3.93 & -2.94 & -3.84 & -4.66 \\
\hline 2 & -5.72 & -26.96 & -29.17 & -2.74 & -5.60 & -1.63 & -1.99 & -2.30 & -2.43 \\
\hline 3 & -2.29 & -4.28 & -8.47 & -8.09 & -2.95 & -8.04 & -4.73 & -8.66 & -5.87 \\
\hline 4 & -3.45 & -2.98 & -34.19 & -2.84 & -1.63 & -3.96 & -2.99 & -3.02 & -1.87 \\
\hline 5 & -9.81 & -13.76 & -14.19 & -1.56 & -3.77 & -2.87 & -2.45 & -1.35 & -3.53 \\
\hline 6 & -2.81 & -2.26 & -4.65 & -1.58 & -3.00 & -3.56 & -0.81 & -2.87 & -2.89 \\
\hline 7 & -6.17 & -8.59 & -6.57 & -7.64 & -8.12 & -5.86 & -6.57 & -7.44 & -7.52 \\
\hline 8 & -5.40 & -20.29 & -36.25 & -15.13 & -16.04 & -23.28 & -4.29 & -21.03 & -16.51 \\
\hline 9 & -18.54 & -23.05 & -23.70 & -1.80 & -2.42 & -3.22 & -5.12 & -1.75 & -1.05 \\
\hline 10 & -7.47 & -4.73 & -3.56 & -1.47 & -2.83 & -2.49 & -2.50 & -2.32 & -3.47 \\
\hline 11 & -2.75 & -18.65 & -4.67 & -6.68 & -3.93 & -4.42 & -10.21 & -6.45 & -5.34 \\
\hline 12 & -2.32 & -2.04 & -2.87 & -2.90 & -1.44 & -2.25 & -1.01 & -1.41 & -0.95 \\
\hline 13 & -2.23 & -5.34 & -3.15 & -2.22 & -2.33 & -2.43 & -2.52 & -3.31 & -3.77 \\
\hline 14 & -16.18 & -17.87 & -42.19 & -2.43 & -13.58 & -21.05 & -8.73 & -2.56 & -3.81 \\
\hline 15 & -3.98 & -3.17 & -8.67 & -2.73 & -4.11 & -7.33 & -1.04 & -2.78 & -1.88 \\
\hline 16 & -5.66 & -12.83 & -6.38 & -2.20 & -5.93 & -3.96 & -5.05 & -3.58 & -2.83 \\
\hline 17 & -15.29 & -18.09 & -19.16 & -16.95 & -19.59 & -19.76 & -2.86 & -19.22 & -16.44 \\
\hline 18 & -4.64 & -18.98 & -5.80 & -6.39 & -16.13 & -4.35 & -9.18 & -6.63 & -10.40 \\
\hline 19 & -3.20 & -3.87 & -16.87 & -2.97 & -1.30 & -3.68 & -3.57 & -0.91 & -2.22 \\
\hline 20 & -29.55 & -51.41 & -49.98 & -5.84 & -41.09 & -35.56 & -25.79 & -11.28 & -30.51 \\
\hline 21 & -3.74 & -5.95 & -6.09 & -12.31 & -3.46 & -5.51 & -7.93 & -10.37 & -4.22 \\
\hline 22 & -2.51 & -3.86 & -4.70 & -1.97 & -4.50 & -15.54 & -0.95 & -13.76 & -15.66 \\
\hline 23 & -2.92 & -3.52 & -2.52 & -0.74 & -1.95 & -2.02 & -0.58 & -2.36 & -2.22 \\
\hline 24 & -2.22 & -1.64 & -2.01 & -1.64 & -1.74 & -2.25 & -1.45 & -1.39 & -1.33 \\
\hline 25 & -1.66 & -2.48 & -5.32 & -1.38 & -2.67 & -2.64 & -2.79 & -1.43 & -5.36 \\
\hline 26 & -2.52 & -11.83 & -15.14 & -3.29 & -2.38 & -16.24 & -2.66 & -3.43 & -3.23 \\
\hline 27 & -2.43 & -2.21 & -6.71 & -6.43 & -6.43 & -1.97 & -3.51 & -4.24 & -7.13 \\
\hline 28 & -16.42 & -24.84 & -17.73 & -3.72 & -32.38 & -35.99 & -3.33 & -22.37 & -6.33 \\
\hline Média & -7.53 & -12.16 & -14.24 & -4.53 & -7.78 & -8.78 & -4.56 & -6.14 & -6.19 \\
\hline
\end{tabular}

Ao se comparar as médias dos tratamentos, parece que existiu efeito do crescimento do comprimento das tangentes de aproximação $(\mathrm{Tp}=50 \mathrm{~m} \rightarrow \mathrm{Tm}=310 \mathrm{~m} \rightarrow \mathrm{Tg}=570 \mathrm{~m})$ e da diminuição do comprimento dos raios de curvatura $(\mathrm{Rg}=615 \mathrm{~m} \rightarrow \mathrm{Rm}=370 \mathrm{~m} \rightarrow \mathrm{Rp}=125 \mathrm{~m})$ nos valores de jerk mínimo registrados. Porém, existiram casos onde os comportamentos divergiram dessa suposição. Como exemplo, o Condutor 1, quando experimentou um raio pequeno, diminuiu o valor do jerk mínimo registrado conforme o comprimento da tangente aumentou. Para entender a influência dos dois fatores geométricos estudados no indicador proposto realizou-se uma análise de variância. 


\subsection{Avaliar a influência de características geométricas no jerk}

Para o cumprimento do objetivo específico proposto, realizou-se uma análise de variância fatorial de medidas repetidas (ANOVA RM fatorial) nos resultados do ensaio, apresentados anteriormente. Essa técnica é indicada para analisar diferenças ocasionadas pela variação de mais de uma variável independente em uma variável resposta. Para a realização de uma ANOVA, algumas suposições deveriam ser respeitadas: a distribuição normal das respostas, a homogeneidade das variâncias entre grupos e a independência das observações. Como o experimento adotou medidas repetidas no seu design, a hipótese de independência entre as respostas em condições diferentes seria violada (a mesma pessoa responderia em todos os níveis). Para contornar essa falha, seria necessária respeitar a suposição adicional da Esfericidade (FIELD, 2009).

\subsubsection{Normalidade das respostas}

Depois de encontrado o valor do jerk mínimo para cada combinação tratamento-condutor, avaliou-se o efeito da modificação da combinação das variáveis independentes (características geométricas) nas respostas da variável dependente (jerk mínimo). Para tanto, inicialmente, avaliou-se a normalidade das respostas. A Figura 22 apresenta a distribuição desses escores, para todos as combinações.

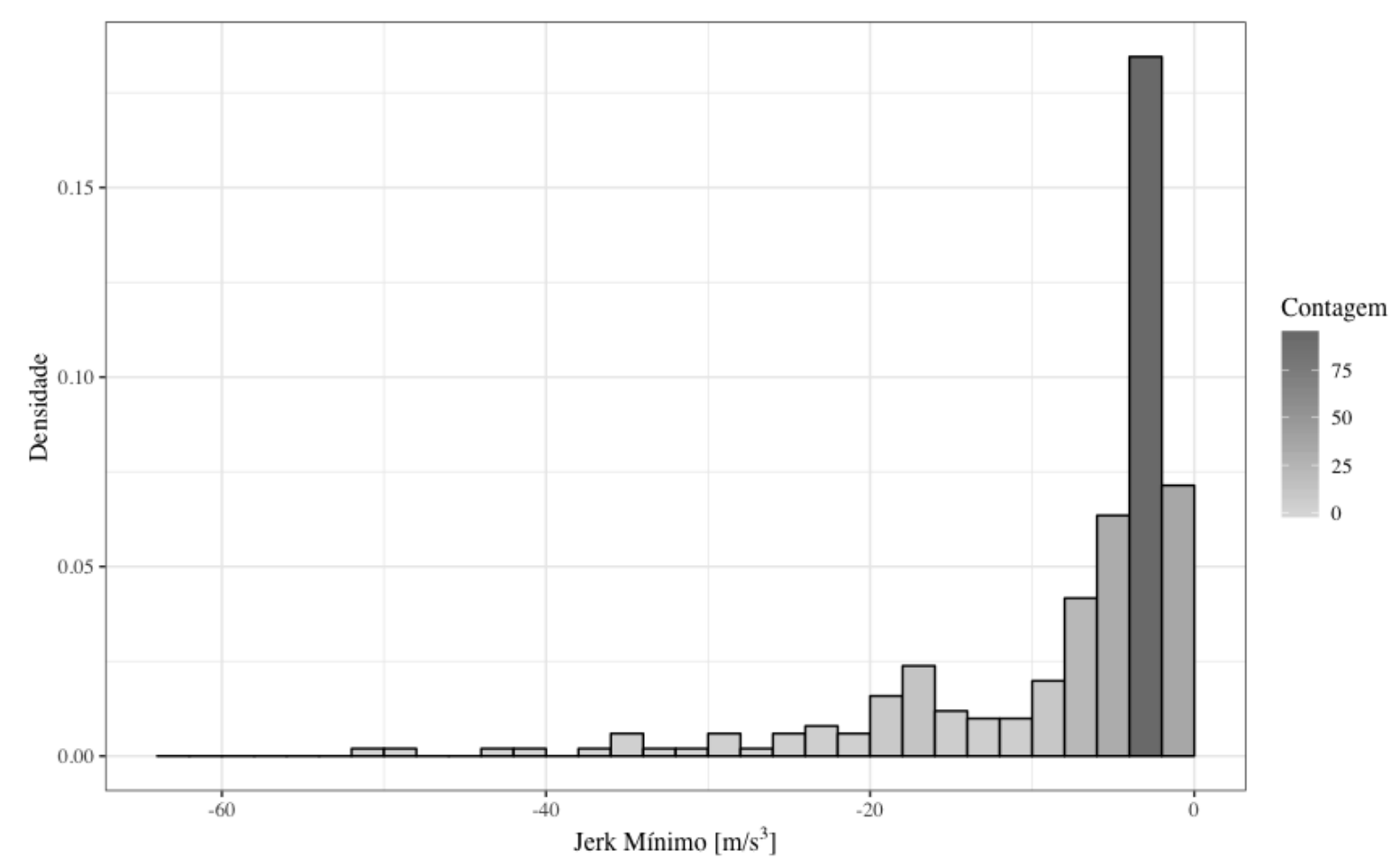

Figura 22 - Distribuição dos jerks mínimos encontrados 
Essa distribuição não se assemelha a uma normal. Ela apresenta assimetria negativa $(-2.18)-$ muitos valores próximos da extremidade direita; e curtose positiva (8.07) - a distribuição é pontiaguda. Para uma distribuição normal, essas duas características deveriam ser próximas de zero.

Como se desejava utilizar uma análise de variância para comparar as médias, optou-se por transformar as respostas, a partir do logaritmo natural dos valores absolutos dessas, a fim de cumprir com a suposição da normalidade exigida. A Figura 23 apresenta a nova distribuição encontrada depois de realizada a transformação referida.

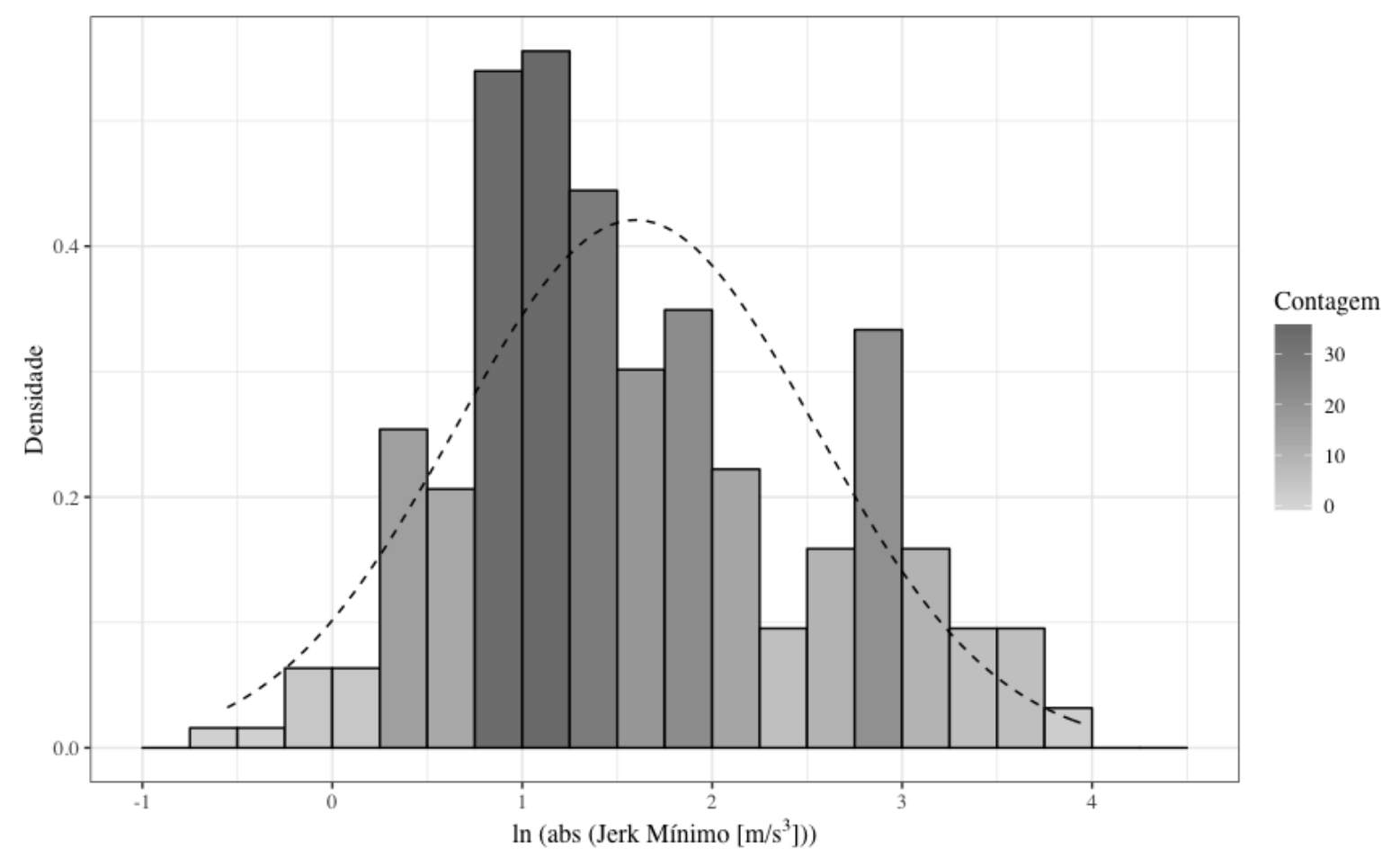

Figura 23 - Distribuição dos dos jerks mínimos encontrados

Observa-se que a transformação pareceu ter efeito na adequação dos dados à suposição da normalidade (curva normal tracejada). A assimetria diminuiu (0.45) e a curtose parece menor (2.48). Partiu-se então para a avaliação da normalidade para cada tratamento. A Figura 24 apresenta diagramas de caixa desses, já com a transformação supracitada aplicada. A linha grossa horizontal, dentro de cada caixa, representa o valor da mediana desses dados. 


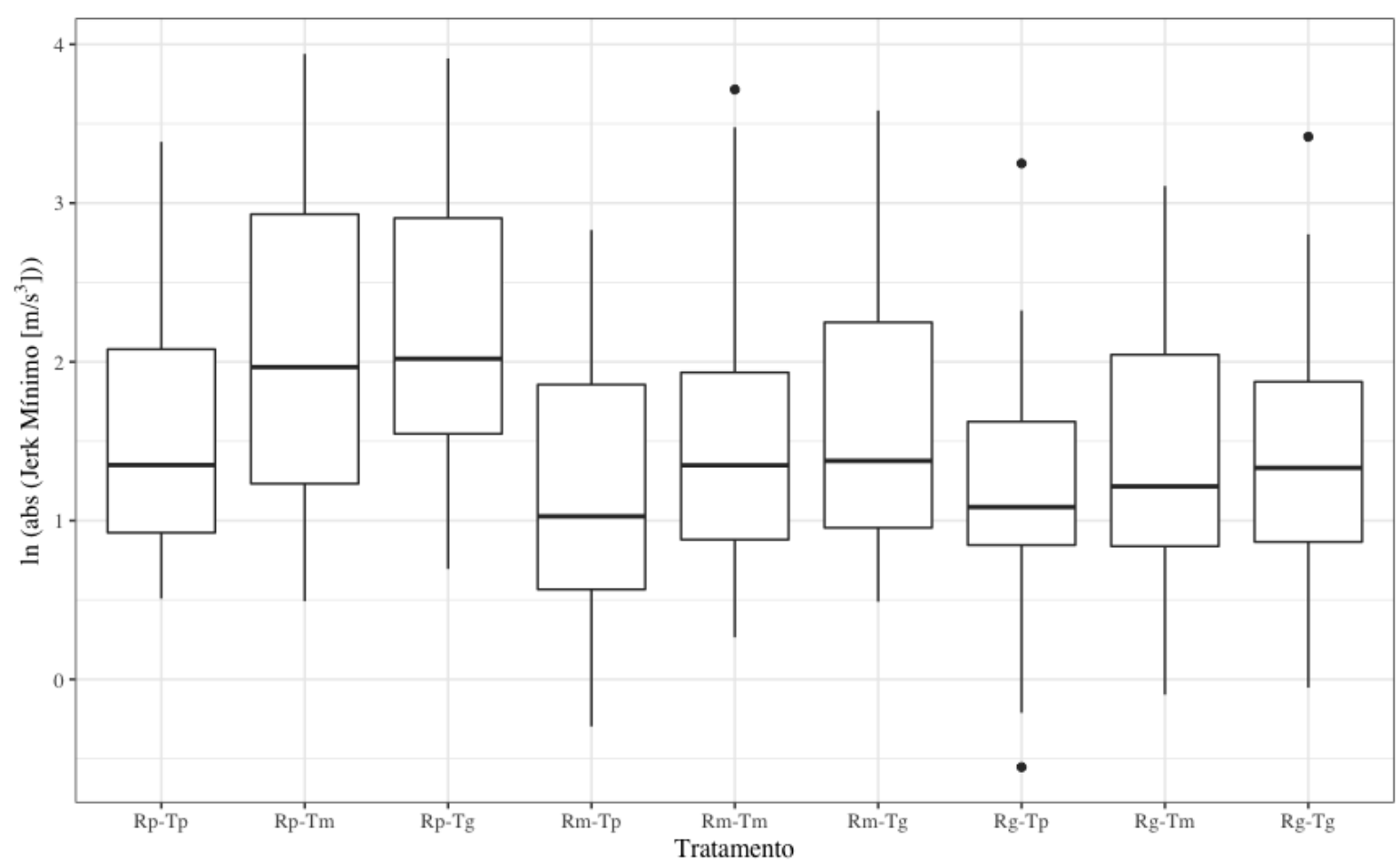

Figura 24 - Diagramas de caixa dos tratamentos

Dos diagramas é possível pressupor que a variação no comprimento das tangentes $(\mathrm{Tp}=50 \mathrm{~m}$ $\rightarrow \mathrm{Tm}=310 \mathrm{~m} \rightarrow \mathrm{Tg}=570 \mathrm{~m}$ ) teve efeito nas medianas dos valores de jerk mínimo dentre grupos. Não fica claro esse efeito para a variação do comprimento dos raios $(\mathrm{Rg}=615 \mathrm{~m} \rightarrow \mathrm{Rm}$ $=370 \mathrm{~m} \rightarrow \mathrm{Rp}=125 \mathrm{~m})$.

A equidistância entre o valor da mediana de cada caixa (linha horizontal grossa) e os quartis inferiores e superiores (bordas horizontais das caixas) sinalizaria uma suposta normalidade das respostas. A Tabela 22 apresenta, para cada tratamento, estatísticas descritivas e os valores de significância do teste de normalidade de Kolgomorov-Smirnov (K-S), após a transformação.

Tabela 22 - Estatísticas descritivas e teste de normalidade do jerk para cada tratamento

\begin{tabular}{lcrccccccc}
\hline \multirow{2}{*}{ Trat. } & \multicolumn{1}{c}{$\mathbf{R}$} & \multicolumn{1}{c}{$\mathbf{T}$} & \multicolumn{1}{c}{ Média } & \multicolumn{1}{c}{ Desvio } & \multicolumn{2}{c}{ Int. Conf. 95\% } & Mínimo & Máximo & K-S \\
\cline { 2 - 10 } & \multicolumn{1}{c}{$[\mathrm{m}]$} & \multicolumn{1}{c}{$[\mathrm{m}]$} & {$\left[\mathrm{m} / \mathrm{s}^{3}\right]$} & {$\left[\mathrm{m} / \mathrm{s}^{3}\right]$} & {$\left[\mathrm{m} / \mathrm{s}^{3}\right]$} & {$\left[\mathrm{m} / \mathrm{s}^{3}\right]$} & {$\left[\mathrm{m} / \mathrm{s}^{3}\right]$} & {$\left[\mathrm{m} / \mathrm{s}^{3}\right]$} & $\mathrm{p}$ \\
\hline Rp-Tp & 125 & 50 & -5.08 & -2.33 & -7.06 & -3.66 & -29.55 & -1.66 & 0.11 \\
Rp-Tm & 125 & 310 & -7.84 & -2.69 & -11.50 & -5.34 & -51.41 & -1.64 & 0.08 \\
Rp-Tg & 125 & 570 & -9.53 & -2.52 & -13.63 & -6.66 & -49.98 & -2.01 & 0.12 \\
Rm-Tp & 370 & 50 & -3.24 & -2.24 & -4.43 & -2.37 & -16.95 & -0.74 & 0.10 \\
Rm-Tm & 370 & 310 & -4.76 & -2.55 & -6.84 & -3.31 & -41.09 & -1.30 & 0.20 \\
Rm-Tg & 370 & 570 & -5.46 & -2.54 & -7.84 & -3.81 & -35.99 & -1.63 & $\mathbf{0 . 0 1}$ \\
Rg-Tp & 615 & 50 & -3.15 & -2.36 & -4.40 & -2.26 & -25.79 & -0.58 & 0.20 \\
Rg-Tm & 615 & 310 & -4.08 & -2.46 & -5.78 & -2.87 & -22.37 & -0.91 & 0.20 \\
Rg-Tg & 615 & 570 & -4.25 & -2.34 & -5.91 & -3.06 & -30.51 & -0.95 & 0.20 \\
\hline
\end{tabular}


Como valores significantes do teste, $\mathrm{p}<0.05$, de Kolgomorov-Smirnov indicariam desvios na normalidade, apenas o tratamento com o nível intermediário do Raio e o nível mais alto da Tangente (Rm-Tg) falharia nesse pressuposto, as outras distribuições seriam possivelmente normais. Como não existiam outliers evidentes e nem desvios no gráfico de valores normais observados vs. esperados para esse tratamento, seguiu-se com a análise.

\subsubsection{Homogeneidade das variâncias}

O teste de Levene demostrou que, entre tratamentos, a homogeneidade das variâncias não era significativamente diferente, $F(8,243)=0.756, \mathrm{p}>0.05$. Com isso manteve-se a suposição de variâncias homogêneas.

\subsubsection{Esfericidade}

Para avaliar a suposição da esfericidade, realizou-se o teste de Mauchly. Essa hipótese foi violada apenas para o efeito principal do Raio, $\chi^{2}(2)=17.531, \mathrm{p}<0.001$. Por isso, para analisar os resultados desse efeito utilizou-se o Épsilon de Greenhouse-Geisser $(\varepsilon=0.819)$ para corrigir seus graus de liberdade e, por consequência, o valor da estatística $F$.

A esfericidade foi assumida para o efeito principal da Tangente, $\chi^{2}(2)=0.556, p=0.757$, e para o efeito da interação entre as variáveis, $\chi^{2}(9)=8.439, \mathrm{p}=0.492$.

\subsubsection{Resultados da ANOVA}

Com os pressupostos cumpridos, partiu-se para a execução da ANOVA fatorial de medidas repetidas, com as variáveis explicativas Raio (125m, 370m e 615m) e Tangente (50m, 310m e 570m) e a variável resposta jerk mínimo.

Os efeitos principais das variáveis Raio e Tangente foram significativos, $\mathrm{p}<0.001$. Porém, não houve efeito significativo da interação entre essas, $F(4,108)=0.648, r=0.15$. A mudança dos valores de raios teve um efeito significativo no valor médio do jerk, $F(2,54)=16.178$. Os contrastes do Raio mostraram que houve tanto uma tendência linear significativa nos efeitos, $F$ $(1,27)=20.180, r=0.65$, quanto quadrática, $F(1,27)=5.484, r=0.41$. A comparação entre pares, ajustadas pela correção de Bonferroni, mostrou que houve diferenças significativas, $\mathrm{p}<$ 0.05, entre o nível mais baixo e os mais altos (125m vs 370m; 125m vs 615m) da variável Raio, o que não ocorreu na comparação dos níveis mais altos (370m vs 615m). A Figura 25 apresenta essas médias. 


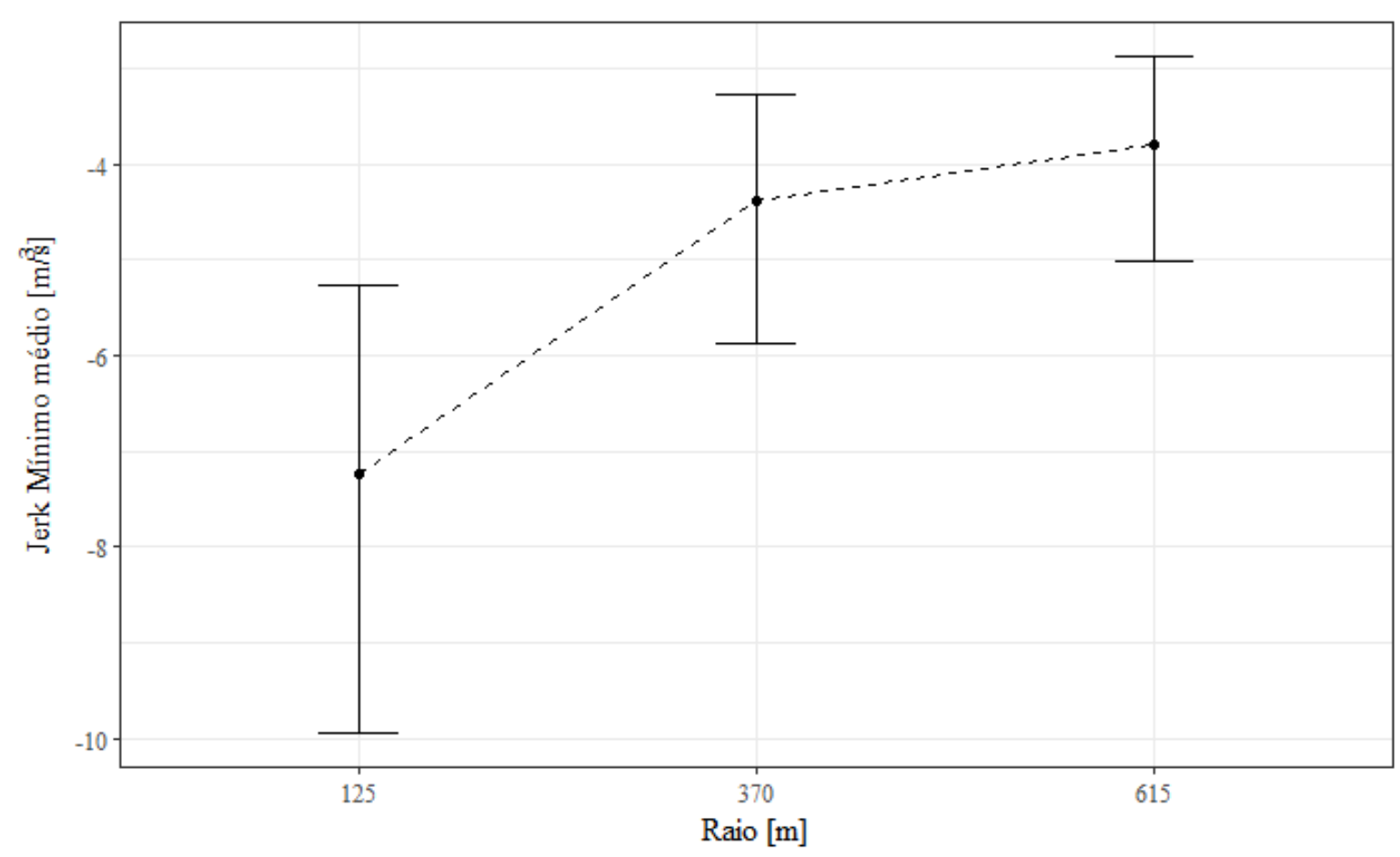

Figura 25 - Diagrama de barras de erros para os diferentes níveis da variável Raio

Do diagrama é possível reforçar que existiu uma tendência linear de crescimento do valor médio do jerk mínimo, conforme se aumentou o valor do raio. As barras de erro representariam os limites superiores e inferiores dos intervalos de confiança de $95 \%$ dessas médias. Conforme aumentou-se o comprimento do raio, aumentou-se o valor do jerk médio aplicado. Do gráfico também foi possível supor que não haveria diferença significativa entre os níveis mais altos desse fator.

A mudança dos valores de comprimentos de tangente obteve um efeito significativo no valor médio do jerk mínimo encontrado, $F(2,54)=15.179$. Os contrastes da Tangente mostraram que houve apenas uma tendência linear significativa nos efeitos, $F(1,27)=25.252, r=0.69$.

Como aconteceu com a variável Raio, a comparação entre pares, ajustadas pela correção de Bonferroni, mostrou que houve diferenças significativas, $\mathrm{p}<0.05$, entre o nível mais baixo e os mais altos (50m vs 310m; 50m vs 570m) da variável Tangente, o que não ocorreu na comparação dos níveis mais altos (310m vs 570m). A Figura 26 apresenta as médias para essa variável. 


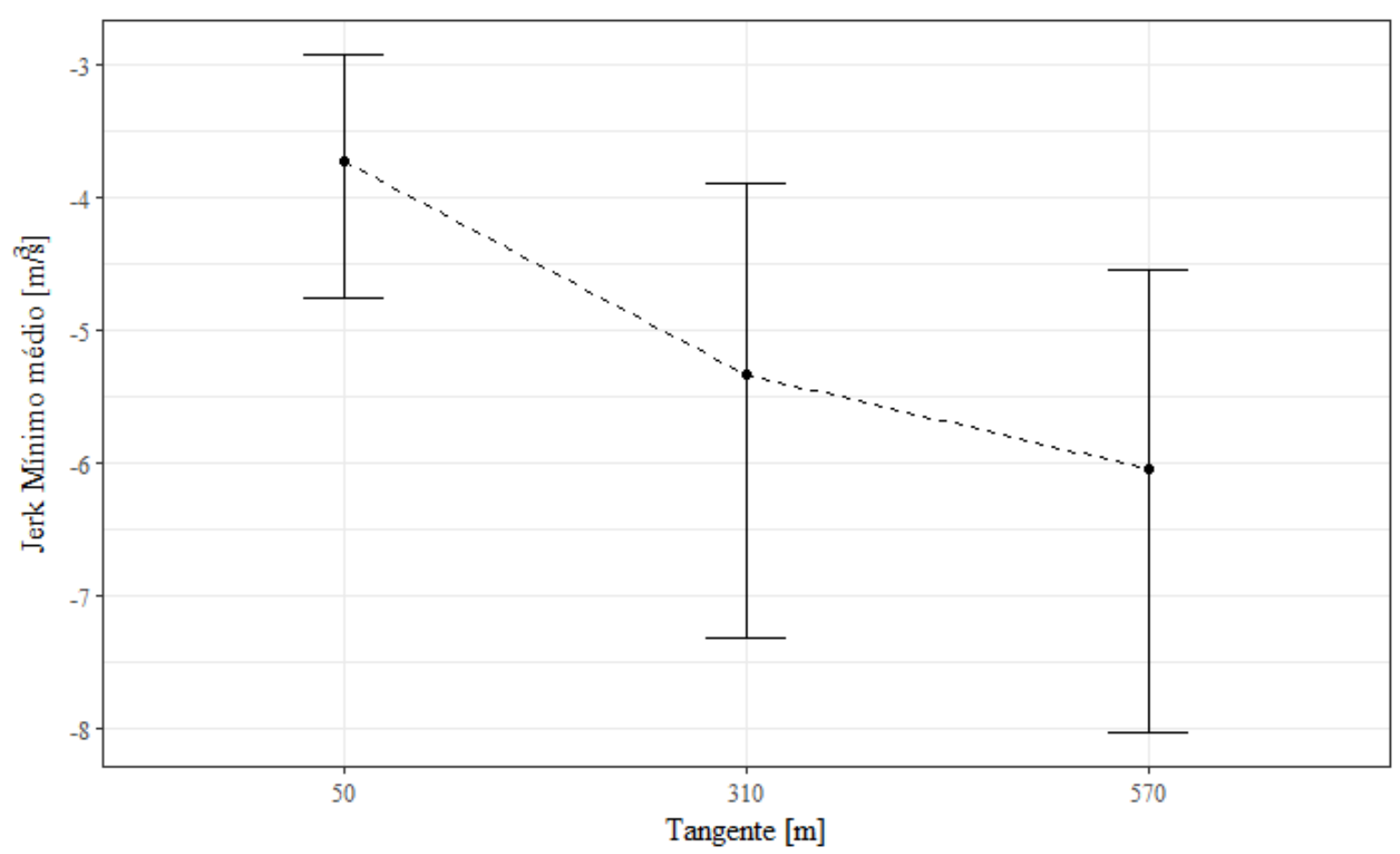

Figura 26 - Diagrama de barras de erros para os diferentes níveis da variável Tangente

O gráfico demonstrou a tendência linear de crescimento. Conforme aumentou o comprimento da tangente de aproximação, aumentou o valor do jerk mínimo médio aplicado. As médias encontradas para a combinação das variáveis estão apresentadas na Figura 27. Vale ressaltar que os resultados da ANOVA não mostraram efeito da interação entre essas.

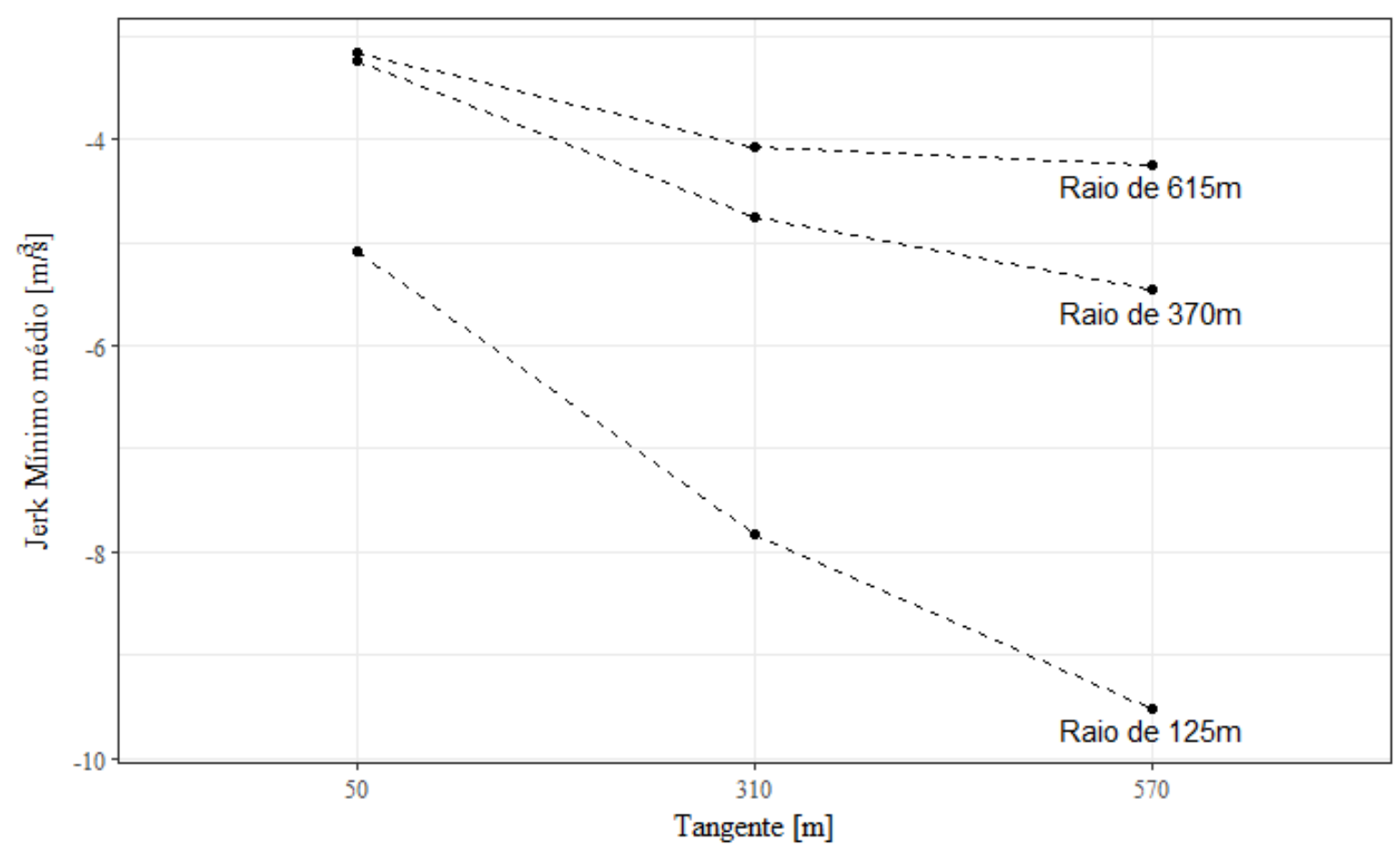

Figura 27 - Jerk médio para os diferentes níveis da combinação das variáveis estudadas 
O gráfico ratifica que não pareceria haver interação entre as variáveis estudadas. A inclinação das linhas pontilhadas pareceria não diferir entre o nível mais baixo (125m) e o nível médio (370m) do Raio, para todos os níveis de tangente. Já entre o nível médio (370m) e o nível mais alto $(615 \mathrm{~m})$ do Raio, o paralelismo das retas não fica claro, principalmente entre o nível mais baixo (50m) e o nível mais alto $(570 \mathrm{~m})$ da Tangente. De maneira geral, conforme o comprimento dos raios diminuiu e das tangentes de aproximação aumentaram, o jerk mínimo médio diminuiu de valor.

\subsubsection{Considerações}

A análise desses resultados mostrou que existiu efeito significativo da variação das características geométricas no valor médio do jerk mínimo adotado pelos condutores, diminuiuse assim a probabilidade de aceitar a hipótese nula de que não haveria esse efeito.

Com base nas limitações desse experimento, seria necessária a replicação do estudo com o emprego de outras variáveis explicativas, como, por exemplo, a variação do tráfego, das condições climáticas, da potência do veículo utilizado, do tipo de mudança de marcha.

Também seria imprescindível estudar o comportamento dos condutores em campo, em estudos naturalísticos. Fomenta-se assim a continuidade dos estudos do uso da variável jerk para a identificação de trechos de geometria inconsistente.

Partiu-se então para o desenvolvimento das comparações das respostas desse método com duas das abordagens tradicionais utilizadas para indicar trechos com problemas de consistência geométrica $\left(\Delta \mathrm{V}_{85}\right.$ e $\left.85 \mathrm{MSR}\right)$. 


\subsection{Comparar as respostas do indicador proposto com métodos tradicionais}

Para comparar as respostas do indicador proposto (jerk mínimo) com os métodos tradicionais (85MSR e $\Delta \mathrm{V}_{85}$ ), imaginou-se avaliar as relações entre esses de duas formas: 1. A partir da avaliação de caso a caso, ou seja, todas as respostas dos condutores seriam correlacionadas diretamente; 2. A partir da correlação dos percentis 85 das respostas de todos os condutores, como tradicionalmente se avaliava um segmento de rodovia.

Como a abordagem $\Delta \mathrm{V}_{85}$ não considerava diferenças para cada condutor de maneira isolada, esse método não foi considerado para a primeira forma de comparação. Antes de realizar as comparações, levantaram-se as respostas de cada condutor para os métodos tradicionais.

\subsubsection{Respostas dos condutores para os métodos tradicionais}

Inicialmente, para cada tratamento agrupou-se os perfis de velocidades dos condutores. Esses estão apresentados na sequência, da Figura 28 até a Figura 36. Nesses perfis estão indicados (linhas pontilhadas cinzas) os pontos de mudança de tangente para espiral (TS), de espiral para setor circular da curva (SC), de setor circular para espiral (CS) e de espiral para a tangente seguinte (ST). A Figura 28 apresenta os perfis para o tratamento 1, esse era composto por uma tangente de aproximação de 50 metros e uma curva com raio de 125 metros de comprimento.

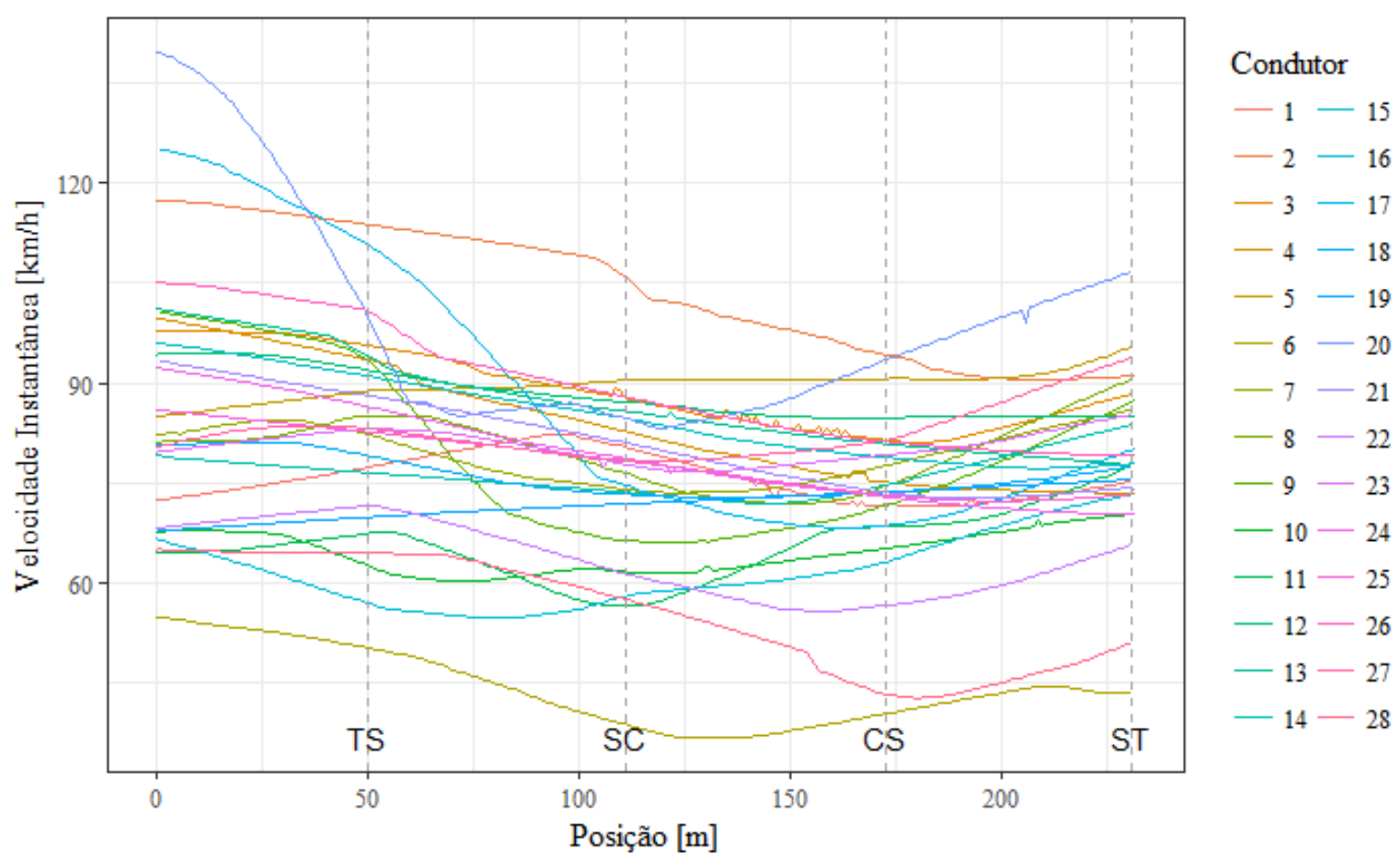

Figura 28 - Perfis de velocidades dos condutores no tratamento 1 
A Figura 29 apresenta os perfis para o tratamento 2 (tangente de $310 \mathrm{~m}$ e raio de $125 \mathrm{~m}$ ).

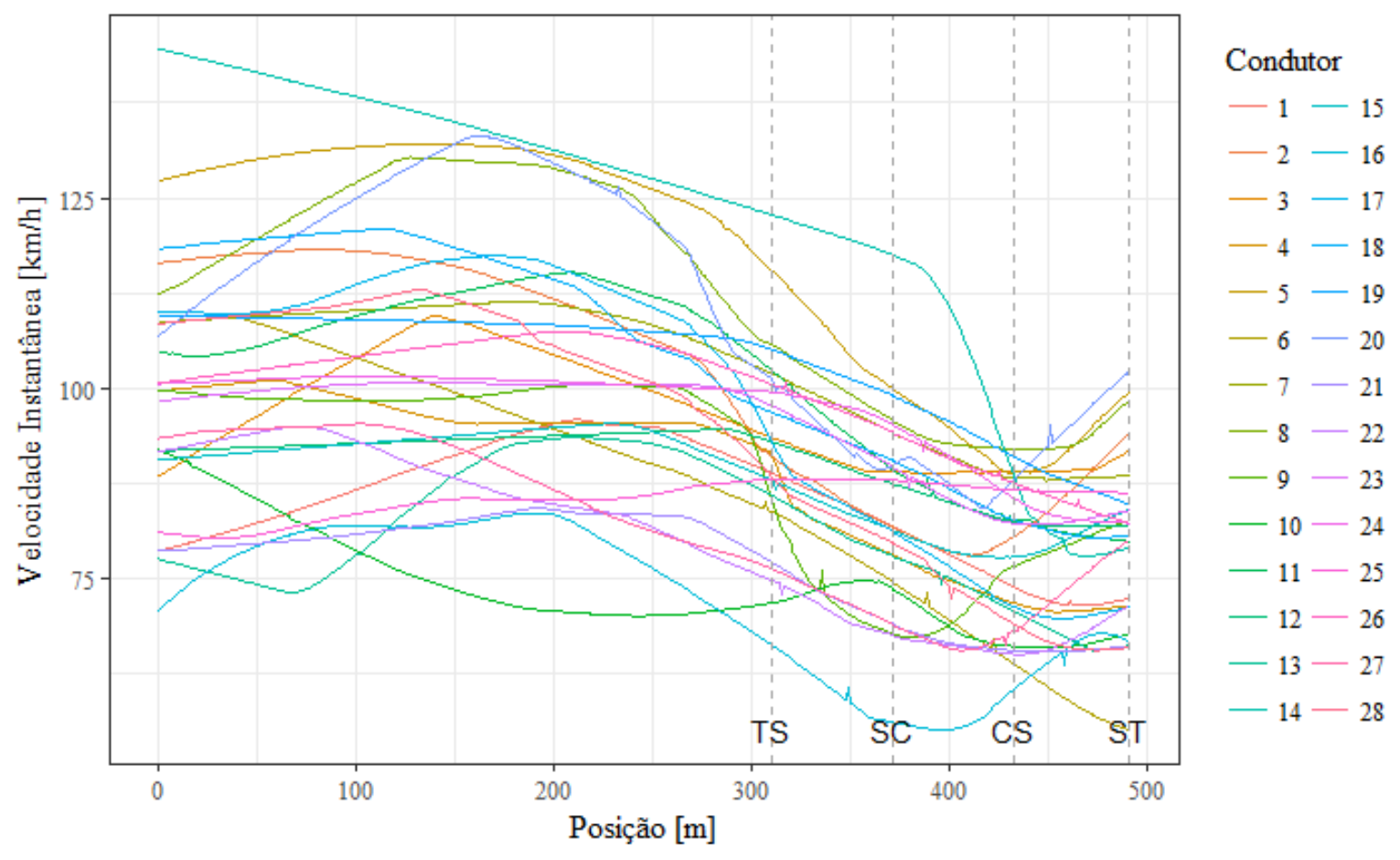

Figura 29 - Perfis de velocidades dos condutores no tratamento 2

A Figura 30 apresenta os perfis para o tratamento 3 (tangente de $570 \mathrm{~m}$ e raio de $125 \mathrm{~m}$ ).

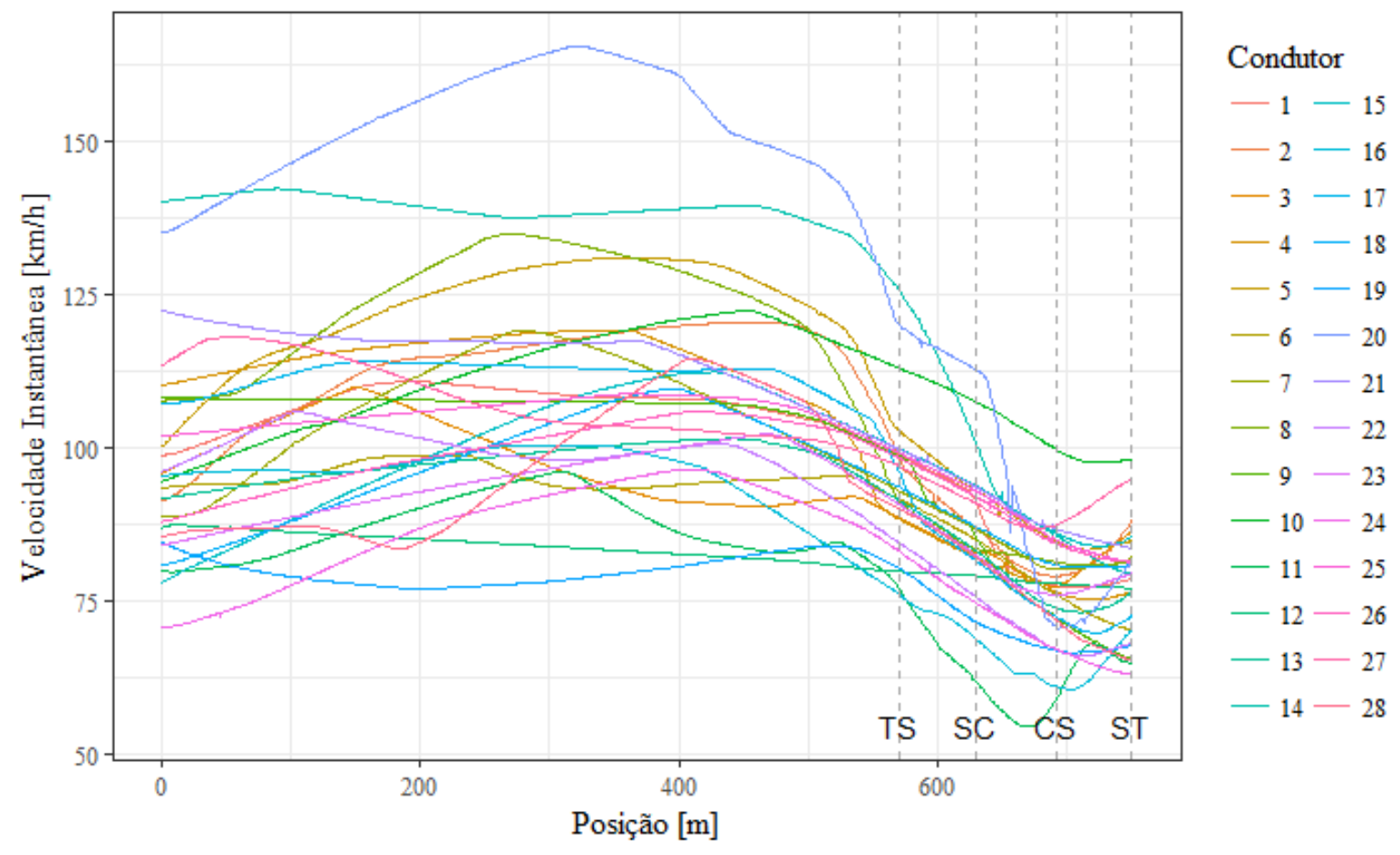

Figura 30 - Perfis de velocidades dos condutores no tratamento 3 
A Figura 31 apresenta os perfis para o tratamento 4 (tangente de $50 \mathrm{~m}$ e raio de $370 \mathrm{~m}$ ).

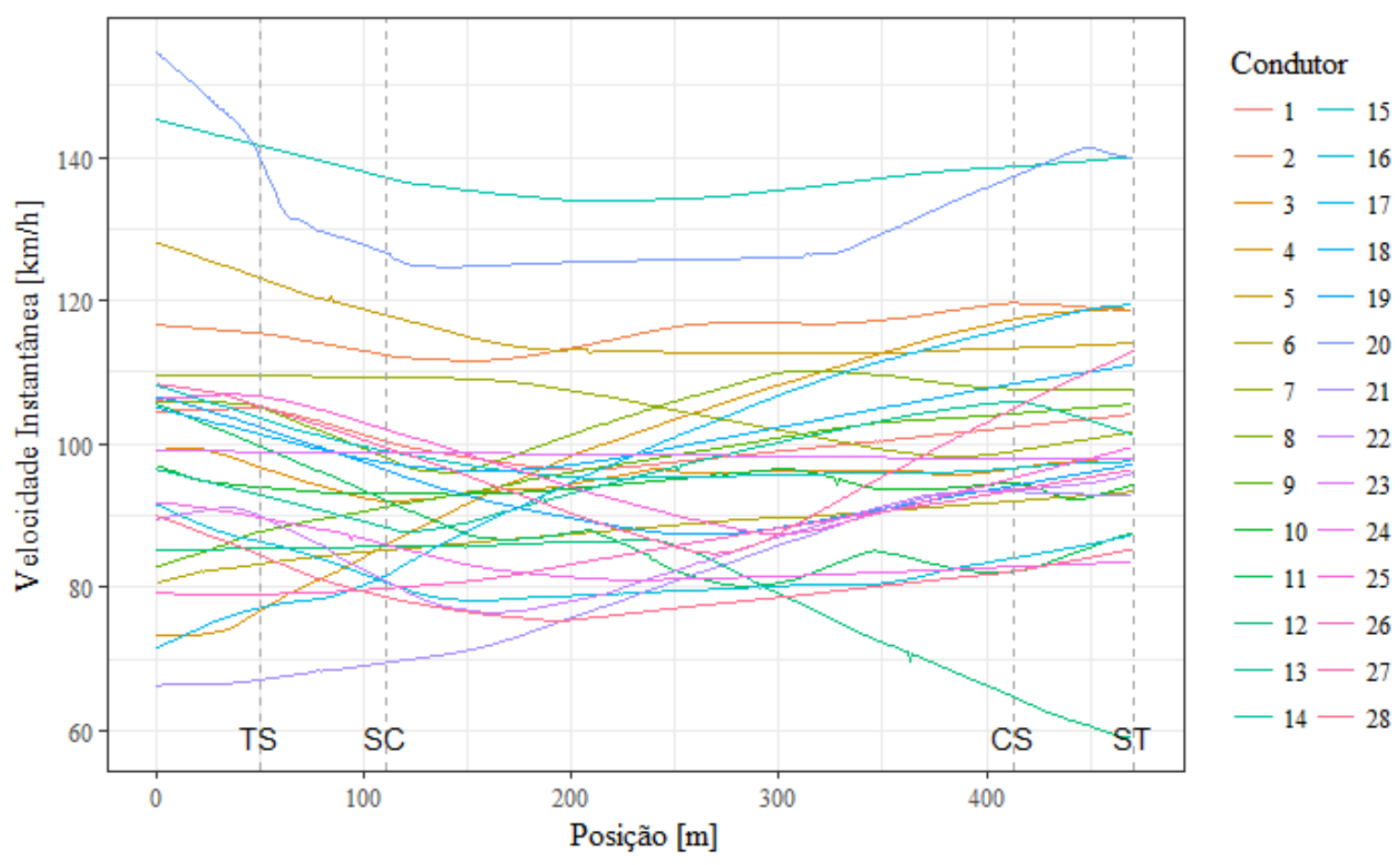

Figura 31 - Perfis de velocidades dos condutores no tratamento 4

A Figura 32 apresenta os perfis para o tratamento 5 (tangente de $310 \mathrm{~m}$ e raio de $370 \mathrm{~m}$ ).

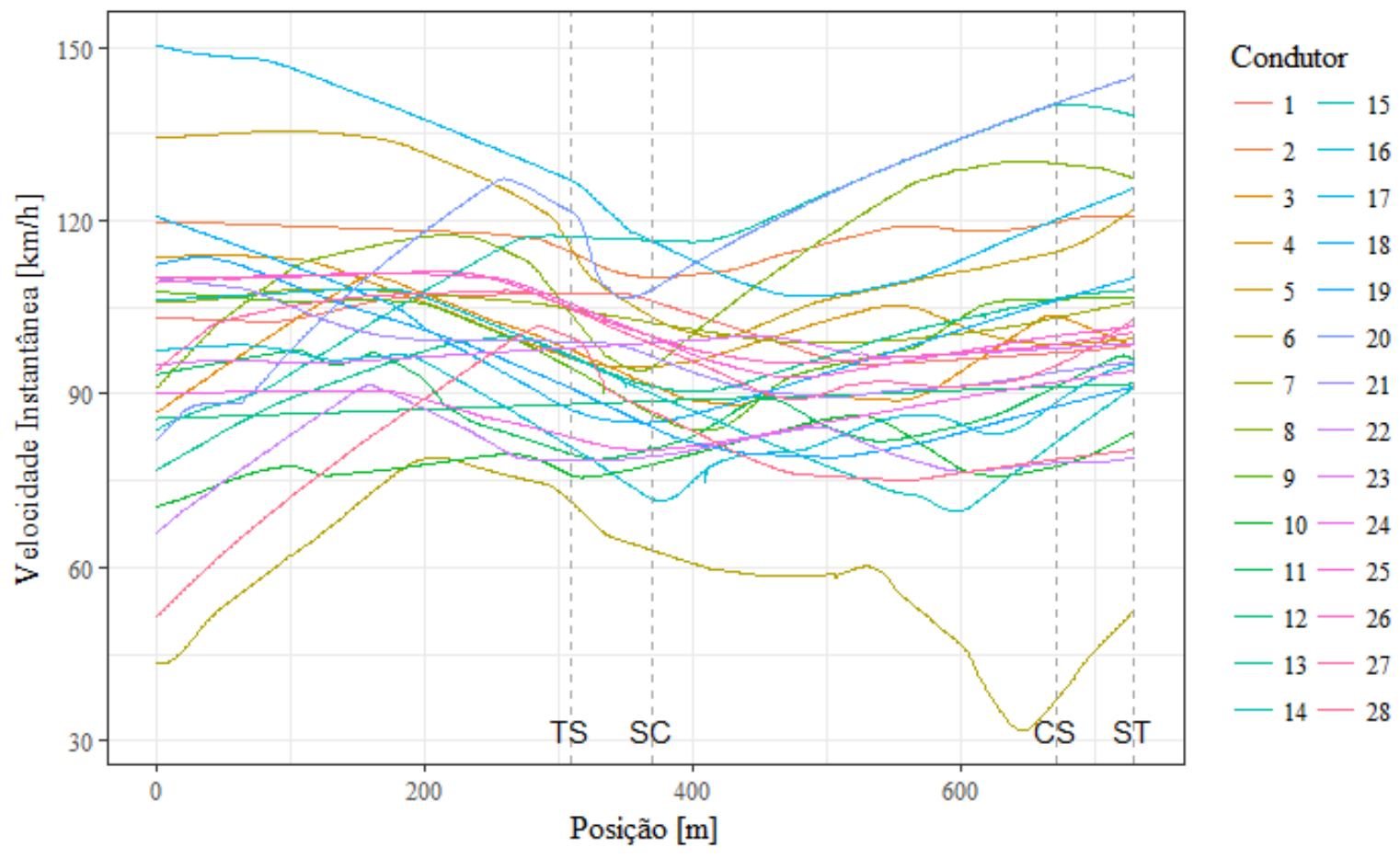

Figura 32 - Perfis de velocidades dos condutores no tratamento 5 
A Figura 33 apresenta os perfis para o tratamento 6 (tangente de $570 \mathrm{~m}$ e raio de $370 \mathrm{~m}$ ).

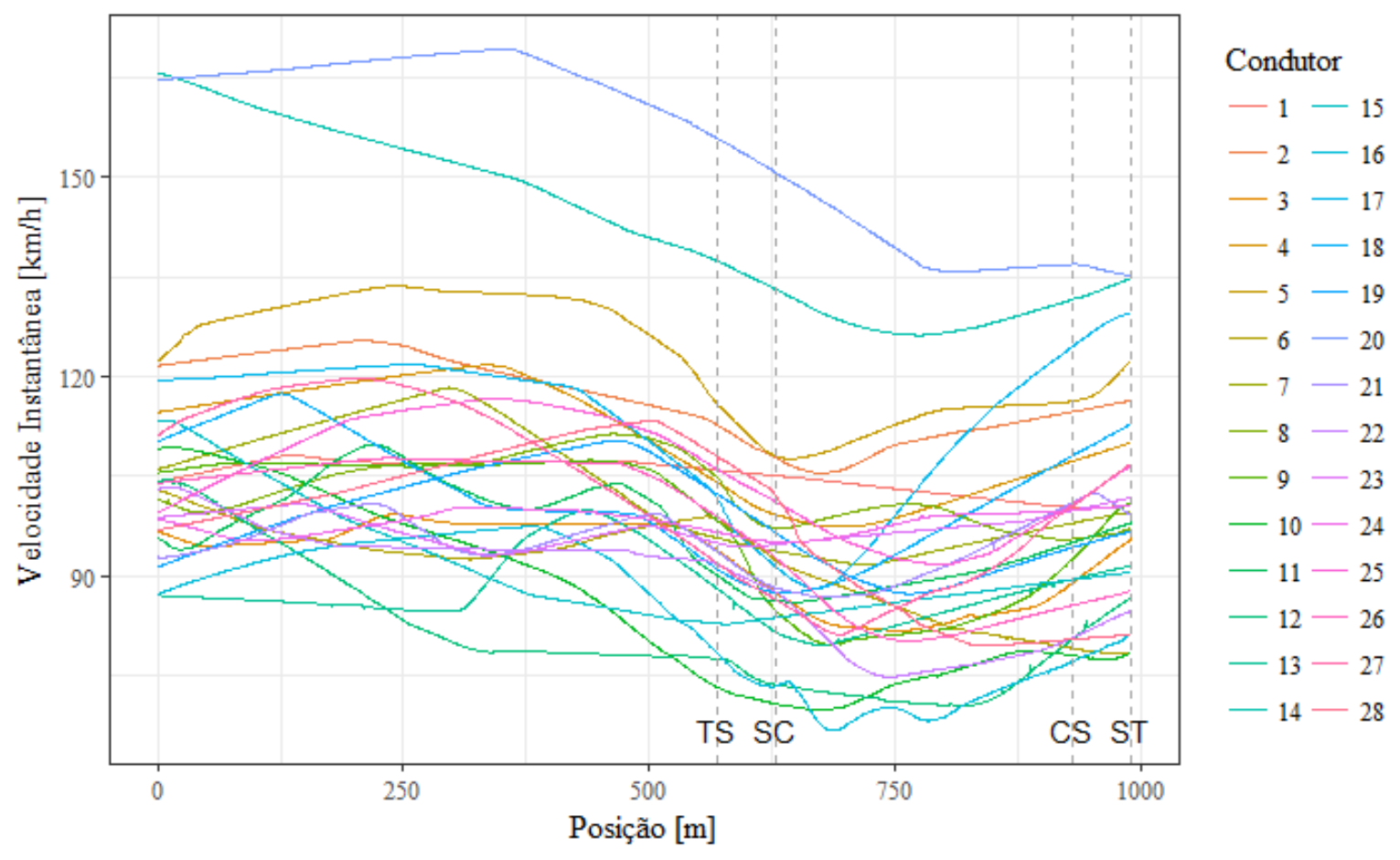

Figura 33 - Perfis de velocidades dos condutores no tratamento 6

A Figura 34 apresenta os perfis para o tratamento 7 (tangente de $50 \mathrm{~m}$ e raio de $615 \mathrm{~m}$ ).

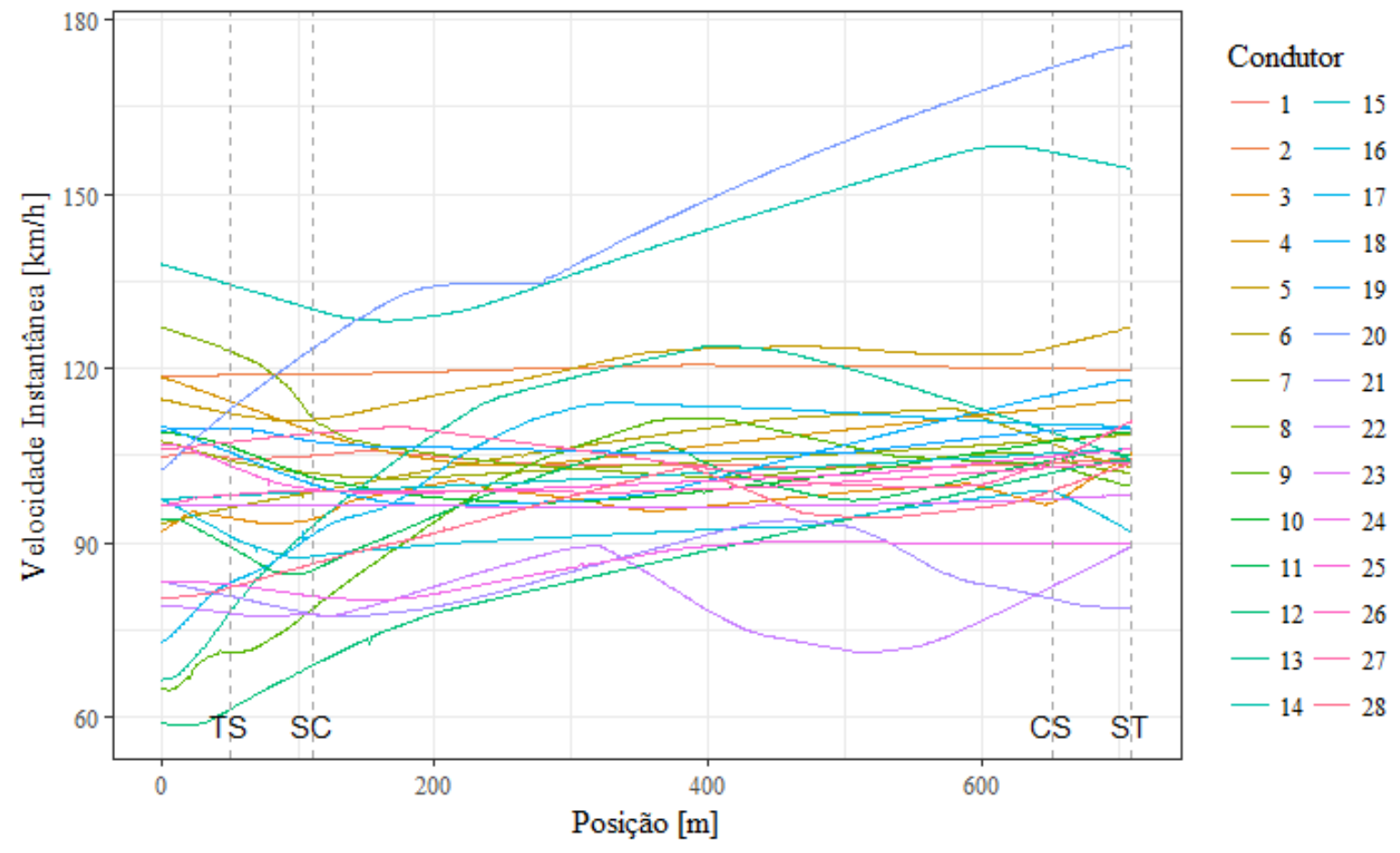

Figura 34 - Perfis de velocidades dos condutores no tratamento 7 
A Figura 35 apresenta os perfis para o tratamento 8 (tangente de $310 \mathrm{~m}$ e raio de $615 \mathrm{~m}$ ).

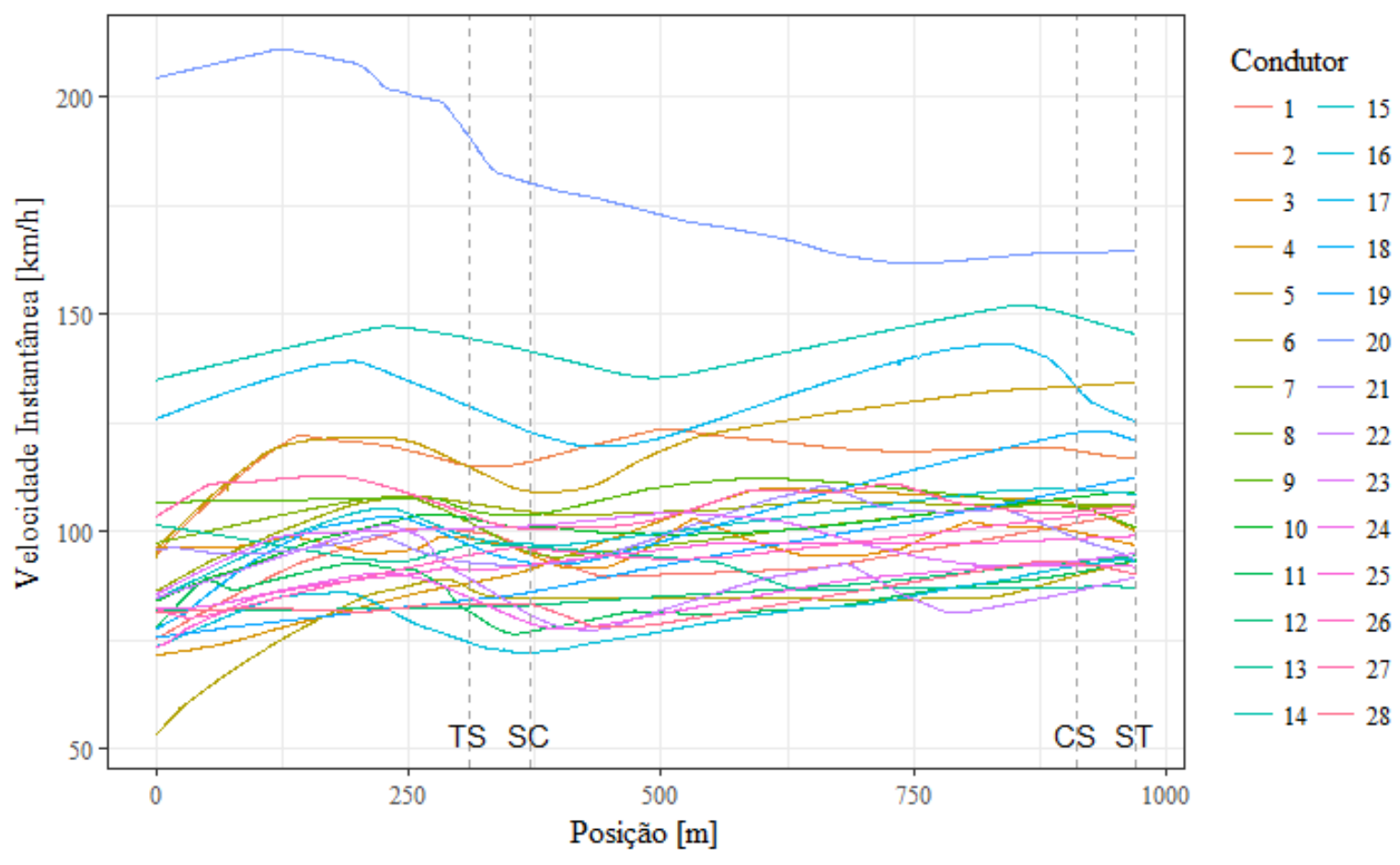

Figura 35 - Perfis de velocidades dos condutores no tratamento 8

A Figura 36 apresenta os perfis para o tratamento 9 (tangente de $570 \mathrm{~m}$ e raio de $615 \mathrm{~m}$ ).

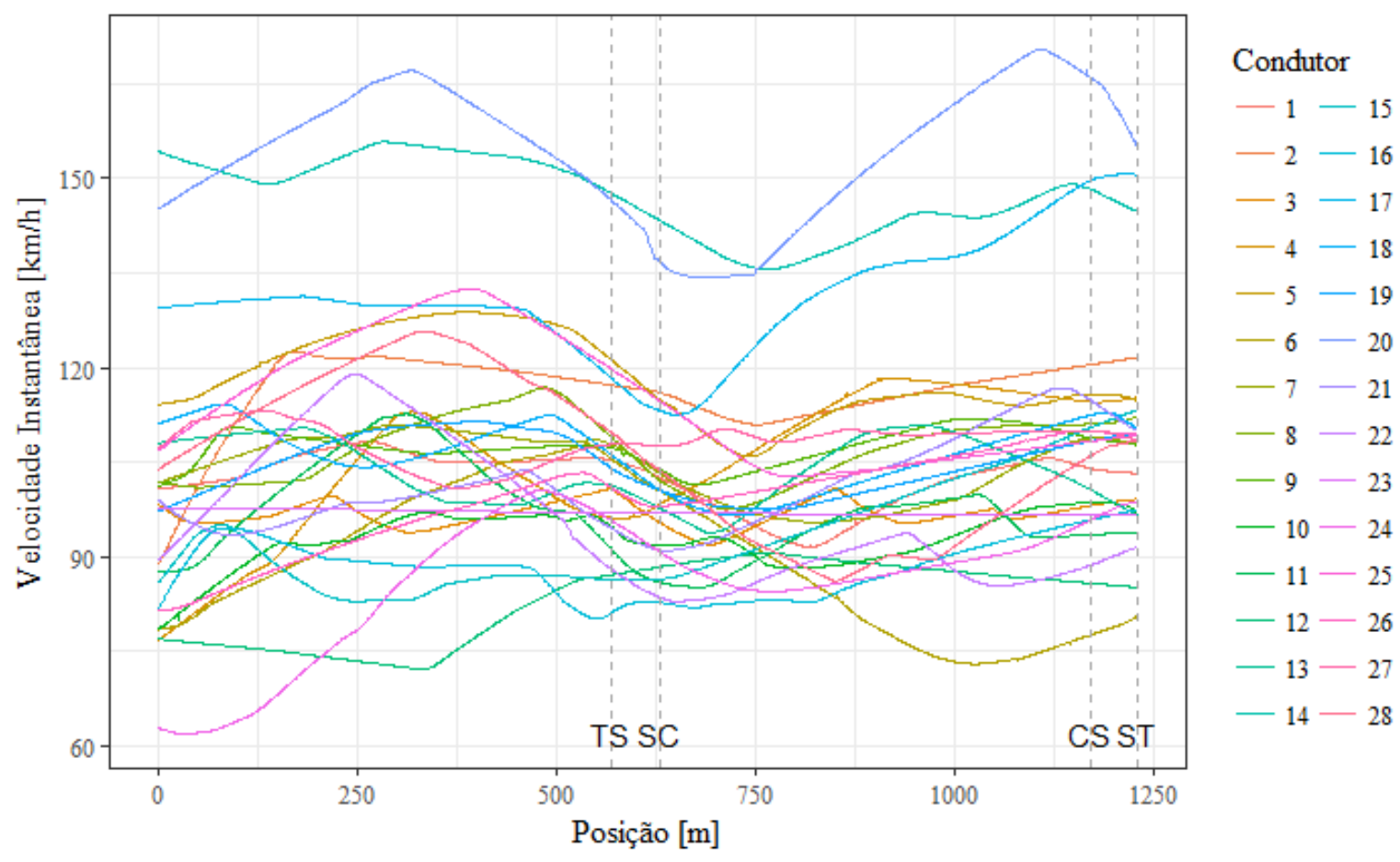

Figura 36 - Perfis de velocidades dos condutores no tratamento 9 
Observa-se que nos tratamentos 1, 4 e 7, nos quais as tangentes de aproximação tinham valores menores (50 metros), os condutores, como esperado, não atingiram uma velocidade máxima antes do ponto de curva e tiveram então uma desaceleração.

Ademais, alguns condutores conseguiram negociar com as curvas de menor raio (125 metros), mesmo que com o emprego de velocidade muito altas, o que é diferente do esperado ao se adotar uma superelevação menos permissiva a manobras assim. A explicação pode se dar pelo coeficiente de atrito disponível pela calibragem do modelo do veículo.

O método 85MSR qualificava as consistências geométricas a partir do percentil 85 das diferenças máximas de velocidades experimentadas pelos condutores quando transitavam entre tangentes e as curvas subsequentes.

Esse método encontrava essas diferenças a partir da velocidade máxima pontual registrada dentro das tangentes - a cada 50 metros, limitado a distâncias menores que 200 metros do ponto de curva - e da velocidade mínima registrada dentre 4 pontos do desenvolvimento das curvas - primeiro quarto da curva, meio da curva, terceiro quarto da curva e ponto de tangente.

Para essa tese, adicionalmente, registrou-se o valor do 85MSR com todos os registros disponibilizados pelo simulador, apenas com a restrição da distância de 200 metros do ponto de curva. Esse será denominado $85 \mathrm{MSR}_{60}$. As diferenças registradas para cada tratamento estão apresentadas na sequência, da Tabela 23 a Tabela 31. 
Tabela 23 - Diferenças de velocidade registradas no tratamento 1

\begin{tabular}{|c|c|c|c|c|c|c|c|c|c|c|}
\hline \multirow{2}{*}{ Condutor } & \multicolumn{3}{|c|}{ Tangente } & \multicolumn{5}{|c|}{ Curva } & \multirow{2}{*}{ MSR } & \multirow{2}{*}{ MSR60 $_{6}$} \\
\hline & $\mathrm{TS}-50 \mathrm{~m}$ & $\mathrm{TS}$ & Máx & $1 / 4$ & $1 / 2$ & $3 / 4$ & ST & Mín & & \\
\hline 1 & 72.4 & 77.4 & 77.2 & 82.3 & 75.6 & 71.6 & 75.2 & 71.5 & -5.8 & -5.7 \\
\hline 2 & 117.4 & 113.8 & 117.4 & 109.7 & 99.3 & 91.9 & 91.1 & 90.5 & -26.3 & -26.9 \\
\hline 3 & 97.9 & 95.7 & 97.9 & 89.6 & 85.2 & 81.3 & 88.2 & 81.0 & -16.5 & -16.8 \\
\hline 4 & 99.7 & 93.6 & 99.8 & 85.2 & 78.9 & 74.4 & 73.4 & 73.4 & -26.2 & -26.4 \\
\hline 5 & 85.0 & 88.8 & 88.7 & 89.7 & 90.6 & 90.5 & 95.5 & 88.8 & 1.0 & 0.1 \\
\hline 6 & 54.9 & 50.4 & 55.0 & 41.8 & 36.9 & 42.0 & 43.5 & 36.8 & -18.0 & -18.2 \\
\hline 7 & 82.2 & 82.3 & 84.6 & 75.4 & 73.9 & 79.6 & 86.0 & 73.6 & -8.5 & -11.0 \\
\hline 8 & 81.2 & 85.0 & 85.0 & 79.6 & 72.3 & 78.0 & 90.5 & 71.9 & -12.8 & -13.1 \\
\hline 9 & 100.6 & 93.4 & 100.6 & 68.4 & 67.2 & 74.6 & 87.1 & 66.1 & -33.5 & -34.6 \\
\hline 10 & 67.7 & 62.8 & 67.9 & 61.7 & 62.5 & 66.3 & 70.4 & 60.3 & -6.0 & -7.6 \\
\hline 11 & 64.6 & 67.4 & 67.4 & 58.6 & 62.3 & 68.9 & 77.4 & 56.6 & -8.8 & -10.8 \\
\hline 12 & 94.3 & 92.0 & 94.6 & 88.1 & 85.4 & 84.9 & 85.1 & 84.7 & -9.4 & -9.8 \\
\hline 13 & 101.0 & 94.0 & 101.1 & 87.2 & 83.3 & 80.1 & 77.6 & 77.6 & -23.4 & -23.5 \\
\hline 14 & 79.1 & 76.6 & 79.2 & 74.4 & 72.0 & 76.7 & 83.7 & 71.9 & -7.1 & -7.3 \\
\hline 15 & 95.9 & 91.1 & 96.0 & 86.4 & 81.3 & 78.1 & 77.9 & 77.2 & -18.0 & -18.8 \\
\hline 16 & 66.5 & 57.1 & 66.6 & 55.6 & 59.9 & 65.9 & 73.3 & 54.8 & -10.9 & -11.8 \\
\hline 17 & 125.0 & 110.8 & 125.0 & 82.9 & 69.8 & 70.0 & 80.0 & 68.4 & -55.2 & -56.7 \\
\hline 18 & 80.9 & 79.1 & 81.1 & 74.1 & 72.9 & 74.1 & 77.5 & 72.9 & -7.9 & -8.2 \\
\hline 19 & 67.8 & 69.9 & 69.9 & 71.4 & 72.7 & 74.1 & 75.5 & 69.9 & 1.5 & 0.0 \\
\hline 20 & 139.5 & 99.7 & 139.6 & 86.8 & 85.8 & 96.5 & 106.7 & 83.2 & -53.7 & -56.4 \\
\hline 21 & 93.3 & 88.2 & 93.3 & 83.0 & 77.2 & 72.8 & 74.4 & 72.8 & -20.5 & -20.6 \\
\hline 22 & 68.3 & 71.6 & 71.6 & 64.5 & 57.3 & 57.8 & 65.7 & 55.8 & -14.3 & -15.7 \\
\hline 23 & 79.7 & 83.1 & 83.0 & 79.8 & 77.1 & 80.0 & 85.3 & 76.8 & -6.0 & -6.3 \\
\hline 24 & 92.2 & 86.5 & 92.3 & 80.3 & 75.6 & 72.0 & 70.5 & 70.4 & -21.7 & -21.9 \\
\hline 25 & 85.9 & 82.7 & 85.9 & 79.5 & 75.9 & 72.6 & 73.3 & 72.3 & -13.3 & -13.6 \\
\hline 26 & 105.0 & 100.9 & 105.0 & 90.2 & 84.3 & 80.5 & 79.1 & 79.1 & -25.9 & -25.9 \\
\hline 27 & 80.4 & 83.2 & 83.6 & 79.4 & 79.0 & 84.0 & 93.7 & 78.2 & -4.2 & -5.4 \\
\hline 28 & 65.1 & 64.5 & 65.1 & 60.3 & 52.4 & 43.1 & 51.0 & 42.8 & -22.0 & -22.3 \\
\hline
\end{tabular}


Tabela 24 - Diferenças de velocidade registradas no tratamento 2

\begin{tabular}{|c|c|c|c|c|c|c|c|c|c|c|c|c|c|}
\hline \multirow{2}{*}{ Condutor } & \multicolumn{6}{|c|}{ Tangente } & \multicolumn{5}{|c|}{ Curva } & \multirow{2}{*}{ MSR } & \multirow{2}{*}{ MSR $_{60}$} \\
\hline & $\mathrm{TS}-200 \mathrm{~m}$ & $\mathrm{TS}-150 \mathrm{~m}$ & $\mathrm{TS}-100 \mathrm{~m}$ & $\mathrm{TS}-50 \mathrm{~m}$ & TS & Máx & $1 / 4$ & $1 / 2$ & $3 / 4$ & ST & Mín & & \\
\hline 1 & 87.6 & 92.1 & 95.8 & 94.2 & 88.9 & 95.9 & 83.9 & 78.2 & 72.4 & 72.2 & 71.5 & -22.0 & -24.4 \\
\hline 2 & 117.8 & 115.4 & 110.7 & 105.3 & 91.2 & 118.3 & 83.9 & 78.6 & 83.0 & 93.1 & 78.1 & -26.7 & -40.2 \\
\hline 3 & 105.4 & 108.1 & 103.5 & 98.6 & 93.5 & 109.6 & 89.3 & 88.9 & 89.2 & 91.2 & 88.8 & -9.7 & -20.9 \\
\hline 4 & 98.0 & 95.3 & 95.5 & 95.5 & 91.3 & 101.0 & 80.1 & 74.8 & 71.0 & 71.3 & 70.5 & -24.4 & -30.5 \\
\hline 5 & 131.8 & 131.9 & 129.9 & 125.1 & 115.4 & 132.1 & 102.9 & 94.8 & 89.4 & 98.6 & 88.9 & -35.7 & -43.2 \\
\hline 6 & 103.0 & 98.5 & 93.8 & 89.2 & 83.8 & 109.3 & 77.3 & 69.6 & 61.5 & 55.5 & 55.1 & -33.7 & -54.2 \\
\hline 7 & 110.4 & 111.1 & 110.6 & 107.4 & 101.9 & 111.3 & 96.3 & 91.1 & 88.2 & 88.5 & 87.9 & -19.2 & -23.5 \\
\hline 8 & 128.4 & 129.8 & 128.1 & 119.3 & 105.7 & 130.3 & 98.4 & 92.7 & 92.0 & 97.5 & 91.9 & -27.4 & -38.4 \\
\hline 9 & 98.3 & 98.9 & 100.4 & 100.2 & 85.3 & 100.6 & 69.4 & 69.0 & 78.1 & 82.3 & 67.4 & -31.2 & -33.2 \\
\hline 10 & 77.5 & 72.7 & 70.6 & 70.3 & 71.9 & 91.9 & 74.7 & 68.7 & 65.9 & 67.5 & 65.9 & -5.9 & -26.0 \\
\hline 11 & 110.2 & 113.0 & 115.2 & 111.2 & 102.3 & 115.2 & 92.7 & 85.4 & 81.9 & 80.0 & 79.9 & -31.2 & -35.4 \\
\hline 12 & 92.9 & 93.3 & 93.9 & 94.4 & 93.0 & 94.6 & 88.8 & 85.0 & 82.0 & 81.8 & 81.8 & -12.6 & -12.8 \\
\hline 13 & 80.2 & 90.1 & 93.6 & 92.1 & 85.9 & 93.6 & 79.7 & 75.1 & 69.0 & 66.0 & 65.6 & -26.0 & -28.0 \\
\hline 14 & 137.6 & 134.2 & 130.5 & 126.7 & 122.8 & 144.6 & 119.1 & 110.7 & 82.3 & 78.8 & 78.0 & -47.9 & -66.6 \\
\hline 15 & 92.9 & 94.0 & 95.0 & 93.3 & 88.0 & 95.3 & 83.0 & 78.7 & 78.6 & 83.6 & 77.8 & -14.8 & -17.5 \\
\hline 16 & 81.9 & 82.5 & 82.4 & 74.7 & 66.3 & 83.6 & 57.7 & 55.3 & 63.2 & 67.3 & 55.1 & -19.5 & -28.5 \\
\hline 17 & 114.5 & 117.2 & 115.0 & 109.4 & 93.1 & 117.3 & 83.6 & 76.6 & 70.1 & 71.0 & 69.8 & -39.3 & -47.5 \\
\hline 18 & 120.9 & 117.6 & 113.4 & 104.6 & 96.8 & 120.9 & 92.3 & 86.8 & 81.7 & 80.6 & 80.4 & -24.0 & -40.5 \\
\hline 19 & 109.0 & 108.6 & 108.2 & 107.2 & 105.1 & 109.6 & 100.8 & 95.6 & 89.3 & 85.2 & 84.7 & -22.1 & -24.9 \\
\hline 20 & 126.5 & 133.1 & 128.3 & 119.9 & 101.3 & 133.1 & 90.9 & 87.5 & 91.4 & 101.3 & 84.2 & -32.4 & -48.9 \\
\hline 21 & 81.2 & 83.0 & 83.7 & 83.2 & 77.2 & 84.3 & 70.9 & 66.6 & 65.4 & 66.1 & 65.4 & -17.8 & -18.9 \\
\hline 22 & 92.1 & 87.4 & 84.4 & 80.5 & 74.8 & 95.0 & 68.8 & 66.3 & 65.4 & 70.9 & 65.1 & -15.1 & -29.9 \\
\hline 23 & 100.7 & 100.6 & 100.6 & 100.5 & 97.7 & 100.7 & 91.9 & 85.4 & 82.1 & 83.7 & 82.1 & -18.4 & -18.7 \\
\hline 24 & 101.6 & 101.2 & 100.8 & 100.2 & 99.5 & 101.6 & 97.1 & 91.1 & 83.8 & 82.3 & 82.3 & -17.9 & -19.3 \\
\hline 25 & 83.9 & 85.5 & 85.3 & 86.5 & 88.1 & 88.1 & 88.1 & 87.3 & 86.5 & 86.3 & 86.0 & -1.8 & -2.0 \\
\hline 26 & 104.5 & 106.2 & 107.5 & 105.0 & 100.5 & 107.5 & 96.0 & 90.7 & 86.3 & 82.6 & 82.3 & -22.4 & -25.2 \\
\hline 27 & 95.2 & 91.3 & 85.5 & 80.3 & 76.3 & 95.3 & 71.0 & 65.9 & 70.8 & 79.3 & 65.6 & -14.5 & -29.7 \\
\hline 28 & 111.8 & 110.8 & 104.5 & 99.7 & 88.4 & 113.0 & 81.7 & 74.1 & 67.2 & 65.8 & 65.6 & -33.9 & -47.3 \\
\hline
\end{tabular}


Tabela 25 - Diferenças de velocidade registradas no tratamento 3

\begin{tabular}{|c|c|c|c|c|c|c|c|c|c|c|c|c|c|}
\hline \multirow{2}{*}{ Condutor } & \multicolumn{6}{|c|}{ Tangente } & \multicolumn{5}{|c|}{ Curva } & \multirow{2}{*}{ MSR } & \multirow{2}{*}{ MSR60 $_{60}$} \\
\hline & $\mathrm{TS}-200 \mathrm{~m}$ & $\mathrm{TS}-150 \mathrm{~m}$ & $\mathrm{TS}-100 \mathrm{~m}$ & TS - 50m & TS & Máx & $1 / 4$ & $1 / 2$ & $3 / 4$ & ST & Mín & & \\
\hline 1 & 108.0 & 107.9 & 106.0 & 103.5 & 98.7 & 110.9 & 94.2 & 79.9 & 77.2 & 78.4 & 77.2 & -26.3 & -33.7 \\
\hline 2 & 119.2 & 120.1 & 120.3 & 117.0 & 98.0 & 120.4 & 89.3 & 81.0 & 79.6 & 86.9 & 79.0 & -37.4 & -41.4 \\
\hline 3 & 92.4 & 90.9 & 90.4 & 91.7 & 88.6 & 110.0 & 83.6 & 80.0 & 79.2 & 85.7 & 77.2 & -12.5 & -32.7 \\
\hline 4 & 118.5 & 114.4 & 110.0 & 104.7 & 88.3 & 119.1 & 83.6 & 79.2 & 75.5 & 76.2 & 75.1 & -29.2 & -44.0 \\
\hline 5 & 130.9 & 130.1 & 126.1 & 120.5 & 102.7 & 131.0 & 95.3 & 88.7 & 83.7 & 84.6 & 83.3 & -36.8 & -47.7 \\
\hline 6 & 93.4 & 94.3 & 94.8 & 95.3 & 91.6 & 98.7 & 86.8 & 80.4 & 74.1 & 70.4 & 70.1 & -24.9 & -28.6 \\
\hline 7 & 113.5 & 108.6 & 103.4 & 98.2 & 92.9 & 119.0 & 88.3 & 83.0 & 80.3 & 81.7 & 80.1 & -18.0 & -38.9 \\
\hline 8 & 130.7 & 127.3 & 123.0 & 112.7 & 91.0 & 134.8 & 85.1 & 82.5 & 80.9 & 81.1 & 80.9 & -31.7 & -53.9 \\
\hline 9 & 107.3 & 107.1 & 106.3 & 103.4 & 98.6 & 108.1 & 88.7 & 76.5 & 70.2 & 65.7 & 65.2 & -37.7 & -42.9 \\
\hline 10 & 119.6 & 121.5 & 121.3 & 117.2 & 113.0 & 122.3 & 109.0 & 103.7 & 98.2 & 97.9 & 97.6 & -19.3 & -24.7 \\
\hline 11 & 89.1 & 84.8 & 82.9 & 84.5 & 76.9 & 96.1 & 65.0 & 55.1 & 64.8 & 64.9 & 54.4 & -29.4 & -41.7 \\
\hline 12 & 83.0 & 82.4 & 81.7 & 80.7 & 79.8 & 87.3 & 79.3 & 78.3 & 77.6 & 77.1 & 77.0 & -3.7 & -10.3 \\
\hline 13 & 100.7 & 101.3 & 100.7 & 97.7 & 91.3 & 101.4 & 85.4 & 78.0 & 73.2 & 75.9 & 73.1 & -24.5 & -28.3 \\
\hline 14 & 138.5 & 139.1 & 139.0 & 135.5 & 125.7 & 142.2 & 108.5 & 89.6 & 83.7 & 79.5 & 79.2 & -56.0 & -63.0 \\
\hline 15 & 110.9 & 112.2 & 109.1 & 104.6 & 99.8 & 112.3 & 95.5 & 89.8 & 84.7 & 85.0 & 83.9 & -19.9 & -28.4 \\
\hline 16 & 99.2 & 96.5 & 90.1 & 83.2 & 76.1 & 100.4 & 71.4 & 63.1 & 60.6 & 69.5 & 60.5 & -22.6 & -39.9 \\
\hline 17 & 112.5 & 112.6 & 112.7 & 107.8 & 95.9 & 114.0 & 83.8 & 76.5 & 70.7 & 71.9 & 69.8 & -37.1 & -44.2 \\
\hline 18 & 108.7 & 108.0 & 103.4 & 98.5 & 93.5 & 109.5 & 88.7 & 83.6 & 80.4 & 80.7 & 80.4 & -18.1 & -29.1 \\
\hline 19 & 79.8 & 81.2 & 82.9 & 83.8 & 80.3 & 84.5 & 73.6 & 68.8 & 66.5 & 67.5 & 66.5 & -17.3 & -18.0 \\
\hline 20 & 162.8 & 155.8 & 149.1 & 143.7 & 119.9 & 165.5 & 114.5 & 92.0 & 71.2 & 80.4 & 70.5 & -72.6 & -95.0 \\
\hline 21 & 117.2 & 113.4 & 109.0 & 104.5 & 99.7 & 122.4 & 95.2 & 89.4 & 85.8 & 83.7 & 83.4 & -20.8 & -39.0 \\
\hline 22 & 99.1 & 100.5 & 97.8 & 91.5 & 84.5 & 105.8 & 78.0 & 71.1 & 66.1 & 67.9 & 65.9 & -25.5 & -39.9 \\
\hline 23 & 99.0 & 100.7 & 102.1 & 97.1 & 90.7 & 102.2 & 84.7 & 77.5 & 76.3 & 79.2 & 76.0 & -20.8 & -26.1 \\
\hline 24 & 95.3 & 96.2 & 93.0 & 88.8 & 83.1 & 96.4 & 76.6 & 70.7 & 65.8 & 63.1 & 62.9 & -25.7 & -33.5 \\
\hline 25 & 108.7 & 108.3 & 107.3 & 103.9 & 99.1 & 108.7 & 94.6 & 89.0 & 83.6 & 81.4 & 81.2 & -22.5 & -27.5 \\
\hline 26 & 104.5 & 105.8 & 104.7 & 102.8 & 98.3 & 105.8 & 93.7 & 88.1 & 83.1 & 81.5 & 81.5 & -21.3 & -24.3 \\
\hline 27 & 103.3 & 102.7 & 101.8 & 100.5 & 96.9 & 118.0 & 92.5 & 87.5 & 88.9 & 94.5 & 86.9 & -13.0 & -31.1 \\
\hline 28 & 109.6 & 114.2 & 110.0 & 100.9 & 90.0 & 114.5 & 84.4 & 77.0 & 69.3 & 65.5 & 65.1 & -35.4 & -49.4 \\
\hline
\end{tabular}


Tabela 26 - Diferenças de velocidade registradas no tratamento 4

\begin{tabular}{|c|c|c|c|c|c|c|c|c|c|c|}
\hline \multirow{2}{*}{ Condutor } & \multicolumn{3}{|c|}{ Tangente } & \multicolumn{5}{|c|}{ Curva } & \multirow{2}{*}{ MSR } & \multirow{2}{*}{ MSR $_{60}$} \\
\hline & $\mathrm{TS}-50 \mathrm{~m}$ & $\mathrm{TS}$ & Máx & $1 / 4$ & $1 / 2$ & $3 / 4$ & ST & Mín & & \\
\hline 1 & 104.5 & 105.0 & 105.0 & 97.9 & 97.8 & 100.9 & 104.0 & 96.4 & -7.2 & -8.6 \\
\hline 2 & 116.6 & 115.4 & 116.6 & 111.6 & 116.7 & 117.8 & 118.7 & 111.6 & -5.0 & -5.0 \\
\hline 3 & 99.2 & 96.7 & 99.2 & 93.4 & 95.9 & 96.3 & 97.9 & 92.0 & -5.8 & -7.2 \\
\hline 4 & 73.4 & 76.7 & 76.6 & 92.3 & 104.4 & 114.1 & 118.8 & 76.7 & 15.6 & 0.2 \\
\hline 5 & 128.0 & 123.1 & 128.1 & 114.6 & 112.7 & 112.8 & 114.0 & 112.6 & -15.3 & -15.5 \\
\hline 6 & 80.7 & 83.2 & 83.2 & 86.3 & 88.9 & 91.0 & 93.2 & 83.2 & 3.0 & 0.1 \\
\hline 7 & 109.6 & 109.6 & 109.7 & 109.0 & 104.1 & 98.6 & 101.5 & 98.2 & -11.0 & -11.4 \\
\hline 8 & 105.9 & 105.2 & 105.9 & 96.7 & 106.8 & 109.0 & 107.6 & 96.0 & -9.2 & -9.9 \\
\hline 9 & 82.9 & 87.7 & 87.6 & 93.4 & 98.9 & 103.3 & 105.5 & 87.7 & 5.7 & 0.0 \\
\hline 10 & 96.8 & 93.9 & 96.8 & 93.0 & 95.3 & 93.6 & 93.9 & 92.3 & -3.8 & -4.6 \\
\hline 11 & 105.4 & 99.7 & 105.5 & 87.0 & 81.4 & 83.8 & 87.3 & 80.1 & -24.0 & -25.4 \\
\hline 12 & 85.1 & 85.4 & 85.4 & 85.7 & 84.8 & 70.4 & 59.1 & 59.0 & -26.3 & -26.4 \\
\hline 13 & 96.4 & 92.9 & 96.4 & 89.4 & 97.5 & 104.1 & 101.6 & 87.7 & -7.0 & -8.8 \\
\hline 14 & 145.1 & 141.6 & 145.2 & 135.2 & 134.3 & 137.7 & 139.9 & 134.0 & -10.8 & -11.2 \\
\hline 15 & 108.0 & 103.6 & 108.1 & 96.8 & 95.4 & 96.0 & 97.5 & 95.2 & -12.7 & -13.0 \\
\hline 16 & 91.4 & 86.4 & 91.5 & 78.1 & 79.6 & 81.3 & 87.0 & 78.1 & -13.4 & -13.5 \\
\hline 17 & 71.7 & 77.1 & 77.0 & 88.5 & 102.1 & 112.8 & 119.4 & 77.1 & 11.4 & 0.1 \\
\hline 18 & 105.0 & 101.3 & 105.1 & 96.3 & 100.1 & 105.9 & 110.9 & 96.3 & -8.8 & -8.8 \\
\hline 19 & 106.5 & 102.3 & 106.5 & 92.4 & 87.3 & 91.7 & 97.0 & 87.3 & -19.2 & -19.2 \\
\hline 20 & 154.4 & 140.0 & 154.7 & 124.8 & 125.7 & 131.5 & 140.1 & 124.7 & -29.6 & -30.0 \\
\hline 21 & 66.3 & 67.1 & 67.0 & 71.5 & 81.8 & 92.2 & 92.9 & 67.1 & 4.4 & 0.0 \\
\hline 22 & 89.6 & 89.9 & 91.1 & 76.6 & 83.2 & 92.5 & 95.6 & 76.4 & -13.3 & -14.7 \\
\hline 23 & 99.0 & 98.9 & 99.0 & 98.7 & 98.4 & 98.0 & 97.8 & 97.8 & -1.1 & -1.2 \\
\hline 24 & 91.8 & 89.7 & 91.8 & 82.9 & 81.2 & 82.2 & 83.4 & 81.0 & -10.6 & -10.8 \\
\hline 25 & 106.2 & 106.7 & 106.9 & 98.1 & 89.4 & 91.6 & 99.3 & 87.4 & -17.3 & -19.5 \\
\hline 26 & 79.1 & 79.0 & 79.1 & 81.0 & 86.3 & 91.2 & 96.2 & 79.0 & 1.9 & -0.2 \\
\hline 27 & 108.3 & 105.2 & 108.3 & 95.0 & 84.9 & 97.8 & 112.5 & 84.7 & -23.4 & -23.6 \\
\hline 28 & 89.8 & 84.5 & 89.9 & 76.4 & 77.4 & 80.7 & 85.1 & 75.2 & -13.5 & -14.7 \\
\hline
\end{tabular}


Tabela 27 - Diferenças de velocidade registradas no tratamento 5

\begin{tabular}{|c|c|c|c|c|c|c|c|c|c|c|c|c|c|}
\hline \multirow{2}{*}{ Condutor } & \multicolumn{6}{|c|}{ Tangente } & \multicolumn{5}{|c|}{ Curva } & \multirow{2}{*}{ MSR } & \multirow{2}{*}{$\operatorname{MSR}_{60}$} \\
\hline & $\mathrm{TS}-200 \mathrm{~m}$ & $\mathrm{TS}-150 \mathrm{~m}$ & $\mathrm{TS}-100 \mathrm{~m}$ & $\mathrm{TS}-50 \mathrm{~m}$ & $\mathrm{TS}$ & Máx & $1 / 4$ & $1 / 2$ & $3 / 4$ & ST & Mín & & \\
\hline 1 & 103.3 & 105.9 & 106.9 & 107.2 & 107.4 & 107.5 & 102.8 & 95.3 & 96.4 & 98.4 & 95.2 & -12.1 & -12.3 \\
\hline 2 & 119.0 & 118.6 & 118.2 & 117.5 & 114.5 & 119.8 & 111.0 & 117.3 & 118.2 & 120.8 & 110.0 & -6.5 & -9.8 \\
\hline 3 & 103.8 & 110.8 & 106.5 & 102.0 & 97.6 & 110.8 & 88.6 & 89.3 & 97.9 & 98.6 & 88.1 & -13.5 & -22.7 \\
\hline 4 & 113.2 & 109.3 & 105.1 & 100.3 & 96.1 & 114.0 & 96.5 & 104.0 & 99.9 & 99.5 & 94.6 & -3.8 & -19.4 \\
\hline 5 & 135.4 & 134.4 & 130.7 & 125.4 & 115.3 & 135.5 & 99.8 & 107.3 & 112.2 & 121.3 & 99.8 & -25.6 & -35.7 \\
\hline 6 & 63.5 & 72.8 & 79.0 & 76.1 & 71.3 & 79.0 & 59.8 & 59.7 & 36.6 & 51.7 & 31.8 & -39.5 & -47.3 \\
\hline 7 & 108.1 & 108.0 & 107.1 & 106.2 & 104.7 & 108.2 & 100.7 & 99.0 & 101.2 & 105.7 & 98.9 & -7.2 & -9.2 \\
\hline 8 & 112.7 & 115.5 & 117.4 & 114.8 & 103.7 & 117.5 & 102.9 & 120.1 & 129.8 & 127.6 & 94.1 & -11.9 & -23.4 \\
\hline 9 & 106.0 & 106.3 & 104.9 & 100.1 & 94.5 & 107.7 & 83.9 & 95.7 & 105.9 & 106.7 & 83.7 & -16.3 & -24.0 \\
\hline 10 & 77.1 & 76.6 & 78.1 & 79.6 & 75.9 & 79.7 & 80.5 & 86.3 & 75.8 & 83.1 & 75.6 & -3.8 & -4.1 \\
\hline 11 & 97.4 & 97.1 & 89.7 & 83.4 & 79.6 & 97.6 & 84.5 & 82.8 & 86.4 & 96.4 & 78.7 & -0.6 & -18.9 \\
\hline 12 & 86.6 & 87.0 & 87.4 & 87.8 & 88.3 & 88.3 & 89.2 & 89.9 & 90.9 & 91.7 & 88.3 & 0.9 & 0.0 \\
\hline 13 & 90.1 & 94.3 & 98.1 & 100.0 & 96.5 & 100.0 & 90.6 & 97.9 & 104.2 & 107.9 & 90.4 & -9.3 & -9.5 \\
\hline 14 & 94.9 & 102.2 & 109.1 & 115.6 & 117.2 & 117.4 & 116.6 & 126.6 & 136.3 & 138.4 & 116.3 & -0.6 & -1.1 \\
\hline 15 & 107.7 & 108.2 & 105.9 & 101.2 & 96.3 & 108.2 & 85.8 & 75.8 & 73.8 & 90.6 & 69.8 & -27.4 & -38.4 \\
\hline 16 & 96.9 & 96.5 & 94.4 & 87.8 & 80.8 & 98.5 & 77.5 & 83.7 & 83.0 & 95.1 & 71.5 & -10.3 & -27.0 \\
\hline 17 & 145.6 & 141.1 & 136.6 & 131.8 & 126.9 & 150.3 & 111.5 & 107.6 & 115.7 & 125.3 & 106.9 & -24.2 & -43.4 \\
\hline 18 & 111.4 & 107.0 & 100.2 & 93.6 & 87.2 & 120.7 & 87.3 & 95.2 & 103.0 & 109.9 & 85.1 & -6.3 & -35.7 \\
\hline 19 & 108.1 & 104.1 & 100.4 & 95.9 & 90.9 & 113.8 & 80.9 & 79.4 & 85.0 & 91.1 & 79.1 & -16.5 & -34.7 \\
\hline 20 & 99.8 & 110.7 & 119.7 & 127.2 & 121.5 & 127.2 & 114.2 & 126.6 & 136.4 & 144.7 & 106.5 & -13.0 & -20.7 \\
\hline 21 & 104.3 & 100.5 & 99.2 & 99.4 & 99.0 & 110.1 & 92.8 & 89.7 & 92.2 & 95.5 & 89.4 & -9.7 & -20.7 \\
\hline 22 & 84.5 & 91.5 & 86.3 & 80.2 & 78.5 & 91.5 & 80.9 & 82.4 & 77.0 & 78.9 & 76.6 & -3.1 & -14.9 \\
\hline 23 & 95.4 & 95.9 & 96.6 & 97.3 & 98.0 & 98.0 & 99.5 & 97.0 & 97.3 & 98.7 & 96.4 & -1.0 & -1.6 \\
\hline 24 & 90.5 & 90.6 & 88.4 & 85.3 & 82.5 & 90.6 & 81.5 & 86.0 & 90.4 & 93.9 & 80.4 & -3.9 & -10.2 \\
\hline 25 & 110.6 & 110.9 & 110.6 & 109.8 & 105.5 & 111.0 & 95.7 & 94.1 & 98.4 & 101.6 & 92.8 & -15.7 & -18.2 \\
\hline 26 & 110.4 & 110.8 & 111.2 & 109.3 & 104.9 & 111.2 & 97.0 & 95.8 & 97.6 & 100.5 & 95.4 & -13.5 & -15.8 \\
\hline 27 & 105.6 & 107.0 & 107.5 & 107.9 & 104.7 & 107.9 & 94.3 & 91.6 & 91.8 & 102.4 & 89.1 & -16.3 & -18.8 \\
\hline 28 & 74.0 & 82.7 & 90.7 & 98.5 & 99.7 & 101.8 & 82.1 & 75.5 & 77.2 & 80.2 & 75.1 & -24.2 & -26.7 \\
\hline
\end{tabular}


Tabela 28 - Diferenças de velocidade registradas no tratamento 6

\begin{tabular}{|c|c|c|c|c|c|c|c|c|c|c|c|c|c|}
\hline \multirow{2}{*}{ Condutor } & \multicolumn{6}{|c|}{ Tangente } & \multicolumn{5}{|c|}{ Curva } & \multirow{2}{*}{ MSR } & \multirow{2}{*}{ MSR60 $_{60}$} \\
\hline & $\mathrm{TS}-200 \mathrm{~m}$ & $\mathrm{TS}-150 \mathrm{~m}$ & $\mathrm{TS}-100 \mathrm{~m}$ & $\mathrm{TS}-50 \mathrm{~m}$ & TS & Máx & $1 / 4$ & $1 / 2$ & $3 / 4$ & ST & Mín & & \\
\hline 1 & 107.3 & 107.3 & 107.3 & 106.6 & 105.9 & 108.3 & 104.4 & 102.6 & 101.0 & 100.7 & 100.2 & -6.0 & -8.1 \\
\hline 2 & 119.9 & 118.3 & 116.7 & 115.1 & 112.6 & 125.5 & 105.5 & 110.7 & 113.4 & 116.3 & 105.5 & -9.6 & -20.0 \\
\hline 3 & 97.9 & 97.9 & 97.9 & 97.6 & 93.8 & 99.3 & 83.4 & 82.3 & 85.2 & 95.0 & 81.7 & -15.3 & -17.6 \\
\hline 4 & 120.5 & 117.2 & 113.0 & 108.6 & 104.1 & 121.7 & 97.6 & 100.1 & 105.1 & 109.9 & 97.4 & -11.1 & -24.3 \\
\hline 5 & 132.4 & 131.7 & 129.2 & 124.2 & 115.5 & 133.6 & 108.4 & 114.3 & 115.8 & 121.8 & 107.6 & -15.8 & -26.0 \\
\hline 6 & 93.4 & 94.5 & 96.6 & 98.1 & 98.4 & 103.0 & 89.6 & 83.8 & 80.3 & 78.5 & 78.5 & -19.9 & -24.5 \\
\hline 7 & 112.5 & 107.5 & 102.5 & 97.8 & 95.8 & 118.3 & 92.7 & 93.4 & 96.6 & 99.6 & 91.7 & -5.2 & -26.7 \\
\hline 8 & 108.5 & 110.3 & 111.3 & 109.8 & 104.8 & 111.4 & 98.5 & 100.7 & 96.2 & 96.9 & 95.4 & -13.6 & -16.0 \\
\hline 9 & 107.0 & 107.3 & 107.1 & 104.2 & 98.3 & 107.4 & 80.0 & 81.7 & 87.0 & 100.7 & 79.7 & -24.2 & -27.7 \\
\hline 10 & 92.0 & 88.8 & 83.8 & 78.2 & 73.3 & 109.4 & 69.9 & 74.8 & 78.8 & 78.2 & 69.9 & -8.3 & -39.4 \\
\hline 11 & 100.1 & 101.9 & 103.9 & 98.8 & 90.0 & 109.8 & 86.5 & 89.2 & 92.8 & 97.8 & 86.1 & -12.3 & -23.7 \\
\hline 12 & 78.7 & 78.4 & 78.2 & 77.9 & 77.6 & 104.5 & 72.7 & 70.8 & 75.3 & 86.3 & 70.6 & -7.1 & -33.9 \\
\hline 13 & 95.2 & 99.3 & 98.0 & 93.4 & 88.1 & 99.9 & 79.6 & 83.8 & 87.9 & 91.4 & 79.6 & -13.8 & -20.3 \\
\hline 14 & 149.4 & 146.1 & 142.5 & 140.0 & 137.3 & 165.7 & 129.7 & 126.2 & 129.6 & 134.5 & 126.2 & -13.8 & -39.4 \\
\hline 15 & 87.7 & 86.2 & 84.9 & 83.6 & 82.9 & 113.5 & 84.6 & 86.6 & 88.7 & 90.5 & 82.8 & 0.9 & -30.7 \\
\hline 16 & 97.4 & 95.6 & 91.4 & 84.6 & 78.3 & 97.5 & 67.9 & 68.3 & 74.7 & 80.8 & 66.8 & -16.7 & -30.7 \\
\hline 17 & 119.5 & 118.5 & 113.6 & 108.0 & 101.6 & 121.8 & 88.1 & 104.4 & 119.5 & 129.3 & 88.1 & -19.8 & -33.7 \\
\hline 18 & 100.0 & 99.6 & 99.5 & 96.2 & 91.0 & 117.4 & 88.3 & 95.6 & 104.5 & 112.5 & 87.4 & -7.9 & -30.0 \\
\hline 19 & 107.7 & 109.2 & 110.3 & 106.9 & 102.3 & 110.3 & 92.4 & 87.6 & 92.3 & 96.6 & 87.3 & -19.3 & -23.0 \\
\hline 20 & 168.8 & 165.8 & 162.8 & 159.6 & 155.7 & 169.3 & 146.6 & 136.5 & 136.5 & 135.3 & 135.1 & -24.3 & -34.2 \\
\hline 21 & 93.9 & 96.1 & 98.3 & 98.6 & 93.6 & 101.0 & 86.9 & 90.2 & 97.7 & 99.6 & 86.9 & -11.8 & -14.1 \\
\hline 22 & 94.0 & 94.0 & 93.9 & 92.7 & 91.7 & 103.5 & 81.6 & 75.6 & 78.4 & 84.5 & 74.8 & -17.1 & -28.6 \\
\hline 23 & 93.6 & 95.2 & 96.8 & 96.9 & 95.0 & 100.9 & 95.4 & 96.9 & 98.4 & 101.6 & 94.5 & -1.5 & -6.4 \\
\hline 24 & 100.1 & 99.9 & 99.1 & 98.0 & 96.6 & 100.4 & 95.4 & 98.8 & 99.6 & 100.5 & 95.0 & -2.6 & -5.4 \\
\hline 25 & 116.4 & 115.1 & 113.3 & 110.5 & 106.0 & 116.6 & 97.3 & 92.0 & 97.0 & 106.2 & 91.8 & -18.5 & -24.9 \\
\hline 26 & 107.3 & 107.1 & 107.0 & 103.6 & 98.9 & 107.7 & 86.8 & 80.4 & 84.0 & 87.6 & 80.3 & -23.2 & -27.4 \\
\hline 27 & 111.1 & 106.6 & 101.9 & 97.0 & 91.9 & 119.8 & 82.4 & 87.1 & 95.2 & 106.4 & 81.2 & -14.7 & -38.6 \\
\hline 28 & 109.7 & 111.5 & 112.8 & 112.4 & 107.1 & 113.4 & 92.7 & 82.4 & 80.0 & 81.1 & 79.5 & -32.4 & -33.9 \\
\hline
\end{tabular}


Tabela 29 - Diferenças de velocidade registradas no tratamento 7

\begin{tabular}{|c|c|c|c|c|c|c|c|c|c|c|}
\hline \multirow{2}{*}{ Condutor } & \multicolumn{3}{|c|}{ Tangente } & \multicolumn{5}{|c|}{ Curva } & \multirow{2}{*}{ MSR } & \multirow{2}{*}{ MSR $_{60}$} \\
\hline & $\mathrm{TS}-50 \mathrm{~m}$ & TS & Máx & $1 / 4$ & $1 / 2$ & $3 / 4$ & ST & Mín & & \\
\hline 1 & 104.7 & 104.6 & 105.5 & 104.7 & 103.4 & 103.1 & 104.4 & 103.1 & -1.6 & -2.4 \\
\hline 2 & 118.6 & 118.9 & 118.9 & 119.6 & 120.6 & 120.3 & 119.8 & 118.9 & 0.6 & 0.0 \\
\hline 3 & 92.1 & 94.3 & 95.4 & 100.7 & 95.9 & 99.5 & 104.8 & 93.3 & 1.5 & -2.1 \\
\hline 4 & 118.4 & 114.4 & 118.5 & 103.8 & 106.2 & 110.6 & 114.5 & 103.3 & -14.6 & -15.2 \\
\hline 5 & 114.6 & 112.3 & 114.7 & 116.0 & 123.2 & 122.7 & 127.0 & 110.9 & 1.4 & -3.8 \\
\hline 6 & 93.4 & 96.1 & 96.0 & 103.2 & 109.1 & 112.7 & 103.3 & 96.1 & 7.2 & 0.0 \\
\hline 7 & 107.5 & 104.2 & 107.5 & 101.5 & 103.8 & 106.0 & 108.6 & 101.1 & -5.9 & -6.4 \\
\hline 8 & 127.0 & 123.0 & 127.0 & 104.8 & 101.6 & 104.1 & 102.1 & 101.3 & -25.4 & -25.7 \\
\hline 9 & 65.0 & 71.2 & 71.5 & 95.9 & 111.4 & 104.8 & 99.9 & 71.2 & 24.7 & -0.3 \\
\hline 10 & 108.9 & 106.6 & 108.9 & 97.6 & 98.5 & 103.6 & 109.1 & 96.9 & -11.3 & -12.0 \\
\hline 11 & 93.9 & 89.4 & 94.0 & 96.0 & 105.9 & 98.7 & 105.1 & 84.7 & 2.1 & -9.3 \\
\hline 12 & 59.0 & 61.4 & 61.2 & 78.7 & 87.7 & 96.4 & 104.2 & 61.4 & 17.4 & 0.1 \\
\hline 13 & 66.5 & 78.0 & 77.7 & 111.0 & 122.9 & 117.0 & 104.7 & 78.0 & 26.6 & 0.3 \\
\hline 14 & 137.9 & 134.5 & 137.9 & 129.6 & 142.4 & 154.5 & 154.5 & 128.2 & -8.2 & -9.7 \\
\hline 15 & 97.6 & 98.1 & 98.1 & 99.9 & 101.9 & 104.0 & 106.1 & 98.1 & 1.7 & 0.0 \\
\hline 16 & 97.4 & 91.2 & 97.4 & 90.0 & 92.0 & 96.1 & 92.4 & 87.5 & -7.4 & -9.9 \\
\hline 17 & 73.1 & 83.1 & 83.0 & 104.3 & 113.7 & 111.7 & 110.1 & 83.1 & 21.2 & 0.1 \\
\hline 18 & 110.1 & 105.7 & 110.2 & 96.5 & 99.7 & 109.6 & 118.1 & 96.5 & -13.5 & -13.6 \\
\hline 19 & 109.5 & 109.7 & 109.7 & 106.4 & 105.5 & 106.7 & 109.7 & 105.4 & -4.2 & -4.3 \\
\hline 20 & 102.7 & 112.9 & 112.7 & 134.5 & 146.9 & 163.2 & 175.5 & 112.9 & 21.6 & 0.2 \\
\hline 21 & 83.3 & 80.9 & 83.4 & 79.7 & 90.2 & 88.2 & 78.8 & 77.3 & -4.5 & -6.1 \\
\hline 22 & 79.0 & 77.9 & 79.2 & 83.5 & 81.3 & 71.9 & 89.0 & 71.1 & -7.1 & -8.1 \\
\hline 23 & 96.6 & 96.5 & 96.6 & 96.3 & 96.3 & 96.8 & 98.3 & 96.2 & -0.3 & -0.4 \\
\hline 24 & 83.4 & 82.8 & 83.4 & 81.9 & 89.0 & 90.0 & 90.1 & 80.2 & -1.6 & -3.3 \\
\hline 25 & 106.8 & 103.4 & 106.9 & 98.8 & 100.5 & 102.5 & 106.1 & 98.5 & -8.0 & -8.4 \\
\hline 26 & 96.4 & 98.3 & 98.3 & 98.9 & 99.1 & 101.3 & 103.9 & 98.3 & 0.6 & 0.0 \\
\hline 27 & 106.1 & 107.3 & 107.3 & 108.8 & 103.5 & 99.7 & 110.6 & 99.7 & -7.6 & -7.7 \\
\hline 28 & 80.4 & 82.3 & 82.3 & 92.6 & 102.9 & 94.7 & 103.4 & 82.3 & 10.3 & 0.1 \\
\hline
\end{tabular}


Tabela 30 - Diferenças de velocidade registradas no tratamento 8

\begin{tabular}{|c|c|c|c|c|c|c|c|c|c|c|c|c|c|}
\hline \multirow{2}{*}{ Condutor } & \multicolumn{6}{|c|}{ Tangente } & \multicolumn{5}{|c|}{ Curva } & \multirow{2}{*}{ MSR } & \multirow{2}{*}{ MSR60 $_{60}$} \\
\hline & $\mathrm{TS}-200 \mathrm{~m}$ & $\mathrm{TS}-150 \mathrm{~m}$ & $\mathrm{TS}-100 \mathrm{~m}$ & $\mathrm{TS}-50 \mathrm{~m}$ & TS & Máx & $1 / 4$ & $1 / 2$ & $3 / 4$ & ST & Mín & & \\
\hline 1 & 89.1 & 94.1 & 97.9 & 100.6 & 99.9 & 100.9 & 89.8 & 91.4 & 97.5 & 104.1 & 89.5 & -10.8 & -11.4 \\
\hline 2 & 117.6 & 121.5 & 120.3 & 118.0 & 115.1 & 122.1 & 122.2 & 119.9 & 118.8 & 116.7 & 114.9 & -1.3 & -7.2 \\
\hline 3 & 97.6 & 97.5 & 95.0 & 96.1 & 98.4 & 98.9 & 94.6 & 94.5 & 102.3 & 97.1 & 91.6 & -3.9 & -7.3 \\
\hline 4 & 76.9 & 80.0 & 83.0 & 85.9 & 88.1 & 88.0 & 100.2 & 109.7 & 107.9 & 100.5 & 88.1 & 12.1 & 0.1 \\
\hline 5 & 118.1 & 121.1 & 121.7 & 120.0 & 114.8 & 121.8 & 115.7 & 126.1 & 131.6 & 134.2 & 109.0 & -4.4 & -12.8 \\
\hline 6 & 73.1 & 79.6 & 85.3 & 88.1 & 86.8 & 89.0 & 84.5 & 84.4 & 84.6 & 93.0 & 84.4 & -3.6 & -4.6 \\
\hline 7 & 98.7 & 103.3 & 106.8 & 108.0 & 106.5 & 108.1 & 104.2 & 106.6 & 106.2 & 105.8 & 103.7 & -3.8 & -4.4 \\
\hline 8 & 103.0 & 105.4 & 107.5 & 107.2 & 102.1 & 108.0 & 96.1 & 100.8 & 105.1 & 106.0 & 94.2 & -11.0 & -13.9 \\
\hline 9 & 107.2 & 107.3 & 107.6 & 107.6 & 104.9 & 107.7 & 109.0 & 111.8 & 108.1 & 101.2 & 100.7 & -6.4 & -7.0 \\
\hline 10 & 93.7 & 98.1 & 101.0 & 103.7 & 103.0 & 104.0 & 99.4 & 100.6 & 105.1 & 108.9 & 99.2 & -4.2 & -4.7 \\
\hline 11 & 88.4 & 91.2 & 92.4 & 90.6 & 81.6 & 92.7 & 81.6 & 82.1 & 87.5 & 93.1 & 76.4 & -9.0 & -16.3 \\
\hline 12 & 81.9 & 82.0 & 82.1 & 82.3 & 82.5 & 82.5 & 84.6 & 87.0 & 90.6 & 94.2 & 82.5 & 2.1 & 0.0 \\
\hline 13 & 97.2 & 95.2 & 93.4 & 93.8 & 96.9 & 101.5 & 94.6 & 86.4 & 87.0 & 87.1 & 86.3 & -10.5 & -15.1 \\
\hline 14 & 141.1 & 143.8 & 146.5 & 146.4 & 144.4 & 147.1 & 135.6 & 142.0 & 150.0 & 145.6 & 135.3 & -10.8 & -11.8 \\
\hline 15 & 96.8 & 101.4 & 104.9 & 103.1 & 98.8 & 105.4 & 98.9 & 103.7 & 108.5 & 108.6 & 96.9 & -4.2 & -8.6 \\
\hline 16 & 84.1 & 85.6 & 84.3 & 78.4 & 74.4 & 85.9 & 75.9 & 82.1 & 87.6 & 93.3 & 72.1 & -2.5 & -13.8 \\
\hline 17 & 135.0 & 138.1 & 138.3 & 133.6 & 128.8 & 139.1 & 120.2 & 132.4 & 142.6 & 125.6 & 119.5 & -13.4 & -19.6 \\
\hline 18 & 95.1 & 100.7 & 102.8 & 101.8 & 97.0 & 103.5 & 95.9 & 107.2 & 117.2 & 121.2 & 92.4 & -5.9 & -11.1 \\
\hline 19 & 78.9 & 80.3 & 81.6 & 82.9 & 84.2 & 84.2 & 90.9 & 98.0 & 104.7 & 112.2 & 84.2 & 6.7 & 0.0 \\
\hline 20 & 210.4 & 209.5 & 205.9 & 199.9 & 190.9 & 210.9 & 174.4 & 166.0 & 162.5 & 164.5 & 161.6 & -37.4 & -49.4 \\
\hline 21 & 95.1 & 96.4 & 98.8 & 95.5 & 92.8 & 99.1 & 96.7 & 109.2 & 104.7 & 93.9 & 92.0 & -1.5 & -7.1 \\
\hline 22 & 93.2 & 96.9 & 100.6 & 98.9 & 89.1 & 101.5 & 79.8 & 90.8 & 81.6 & 89.2 & 77.3 & -19.1 & -24.2 \\
\hline 23 & 97.9 & 99.6 & 100.0 & 100.3 & 100.7 & 100.7 & 103.6 & 101.0 & 92.4 & 94.8 & 91.9 & -8.3 & -8.8 \\
\hline 24 & 85.7 & 88.1 & 90.1 & 89.3 & 84.8 & 90.3 & 79.8 & 87.1 & 91.3 & 91.9 & 77.6 & -9.4 & -12.8 \\
\hline 25 & 85.6 & 87.6 & 89.2 & 90.4 & 91.1 & 91.6 & 95.1 & 97.3 & 97.2 & 98.9 & 91.0 & 4.0 & -0.6 \\
\hline 26 & 84.1 & 86.9 & 89.6 & 92.2 & 94.5 & 94.5 & 93.9 & 96.1 & 100.6 & 105.0 & 93.6 & -0.6 & -0.9 \\
\hline 27 & 111.8 & 112.6 & 111.4 & 107.9 & 103.8 & 112.7 & 101.8 & 109.1 & 106.1 & 105.9 & 100.6 & -6.1 & -12.1 \\
\hline 28 & 82.3 & 81.8 & 81.5 & 82.8 & 83.1 & 83.2 & 78.1 & 84.1 & 90.5 & 90.3 & 77.9 & -5.0 & -5.3 \\
\hline
\end{tabular}


Tabela 31 - Diferenças de velocidade registradas no tratamento 9

\begin{tabular}{|c|c|c|c|c|c|c|c|c|c|c|c|c|c|}
\hline \multirow{2}{*}{ Condutor } & \multicolumn{6}{|c|}{ Tangente } & \multicolumn{5}{|c|}{ Curva } & \multirow{2}{*}{ MSR } & \multirow{2}{*}{$\operatorname{MSR}_{60}$} \\
\hline & $\mathrm{TS}-200 \mathrm{~m}$ & $\mathrm{TS}-150 \mathrm{~m}$ & $\mathrm{TS}-100 \mathrm{~m}$ & $\mathrm{TS}-50 \mathrm{~m}$ & $\mathrm{TS}$ & Máx & $1 / 4$ & $1 / 2$ & $3 / 4$ & ST & Mín & & \\
\hline 1 & 105.0 & 104.9 & 105.2 & 105.6 & 105.3 & 108.3 & 96.0 & 97.0 & 104.3 & 103.3 & 91.5 & -9.6 & -16.8 \\
\hline 2 & 120.5 & 119.8 & 119.1 & 118.1 & 117.2 & 122.4 & 111.3 & 114.6 & 118.4 & 121.5 & 111.0 & -6.9 & -11.5 \\
\hline 3 & 95.0 & 96.4 & 97.9 & 99.4 & 100.8 & 100.8 & 94.0 & 96.9 & 96.4 & 99.1 & 92.0 & -6.8 & -8.8 \\
\hline 4 & 110.1 & 105.7 & 101.7 & 97.9 & 96.2 & 113.0 & 105.7 & 117.7 & 116.4 & 115.2 & 96.1 & 7.8 & -16.8 \\
\hline 5 & 128.7 & 128.5 & 127.7 & 125.9 & 121.1 & 128.7 & 106.0 & 115.0 & 114.2 & 115.0 & 105.9 & -19.9 & -22.8 \\
\hline 6 & 101.7 & 104.4 & 105.8 & 107.2 & 105.5 & 107.8 & 92.7 & 79.0 & 73.6 & 80.3 & 73.1 & -33.6 & -34.8 \\
\hline 7 & 110.0 & 109.3 & 108.4 & 108.3 & 107.7 & 111.0 & 97.2 & 96.3 & 103.4 & 107.9 & 95.5 & -12.0 & -15.5 \\
\hline 8 & 112.9 & 114.3 & 116.3 & 114.4 & 108.9 & 116.8 & 97.9 & 106.9 & 110.7 & 112.0 & 97.6 & -16.5 & -19.2 \\
\hline 9 & 106.5 & 106.9 & 107.4 & 107.7 & 107.3 & 110.5 & 103.0 & 108.6 & 111.6 & 107.8 & 101.4 & -4.7 & -9.1 \\
\hline 10 & 96.2 & 96.1 & 96.5 & 96.0 & 94.7 & 97.1 & 91.5 & 89.8 & 96.5 & 97.5 & 88.2 & -6.2 & -8.9 \\
\hline 11 & 107.7 & 102.1 & 98.2 & 97.1 & 91.1 & 112.6 & 88.3 & 98.1 & 96.4 & 93.9 & 85.2 & -8.8 & -27.5 \\
\hline 12 & 74.8 & 79.1 & 82.8 & 85.9 & 87.2 & 87.2 & 90.2 & 88.9 & 87.0 & 85.2 & 85.2 & -2.0 & -2.0 \\
\hline 13 & 98.7 & 98.4 & 98.9 & 101.4 & 101.3 & 110.4 & 96.3 & 110.0 & 106.6 & 96.9 & 93.8 & -5.0 & -16.6 \\
\hline 14 & 154.5 & 153.7 & 152.7 & 150.7 & 147.5 & 155.7 & 136.3 & 141.5 & 144.9 & 144.9 & 135.6 & -14.4 & -20.2 \\
\hline 15 & 85.9 & 86.9 & 87.1 & 86.9 & 86.4 & 95.1 & 90.5 & 97.9 & 105.1 & 113.1 & 86.4 & 3.6 & -8.8 \\
\hline 16 & 88.6 & 88.5 & 88.1 & 82.0 & 81.2 & 94.6 & 82.8 & 86.5 & 92.7 & 97.4 & 81.2 & 0.8 & -13.4 \\
\hline 17 & 129.7 & 129.6 & 128.4 & 123.4 & 118.2 & 131.3 & 121.2 & 135.8 & 141.0 & 150.6 & 112.5 & -2.2 & -18.8 \\
\hline 18 & 107.5 & 109.7 & 111.8 & 110.6 & 106.1 & 114.2 & 96.7 & 102.5 & 108.7 & 110.7 & 96.6 & -13.9 & -17.6 \\
\hline 19 & 111.2 & 111.3 & 110.2 & 108.5 & 104.0 & 111.4 & 97.8 & 100.7 & 105.5 & 109.5 & 97.6 & -10.7 & -13.8 \\
\hline 20 & 163.6 & 159.7 & 155.6 & 151.5 & 146.3 & 167.0 & 134.6 & 152.3 & 167.4 & 156.0 & 134.3 & -16.8 & -32.7 \\
\hline 21 & 101.0 & 102.4 & 103.3 & 98.6 & 94.5 & 103.8 & 94.6 & 103.7 & 113.1 & 110.3 & 91.0 & -3.9 & -12.8 \\
\hline 22 & 109.0 & 104.5 & 99.7 & 93.3 & 88.0 & 118.9 & 85.0 & 92.4 & 85.4 & 91.4 & 83.0 & -8.3 & -35.9 \\
\hline 23 & 97.3 & 97.2 & 97.1 & 97.1 & 97.0 & 97.8 & 96.9 & 96.8 & 96.6 & 96.6 & 96.6 & -0.5 & -1.3 \\
\hline 24 & 93.0 & 97.1 & 100.3 & 99.1 & 95.7 & 100.6 & 84.9 & 86.9 & 90.5 & 98.5 & 84.5 & -14.2 & -16.1 \\
\hline 25 & 132.0 & 131.3 & 127.6 & 123.7 & 119.7 & 132.5 & 105.5 & 103.8 & 106.6 & 109.2 & 102.7 & -19.9 & -29.8 \\
\hline 26 & 97.5 & 99.3 & 101.4 & 103.2 & 100.9 & 103.3 & 100.0 & 103.7 & 107.6 & 109.4 & 98.0 & -3.2 & -5.3 \\
\hline 27 & 100.9 & 101.8 & 103.9 & 106.5 & 107.8 & 113.1 & 109.7 & 109.8 & 109.8 & 108.6 & 107.5 & 0.8 & -5.6 \\
\hline 28 & 124.6 & 121.4 & 117.4 & 114.0 & 109.7 & 125.7 & 93.4 & 89.2 & 97.4 & 108.3 & 86.2 & -24.8 & -39.5 \\
\hline
\end{tabular}


Já para a abordagem $\Delta V 85$, como fora apresentado na revisão, LAMM et al. (1990) calcularam as velocidades médias nos centros das curvas a partir do tempo que os veículos de passeio levavam para cumprir uma distância fixa de 150 pés $(\approx 45.72$ metros $)$. Para comparar métodos, McFadden e Elefteriadou (2000) registraram essas velocidades a partir de medidas pontuais no centro dos elementos, com radares de mão. Esse ajuste também será adotado nesse trabalho, a fim, de ampliar as possibilidades de comparação com os dois métodos. Assim, a diferença de velocidade encontrada em cada tratamento $(\Delta \mathrm{V})$ será igual a subtração da velocidade pontual registrada no centro da curva $(\Delta \mathrm{Vc})$ pela velocidade pontual registrada no centro da tangente de aproximação $(\Delta \mathrm{Vt})$. A Tabela 32 apresenta as diferenças para os primeiros três tratamentos e a Tabela 33 apresenta os resultados dos restantes.

Tabela 32 - Diferenças de velocidade registradas nos tratamentos 1, 2 e 3

\begin{tabular}{|c|c|c|c|c|c|c|c|c|c|}
\hline \multirow{2}{*}{ Condutor } & \multicolumn{3}{|c|}{ Tratamento 1} & \multicolumn{3}{|c|}{ Tratamento 2} & \multicolumn{3}{|c|}{ Tratamento 3} \\
\hline & $\Delta \mathrm{V}_{\mathrm{t}}$ & $\Delta \mathrm{V}_{\mathrm{c}}$ & $\Delta \mathrm{V}$ & $\Delta \mathrm{V}_{\mathrm{t}}$ & $\Delta \mathrm{V}_{\mathrm{c}}$ & $\Delta \mathrm{V}$ & $\Delta \mathrm{V}_{\mathrm{t}}$ & $\Delta \mathrm{V}_{\mathrm{c}}$ & $\Delta \mathrm{V}$ \\
\hline 1 & 98.0 & 77.9 & -20.1 & 105.1 & 80.6 & -24.5 & 118.3 & 78.7 & -39.6 \\
\hline 2 & 86.6 & 76.0 & -10.6 & 120.4 & 89.5 & -30.9 & 118.7 & 85.1 & -33.6 \\
\hline 3 & 91.5 & 83.3 & -8.2 & 107.5 & 83.4 & -24.1 & 98.0 & 87.7 & -10.3 \\
\hline 4 & 93.4 & 80.1 & -13.3 & 102.5 & 75.5 & -26.9 & 102.4 & 78.2 & -24.2 \\
\hline 5 & 102.1 & 81.5 & -20.6 & 113.8 & 92.4 & -21.4 & 120.3 & 82.5 & -37.8 \\
\hline 6 & 52.8 & 37.1 & -15.7 & 99.1 & 69.1 & -29.9 & 94.7 & 79.8 & -14.9 \\
\hline 7 & 84.5 & 73.9 & -10.6 & 111.1 & 90.8 & -20.3 & 119.0 & 82.9 & -36.1 \\
\hline 8 & 107.8 & 91.3 & -16.5 & 106.0 & 80.7 & -25.2 & 124.2 & 82.1 & -42.1 \\
\hline 9 & 97.8 & 78.7 & -19.0 & 106.0 & 80.2 & -25.8 & 110.0 & 77.0 & -33.0 \\
\hline 10 & 67.5 & 62.7 & -4.8 & 73.0 & 68.3 & -4.7 & 115.3 & 103.4 & -11.9 \\
\hline 11 & 78.7 & 64.7 & -14.0 & 89.4 & 62.8 & -26.6 & 94.6 & 61.7 & -32.9 \\
\hline 12 & 89.8 & 86.0 & -3.8 & 88.3 & 85.0 & -3.3 & 85.2 & 83.0 & -2.1 \\
\hline 13 & 66.4 & 64.3 & -2.0 & 81.2 & 74.5 & -6.7 & 105.4 & 92.8 & -12.6 \\
\hline 14 & 114.8 & 87.9 & -26.9 & 137.2 & 94.7 & -42.5 & 153.3 & 86.2 & -67.2 \\
\hline 15 & 90.0 & 81.4 & -8.6 & 111.5 & 87.7 & -23.8 & 108.2 & 95.0 & -13.2 \\
\hline 16 & 59.6 & 60.4 & 0.7 & 87.4 & 56.6 & -30.8 & 90.7 & 59.8 & -30.9 \\
\hline 17 & 113.0 & 71.8 & -41.3 & 163.5 & 81.3 & -82.2 & 134.6 & 92.9 & -41.6 \\
\hline 18 & 81.0 & 73.0 & -8.1 & 118.2 & 86.3 & -31.9 & 102.9 & 83.3 & -19.6 \\
\hline 19 & 92.6 & 77.3 & -15.3 & 73.3 & 73.9 & 0.6 & 97.2 & 76.9 & -20.3 \\
\hline 20 & 114.7 & 93.3 & -21.4 & 134.2 & 94.2 & -40.0 & 174.6 & 99.0 & -75.7 \\
\hline 21 & 81.6 & 66.7 & -14.8 & 88.7 & 64.3 & -24.4 & 96.5 & 66.5 & -30.0 \\
\hline 22 & 87.9 & 76.2 & -11.7 & 87.6 & 69.1 & -18.5 & 110.6 & 80.0 & -30.6 \\
\hline 23 & 81.7 & 77.2 & -4.4 & 100.6 & 85.0 & -15.6 & 96.1 & 77.3 & -18.8 \\
\hline 24 & 75.9 & 72.2 & -3.6 & 98.5 & 82.5 & -16.1 & 95.9 & 77.5 & -18.5 \\
\hline 25 & 106.1 & 93.8 & -12.3 & 110.1 & 88.5 & -21.6 & 113.1 & 103.6 & -9.5 \\
\hline 26 & 99.9 & 86.7 & -13.2 & 113.5 & 86.8 & -26.6 & 99.0 & 79.1 & -19.9 \\
\hline 27 & 83.3 & 79.2 & -4.1 & 91.8 & 65.8 & -26.1 & 104.7 & 87.4 & -17.3 \\
\hline 28 & 102.1 & 87.2 & -14.9 & 113.4 & 89.6 & -23.8 & 116.0 & 82.0 & -34.0 \\
\hline
\end{tabular}


Tabela 33 - Diferenças de velocidade registradas nos tratamentos restantes

\begin{tabular}{|c|c|c|c|c|c|c|c|c|c|c|c|c|c|c|c|c|c|c|}
\hline \multirow{2}{*}{ Condutor } & \multicolumn{3}{|c|}{ Tratamento 4} & \multicolumn{3}{|c|}{ Tratamento 5} & \multicolumn{3}{|c|}{ Tratamento 6} & \multicolumn{3}{|c|}{ Tratamento 7} & \multicolumn{3}{|c|}{ Tratamento 8} & \multicolumn{3}{|c|}{ Tratamento 9} \\
\hline & $\Delta \mathrm{V}_{\mathrm{t}}$ & $\Delta \mathrm{V}_{\mathrm{c}}$ & $\Delta \mathrm{V}$ & $\Delta \mathrm{V}_{\mathrm{t}}$ & $\Delta \mathrm{V}_{\mathrm{c}}$ & $\Delta \mathrm{V}$ & $\Delta \mathrm{V}_{\mathrm{t}}$ & $\Delta \mathrm{V}_{\mathrm{c}}$ & $\Delta \mathrm{V}$ & $\Delta \mathrm{V}_{\mathrm{t}}$ & $\Delta \mathrm{V}_{\mathrm{c}}$ & $\Delta \mathrm{V}$ & $\Delta \mathrm{V}_{\mathrm{t}}$ & $\Delta \mathrm{V}_{\mathrm{c}}$ & $\Delta \mathrm{V}$ & $\Delta \mathrm{V}_{\mathrm{t}}$ & $\Delta \mathrm{V}_{\mathrm{c}}$ & $\Delta \mathrm{V}$ \\
\hline 1 & 79.2 & 98.1 & 18.9 & 105.0 & 88.3 & -16.7 & 117.5 & 92.9 & -24.6 & 107.7 & 97.5 & -10.2 & 90.9 & 94.7 & 3.8 & 87.3 & 98.1 & 10.8 \\
\hline 2 & 117.5 & 118.7 & 1.1 & 121.1 & 125.1 & 4.1 & 119.5 & 120.1 & 0.6 & 122.3 & 119.8 & -2.5 & 120.8 & 119.3 & -1.5 & 114.2 & 117.7 & 3.5 \\
\hline 3 & 100.7 & 97.4 & -3.3 & 98.4 & 99.9 & 1.6 & 104.9 & 101.1 & -3.8 & 91.6 & 100.7 & 9.1 & 97.7 & 101.0 & 3.2 & 95.1 & 100.7 & 5.7 \\
\hline 4 & 103.2 & 96.5 & -6.6 & 109.6 & 102.9 & -6.6 & 118.3 & 104.3 & -14.0 & 102.4 & 106.5 & 4.0 & 98.6 & 120.4 & 21.8 & 106.4 & 115.7 & 9.3 \\
\hline 5 & 108.9 & 110.7 & 1.8 & 112.6 & 110.1 & -2.5 & 122.4 & 112.5 & -9.9 & 105.1 & 119.4 & 14.3 & 119.7 & 118.9 & -0.9 & 118.6 & 120.7 & 2.1 \\
\hline 6 & 82.3 & 89.0 & 6.6 & 71.9 & 59.8 & -12.0 & 92.9 & 83.7 & -9.2 & 94.8 & 109.2 & 14.4 & 79.2 & 84.4 & 5.2 & 96.8 & 78.9 & -17.9 \\
\hline 7 & 109.6 & 103.7 & -5.9 & 108.0 & 99.0 & -8.9 & 117.7 & 93.6 & -24.1 & 105.9 & 103.8 & -2.1 & 102.1 & 106.6 & 4.5 & 110.8 & 96.5 & -14.4 \\
\hline 8 & 101.4 & 95.2 & -6.1 & 114.5 & 100.6 & -13.8 & 135.2 & 94.3 & -40.9 & 81.1 & 104.4 & 23.3 & 123.4 & 112.9 & -10.5 & 124.0 & 107.9 & -16.1 \\
\hline 9 & 107.5 & 104.2 & -3.3 & 105.1 & 90.3 & -14.8 & 109.6 & 95.0 & -14.5 & 93.8 & 111.6 & 17.8 & 107.8 & 106.9 & -0.9 & 107.7 & 107.5 & -0.2 \\
\hline 10 & 94.7 & 95.4 & 0.8 & 76.6 & 86.3 & 9.7 & 96.2 & 74.9 & -21.3 & 108.2 & 98.5 & -9.7 & 97.9 & 100.6 & 2.8 & 95.2 & 89.8 & -5.4 \\
\hline 11 & 89.4 & 83.6 & -5.8 & 81.5 & 85.8 & 4.3 & 99.7 & 87.1 & -12.6 & 72.7 & 82.4 & 9.6 & 101.3 & 87.8 & -13.5 & 101.4 & 93.8 & -7.6 \\
\hline 12 & 95.6 & 94.9 & -0.7 & 82.9 & 80.1 & -2.8 & 92.3 & 86.3 & -6.0 & 97.6 & 99.0 & 1.3 & 89.8 & 94.1 & 4.4 & 85.5 & 90.9 & 5.4 \\
\hline 13 & 115.2 & 110.8 & -4.3 & 108.0 & 102.5 & -5.5 & 104.1 & 105.2 & 1.2 & 105.8 & 101.7 & -4.1 & 81.6 & 98.5 & 16. & 99.9 & 104.0 & 4.2 \\
\hline 14 & 97.0 & 115.3 & 18.3 & 148.5 & 121.5 & -27.0 & 144.2 & 123.5 & -20.7 & 76.7 & 112.3 & 35.6 & 137.4 & 150.9 & 13.5 & 134.7 & 142.7 & 8.0 \\
\hline 15 & 113.1 & 102.4 & -10.7 & 113.3 & 108.1 & -5.2 & 109.4 & 87.7 & -21.7 & 113.4 & 118.5 & 5.1 & 114.2 & 110.4 & -3.8 & 106.6 & 111.2 & 4.6 \\
\hline 16 & 67.3 & 82.0 & 14.7 & 95.4 & 81.6 & -13.8 & 89.3 & 80.9 & -8.3 & 91.7 & 84.7 & -7.0 & 76.4 & 80.6 & 4.2 & 90.0 & 82.6 & -7.4 \\
\hline 17 & 137.8 & 121.5 & -16.4 & 163.3 & 109.3 & -54.0 & 140.0 & 119.5 & -20.5 & 92.0 & 131.1 & 39.1 & 167.7 & 172.0 & 4.2 & 176.3 & 150.6 & -25.6 \\
\hline 18 & 102.5 & 99.8 & -2.6 & 107.7 & 95.4 & -12.3 & 103.7 & 95.3 & -8.4 & 106.9 & 99.8 & -7.1 & 101.0 & 107.4 & 6.4 & 104.5 & 102.4 & -2.2 \\
\hline 19 & 99.1 & 95.3 & -3.8 & 78.8 & 94.8 & 16.0 & 97.8 & 81.4 & -16.4 & 87.6 & 98.8 & 11.3 & 99.7 & 98.4 & -1.3 & 99.1 & 97.2 & -1.8 \\
\hline 20 & 162.7 & 155.7 & -7.0 & 198.4 & 151.1 & -47.3 & 186.9 & 151.1 & -35.8 & 211.1 & 169.8 & -41.3 & 135.0 & 168.8 & 33.8 & 176.9 & 172.4 & -4.5 \\
\hline 21 & 92.5 & 82.9 & -9.6 & 90.4 & 85.8 & -4.6 & 79.0 & 91.0 & 11.9 & 66.8 & 86.4 & 19.7 & 81.4 & 86.0 & 4.7 & 100.2 & 88.3 & -11.9 \\
\hline 22 & 66.8 & 74.8 & 8.0 & 98.7 & 74.1 & -24.6 & 112.9 & 79.8 & -33.1 & 66.0 & 87.7 & 21.8 & 101.4 & 86.7 & -14.7 & 115.6 & 78.8 & -36.8 \\
\hline 23 & 98.9 & 98.4 & -0.5 & 95.8 & 97.0 & 1.2 & 95.0 & 97.0 & 1.9 & 96.5 & 96.3 & -0.3 & 99.6 & 100.9 & 1.3 & 97.4 & 96.8 & -0.7 \\
\hline 24 & 98.1 & 90.2 & -7.9 & 83.7 & 86.6 & 2.9 & 99.1 & 87.7 & -11.4 & 89.4 & 94.2 & 4.8 & 94.7 & 94.9 & 0.2 & 98.9 & 99.9 & 1.0 \\
\hline 25 & 85.7 & 94.9 & 9.2 & 130.0 & 102.9 & -27.1 & 117.7 & 102.1 & -15.6 & 106.9 & 103.4 & -3.5 & 87.9 & 99.9 & 11.9 & 109.2 & 109.6 & 0.5 \\
\hline 26 & 105.7 & 97.2 & -8.5 & 105.4 & 102.8 & -2.6 & 112.9 & 93.5 & -19.5 & 117.9 & 100.1 & -17.8 & 99.8 & 116.5 & 16.7 & 103.4 & 106.2 & 2.8 \\
\hline 27 & 107.2 & 84.8 & -22.4 & 106.9 & 91.7 & -15.2 & 117.1 & 87.2 & -29.9 & 106.7 & 103.5 & -3.3 & 112.6 & 109.1 & -3.5 & 105.0 & 109.8 & 4.8 \\
\hline 28 & 84.0 & 90.1 & 6.1 & 117.4 & 96.8 & -20.6 & 114.9 & 87.9 & -27.0 & 68.8 & 86.3 & 17.5 & 125.6 & 106.0 & -19.7 & 110.9 & 92.1 & -18.9 \\
\hline
\end{tabular}




\subsubsection{Comparação caso a caso}

A fim de comparar o método proposto com a abordagem $85 \mathrm{MSR}$ e a $85 \mathrm{MSR}_{60}$, citadas anteriormente, primeiro avaliou-se a normalidade da distribuição das respostas dessas abordagens. No item anterior (5.2), mostrou-se necessária a transformação logarítmica dos escores relativos ao jerk mínimo para melhor se adequar à suposição da normalidade. A Figura 23 apresentou essa distribuição transformada.

A Figura 37 apresenta a distribuição para a abordagem 85MSR. Dentre as possibilidades estudadas para essa distribuição melhor se aproximar de uma normal, optou-se por excluir o condutor 20 da amostra (outra possibilidade era utilizar a raiz quadrada, porém essa medida acarretaria a exclusão de 30 valores maiores que zero, já que esses inflariam a extremidade esquerda da distribuição transformada).

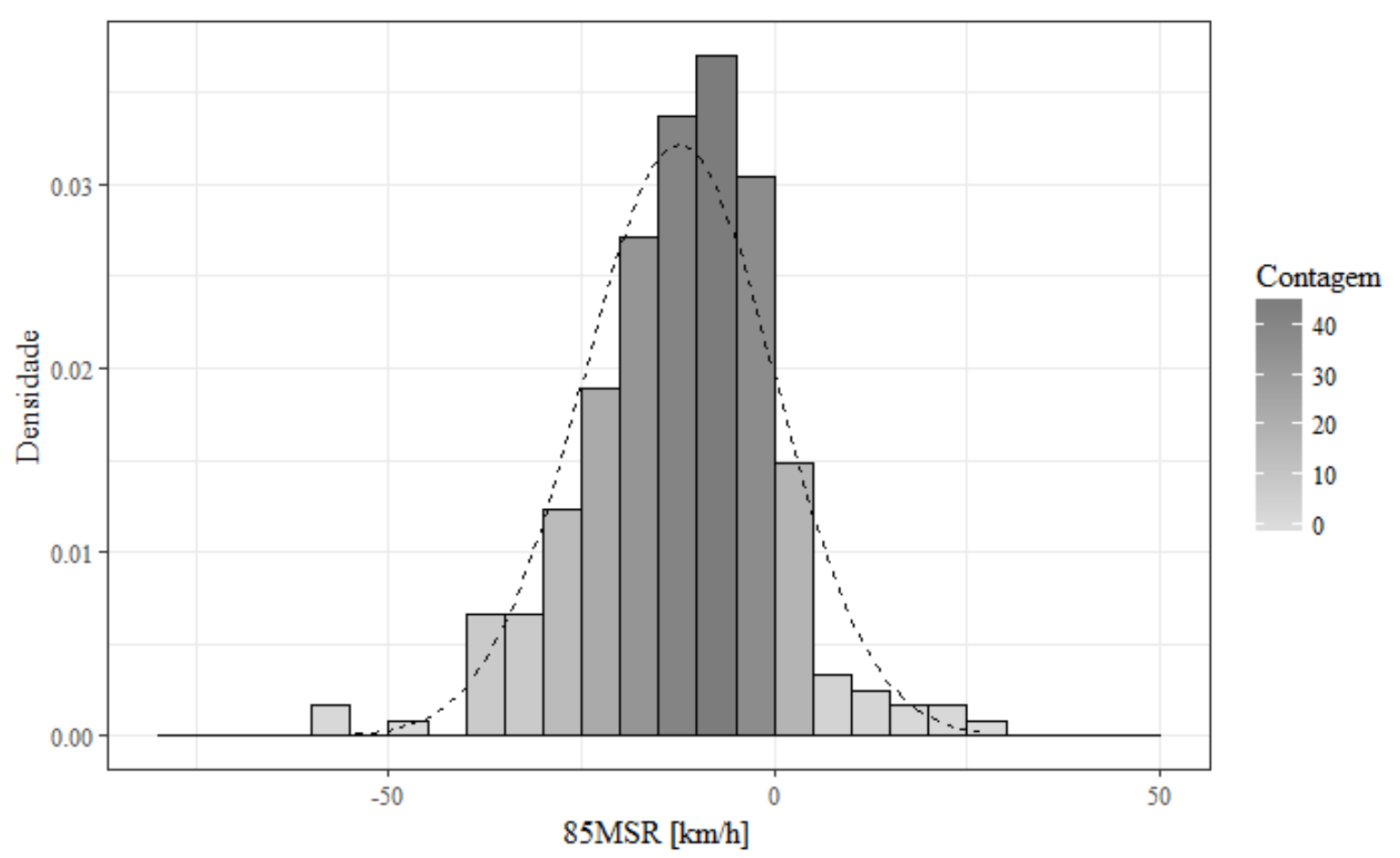

Figura 37 - Distribuição dos valores encontrados para a abordagem 85MSR

Com essa exclusão, essa distribuição se aproximou mais da normal (curtose $=4.15$ e assimetria $=-0.28)$, o teste de Kolgomorov-Smirnov também não foi significativo $(\mathrm{p}=0.053)$. A Figura 38 apresenta a distribuição para a abordagem $85 \mathrm{MSR}_{60}$. Foi necessária a transformação dos valores a partir da raiz quadrada dos valores absolutos para se aproximar da normal. Isso fez com que a extremidade esquerda da distribuição ficasse ligeiramente inflada já que existiam valores maiores que zero (18). Porém, esses eram próximos de zero, 0.008 a 0.18. 


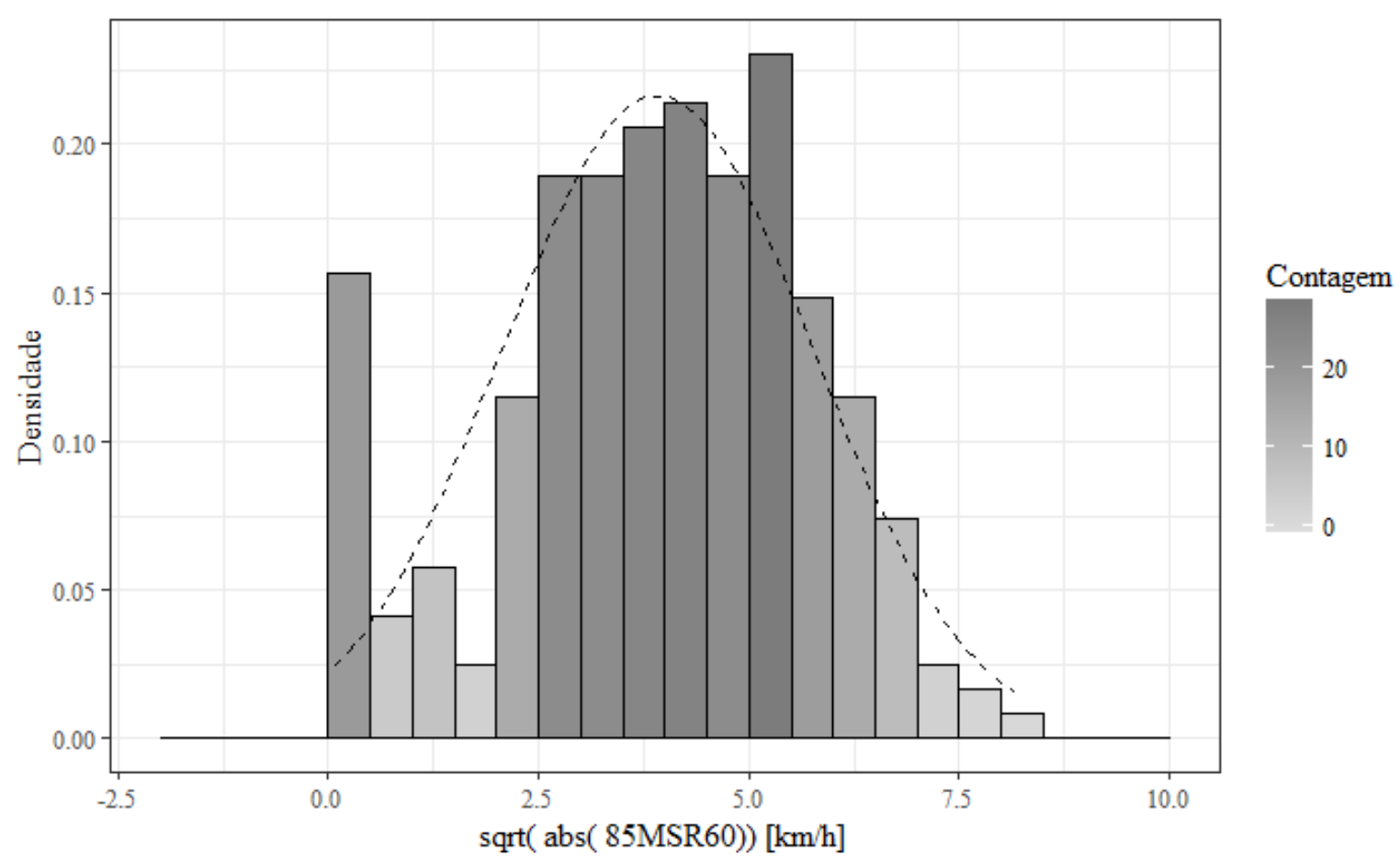

Figura 38 - Distribuição dos valores encontrados para a abordagem $85 \mathrm{MSR}_{60}$

Com a transformação, essa distribuição se aproximou da normal (curtose $=2.58$ e assimetria $=$ -0.34), o teste de Kolgomorov-Smirnov também não foi significativo ( $\mathrm{p}=0.062$ ). Partiu-se então para a avaliação da suposição da normalidade para cada tratamento. A Tabela 34 traz a significância do teste de Kolgomorov-Smirnov para cada uma das combinações.

Tabela 34 - Teste de normalidade para cada método em função do tratamento

\begin{tabular}{crrrrrrrrr}
\hline \multirow{2}{*}{ Método } & \multicolumn{8}{c}{ Kolgomorov-Smirnov $[\mathrm{p}]$} \\
\cline { 2 - 10 } & $\mathrm{Rp}-\mathrm{Tp}$ & $\mathrm{Rp}-\mathrm{Tm}$ & $\mathrm{Rp}-\mathrm{Tg}$ & $\mathrm{Rm}-\mathrm{Tp}$ & $\mathrm{Rm}-\mathrm{Tm}$ & $\mathrm{Rm}-\mathrm{Tg}$ & $\mathrm{Rg}-\mathrm{Tp}$ & $\mathrm{Rg}-\mathrm{Tm}$ & $\mathrm{Rg}-\mathrm{Tg}$ \\
\hline 85MSR & 0.200 & 0.200 & 0.200 & 0.200 & 0.200 & 0.200 & $\mathbf{0 . 0 0 6}$ & 0.200 & 0.200 \\
sqrt (abs $\left.\left(85 \mathrm{MSR}_{60}\right)\right)$ & 0.200 & 0.200 & 0.200 & $\mathbf{0 . 0 3 6}$ & 0.200 & $\mathbf{0 . 0 4 9}$ & $\mathbf{0 . 0 1 5}$ & 0.137 & 0.200 \\
\hline
\end{tabular}

O teste mostrou que não se pode considerar que houve uma distribuição normal em alguns tratamentos. A análise de cada caso identificou alguns potenciais outliers, porém como esses condutores tiveram comportamento dentro do esperado nos outros tratamentos, a análise continuou com essa falha considerada. O teste de Levene demostrou que, entre tratamentos, as variâncias não eram significativamente diferentes $\left(\operatorname{sqrt}\left(\operatorname{abs}\left(85 \mathrm{MSR}_{60}\right)\right): F(8,234)=1.628, \mathrm{p}\right.$ $>0.05 ; 85$ MSR: $F(8,234)=1.290, \mathrm{p}>0.05$. 
Partiu-se então para a análise da dispersão dos valores registrados para cada condutor. A Figura 39 apresenta visualmente a relação dos valores encontrados para os métodos 85MSR e o jerk mínimo. Nesse gráfico, está presente uma reta que simboliza o ajuste linear desses pontos, bem como seus coeficientes de determinação $\left(\mathrm{R}^{2}\right)$, de correlação de Person $(\mathrm{R})$, o valor do teste de t de Student e a significância da correlação.

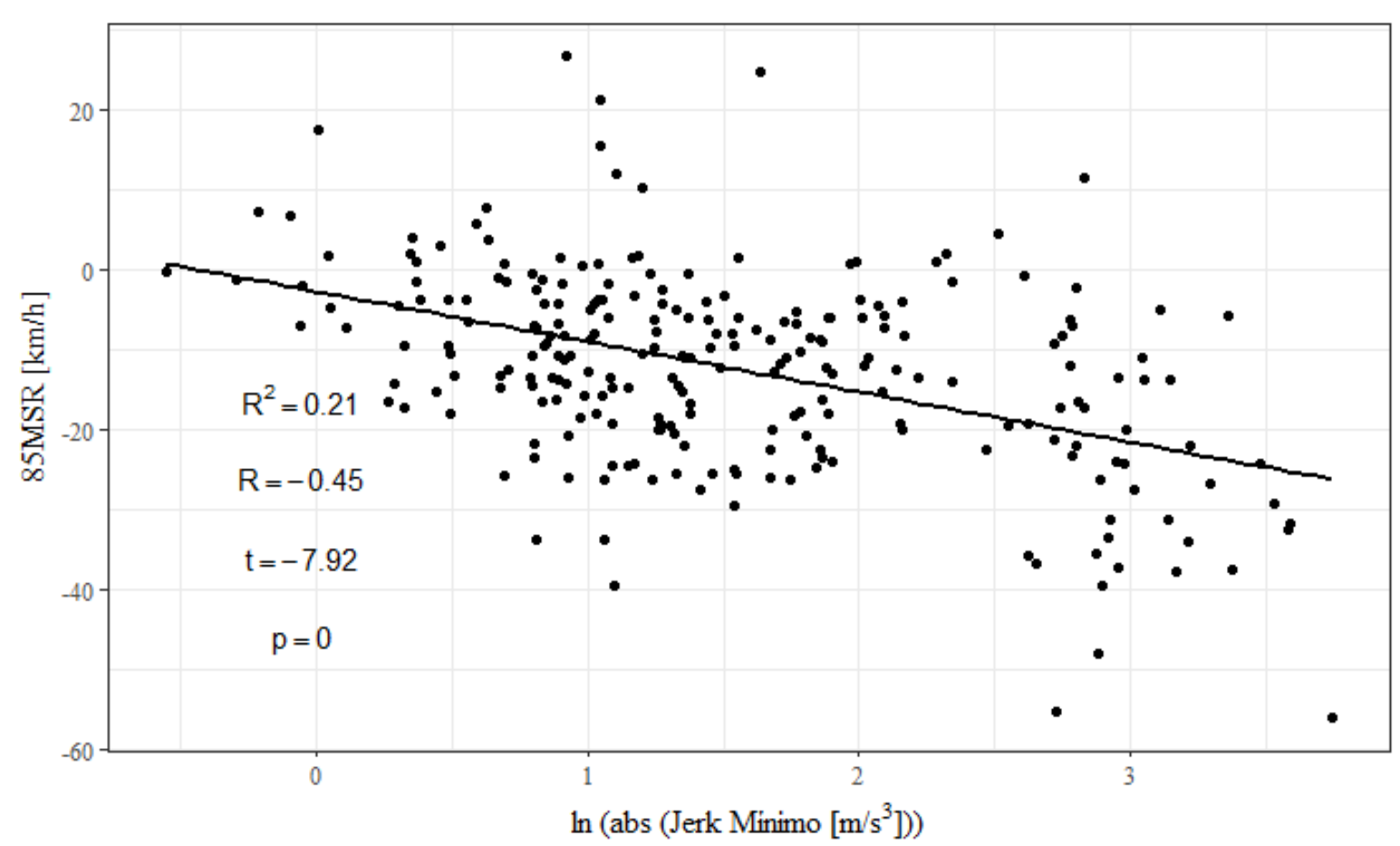

Figura 39 - Dispersão dos pontos entre as respostas da abordagem 85MSR e da tese

Apesar da correlação moderada dos pontos (-0.45), a determinação é baixa (0.21), distante do valor 1. A Figura 40 apresenta a mesma dispersão do gráfico anterior, agrupada em função do tratamento. 


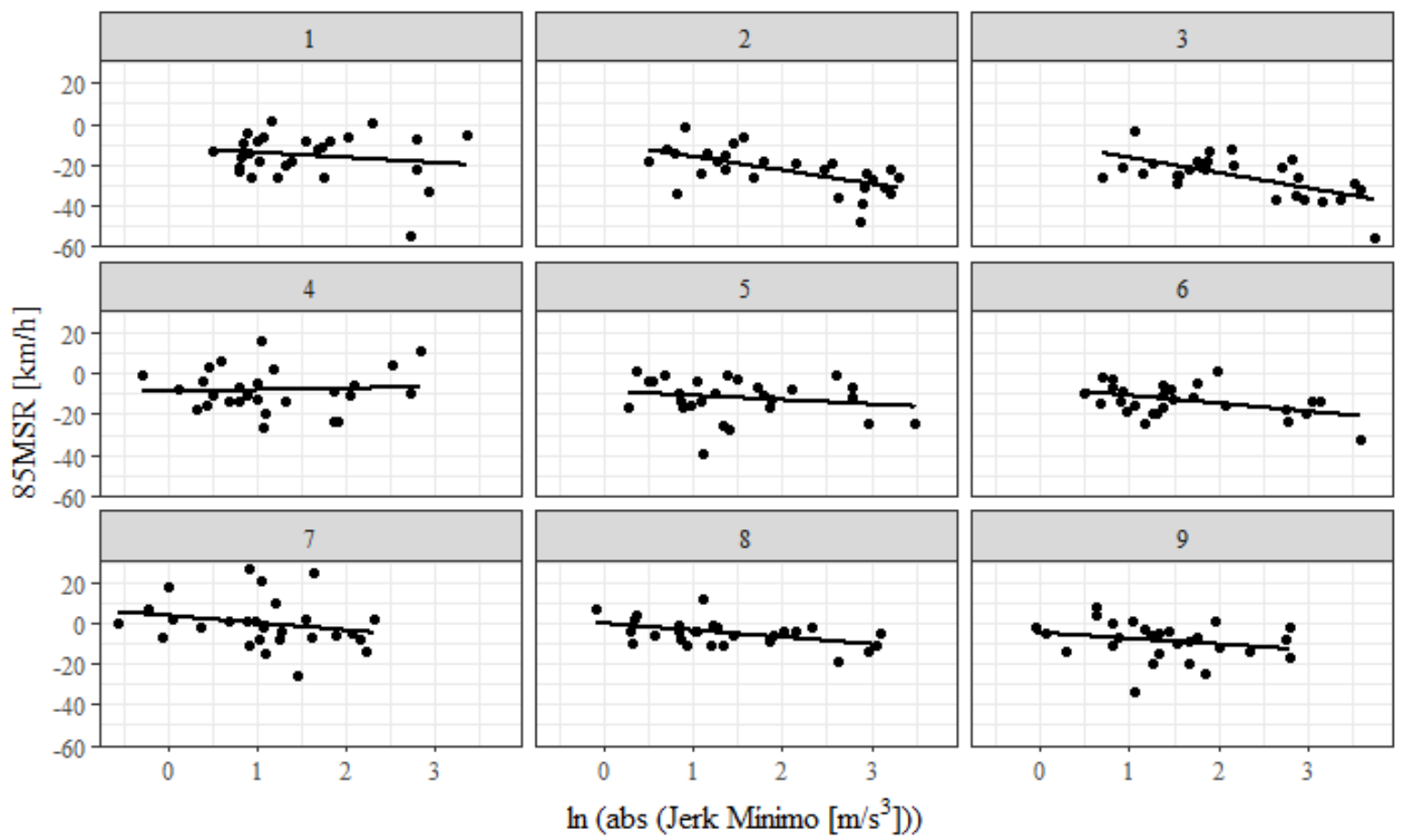

Figura 40 - Dispersão dos pontos por tratamento entre as abordagens 85MSR e da tese

Quando as dispersões estão agrupadas em função dos tratamentos, parece haver um melhor ajuste dos pontos. Na sequência, a Figura 41 apresenta a dispersão dos valores encontrados para o método $85 \mathrm{MSR}_{60}$ e o jerk mínimo. A Figura 42 apresenta esses dados em função do tratamento.

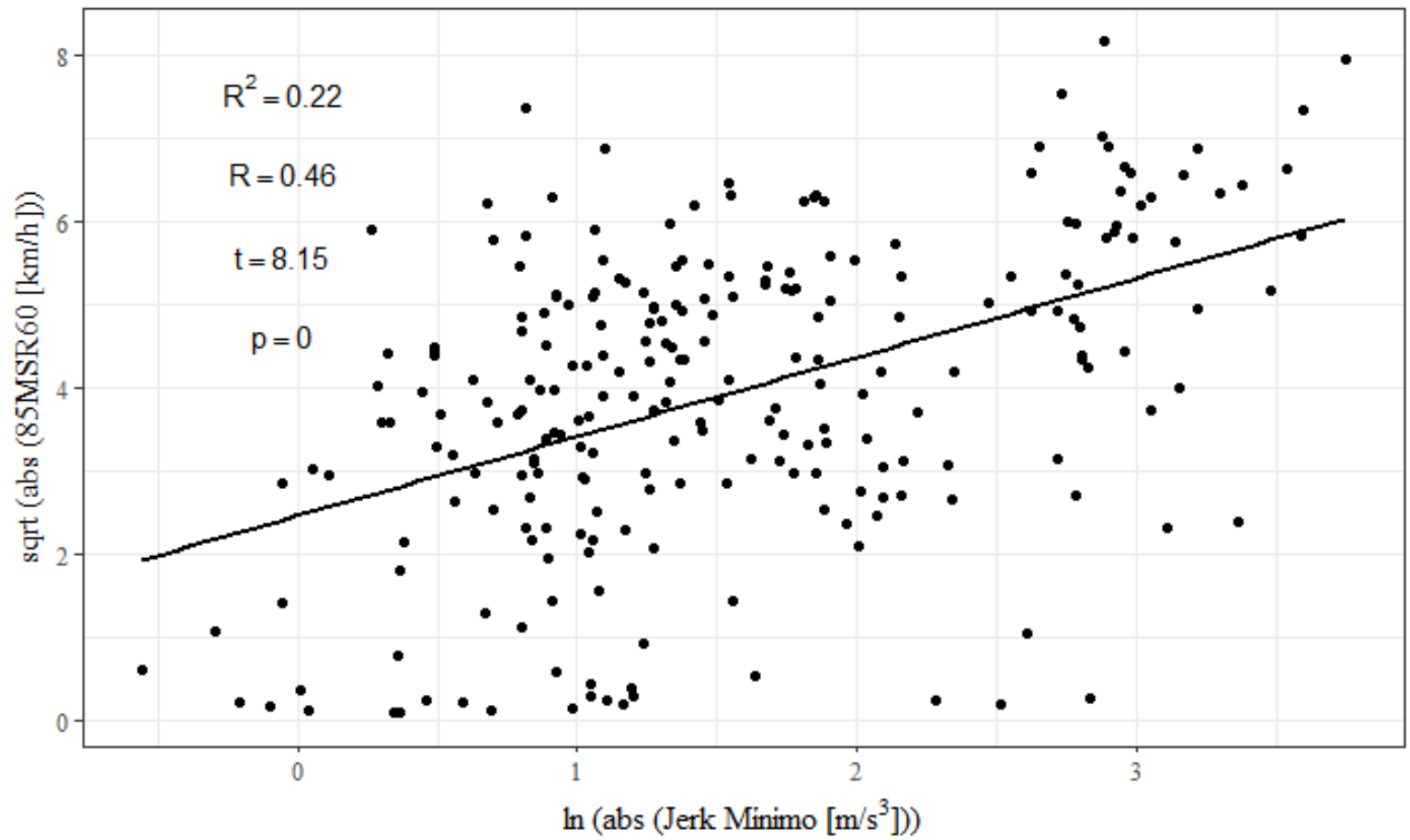

Figura 41 - Dispersão dos pontos entre as respostas da abordagem $85 \mathrm{MSR}_{60}$ e da tese 

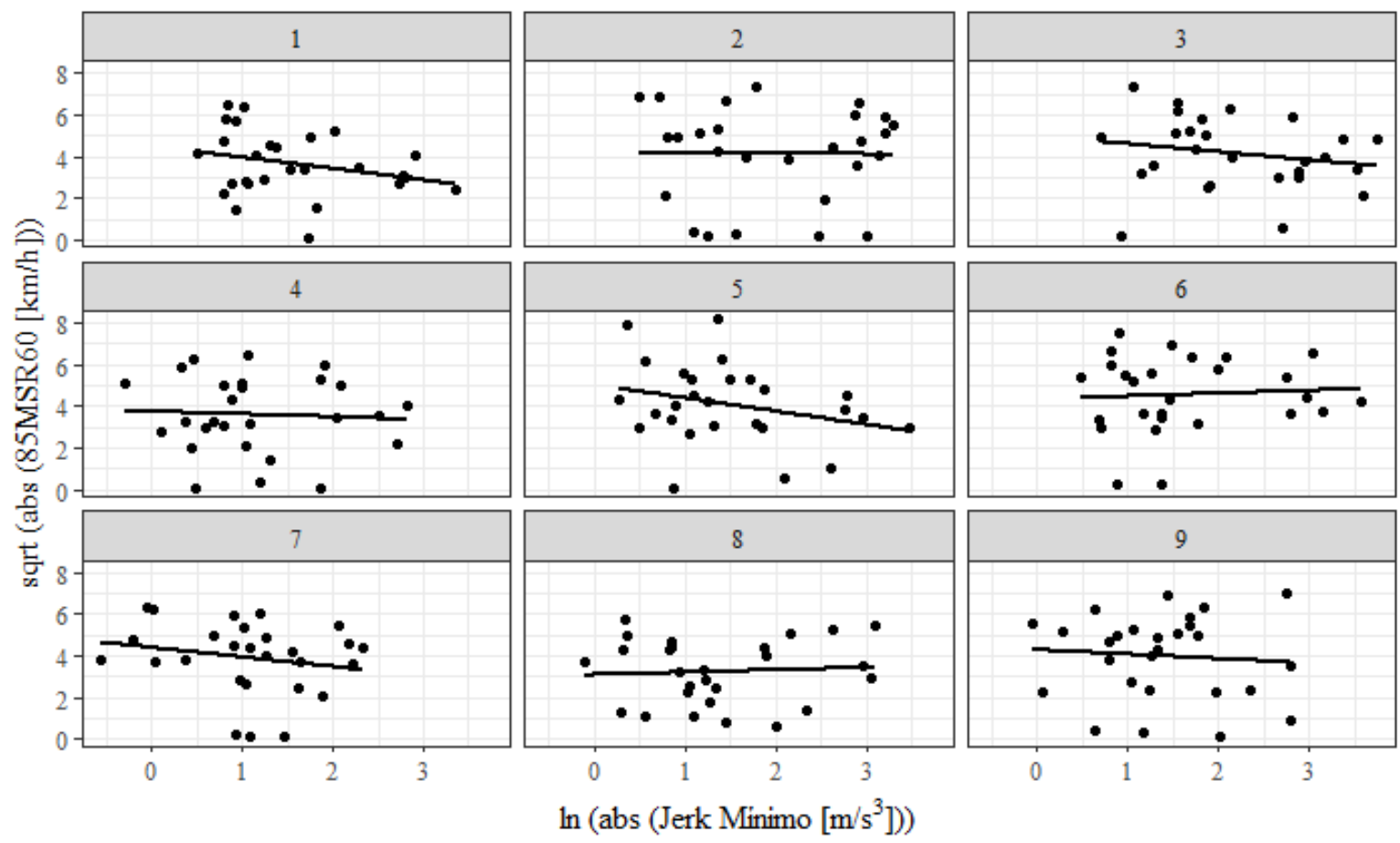

Figura 42 - Dispersão dos pontos por tratamento entre as abordagens $85 \mathrm{MSR}_{60}$ e da tese

Apesar do valor dos coeficientes de correlação (0.46) e determinação (0.22) serem semelhantes aos da abordagem anterior, a qualidade desse ajuste pode estar comprometida pela influência da transformação utilizada. A dispersão por tratamento parece alimentar a impressão de que os pontos estão mais distantes da reta de ajuste.

Os resultados da comparação de todos os pontos mostraram uma correlação moderada entre os métodos na comparação caso a caso. Para essas comparações foi utilizado o coeficiente de Pearson em função do número de pares (27) e da consideração da distribuição normal entre os métodos comparados. 


\subsubsection{Comparação do percentil 85}

Como abordado na revisão, os métodos tradicionais utilizavam o percentil 85 para avaliar a consistência dos elementos. A adoção dessa posição, proporcionaria a eliminação matemática de valores extremos e categorizaria um elemento em função de grande porção da população de condutores que passariam por aquela situação. Mesmo que a execução desse trabalho resultasse em uma amostra menor que os valores utilizados para análises da posição 85 (28 coletas $<<100$ dados), partiu-se para essa comparação. Vale ressaltar que algumas referências (LAMM; CHOUEIRI, 1987; LAMM et al., 1990) utilizaram valores menores para calcular a velocidade operacional. Alguns modelos utilizaram entre 30 e 100 coletas, porém a acurácia desses poderia ser questionável (MISAGHI; HASSAN, 2005).

Primeiro, construíram-se gráficos das funções empíricas cumulativas dos métodos comparados.

A Figura 43 apresenta as respostas para o jerk mínimo em função dos tratamentos, com a transformação logarítmica natural.
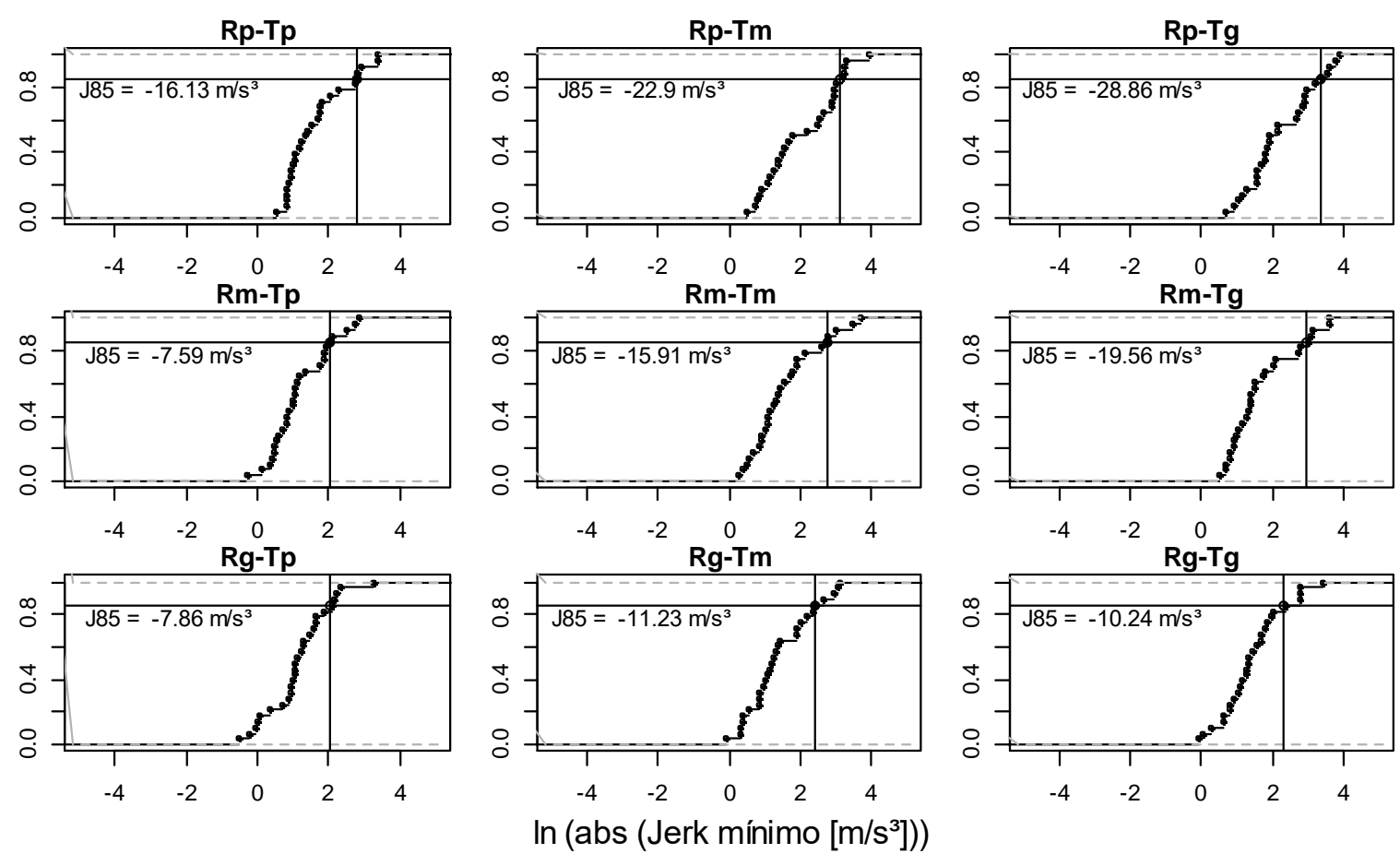

Figura 43 - Função de distribuição empírica cumulativa do jerk mínimo 85

Observa-se que, na maioria dos casos, conforme o comprimento das tangentes de aproximação (colunas da esquerda para a direita) aumentou, diminuiu o valor do jerk mínimo 85 encontrado. De maneiras contrária, conforme aumentou o comprimento dos raios (linhas de cima para baixo), aumentou o valor do jerk mínimo 85 encontrado. 
A Figura 44 apresenta a distribuição para a variável 85MSR.
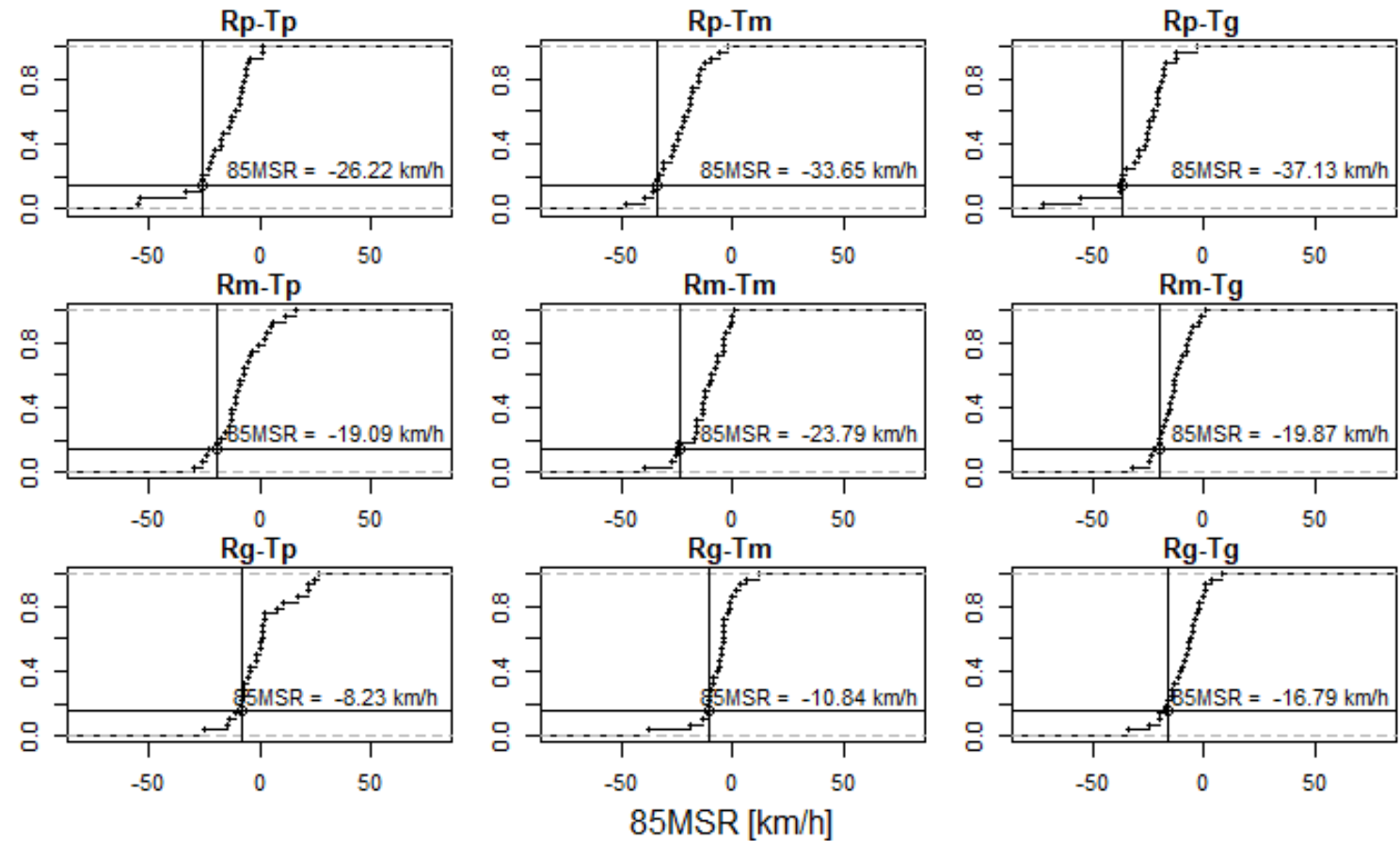

Figura 44 - Função de distribuição empírica cumulativa do 85MSR

Essas distribuições tiveram semelhanças com as anteriores. A Figura 45 traz a distribuição para a variável $85 \mathrm{MSR}_{60}$. O tratamento "Rm-Tm" teve resposta diferente, a posição 85 dessa distribuição teve valor maior que o esperado.
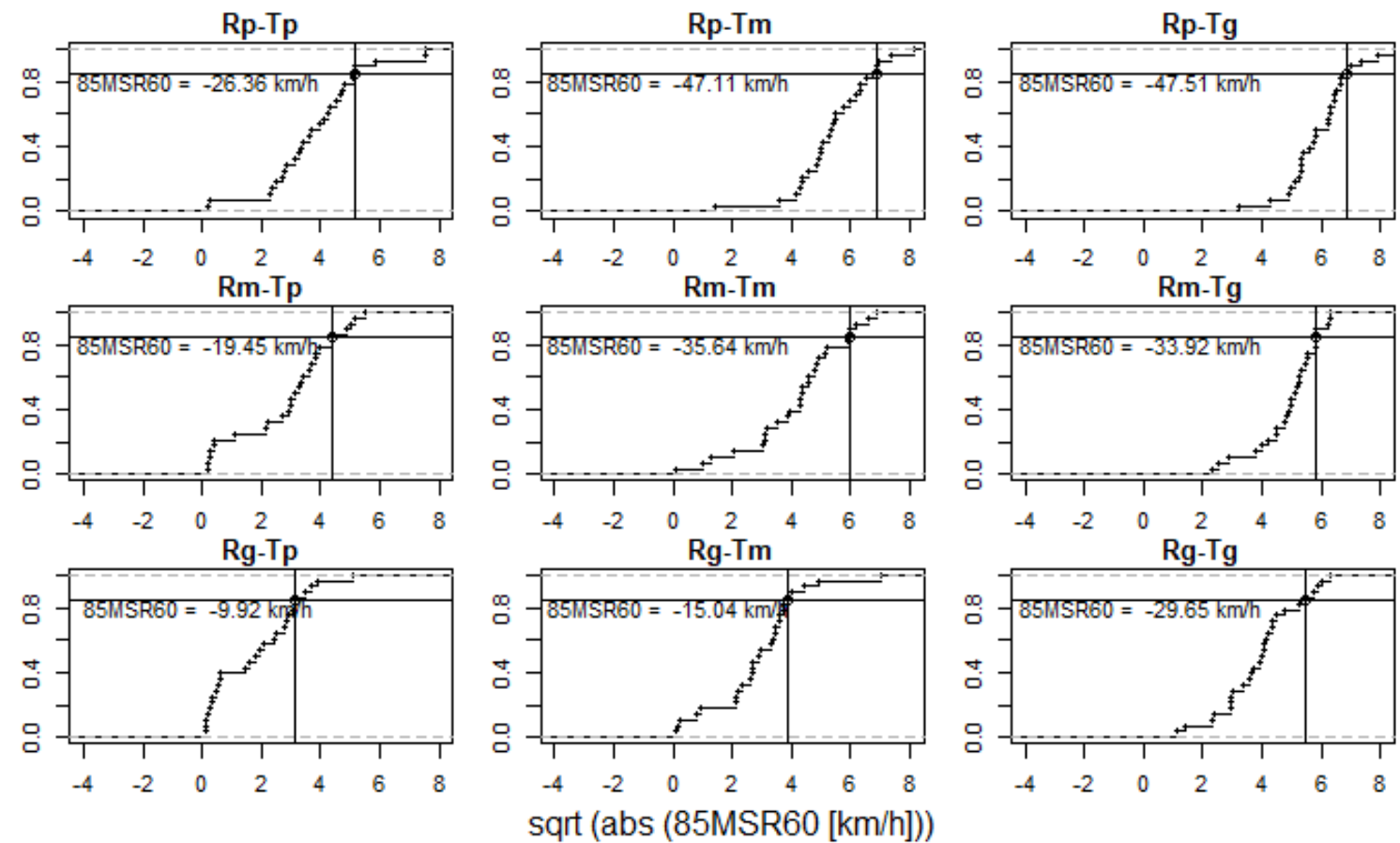

Figura 45 - Função de distribuição empírica cumulativa do $85 \mathrm{MSR}_{60}$ 
Como a abordagem $\Delta \mathrm{V}_{85}$ adotava a diferença entre o percentil 85 da velocidade no meio da curva (Figura 46) e o percentil 85 da velocidade no meio da tangente de aproximação (Figura 47), as duas distribuições serão apresentadas. Essas distribuições sofreram transformações a partir do logaritmo natural para se adequar à distribuição normal.
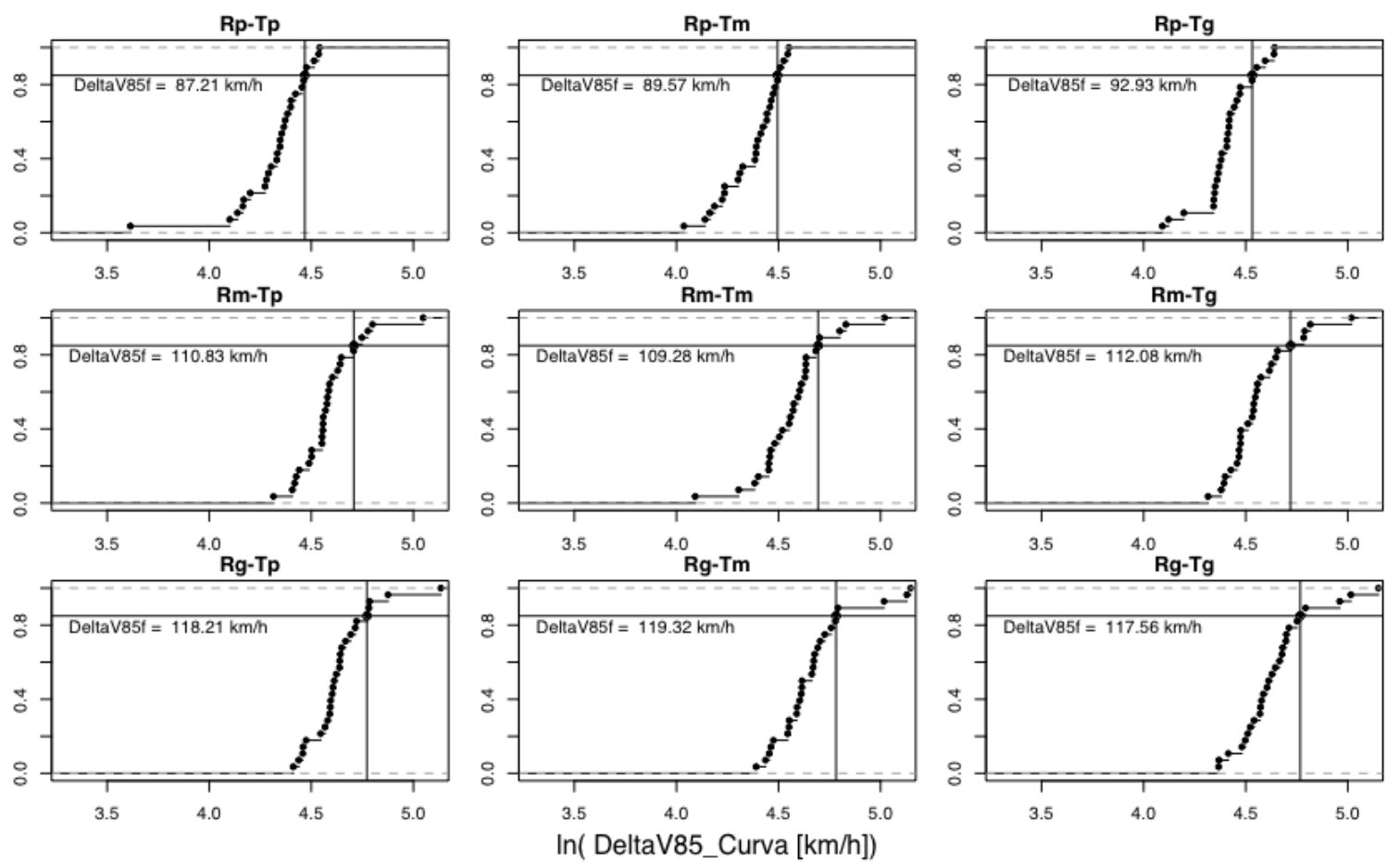

Figura 46 - Função de distribuição empírica cumulativa do $\Delta \mathrm{V}_{85}$ para o meio da curva
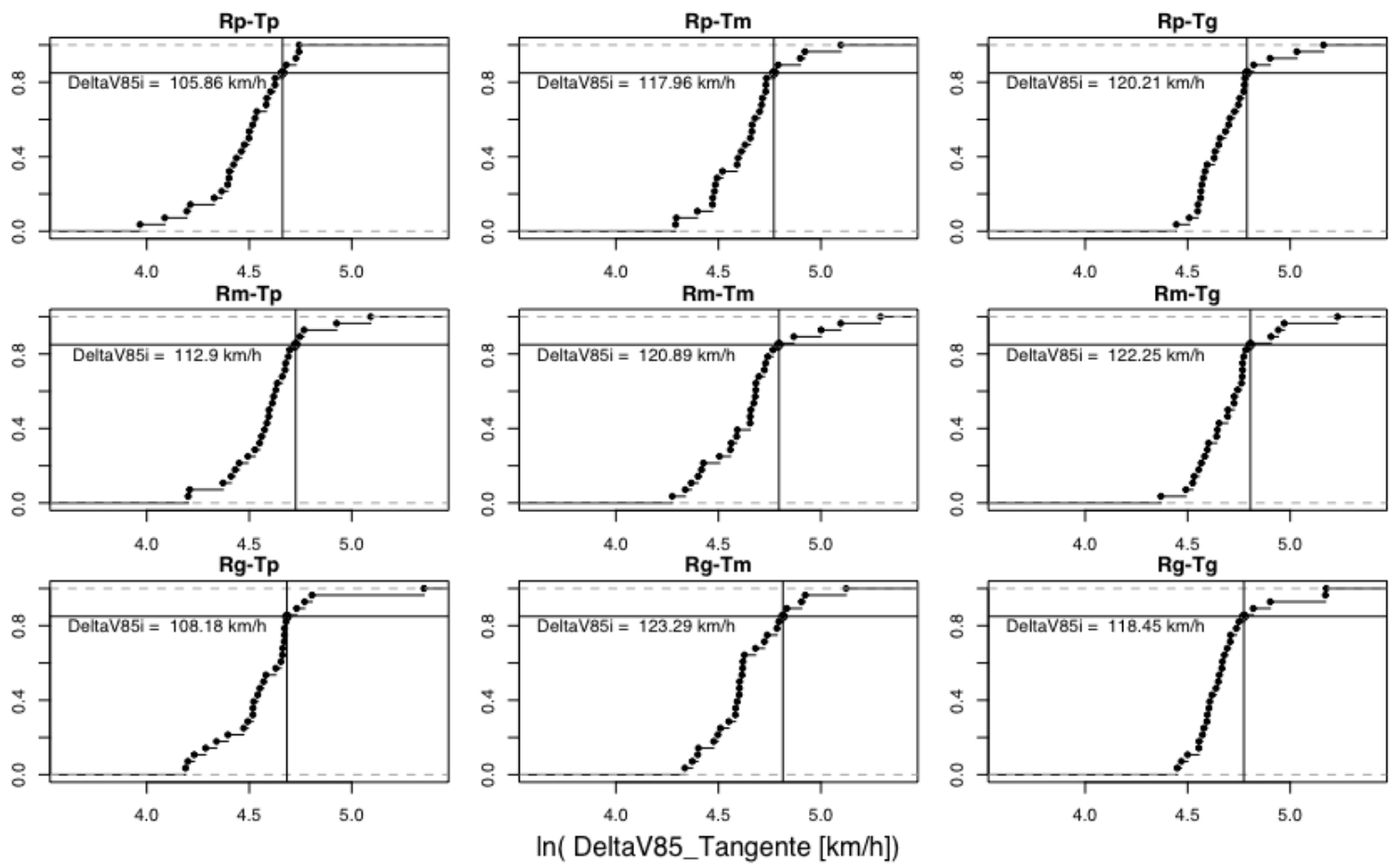

Figura 47 - Função de distribuição empírica cumulativa do $\Delta \mathrm{V}_{85}$ para o meio da tangente 
As posições 85 das respostas pareceram se situar próximo do valor de quebra da distribuição, onde existia a inflexão da curva. Alguns tratamentos tiveram regiões mal definidas, ou seja, houve falha na distribuição. Ainda assim, as distribuições tiveram, na maioria dos tratamentos, o valor da posição 85 diminuindo de acordo: com o crescimento do comprimento das tangentes de aproximação e com a redução do comprimento dos raios.

A Tabela 35 sintetiza os valores apresentados nas figuras anteriores e apresenta um valor de

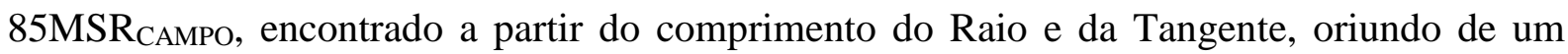
modelo calibrado em campo (MCFADDEN; ELEFTERIADOU, 2000).

Tabela 35 - Comparação dos valores encontrados

\begin{tabular}{ccccccccc}
\hline \multirow{2}{*}{ Tratamento } & Rai & Tan & Jm85 & 85MSR & 85MSR 60 & $\mathbf{8 5 M S R}$ CAMPo & $\Delta \mathbf{V}_{\mathbf{8 5}}$ \\
\cline { 2 - 9 }$[\mathrm{m}]$ & {$[\mathrm{m}]$} & {$\left[\mathrm{m} / \mathrm{s}^{3}\right]$} & {$[\mathrm{km} / \mathrm{h}]$} & {$[\mathrm{km} / \mathrm{h}]$} & {$[\mathrm{km} / \mathrm{h}]$} & {$[\mathrm{km} / \mathrm{h}]$} \\
\hline Rp-Tp & 125 & 50 & -16.13 & -26.22 & -26.36 & -8.02 & -18.65 \\
Rp-Tm & 125 & 310 & -22.90 & -33.65 & -47.11 & -12.44 & -28.39 \\
Rp-Tg & 125 & 570 & -28.86 & -37.13 & -47.51 & -16.86 & -27.28 \\
Rm-Tp & 370 & 50 & -7.59 & -19.09 & -19.45 & -2.74 & -2.07 \\
Rm-Tm & 370 & 310 & -15.91 & -23.79 & -35.64 & -7.16 & -11.61 \\
Rm-Tg & 370 & 570 & -19.56 & -19.87 & -33.92 & -11.58 & -10.17 \\
Rg-Tp & 615 & 50 & -7.86 & -8.23 & -9.92 & -1.66 & 10.03 \\
Rg-Tm & 615 & 310 & -11.23 & -10.84 & -15.04 & -6.08 & -3.96 \\
Rg-Tg & 615 & 570 & -10.24 & -16.79 & -29.65 & -10.50 & -0.90 \\
\hline
\end{tabular}

Dessa tabela é interessante salientar que os tratamentos que continham os menores raios (fora dos limites mínimos recomendados por norma) registraram diferenças de velocidades operacionais $\left(\Delta \mathrm{V}_{85}\right)$ maiores que os limites estipulados para se definir um projeto fraco. Observa-se ainda que os valores encontrados no simulador (85MSR) foram maiores que os calibrados em campo (85MSR $\mathrm{CAMPO}$ ), esse fato já era esperado em função das diferenças comportamentais dos ambientes e dos critérios adotados nas duas pesquisas, porém existiu um relacionamento significante entre esses valores. Vale ressaltar ainda que as menores tangentes (tratamentos 1, 4 e 7) deveriam ser consideradas não-independentes, assim dever-se-ia considerar as velocidades no meio dos setores circulares das curvas anteriores para avaliar as diferenças de velocidades daquele trecho. Porém, em função da aleatoriedade imposta na atribuição da ordem das curvas para cada condutor da amostra, essa identificação seria impossível, assim realizou-se a correlação dos métodos com esses tratamentos e sem. Como a inclusão trouxe coeficientes de correlação menores, a análise seguiu sem a exclusão desses. A Tabela 36 apresenta a correlação entre os valores encontrados. 
Tabela 36 - Correlações entre os métodos

\begin{tabular}{lllllllll}
\hline & \multicolumn{2}{c}{ 85MSR } & \multicolumn{2}{c}{ 85MSR60 } & \multicolumn{2}{c}{ 85MSRCAM } & \multicolumn{2}{c}{$\Delta$ V85 } \\
\hline & $r$ & $\mathrm{p}$ & $r$ & $\mathrm{p}$ & $r$ & $\mathrm{p}$ & $r$ & $\mathrm{p}$ \\
\hline Jm85 & 0.88 & 0.001 & 0.89 & 0.001 & 0.90 & 0.001 & 0.90 & 0.000 \\
85MSR & & & 0.91 & 0.001 & 0.78 & 0.014 & 0.95 & 0.000 \\
85MSR $_{60}$ & & & & & 0.89 & 0.001 & 0.87 & 0.002 \\
85MSR $_{\text {CAMPO }}$ & & & & & & & 0.79 & 0.011 \\
\hline
\end{tabular}

Houve forte correlação entre as variáveis estudadas, na maioria dos casos, mesmo que com abordagens diferentes. Apesar da diferença de magnitude dos resultados encontrados em simulador e em campo, partiu-se para a calibração de um valor limite para caracterizar um elemento, assim como propuseram Lamm e Smith (1994).

Em um dos critérios formulados pelos autores, uma diminuição maior que $20 \mathrm{~km} / \mathrm{h}$ na velocidade operacional, entre dois elementos sucessivos, caracterizaria uma concepção de projeto fraca. E a diminuição entre $10 \mathrm{~km} / \mathrm{h}$ e $20 \mathrm{~km} / \mathrm{h}$ na velocidade operacional, entre dois elementos sucessivos, caracterizaria uma concepção de projeto razoável. Para tanto, esses valores foram adotados na tentativa de encontrar valores para o método proposto por essa tese, jerk mínimo 85 .

A Figura 48 apresenta a dispersão dos valores encontrados na Tabela 35 para a abordagem $\Delta \mathrm{V}_{85}$ e Jm85 extraídas da simulação. O gráfico apresenta ainda os coeficientes da reta de ajuste desses pontos ("a" e "b"), os coeficientes de determinação e de correlação de Pearson, a estatística Student t e a significância.

Como a abordagem $\Delta \mathrm{V}_{85}$ pressupunha que tangentes menores que $200 \mathrm{~m}$ seriam dependentes e, em função da aleatorização dos tratamentos, as curvas anteriores a essas eram diferentes, optouse por avaliar a dispersão com esses pontos (marcados com cruzes vermelhas) e sem eles (Figura 49). 


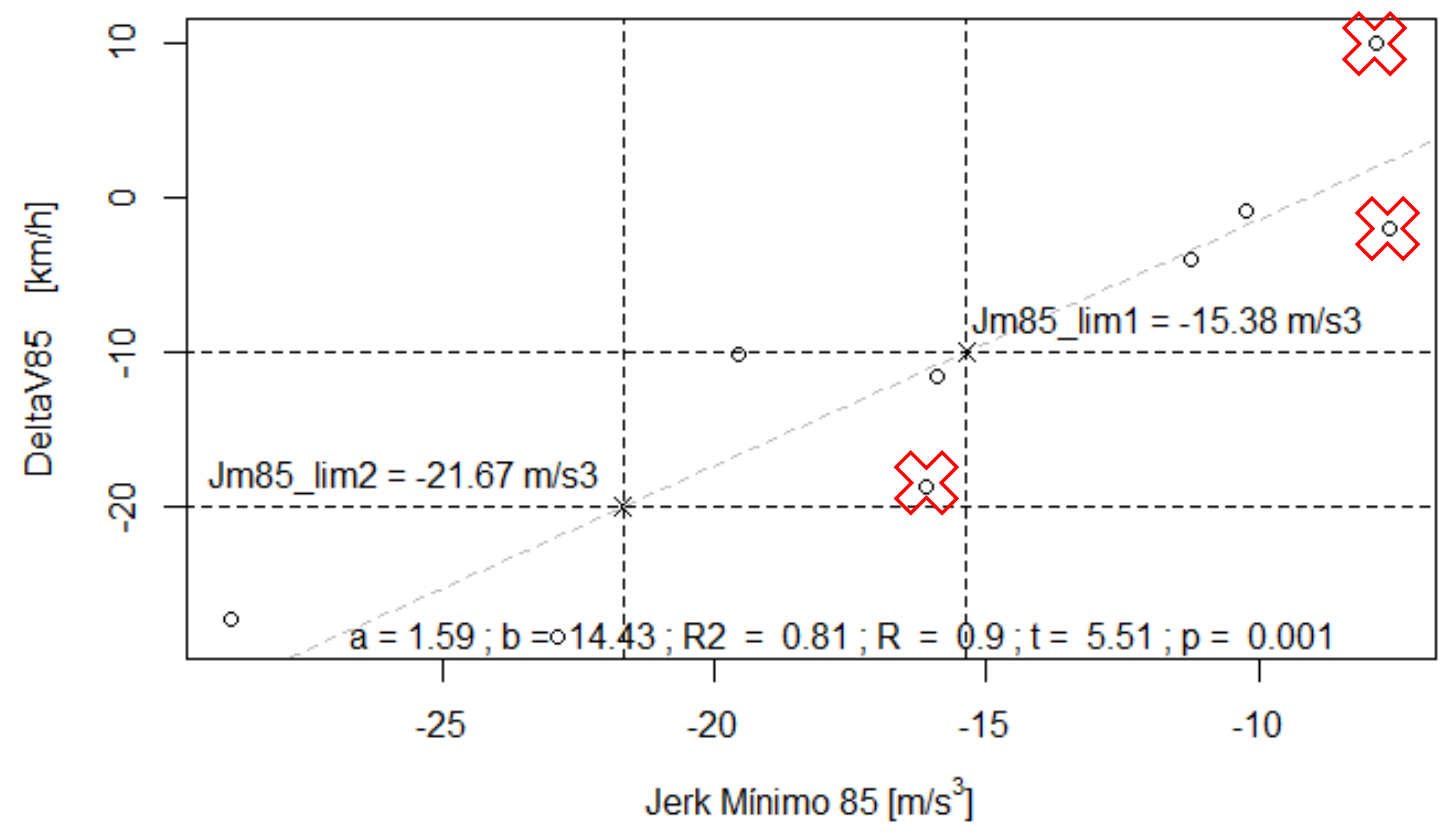

Figura 48 - Dispersão dos pontos entre as respostas da abordagem $\Delta \mathrm{V}_{85} \mathrm{e}$ da tese

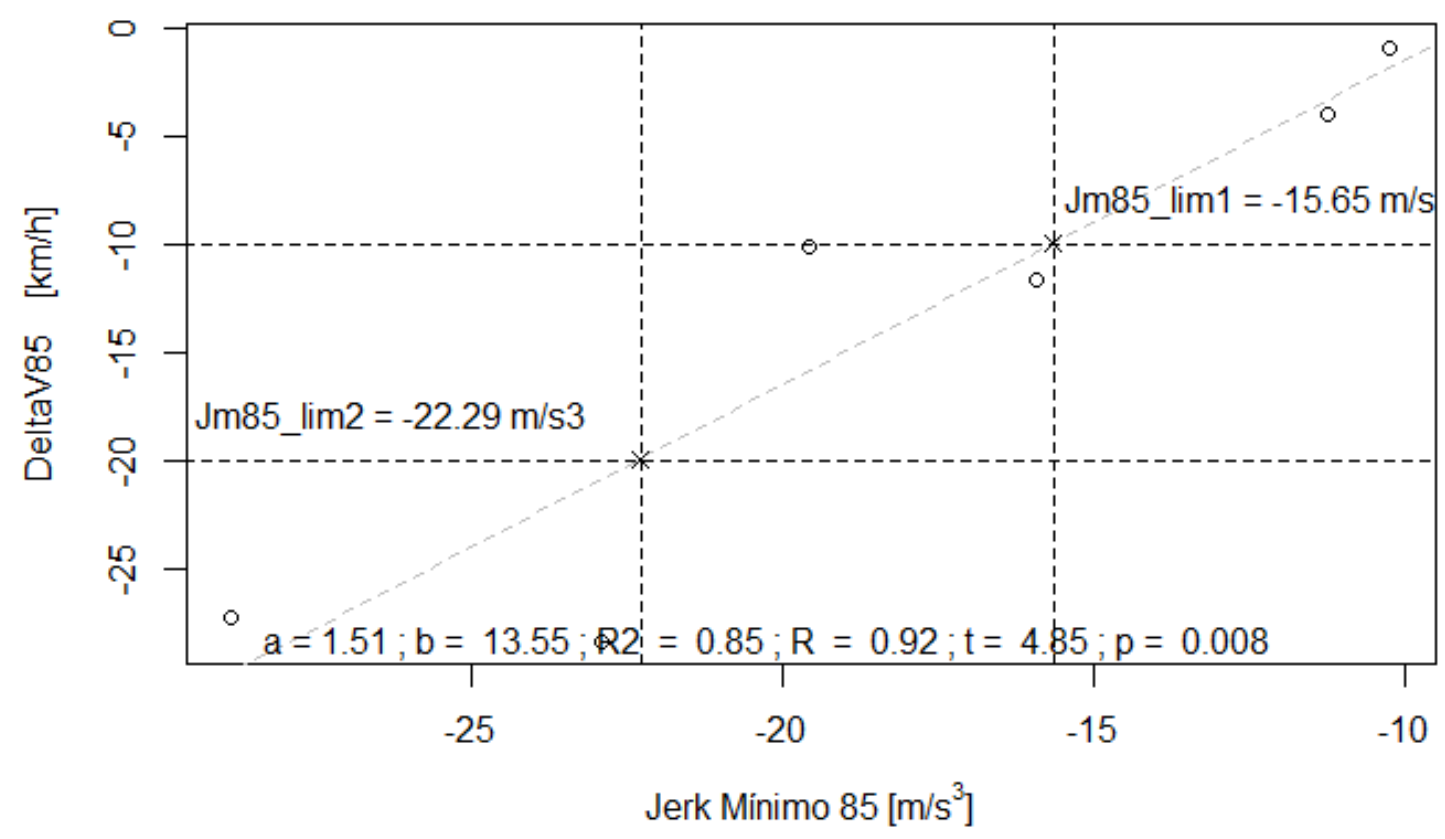

Figura 49 - Dispersão dos pontos entre as respostas da abordagem $\Delta \mathrm{V}_{85} \mathrm{e}$ da tese

Em função dos limites encontrados, optou-se por manter os valores encontrados na Figura 48. Esses seriam muito próximos dos estimados na Figura 47 e ainda estariam a favor da segurança. 


\subsubsection{Considerações}

A análise dos resultados mostrou que existiram correlações moderadas dos métodos tradicionais com o método proposto por essa tese quando as respostas foram comparadas caso a caso. Quando foram considerados os valores do percentil 85, a correlação foi mais forte. Os valores encontrados no experimento para um dos métodos (85MSR) foi superior ao calibrado em campo por outros autores.

$\mathrm{Na}$ tentativa de se encontrar um valor limite de jerk mínimo, como propuseram Lamm e Smith (1994), fez-se uma regressão com as respostas para ambos os métodos, advindos da simulação de direção. Os valores limites encontrados se situaram próximos ao intervalo de confiança sugerido por Nygård (1999), $-16.1 \mathrm{~m} / \mathrm{s}^{3}$ a $-8.7 \mathrm{~m} / \mathrm{s}^{3}$, para conflitos sérios de tráfego. No campo, esses valores poderiam ser menores, em função da obtenção através do simulador de direção.

Conclui-se que o método proposto tem similaridades relativas de respostas com os métodos tradicionais. 


\section{CONCLUSÕES}

Essa tese investigou o uso da variável jerk como indicador de consistência geométrica para rodovias. Com esse intuito, propôs-se o desenvolvimento de um experimento controlado, do tipo fatorial completo, em simulador de direção estático para investigar essa hipótese. Através desse, foi possibilitada a realização dos seguintes objetivos específicos:

- Avaliar a influência de características geométricas no jerk;

- Comparar as respostas do indicador proposto com métodos tradicionais.

Ao perfazer esses objetivos, os resultados encontrados fortaleceram a hipótese do uso dessa variável como indicador de consistência geométrica. As conclusões específicas, bem como as dificuldades e limitações, para cada um dos objetivos propostos foram:

\subsection{Conclusões específicas}

\subsubsection{Avaliar a influência de características geométricas no jerk}

- A geometria da via teve efeito significativo nos valores mínimos de jerk. Quanto menor os comprimentos dos raios e maiores os comprimentos das tangentes de aproximação, menores os valores de jerk encontrados;

- Não foi possível notar efeito da interação das duas variáveis, mas os efeitos principais delas foram estatisticamente significantes, principalmente com relação às diferenças das médias dos menores níveis (raios de 125 metros e tangentes de 50 metros) para os maiores (raios de 615 metros e tangentes de 570 metros);

- Porém, os valores do jerk só foram significativamente diferentes para os níveis mais baixos das variáveis, que estariam inadequados para o projeto de acordo com as normas vigentes, ou seja, o uso dessa variável poderia ser melhor utilizado para o levantamento de pontos de erros de projeto.

\subsubsection{Comparar as respostas do indicador proposto com métodos tradicionais}

- O indicador proposto teve correlação moderada com os tradicionais quando comparados todos os valores absolutos; 
- Quando comparados os valores do percentil 85, o método proposto e os tradicionais tiveram correlações muito fortes;

- Os valores de diferenças de velocidades encontrados pelos modelos calibrados em campo, por outros autores, foram, aproximadamente, 3 vezes menores que os valores encontrados no simulador;

- Quando se correlacionou os valores dos percentis 85 dessa tese com os estipulados pela abordagem $\Delta \mathrm{V}_{85}$, encontrou-se os valores de $-15,38 \mathrm{~m} / \mathrm{s}^{3}$ e $-21,67 \mathrm{~m} / \mathrm{s}^{3}$ como limites para a identificação de projetos razoáveis e ruins. Mesmo com as limitações da pesquisa, esses valores se situaram próximos ao intervalo de confiança sugerido por Nygård (1999), $-16.1 \mathrm{~m} / \mathrm{s}^{3}$ a $-8.7 \mathrm{~m} / \mathrm{s}^{3}$, para conflitos sérios de tráfego.

\subsection{Dificuldades}

- A tarefa de encontrar o valor mínimo do jerk para cada tratamento de cada condutor não foi trivial. O efeito da mudança de marchas durante a condução dificultou o trabalho de identificar o jerk mínimo em cada trecho. Dentre as possibilidades testadas, utilizou-se a transformada contínua de Wavelet para a filtragem dos dados;

- O grande banco de dados gerado pelo experimento impossibilitou o uso de planilhas eletrônicas típicas para a identificação das variáveis, foi necessário o aprendizado de linguagem de programação específica e o desenvolvimento de um algoritmo durante a realização da análise dos registros;

- A necessidade da aleatorização da aplicação dos tratamentos à amostra, que é uma das bases do experimento controlado, dificultaram as possibilidades de comparação dos resultados dessa pesquisa com os métodos tradicionais;

- Trabalhar entre duas áreas do conhecimento como a Estatística e a Engenharia não foi simples. Enquanto a primeira, principalmente com relação ao planejamento de experimentos, sinaliza para a redução de possibilidades de variáveis independentes (tanto em fatores como em níveis) a segunda deseja sempre a inserção de mais e mais incógnitas;

- A falta de contato do pesquisador com experimentos controlados e, principalmente com os trâmites com a Plataforma Brasil, fizeram com que experimentos preliminares, de grande consumo de tempo, precisassem ser descartados por falta de rigor com a aleatoriedade e com os registros oficiais. 


\subsection{Limitações}

- O simulador de direção utilizado nesse experimento era de base fixa. Essa seria a maior limitação desse trabalho, poderia comprometer a confiança nos resultados desse. Porém, além de existirem na revisão trabalhos com a análise da variável jerk com a mesma base para outros fins, a comparação dos resultados finais com o trabalho de Nygard (1999) fomentaria certa segurança para as conclusões encontradas;

- O modelo do veículo simulado, calibrado por profissionais especializados, poderia ter influência na capacidade dos condutores de negociarem com as curvas, como foi aventado com a percepção das altas velocidades adotadas por alguns condutores em tratamentos cujos comprimentos de raios e inclinações das pistas dificultariam o emprego dessas;

- O ambiente simulado seria mais seguro que a condução em ambiente natural de tráfego. Isso possibilitaria o emprego de um comportamento menos seguro. Para tanto, realizouse um experimento fatorial completo com análise de variância de medidas repetidas. Mesmo assim, pode ter havido influência da percepção maior de segurança nas conduções;

- A amostra era oriunda de pessoas pertencentes às dependências do departamento. A proximidade com a amostra poderia influenciar as respostas. Essa técnica de amostragem por conveniência era amplamente utilizada nos trabalhos revisados. Mesmo assim ela poderia influenciar os resultados;

- Utilizaram-se algumas restrições na simulação, principalmente restrição de tráfego e sinalização de mudanças de alinhamento. Mesmo seguindo os padrões estabelecidos em norma, as sinalizações poderiam ter influência nos resultados. Como a inserção fora sugerida no processo de qualificação, as mesmas foram incluídas. O tráfego, no ensaio piloto, pareceria influir no comportamento dos condutores, os quais passariam a se comportar como em car-following e não em free-flow;

- Os resultados precisariam ser avaliados também em campo. A comparação dos resultados em campo fortaleceria a hipótese levantada. Essa sugestão será melhor explicada no capítulo seguinte. 



\section{RECOMENDAÇÕES}

Essa tese fortaleceu os indícios de se utilizar a variável jerk como indicador de consistência geométrica para rodovias. Porém, esse trabalho se baseou nos resultados de um experimento controlado desenvolvido em simulador de direção. Assim, faz-se necessária a validação dessa conclusão em estudos de campo.

Porém, a identificação do valor de jerk mínimo em campo ainda não é trivial. Ela é altamente influenciada por variáveis estranhas (como condições de tráfego). Para sua identificação, se faz necessário um estudo correlacional de maiores proporções, de preferência longitudinal, para melhor avaliar flutuações não explicadas.

Para tanto, é necessário o desenvolvimento de um sistema de coleta de dados, ao mesmo tempo confiável e de distribuição em massa, como um aplicativo para smartphones.

Sugere-se então, como agenda para futuras pesquisas, o desenvolvimento de um aplicativo para a coleta de dados com enfoque na variável jerk (obtida a partir de acelerômetros e georreferenciada a partir dos sistemas GNSS embarcados); a calibração e validação desse aplicativo; e o desenvolvimento de uma pesquisa correlacional baseada em coletas longitudinais. 



\section{REFERÊNCIAS}

AGERHOLM, N.; LAHRMANN, H. S. Identification of Hazardous Road Locations on the basis of Floating Car Data: Method and first results. In Road safety in a globalised and more sustainable world - current issues and future challenges International Co-operation on Theories and Concepts in Traffic Safety (ICTCT), n. $1,2012$.

ALLEN, R. W.; ROSENTHAL, T. J.; COOK, M. L. A Short History of Driving Simulator. In: Handbook of driving simulation for engineering, medicine, and psychology. [s.1.] CRC Press, 2011. p. 2.1-2.16.

ANDERSEN, G. J. Sensory and Perceptual Factors in the Design of Driving Simulation Displays. In: Handbook of driving simulation for engineering, medicine, and psychology. [s.1.] CRC Press, 2011. p. 8.1-8.11.

ANDERSON, I. B.; BAUER, K. M.; HARWOOD, D. W.; FITZPATRICK, K. Relationship To Safety of Geometric Design Consistency Measures for Rural Two-Lane Highways. Transportation Research Record, n. 1658, p. 43-51, 1999.

ANGELL, L. S. Surrogate Methods and Measures. In: Handbook of driving simulation for engineering, medicine, and psychology. [s.1.] CRC Press, 2011. p. 10.1-10.13.

ANTT. Relatórios Anuais - Rodovias Federais Concedidas, 2017. . Disponível em:

<http://antt.gov.br/rodovias/Relatorios/Relatorios_Anuais_Rodovias_Federais_Concedidas.html>. Acesso em: 18 out. 2017.

ARIËN, C.; JONGEN, E. M. M.; BRIJS, K.; BRIJS, T.; DANIELS, S.; WETS, G. A simulator study on the impact of traffic calming measures in urban areas on driving behavior and workload. Accident Analysis and Prevention, v. 61, p. 43-53, 2013.

BAGDADI, O.; VÁRHELYI, A. Jerky driving - An indicator of accident proneness? Accident Analysis and Prevention, v. 43, n. 4, p. 1359-1363, 2011.

BAGDADI, O.; VÁRHELYI, A. Development of a method for detecting jerks in safety critical events. Accident Analysis and Prevention, v. 50, p. 83-91, 2013.

BELLA, F. Parameters for Evaluation of Speed Differential: Contribution Using Driving Simulator.

Transportation Research Record, v. 2023, n. 1, p. 37-43, 2008.

BEN-BASSAT, T.; SHINAR, D. Effect of shoulder width, guardrail and roadway geometry on driver perception and behavior. Accident Analysis \& Prevention, v. 43, n. 6, p. 2142-2152, 2011.

BENEDETTO, A.; DE ANGELINI, A.; DI RENZO, D.; GUERRIERI, F.; MARKHAM, S. About the standards of a driving simulation for road engineering: a new approach. In: Applications of Advanced Technologies in Transportation (2002). [s.1: s.n.]p. 704-711.

CAIRD, J. K.; HORREY, W. J. Twelve Practical and Useful Questions About Driving Simulation. In:

Handbook of driving simulation for engineering, medicine, and psychology. [s.1.] CRC Press, 2011. p. 5.15.18.

CALVI, A. A study on driving performance along horizontal curves of rural roads. Journal of Transportation Safety \& Security, v. 7, n. 3, p. 243-267, 2015.

CAPELAS, B. Até o fim de 2017, Brasil terá um smartphone por habitante. Fgv, p. 2017-2019, 2017.

CHARLTON, S. G. The role of attention in horizontal curves: A comparison of advance warning, delineation, and road marking treatments. Accident Analysis and Prevention, v. 39, n. 5, p. 873-885, 2007. 
CHOUEIRI, E. M.; LAMM, R.; KLOECKNER, J. H.; MAILAENDER, T. Safety Aspects of Individual Design Elements and Their Interactions on Two-Lane Highways: International Perspective. Transportation Research Record, n. 1445, p. 34-46, 1994.

CNT. Anuário CNT do Transporte, 2017. .

COMTE, S. L.; JAMSON, A. H. Traditional and innovative speed-reducing measures for curves: An investigation of driver behaviour using a driving simulator. Safety Science, v. 36, n. 3, p. 137-150, 2000. DANIELS, S.; VANRIE, J.; DREESEN, A.; BRIJS, T. Additional road markings as an indication of speed limits: Results of a field experiment and a driving simulator study. Accident Analysis and Prevention, v. 42, n. 3, p. 953-960, 2010.

DATASUS. Informações de Saúde (TABNET), 2018. .

DAWSON, J. D. Statistical Concepts. In: Handbook of driving simulation for engineering, medicine, and psychology. [s.1.] CRC Press, 2011. p. 22.1-22.11.

DER-SP. Projeto geométricoDepartamento de Estradas de Rodagem, , 2005. .

DNIT. Manual de sinalização rodoviária, 2010. .

DOS SANTOS, M. I.; DE OLIVEIRA, P. T. M. S.; RIBEIRO, R. L.; LAROCCA, A. P. C.; JUNIOR, F. I. K. Conceito, configuração e aplicação de um simulador de direção no Brasil-Estudo de caso. Transportes, v. 25, n. 2, p. 1-14, 2017.

DPRF. Dados Abertos, 2018. .

EAGER, D.; PENDRILL, A. M.; REISTAD, N. Beyond velocity and acceleration: Jerk, snap and higher derivatives. European Journal of Physics, v. 37, n. 6, p. 1-11, 2016.

FAUL, F.; ERDFELDER, E.; LANG, A.-G.; BUCHNER, A. G* Power 3: A flexible statistical power analysis program for the social, behavioral, and biomedical sciences. Behavior research methods, v. 39, n. 2, p. 175191, 2007.

FHWA. FHWA Roadway Departure (RwD) Strategic Plan, 2013. .

FIELD, A. Descobrindo a estatística usando o SPSS-2. [s.1.] Bookman Editora, 2009.

FIGUEROA MEDINA, A. M.; TARKO, A. P. Speed Changes in the Vicinity of Horizontal Curves on TwoLane Rural Roads. Journal of Transportation Engineering, v. 133, n. 4, p. 215-222, 2007.

FISHER, D. L.; CAIRD, J. K.; RIZZO, M.; LEE, J. D. Handbook of driving simulation for engineering, medicine, and psychology: An Overview. In: Handbook of driving simulation for engineering, medicine, and psychology. [s.1.] CRC Press, 2011. p. 1.1-1.16.

FISHER, D. L.; POLLATSEK, A.; HORREY, W. J. Eye behaviors: how driving simulators can expand their role in science and engineering. In: [s.l: s.n.]

FISHER, D.; PRADHAN, A.; POLLATSEK, A.; KNODLER, M. Empirical Evaluation of Hazard Anticipation Behaviors in the Field and on Driving Simulator Using Eye Tracker. Transportation Research Record:

Journal of the Transportation Research Board, v. 2018, p. 80-86, 2007.

FITZPATRICK, K.; COLLINS, J. M. Speed-Profile Model for Two-Lane Rural Highways. Transport Research Record, v. 1737, n. 00, p. 42-49, 2000.

FREEMAN, P.; NEYENS, D. M.; WAGNER, J.; SWITZER, F.; ALEXANDER, K.; PIDGEON, P. A video based run-off-road training program with practice and evaluation in a simulator. Accident Analysis and Prevention, v. 82, p. 1-9, 2015. 
FUNARO, V. M. B. de O.; PESTANA, M. C.; DZIABAS, M. C. C.; GARCIA, E. M.; DOS SANTOS, M. F.; NASCIMENTO, M. M.; CARDOSO, S. C. Diretrizes para apresentação de dissertações e teses da USP: Parte I (ABNT), 2016. .

GARCÍA, D. S. P. Método para Análise da Consistência Geométrica de Rodovias Brasileiras de Pista Simples. 2008. Universidade Federal do Rio Grande do Sul, 2008.

GLENNON, J. C.; NEUMAN, T. R.; LEISCH, J. E. Safety and Operational Considerations for Design of Rural Highway Curves, 1983. .

GOOGLE. Google Earth Pro, 2017. .

GREENBERG, J.; BLOMMER, M. Physical Fidelity of Driving Simulators. In: Handbook of driving simulation for engineering, medicine, and psychology. [s.1.] CRC Press, 2011. p. 7.1-7.24.

HANCOCK, P. A.; SHERIDAN, T. B. The Future of Driving Simulation. In: Handbook of driving simulation for engineering, medicine, and psychology. [s.1.] CRC Press, 2011. p. 4.1-4.11.

HAYNES, R.; LAKE, I. R.; KINGHAM, S.; SABEL, C. E.; PEARCE, J.; BARNETT, R. The influence of road curvature on fatal crashes in New Zealand. Accident Analysis \& Prevention, v. 40, n. 3, p. 843-850, 2008. HIRSH, M. Probabilistic Approach To Consistency in Geometric Design. Journal of Transportation Engineeri, v. 3, n. 113, p. 268-276, 1987.

HONORATO, C. M. Trânsito Seguro : Direito Fundamental de Segunda Dimensão. Revista dos Tribunais, v. 911, n. 1926, p. 107-169, 2011.

JAMSON, H. Cross-Platform Validation Issues. In: Handbook of driving simulation for engineering, medicine, and psychology. [s.1.] CRC Press, 2011. p. 12.1-12.13.

KANTOWITZ, B. H. Using Driving Simulators Outside of North America. In: Handbook of driving simulation for engineering, medicine, and psychology. [s.1.] CRC Press, 2011. p. 3.1-3.14.

KEARNEY, J. K.; GRECHKIN, T. F. Scenario Authoring. In: Handbook of driving simulation for engineering, medicine, and psychology. [s.1.] CRC Press, 2011. p. 6.1-6.12.

KONSTANTOPOULOS, P.; CHAPMAN, P.; CRUNDALL, D. Driver's visual attention as a function of driving experience and visibility. Using a driving simulator to explore drivers' eye movements in day, night and rain driving. Accident Analysis and Prevention, v. 42, n. 3, p. 827-834, 2010.

KULMALA, R.; LUOMA, J.; NYGÅRD, M. Impact of RDS-TMC receiver use on speed and other driver behaviour. Proceedings of the 12th ICTCT Workshop on Speed Control- Principles, Methods, Measures, v. Bulletin N, p. 42-57, 2000.

LAMM, R.; CHOUEIRI, E. M. Recommendations for Evaluating Horizontal Design Consistency Based on Investigations in the State of New York. Transport Research Record, n. 1122, p. 68-78, 1987.

LAMM, R.; CHOUEIRI, E. M.; HAYWARD, J. C. Tangent as an independent design element. Transportation Research Record, n. 1195, p. 123-131, 1988.

LAMM, R.; CHOUEIRI, E. M.; HAYWARD, J. C.; PALURI, A. Possible Design Procedure To Promote Design Consistency in Highway Geometric Design on Two-Lane Rural Roads. Transportation Research Record, n. 1195, p. 111-122, 1988.

LAMM, R.; CHOUEIRI, E. M.; MAILAENDER, T. Side Friction Demand Versus Side Friction Assumed for Curve Design on Two-Lane Rural Highways. Transportation Research Record, n. 1303, p. 11-21, 1991. LAMM, R.; CHOUEIRI, E. M.; MAILAENDER, T.; SANDNER, T. U. V. Comparison of operating speed on 
dry and wet pavement of two lane rural highways. Transportation Research Record, v. 1280, p. 68-78, 1990.

LAMM, R.; GUENTHER, A. K.; CHOUEIRI, E. M. Safety module for highway geometric design.

Transportation Research Record, n. 1512, p. 7-15, 1995.

LAMM, R.; HAYWARD, J. C.; CARGIN, J. G. Comparison of Different Procedures for Evaluating Speed Consistency. Transportation Research Record, n. 1100, p. 10-20, 1986.

LAMM, R.; PSARIANOS, B.; SOILEMEZOGLOU, G.; KANELLAIDIS, G. Driving dynamic aspects and related safety issues for modern geometric design of non-built-up roads. Transportation Research Record, $\mathrm{n}$. 1523, p. 34-45, 1996.

LAMM, R.; SMITH, R. L. Curvilinear alinement: An important issue for more consistent and safer road characteristic. Transportation Research Record: Transportation Research Board, Washington, DC, n. 1445, p. 12-21, 1994.

LAMM, R.; STEFFEN, H.; GUENTHER, A. K. Procedure for Detecting Errors in Alinement Design and Consequences for Safer Redesign. Transportation Research Record, n. 1445, p. 64-72, 1994.

LEISCH, J. E.; LEISCH, J. P. New concepts in design-speed application. Transportation Research Record, n. 631, p. 4-14, 1977.

LIU, C.; YE, T. J. Run-Off-Road Crashes: An On-Scene Perspective. n. July, 2011.

LLOPIS-CASTELLÓ, D.; BELLA, F.; CAMACHO-TORREGROSA, F. J.; GARCÍA, A. New Consistency

Model Based on Inertial Operating Speed Profiles for Road Safety Evaluation. Journal of Transportation Engineering, Part A: Systems, v. 144, n. 4, p. 04018006, 2018.

MCFADDEN, J.; ELEFTERIADOU, L. Evaluating horizontal alignment design consistency of two-lane rural highways: Development of new procedure. Transportation Research Record: Journal of the Transportation Research Board, n. 1737, p. 9-17, 2000.

MICHAELIS. Michaelis Dicionários Brasileiro da Lingua Portuguesa 2017. [s.1: s.n.]

MILLOY, S. L.; CAIRD, J. K. External Driver Distractions: The Effects of Video Billborads and Wind Farms on Driving Performance. In: Handbook of driving simulation for engineering, medicine, and psychology.

[s.1.] CRC Press, 2011. p. 16.1-16.14.

MISAGHI, P.; HASSAN, Y. Modeling Operating Speed and Speed Differential on Two-Lane Rural Roads.

Journal of Transportation Engineering, v. 131, n. 6, p. 408-418, 2005.

MONTGOMERY, D. C. Design and analysis of experiments, New York: J Wiley \& SonsInc, , 2013. .

MULLEN, N.; CHARLTON, J.; DEVLIN, A.; BÉDARD, M. Simulator Validity: Behaviors Observed on the

Simulator and on the Road. In: Handbook of driving simulation for engineering, medicine, and psychology.

[s.l.] CRC Press, 2011.p. 13.1-13.18.

NAVIDI, N.; LANDRY, R. J. Location Detection of Vehicular Accident Using Global Navigation Satellite Systems / Inertial Measurement Units Navigator. World Academy of Science, Engineering and Technology International Journal of Electrical and Information Engineering, v. 11, n. 8, p. 894-901, 2017.

NHTSA. Traffic Safety Facts 2015: State Traffic Data, 2017. .

NHTSA. Fatality Analysis Reporting System Encyclopedia, 2018. .

NYGÅRD, M. A method for analysing traffic safety with help of speed profiles. 1999. Tampere University of Technology, 1999.

OTHMAN, M. R.; ZHANG, Z.; IMAMURA, T.; MIYAKE, T. A study of analysis method for driver features 
extraction. IEEE International Conference on Systems, Man and Cybernetics, p. 1501-1505, 2008. PÉREZ-ZURIAGA, A. M.; CAMACHO-TORREGROSA, F. J.; GARCÍA, A. Tangent-to-Curve Transition on Two-Lane Rural Roads Based on Continuous Speed Profiles. Journal of Transportation Engineering, v. 139, n. 11, p. 1048-1057, 2013.

POPPER, K. R. Conjecturas e refutações. Brasília: Editora Universidade de Brasília, p. 1-27, 1980. RANNEY, T. A. Psychological Fidelity: Perception of Risk. In: Handbook of driving simulation for engineering, medicine, and psychology. [s.1.] CRC Press, 2011. p. 9.1-9.13.

ROBILLARD, G.; BOUCHARD, S.; RENAUD, P. Validation canadienne-française de deux mesures importantes en réalité virtuelle: L’Immersive Tendencies Questionnaire et le Presence Questionnaire. 2002. ROESCH, A.; SCHMIDBAUER, H. WaveletComp: Computational wavelet analysis. R package version, v. 1, 2014.

SABA, M. F. A.; SINHA, B. K. SuDoKu as an Experimental Design - Beyond the Traditional Latin Square Design. Statistics and Applications, v. 12, n. 1 e 2, p. 15-20, 2014.

SARKAR, J.; SINHA, B. K. Sudoku squares as experimental designs. Resonance, v. 20, n. 9, p. 788-802, 2015. SEGURADORA LÍDER. Boletim Estatístico, 2018. .

SHINAR, D. Traffic Safety and Human Behavior. [s.1.] Emerald Publishing Limited, 2017. v. 2

SHINAR, D.; ROCKWELL, T. H.; MALECKI, J. A. The effects of changes in driver perception on rural curve negotiation. Ergonomics, v. 23, n. 3, p. 263-275, 1980.

SIEGLER, I.; REYMOND, G.; KEMENY, A.; BERTHOZ, A. Sensorimotor integration in a driving simulator: contributions of motion cueing in elementary driving tasks. Proceedings of the Driving Simulation Conference, n. September, p. 21-32, 2001.

SILVA, J. G. C. D. A. Estatística experimental: Planejamento de experimentos. 2007.

TEAM, R. C. R: A language and environment for statistical computing. 2013.

TINGVALL, C.; HAWORTH, N. Vision Zero: an ethical approach to safety and mobility - Monash University Accident Research Centre . Conference Road Safety \& Traffic Enforcement: Beyond 2000, n. December, 1999.

TORBIC, D. J.; HARWOOD, D. W.; GILMORE, D. K.; PFEFER, R.; NEUMAN, T. R.; SLACK, K. L.;

HARDY, K. K. Guidance for implementation of the AASHTO strategic highway safety plan. Volume 7: A guide for reducing collisions on horizontal curves, 2004. .

TRENTIN, L. C. Análise Crítica De Modelos De Verificação De Consistência De Traçado. p. 165, 2007. VERÍSSIMO, É. Olhai os lírios do campo (Editora Companhia das Letras, Ed.), 2005. .

VIEIRA, F. S. Evaluation of drivers behavior performing a curve under mental workloadUniversidade de São Paulo, , 2016. .

VIEIRA, F. S.; LAROCCA, A. P. C. Drivers' speed profile at curves under distraction task. Transportation research part F: traffic psychology and behaviour, v. 44, p. 12-19, 2017.

WHO. Global health stimates 2014 summary tables: deaths by cause, age and sex, 2000-2012., 2014. . WHO. Health in 2015: From MDGs, millennium development goals to SDGs, sustainable development goals., 2015. .

WITMER, B. G.; SINGER, M. J. Measuring presence in virtual environments: A presence questionnaire. Presence, v. 7, n. 3, p. 225-240, 1998. 
ZAKI, M.; SAYED, T.; SHAABAN, K. Use of Drivers' Jerk Profiles in Computer Vision-Based Traffic Safety Evaluations. Transportation Research Record: Journal of the Transportation Research Board, v. 2434, n. January, p. 103-112, 2014.

ZURIAGA, A.; GARCÍA, A.; TORREGROSA, F.; D’ATTOMA, P. Modeling Operating Speed and Deceleration on Two-Lane Rural Roads with Global Positioning System Data. Transportation Research

Record: Journal of the Transportation Research Board, v. 2171, p. 11-20, 2010. 
APÊNDICE

Os perfis de velocidade, de aceleração, de jerk e de velocidade do motor (RPM), bem como os valores das velocidades no meio das tangentes de aproximação, no meio das curvas horizontais, máximas nas tangentes de aproximação e mínimas nas curvas horizontais estão apresentadas na sequência, de acordo com o tratamento experimentado (Tabela 10)e do condutor da amostra: 

Condutor 1 , Tratamento 1 , SegundoTrecho

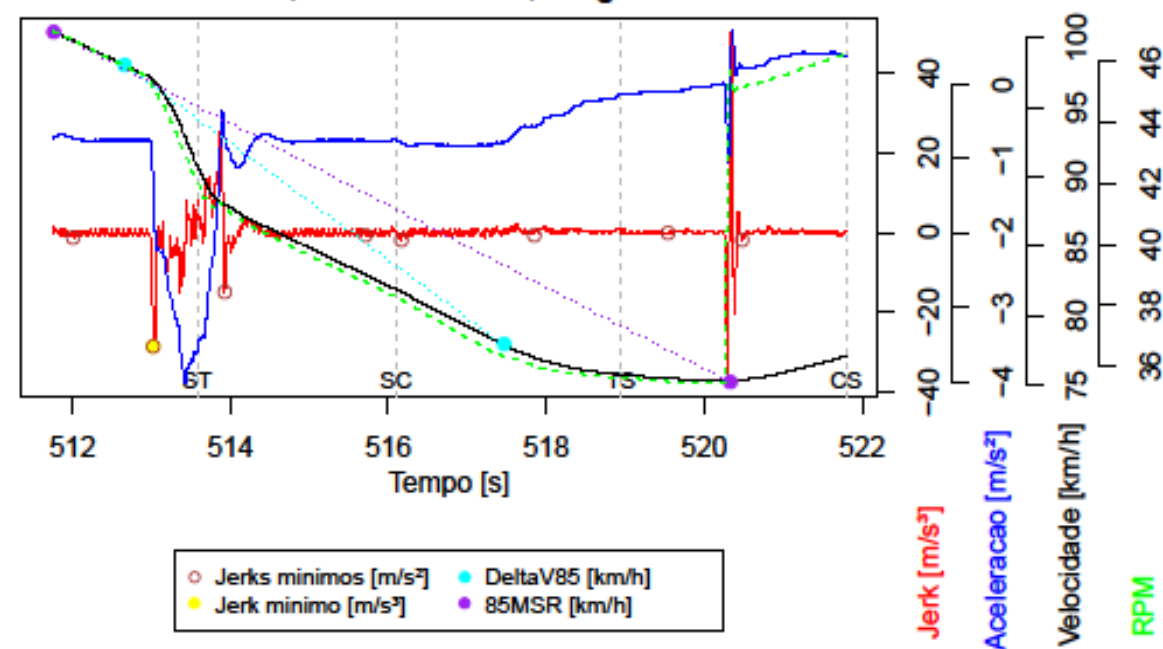

Condutor 1 , Tratamento 3 , SegundoTrecho

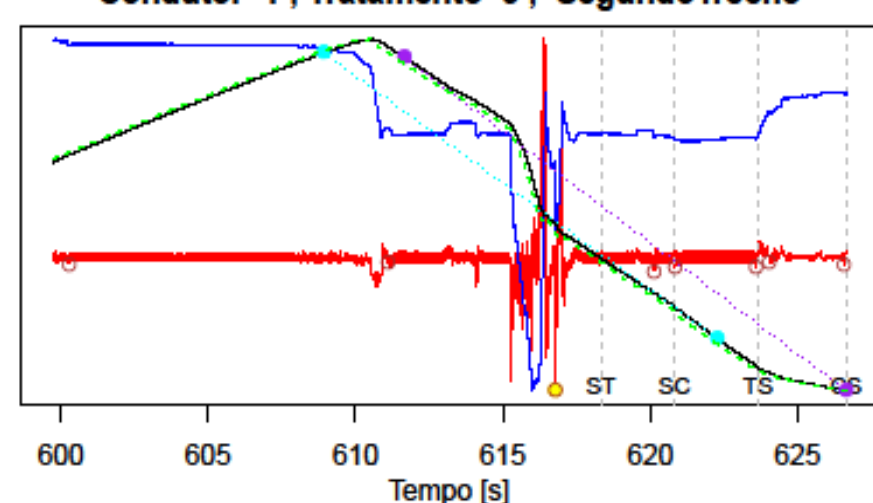

Jerks minimos $[\mathrm{m} / \mathrm{s}]]$ DeltaV85 $[\mathrm{km} / \mathrm{h}]$ Jerk minimo $[\mathrm{m} / \mathrm{s} / \mathrm{s}]$ - $85 \mathrm{MSR}[\mathrm{km} / \mathrm{h}]$

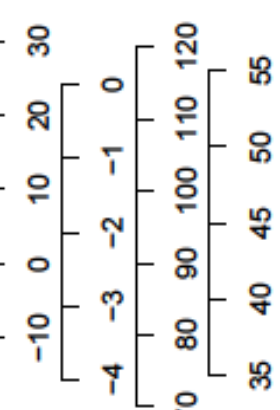

웅

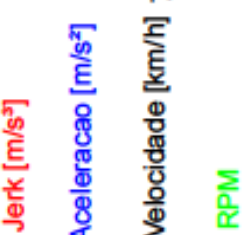

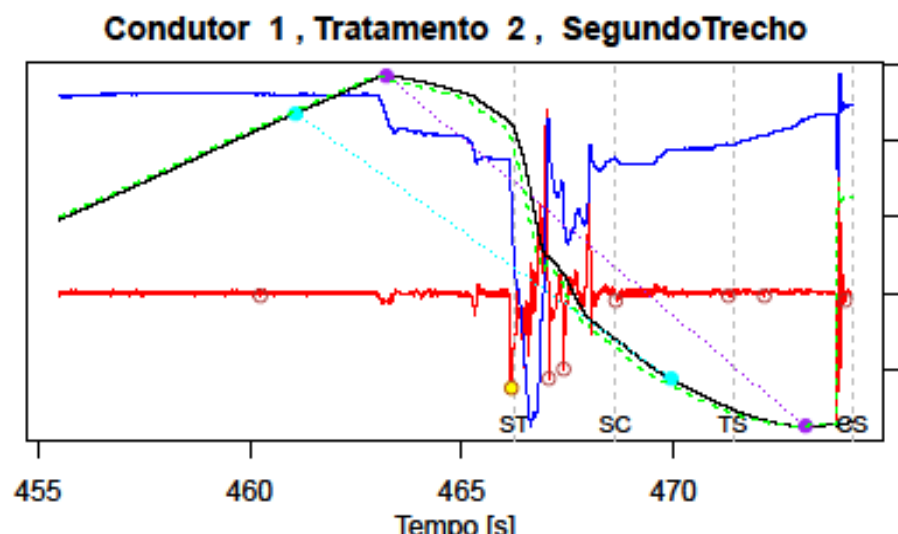

Jerks minimos $\left[\mathrm{m} / \mathrm{s}^{2}\right]$ DeltaV85 $[\mathrm{km} / \mathrm{h}]$ Jerk minimo [m/s'] 85MSR [km/h]

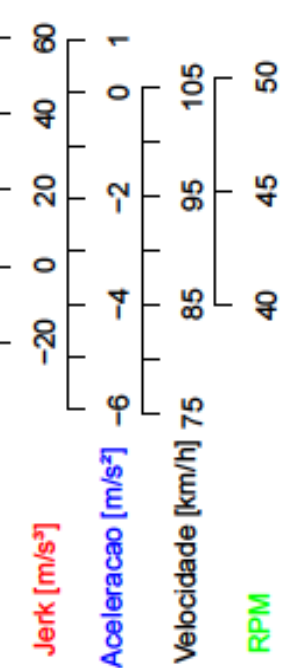

Condutor 1 , Tratamento 4 , SegundoTrecho

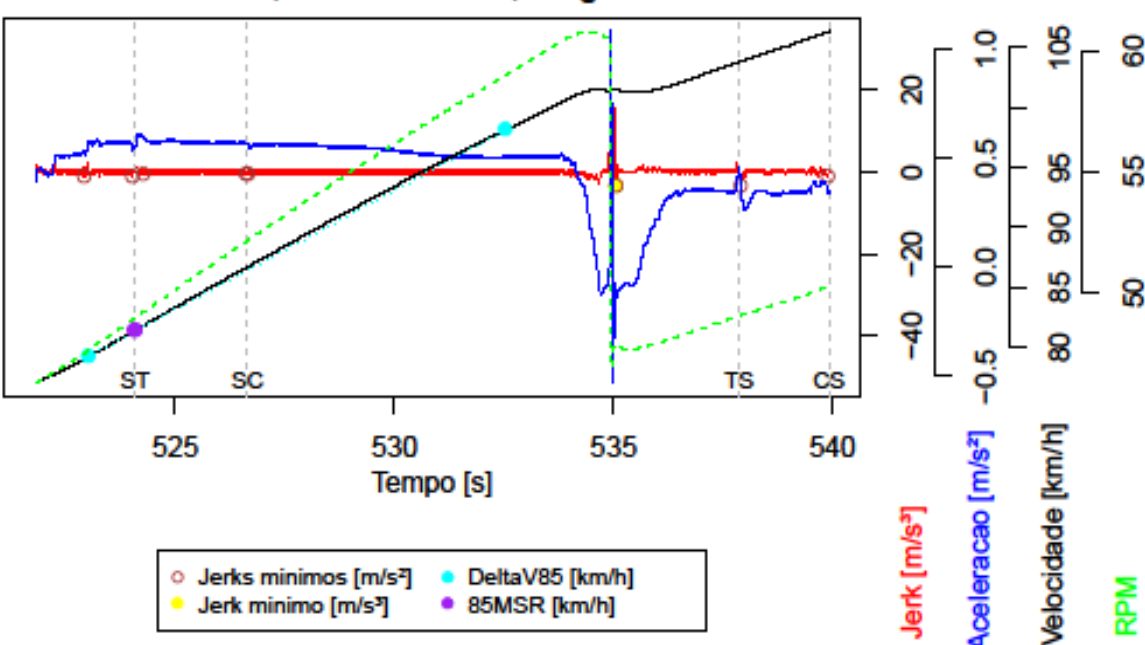


Condutor 1 , Tratamento 5 , SegundoTrecho

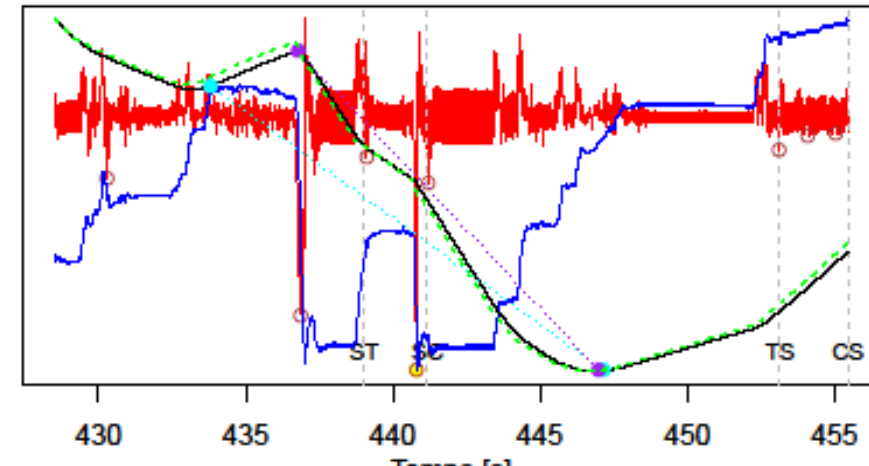

Jerks minimos $[\mathrm{m} / \mathrm{s}]$ - DeltaV85 $[\mathrm{km} / \mathrm{h}]$ Jerk $\operatorname{minimo}[\mathrm{m} / \mathrm{s}][\mathrm{km} / \mathrm{h}]$

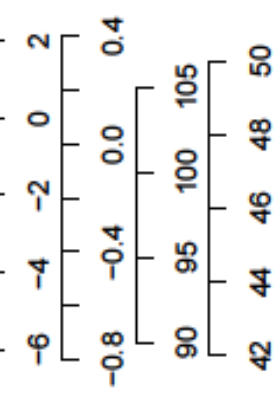

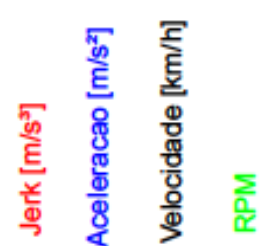

Condutor 1 , Tratamento 6 , SegundoTrecho

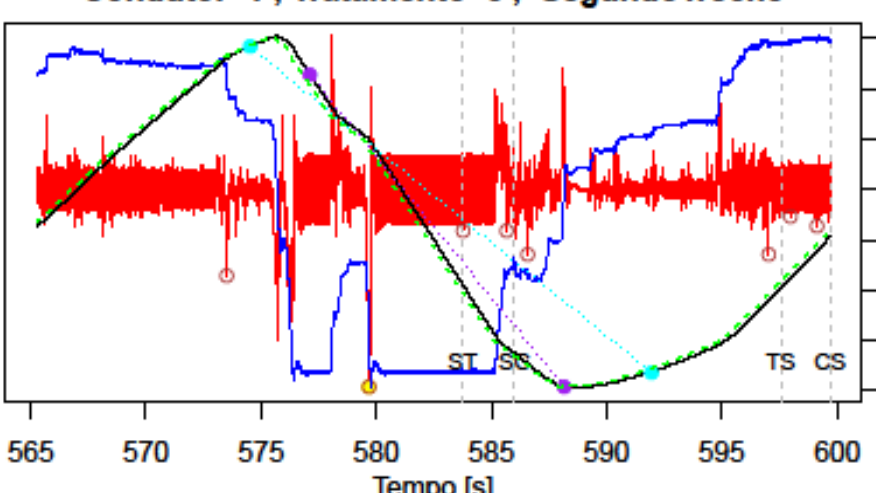

Jerks minimos $[\mathrm{m} / \mathrm{s}] \quad-$ DeltaV85 $[\mathrm{km} / \mathrm{h}]$ Jerk minimo $\left[\mathrm{m} / \mathrm{s}^{\mathrm{s}}\right]$ - $85 \mathrm{MSR}[\mathrm{km} / \mathrm{h}]$

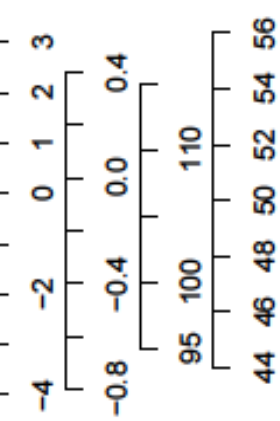

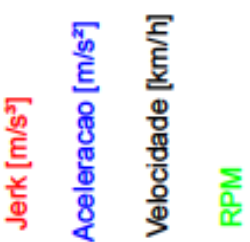

Condutor 1 , Tratamento 7 , SegundoTrecho

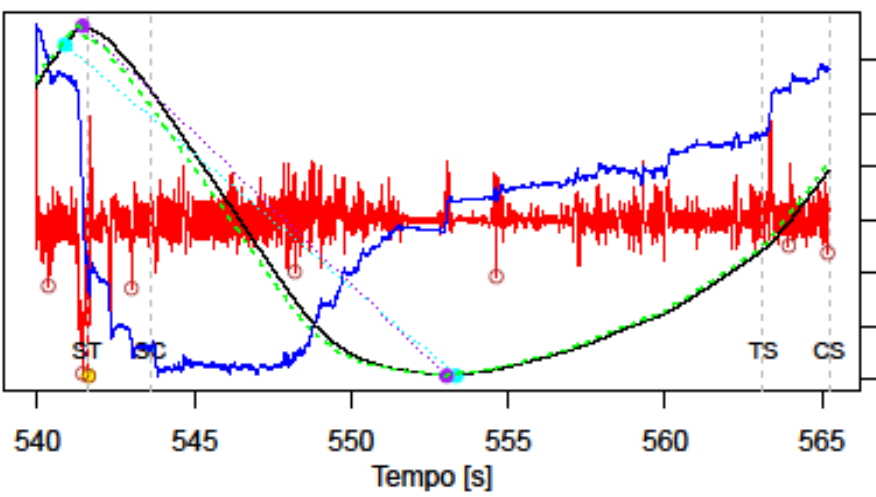
Jerks minimos $\left[\mathrm{m} / \mathrm{s}^{\mathrm{z}}\right]$
Jerk minimo $[\mathrm{m} / \mathrm{s}]$ - DeltaV85 $[\mathrm{km} / \mathrm{h}]$

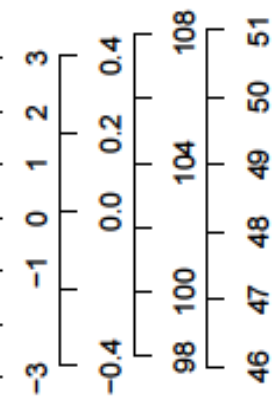

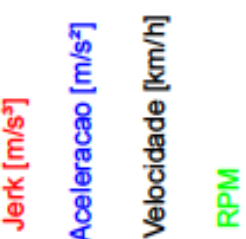

Condutor 1 , Tratamento 8 , SegundoTrecho

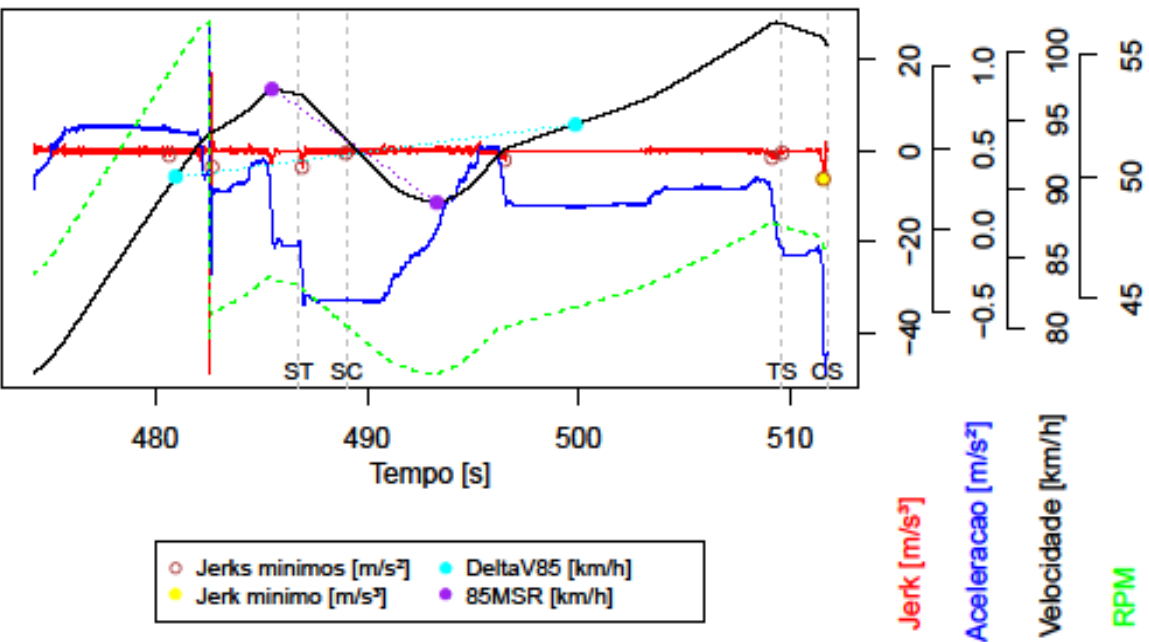


Condutor 1 , Tratamento 9 , SegundoTrecho

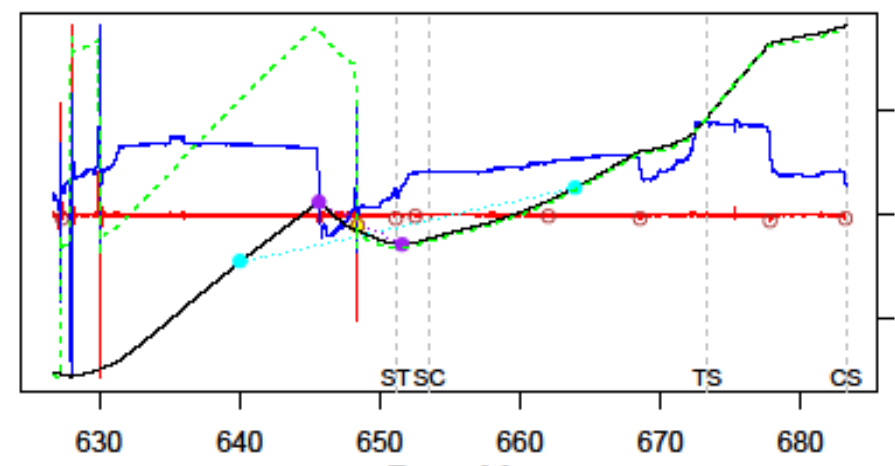

Jerks minimos $\left[\mathrm{m} / \mathrm{s}^{\mathrm{z}}\right]$-DeltaV85 $[\mathrm{km} / \mathrm{h}]$ Jerk minimo [m/s's] 85MSR $[\mathrm{km} / \mathrm{h}]$

Condutor 2 , Tratamento 2 , SegundoTrecho

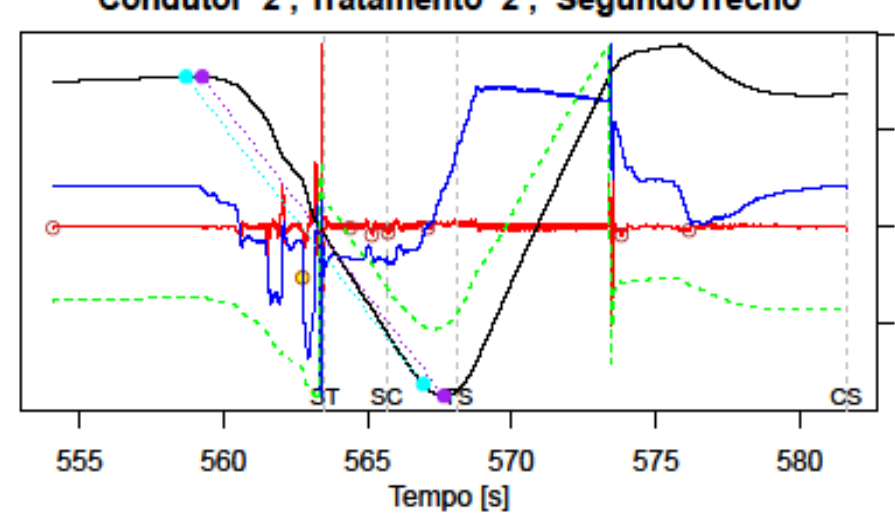

Jerks minimos $\left[\mathrm{m} / \mathrm{s}^{2}\right]$ - DeltaV85 $[\mathrm{km} / \mathrm{h}]$ Jerk minimo $\left.\left[\mathrm{m} / \mathrm{s}^{\mathrm{s}}\right] \mathrm{s}\right]$ : $85 \mathrm{MSR}[\mathrm{km} / \mathrm{h}]$
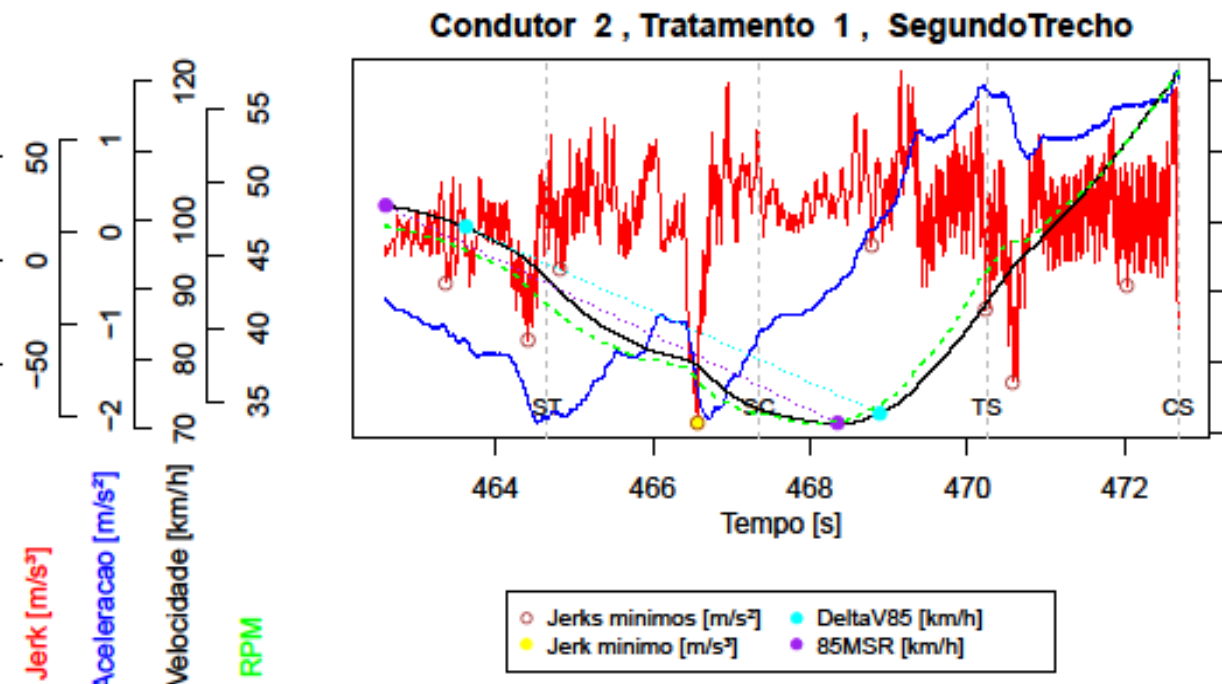

Jerks minimos $[\mathrm{m} / \mathrm{s}]$ - DeltaV85 $[\mathrm{km} / \mathrm{h}]$ Jerk minimo $\left[\mathrm{m} / \mathrm{s}^{\mathrm{s}}\right]$ - $85 \mathrm{MSR}[\mathrm{km} / \mathrm{h}]$ - $85 \mathrm{MSR}[\mathrm{km} / \mathrm{h}]$

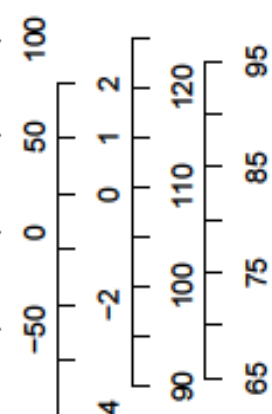

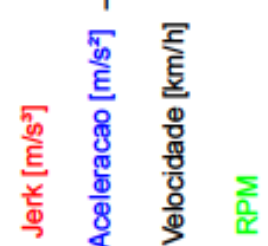

Condutor 2 , Tratamento 3 , SegundoTrecho

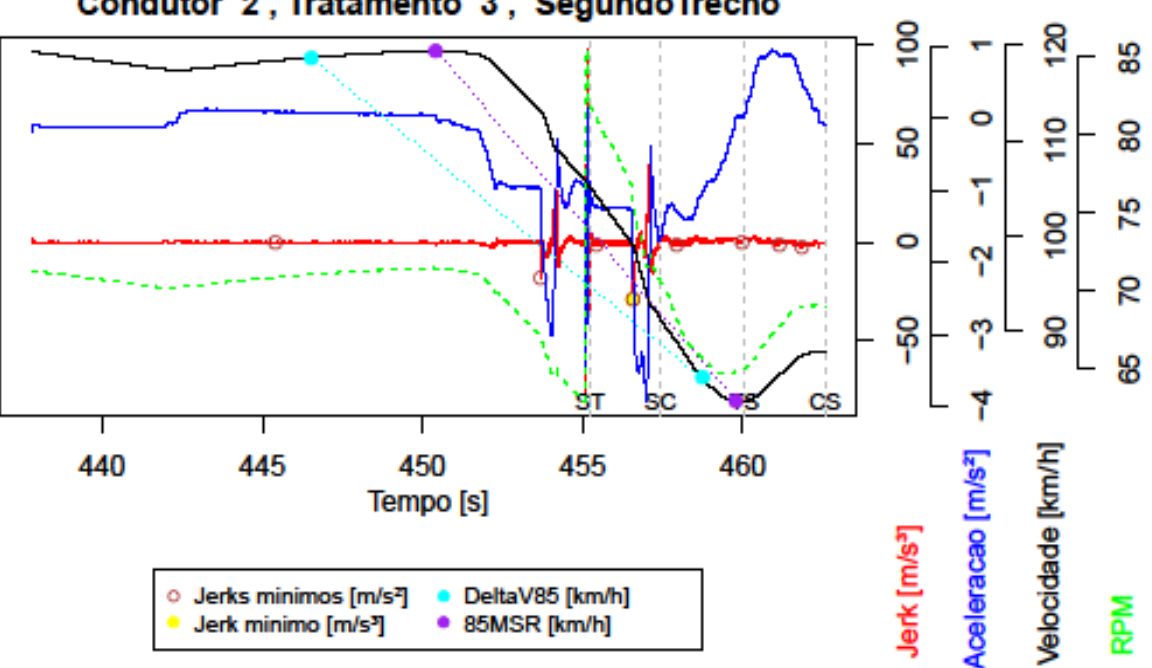


Condutor 2 , Tratamento 4 , SegundoTrecho

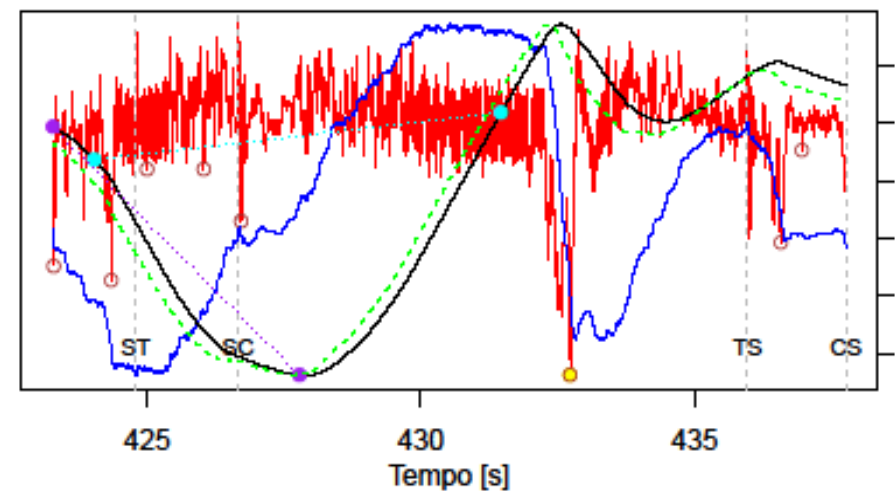

Jerks minimos [m/s $]$ - DeltaV85 $[\mathrm{km} / \mathrm{h}]$ Jerk minimo $\left[\mathrm{m} / \mathrm{s}^{\mathrm{l}}\right] \quad 85 \mathrm{MSR}[\mathrm{km} / \mathrm{h}]$

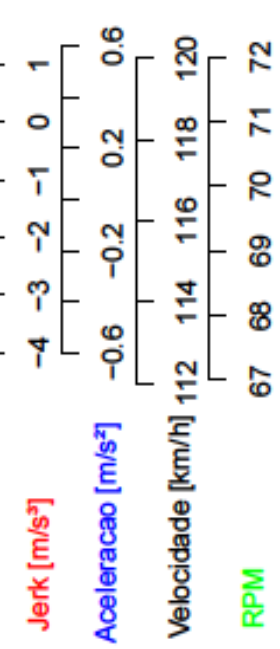

Condutor 2 , Tratamento 6 , SegundoTrecho

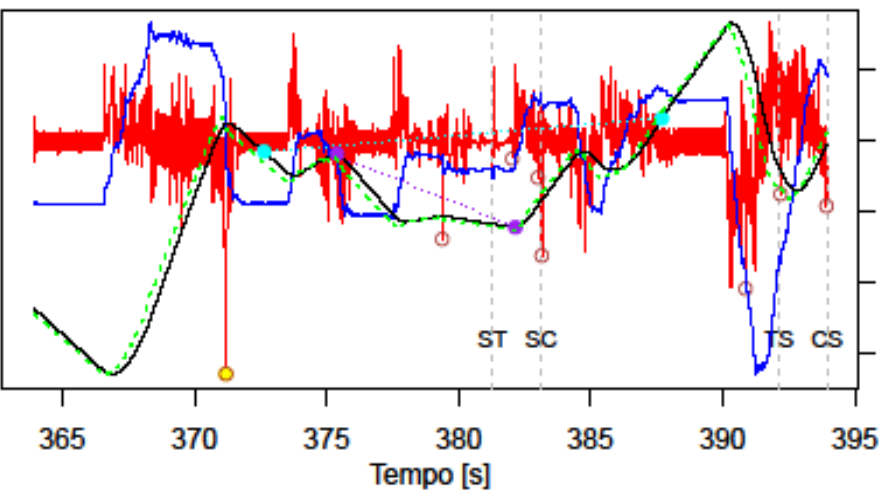

Jerks minimos $[\mathrm{m} / \mathrm{s}]$ - DeltaV85 $[\mathrm{km} / \mathrm{h}]$ Jerk minimo $\left[\mathrm{m} / \mathrm{s}^{\mathrm{s}}\right]$ - 85MSR $[\mathrm{km} / \mathrm{h}]$

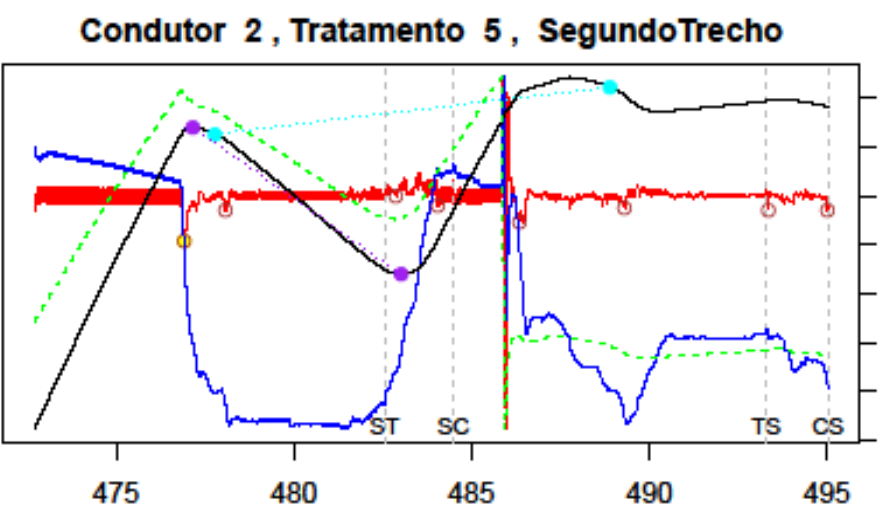

Jerks minimos $[\mathrm{m} / \mathrm{s}] \quad$ DeltaV85 $[\mathrm{km} / \mathrm{h}]$ Jerk minimo [m/s'] $\quad 85 \mathrm{MSR}[\mathrm{km} / \mathrm{h}]$

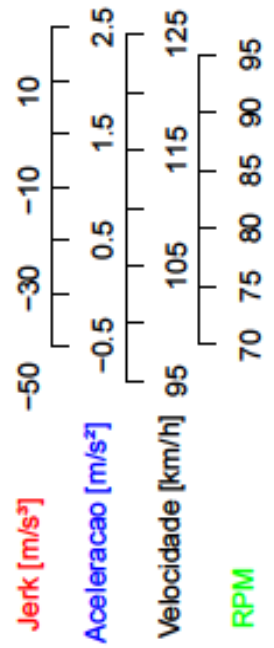

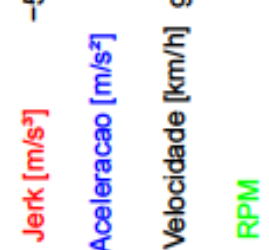

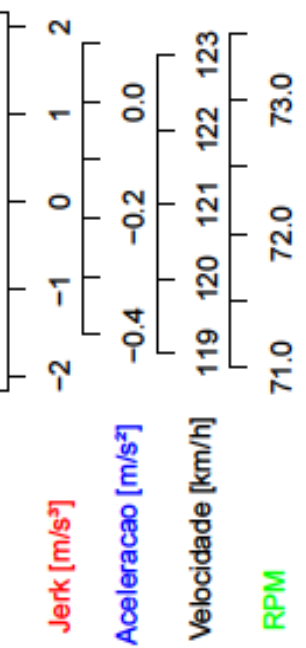




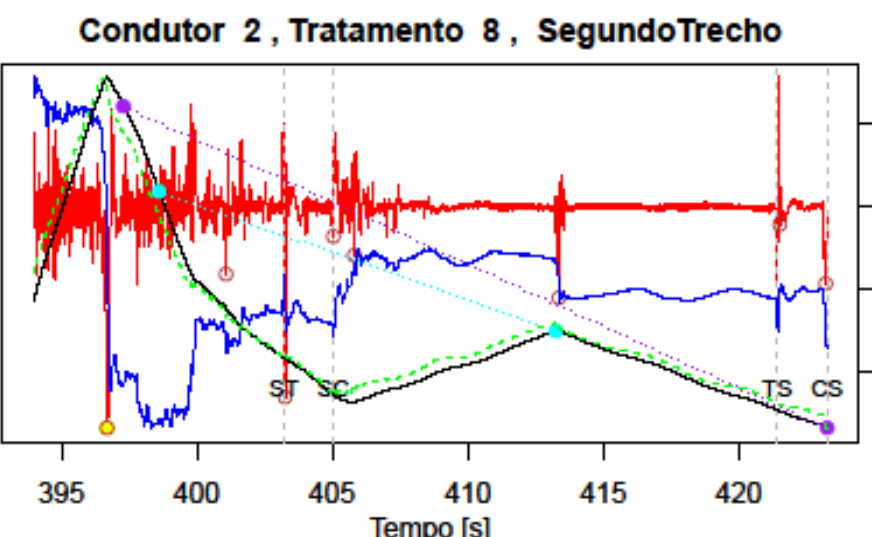

Jerks minimos [m/s 2 ] DeltaV85 $[\mathrm{km} / \mathrm{h}]$ Jerk ming [m/s] • $85 \mathrm{MSR}[\mathrm{km} / \mathrm{h}]$

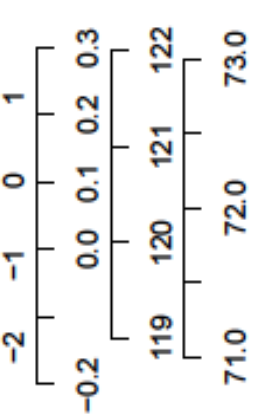

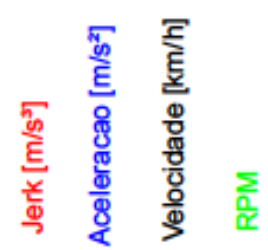

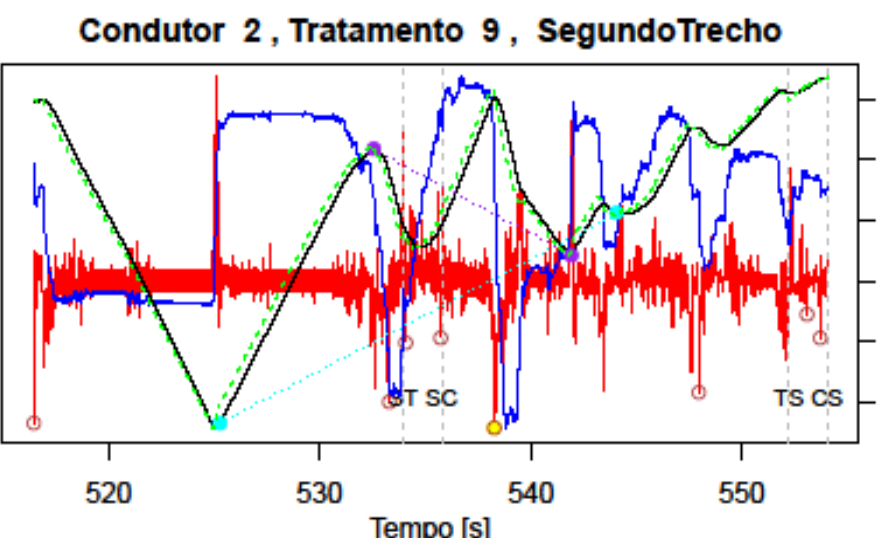

Jerks minimos $[\mathrm{m} / \mathrm{s}] \quad$ DeltaV85 $[\mathrm{km} / \mathrm{h}]$

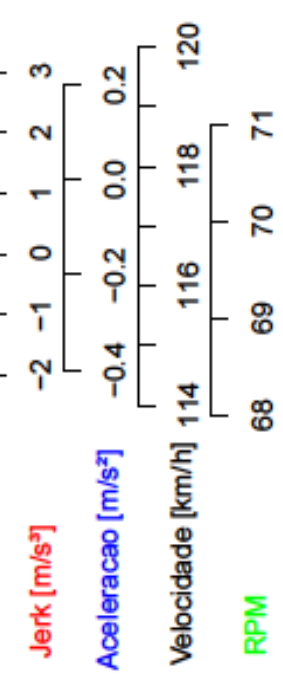

Condutor 3 , Tratamento 2 , SegundoTrecho

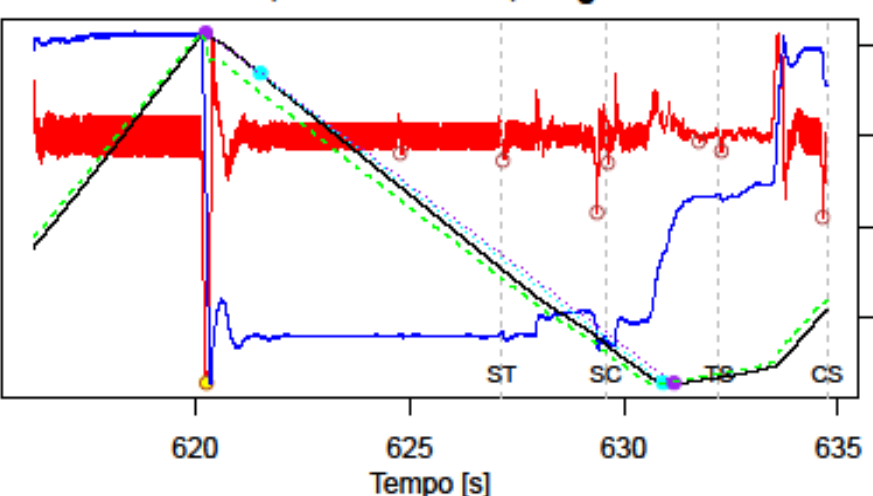

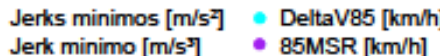

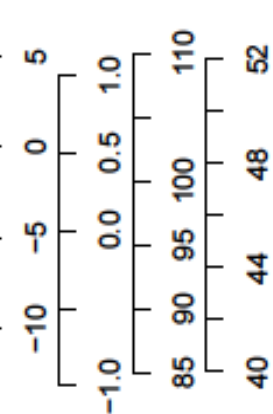

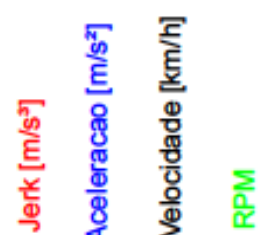

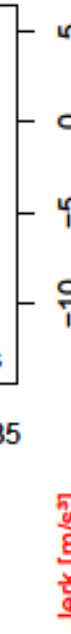

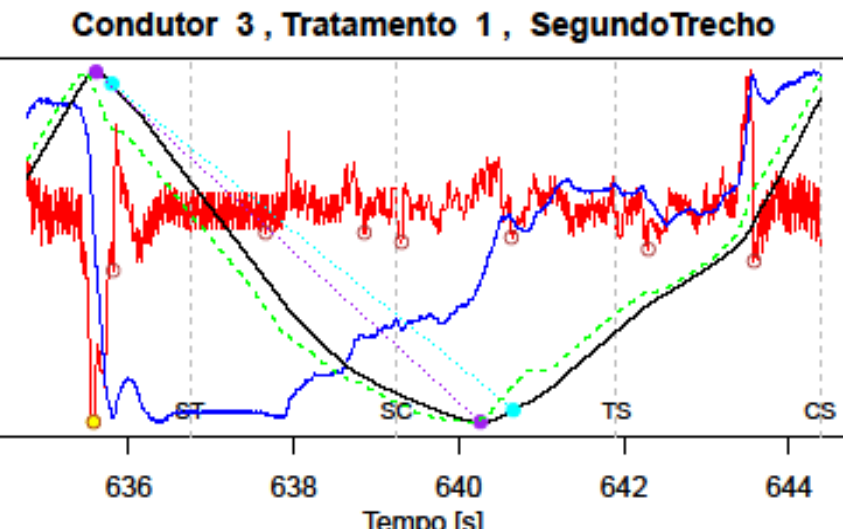

Jerks minimos $[\mathrm{m} / \mathrm{s}]$-DeltaV85 $[\mathrm{km} / \mathrm{h}]$ Jerk minimo $\left[\mathrm{m} / \mathrm{s}^{\mathrm{s}}\right]$ • $85 \mathrm{MSR}[\mathrm{km} / \mathrm{h}]$

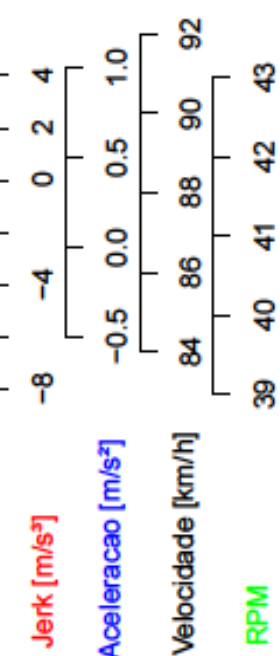


Condutor 3 , Tratamento 3 , SegundoTrecho

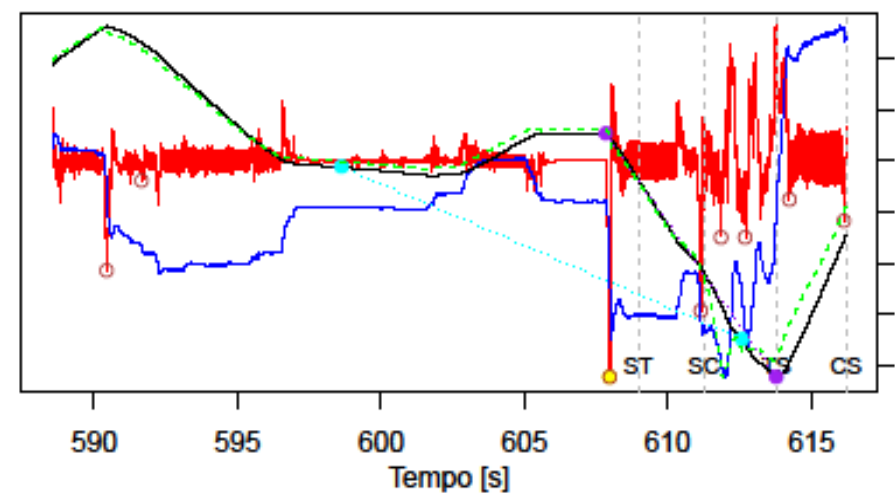

Jerks minimos $[\mathrm{m} / \mathrm{s}]$ DeltaV85 $[\mathrm{km} / \mathrm{h}]$ Jerk minimo $\left[\mathrm{m} / \mathrm{s}^{\mathrm{s}}\right]$ - $85 \mathrm{MSR}[\mathrm{km} / \mathrm{h}]$

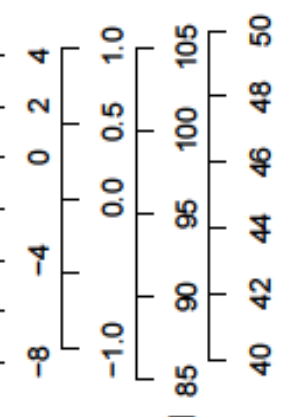

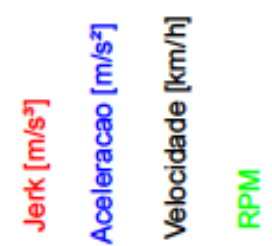

Condutor 3 , Tratamento 5 , SegundoTrecho

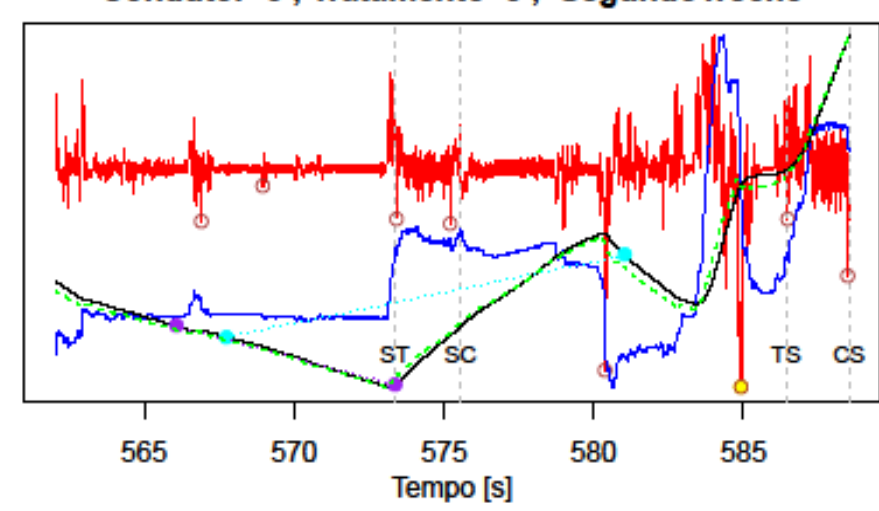

Jerks minimos $[\mathrm{m} / \mathrm{s} 2]$ DeltaV85 $[\mathrm{km} / \mathrm{h}]$ Jerk minimo $\left[\mathrm{m} / \mathrm{s}^{\mathrm{s}}\right]$

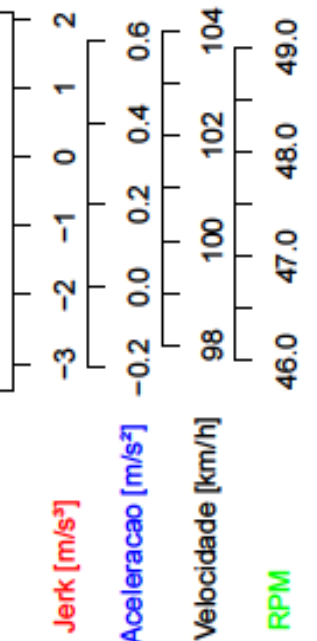

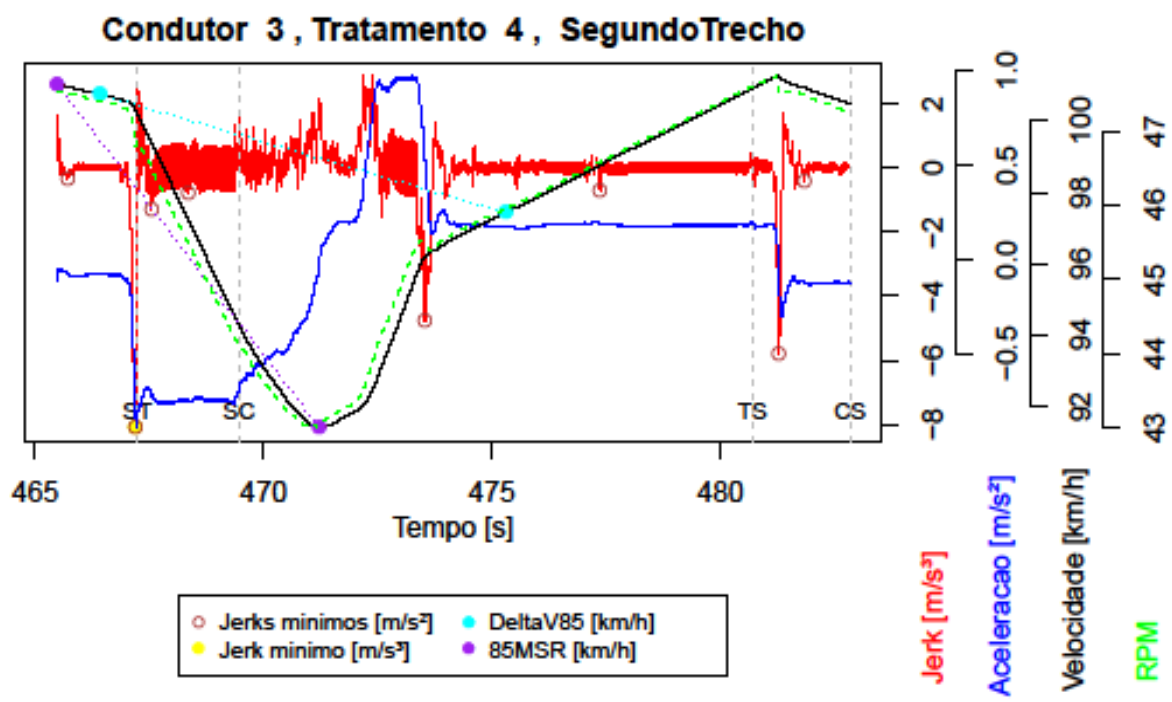

Condutor 3 , Tratamento 6 , SegundoTrecho

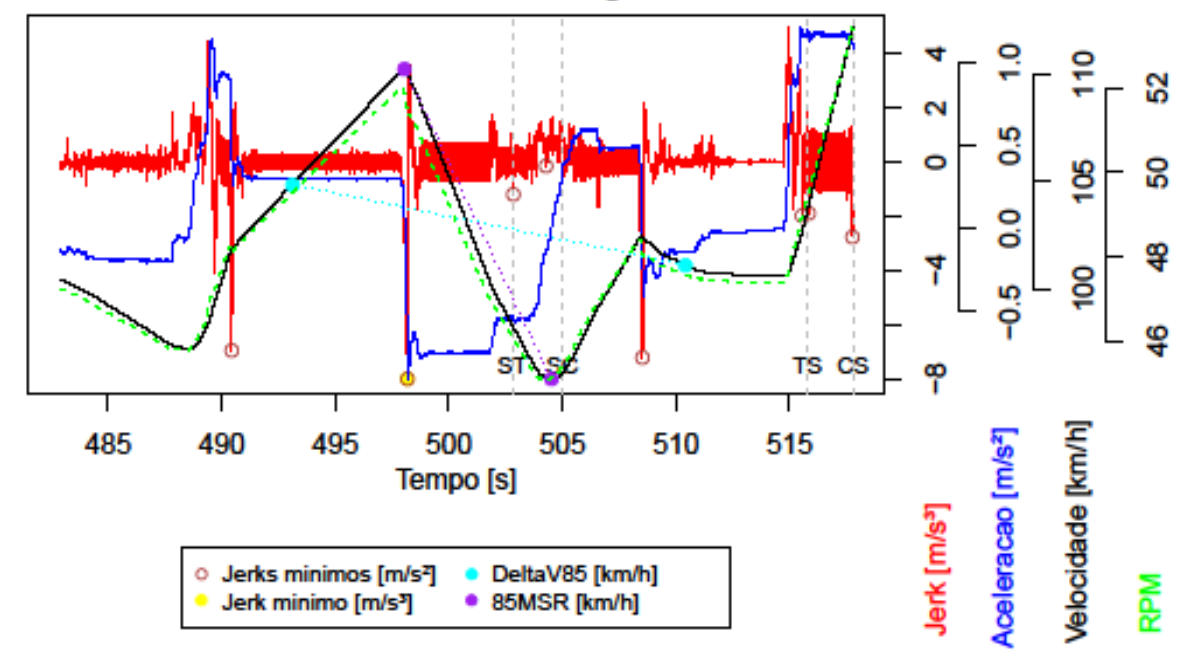



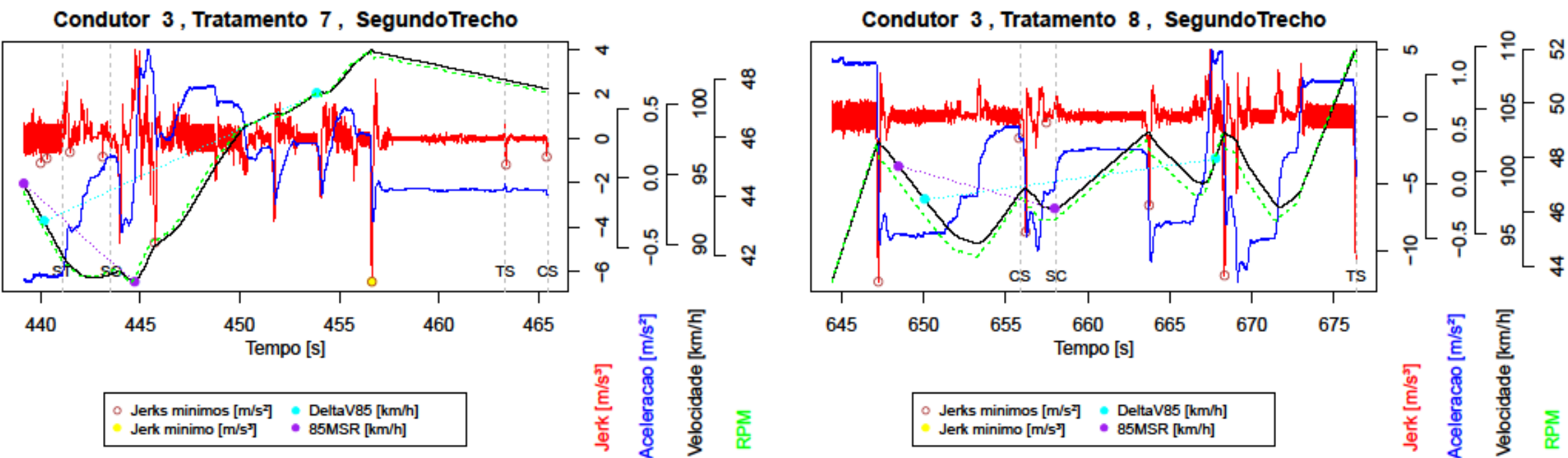

\section{Jerks minimos $\left[\mathrm{m} / \mathrm{s}^{2}\right]$
Jerk minimo $\left[\mathrm{m} / \mathrm{s}^{\mathrm{s}}\right]$ - DeltaV85 $[\mathrm{km} / \mathrm{h}]$}

Condutor 3 , Tratamento 9 , SegundoTrecho

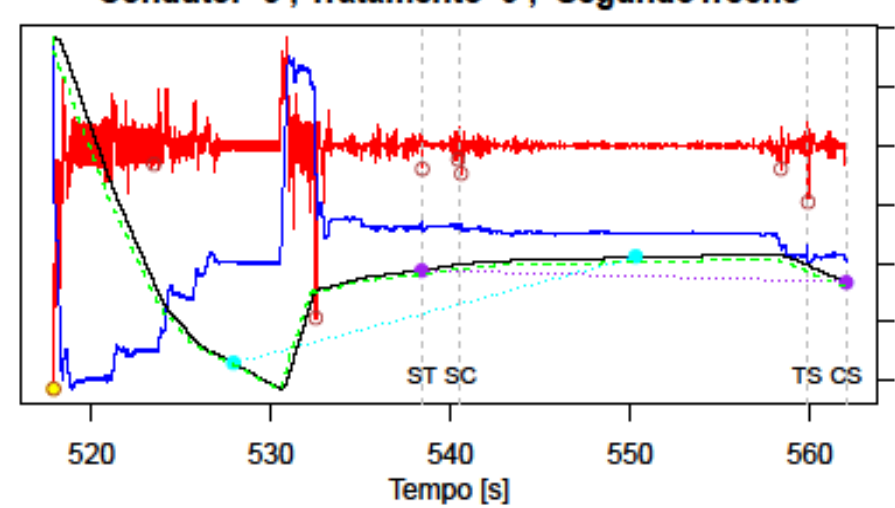

Jerks minimos $[\mathrm{m} / \mathrm{s}]$ - DeltaV85 $[\mathrm{km} / \mathrm{h}]$ Jerk minimo $\left[\mathrm{m} / \mathrm{s}^{\mathrm{s}}\right]$ ? $85 \mathrm{MSR}[\mathrm{km} / \mathrm{h}]$

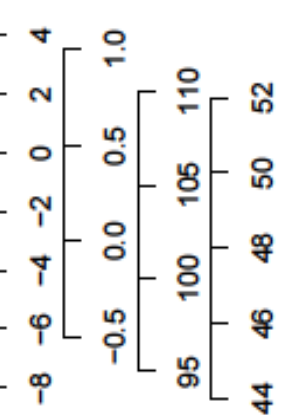

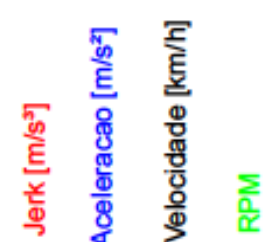

Condutor 4 , Tratamento 1 , SegundoTrecho

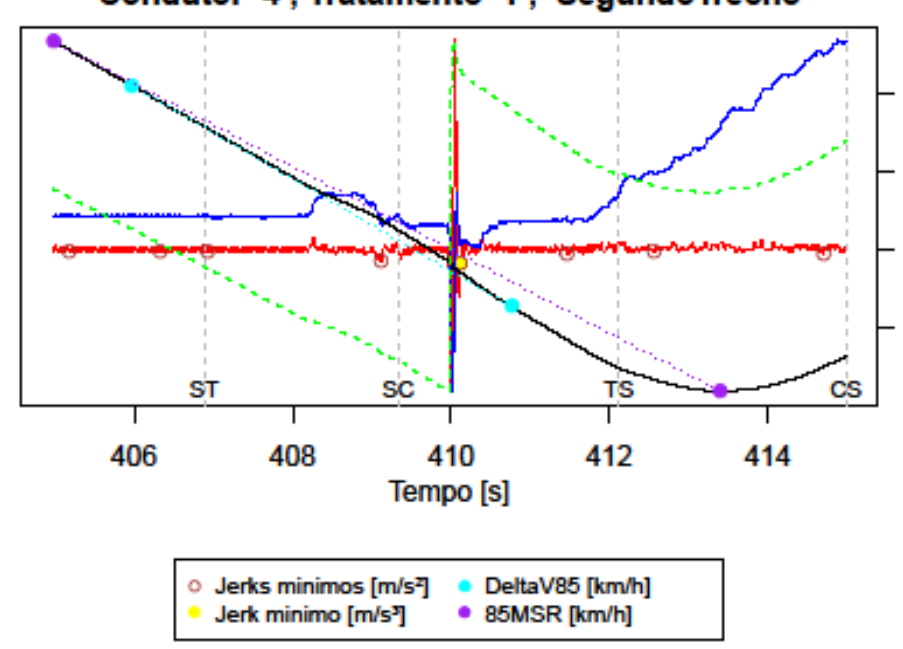

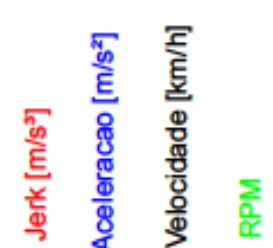

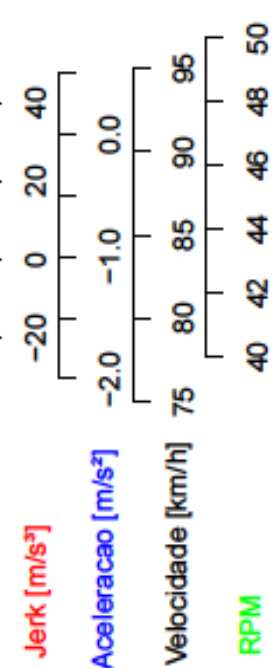


Condutor 4 , Tratamento 2 , SegundoTrecho

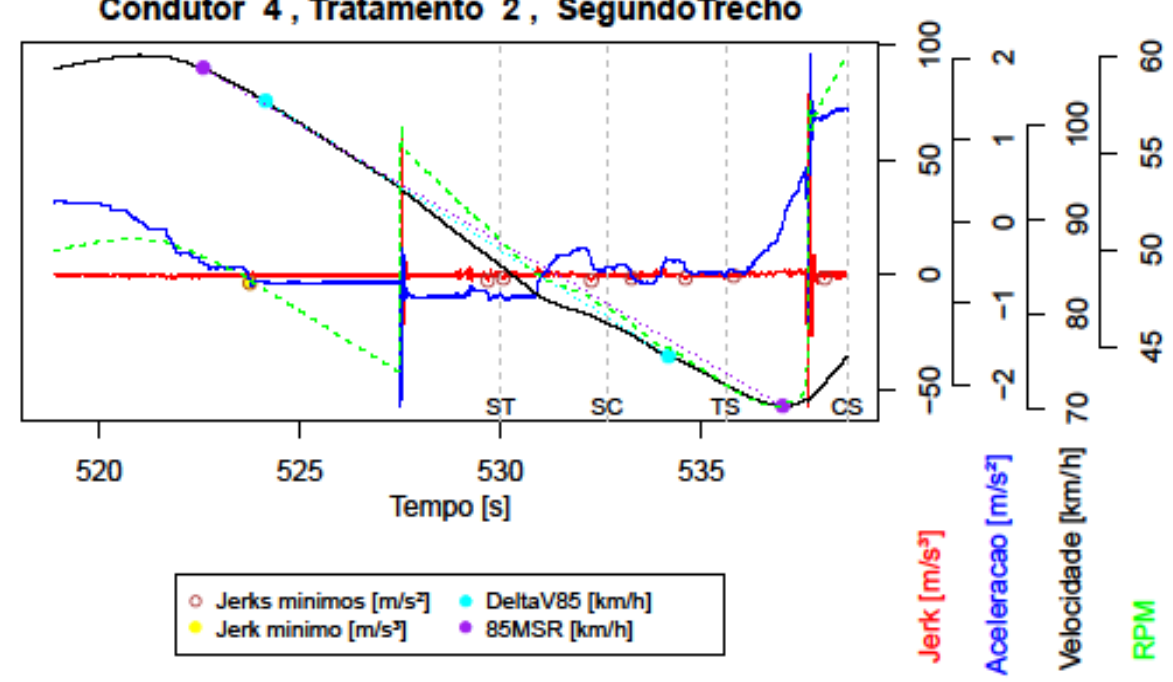

Condutor 4 , Tratamento 4 , SegundoTrecho

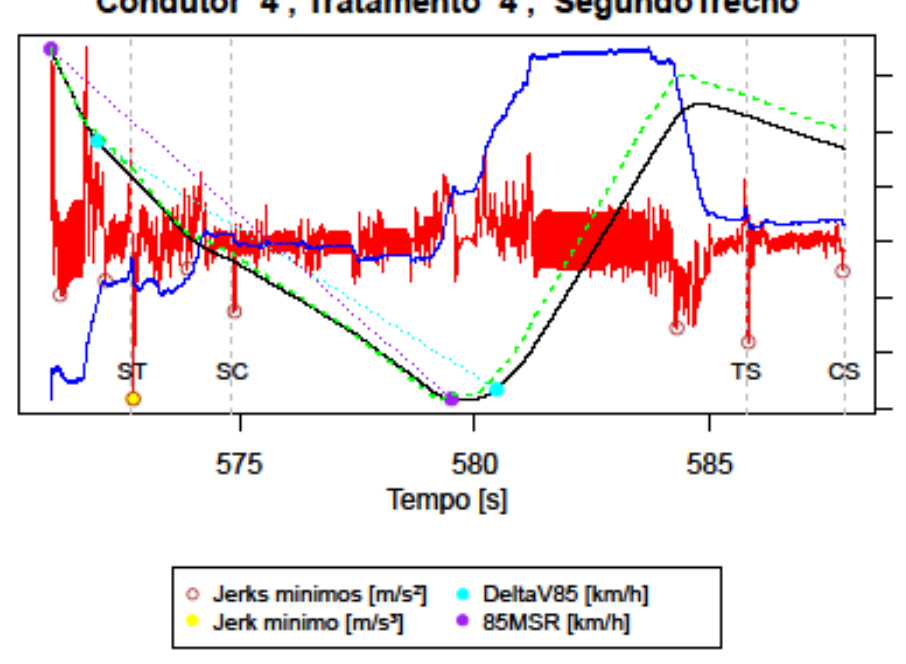

Condutor 4 , Tratamento 3 , SegundoTrecho

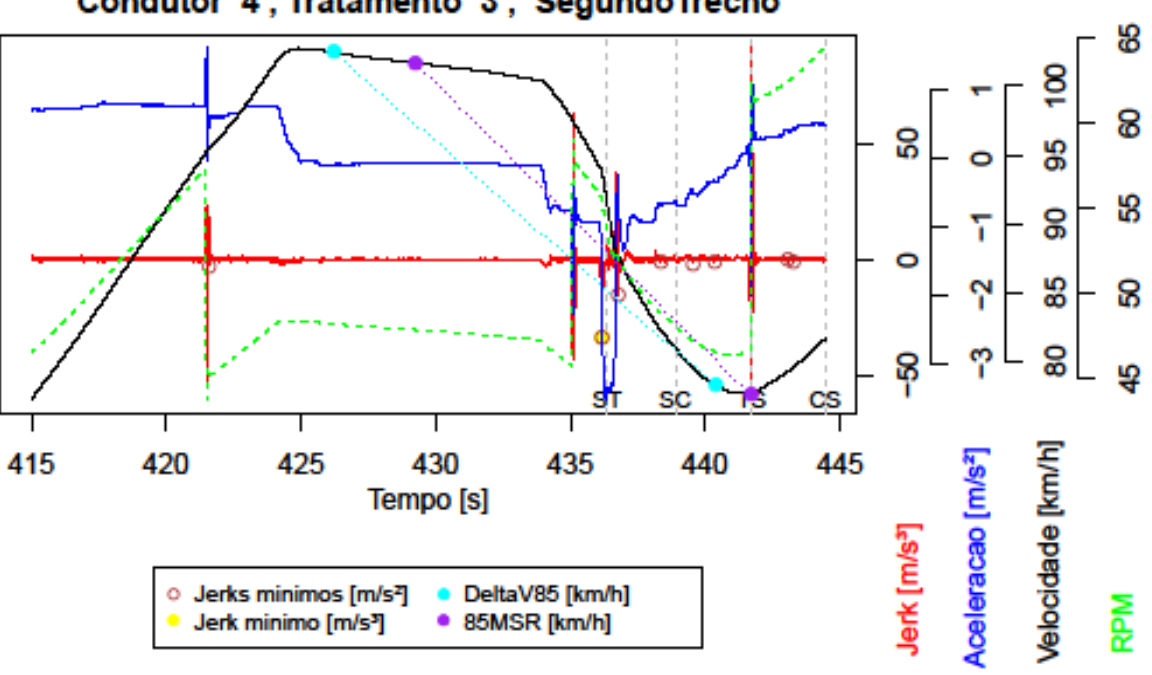

Condutor 4 , Tratamento 5 , SegundoTrecho

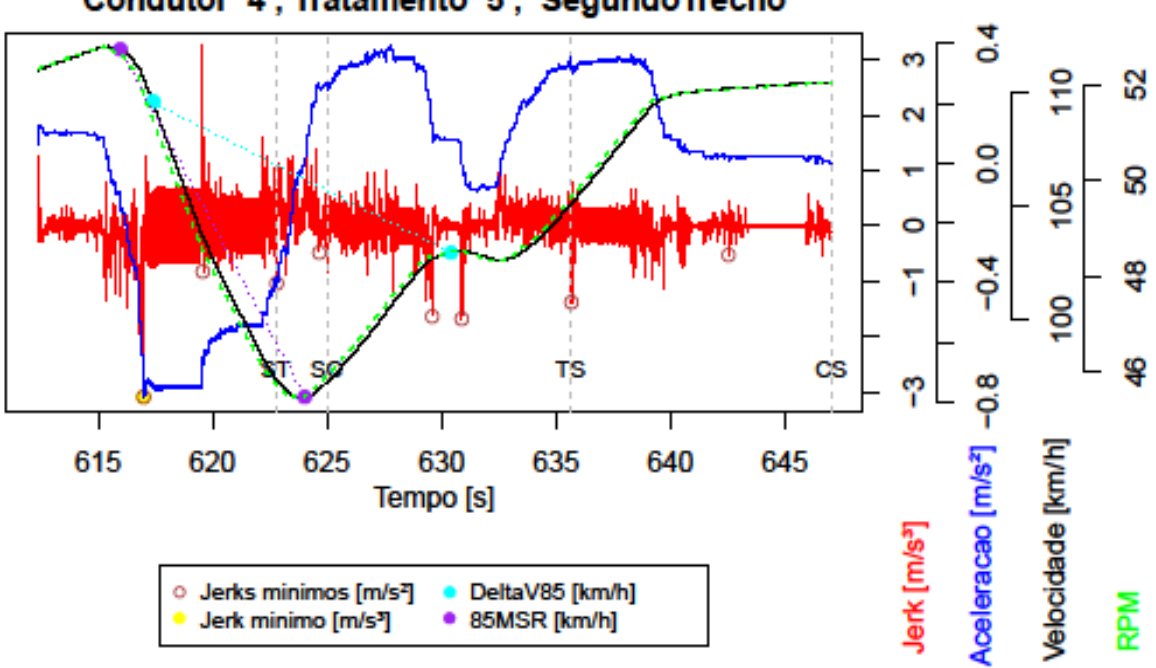


Condutor 4 , Tratamento 6 , SegundoTrecho

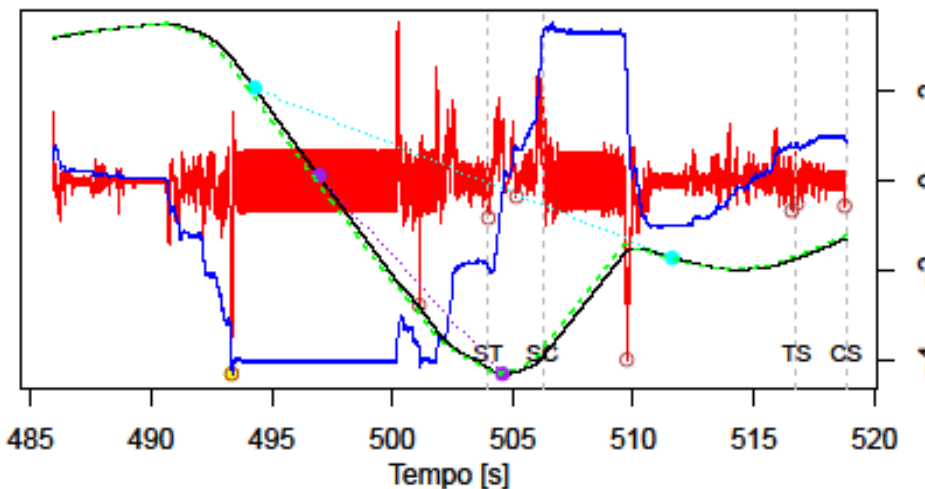

Jerks minimos $[\mathrm{m} / \mathrm{s}]$ - DeltaV85 $[\mathrm{km} / \mathrm{h}]$ Jerk minimo $\left[\mathrm{m} / \mathrm{s}^{\mathrm{j}}\right]$ - $85 \mathrm{MSR}[\mathrm{km} / \mathrm{h}]$

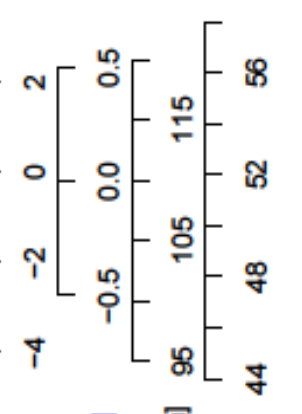

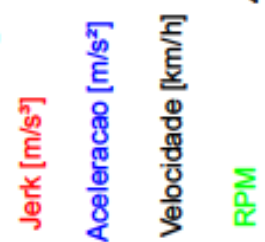

Condutor 4 , Tratamento 7 , SegundoTrecho

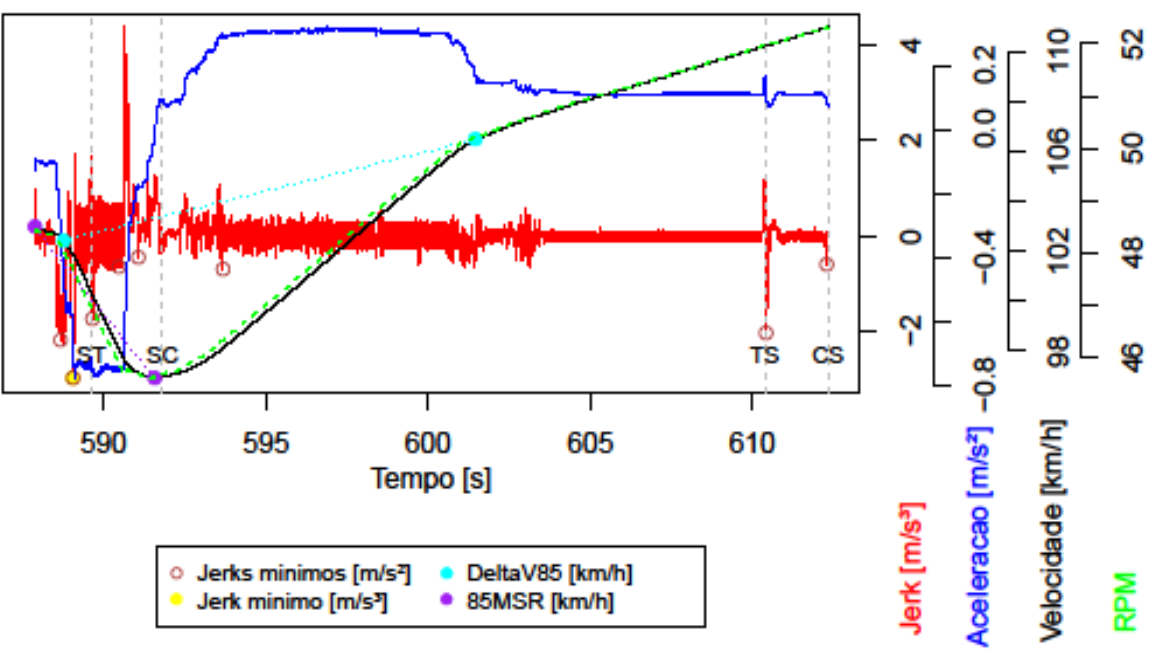

Condutor 4 , Tratamento 9 , SegundoTrecho

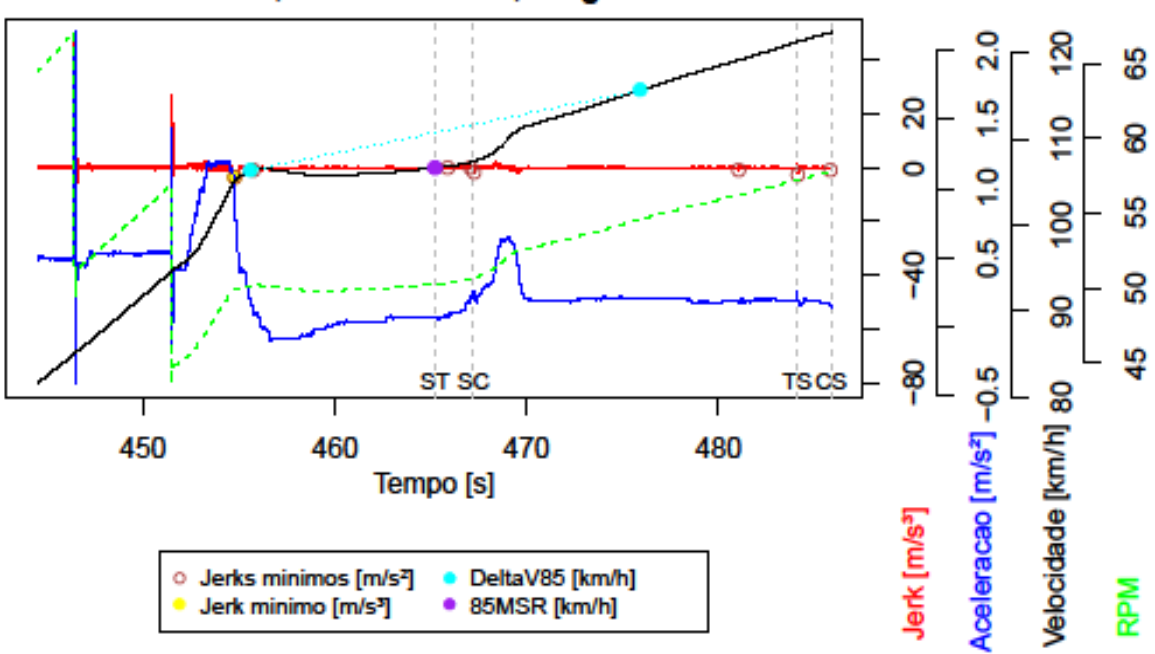

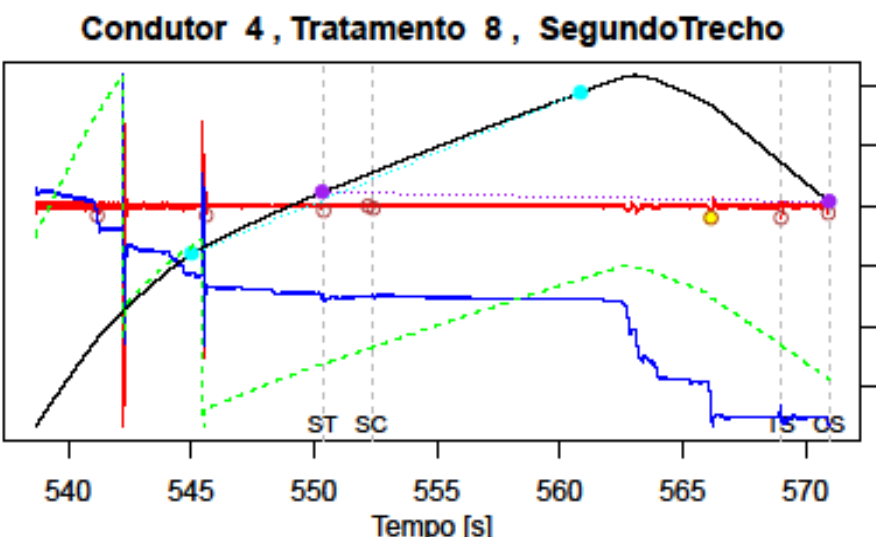

Jerks minimos $\left[\mathrm{m} / \mathrm{s}^{2}\right]$-DeltaV85 $[\mathrm{km} / \mathrm{h}]$ Jerk minimo [m/s $\left./ \mathrm{s}^{\mathrm{s}}\right]$ : $85 \mathrm{MSR}[\mathrm{km} / \mathrm{h}]$

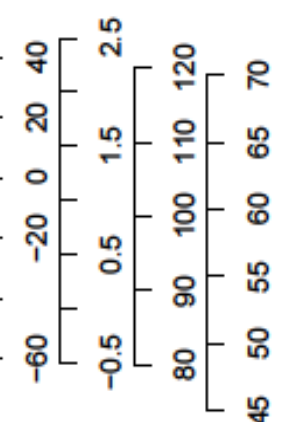

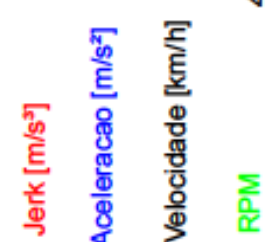



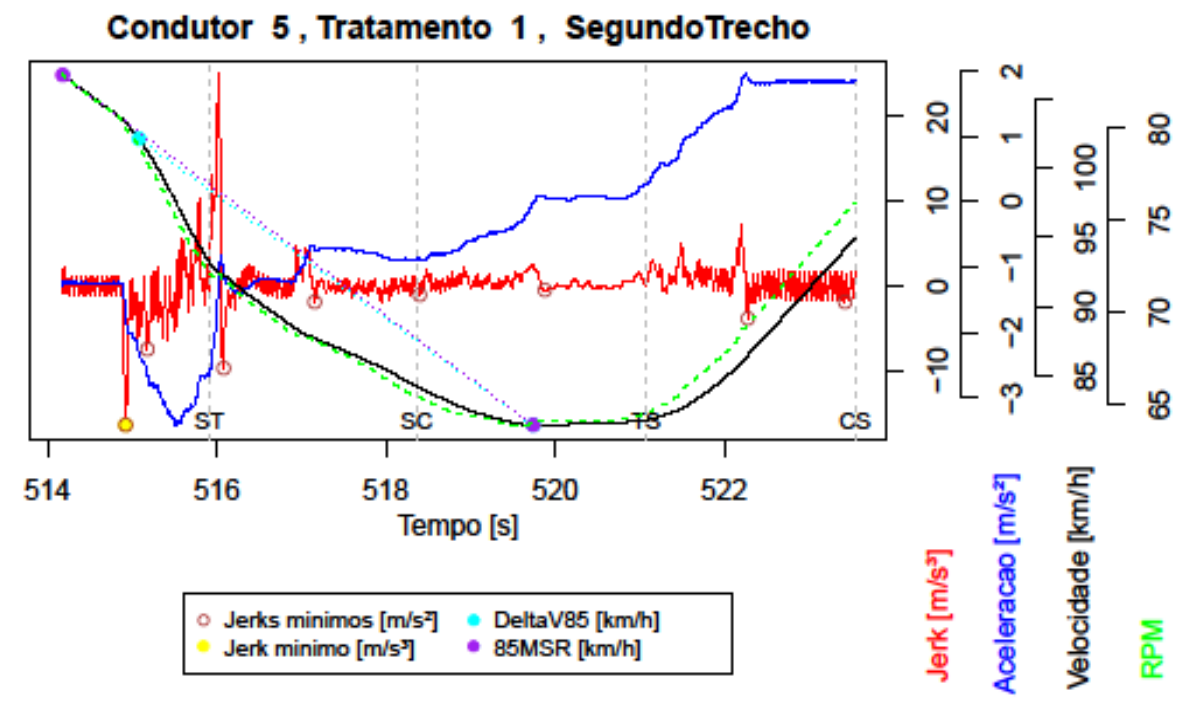

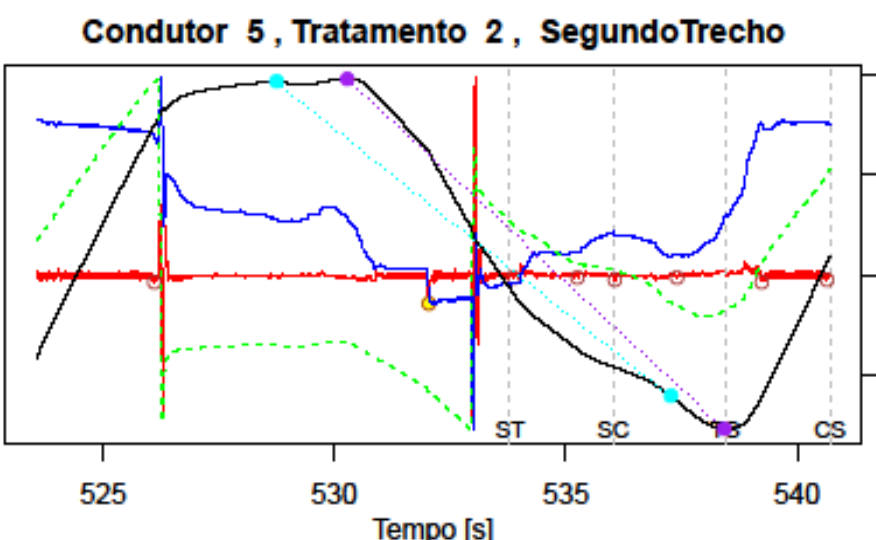

Jerks minimos $\left[\mathrm{m} / \mathrm{s}^{2}\right]$ - DeltaV85 $[\mathrm{km} / \mathrm{h}]$ Jerk minimo $\left[\mathrm{m} / \mathrm{s}^{\mathrm{s}}\right]$ • $85 \mathrm{MSR}[\mathrm{km} / \mathrm{h}]$

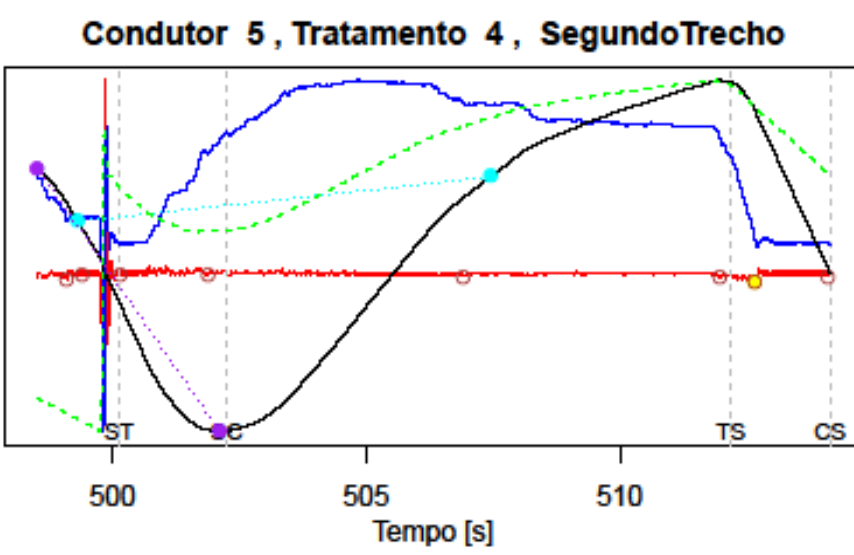
Jerks minimos $[\mathrm{m} / \mathrm{s}]]$
Jerk minimo $\left[\mathrm{m} / \mathrm{s}^{\mathrm{v}}\right]$ - DeltaV85 $[\mathrm{km} / \mathrm{h}]$

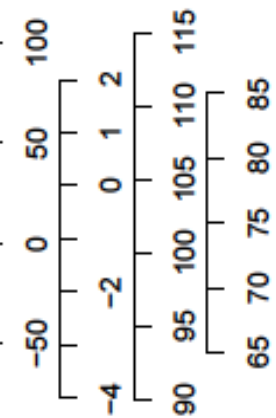

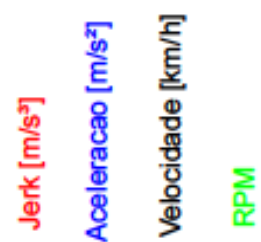

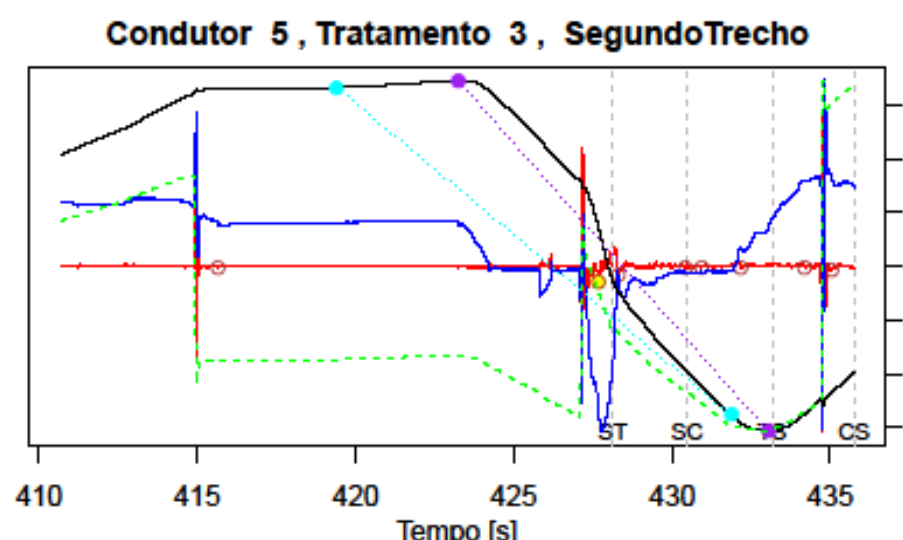

Jerks minimos $[\mathrm{m} / \mathrm{s}$ ₹] DeltaV85 $[\mathrm{km} / \mathrm{h}]$ Jerk minimo $\left[\mathrm{m} / \mathrm{s}^{\mathrm{s}}\right]$ ?

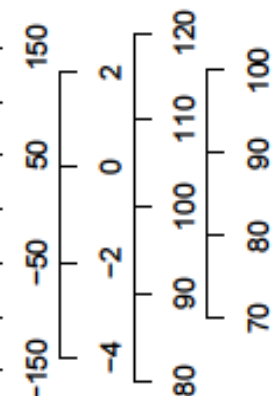

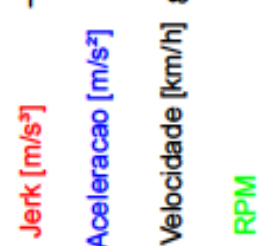

8

둔ㄷㄴㄷำ

० i- :

:

28

कू

है

है $\frac{\mathbb{\pi}}{\mathrm{L}} \frac{\mathrm{\pi}}{\mathrm{i}}$ 


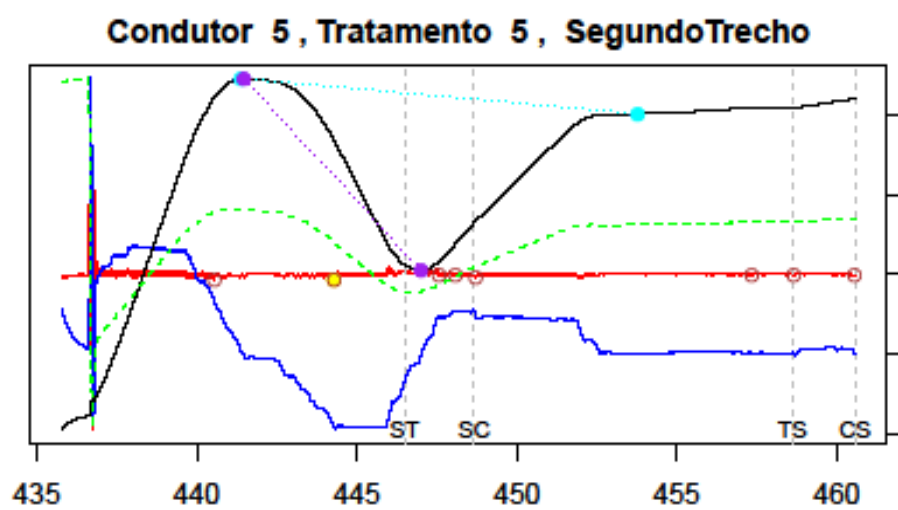

435

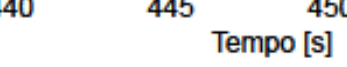

$$
\begin{aligned}
& \circ \text { Jerks minimos }\left[\mathrm{m} / \mathrm{s}^{\mathrm{z}}\right] \\
& \text { Jerk minimo }\left[\mathrm{m} / \mathrm{s}^{\mathrm{s}}\right]
\end{aligned}
$$

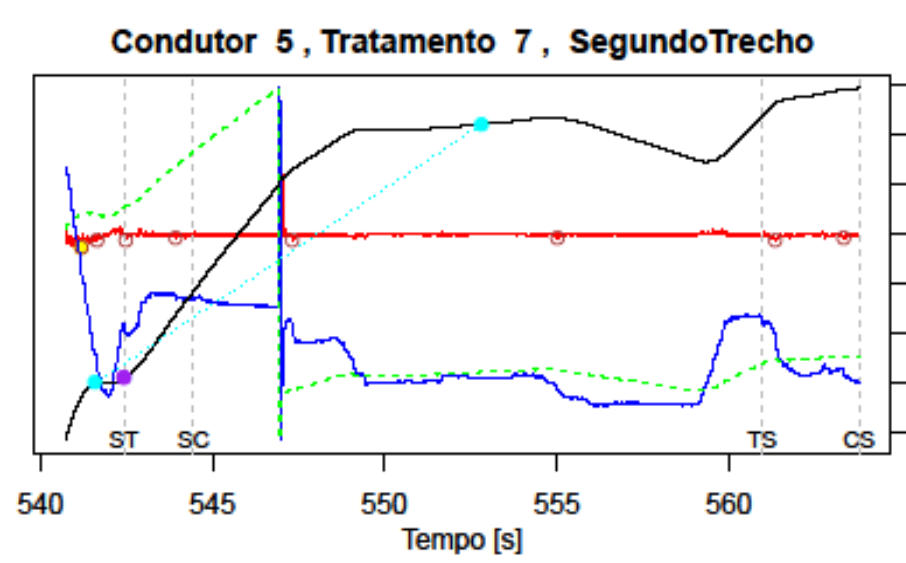

- Jerks minimos $\left[\mathrm{m} / \mathrm{s}^{2}\right]$ - DeltaV85 $[\mathrm{km} / \mathrm{h}]$ Jerk minimo $\left[\mathrm{m} / \mathrm{s}^{\mathrm{s}}\right]$ - $85 \mathrm{MSR}[\mathrm{km} / \mathrm{h}]$
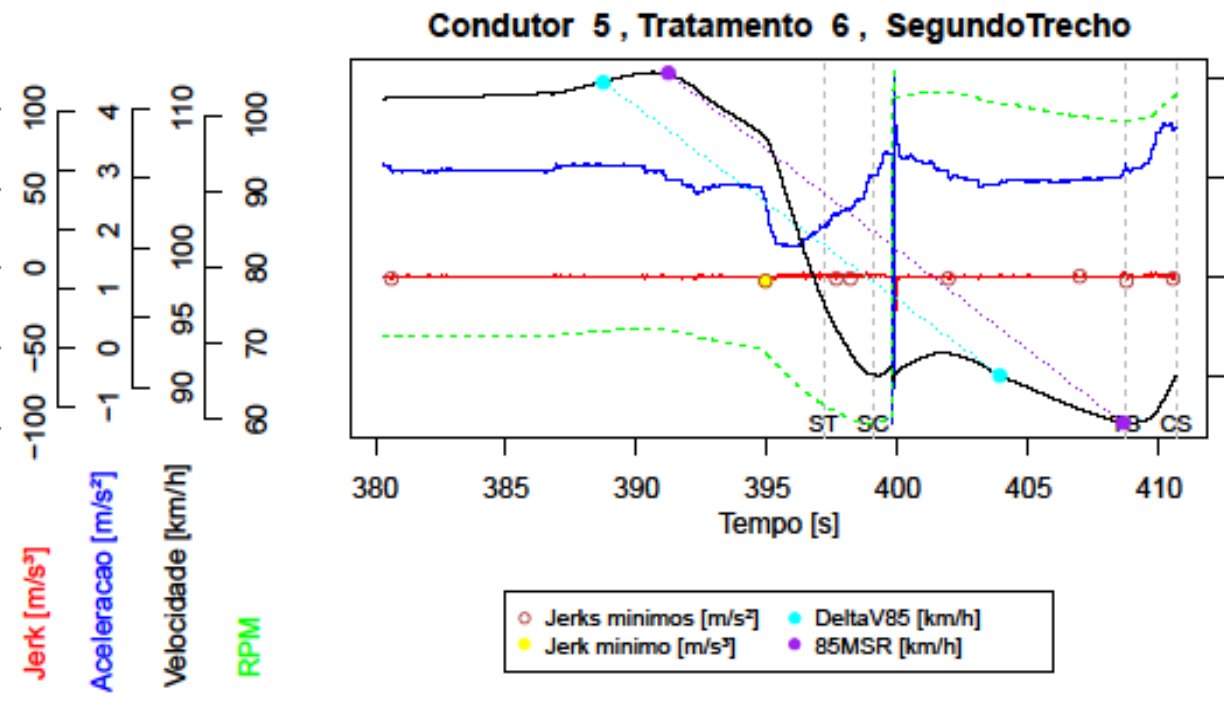

Jerks minimos $[\mathrm{m} / \mathrm{s}]]$ - DeltaV85 $[\mathrm{km} / \mathrm{h}]$ Jerk minimo $\left[\mathrm{m} / \mathrm{s}^{\mathrm{s}}\right]$ - $85 \mathrm{MSR}[\mathrm{km} / \mathrm{h}]$

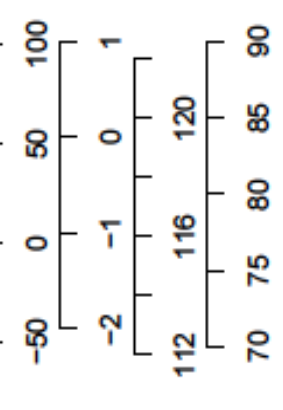

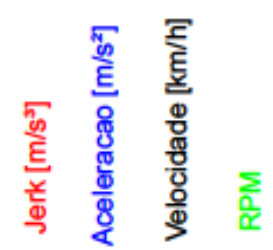

Condutor 5 , Tratamento 8 , SegundoTrecho

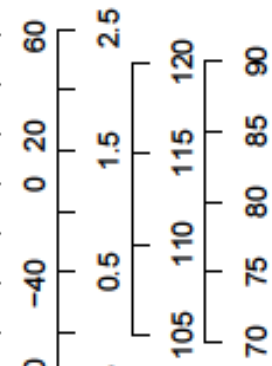

变

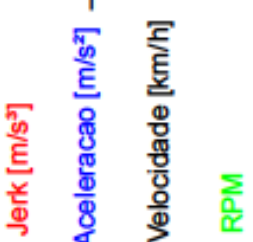

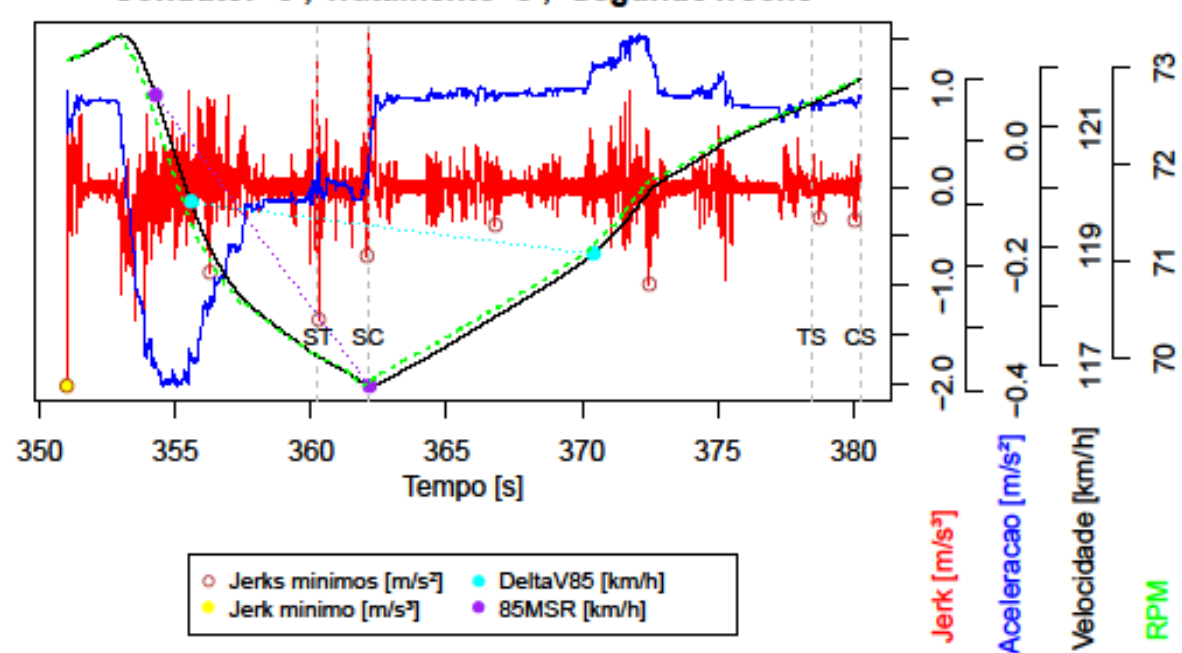


Condutor 5 , Tratamento 9 , SegundoTrecho

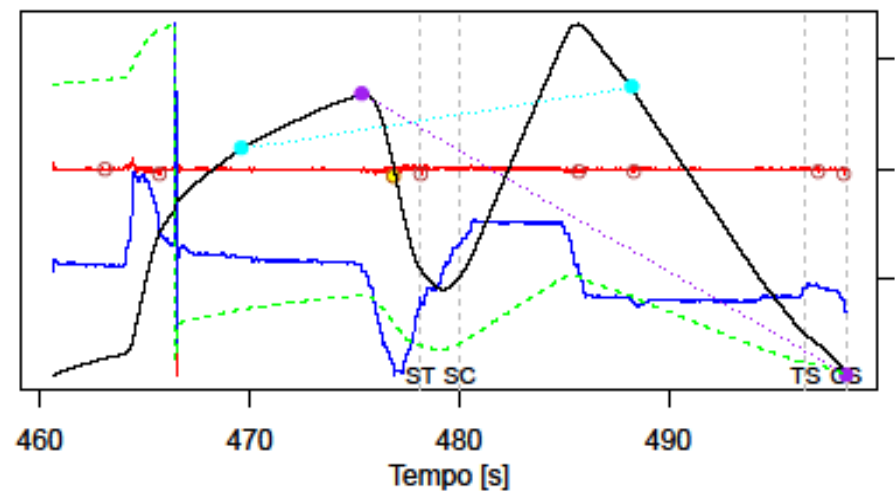

Jerks minimos $[\mathrm{m} / \mathrm{s}]$ : DeltaV85 $[\mathrm{km} / \mathrm{h}]$ Jerk minimo $\left[\mathrm{m} / \mathrm{s}^{\mathrm{s}}\right]$ • $85 \mathrm{MSR}[\mathrm{km} / \mathrm{h}]$

Condutor 6 , Tratamento 2 , SegundoTrecho

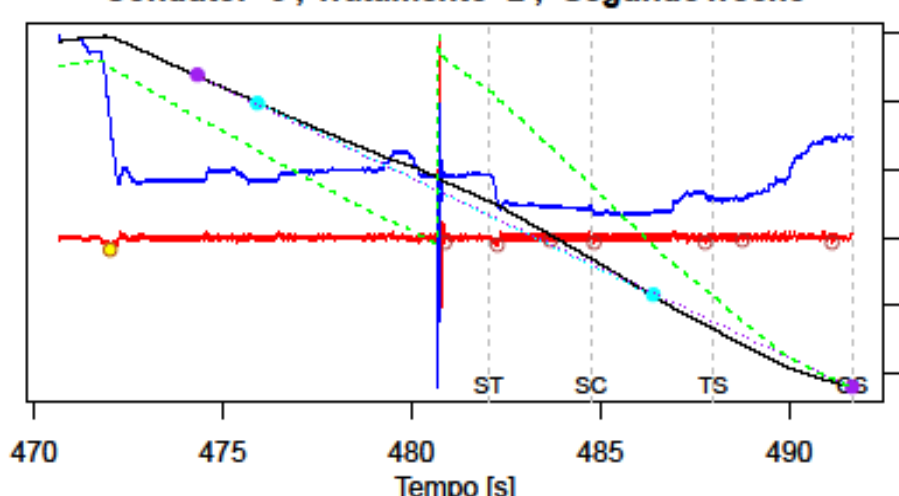

Jerks minimos $\left[\mathrm{m} / \mathrm{s}^{2}\right]$-DeltaV85 $[\mathrm{km} / \mathrm{h}]$ Jerk minimo $\left[\mathrm{m} / \mathrm{s}^{\mathrm{s}}\right]$ ? $85 \mathrm{MSR}[\mathrm{km} / \mathrm{h}]$

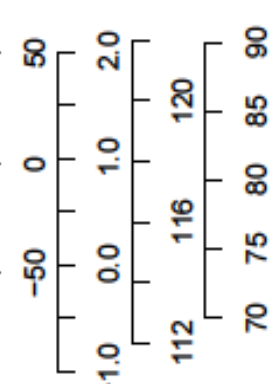

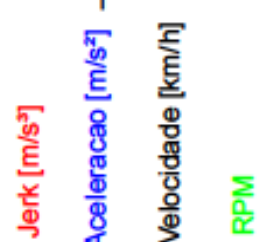

Condutor 6 , Tratamento 1 , SegundoTrecho

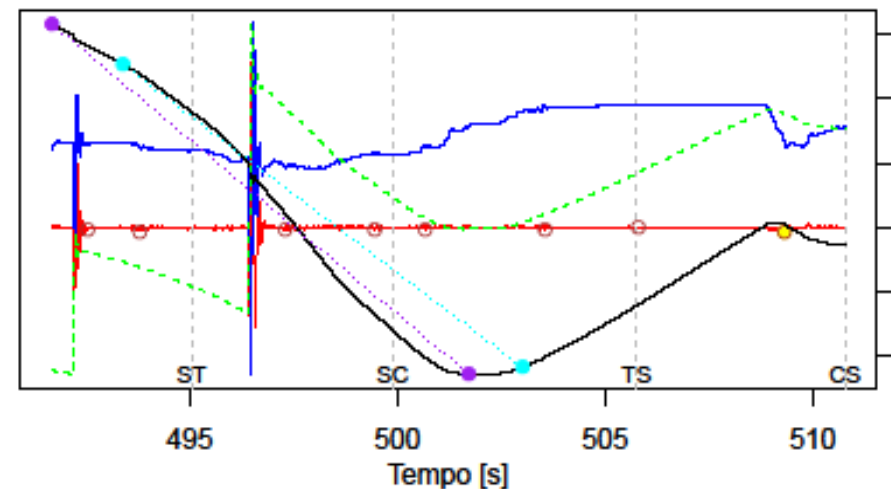

- Jerks minimos $[\mathrm{m} / \mathrm{s}]]$ - DeltaV85 $[\mathrm{km} / \mathrm{h}]$ Jerk minimo $[\mathrm{m} / \mathrm{s}] \mathrm{s}] \quad 85 \mathrm{MSR}[\mathrm{km} / \mathrm{h}]$

Condutor 6 , Tratamento 3 , SegundoTrecho

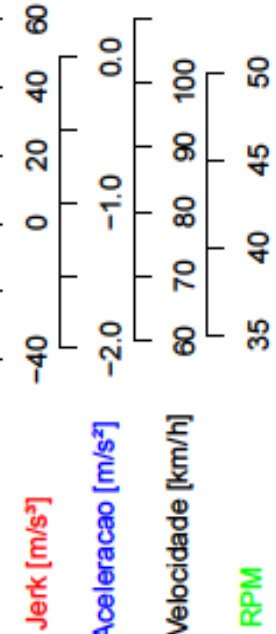

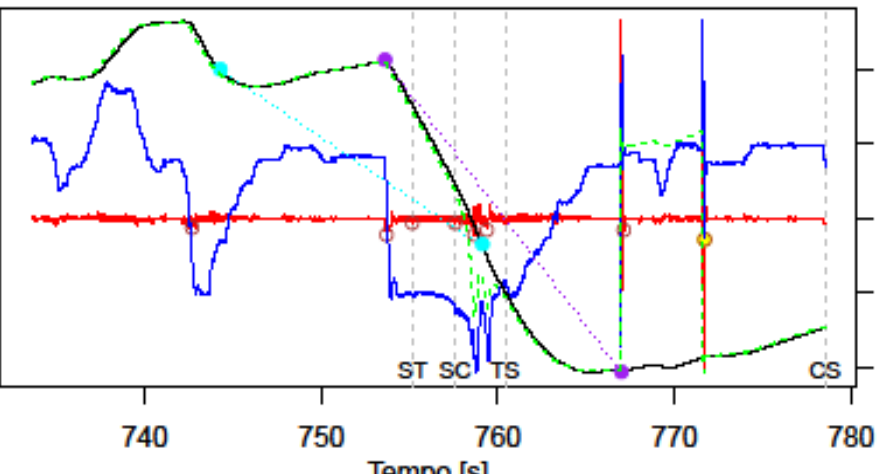
Jerks minimos $[\mathrm{m} / \mathrm{s}]$
Jerk minimo $\left[\mathrm{m} / \mathrm{s}^{\mathrm{s}}\right]$ - DeltaV85 $[\mathrm{km} / \mathrm{h}]$

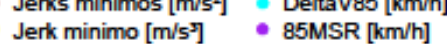

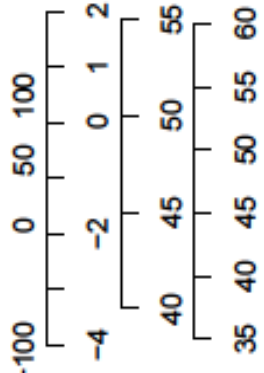

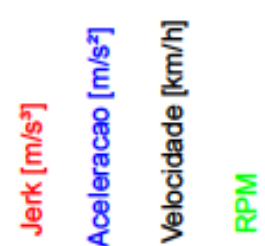

\section{.} . 


\section{Condutor 6 , Tratamento 4 , SegundoTrecho}

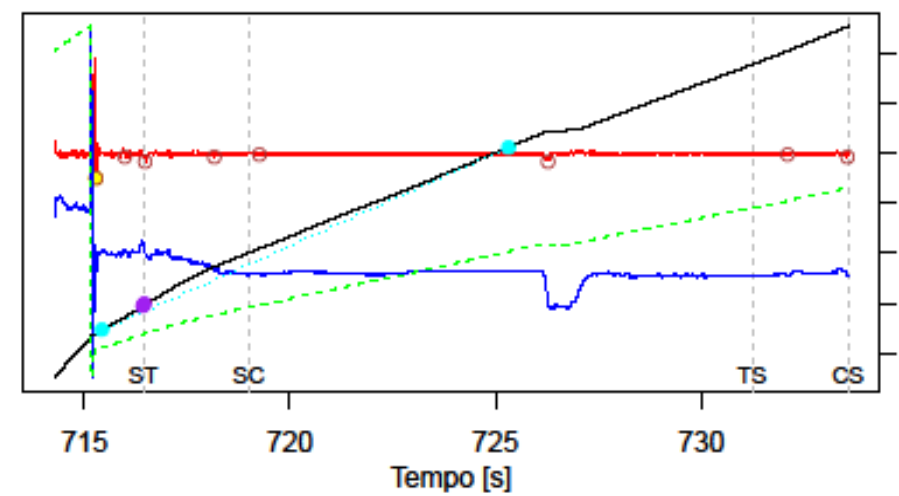

Jerks minimos $[\mathrm{m} / \mathrm{s}]$ DeltaV85 $[\mathrm{km} / \mathrm{h}]$ Jerk minimo $\left[\mathrm{m} / \mathrm{s}^{\mathrm{s}}\right]$ - $85 \mathrm{MSR}[\mathrm{km} / \mathrm{h}]$

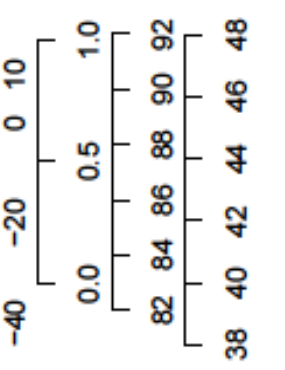

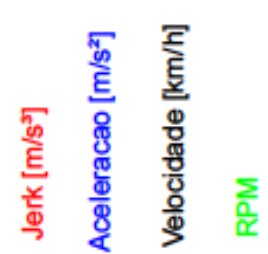

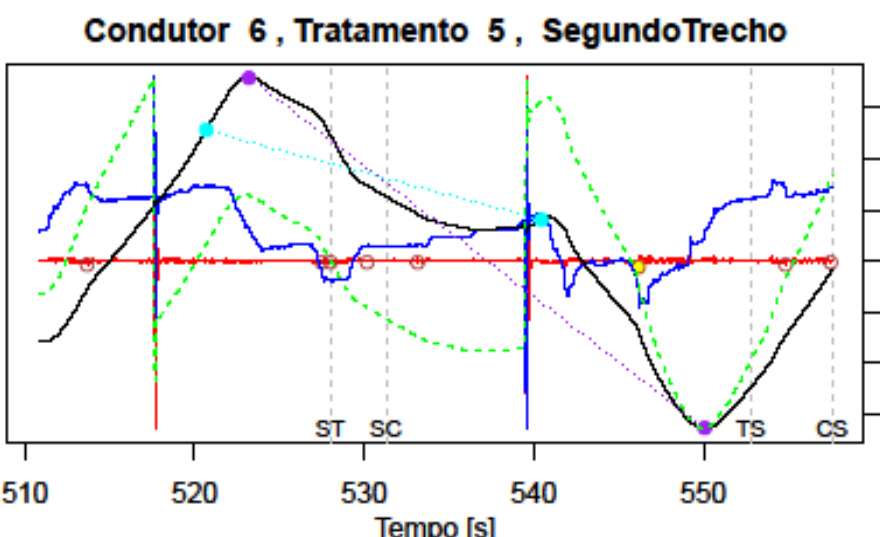

Jerks minimos $[\mathrm{m} / \mathrm{s}]$ - DeltaV85 $[\mathrm{km} / \mathrm{h}]$ Jerk minimo [m/s $/ \mathrm{s}]$ DeltaV85 $[\mathrm{km} / \mathrm{h}]$

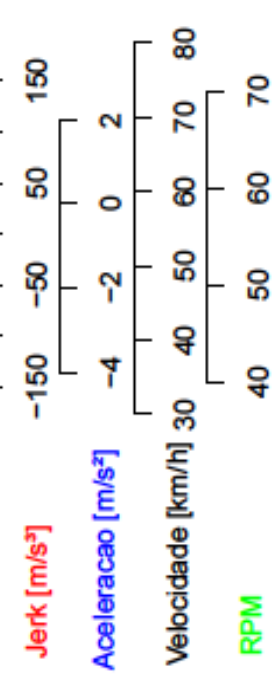

Condutor 6 , Tratamento 7 , SegundoTrecho

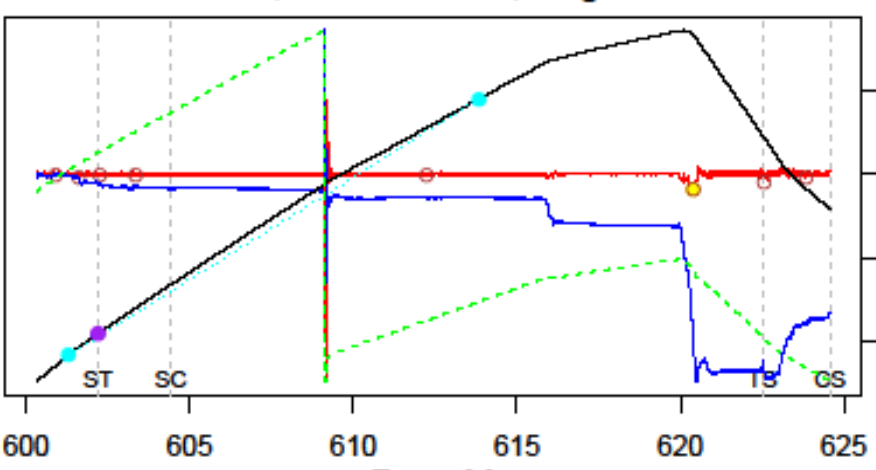

Jerks minimos [m/s'] DeltaV85 $[\mathrm{km} / \mathrm{h}]$
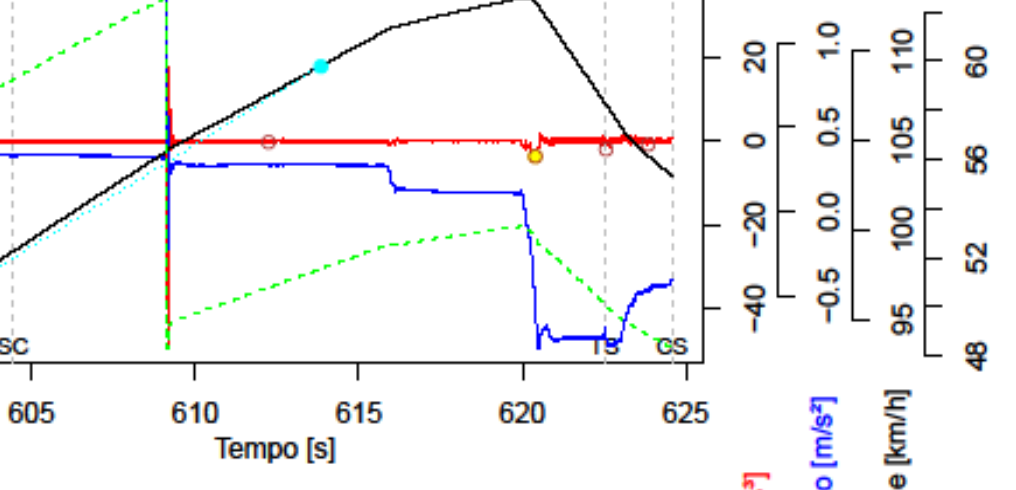

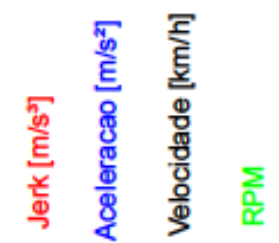

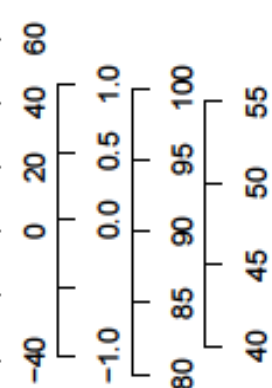

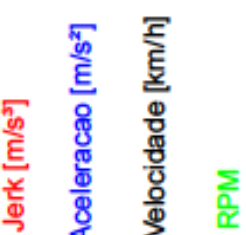

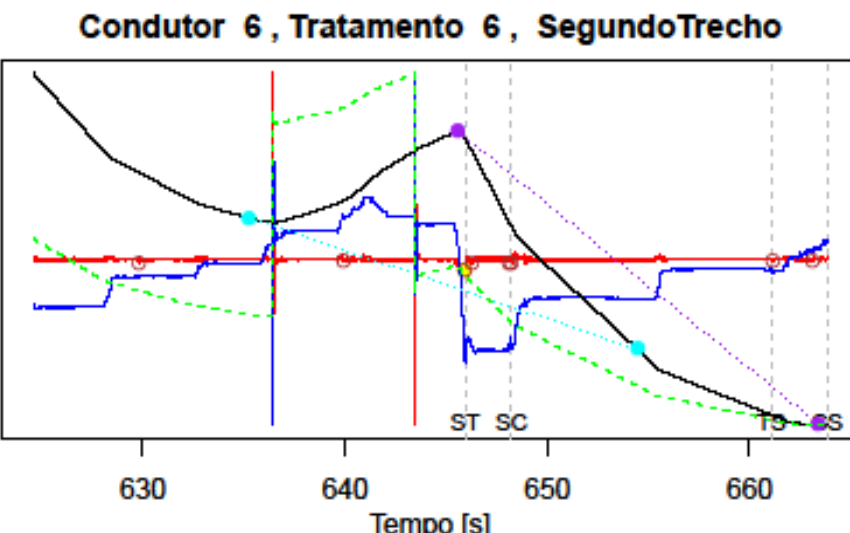

Jerks minimos $\left[\mathrm{m} / \mathrm{s}^{2}\right]$-DeltaV85 $[\mathrm{km} / \mathrm{h}]$ Jerk minimo $\left[\mathrm{m} / \mathrm{s}^{\mathrm{y}}\right]$ - $85 \mathrm{MSR}[\mathrm{km} / \mathrm{h}]$ 
Condutor 6 , Tratamento 8 , SegundoTrecho

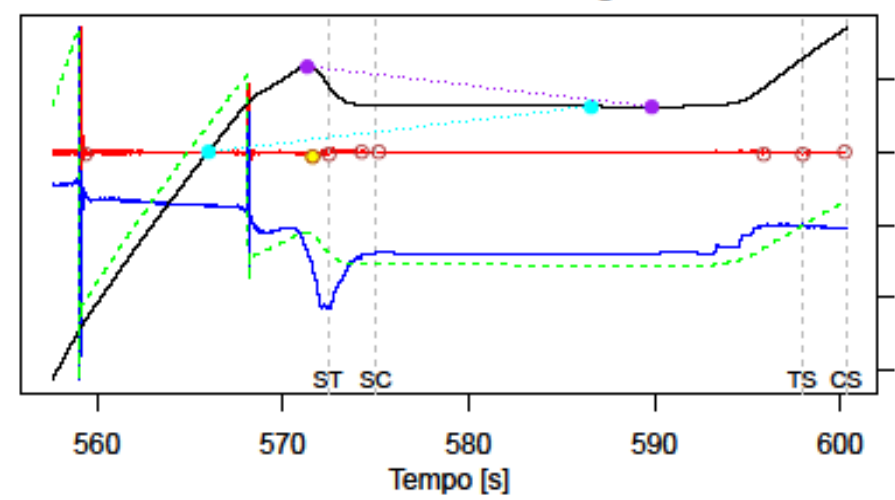

Jerks minimos [m/s'] DeltaV85 $[\mathrm{km} / \mathrm{h}]$ Jerk minimo [m/s?] $\quad 85 \mathrm{MSR}[\mathrm{km} / \mathrm{h}]$
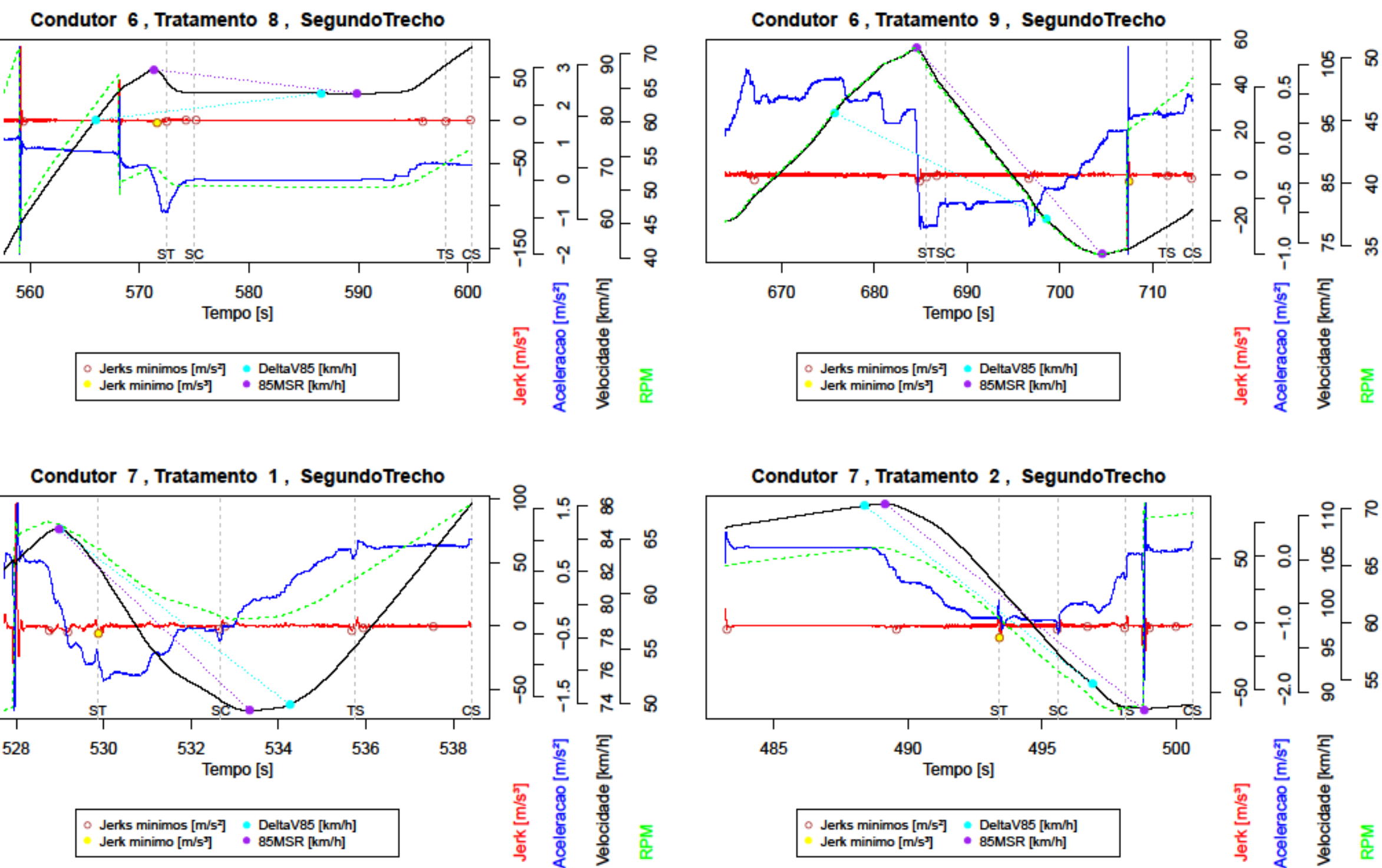
Jerks minimos [m/s $/$ DeltaV85 $[\mathrm{km} / \mathrm{h}]$ Jerk minimo $[\mathrm{m} / \mathrm{s}]$ 


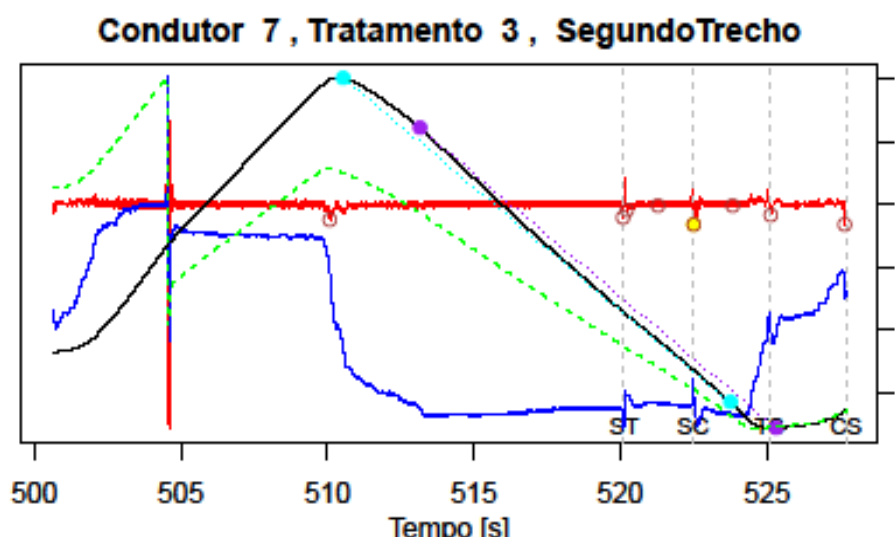

Jerks minimos [m/s $]$ - DeltaV85 $[\mathrm{km} / \mathrm{h}]$ Jerk minimo $\left[\mathrm{m} / \mathrm{s}^{\mathrm{j}}\right]$ - $85 \mathrm{MSR}[\mathrm{km} / \mathrm{h}]$

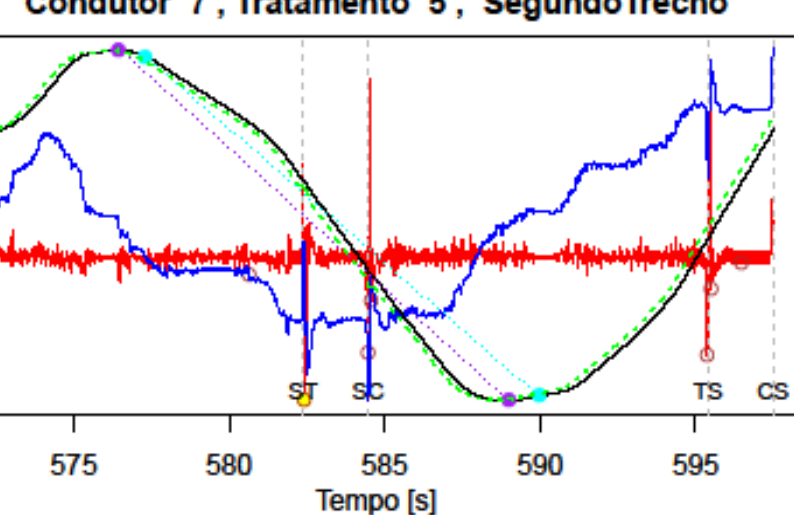

Jerks minimos $[\mathrm{m} / \mathrm{s}]]$ DeltaV85 $[\mathrm{km} / \mathrm{h}]$ Jerk minimo $[\mathrm{m} / \mathrm{s} \mathrm{s}]$ - $85 \mathrm{MSR}[\mathrm{km} / \mathrm{h}]$

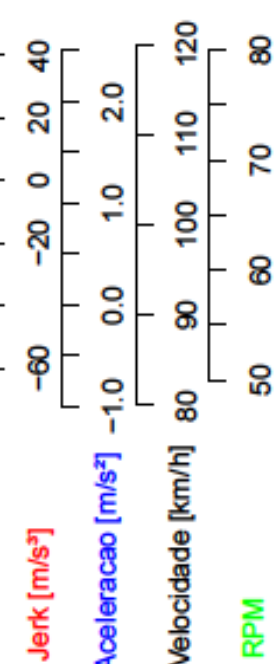

Condutor 7 , Tratamento 4 , SegundoTrecho

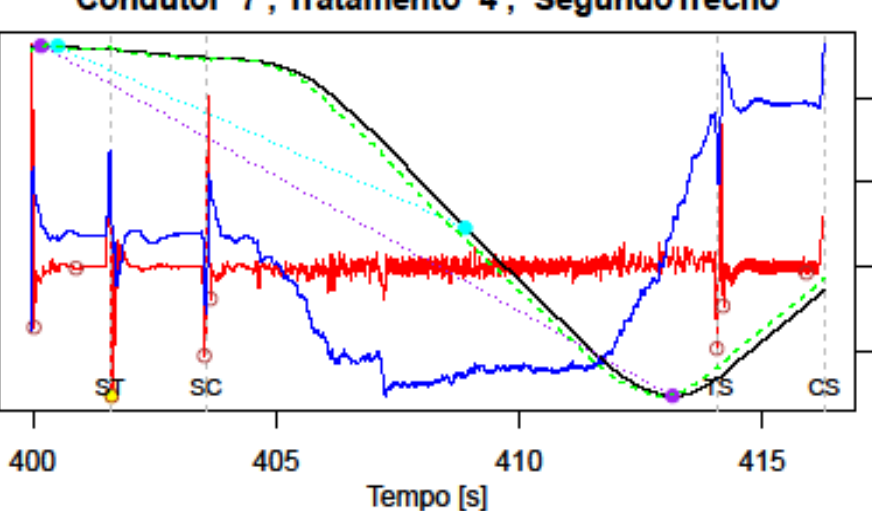

Jerks minimos $[\mathrm{m} / \mathrm{s}$ ₹ $\quad$ DeltaV85 $[\mathrm{km} / \mathrm{h}]$ Jerk minimo $[\mathrm{m} / \mathrm{s} / \mathrm{s}]$ 85MSR $[\mathrm{km} / \mathrm{h}]$

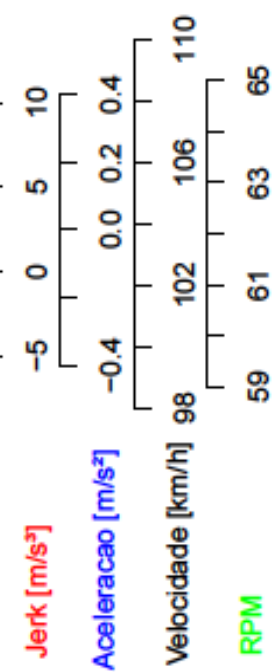

Condutor 7 , Tratamento 6 , SegundoTrecho

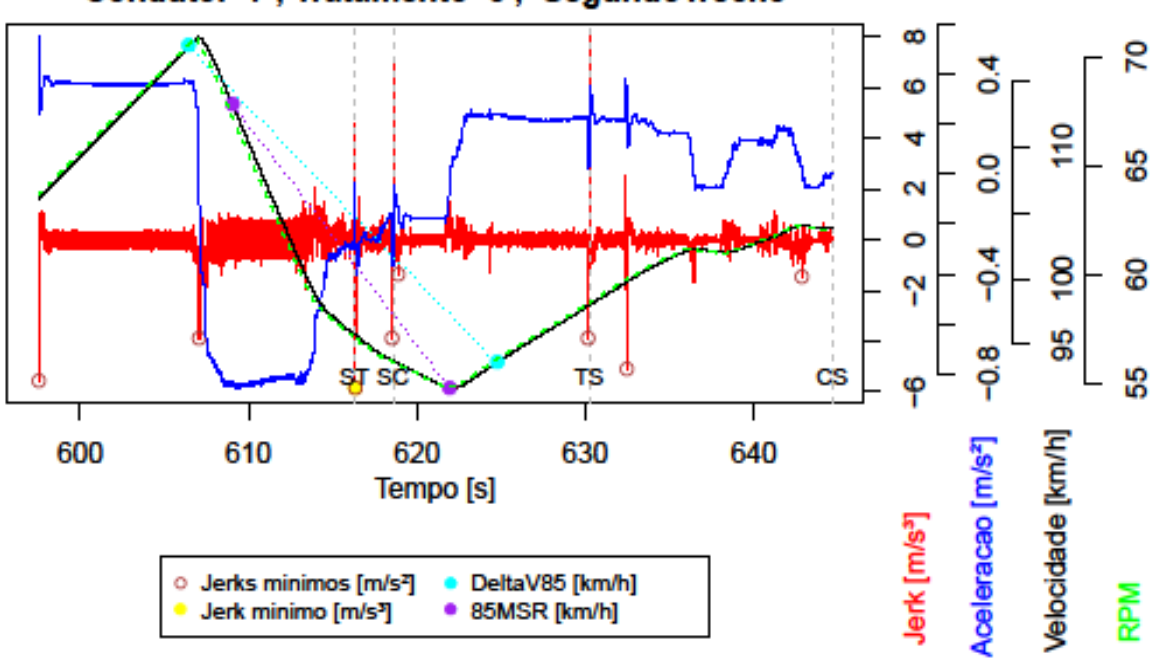


Condutor 7 , Tratamento 7 , SegundoTrecho

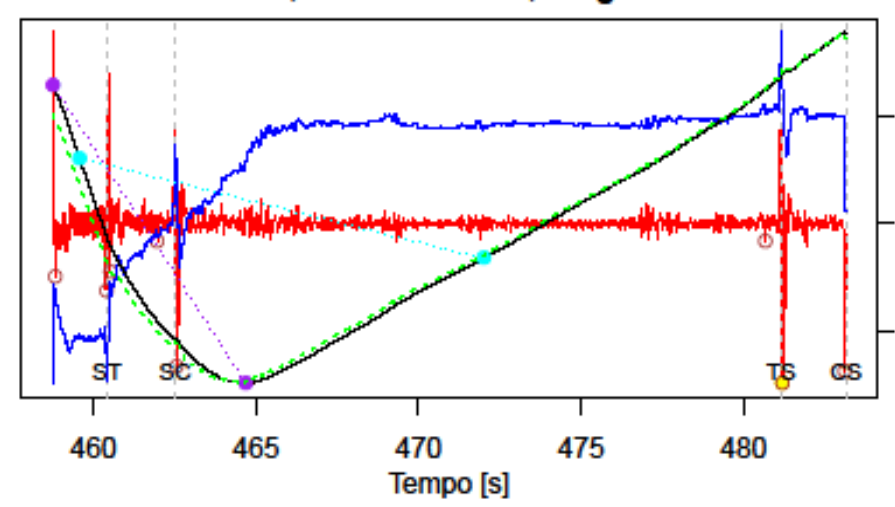

Jerks minimos $[\mathrm{m} / \mathrm{s}]$ - DeltaV85 $[\mathrm{km} / \mathrm{h}]$ Jerk minimo [m/s? $\bullet 85 \mathrm{MSR}[\mathrm{km} / \mathrm{h}]$

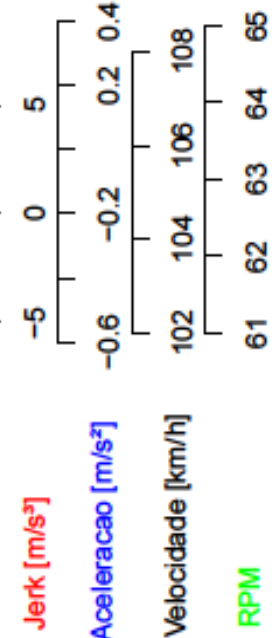

Condutor 7 , Tratamento 9 , SegundoTrecho

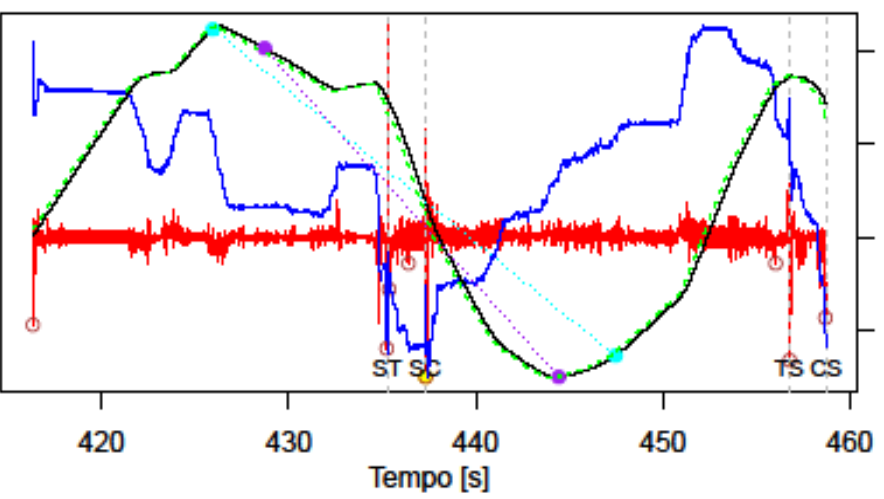

Jerks minimos $\left[\mathrm{m} / \mathrm{s}^{2}\right]$ - DeltaV85 $[\mathrm{km} / \mathrm{h}]$ Jerk minimo $\left[\mathrm{m} / \mathrm{s}^{\mathrm{s}}\right]$ ? $85 \mathrm{MSR}[\mathrm{km} / \mathrm{h}]$

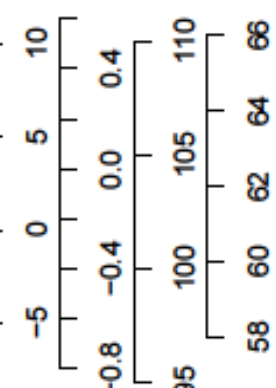

60

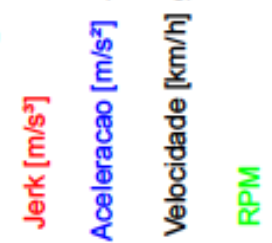

Condutor 7 , Tratamento 8 , SegundoTrecho

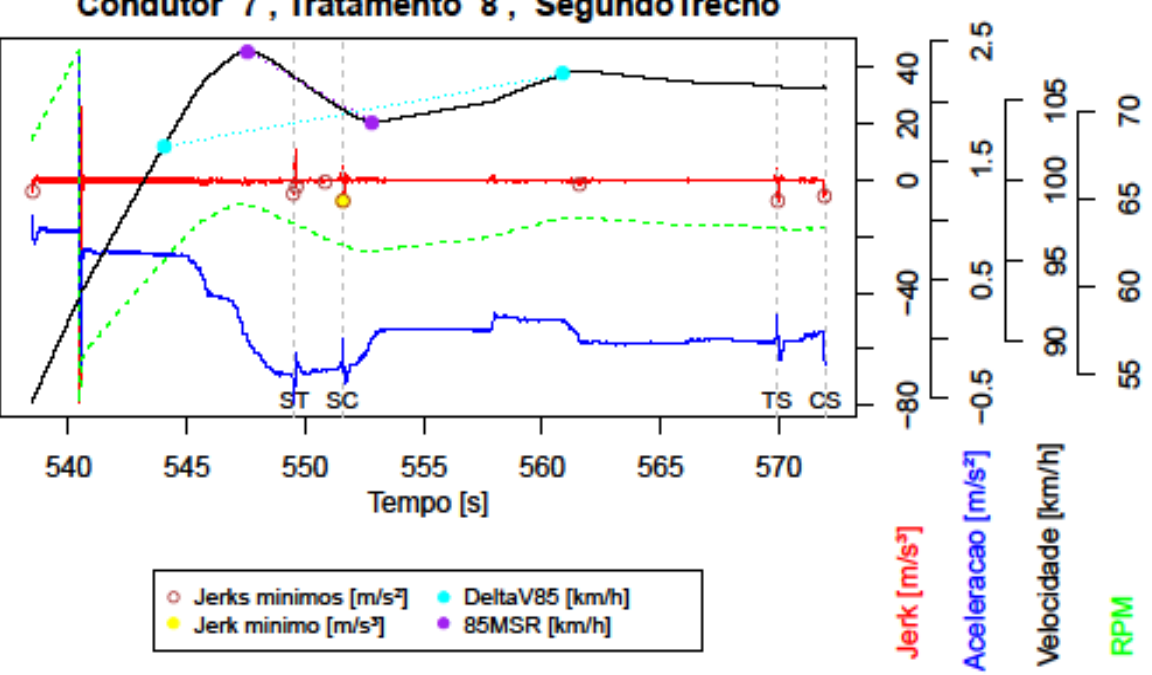

Condutor 8 , Tratamento 1 , SegundoTrecho

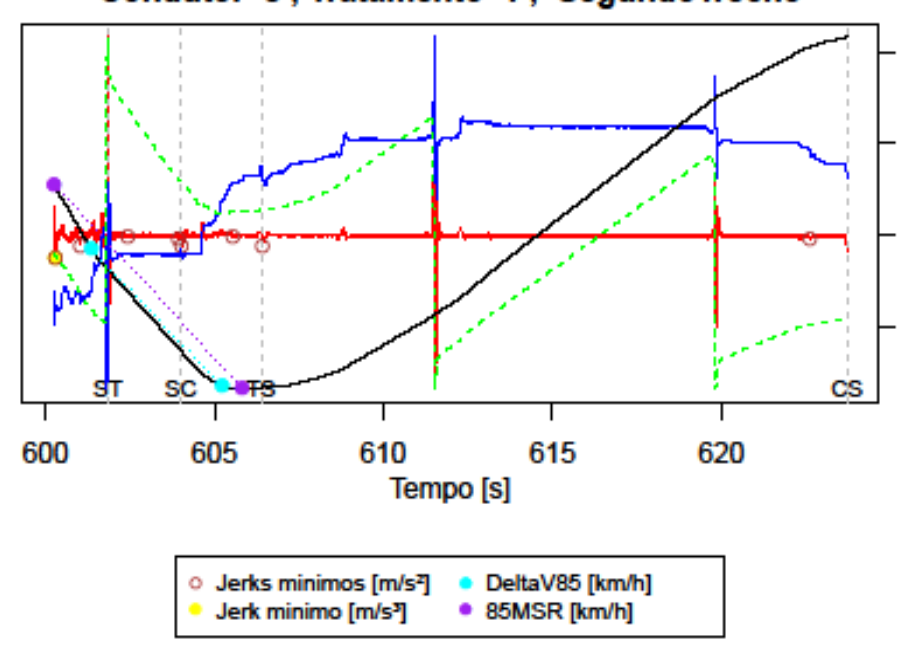



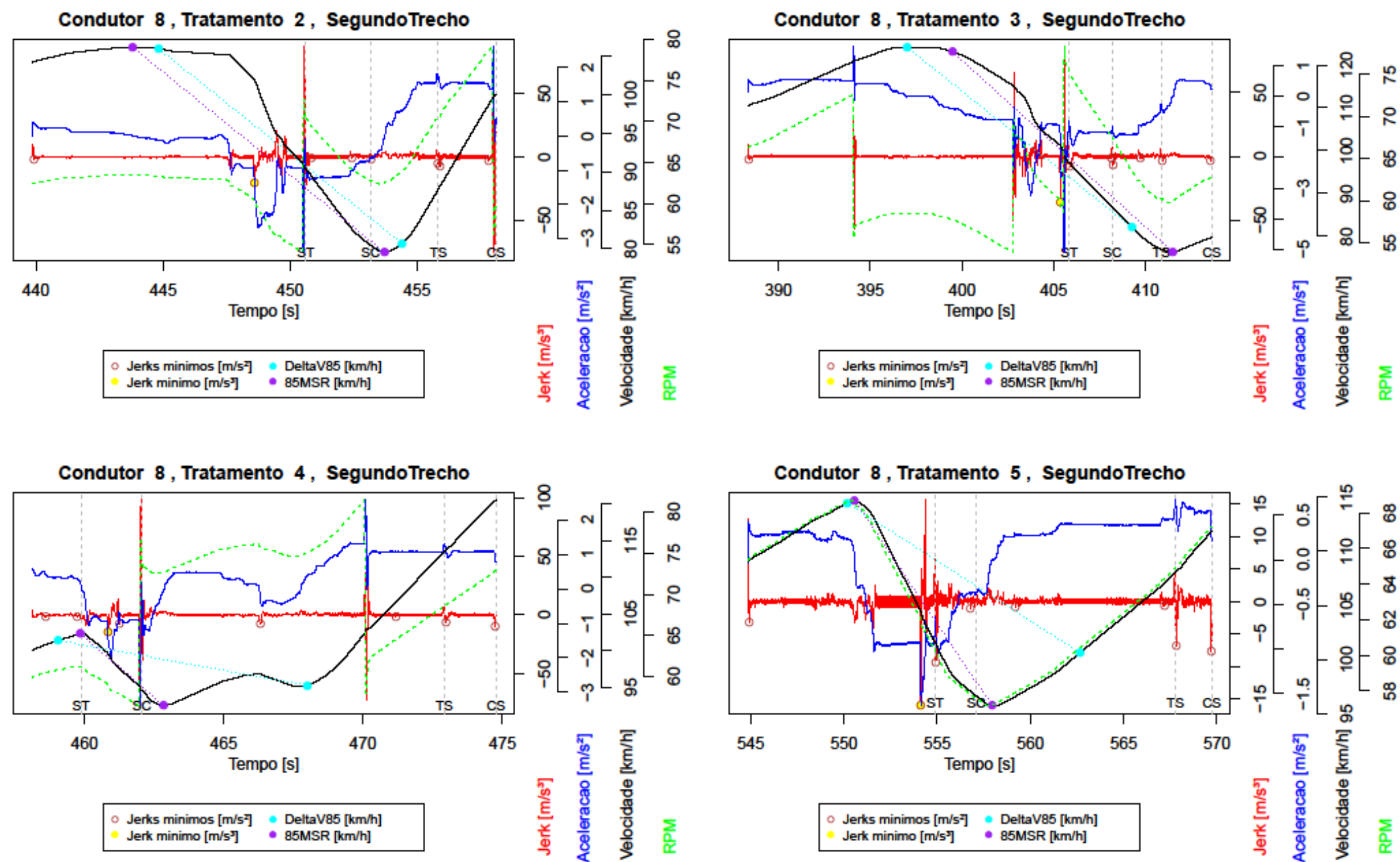
Jerks minimos $\left[\mathrm{m} / \mathrm{s}^{\mathrm{z}}\right]$
Jerk minimo $\left[\mathrm{m} / \mathrm{s}^{\mathrm{s}}\right]$ - DeltaV85 $[\mathrm{km} / \mathrm{h}]$

Jerks minimos $[\mathrm{m} / \mathrm{s}]$ - DeltaV85 $[\mathrm{km} / \mathrm{h}]$ Jerk minimo [m/s $]$ • $85 \mathrm{MSR}[\mathrm{km} / \mathrm{h}]$

Jerks minimos $\left[\mathrm{m} / \mathrm{s}^{2}\right]$ DeltaV85 $[\mathrm{km} / \mathrm{h}]$ • $85 \mathrm{MSR}[\mathrm{km} / \mathrm{h}]$ 
Condutor 8 , Tratamento 6 , SegundoTrecho

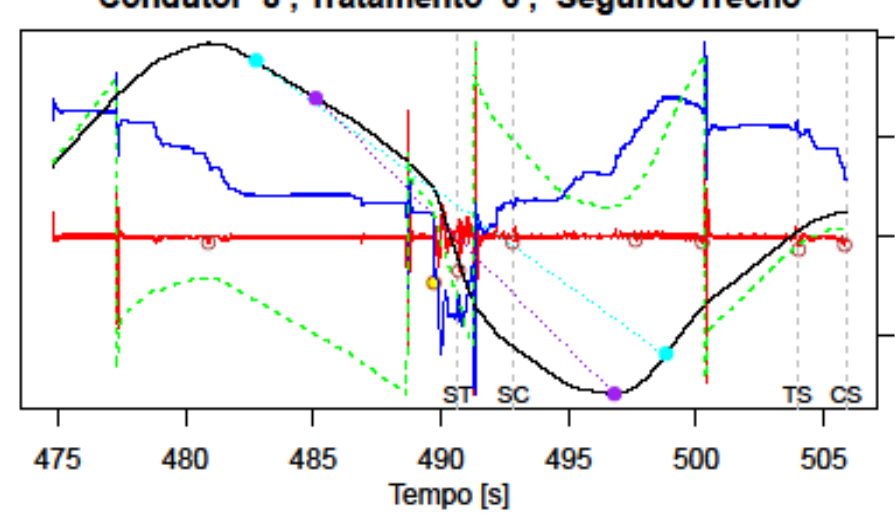

Jerks minimos [m/s'] DeltaV85 $[\mathrm{km} / \mathrm{h}]$ Jerk minimo [m/s

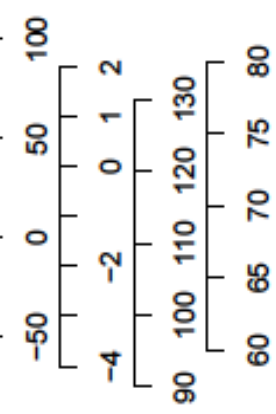

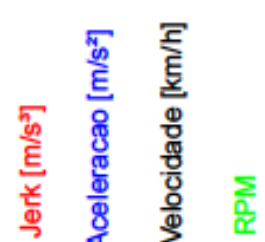

Condutor 8 , Tratamento 8 , SegundoTrecho

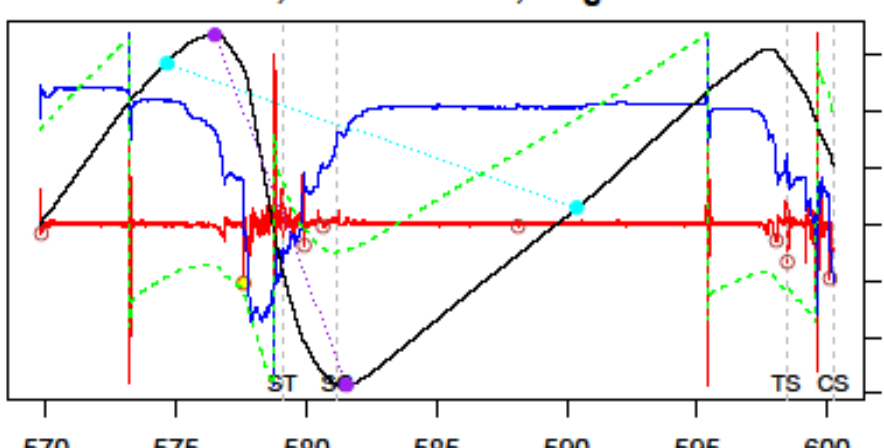

570

575

580

585

600

Tempo [s]

Jerks minimos $[\mathrm{m} / \mathrm{s}$ ] $\rightarrow$ DeltaV85 $[\mathrm{km} / \mathrm{h}]$ Jerk minimo $[\mathrm{m} / \mathrm{s} / \mathrm{s}]$ - $85 \mathrm{MSR}[\mathrm{km} / \mathrm{h}]$
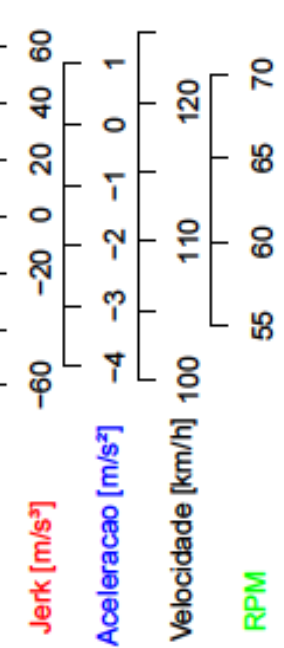

\section{Condutor 8 , Tratamento 7 , SegundoTrecho}

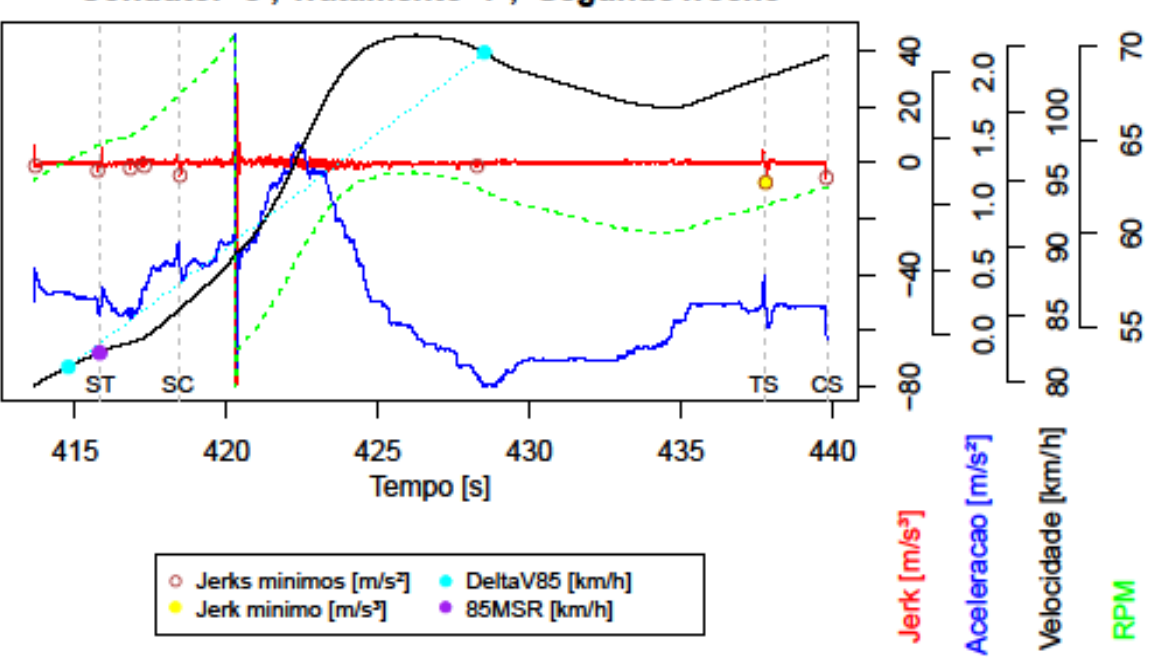

Condutor 8 , Tratamento 9 , SegundoTrecho

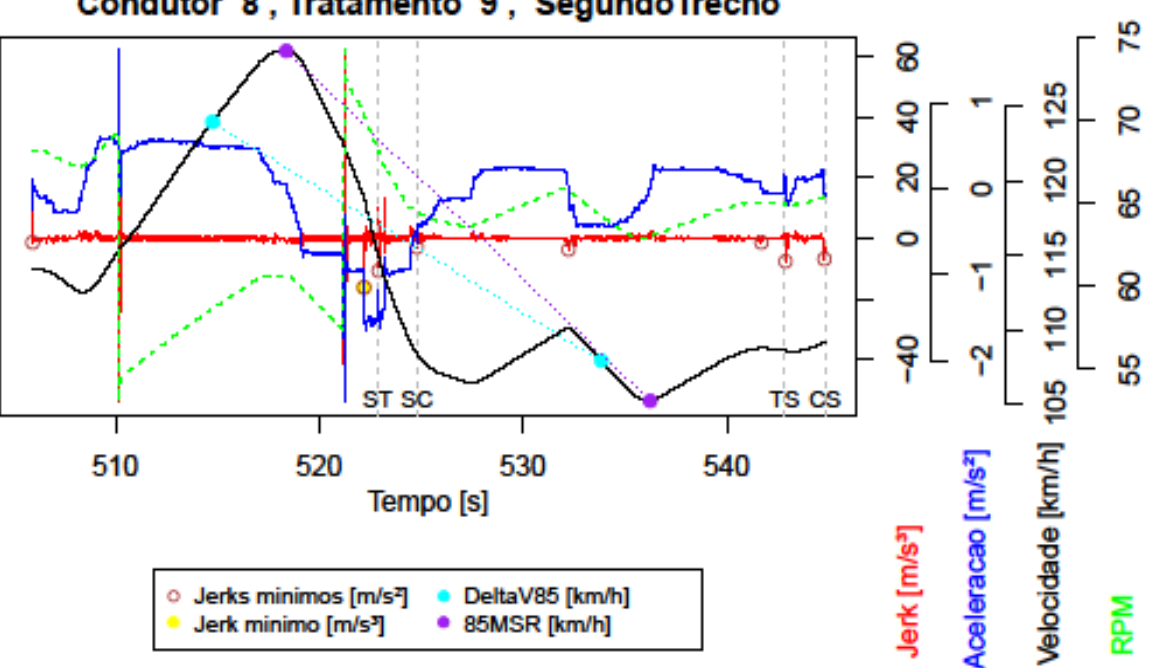


Condutor 9 , Tratamento 1 , SegundoTrecho

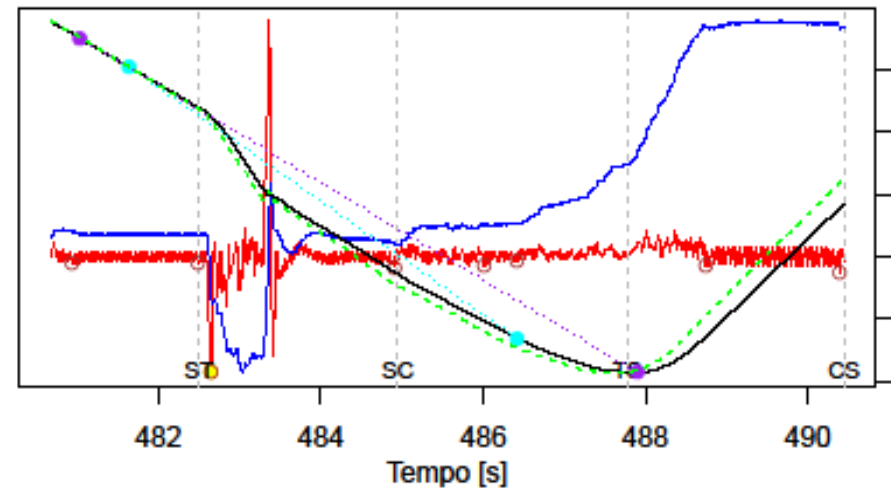

Jerks minimos $[\mathrm{m} / \mathrm{s}]$ - DeltaV85 $[\mathrm{km} / \mathrm{h}]$ Jerk ming [m/s $\bullet \quad 85 \mathrm{MSR}[\mathrm{km} / \mathrm{h}]$ cs

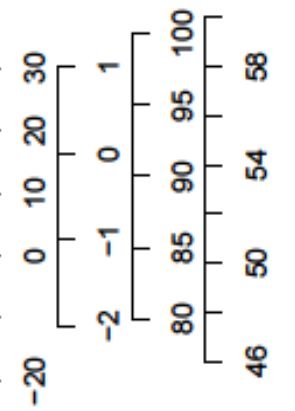

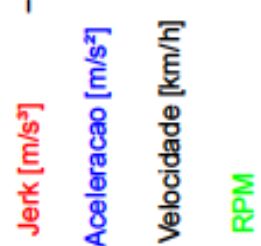

Condutor 9, Tratamento 2 , SegundoTrecho

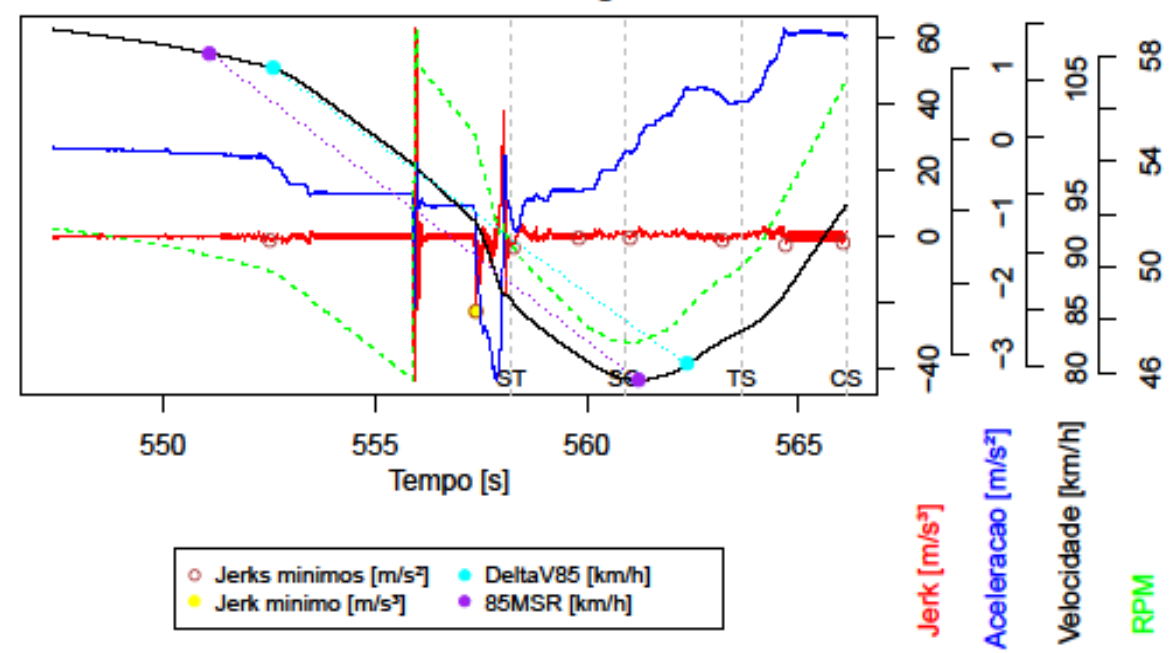

Condutor 9 , Tratamento 4 , SegundoTrecho

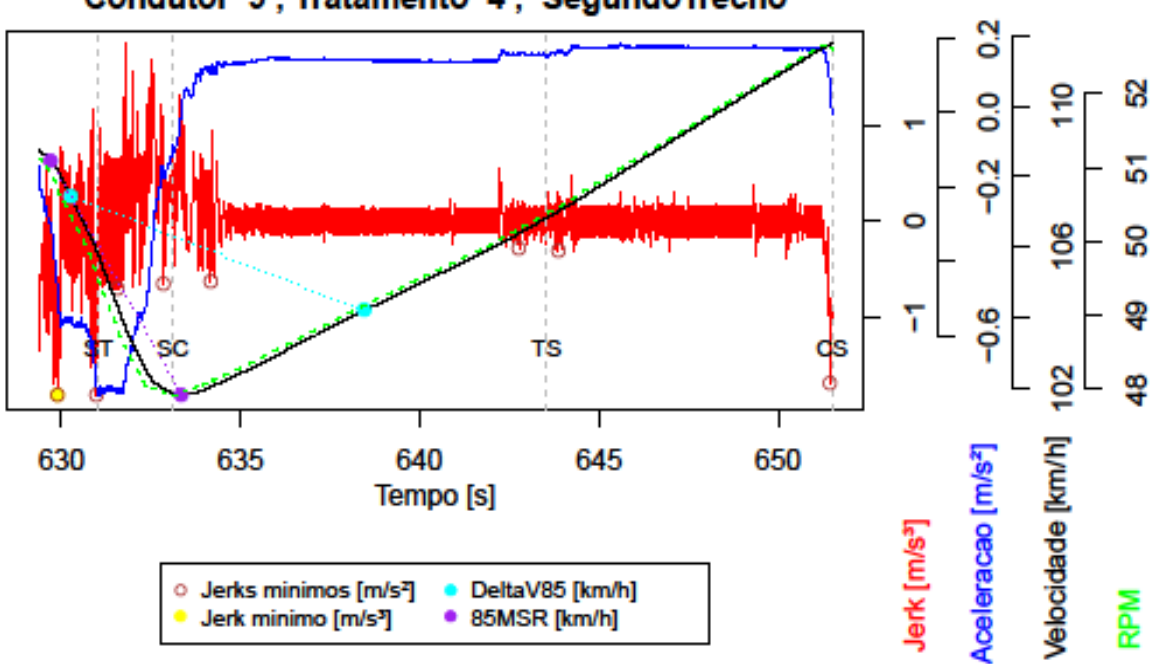

Jerk minim [m/

\section{๓̊}

\section{:}

\section{Condutor 9 , Tratamento 3 , SegundoTrecho}

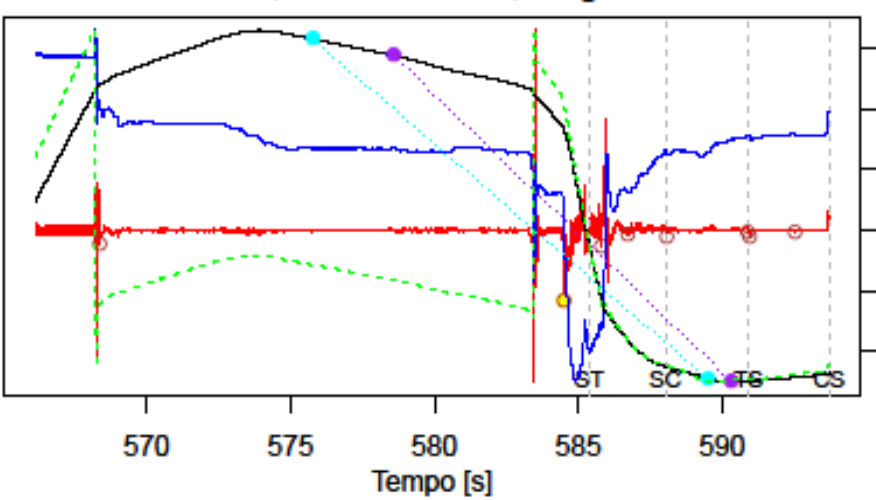
Jerks minimos $\left[\mathrm{m} / \mathrm{s}^{\mathrm{z}}\right]$
Jerk minimo $\left[\mathrm{m} / \mathrm{s}^{2}\right]$ - DeltaV85 $[\mathrm{km} / \mathrm{h}]$

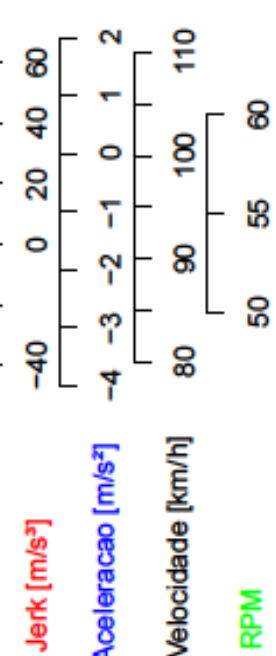


Condutor 9 , Tratamento 5 , SegundoTrecho

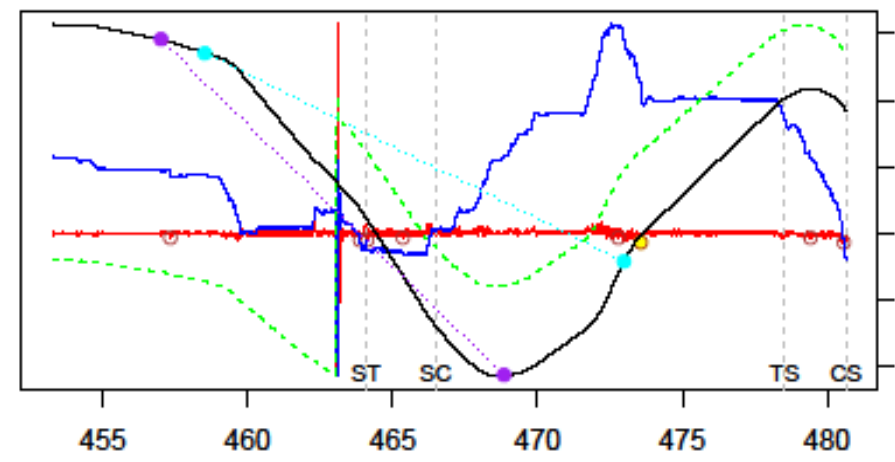

Jerks minimos [m/s'] - DeltaV85 $[\mathrm{km} / \mathrm{h}]$ Jerk minimo $[\mathrm{m} / \mathrm{s}$ ? $\quad$ - $85 \mathrm{MSR}[\mathrm{km} / \mathrm{h}]$

\section{Condutor 9 , Tratamento 7 , SegundoTrecho}

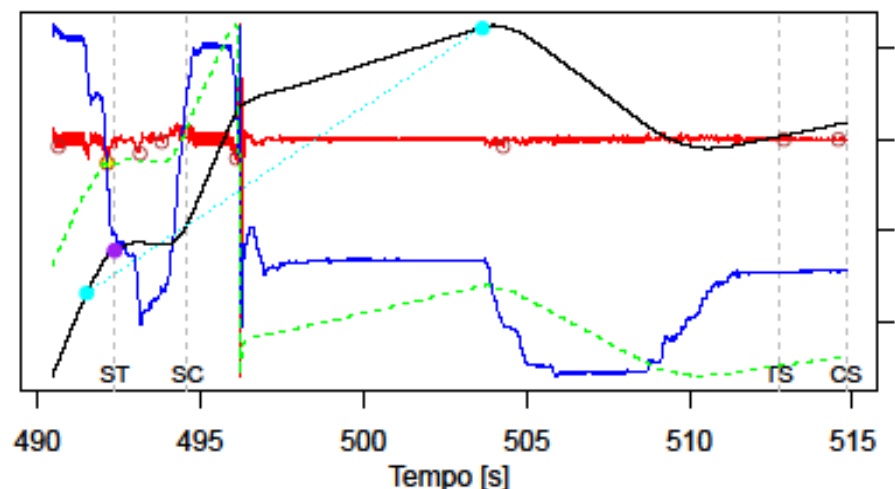

Jerks minimos $[\mathrm{m} / \mathrm{s}$ 2] - DeltaV85 $[\mathrm{km} / \mathrm{h}]$ Jerk minimo $\left.\left[\mathrm{m} / \mathrm{s}^{\mathrm{s}}\right] \mathrm{s}\right]$ : $85 \mathrm{MSR}[\mathrm{km} / \mathrm{h}]$

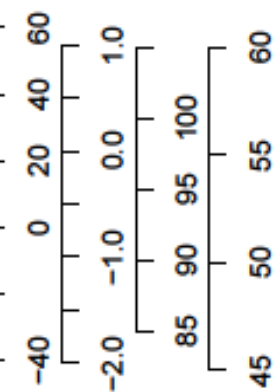

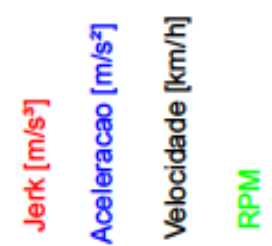

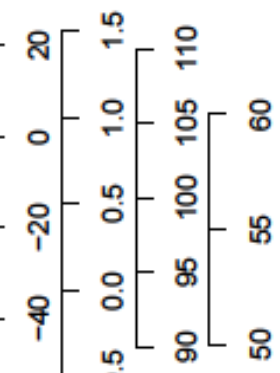

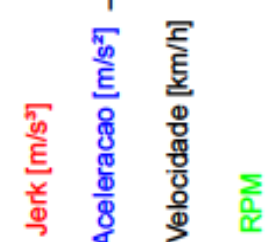

Condutor 9 , Tratamento 6 , SegundoTrecho

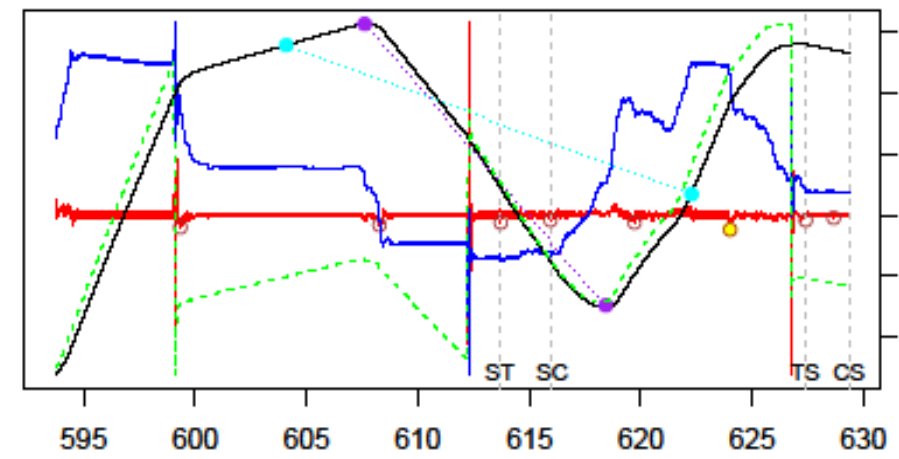

Jerks minimos $\left[\mathrm{m} / \mathrm{s}^{2}\right]$ DeltaV85 $[\mathrm{km} / \mathrm{h}]$ Jerk minimo $\left[\mathrm{m} / \mathrm{s}^{\mathrm{s}}\right]$ - $85 \mathrm{MSR}[\mathrm{km} / \mathrm{h}]$

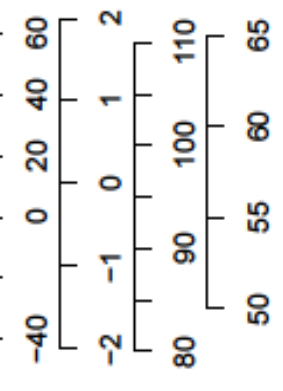

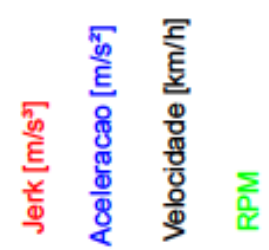

Condutor 9 , Tratamento 8 , SegundoTrecho

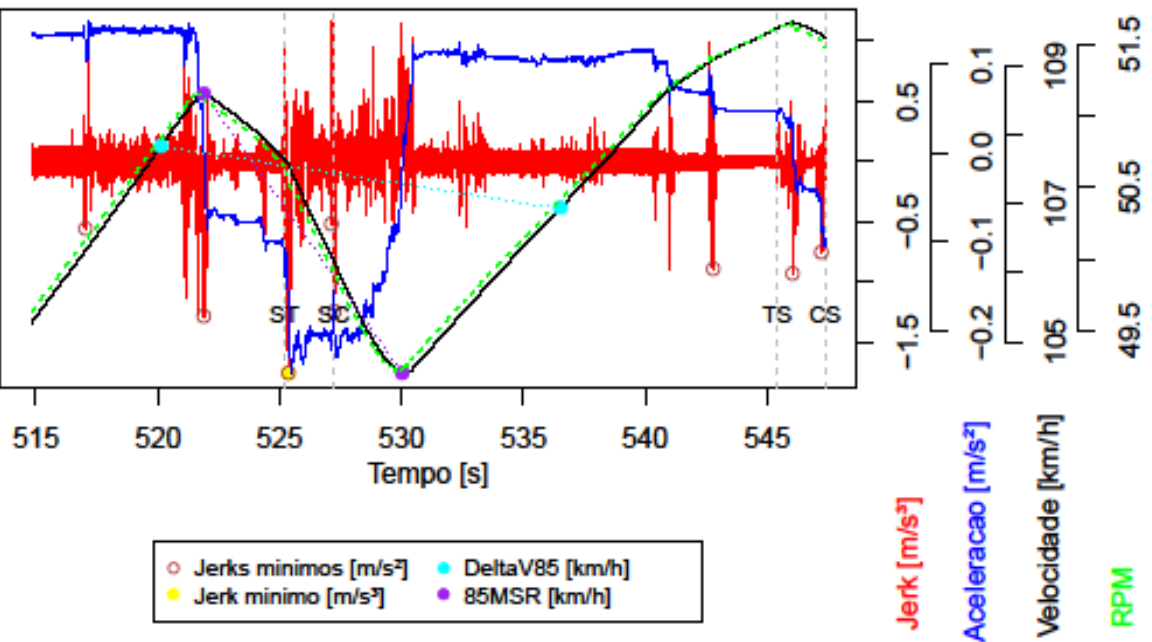




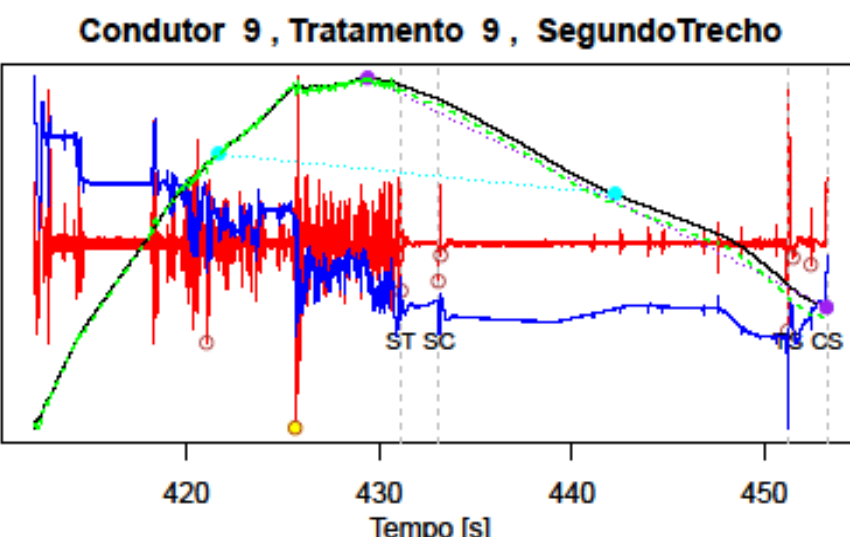

Jerks minimos $[\mathrm{m} / \mathrm{s}]$ - DeltaV85 $[\mathrm{km} / \mathrm{h}]$ Jerk minimo [m/s

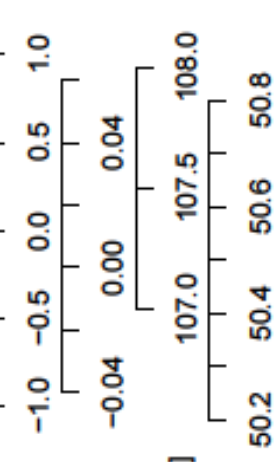

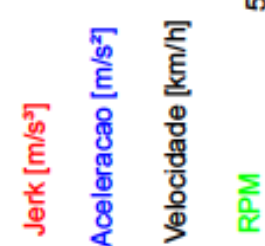

Condutor 10 , Tratamento 1 , SegundoTrecho

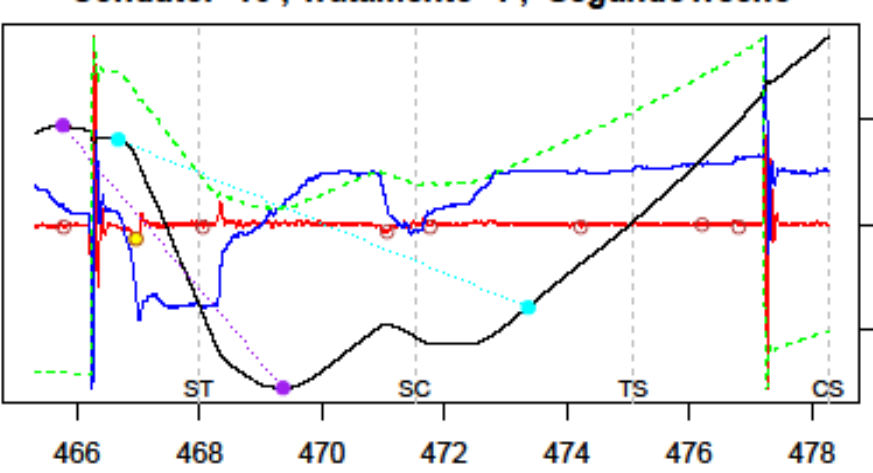
Jerks minimos $\left[\mathrm{m} / \mathrm{s}^{\mathrm{s}}\right]$ : DeltaV85 $[\mathrm{km} / \mathrm{h}]$ Jerk minimo $[\mathrm{m} / \mathrm{s}]$ 85MSR [km/h]

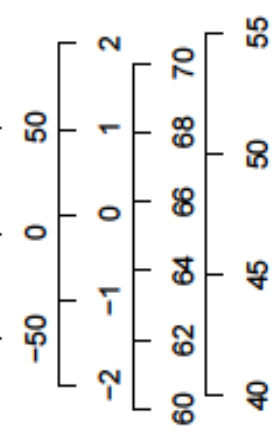

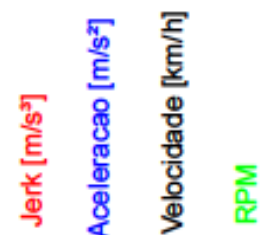

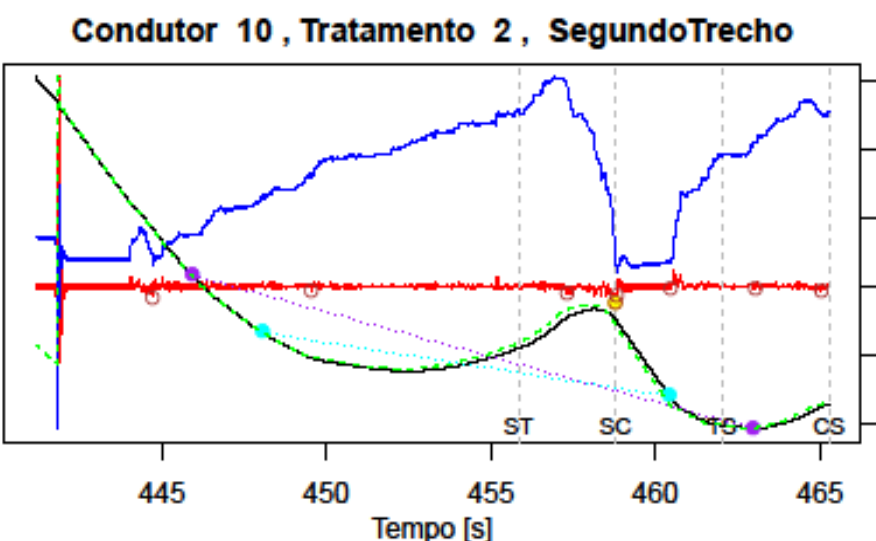

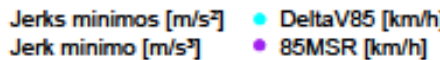

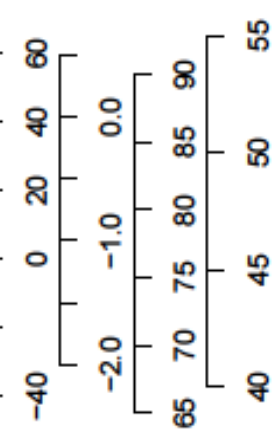

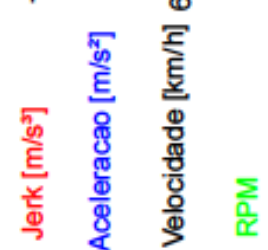

Condutor 10 , Tratamento 3 , SegundoTrecho

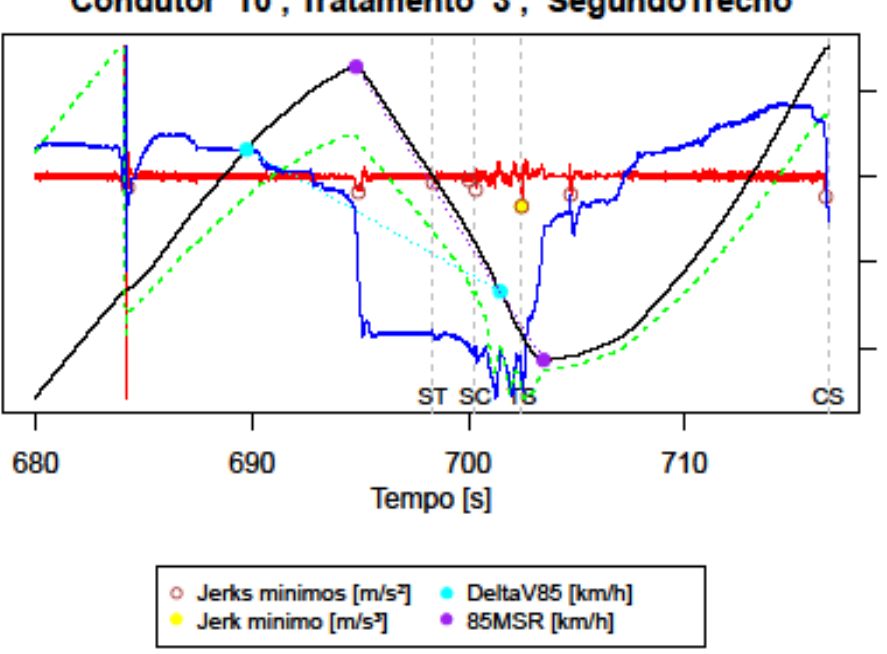

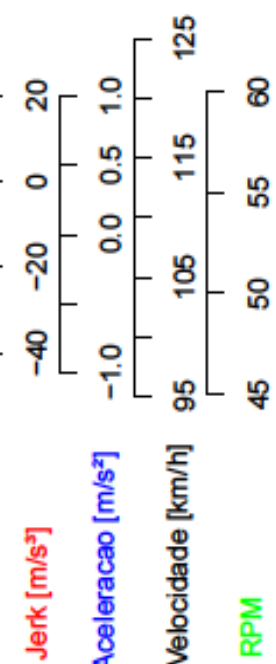


Condutor 10 , Tratamento 4 , SegundoTrecho

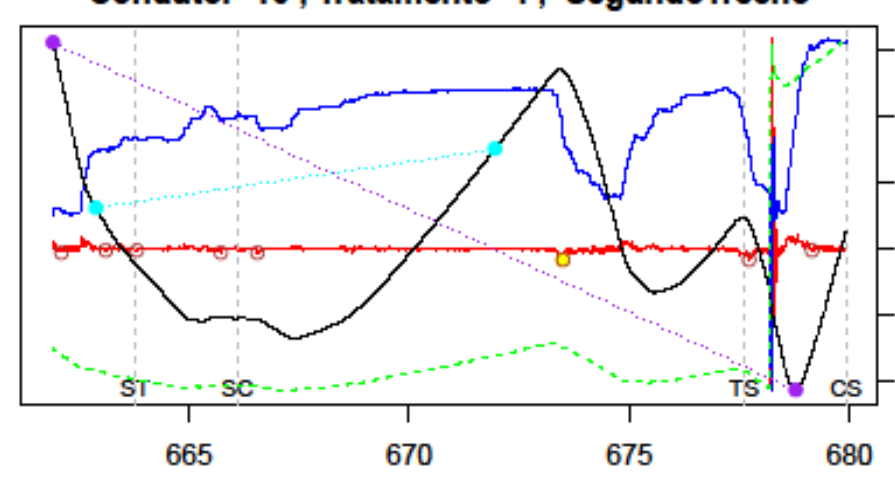
$\begin{aligned} & \text { Jerks minimos }\left[\mathrm{m} / \mathrm{s}^{2}\right] \\ & \text { Jerk minimo }\left[\mathrm{m} / \mathrm{s}^{\mathrm{s}}\right]\end{aligned}-$ DeltaV85 $[\mathrm{km} / \mathrm{h}]$

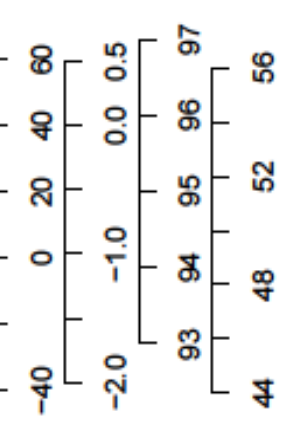

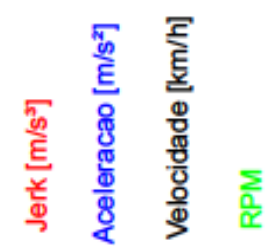

Condutor 10 , Tratamento 5 , SegundoTrecho

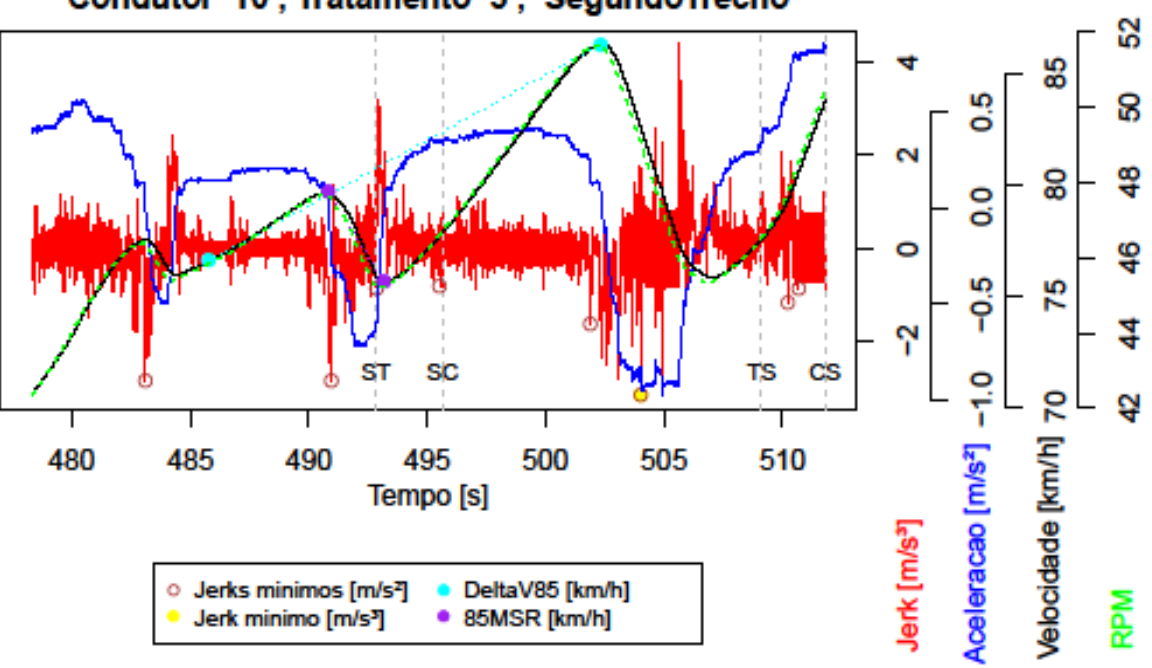

Condutor 10 , Tratamento 7 , SegundoTrecho

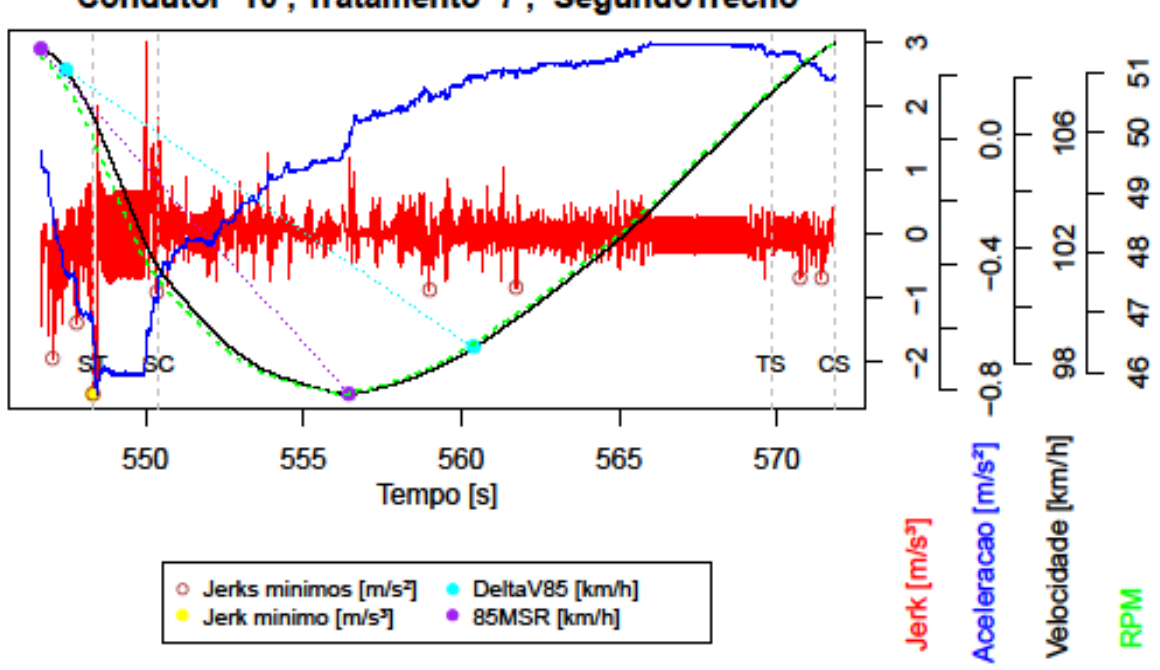

Jerk minimo [m/s']
พ ช
Condutor 10 , Tratamento 6 , SegundoTrecho

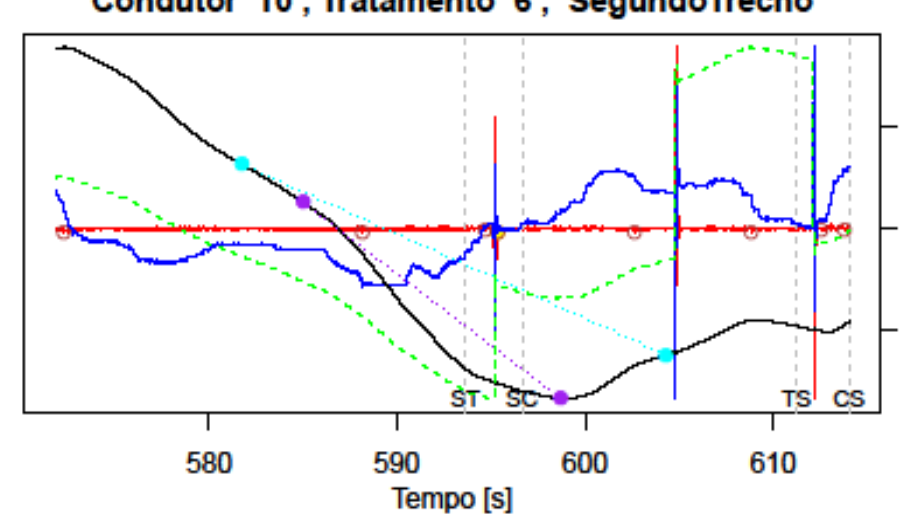

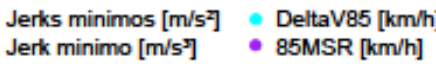

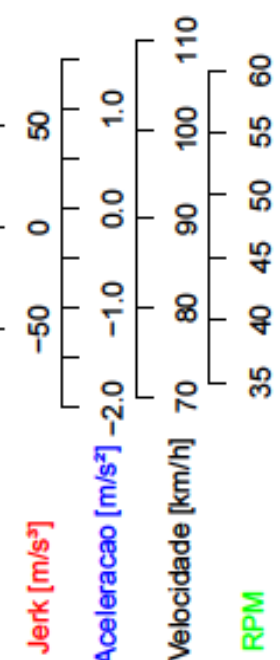


Condutor 10 , Tratamento 8 , SegundoTrecho

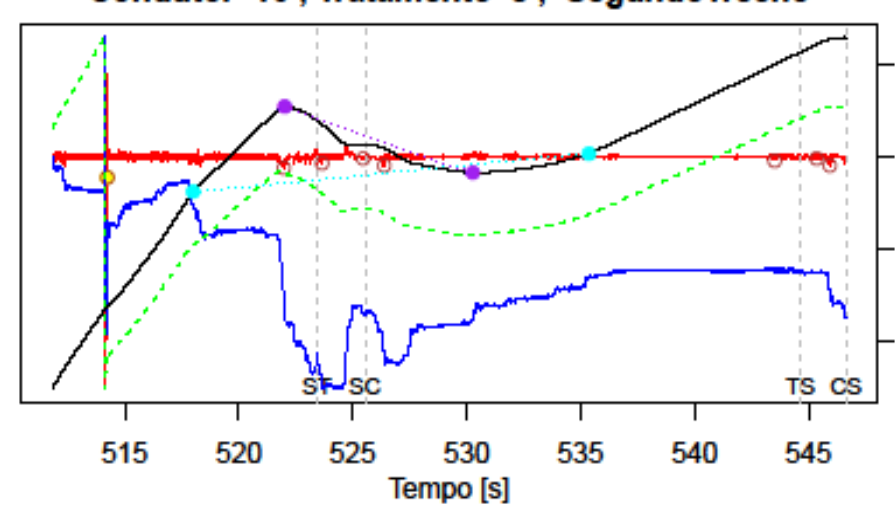

- Jerks minimos $[\mathrm{m} / \mathrm{s}]]$ - DeltaV85 $[\mathrm{km} / \mathrm{h}]$ Jerk minimo [m/s

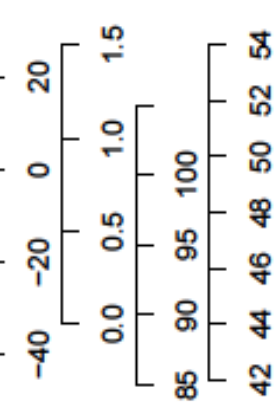

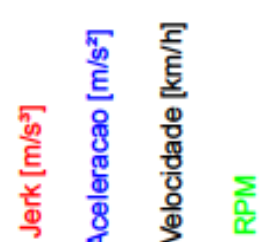

Condutor 10 , Tratamento 9 , SegundoTrecho

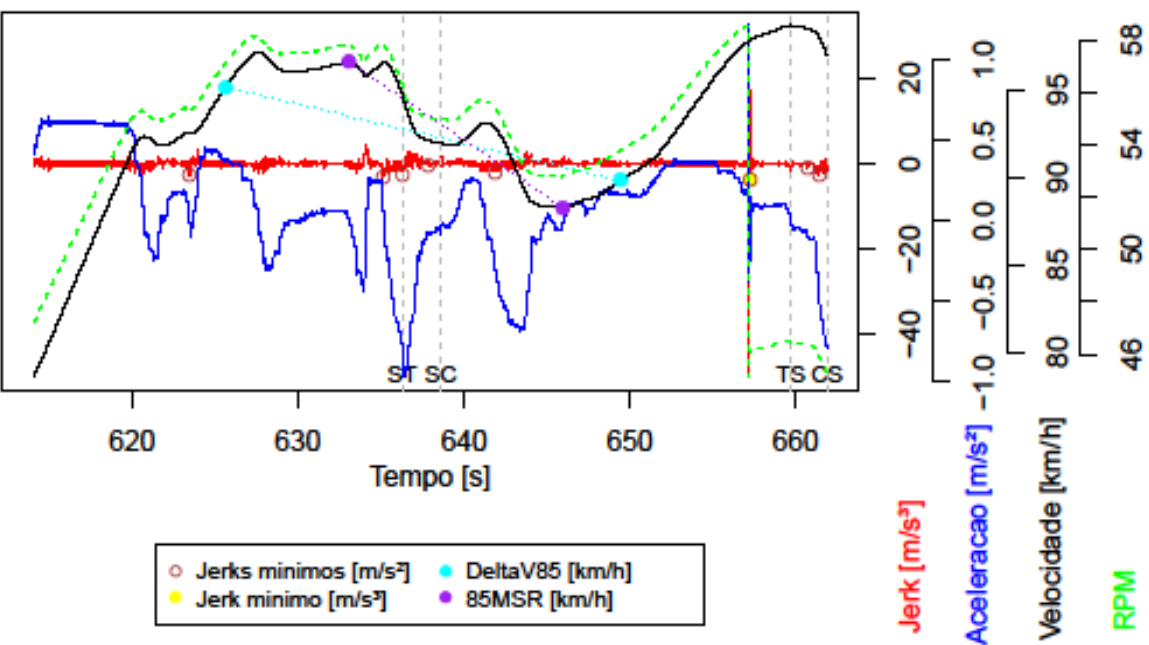

Condutor 11 , Tratamento 2 , SegundoTrecho

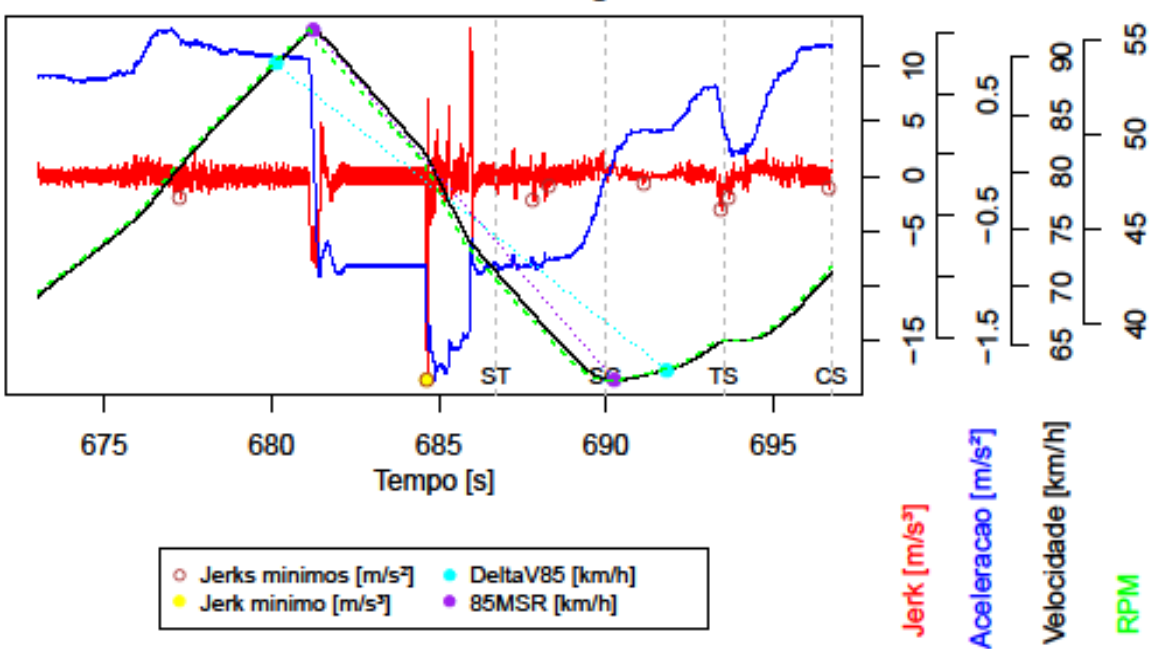

Condutor 11 , Tratamento 1 , SegundoTrecho

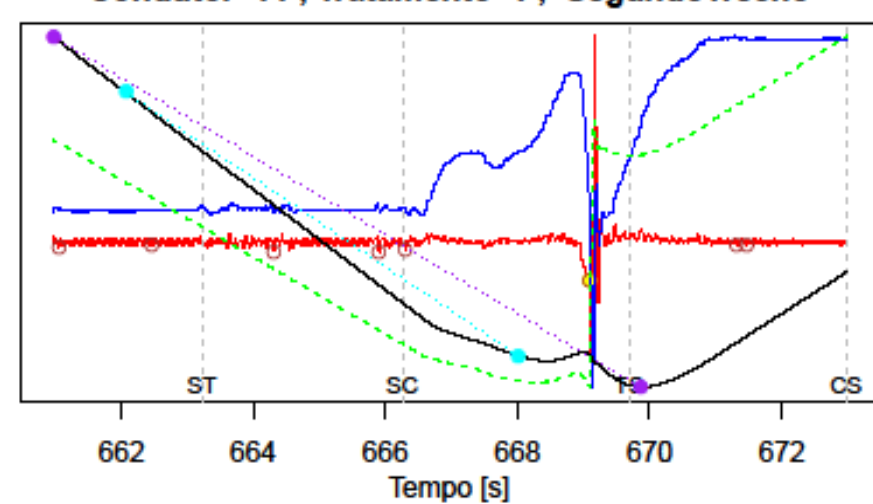

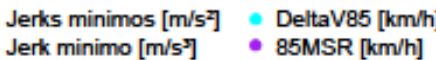

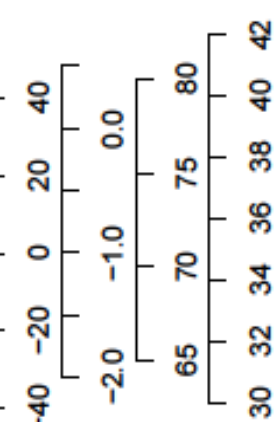

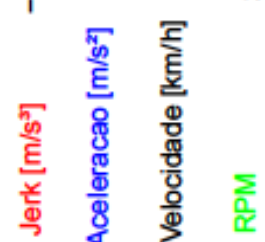


Condutor 11 , Tratamento 3 , SegundoTrecho

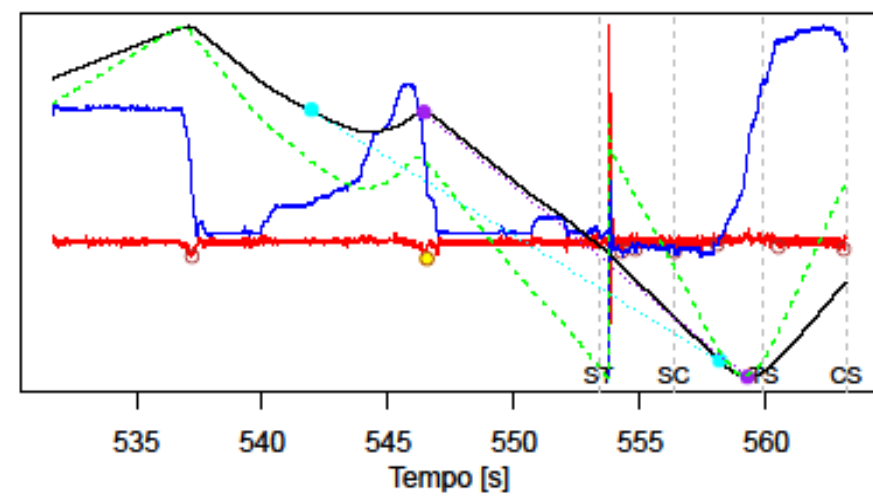

Jerks minimos $[\mathrm{m} / \mathrm{s}]$ DeltaV85 $[\mathrm{km} / \mathrm{h}]$ • $85 \mathrm{MSR}[\mathrm{km} / \mathrm{h}]$

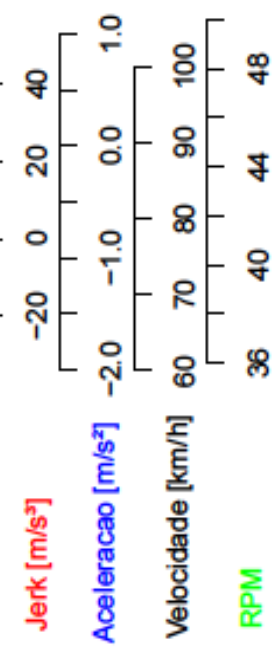

Condutor 11 , Tratamento 5 , SegundoTrecho

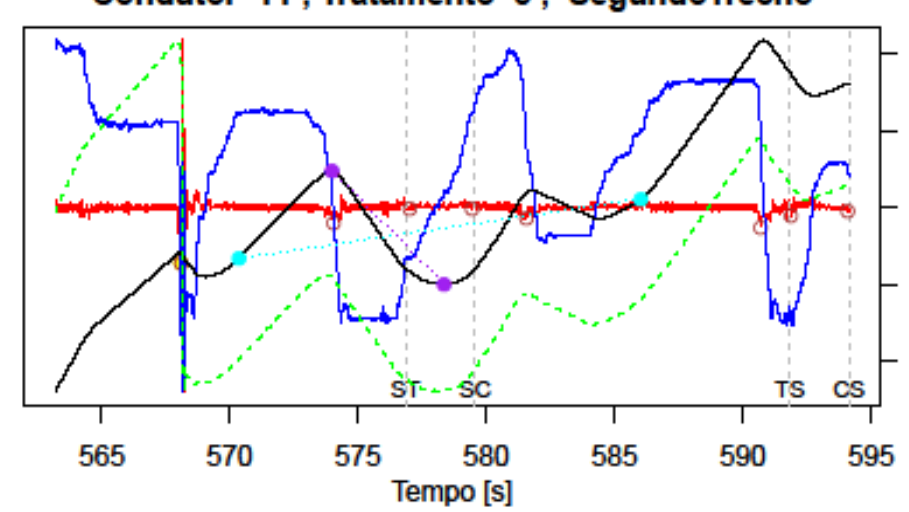

Jerks minimos $[\mathrm{m} / \mathrm{s}]$ - DeltaV85 $[\mathrm{km} / \mathrm{h}]$ Jerk minimo $[\mathrm{m} / \mathrm{s}$ ? $\quad$ 85MSR $[\mathrm{km} / \mathrm{h}]$

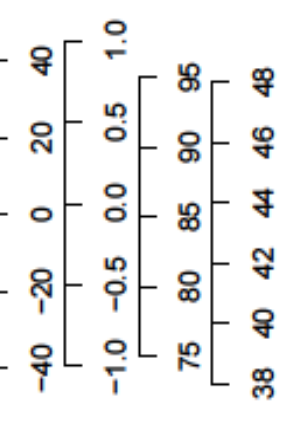

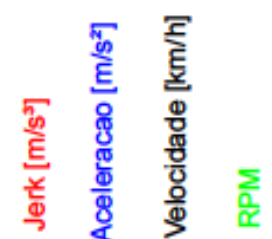

Condutor 11 , Tratamento 4 , SegundoTrecho

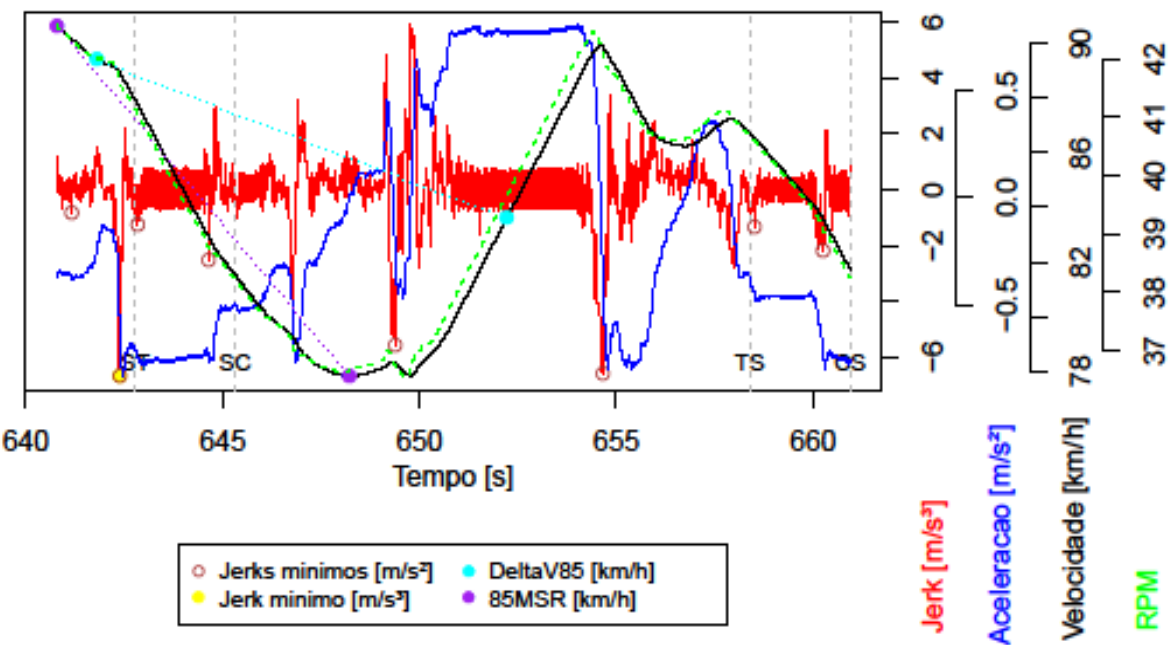

Condutor 11 , Tratamento 6 , SegundoTrecho

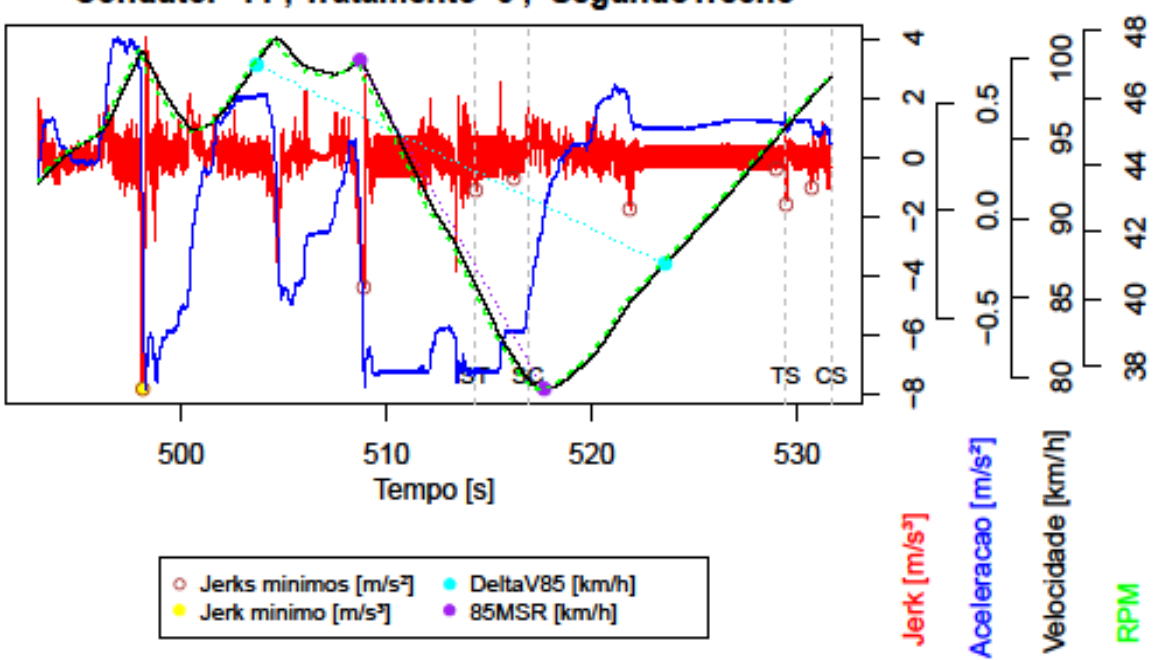


Condutor 11 , Tratamento 7 , SegundoTrecho

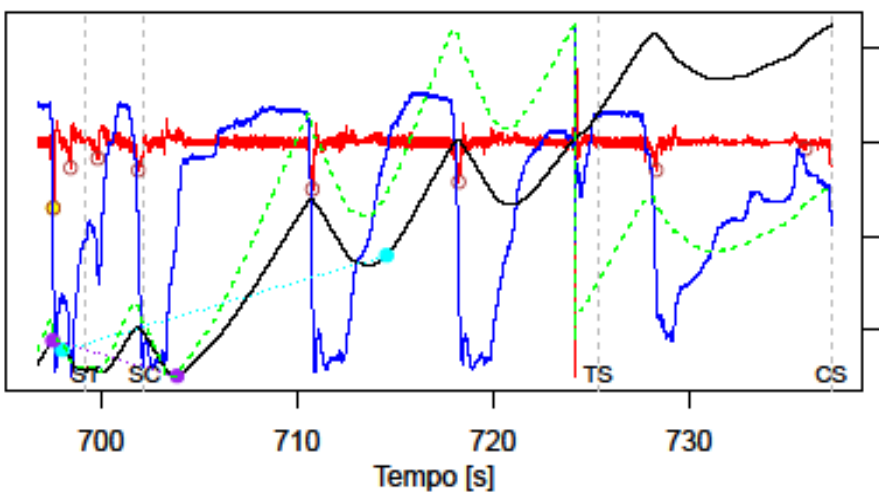

Jerks minimos $[\mathrm{m} / \mathrm{s}]$ - DeltaV85 $[\mathrm{km} / \mathrm{h}]$ Jerk minimo [m/s

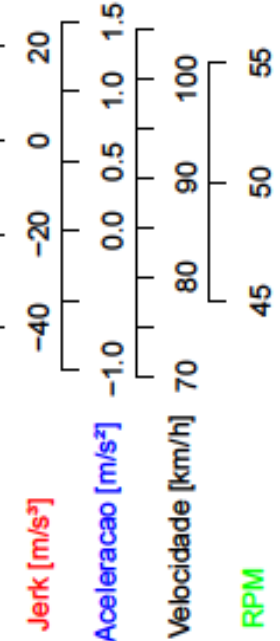

Condutor 11 , Tratamento 8 , SegundoTrecho
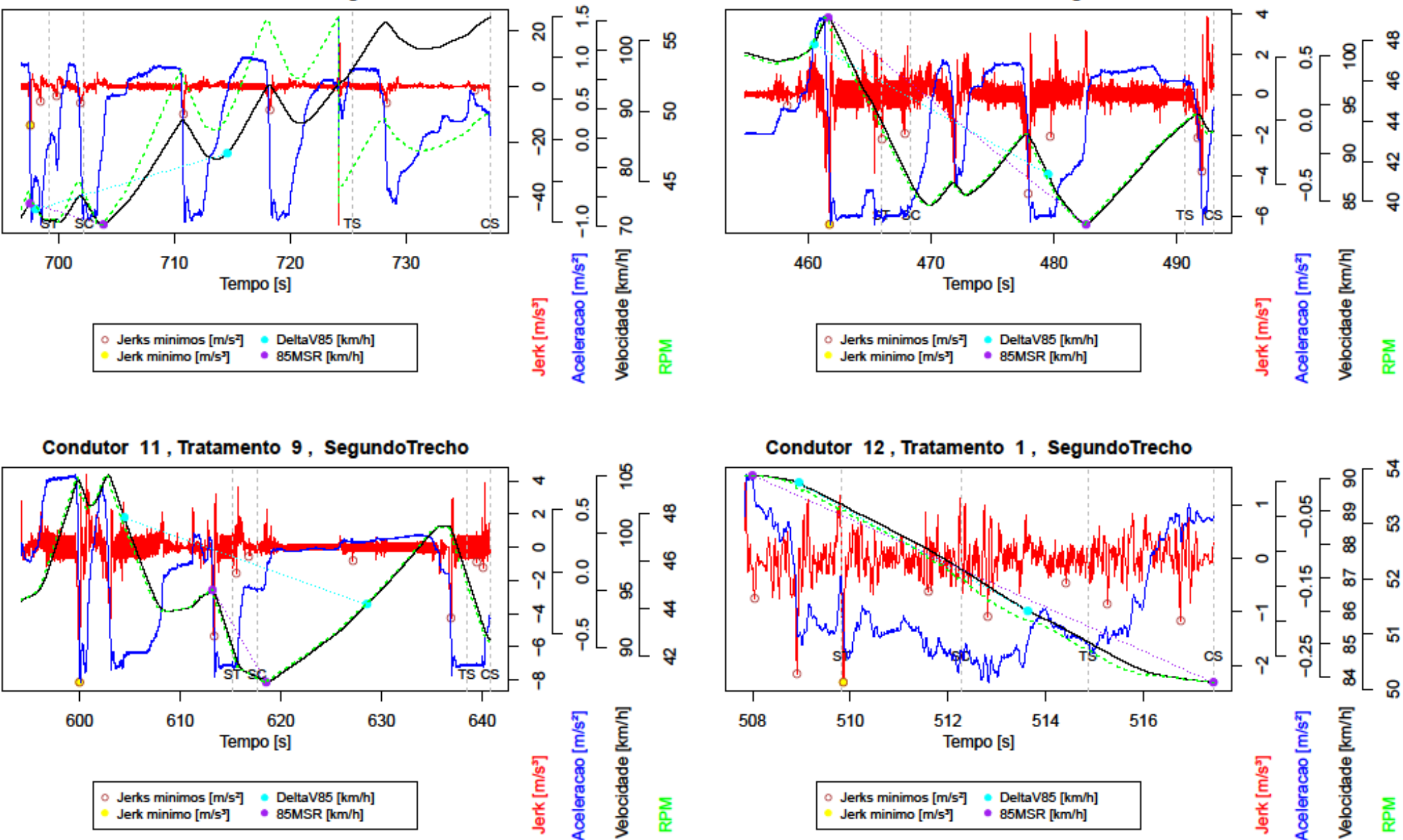

\section{Condutor 12 , Tratamento 1 , SegundoTrecho}

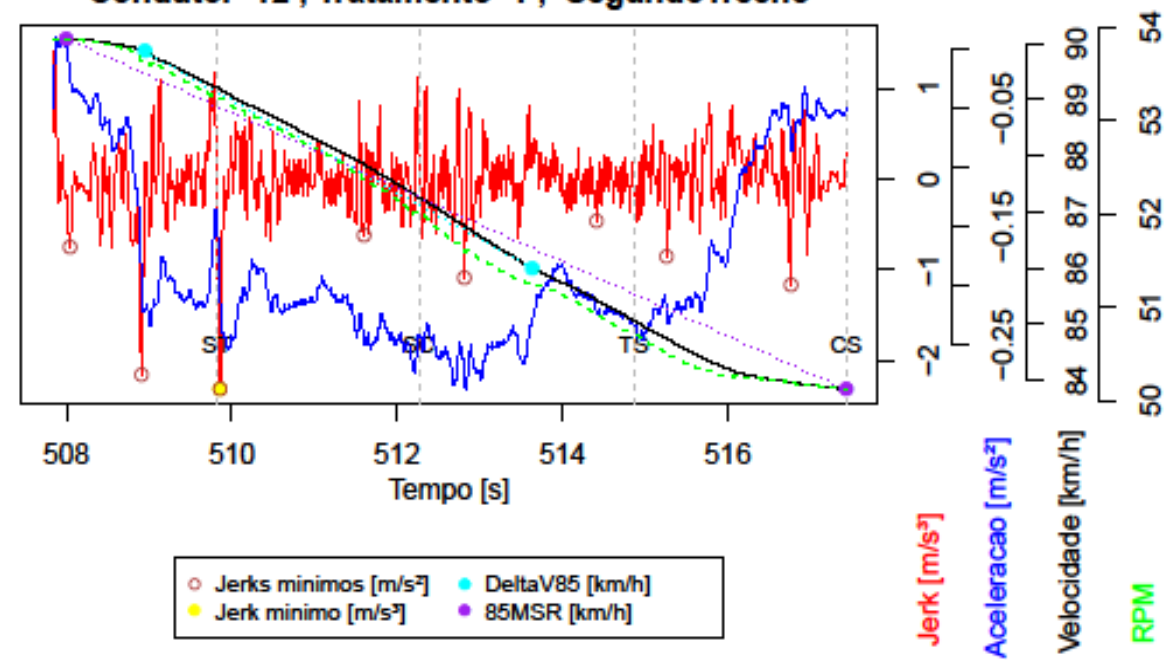


Condutor 12 , Tratamento 2 , SegundoTrecho

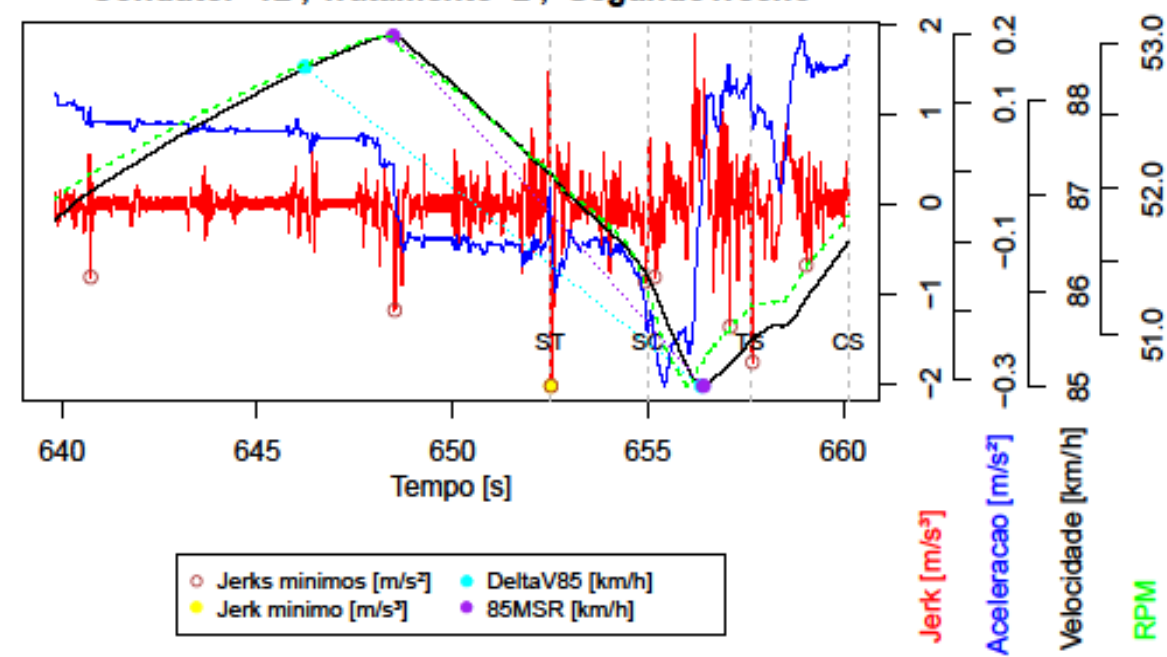

Condutor 12 , Tratamento 4 , SegundoTrecho

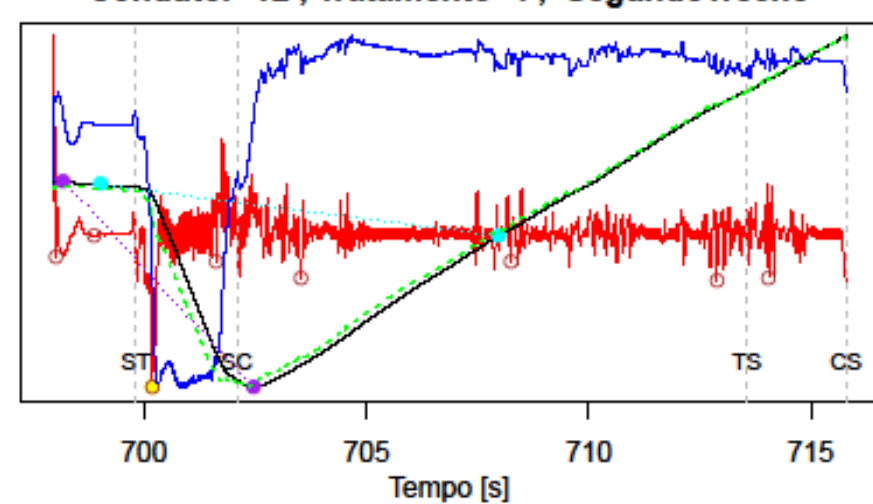

Jerks minimos $[\mathrm{m} / \mathrm{s}]]$ DeltaV85 $[\mathrm{km} / \mathrm{h}]$ Jerk minimo $\left[\mathrm{m} / \mathrm{s}^{\mathrm{s}}\right]$ - 85MSR $[\mathrm{km} / \mathrm{h}]$
Condutor 12 , Tratamento 3 , SegundoTrecho

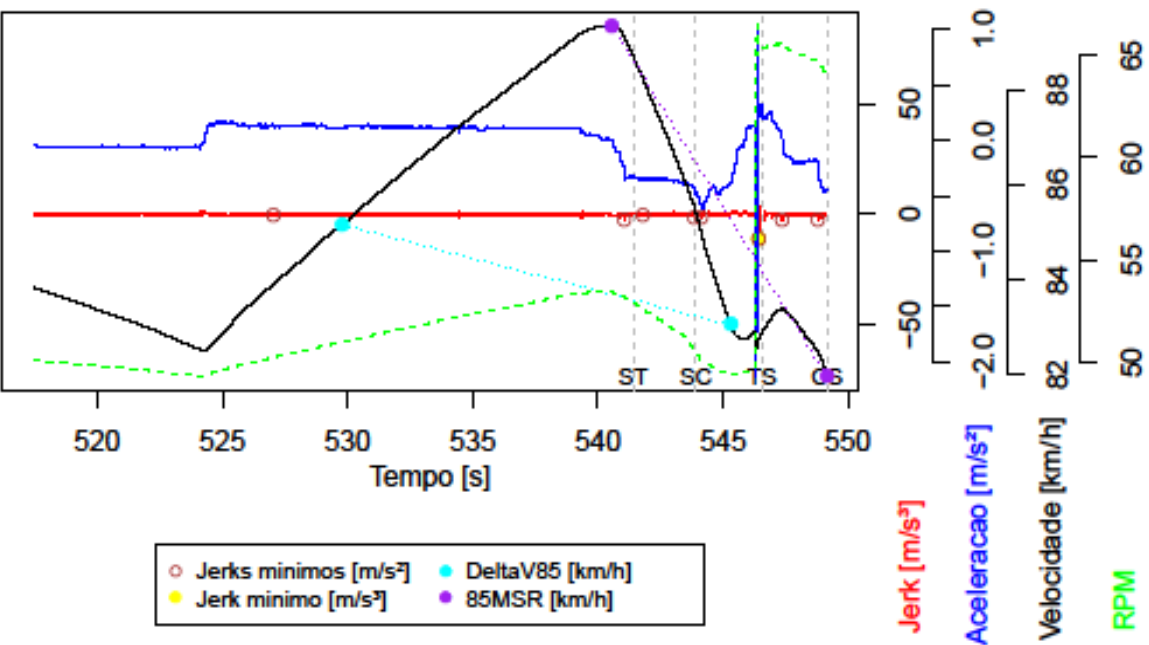

Condutor 12 , Tratamento 5 , SegundoTrecho

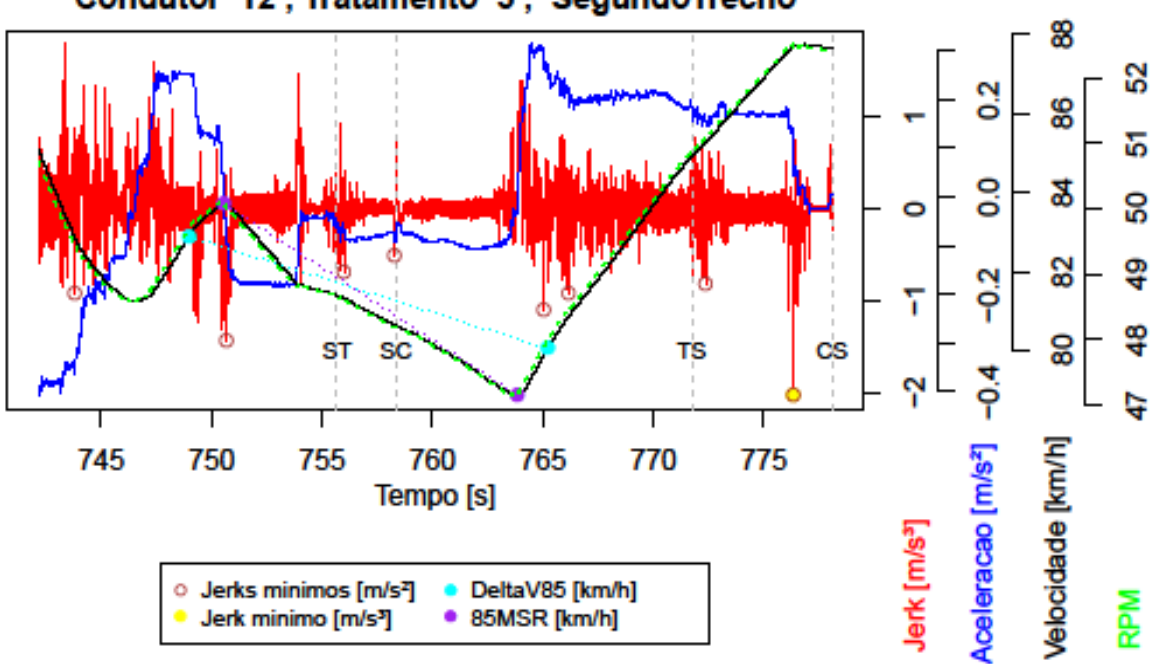


Condutor 12 , Tratamento 6 , SegundoTrecho

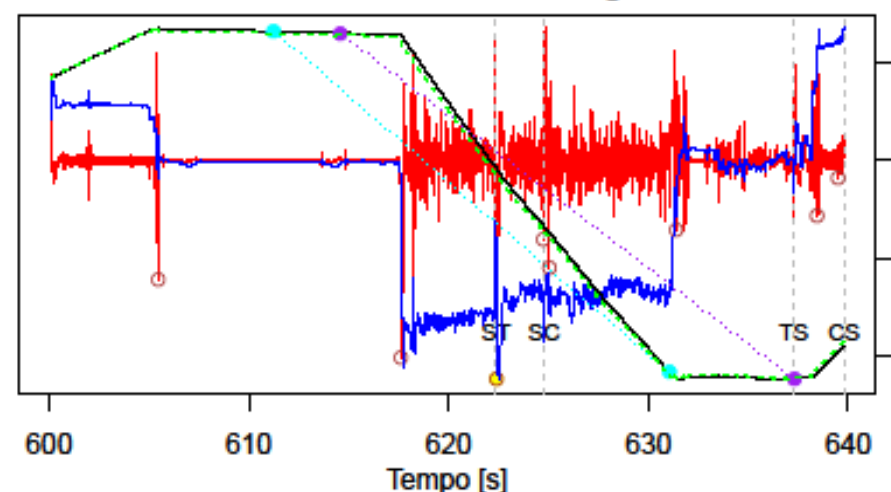

Jerks minimos $[\mathrm{m} / \mathrm{s}]$ - DeltaV85 $[\mathrm{km} / \mathrm{h}]$ Jerk minimo [m/s'] $05 \mathrm{MSR}[\mathrm{km} / \mathrm{h}]$
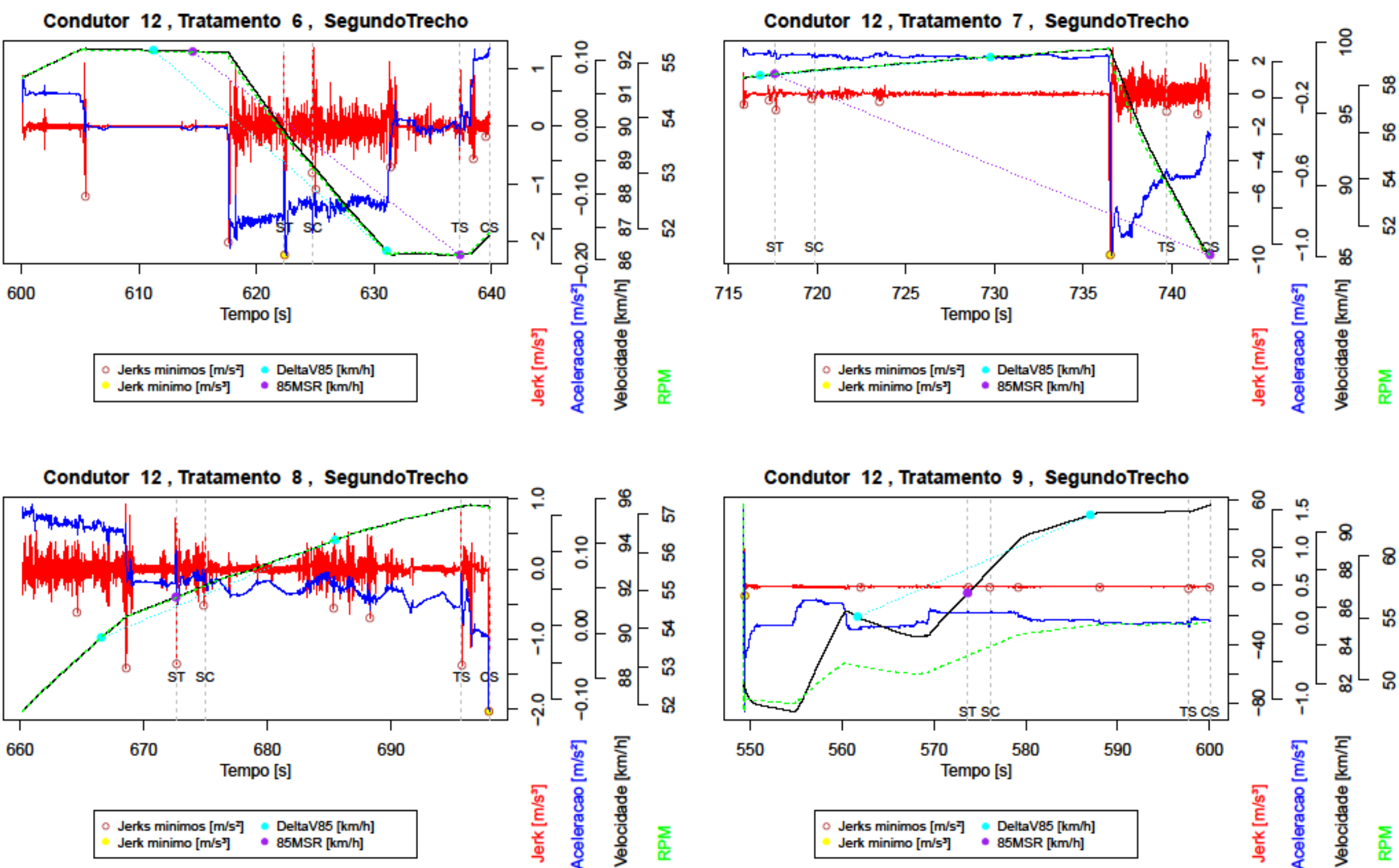

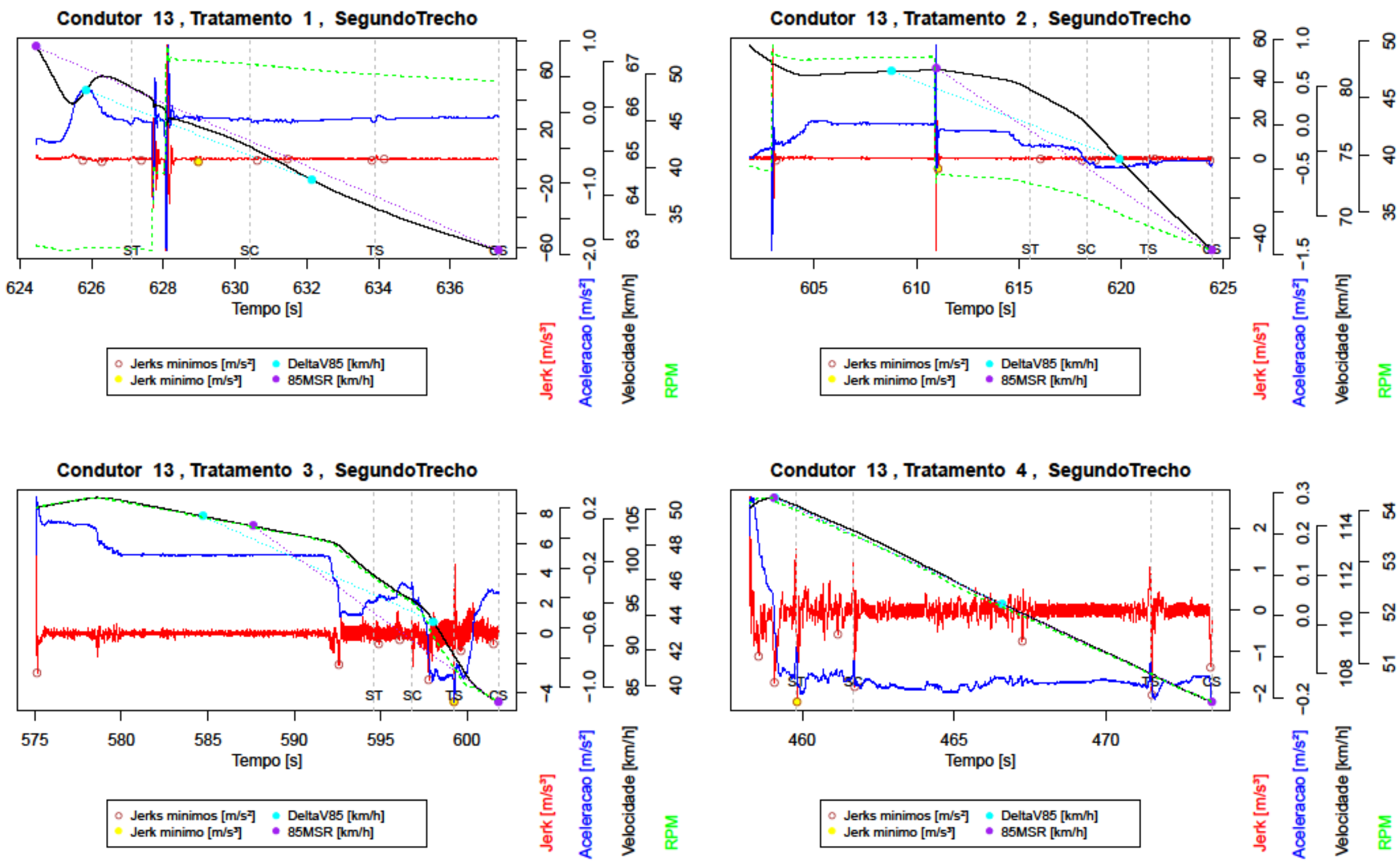
Condutor 13 , Tratamento 5 , SegundoTrecho

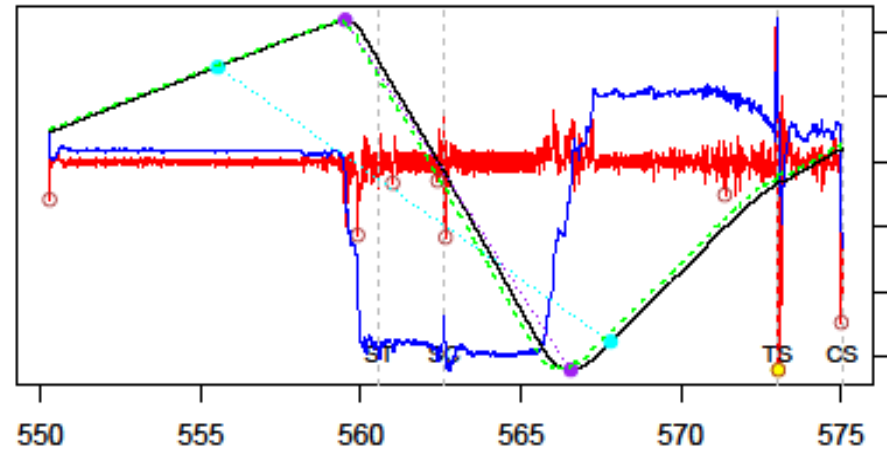

550

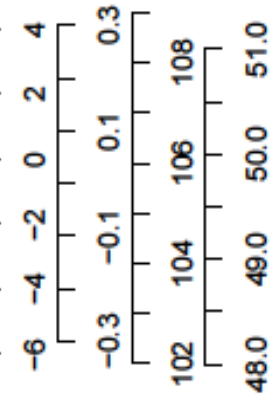

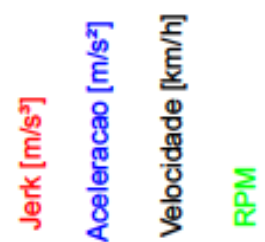

Condutor 13 , Tratamento 6 , SegundoTrecho

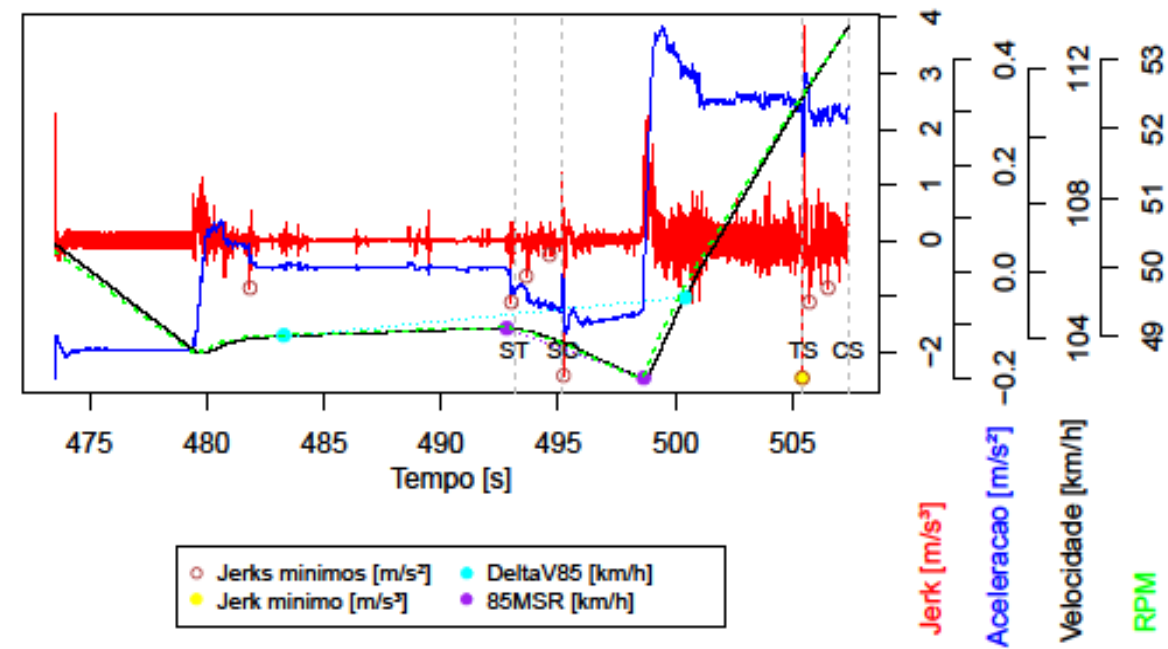

Condutor 13 , Tratamento 8 , SegundoTrecho

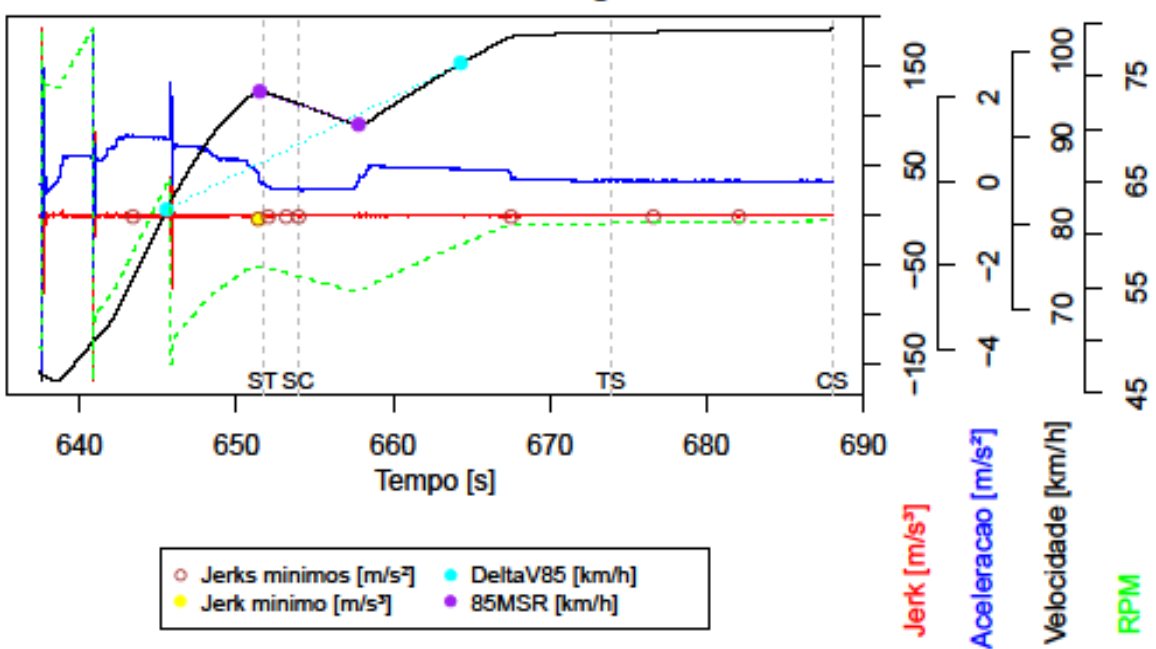

Jerk minimo [m/s] $05 \mathrm{MSR}[\mathrm{km} / \mathrm{hl}$

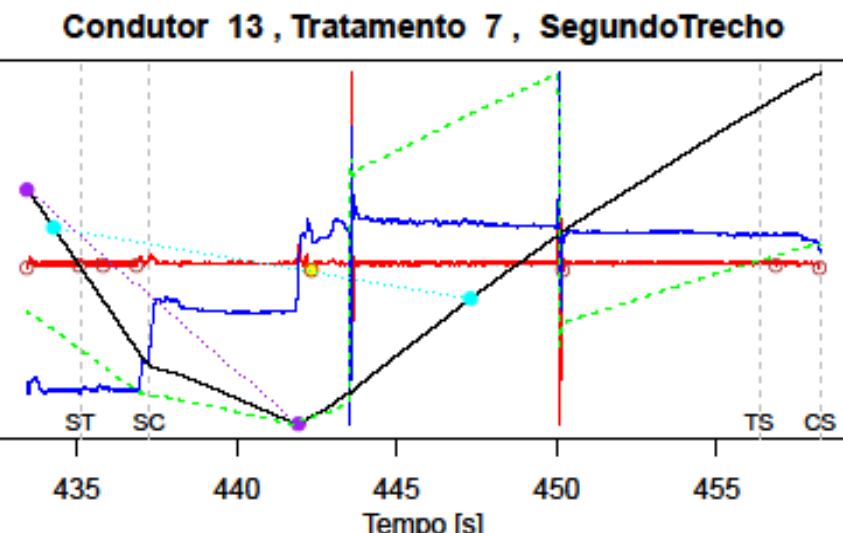
Jerks minimos $\left[\mathrm{m} / \mathrm{s}^{\mathrm{z}}\right]$
Jerk minimo $\left[\mathrm{m} / \mathrm{s}^{2}\right]$ - DeltaV85 $[\mathrm{km} / \mathrm{h}]$

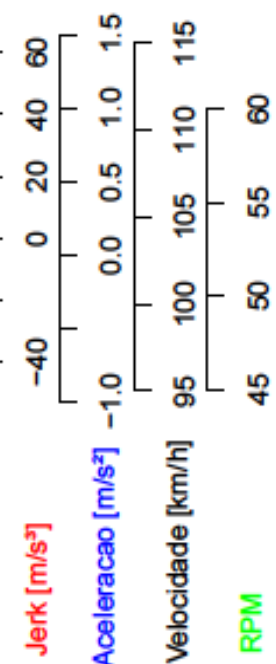




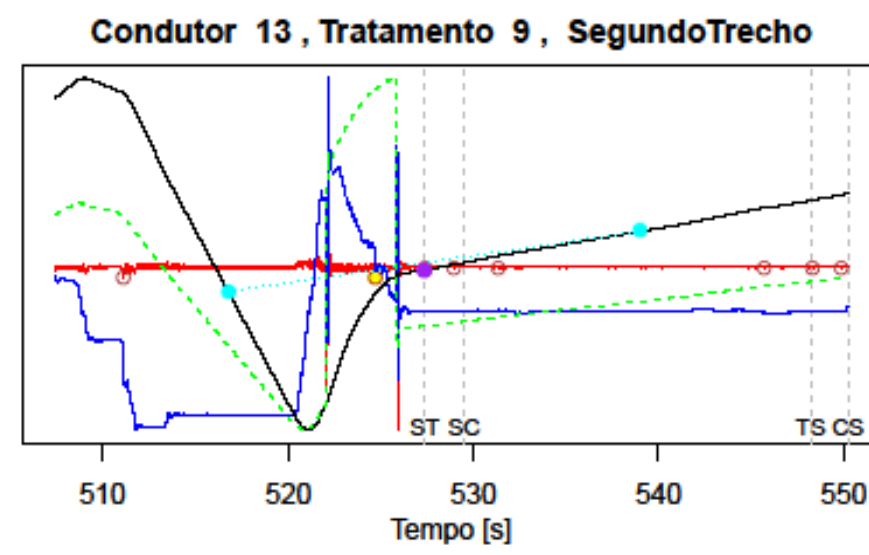

Jerks minimos [m/s'] - DeltaV85 $[\mathrm{km} / \mathrm{h}]$ Jerk minimo $[\mathrm{m} / \mathrm{s}]$ • $85 \mathrm{MSR}[\mathrm{km} / \mathrm{h}]$

\section{Condutor 14 , Tratamento 2 , SegundoTrecho}

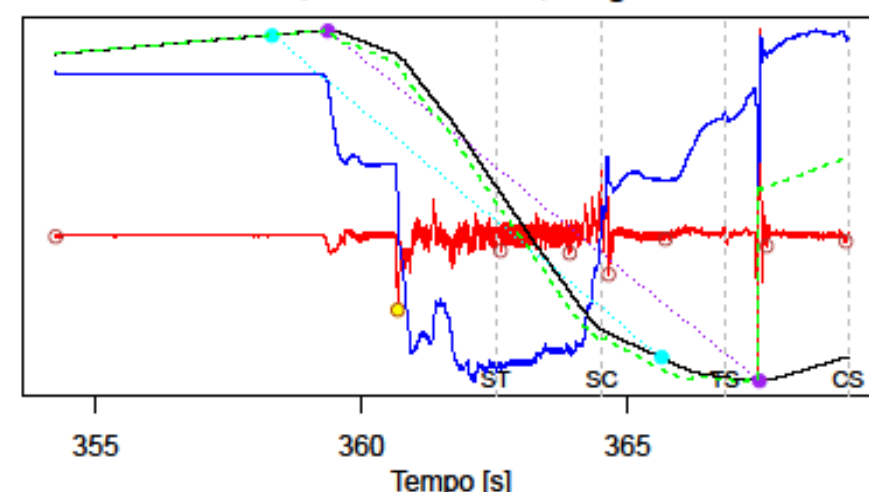

Jerks minimos [m/sz] -DeltaV85 $[\mathrm{km} / \mathrm{h}]$ Jerk minimo $\left.\left[\mathrm{m} / \mathrm{s}^{\mathrm{s}}\right] \mathrm{s}\right]$ : 85MSR $[\mathrm{km} / \mathrm{h}]$
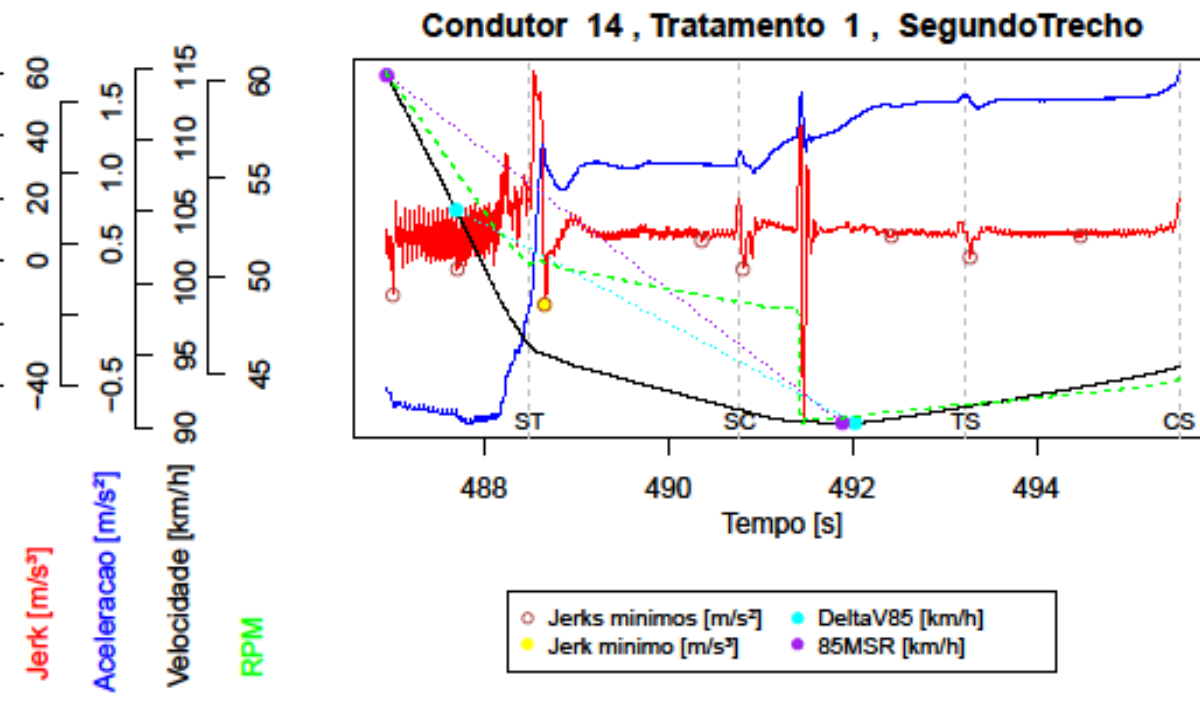

Jerks minimos [m/s $]$ - DeltaV85 $[\mathrm{km} / \mathrm{h}]$ Jerks minimos $\left[\mathrm{m} / \mathrm{s}^{\mathrm{s}}\right]$ - DeltaV $\left.\left[\mathrm{m} / \mathrm{s}^{\mathrm{s}}\right] \mathrm{km} / \mathrm{km} / \mathrm{h}\right]$
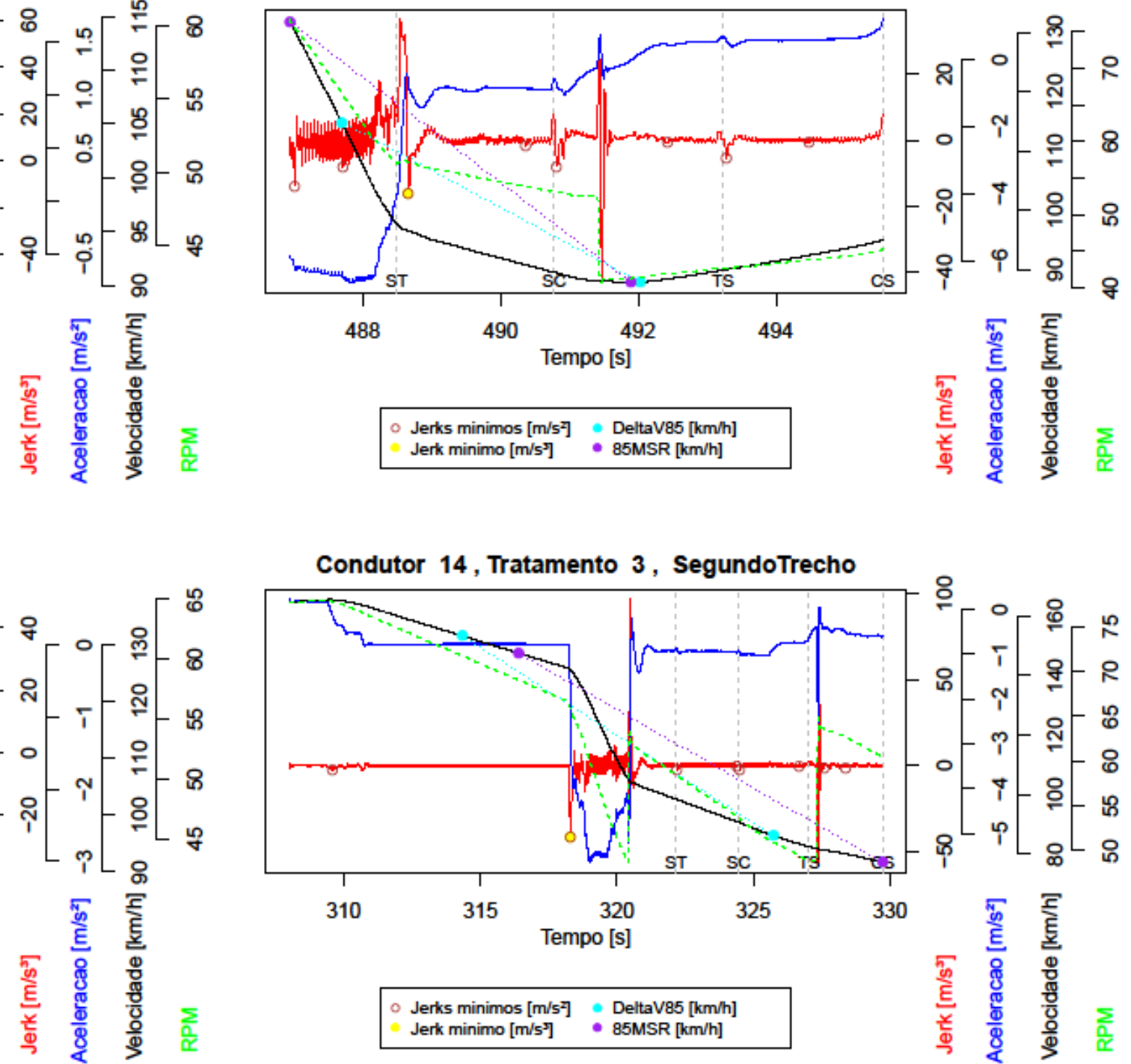

Condutor 14 , Tratamento 3 , SegundoTrecho

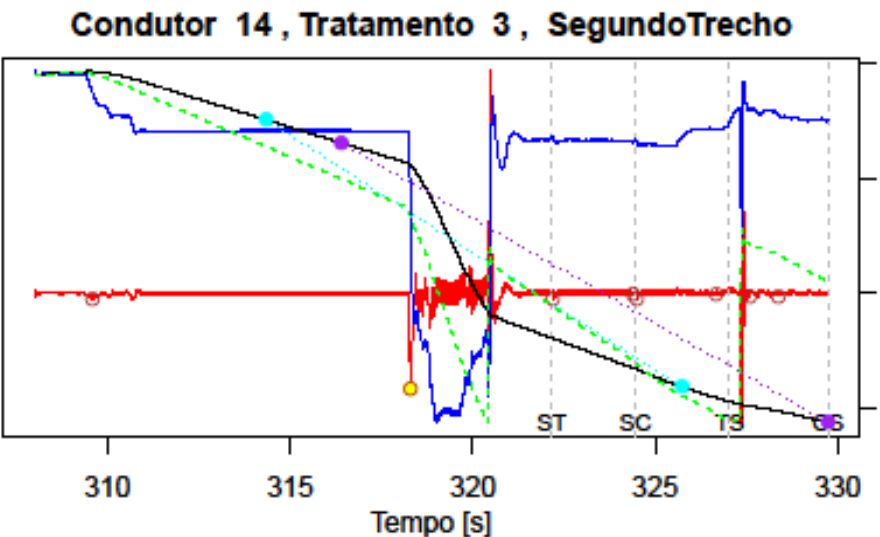
Jerks minimos $[\mathrm{m} / \mathrm{s}]]$
Jerk minimo $[\mathrm{m} / \mathrm{s}]$ DeltaV85 $[\mathrm{km} / \mathrm{h}]$

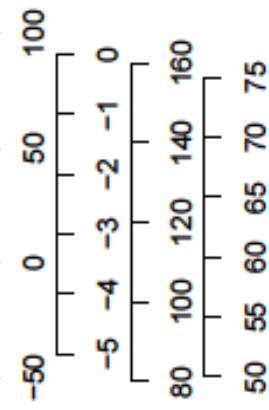

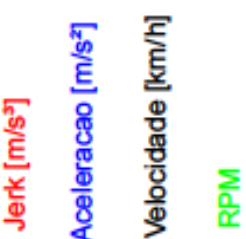




\section{Condutor 14 , Tratamento 4 , SegundoTrecho}

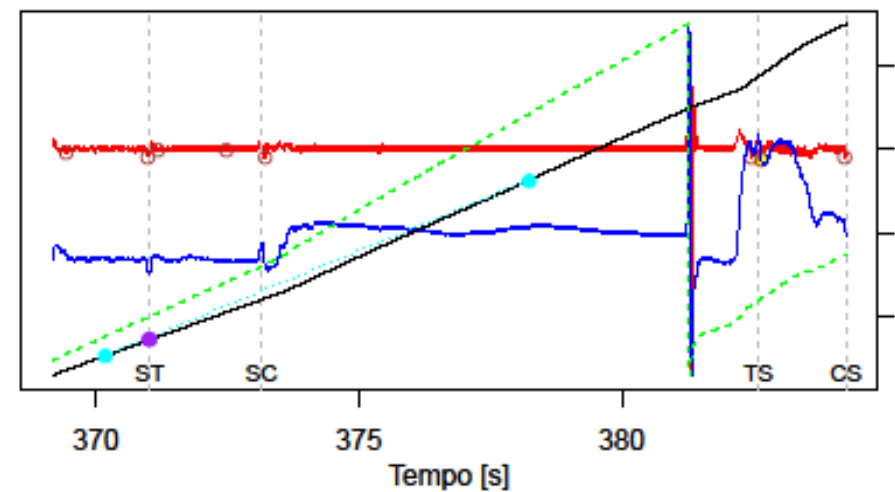

Jerks minimos $[\mathrm{m} / \mathrm{s}]$ - DeltaV85 $[\mathrm{km} / \mathrm{h}]$ Jerk minimo $[\mathrm{m} / \mathrm{s}$ '] $85 \mathrm{MSR}[\mathrm{km} / \mathrm{h}]$

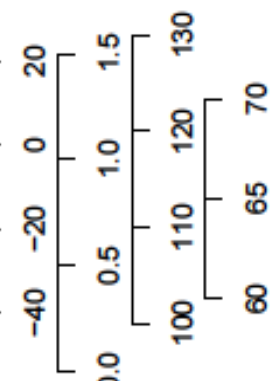

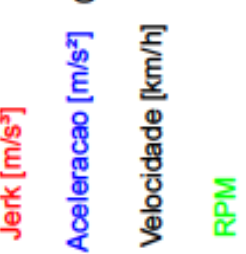

Condutor 14 , Tratamento 5 , SegundoTrecho

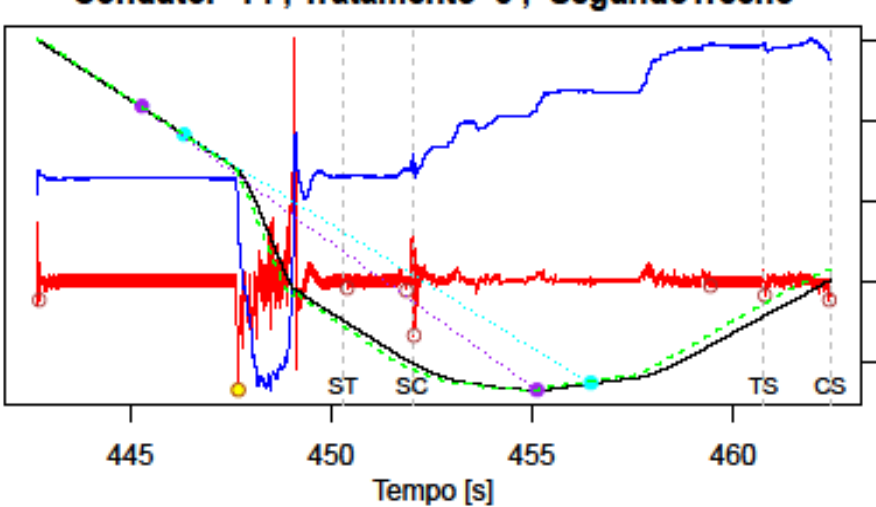

Jerks minimos $\left[\mathrm{m} / \mathrm{s}^{2}\right]$ DeltaV85 $[\mathrm{km} / \mathrm{h}]$ Jerk minimo $\left[\mathrm{m} / \mathrm{s}^{\mathrm{s}}\right]$ ] DeltaV85 $[\mathrm{km} / \mathrm{h}]$

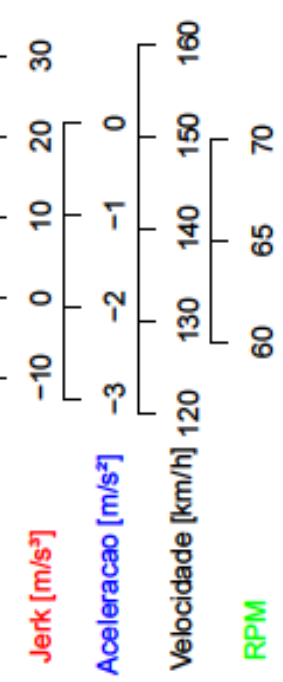

Condutor 14 , Tratamento 6 , SegundoTrecho

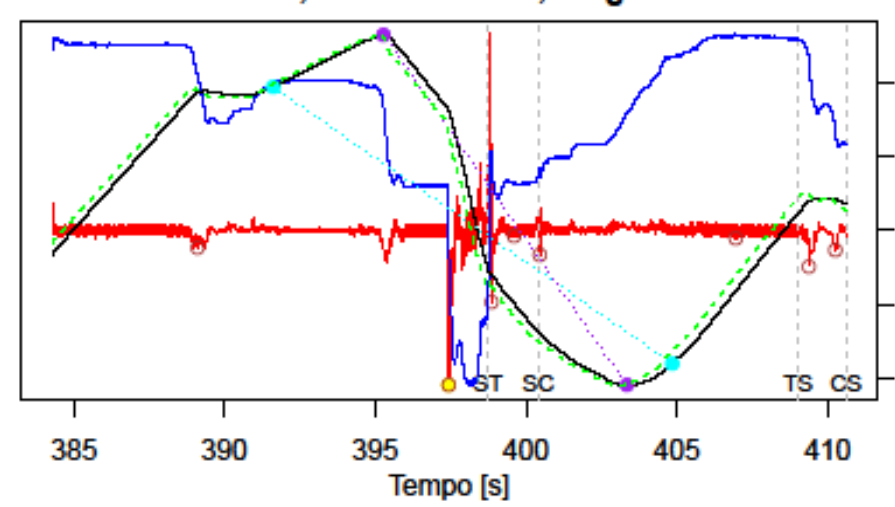

Jerks minimos $[\mathrm{m} / \mathrm{s}$ ₹] DeltaV85 $[\mathrm{km} / \mathrm{h}]$ Jerk minimo $\left[\mathrm{m} / \mathrm{s}^{\mathrm{s}}\right]$ ? $85 \mathrm{MSR}[\mathrm{km} / \mathrm{h}]$

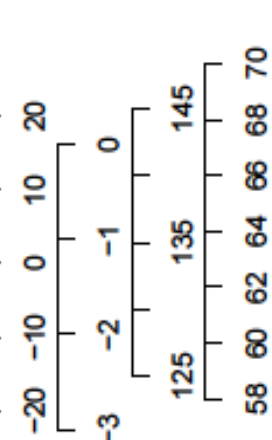

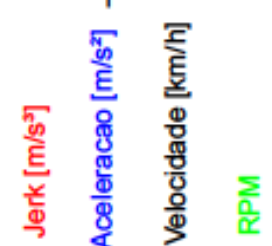

\section{Condutor 14 , Tratamento 7 , SegundoTrecho}

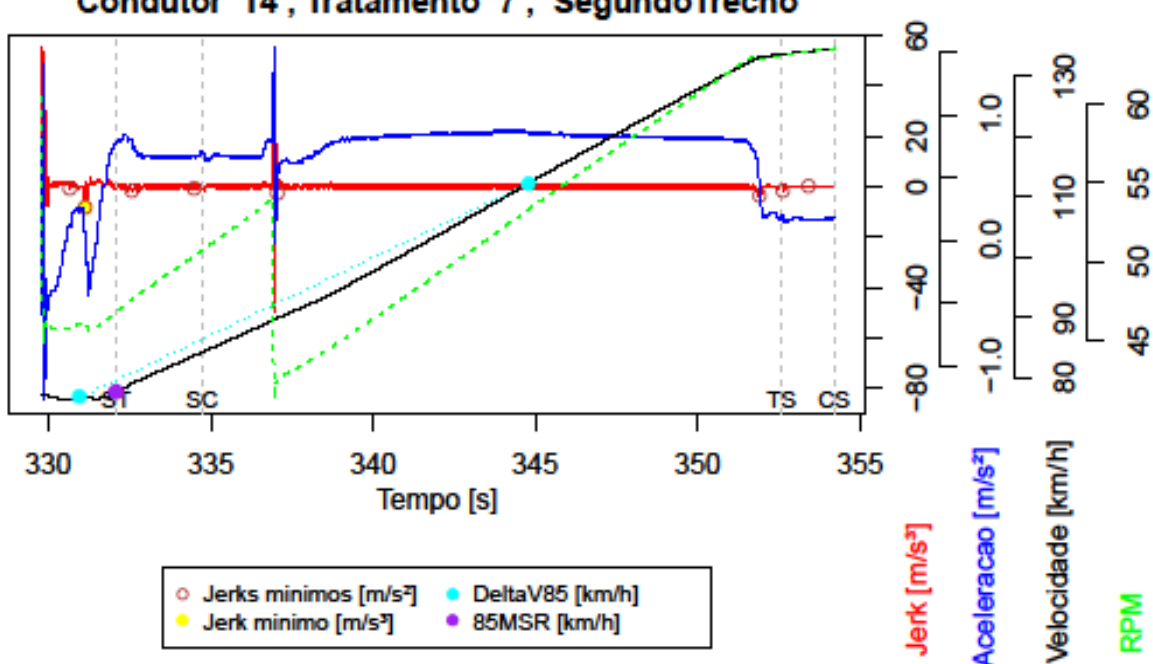


Condutor 14 , Tratamento 8 , SegundoTrecho

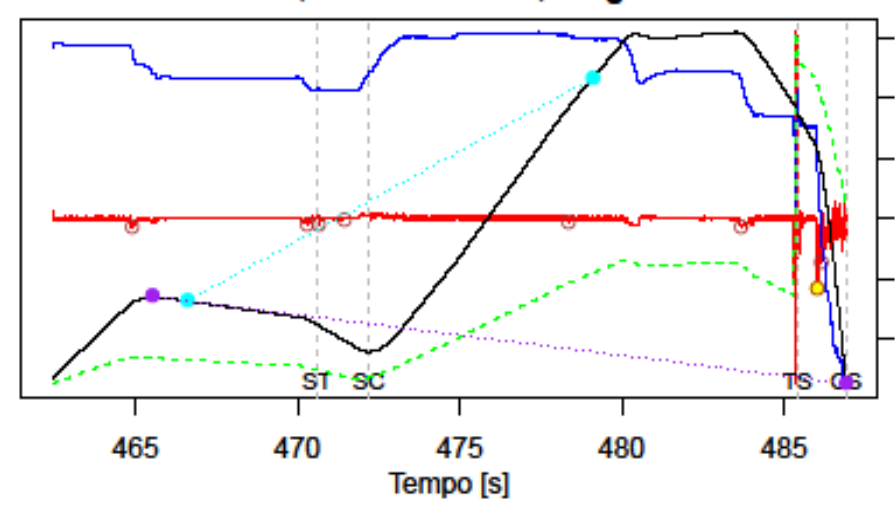

Jerks minimos $[\mathrm{m} / \mathrm{s}]$ - DeltaV85 $[\mathrm{km} / \mathrm{h}]$ Jerk minimo $\left[\mathrm{m} / \mathrm{s}^{\mathrm{s}}\right]$ - $85 \mathrm{MSR}[\mathrm{km} / \mathrm{h}]$

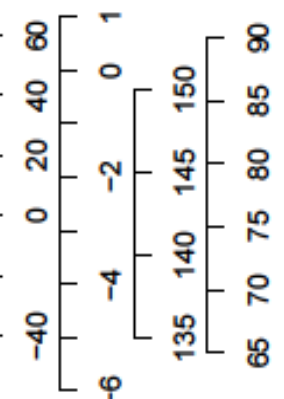

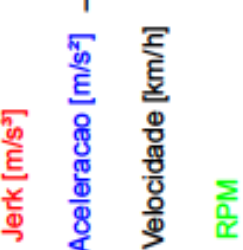

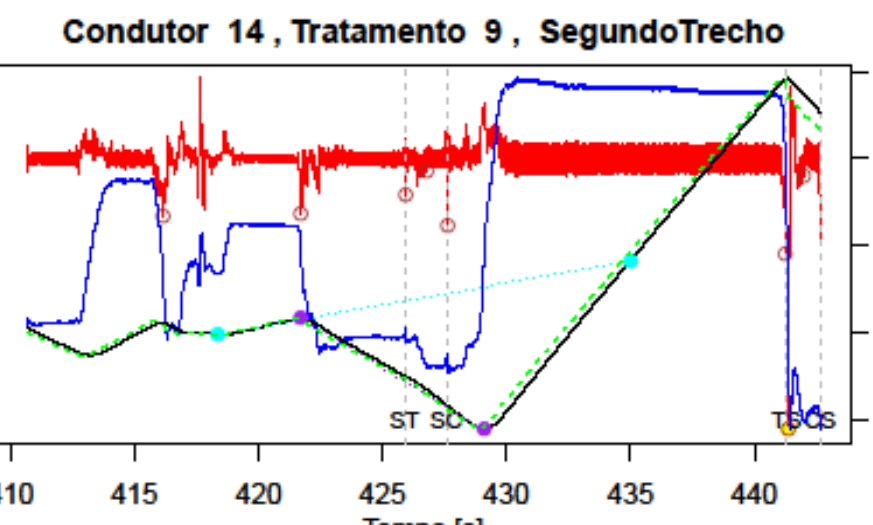

Jerks minimos $\left[\mathrm{m} / \mathrm{s}^{\mathrm{z}}\right]$ - DeltaV85 $[\mathrm{km} / \mathrm{h}]$ Jerks minimos $\left[\mathrm{m} / \mathrm{s}^{\mathrm{s}}\right]$ DeltaV85 $[\mathrm{km} / \mathrm{h}]$
Jerk minimo $\left[\mathrm{m} / \mathrm{s}^{\mathrm{j}}\right]$

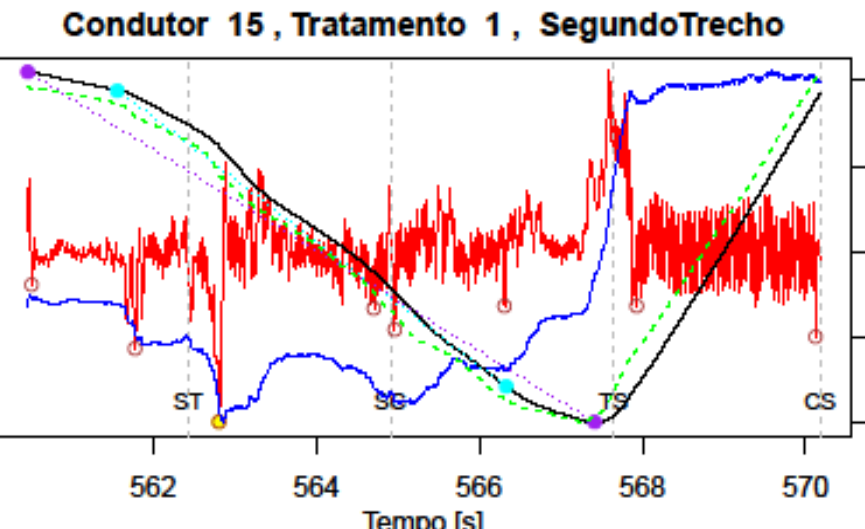

Jerks minimos $[\mathrm{m} / \mathrm{s}]$ - DeltaV85 $[\mathrm{km} / \mathrm{h}]$ Jerk minimo $\left[\mathrm{m} / \mathrm{s}^{\mathrm{r}}\right]$ — $85 \mathrm{MSR}[\mathrm{km} / \mathrm{h}]$

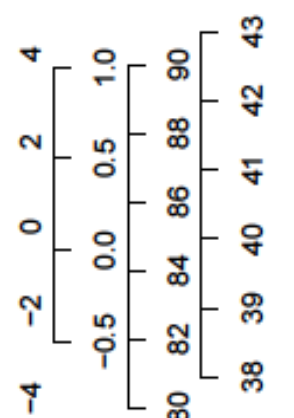

-

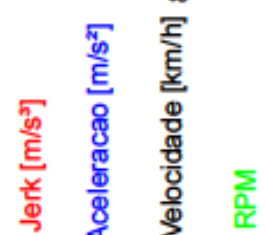

Condutor 15 , Tratamento 2 , SegundoTrecho

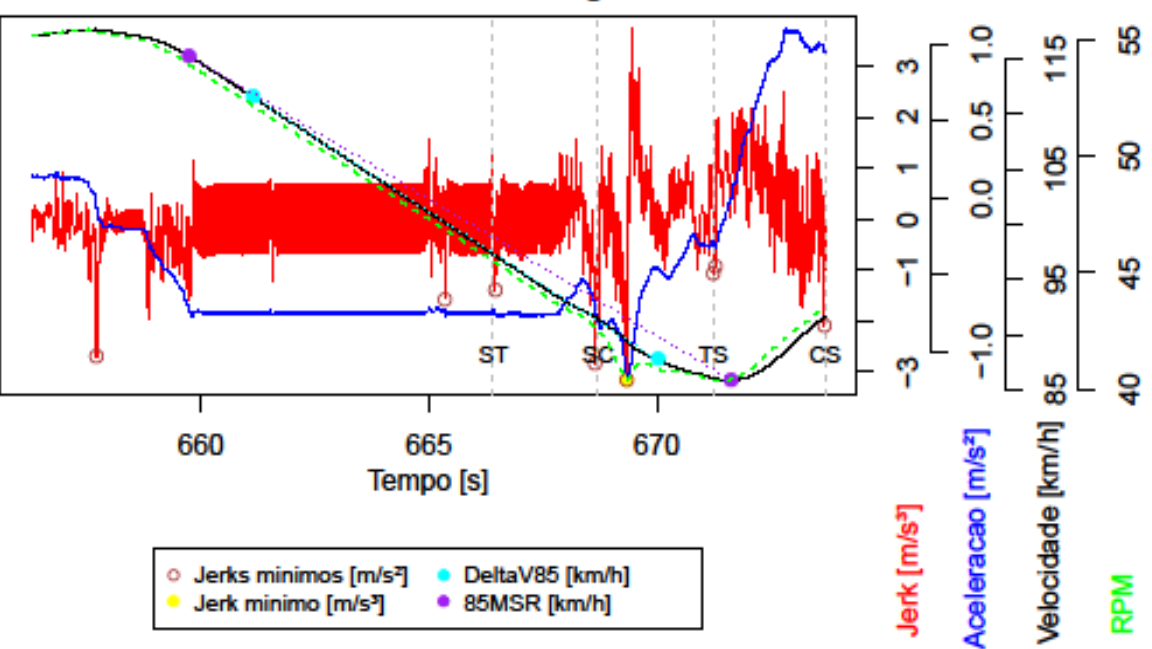


Condutor 15 , Tratamento 3 , SegundoTrecho

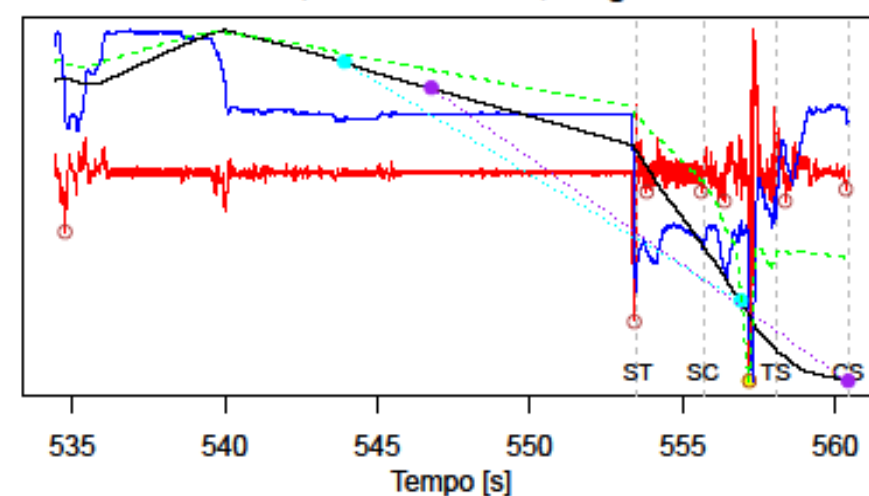

Jerks minimos $[\mathrm{m} / \mathrm{s}]$ DeltaV85 $[\mathrm{km} / \mathrm{h}]$ Jerk minimo $\left[\mathrm{m} / \mathrm{s}^{\mathrm{s}}\right]$ • $85 \mathrm{MSR}[\mathrm{km} / \mathrm{h}]$

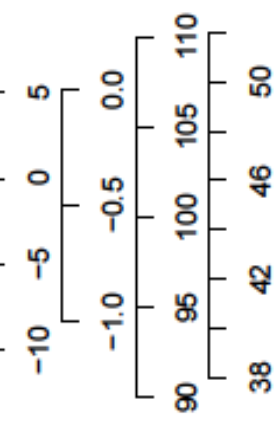

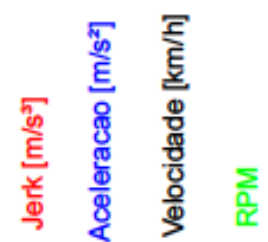

Condutor 15 , Tratamento 4 , SegundoTrecho

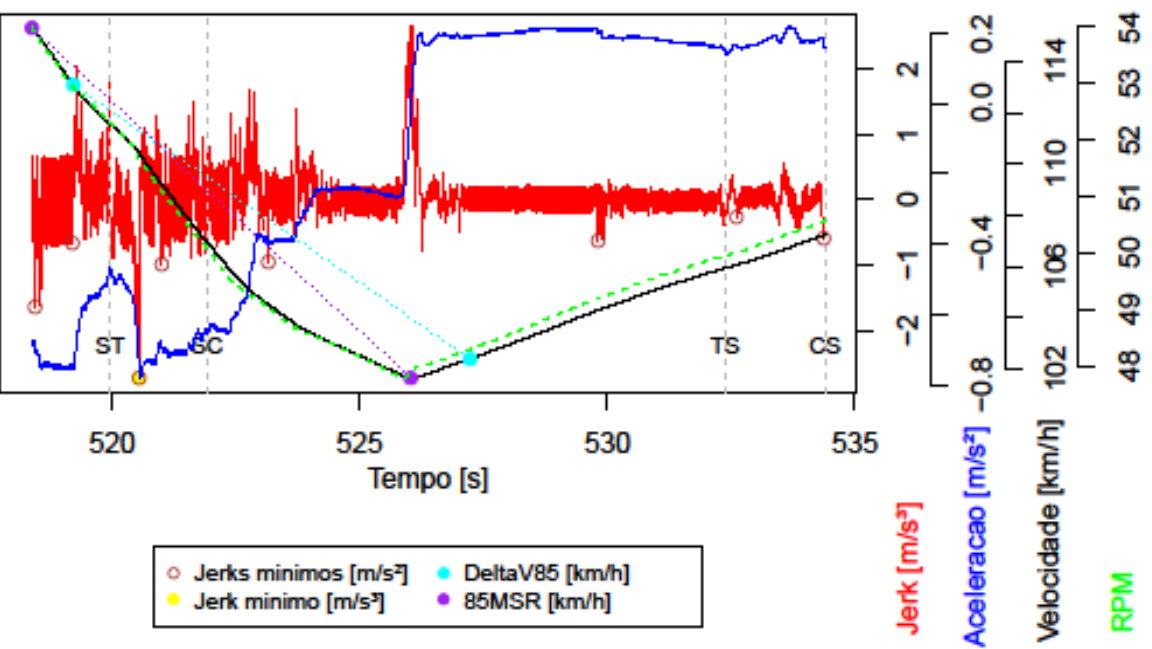

Condutor 15 , Tratamento 6 , SegundoTrecho

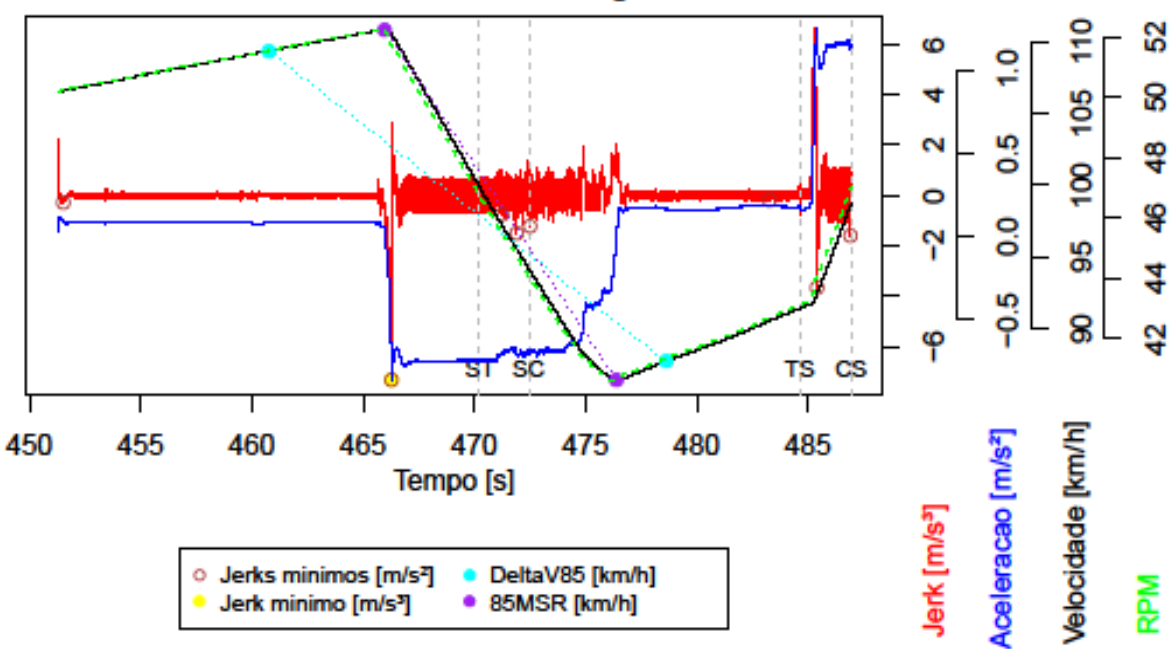

Condutor 15 , Tratamento 5 , SegundoTrecho

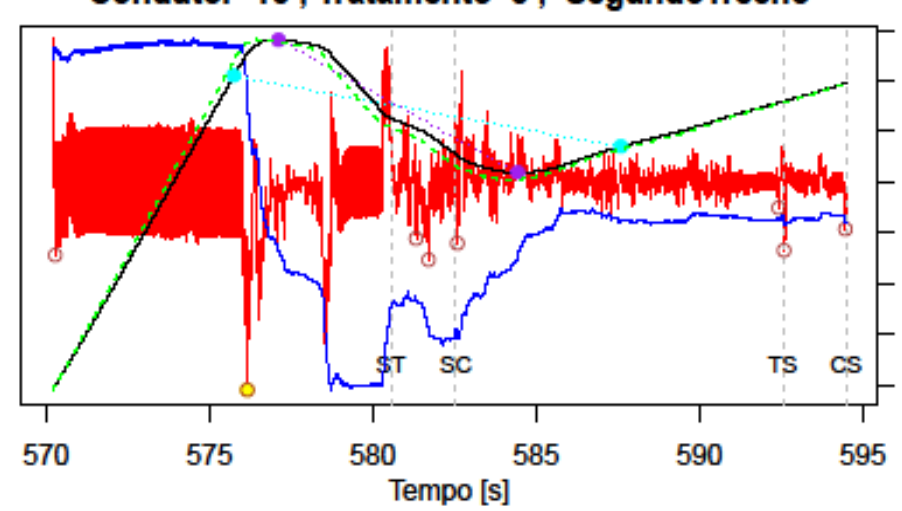

Jerks minimos [m/s'] DeltaV85 $[\mathrm{km} / \mathrm{h}]$ Jerk minimo $\left[\mathrm{m} / \mathrm{s}^{\mathrm{s}}\right]$ - $85 \mathrm{MSR}[\mathrm{km} / \mathrm{h}]$

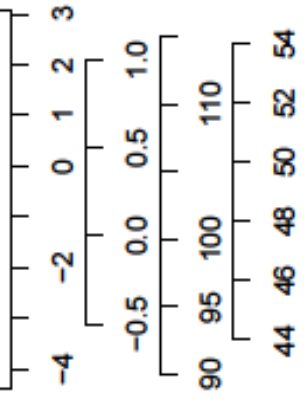

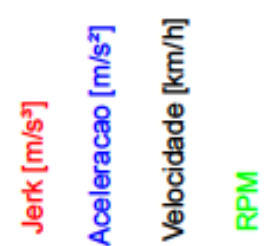


Condutor 15 , Tratamento 7 , SegundoTrecho

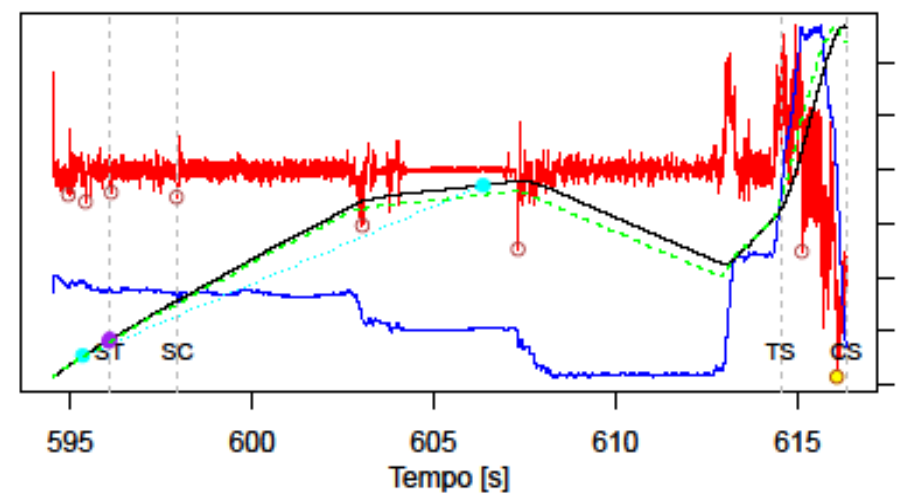

Jerks minimos [m/s'] DeltaV85 $[\mathrm{km} / \mathrm{h}]$ Jerk minimo [m/s

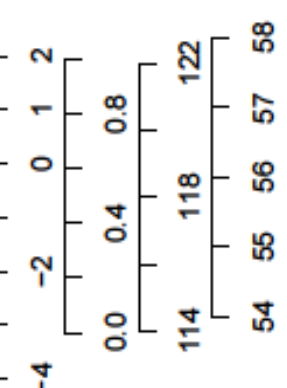

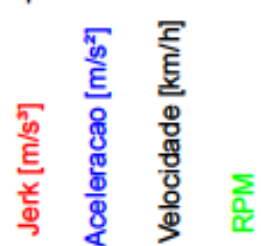

Condutor 15 , Tratamento 8 , SegundoTrecho

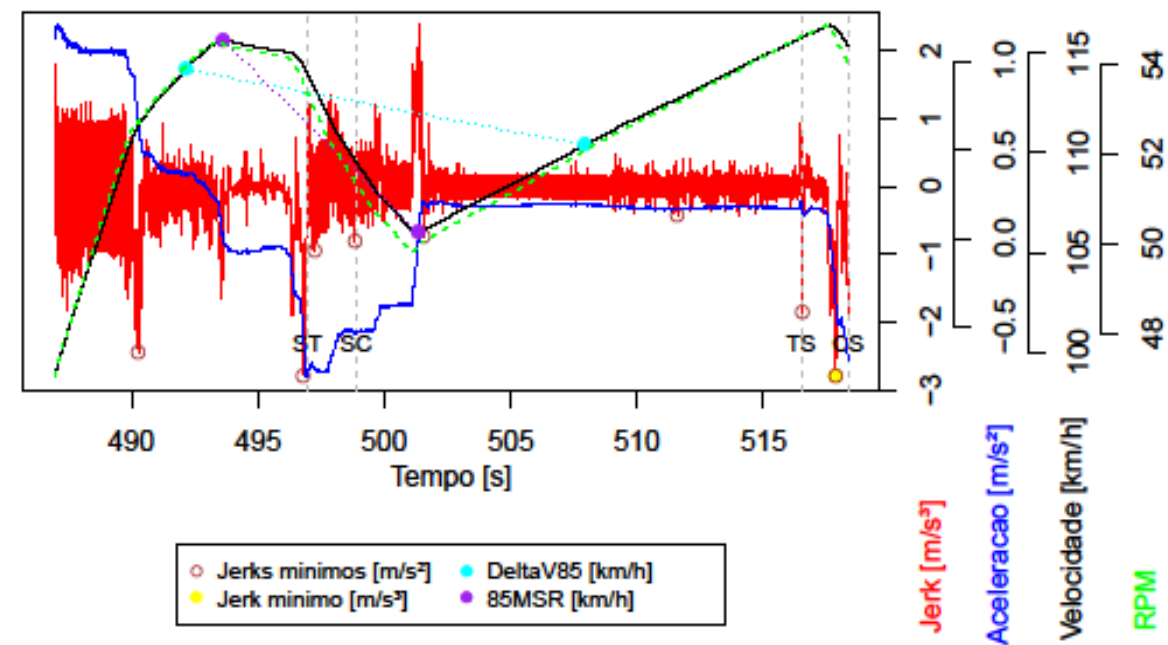

Condutor 16 , Tratamento 1 , SegundoTrecho

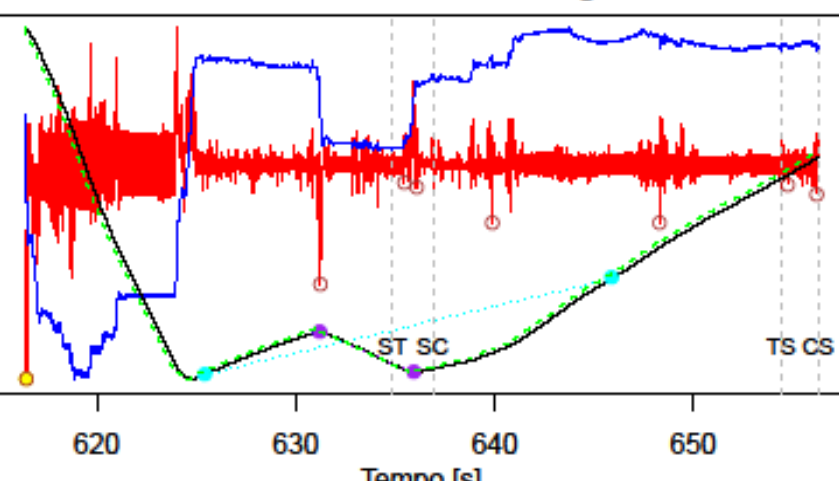

Jerks minimos [m/s'] DeltaV85 $[\mathrm{km} / \mathrm{h}]$ Jerk minimo $\left[\mathrm{m} / \mathrm{s}^{\mathrm{s}}\right]$ - $85 \mathrm{MSR}[\mathrm{km} / \mathrm{h}]$

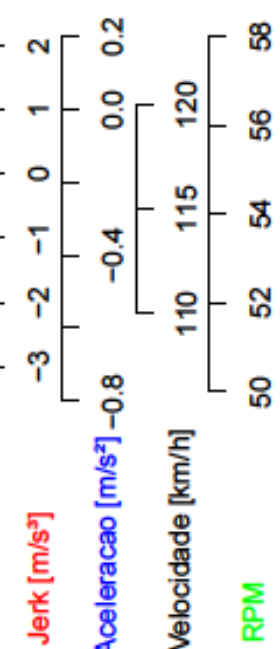

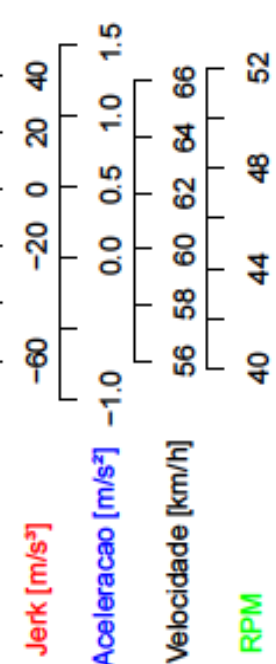


Condutor 16, Tratamento 2 , SegundoTrecho

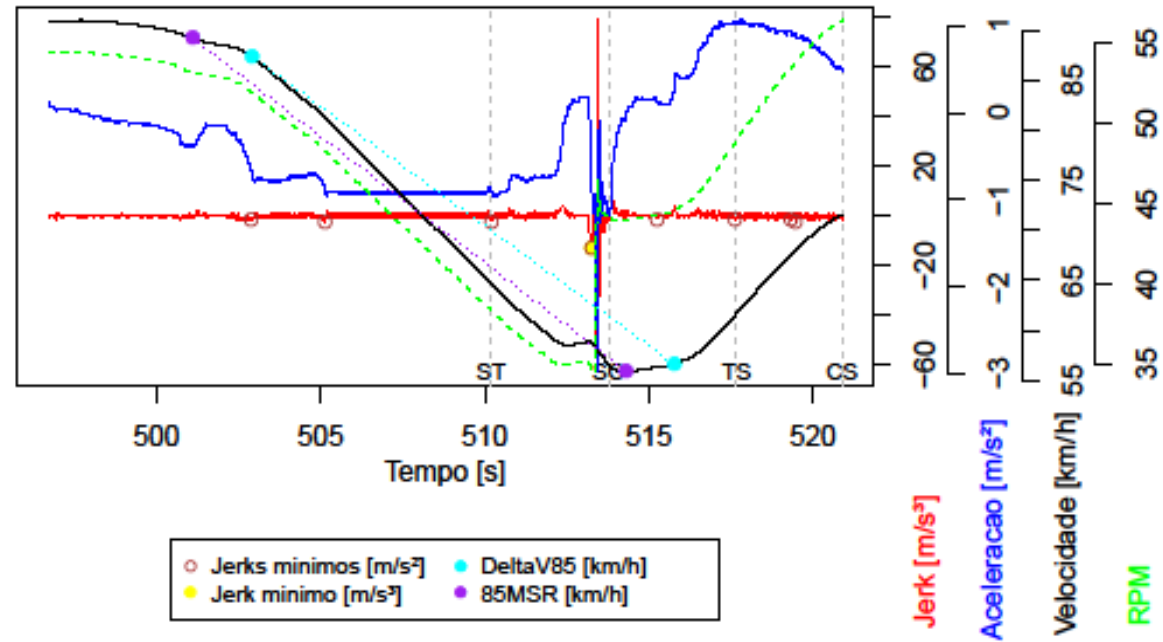

Condutor 16, Tratamento 4 , SegundoTrecho

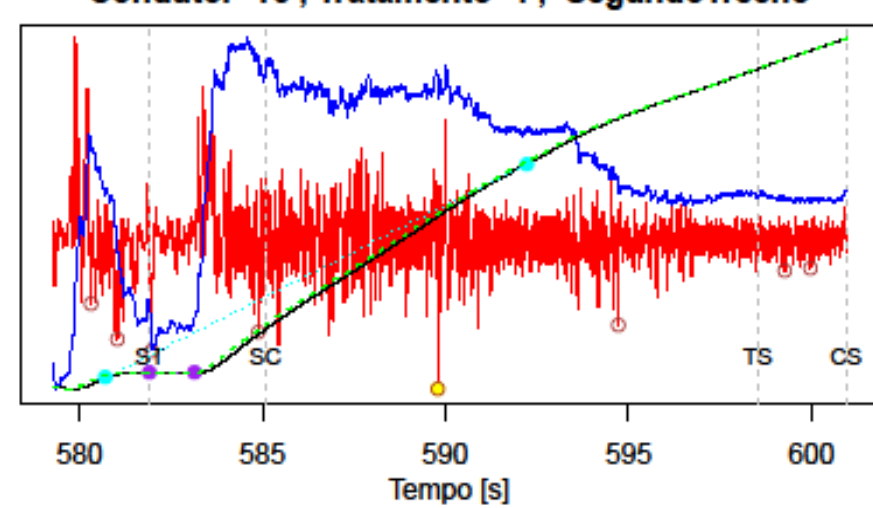

Jerks minimos $[\mathrm{m} / \mathrm{s}]$ - DeltaV85 $[\mathrm{km} / \mathrm{h}]$ Jerk minimo $\left[\mathrm{m} / \mathrm{s}^{\mathrm{s}}\right]$ - $85 \mathrm{MSR}[\mathrm{km} / \mathrm{h}]$
Condutor 16 , Tratamento 3 , SegundoTrecho

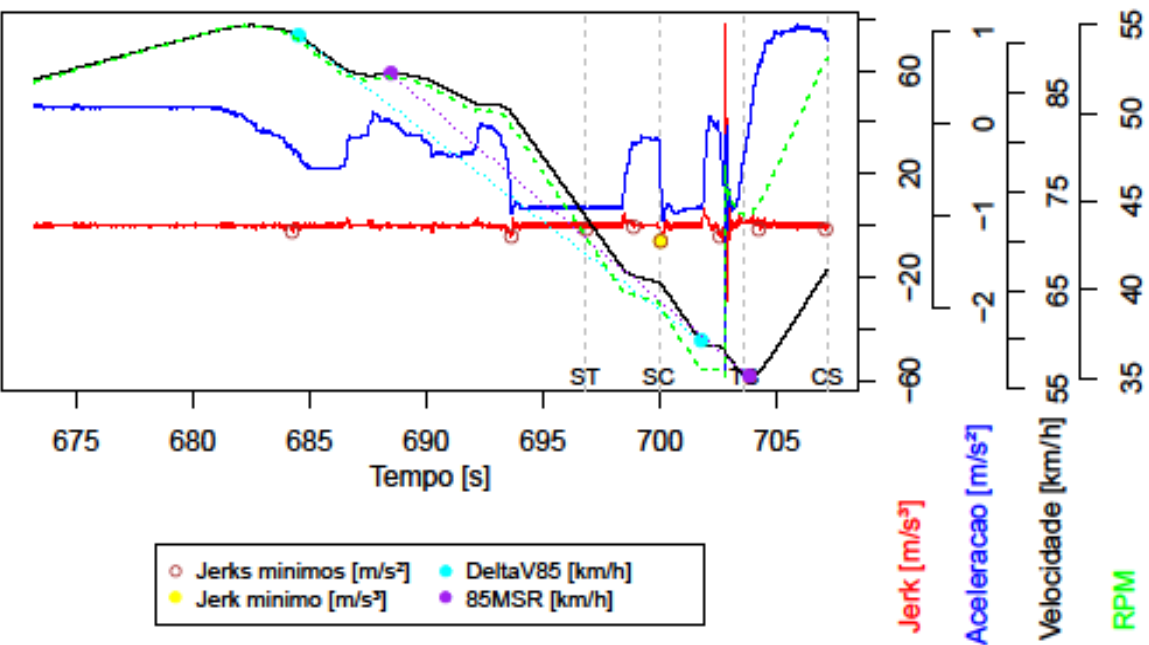

Condutor 16, Tratamento 5, SegundoTrecho

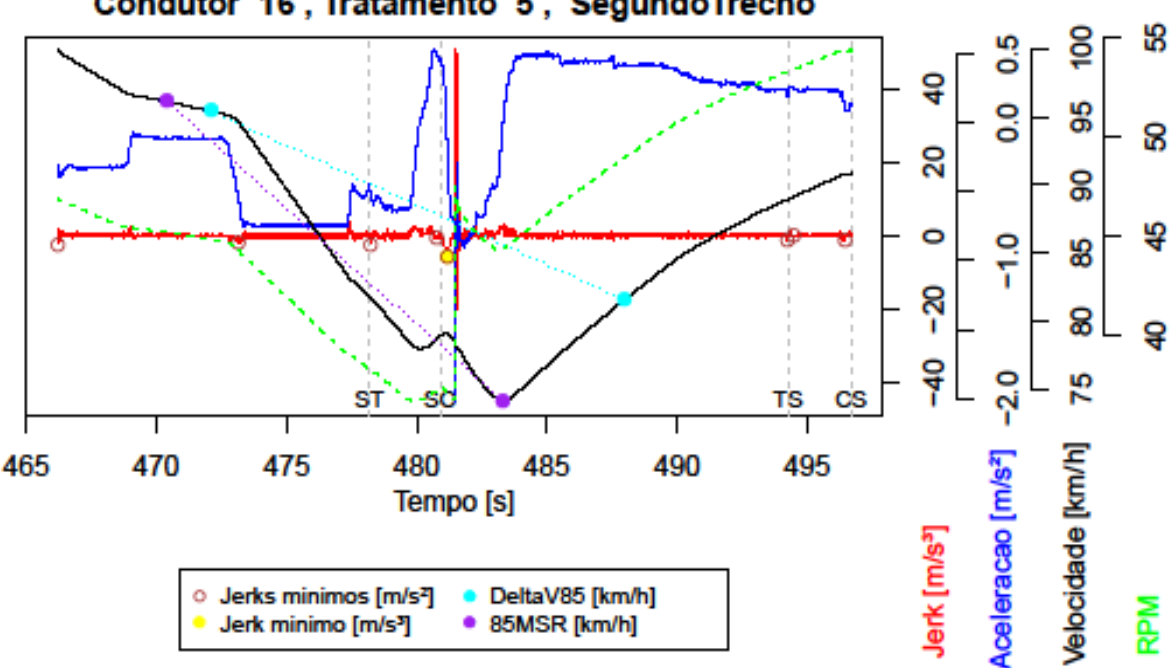


162

Condutor 16, Tratamento 6 , SegundoTrecho

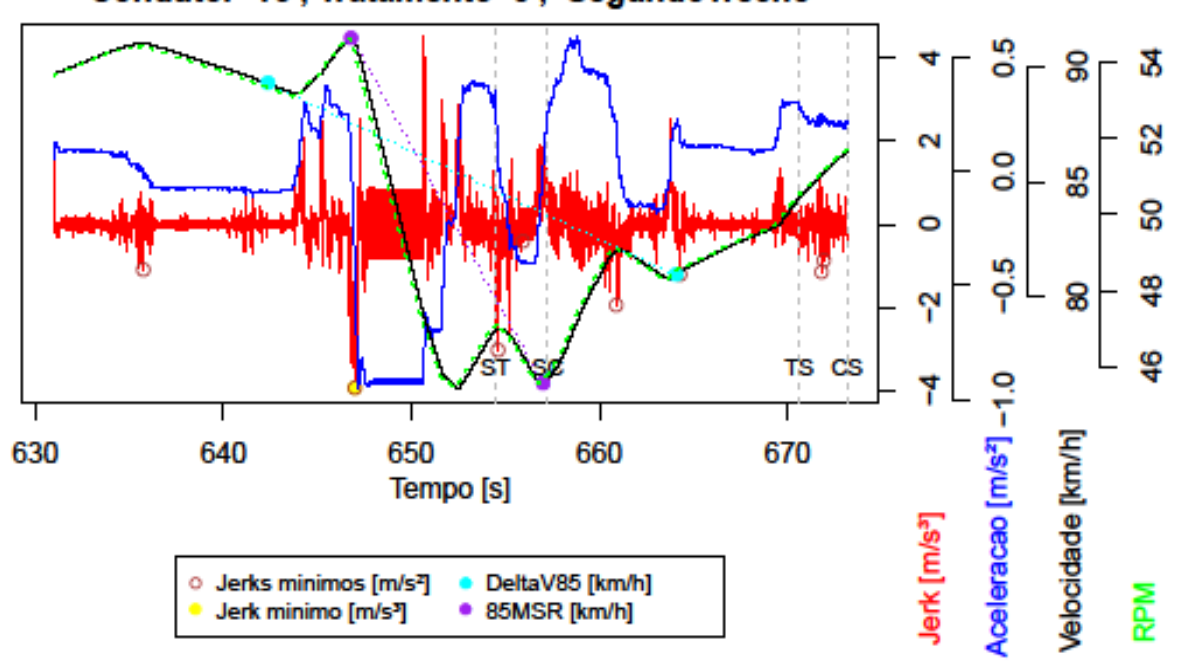

Condutor 16 , Tratamento 8 , SegundoTrecho

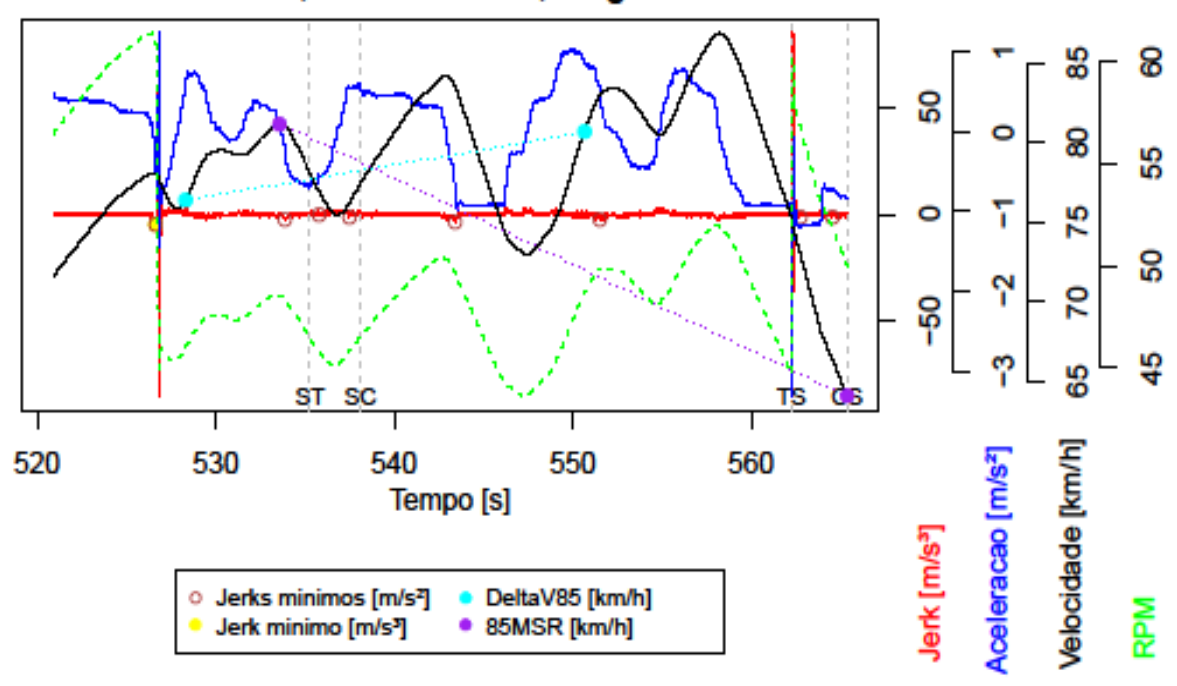

Condutor 16, Tratamento 7 , SegundoTrecho

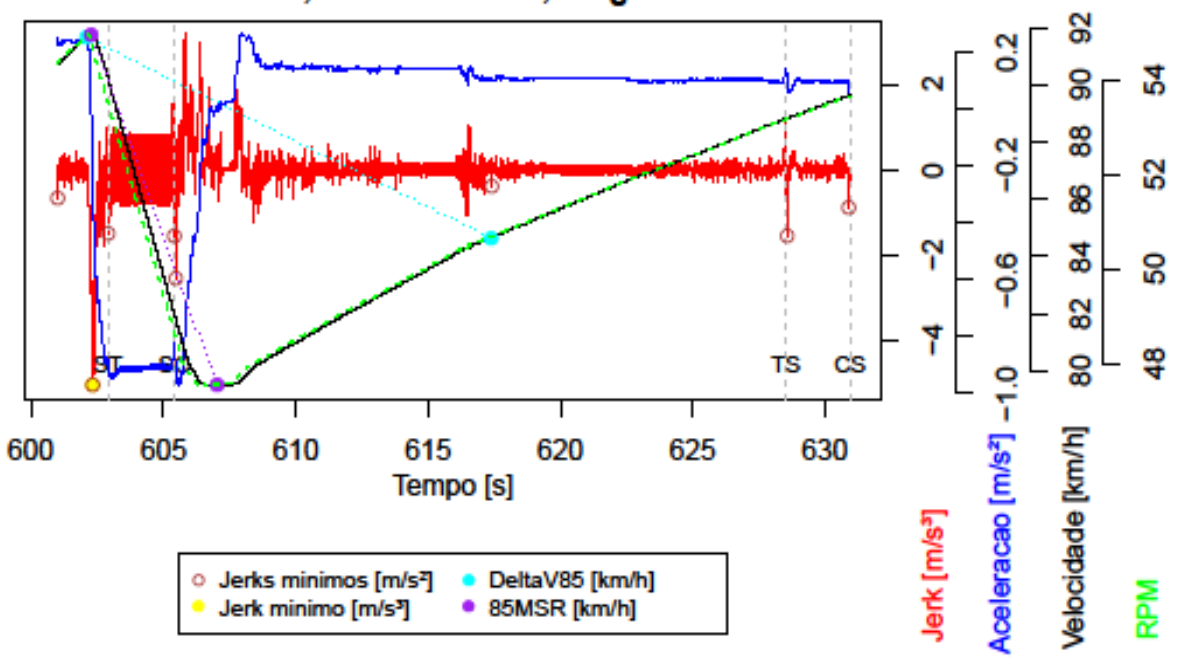

Condutor 16, Tratamento 9 , SegundoTrecho

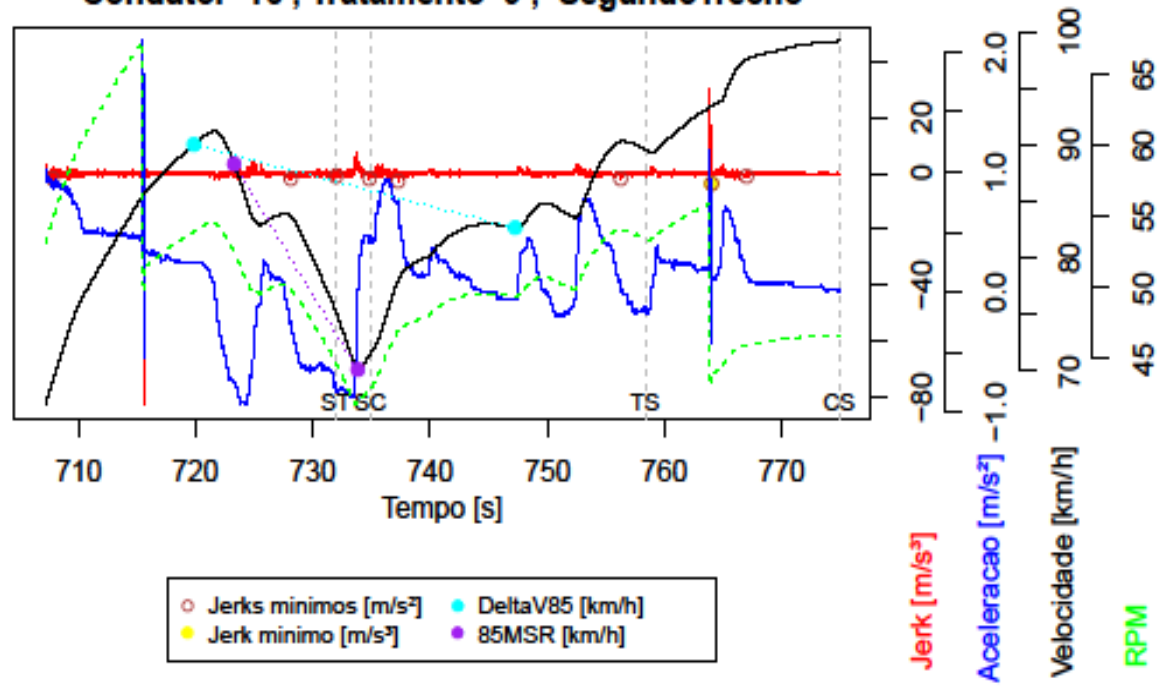



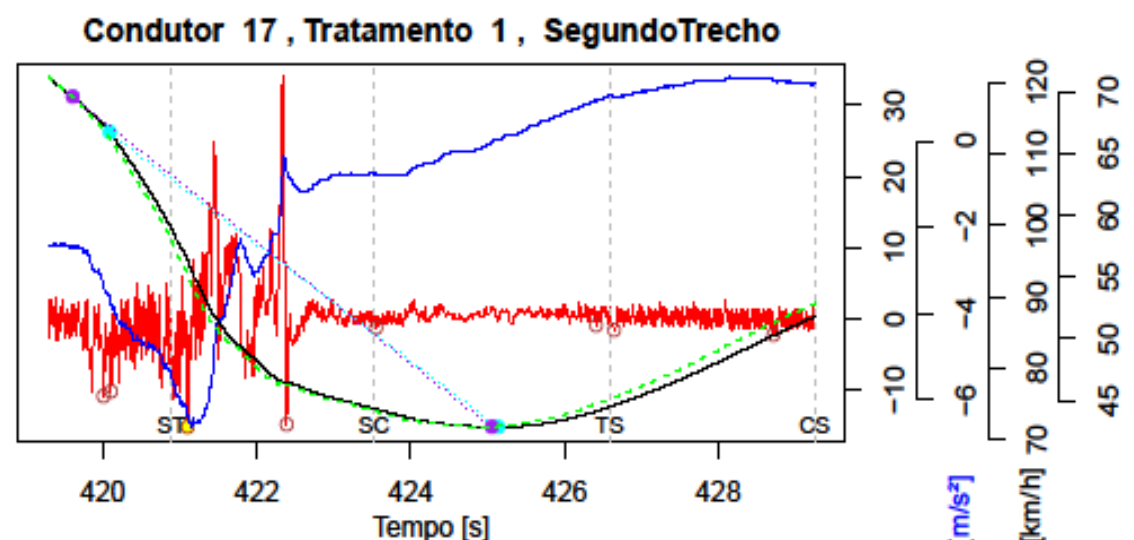

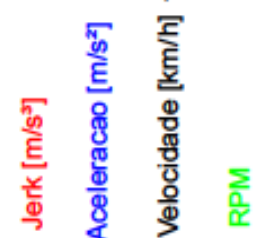

Condutor 17 , Tratamento 3 , SegundoTrecho

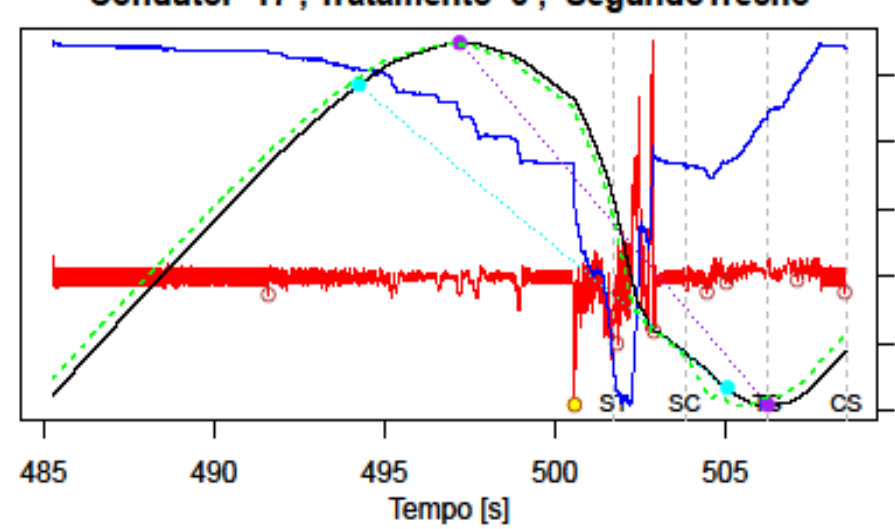

Jerks minimos $[\mathrm{m} / \mathrm{s}]$ - DeltaV85 $[\mathrm{km} / \mathrm{h}]$

Jerks minimos $\left[\mathrm{m} / \mathrm{s}^{\mathrm{s}}\right]$
Jerk minimo $\left[\mathrm{m} / \mathrm{s}^{\mathrm{D}}\right]$

\section{Condutor 17 , Tratamento 2 , SegundoTrecho}
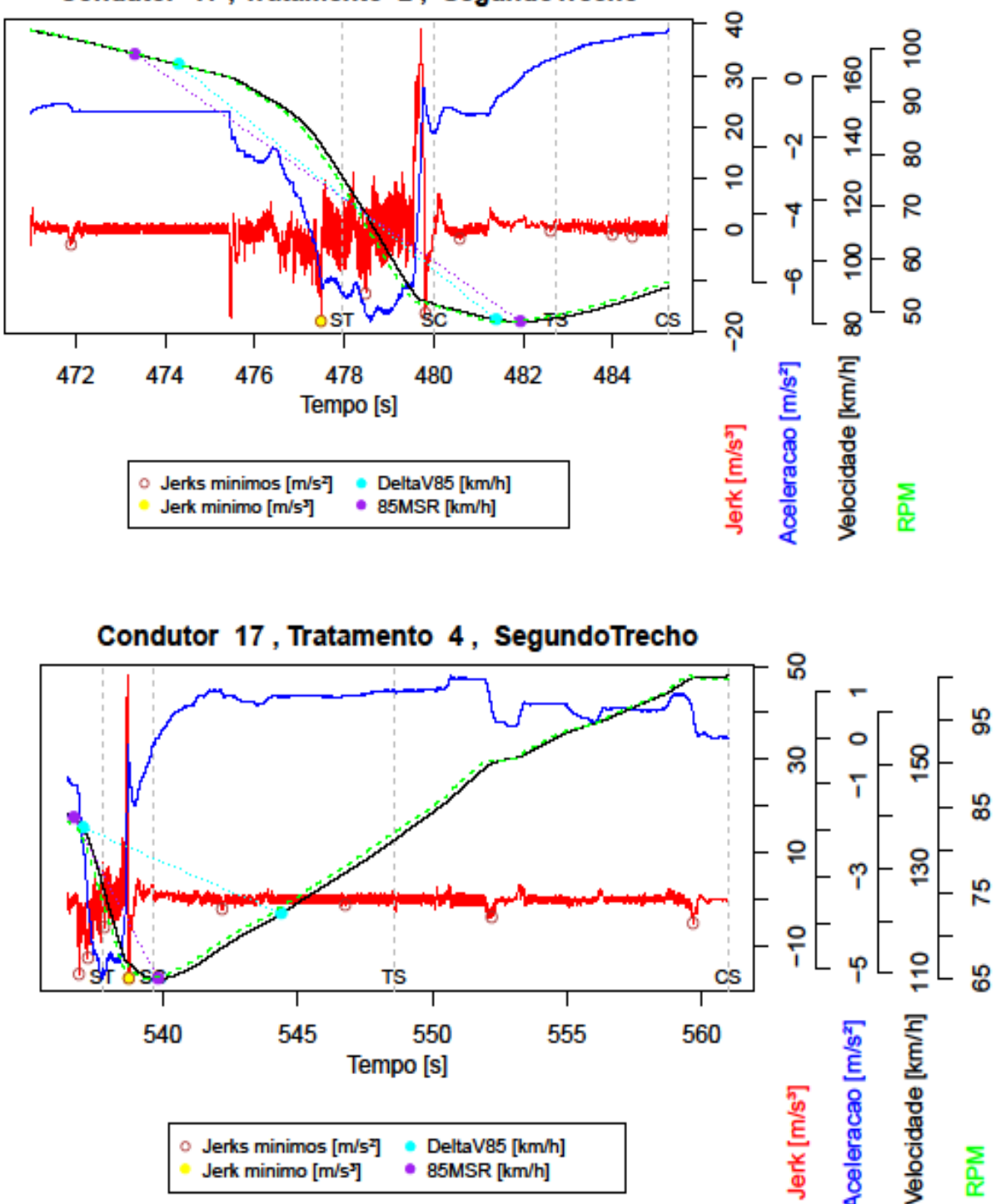
Condutor 17 , Tratamento 5 , SegundoTrecho

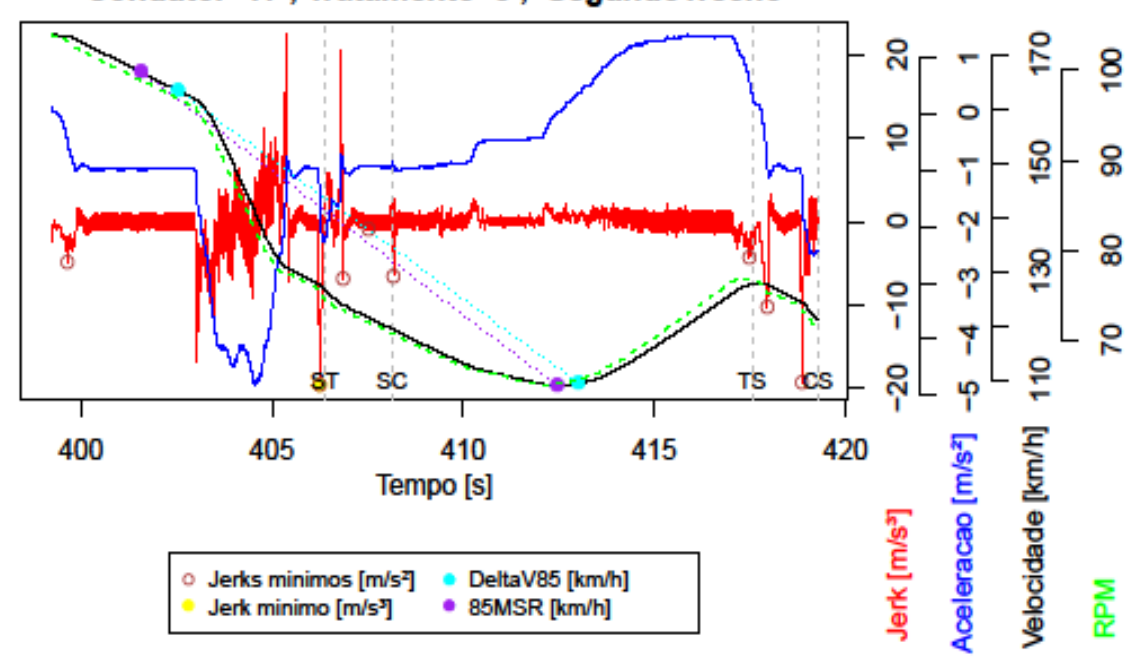

\section{Condutor 17 , Tratamento 7 , SegundoTrecho}

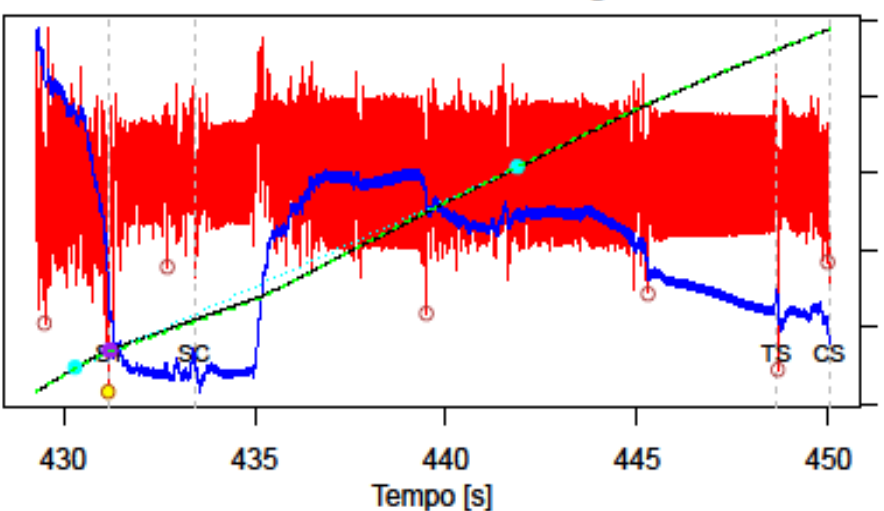

Jerks minimos $[\mathrm{m} / \mathrm{s}]$ - DeltaV85 $[\mathrm{km} / \mathrm{h}]$ Jerk minimo $\left[\mathrm{m} / \mathrm{s}^{\mathrm{s}}\right]$ - $85 \mathrm{MSR}[\mathrm{km} / \mathrm{h}]$
Condutor 17 , Tratamento 6 , SegundoTrecho

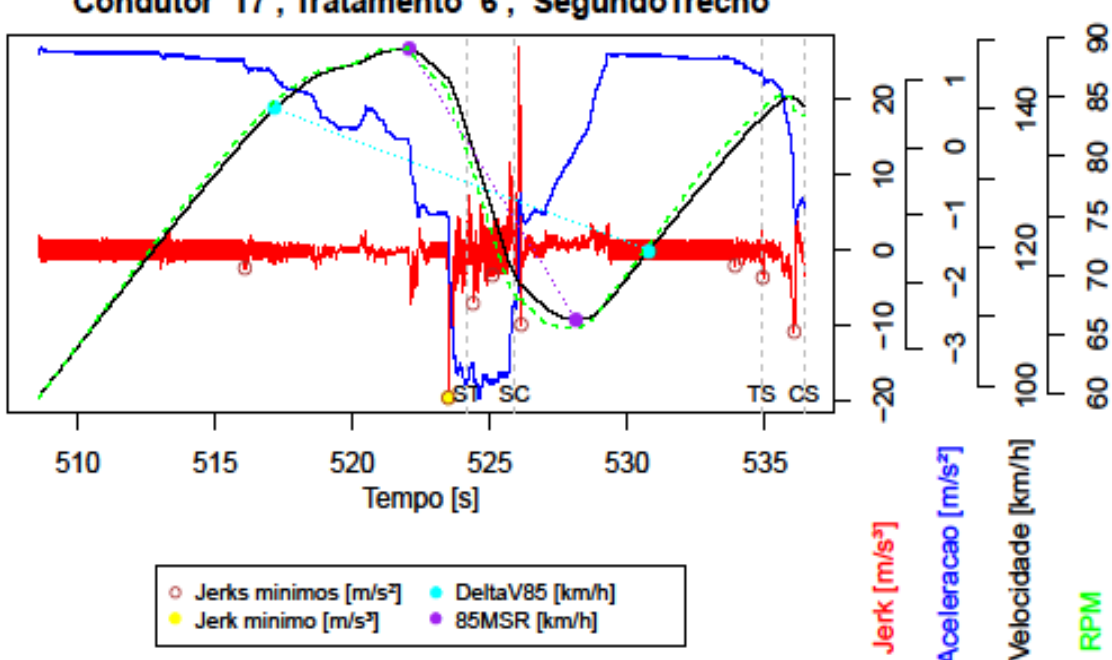

Condutor 17 , Tratamento 8 , SegundoTrecho

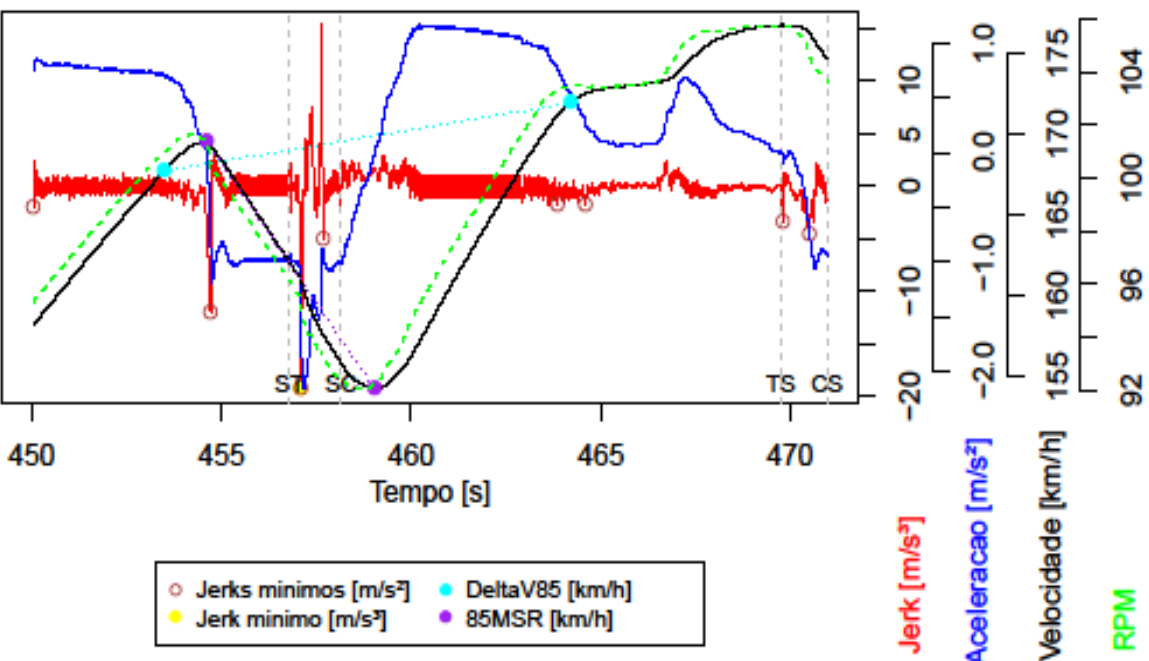


Condutor 17 , Tratamento 9 , SegundoTrecho

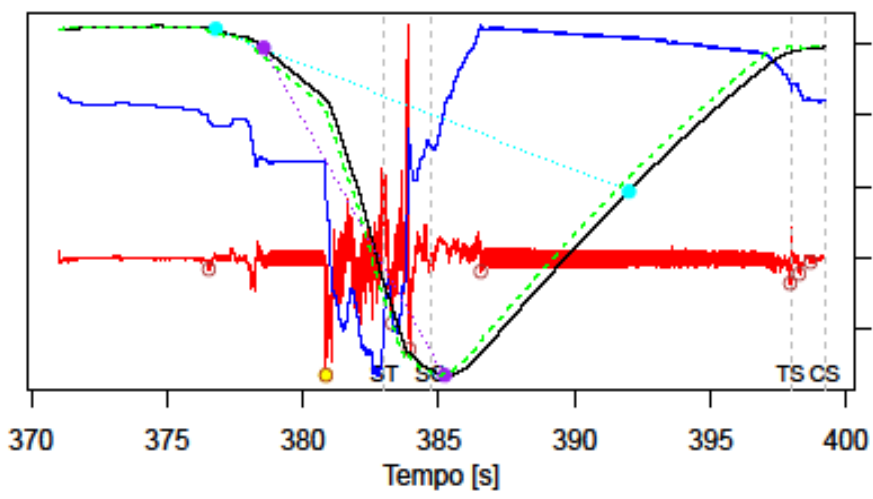

Jerks minimos $\left[\mathrm{m} / \mathrm{s}^{2}\right]$ - DeltaV85 $[\mathrm{km} / \mathrm{h}]$ Jerk minimo $[\mathrm{m} / \mathrm{s}]$ - $85 \mathrm{MSR}[\mathrm{km} / \mathrm{h}]$

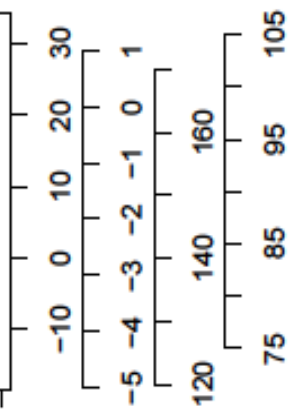

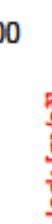

\section{Condutor 18 , Tratamento 1 , SegundoTrecho}

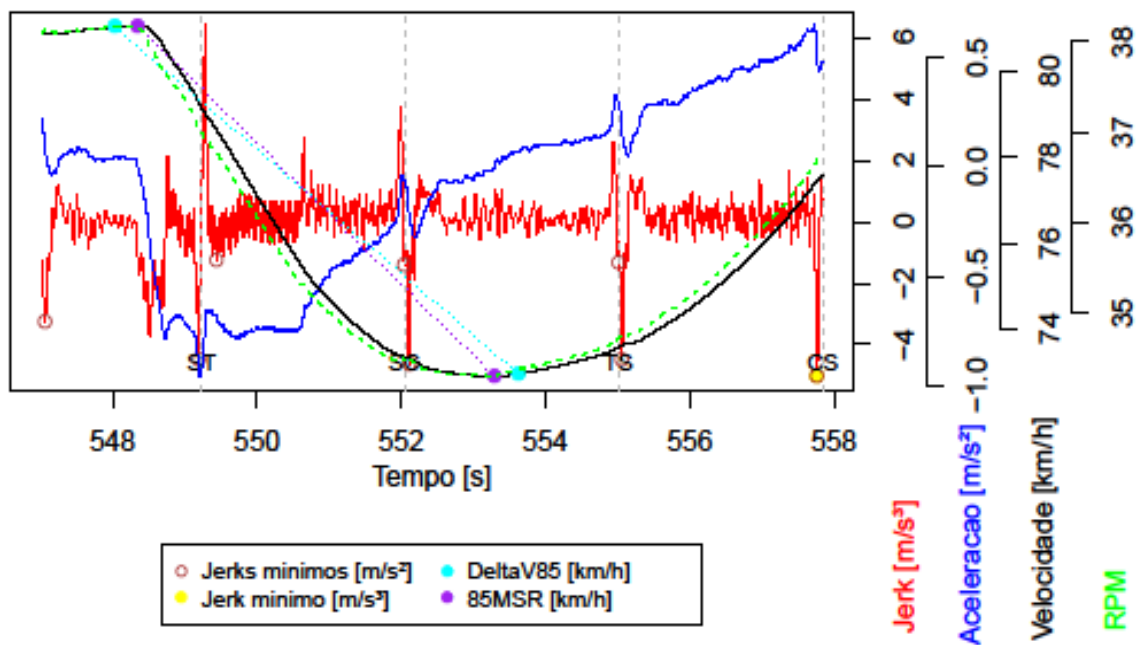

Condutor 18 , Tratamento 2 , SegundoTrecho

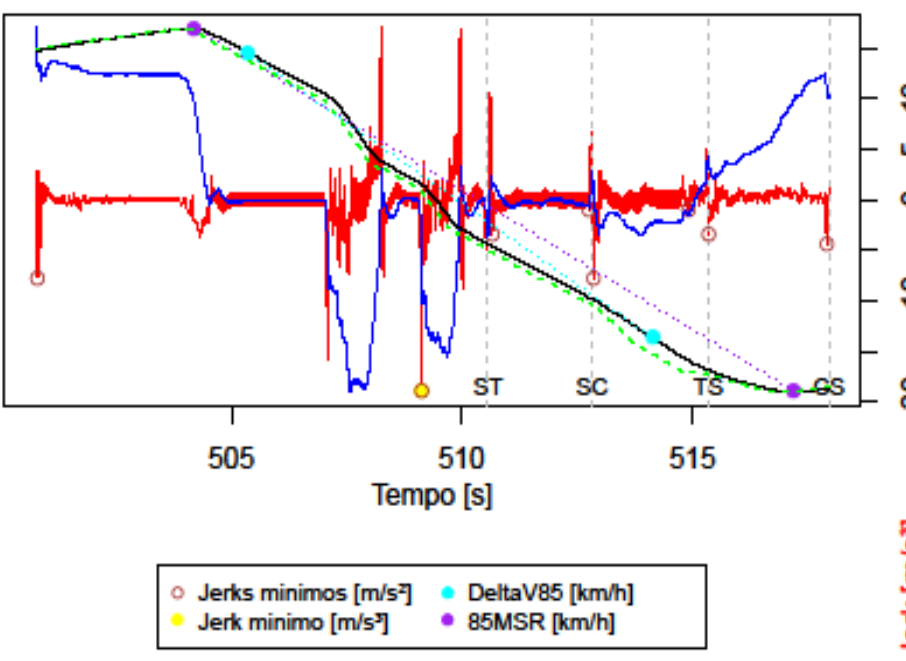

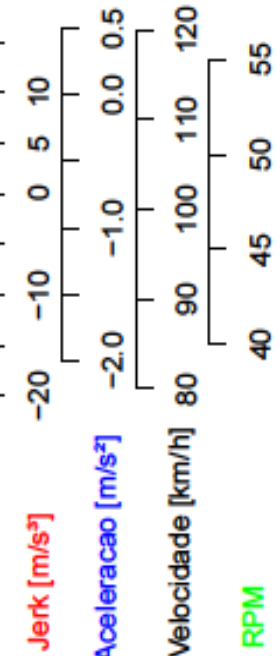

Condutor 18 , Tratamento 3 , SegundoTrecho

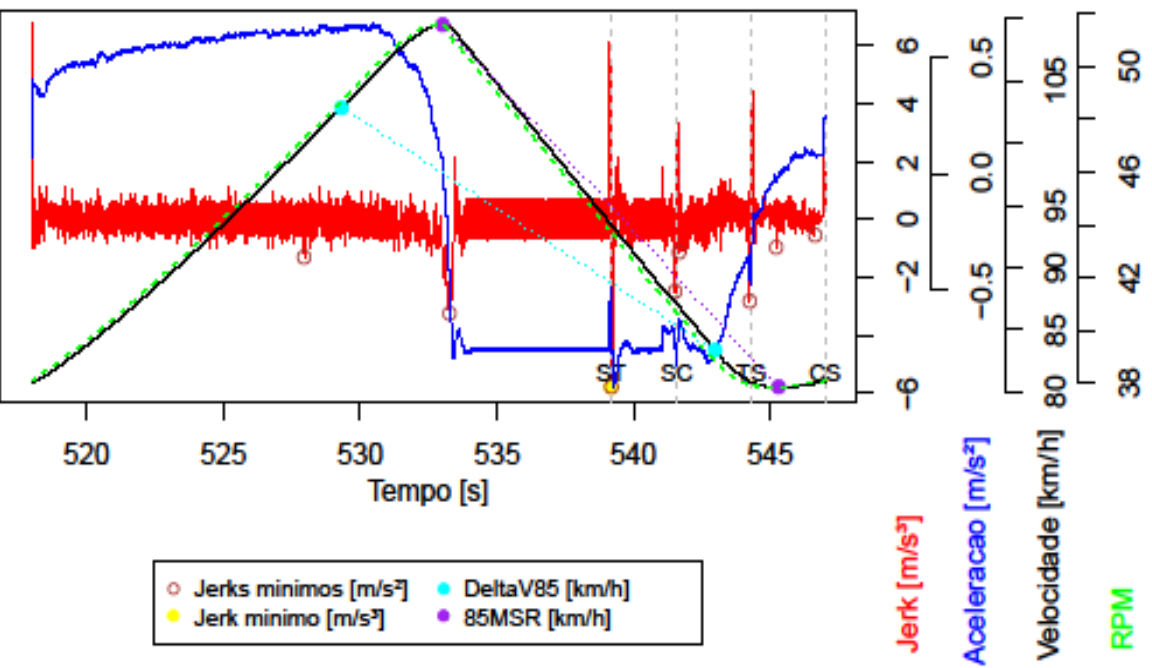


Condutor 18 , Tratamento 4 , SegundoTrecho

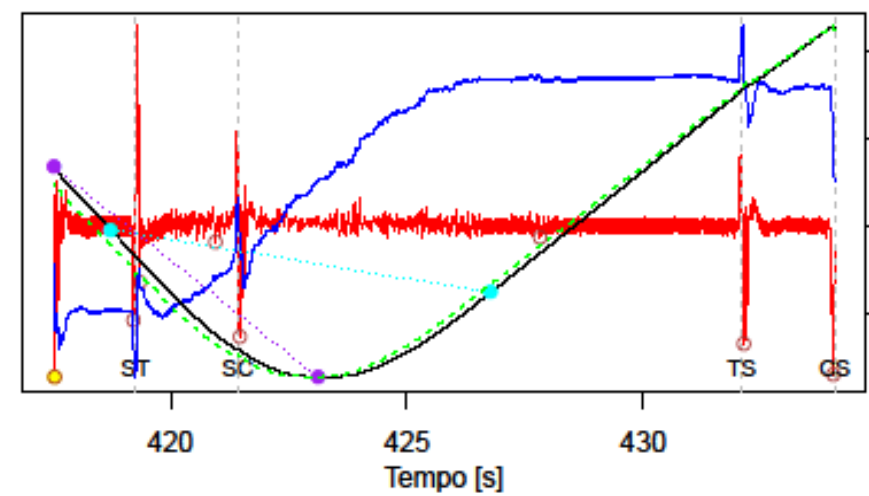

Jerks minimos [m/s $]$ DeltaV85 $[\mathrm{km} / \mathrm{h}]$ Jerk minimo $\left[\mathrm{m} / \mathrm{s}^{\mathrm{s}}\right]$ • $85 \mathrm{MSR}[\mathrm{km} / \mathrm{h}]$

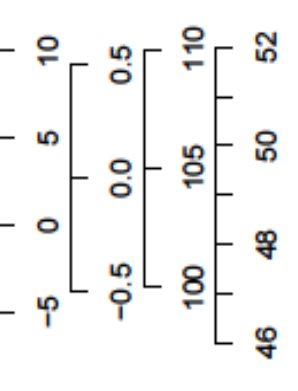

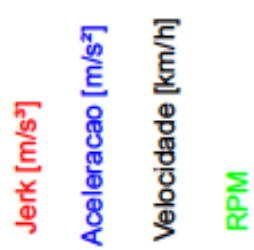

Condutor 18 , Tratamento 5 , SegundoTrecho

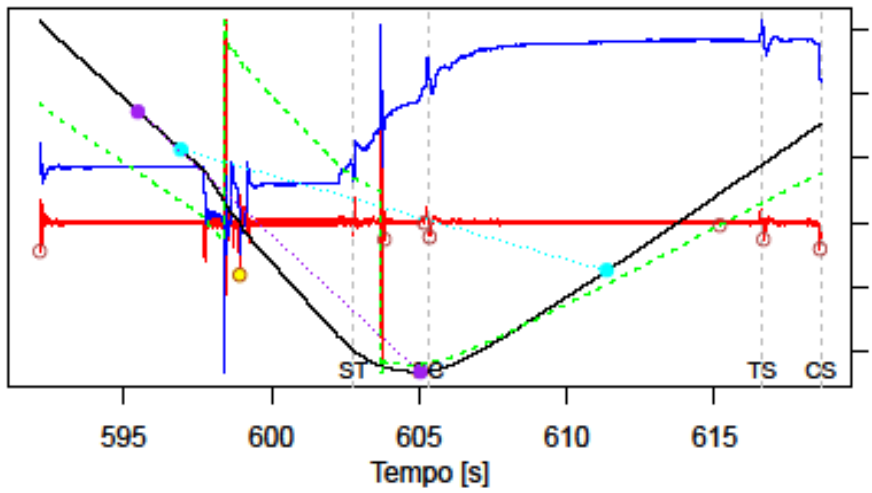

Jerks minimos $[\mathrm{m} / \mathrm{s} \mathrm{s}]$ - DeltaV85 $[\mathrm{km} / \mathrm{h}]$ Jerk minimo $[\mathrm{m} / \mathrm{s} / \mathrm{s}]$ - $85 \mathrm{MSR}[\mathrm{km} / \mathrm{h}]$

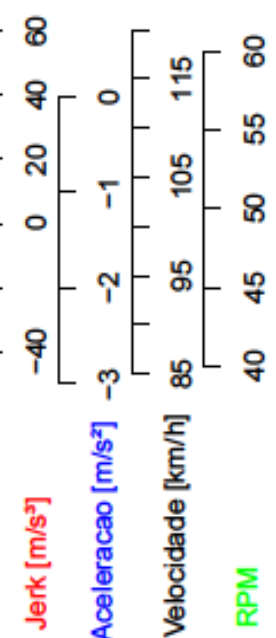

Condutor 18 , Tratamento 6 , SegundoTrecho

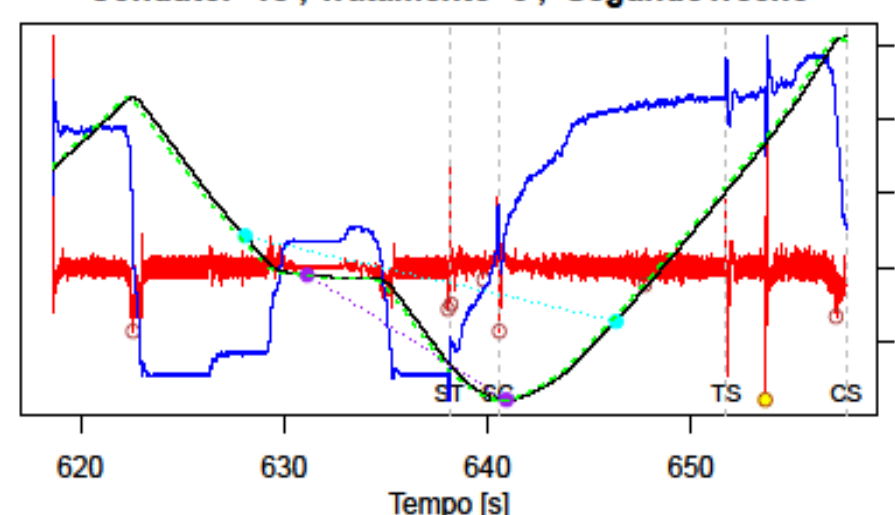

Jerks minimos $\left[\mathrm{m} / \mathrm{s}^{\mathrm{2}}\right]$ DeltaV85 $[\mathrm{km} / \mathrm{h}]$ Jerk minimo $\left[\mathrm{m} / \mathrm{s}^{\mathrm{s}}\right]$ • $85 \mathrm{MSR}[\mathrm{km} / \mathrm{h}]$

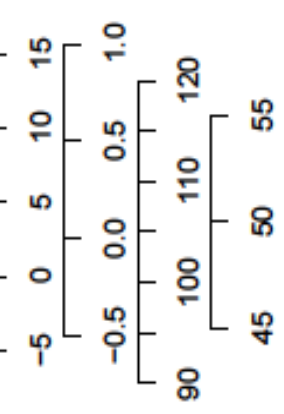

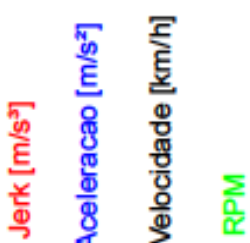

\section{Condutor 18, Tratamento 7 , SegundoTrecho}

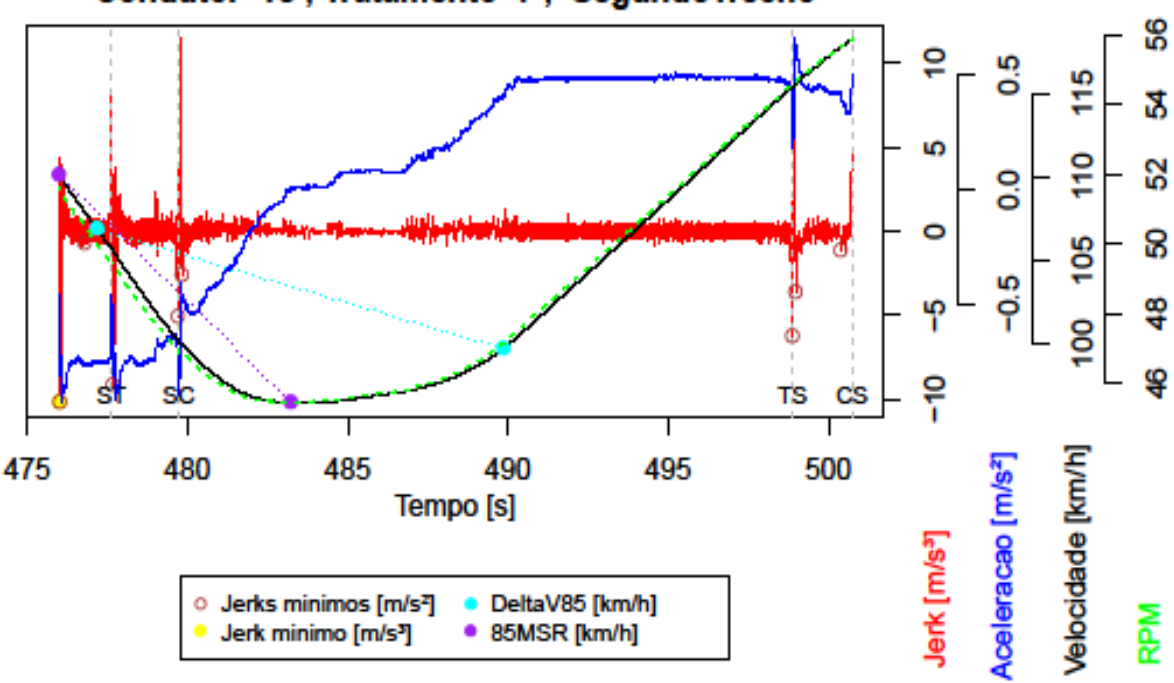



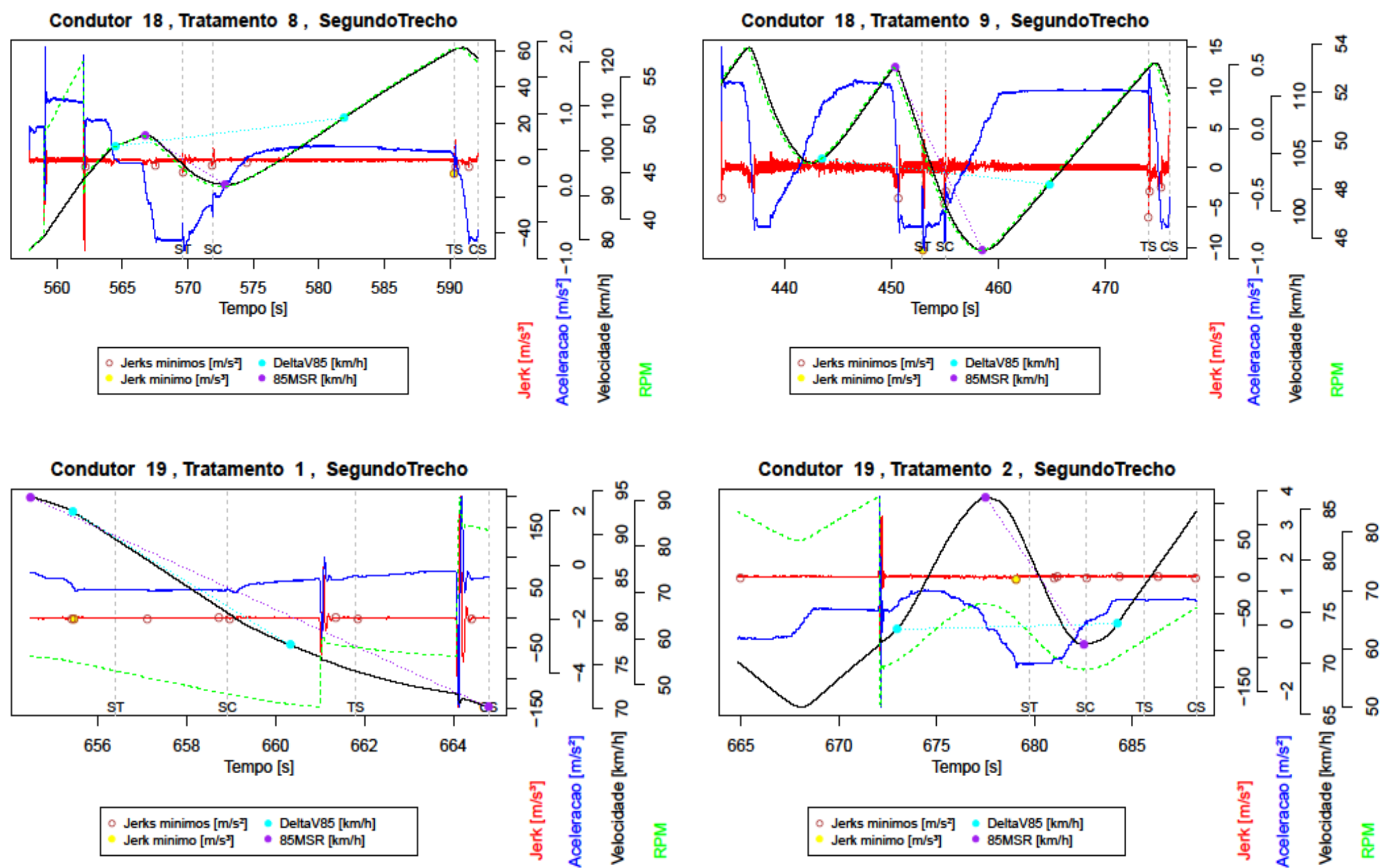

Jerks minimos $[\mathrm{m} / \mathrm{s}]$
Jerk minimo $[\mathrm{m} / \mathrm{s}]$ DeltaV85 $[\mathrm{km} / \mathrm{h}]$

Jerk minimos [m/s $\left./ \mathrm{s}] / \mathrm{s}^{\mathrm{s}}\right]$

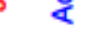



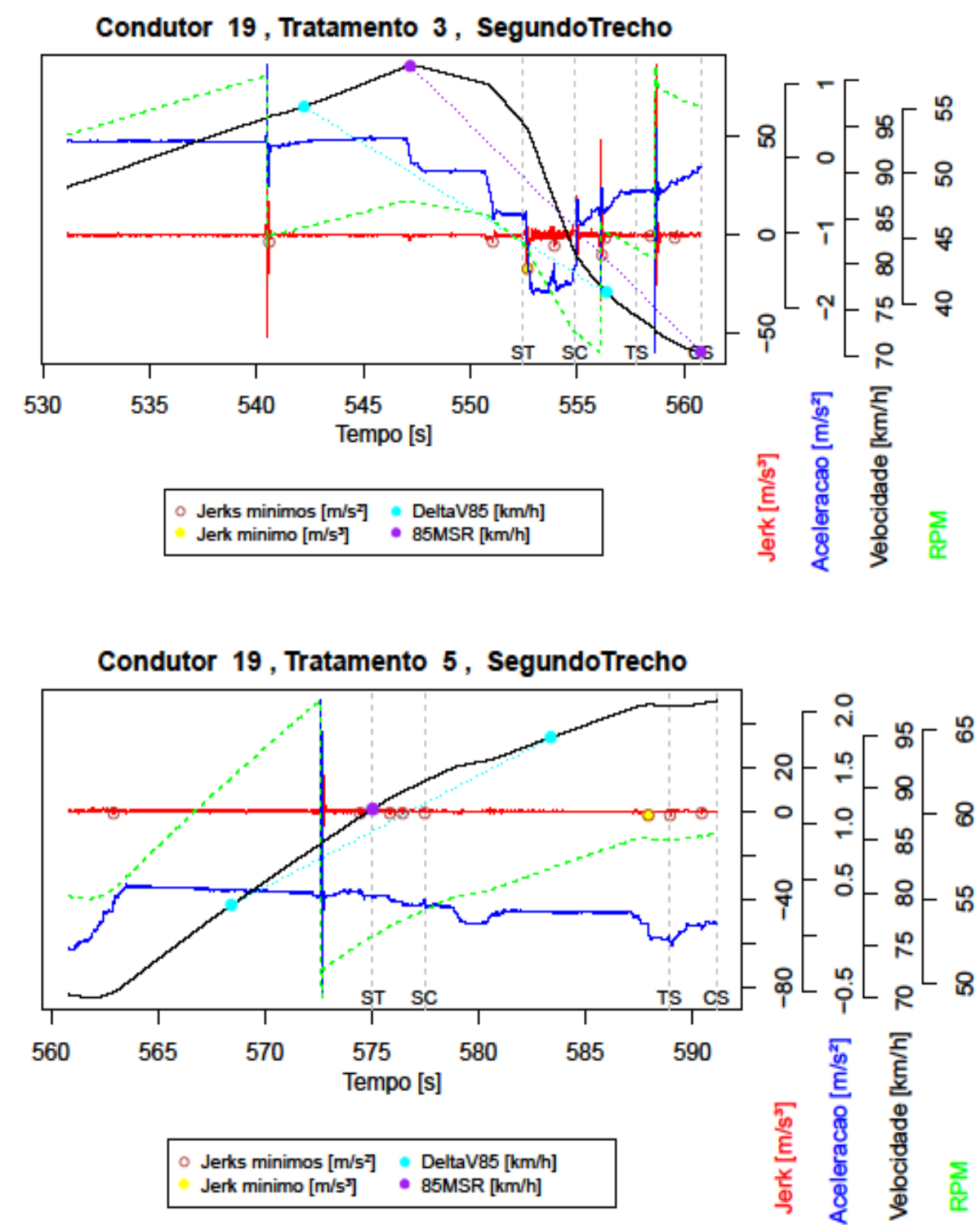

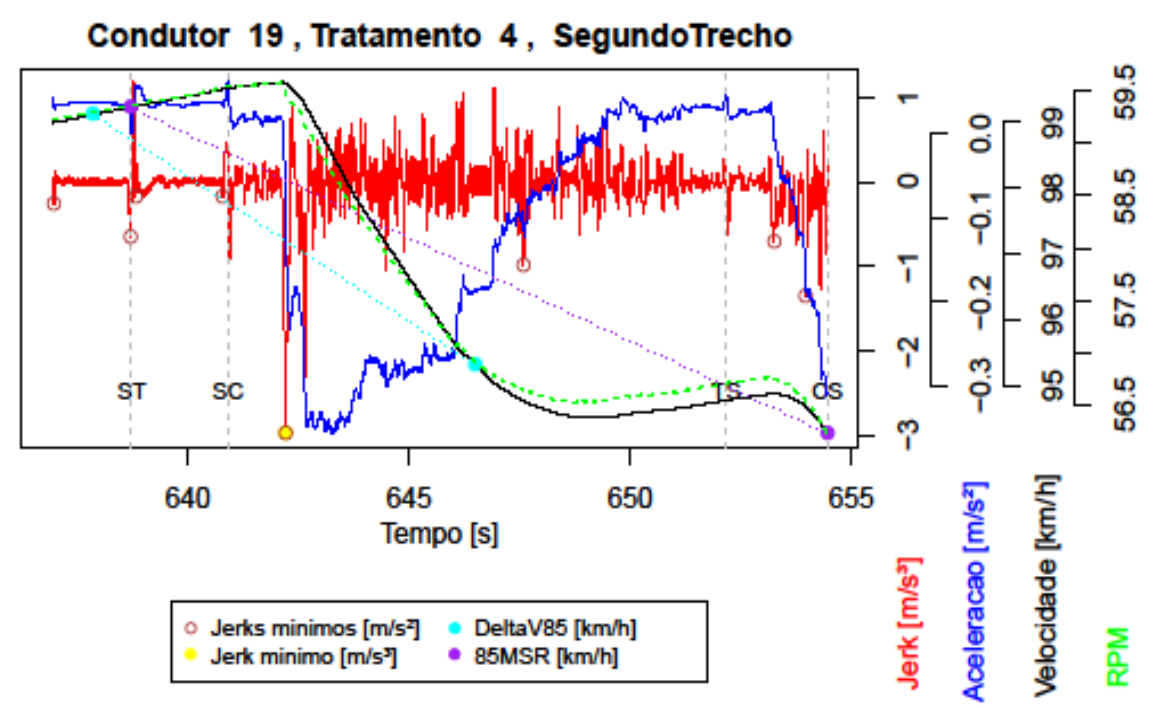

\section{Condutor 19 , Tratamento 6 , SegundoTrecho}

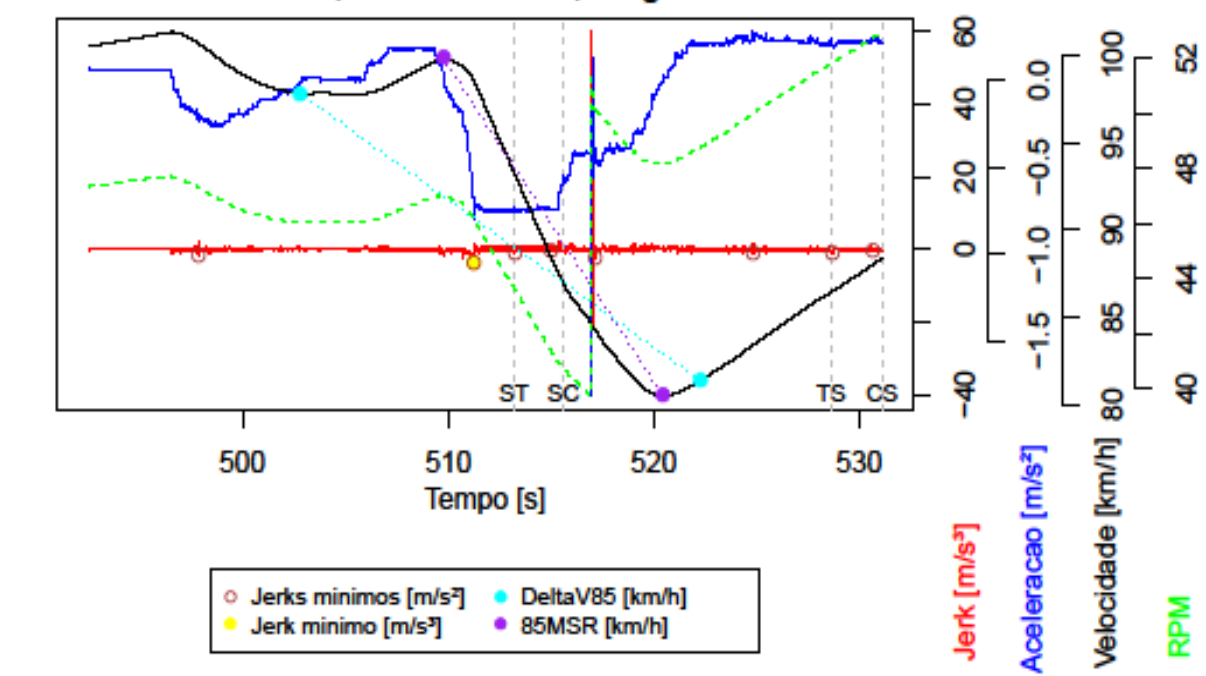




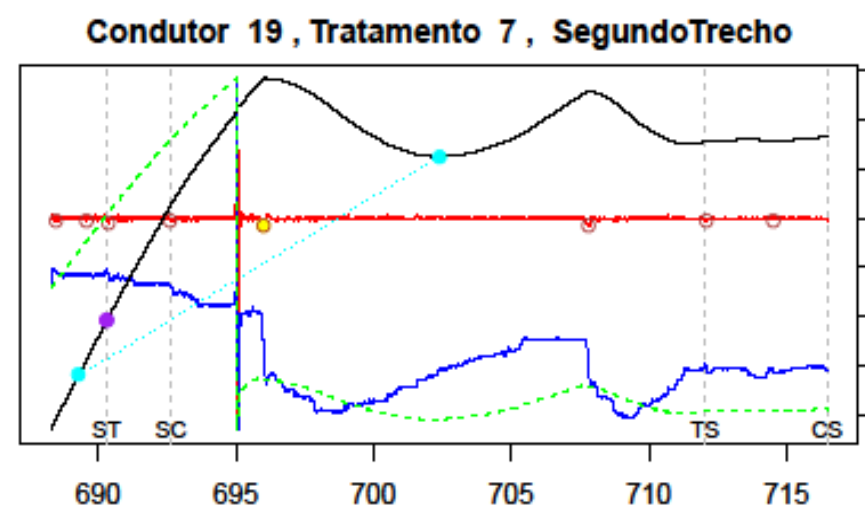

690

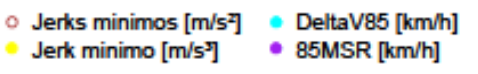
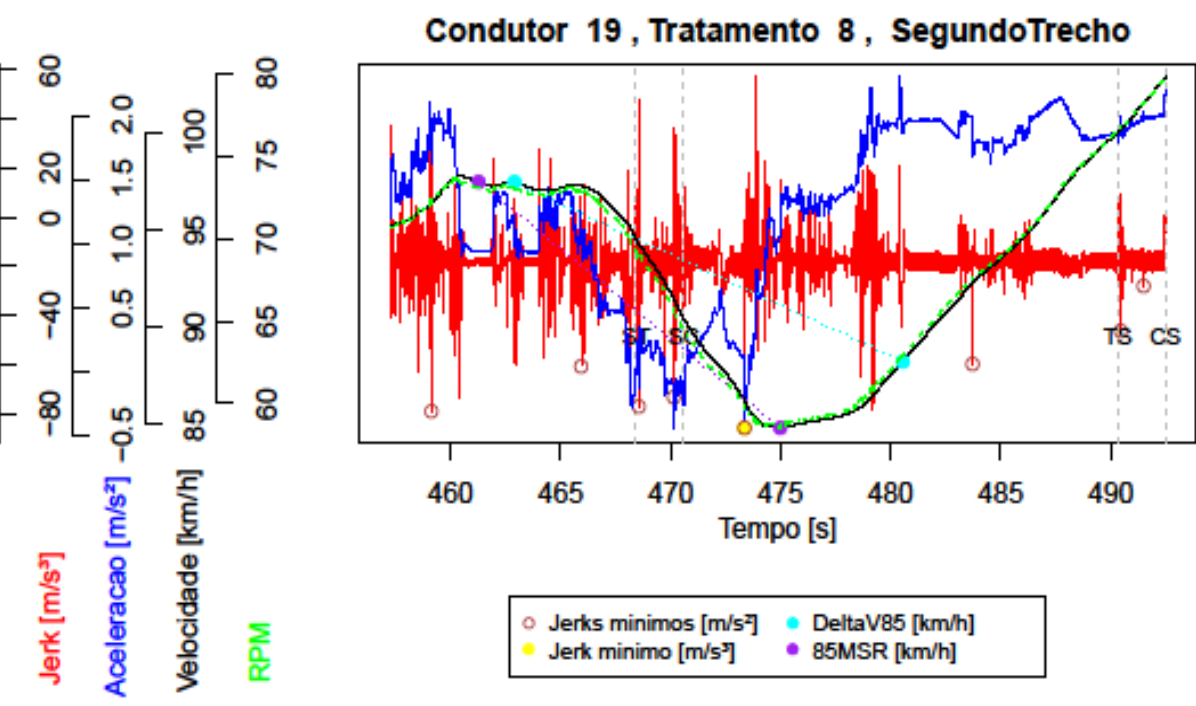

- Jerks minimos $[\mathrm{m} / \mathrm{s}]$ - DeltaV85 $[\mathrm{km} / \mathrm{h}]$ Jerk minimo $\left[\mathrm{m} / \mathrm{s}^{\mathrm{\vartheta}}\right]$ - $85 \mathrm{MSR}[\mathrm{km} / \mathrm{h}]$

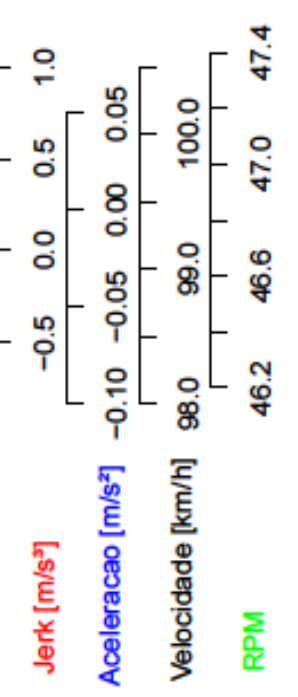

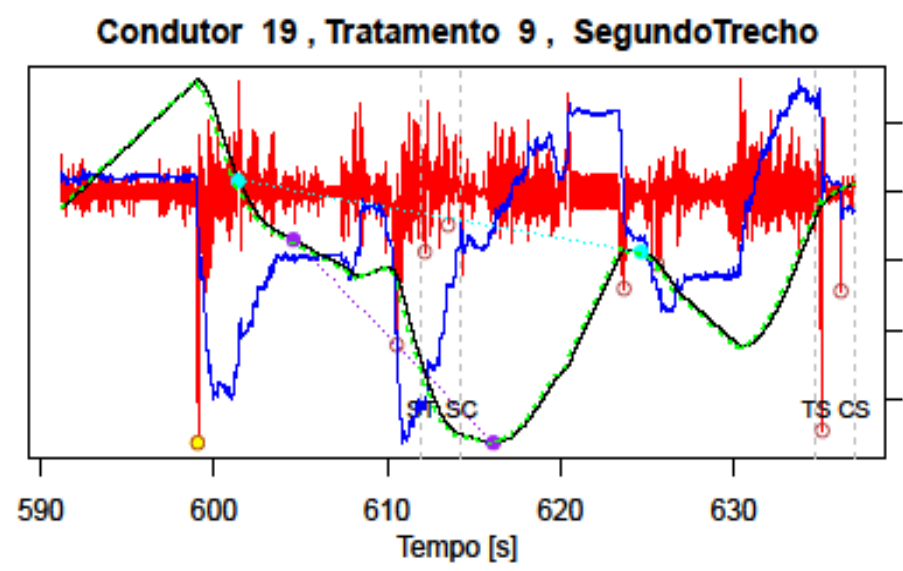

Jerks minimos $\left[\mathrm{m} / \mathrm{s}^{\mathrm{s}}\right]$ DeltaV85 $[\mathrm{km} / \mathrm{h}]$ Jerk minimo $[\mathrm{m} / \mathrm{s}]$ - $85 \mathrm{MSR}[\mathrm{km} / \mathrm{h}]$

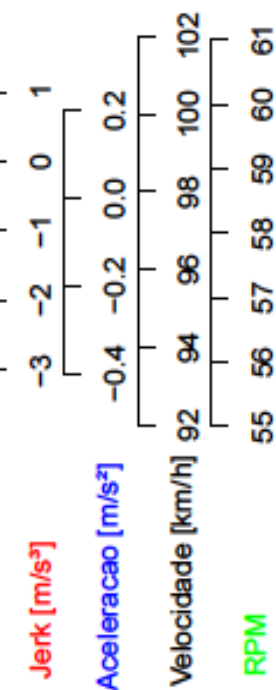

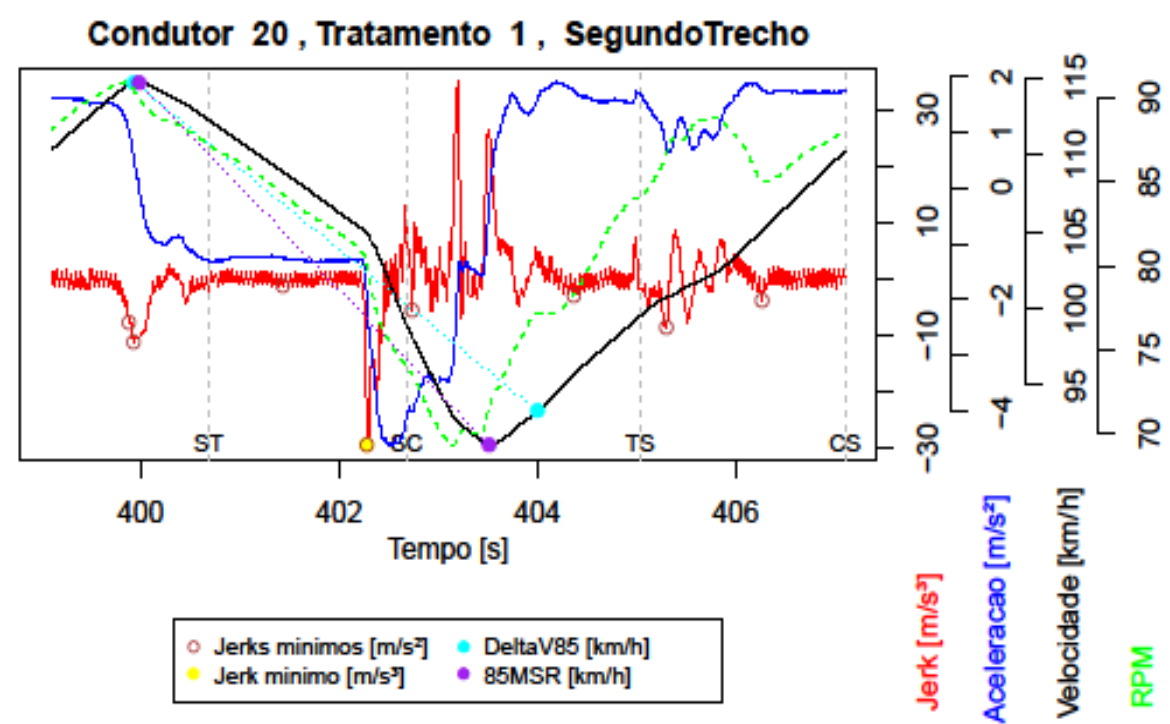


Condutor 20 , Tratamento 2 , SegundoTrecho

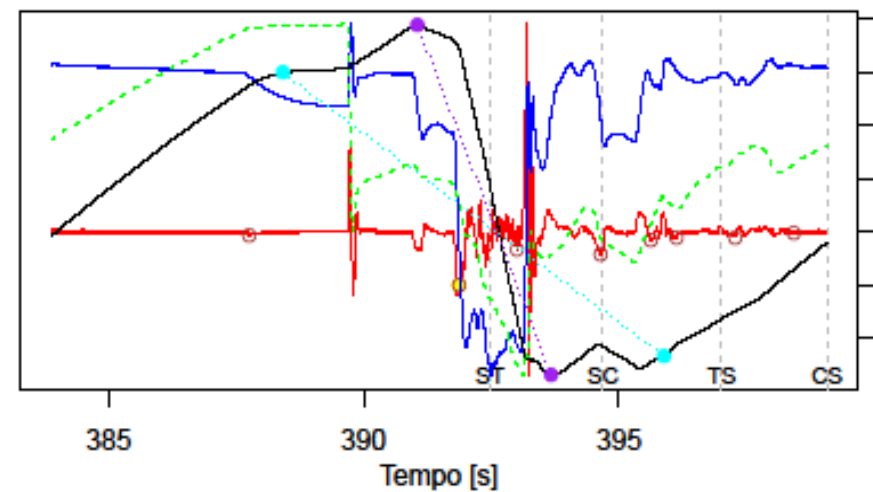

Jerks minimos $[\mathrm{m} / \mathrm{s}]]$ - DeltaV85 $[\mathrm{km} / \mathrm{h}$ Jerk minimo $\left[\mathrm{m} / \mathrm{s}^{\ni}\right] \bullet 85 \mathrm{MSR}[\mathrm{km} / \mathrm{h}]$

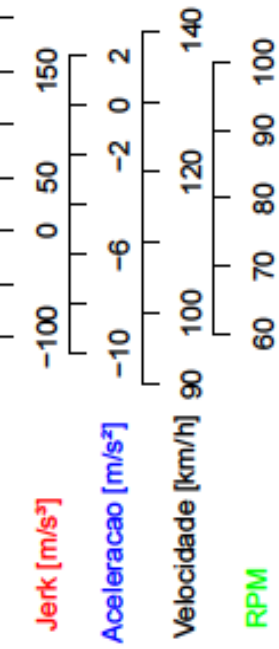

Condutor 20 , Tratamento 3 , SegundoTrecho

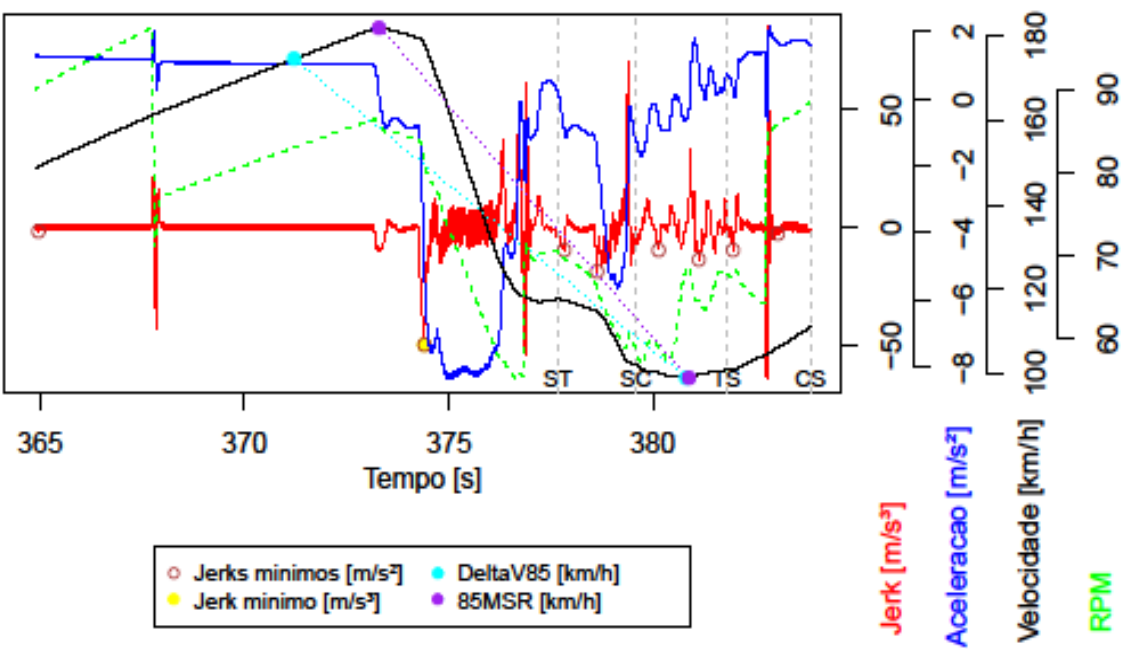

Condutor 20 , Tratamento 4 , SegundoTrecho

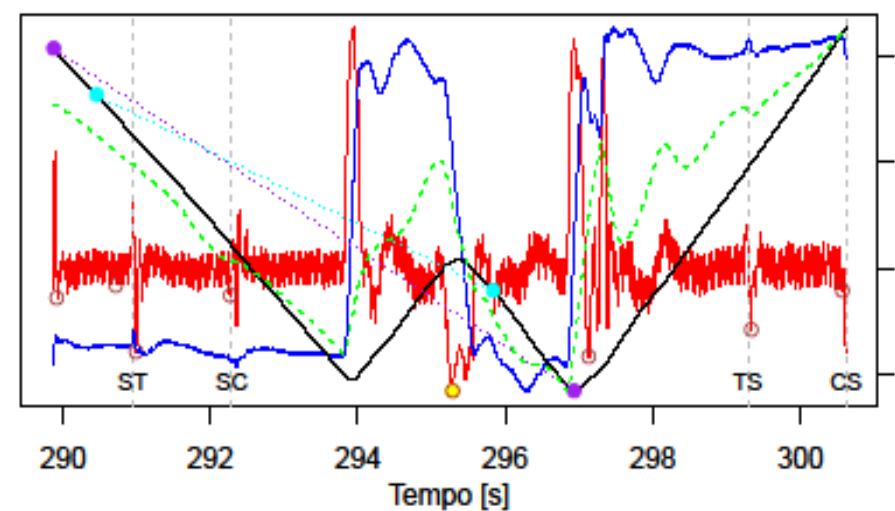

Jerks minimos $\left[\mathrm{m} / \mathrm{s}^{2}\right]$ - DeltaV85 $[\mathrm{km} / \mathrm{h}]$ Jerk minimo $\left[\mathrm{m} / \mathrm{s}^{\mathrm{s}}\right]$ — $85 \mathrm{MSR}[\mathrm{km} / \mathrm{h}]$

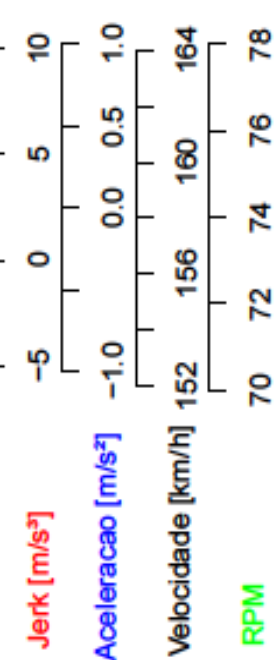

\section{Condutor 20, Tratamento 5 , SegundoTrecho}

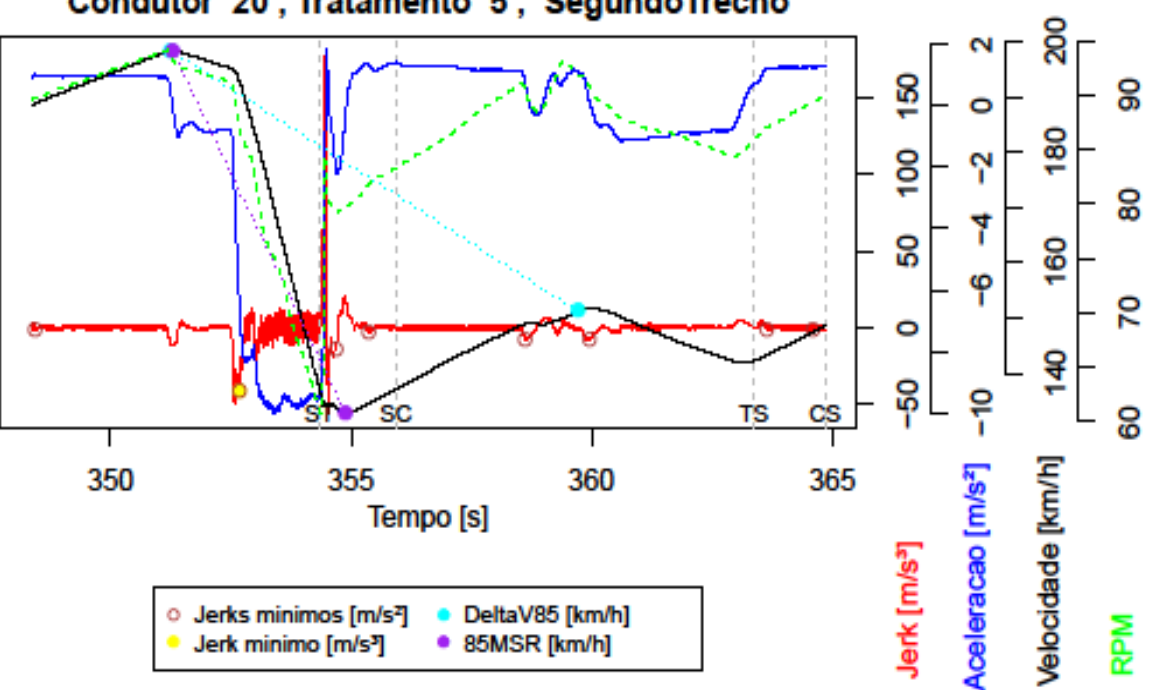


Condutor 20 , Tratamento 6 , SegundoTrecho

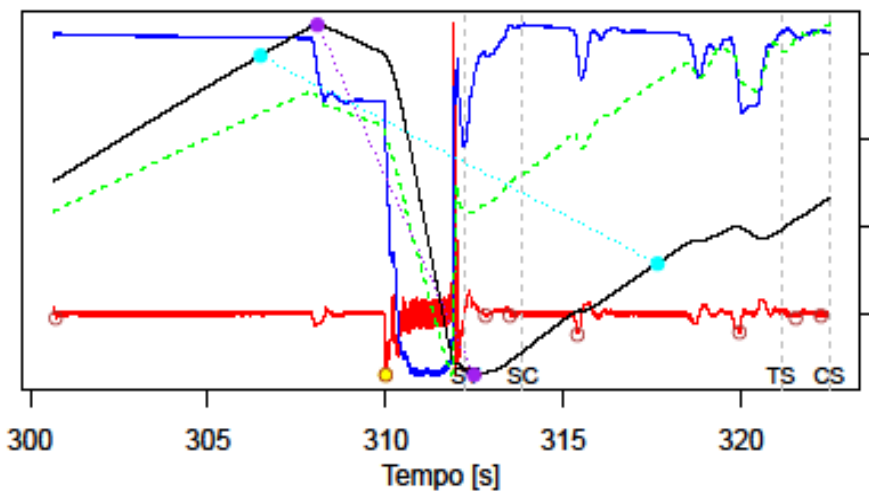
Jerks minimos $\left[\mathrm{m} / \mathrm{s}^{\mathrm{z}}\right]$ ? DeltaV85 $[\mathrm{km} / \mathrm{h}$ Jerk minimo $[\mathrm{m} / \mathrm{s}$ ]

Condutor 20 , Tratamento 8 , SegundoTrecho

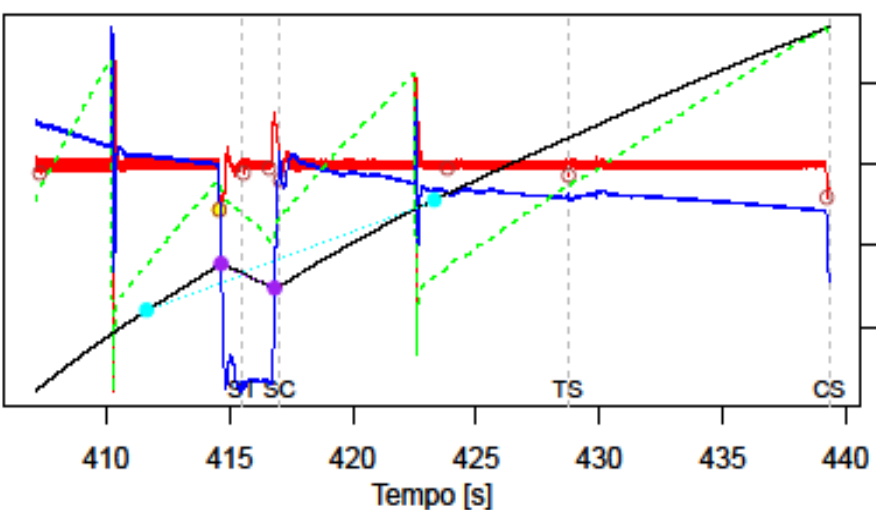

Jerks minimos $[\mathrm{m} / \mathrm{s}$ ] $\quad$ DeltaV85 $[\mathrm{km} / \mathrm{h}]$ Jerk minimo [m/s?] $\bullet 85 \mathrm{MSR}[\mathrm{km} / \mathrm{h}]$
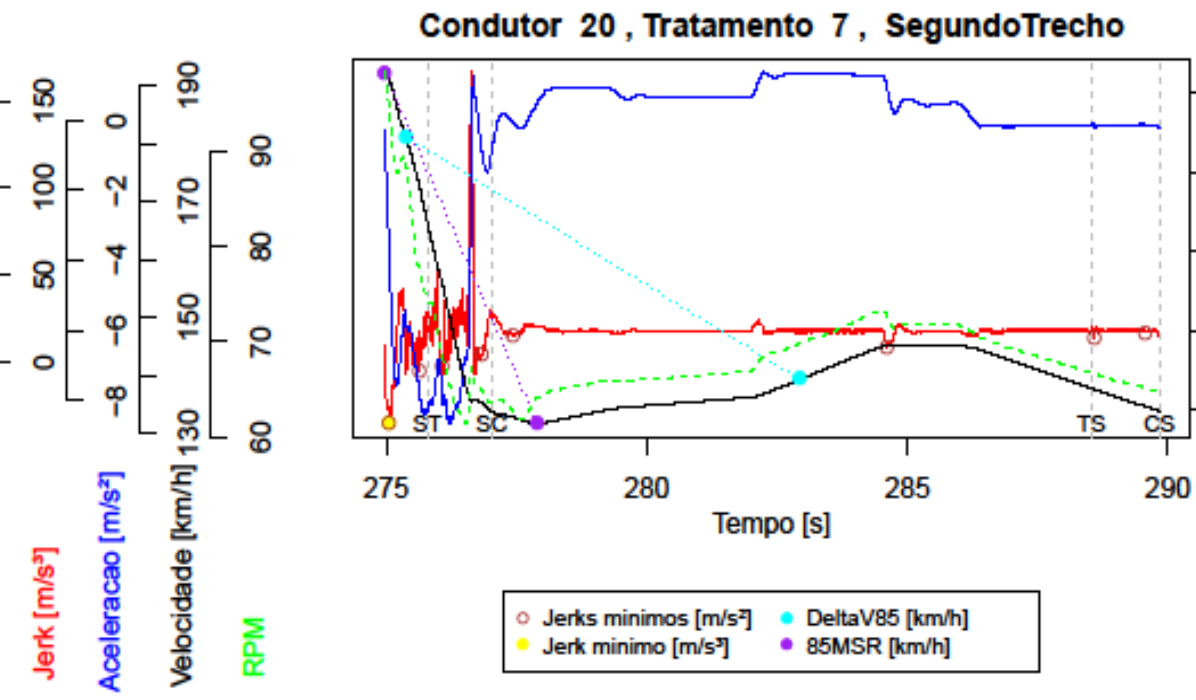

Jerks minimos $\left[\mathrm{m} / \mathrm{s}^{2}\right]$ - DeltaV85 $[\mathrm{km} / \mathrm{h}]$ Jerk minimo $\left[\mathrm{m} / \mathrm{s}^{\mathrm{l}}\right]$ - $85 \mathrm{MSR}[\mathrm{km} / \mathrm{h}]$

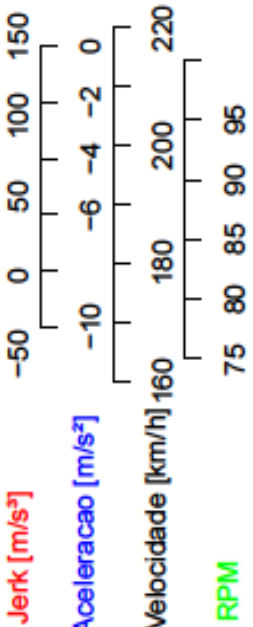

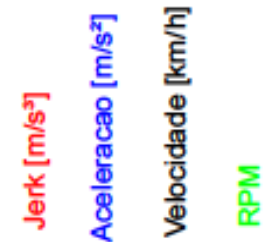

\section{Condutor 20 , Tratamento 9 , SegundoTrecho}
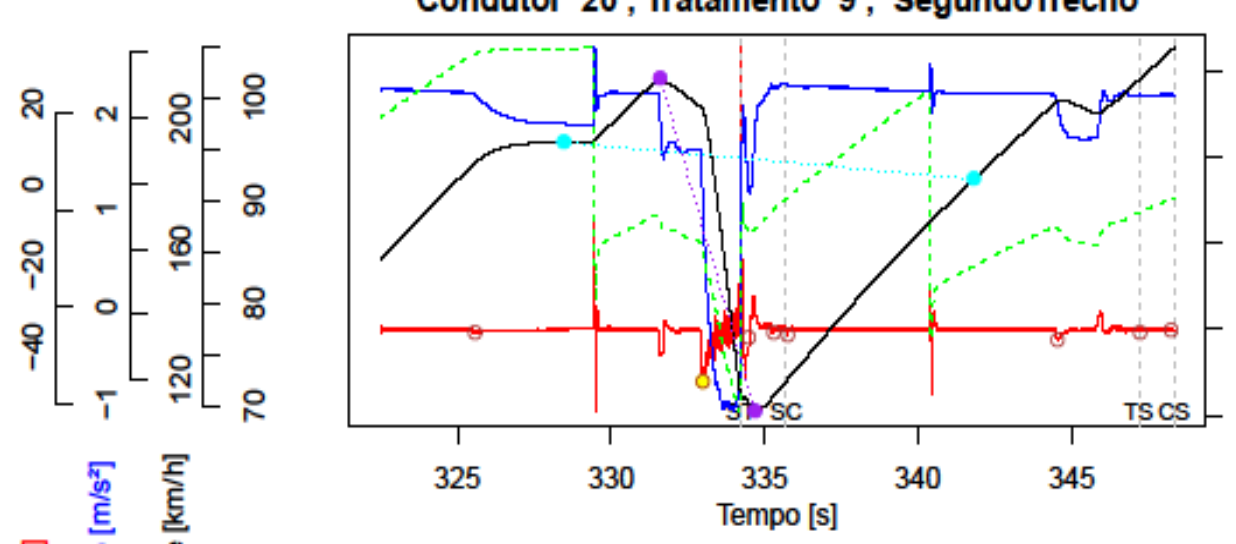

Jerks minimos $\left[\mathrm{m} / \mathrm{s}^{2}\right]$ DeltaV85 $[\mathrm{km} / \mathrm{h}]$ Jerk minimo $\left[\mathrm{m} / \mathrm{s}^{\mathrm{s}}\right]$ - $85 \mathrm{MSR}[\mathrm{km} / \mathrm{h}]$

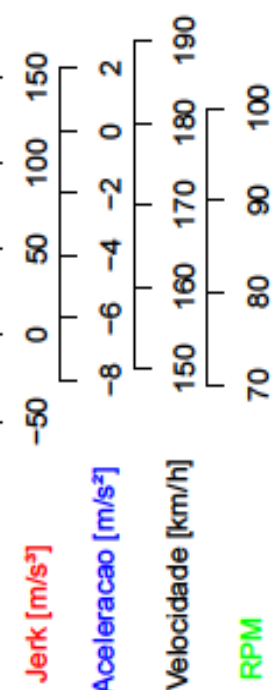



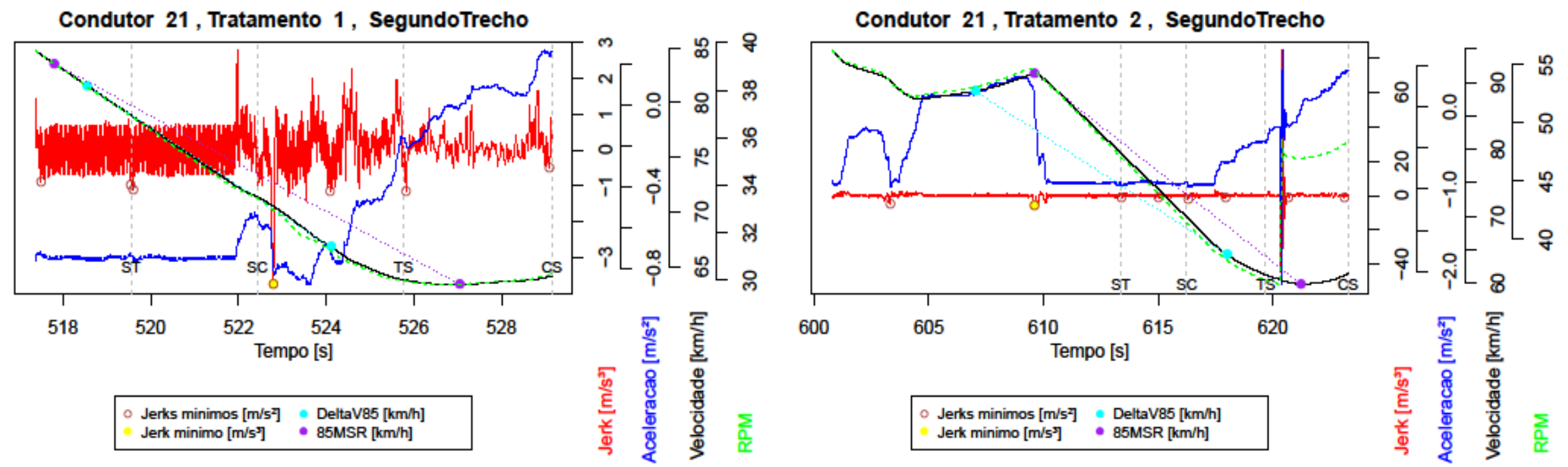

Condutor 21 , Tratamento 3 , SegundoTrecho

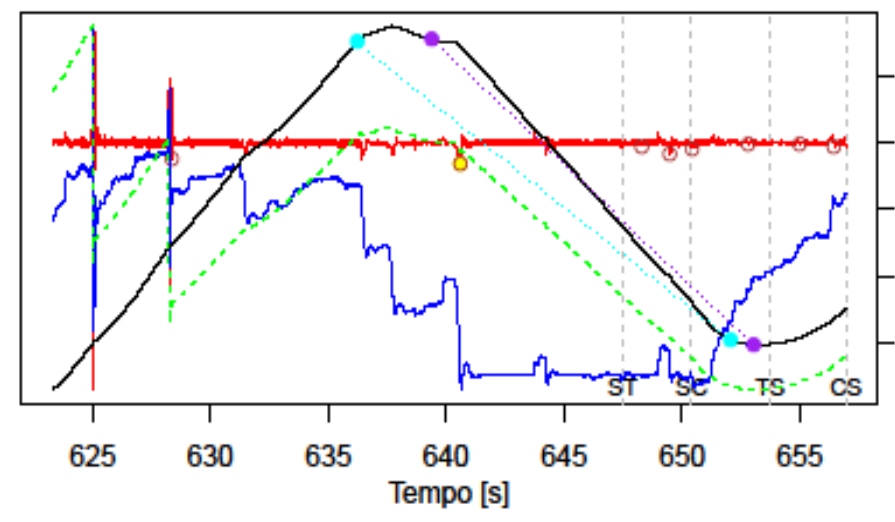

Jerks minimos $[\mathrm{m} / \mathrm{s}]$ - DeltaV85 $[\mathrm{km} / \mathrm{h}]$ Jerk minimo $\left[\mathrm{m} / \mathrm{s}^{\mathrm{s}}\right]$ — $85 \mathrm{MSR}[\mathrm{km} / \mathrm{h}]$

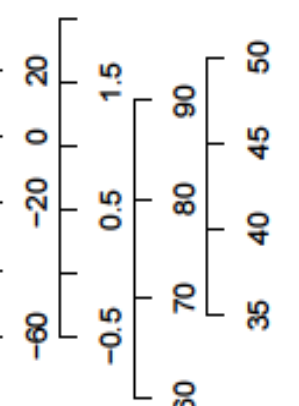

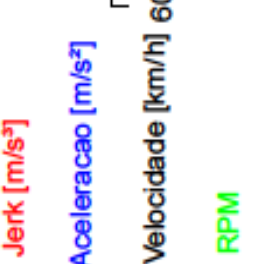

Condutor 21 , Tratamento 4 , SegundoTrecho

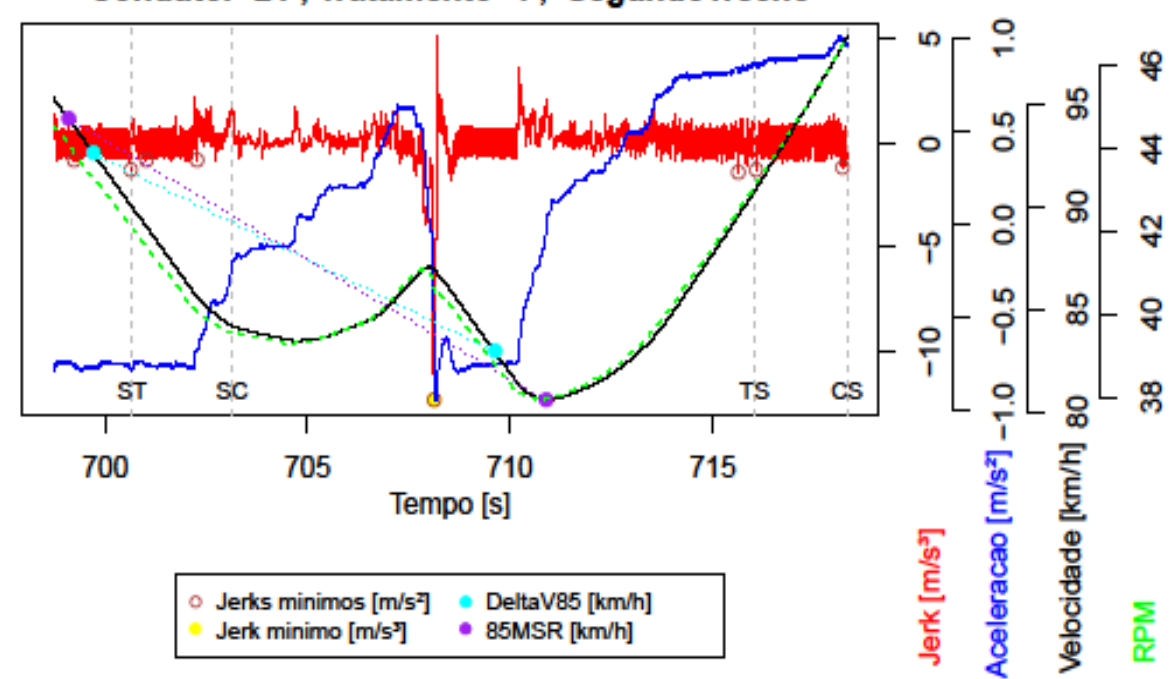


Condutor 21, Tratamento 5, SegundoTrecho

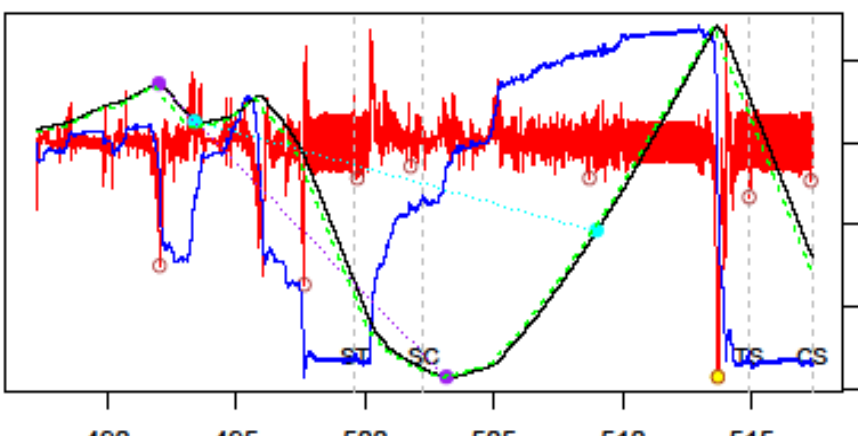

500

Jerks minimos [m/s $\left.{ }^{2}\right]$-DeltaV85 $[\mathrm{km} / \mathrm{h}]$ Jerk minimo [m/s 1 • 85MSR $[\mathrm{km} / \mathrm{h}]$

Condutor 21 , Tratamento 7 , SegundoTrecho

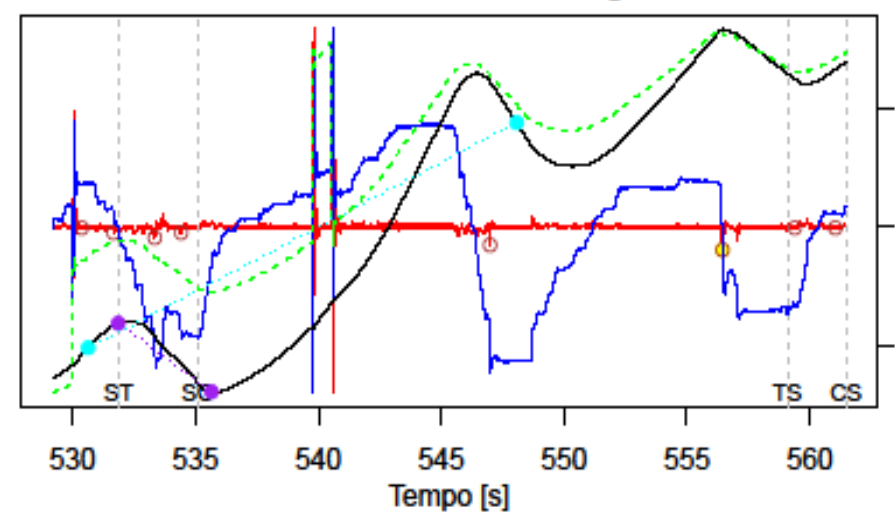

Jerks minimos $\left[\mathrm{m} / \mathrm{s}^{\mathrm{s}}\right]$
Jerk minimo $\left[\mathrm{m} / \mathrm{s}^{\mathrm{s}}\right]$

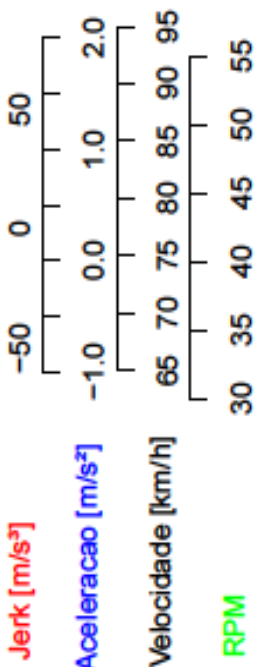

Condutor 21 , Tratamento 6 , SegundoTrecho

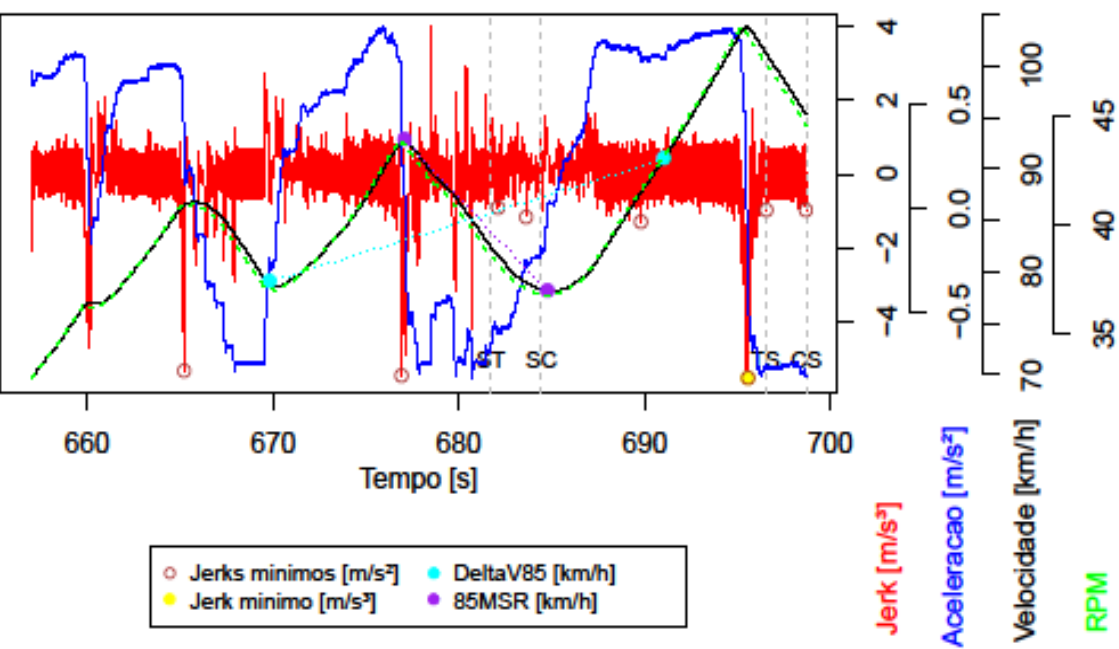

Condutor 21 , Tratamento 8 , SegundoTrecho

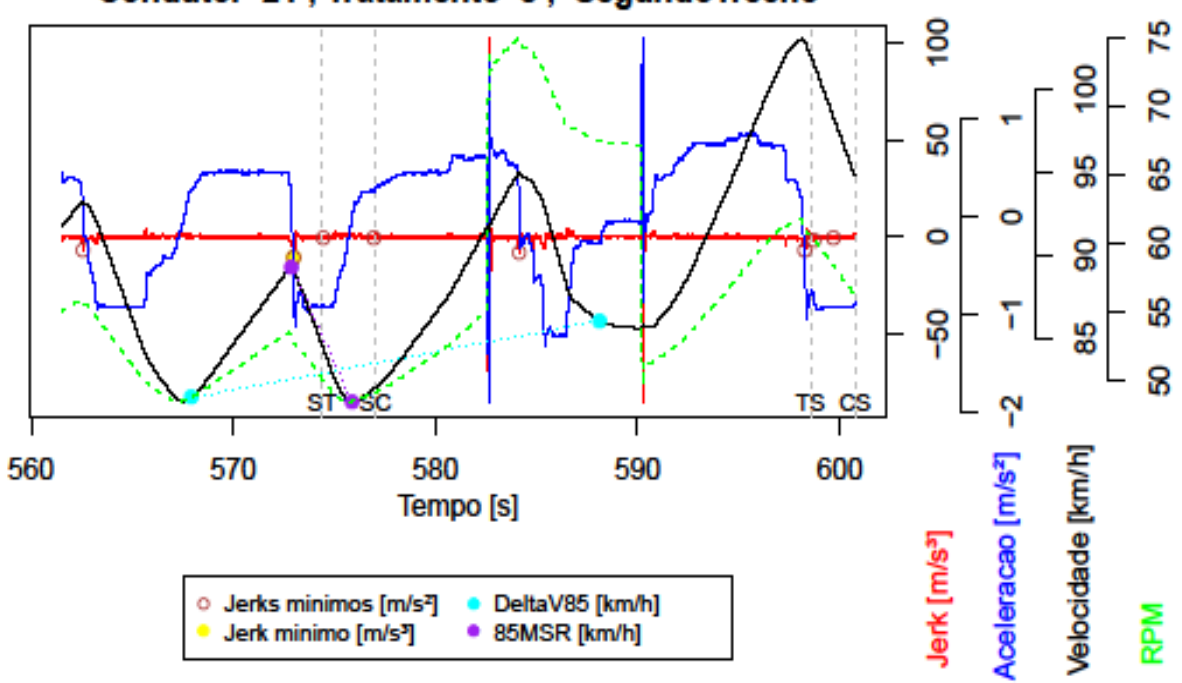




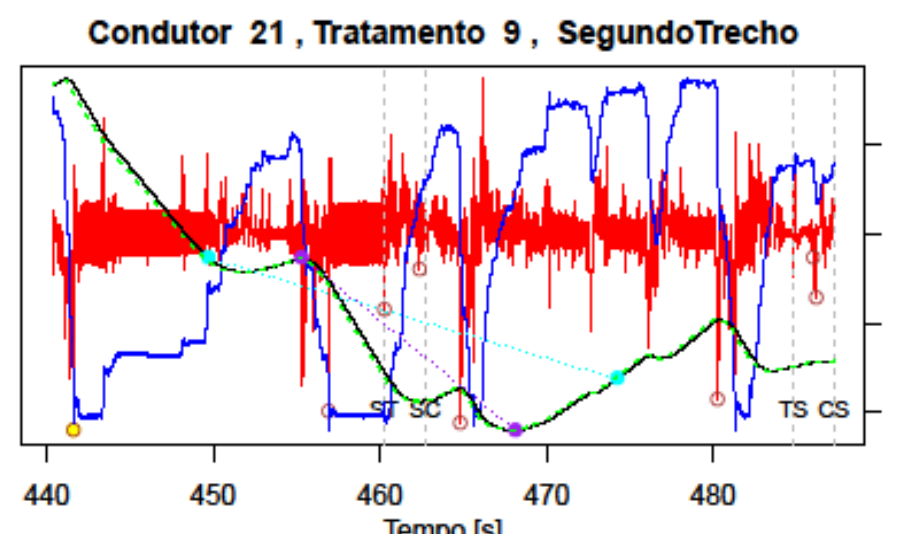

Jerks minimos $[\mathrm{m} / \mathrm{s} \mathrm{s}]$-DeltaV85 $[\mathrm{km} / \mathrm{h}]$ Jerk minimo $\left[\mathrm{m} / \mathrm{s}^{\mathrm{J}}\right]$ - $85 \mathrm{MSR}[\mathrm{km} / \mathrm{h}]$

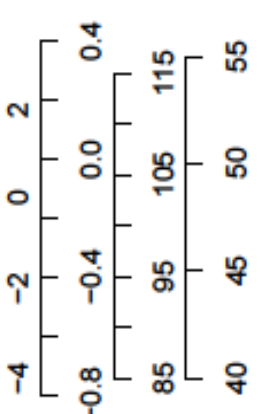

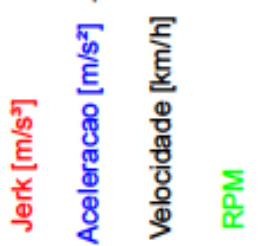

Condutor 22 , Tratamento 1 , SegundoTrecho

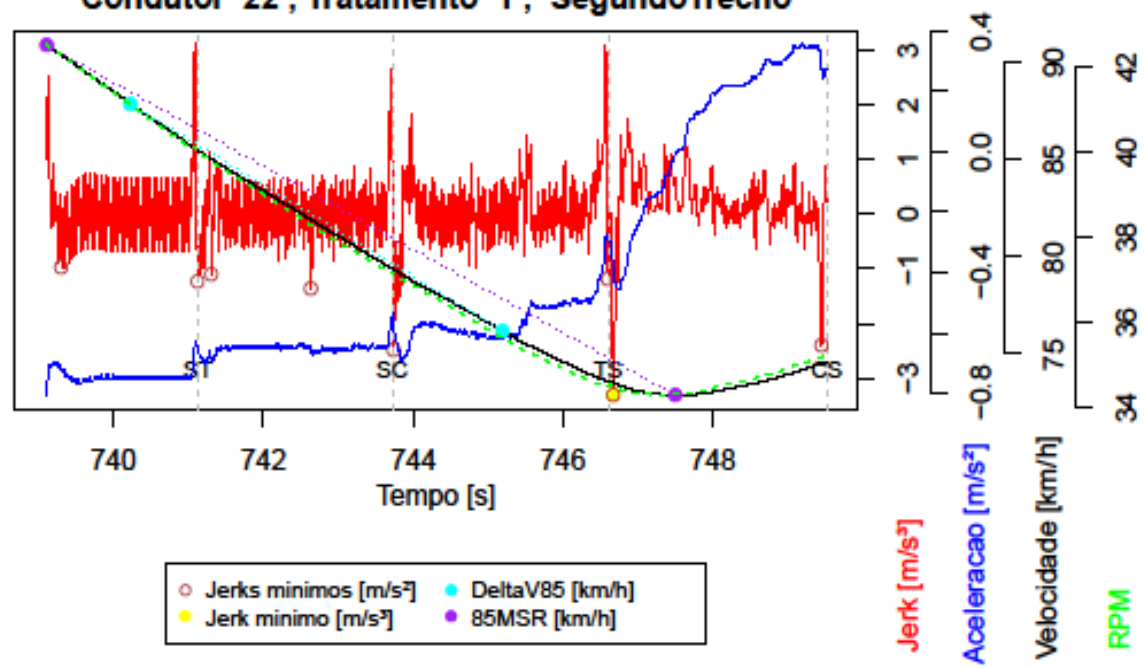

Condutor 22 , Tratamento 2 , SegundoTrecho

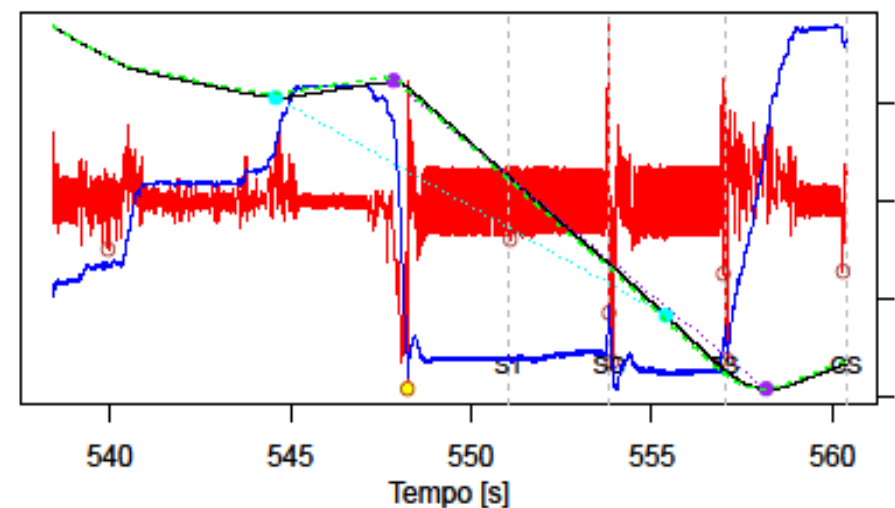

Jerks minimos [m/s'] DeltaV85 $[\mathrm{km} / \mathrm{h}]$ Jerk minimo $\left[\mathrm{m} / \mathrm{s}^{\mathrm{g}}\right]$ - $85 \mathrm{MSR}[\mathrm{km} / \mathrm{h}]$

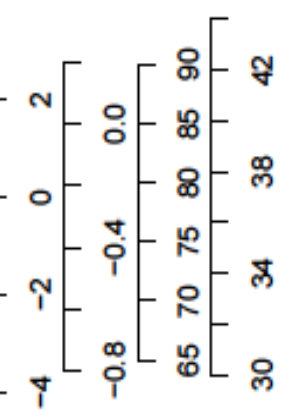

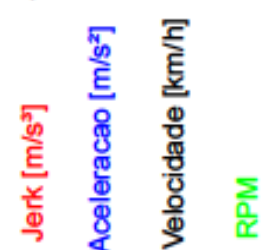

Condutor 22 , Tratamento 3 , SegundoTrecho

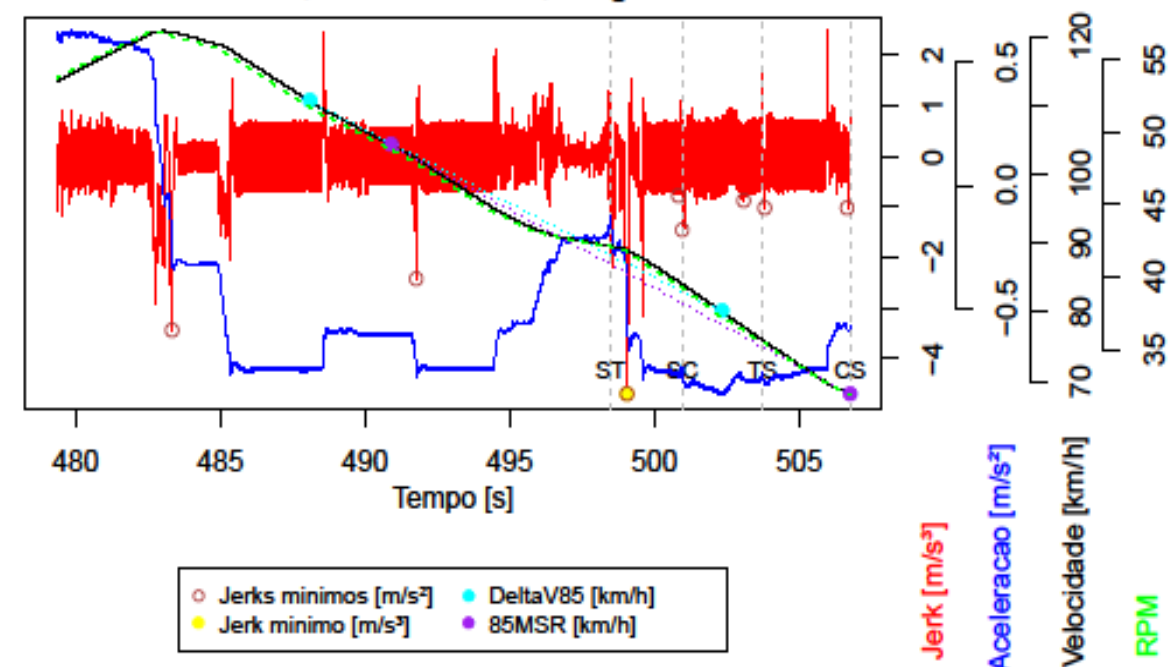



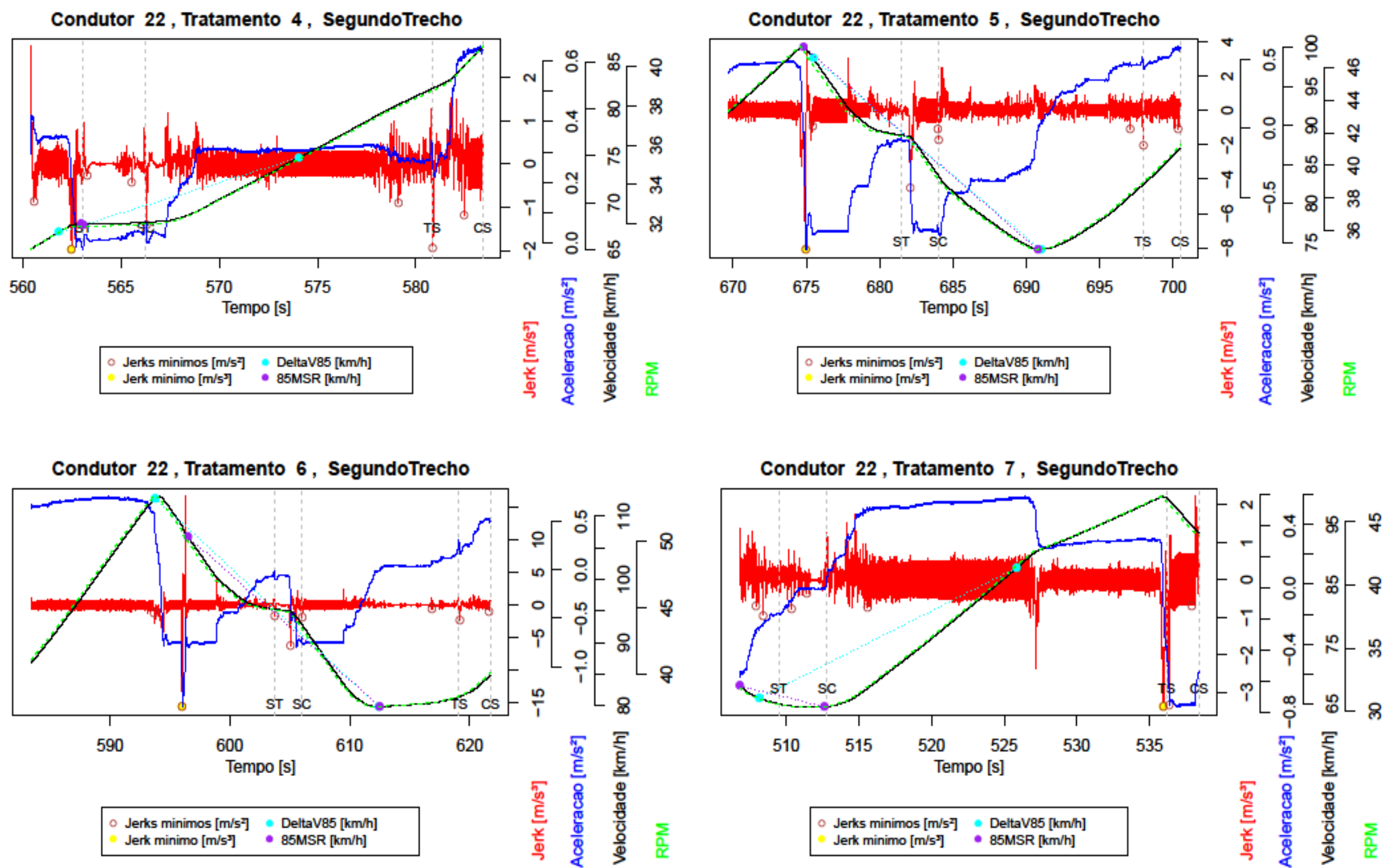

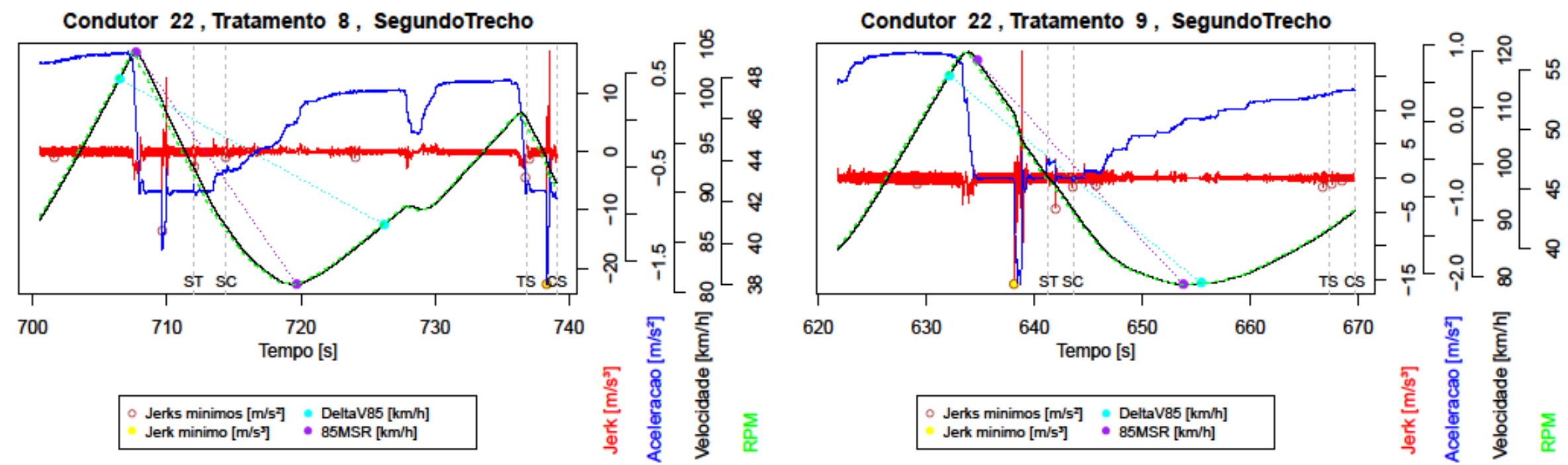

Condutor 23 , Tratamento 1 , SegundoTrecho
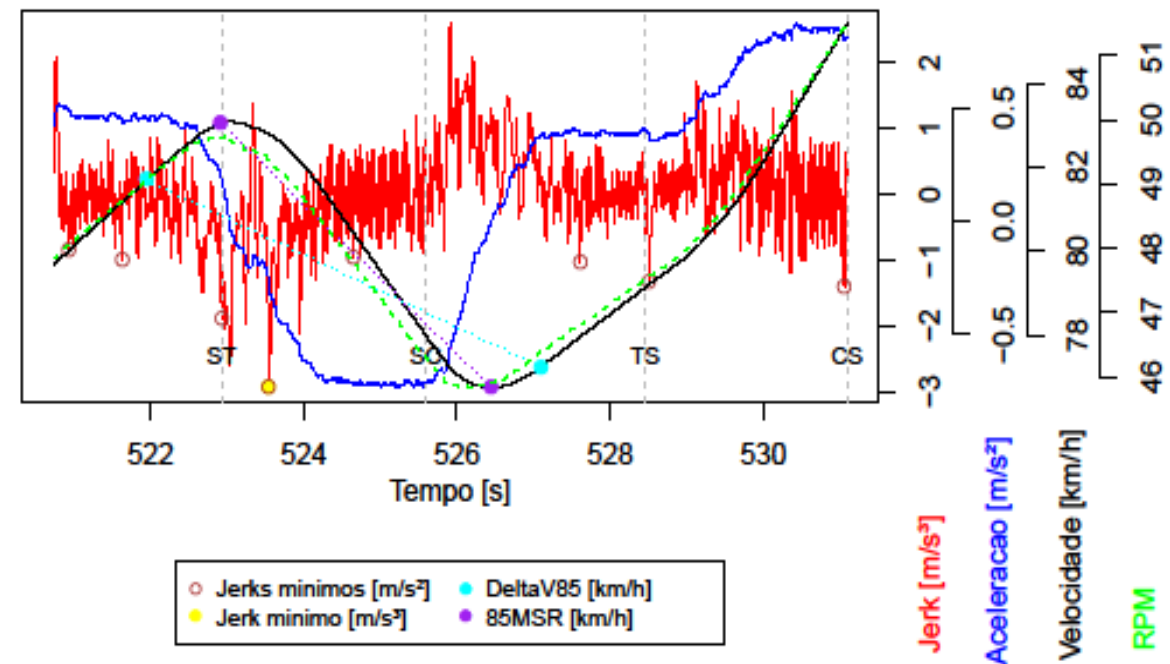

Condutor 23 , Tratamento 2 , SegundoTrecho

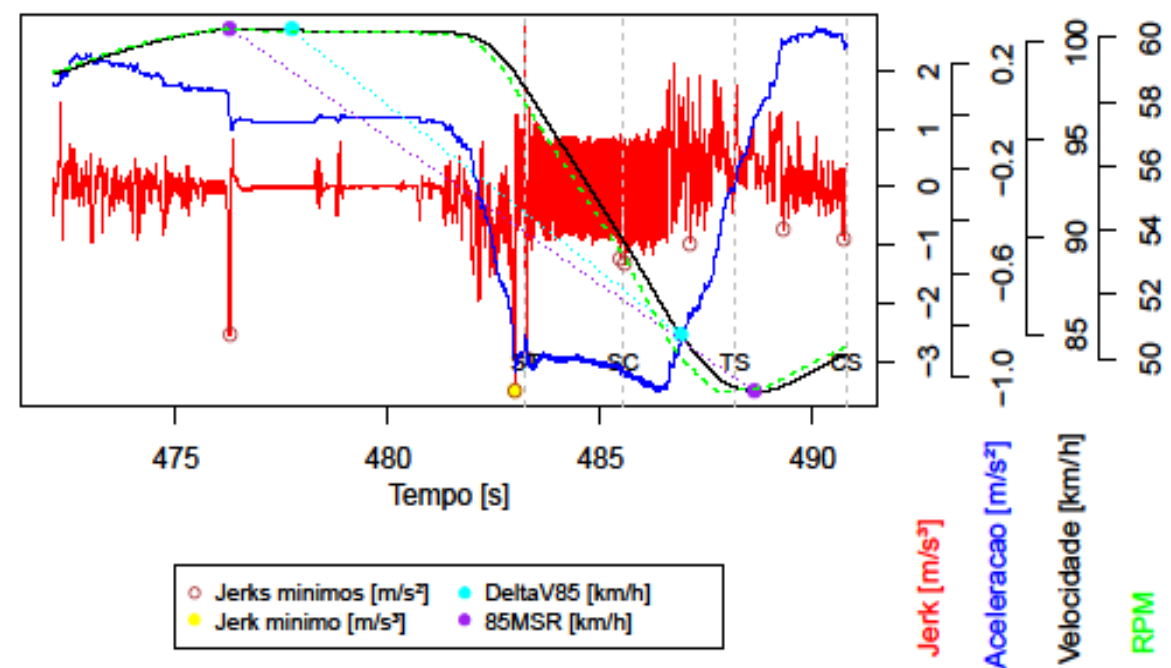




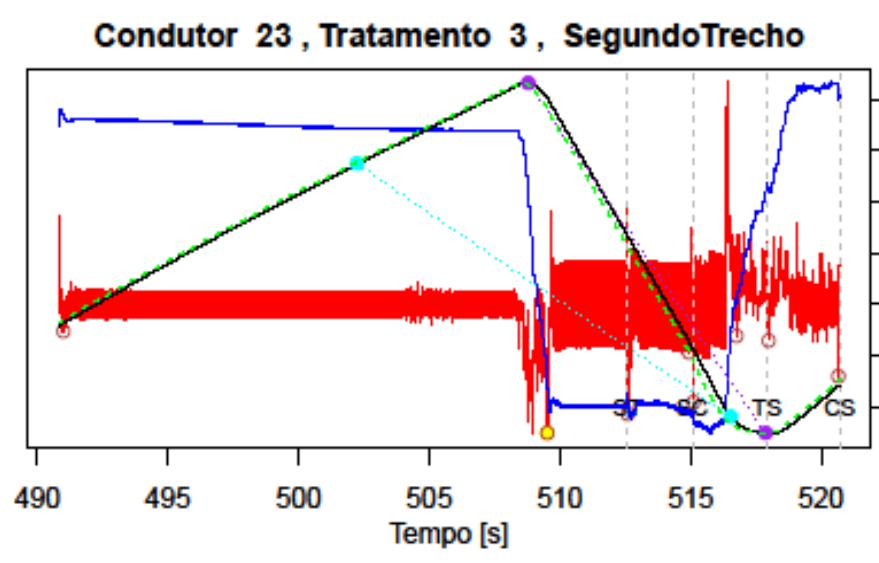

Jerks minimos [m/s'] DeltaV85 $[\mathrm{km} / \mathrm{h}]$ Jerk minimo $\left[\mathrm{m} / \mathrm{s}^{\mathrm{s}}\right]$ • $85 \mathrm{MSR}[\mathrm{km} / \mathrm{h}]$

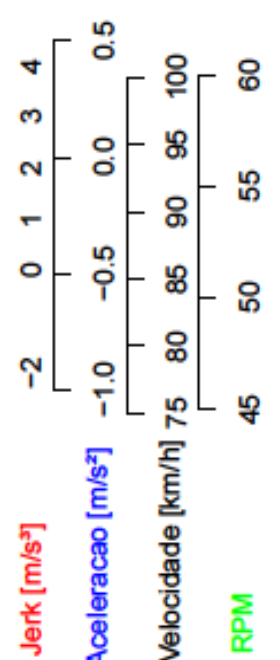

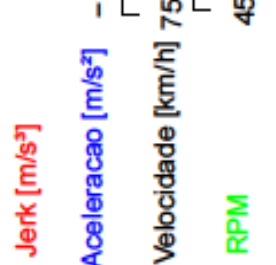

Condutor 23 , Tratamento 4 , SegundoTrecho

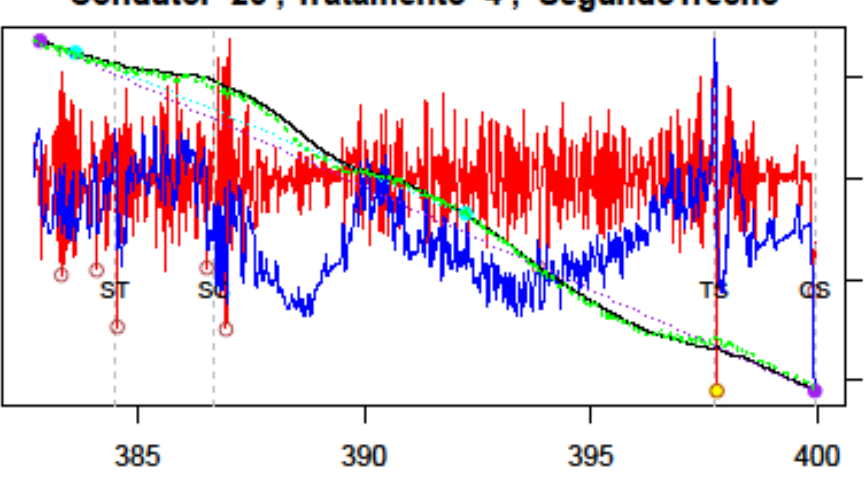

Jerks minimos [m/s $]$ - DeltaV85 $[\mathrm{km} / \mathrm{h}]$ Jerk minimo $\left[\mathrm{m} / \mathrm{s}^{\mathrm{s}}\right]$ - $85 \mathrm{MSR}[\mathrm{km} / \mathrm{h}]$

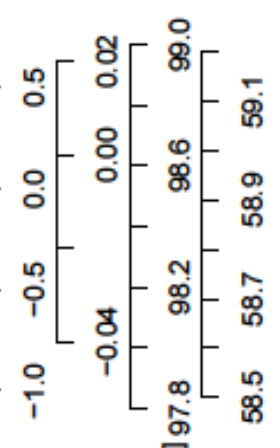

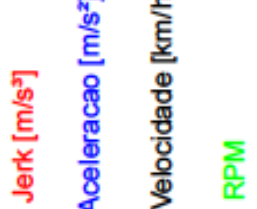

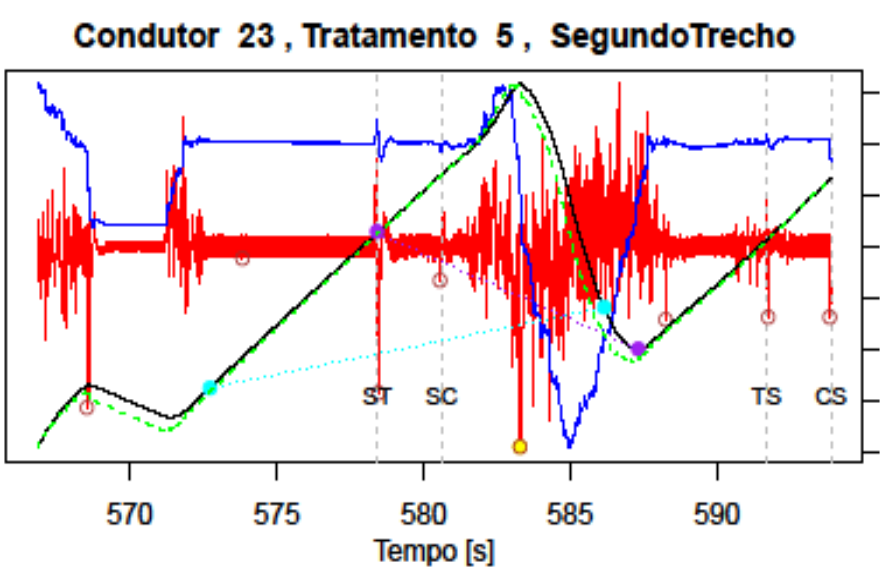

Jerks minimos [m/s $]$ DeltaV85 $[\mathrm{km} / \mathrm{h}]$ Jerk minimo $\left[\mathrm{m} / \mathrm{s}^{\mathrm{j}}\right]$ — $85 \mathrm{MSR}[\mathrm{km} / \mathrm{h}]$

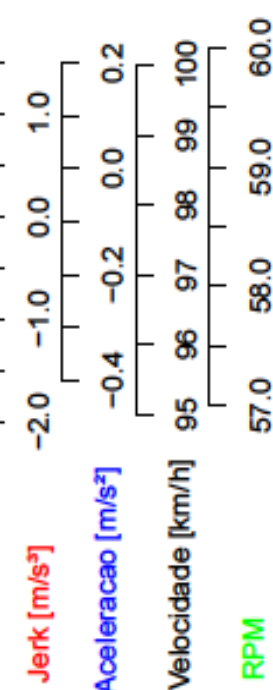

Condutor 23 , Tratamento 6 , SegundoTrecho

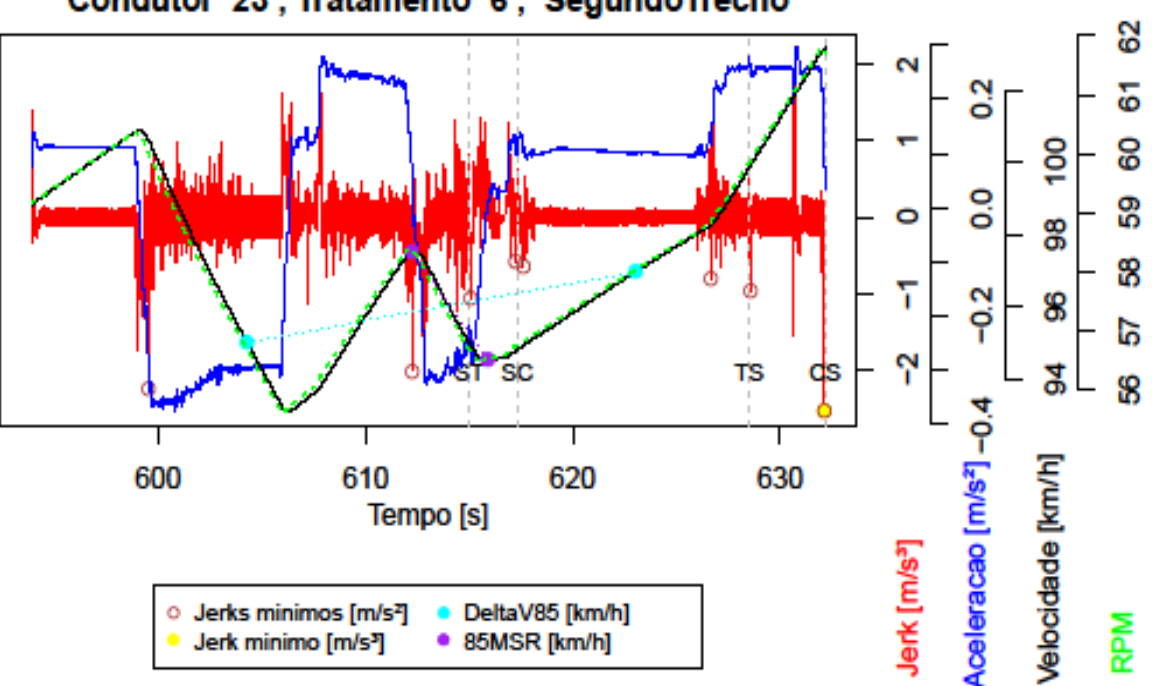



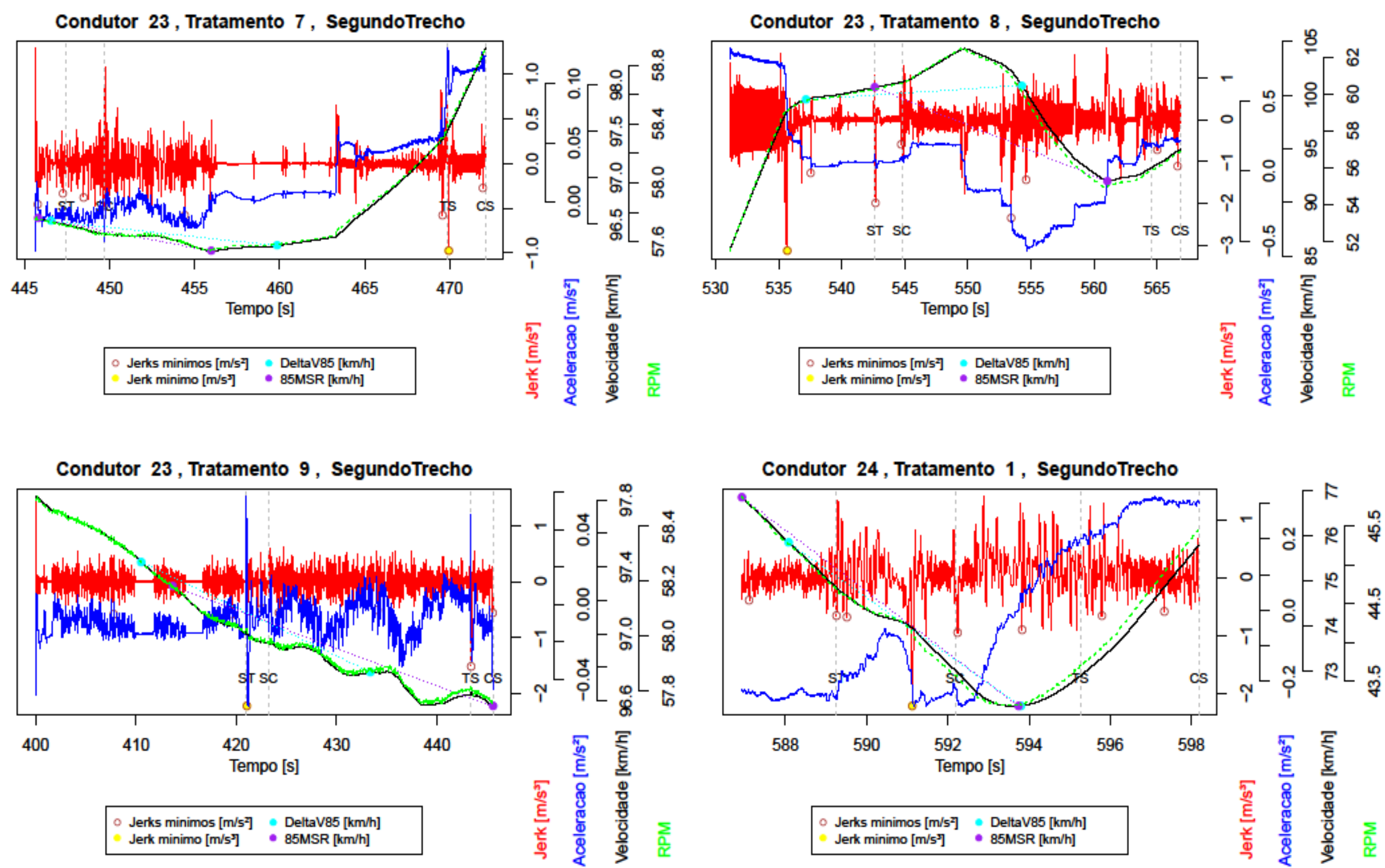
Condutor 24, Tratamento 2 , SegundoTrecho

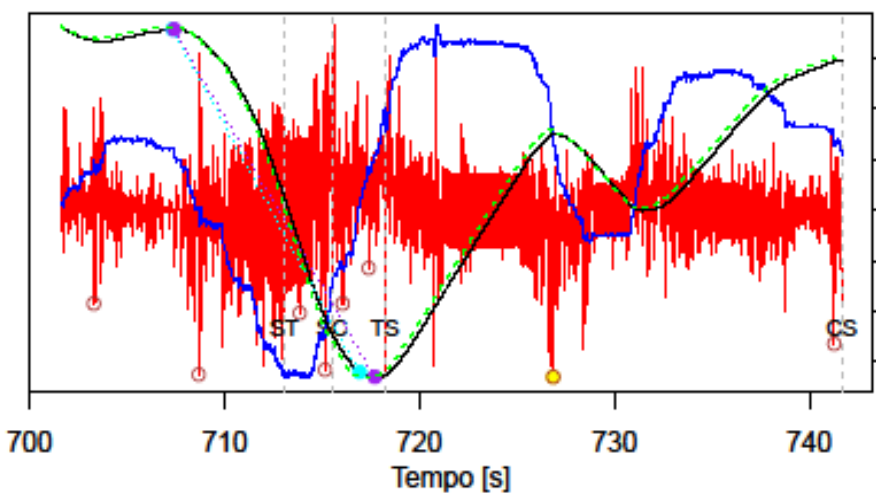

Jerks minimos $\left[\mathrm{m} / \mathrm{s}^{\mathrm{Z}}\right]$ - DeltaV85 $[\mathrm{km} / \mathrm{h}]$ Jerk minimo $\left[\mathrm{m} / \mathrm{s}^{\mathrm{s}}\right]$ • $85 \mathrm{MSR}[\mathrm{km} / \mathrm{h}]$

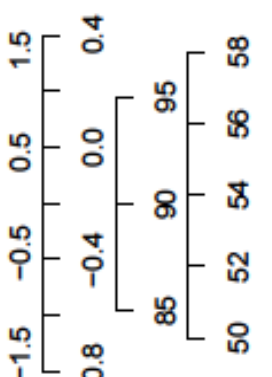

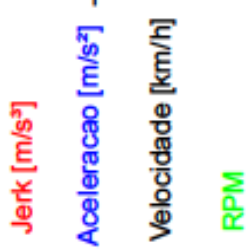

Condutor 24 , Tratamento 3 , SegundoTrecho

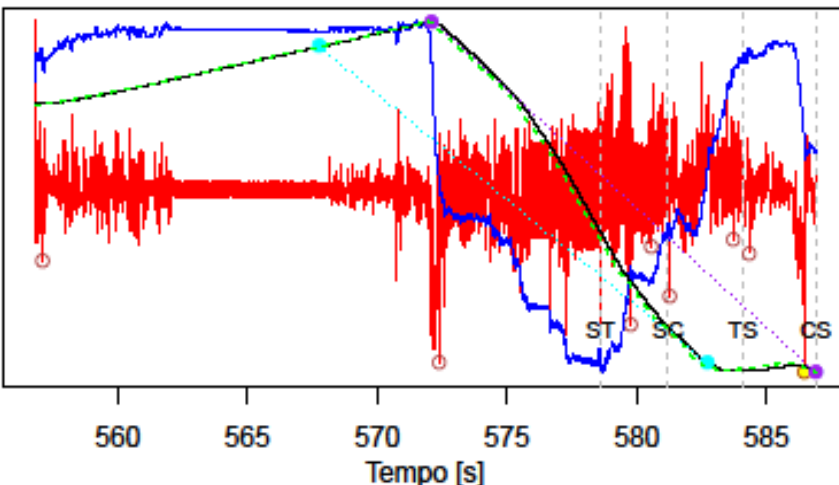
Jerks minimos $\left[\mathrm{m} / \mathrm{s}^{\mathrm{T}}\right]$
Jerk minimo $\left[\mathrm{m} / \mathrm{s}^{\mathrm{s}}\right]$ - DeltaV85 $[\mathrm{km} / \mathrm{h}]$

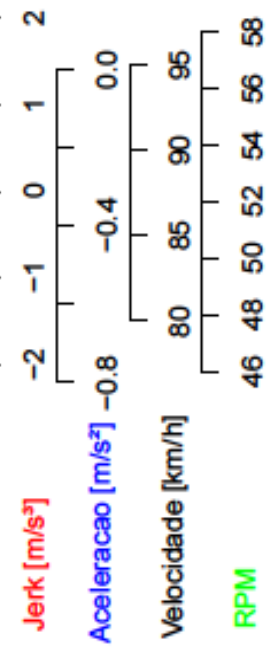

Condutor 24 , Tratamento 4 , SegundoTrecho

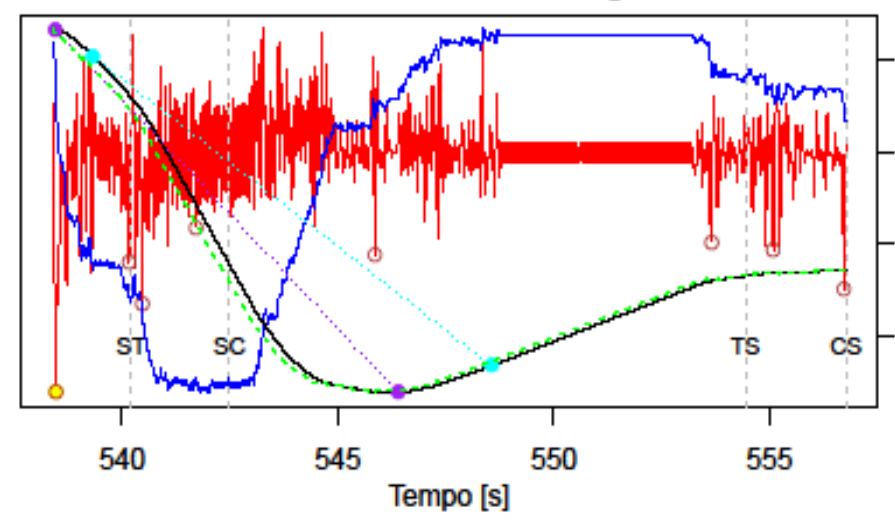

Jerks minimos $\left[\mathrm{m} / \mathrm{s}^{2}\right]$ - DeltaV85 $[\mathrm{km} / \mathrm{h}]$ Jerk minimo $\left[\mathrm{m} / \mathrm{s}^{\mathrm{s}}\right]$ • $85 \mathrm{MSR}[\mathrm{km} / \mathrm{h}]$

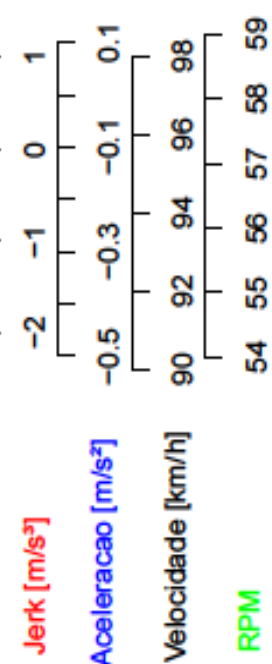

Condutor 24 , Tratamento 5 , SegundoTrecho

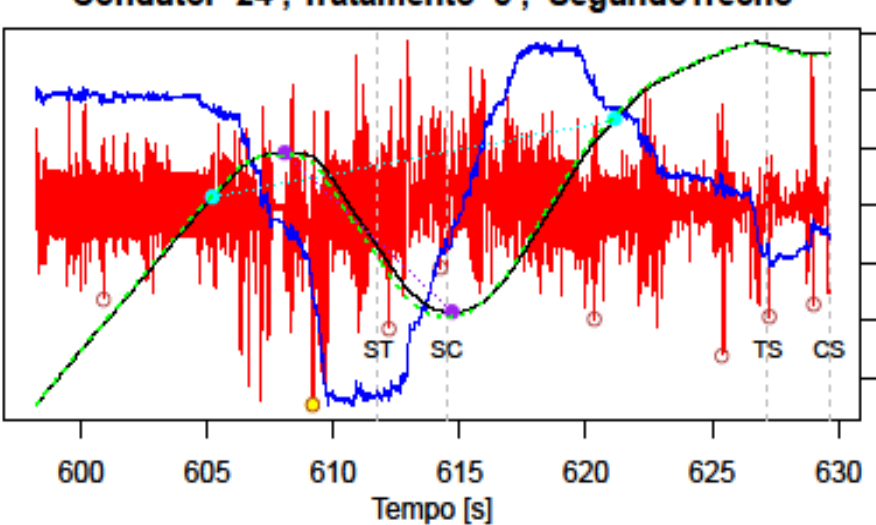

Jerks minimos $[\mathrm{m} / \mathrm{s}$ ] $\quad$ DeltaV85 $[\mathrm{km} / \mathrm{h}]$

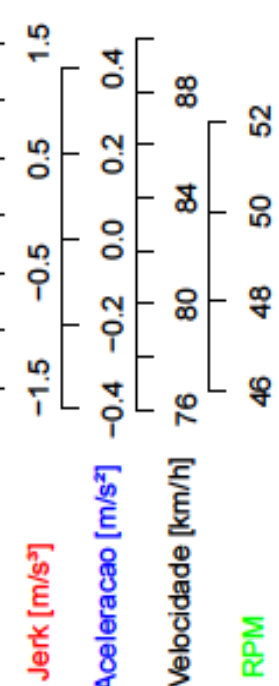


Condutor 24 , Tratamento 6 , SegundoTrecho

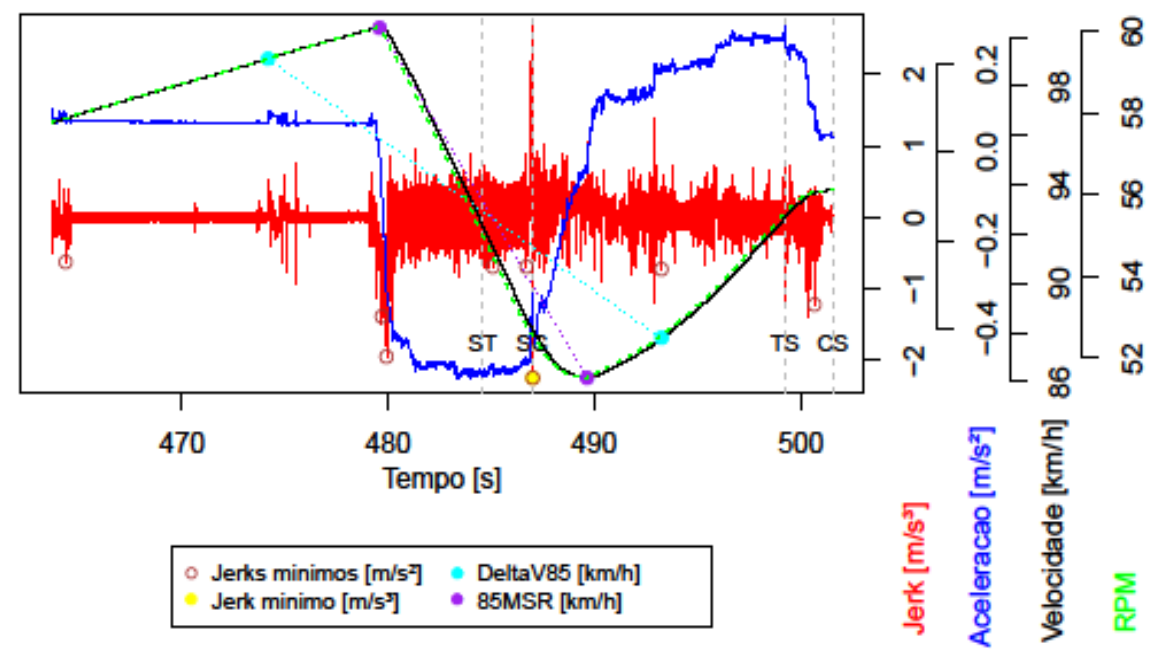

Condutor 24, Tratamento 8 , SegundoTrecho

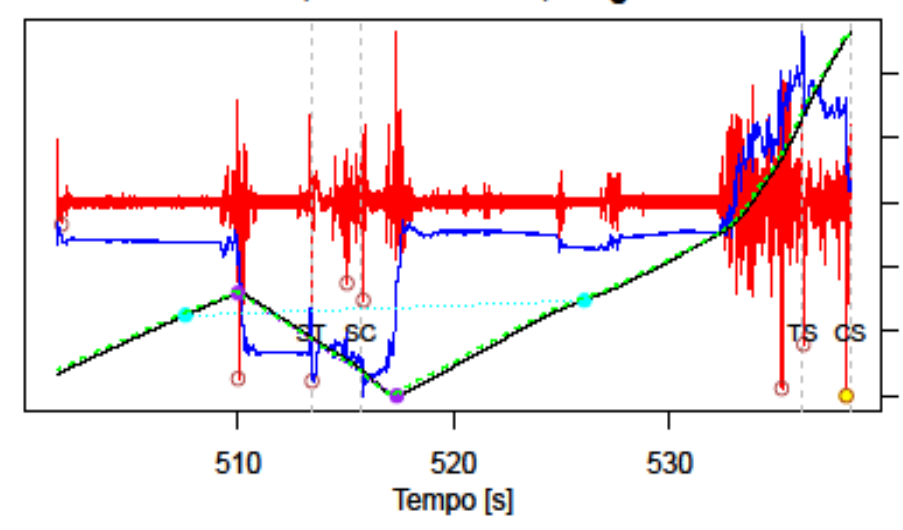

Jerks minimos $[\mathrm{m} / \mathrm{s}]$ - DeltaV85 $[\mathrm{km} / \mathrm{h}]$ Jerk minimo $\left[\mathrm{m} / \mathrm{s}^{\mathrm{s}}\right]$ - $85 \mathrm{MSR}[\mathrm{km} / \mathrm{h}]$
Condutor 24 , Tratamento 7 , SegundoTrecho

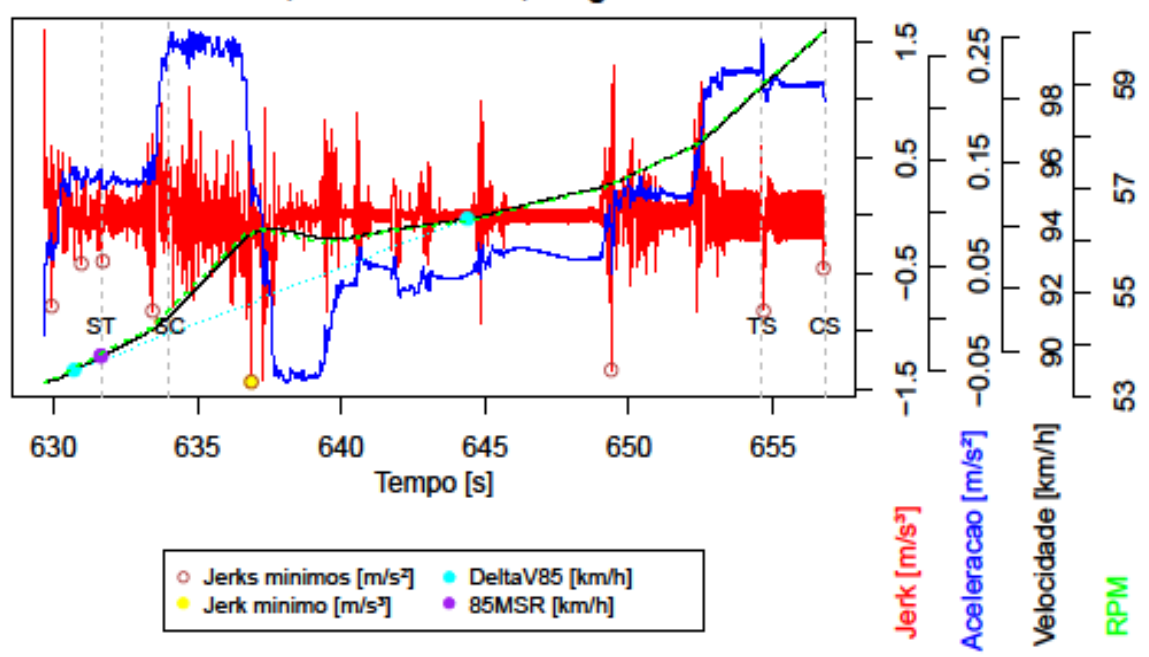

Condutor 24 , Tratamento 9 , SegundoTrecho

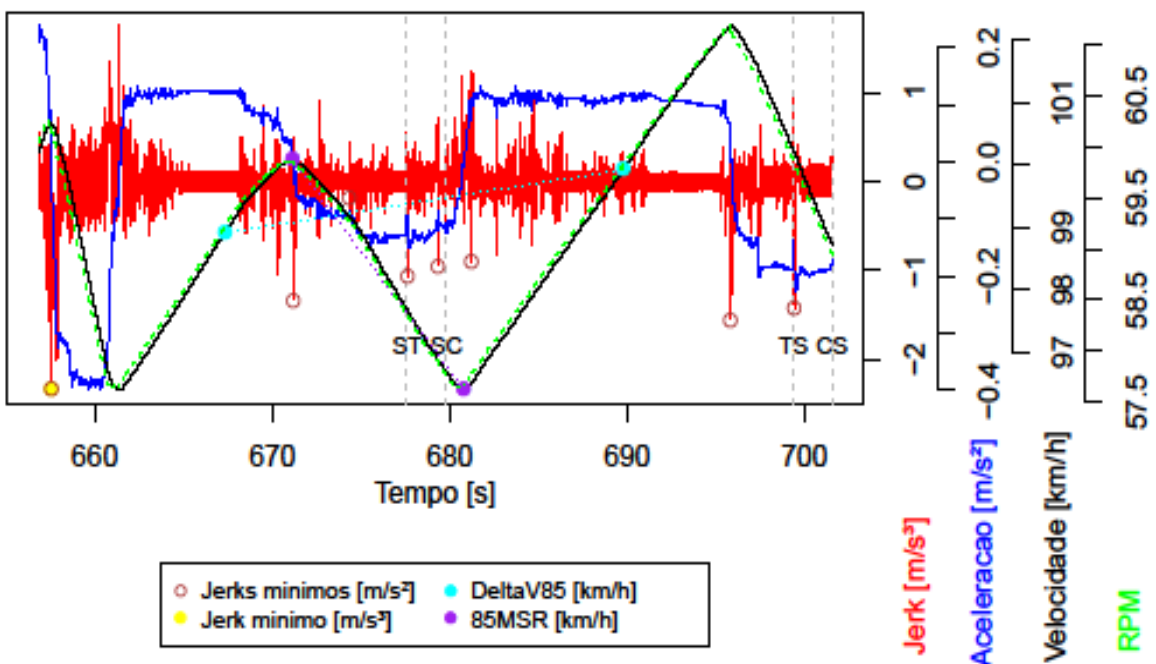


Condutor 25, Tratamento 1 , SegundoTrecho

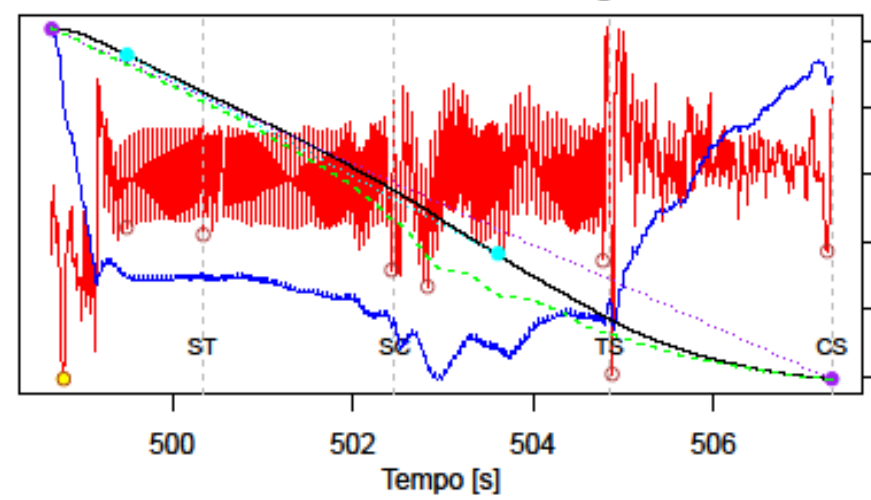

Jerks minimos $[\mathrm{m} / \mathrm{s}]]$ DeltaV85 $[\mathrm{km} / \mathrm{h}]$ Jerk minimo $\left[\mathrm{m} / \mathrm{s}^{\mathrm{s}}\right]$

Condutor 25, Tratamento 3 , SegundoTrecho

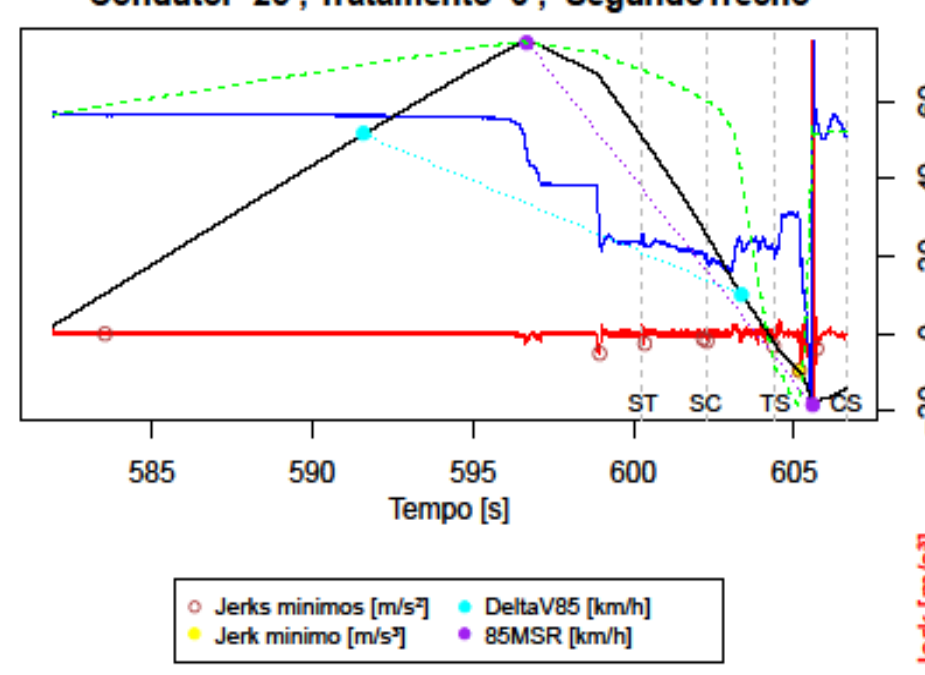

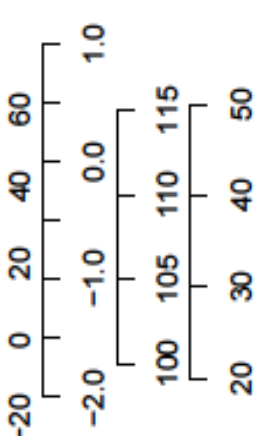

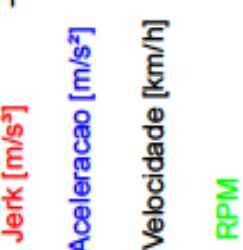

Condutor 25 , Tratamento 2 , SegundoTrecho

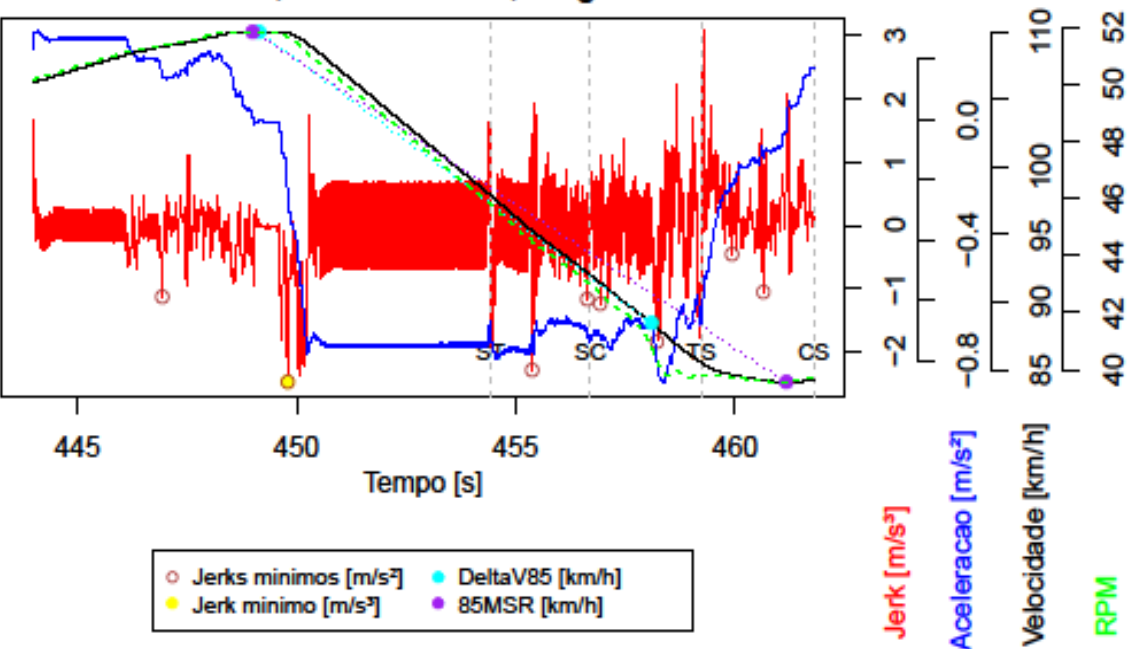

Condutor 25, Tratamento 4 , SegundoTrecho

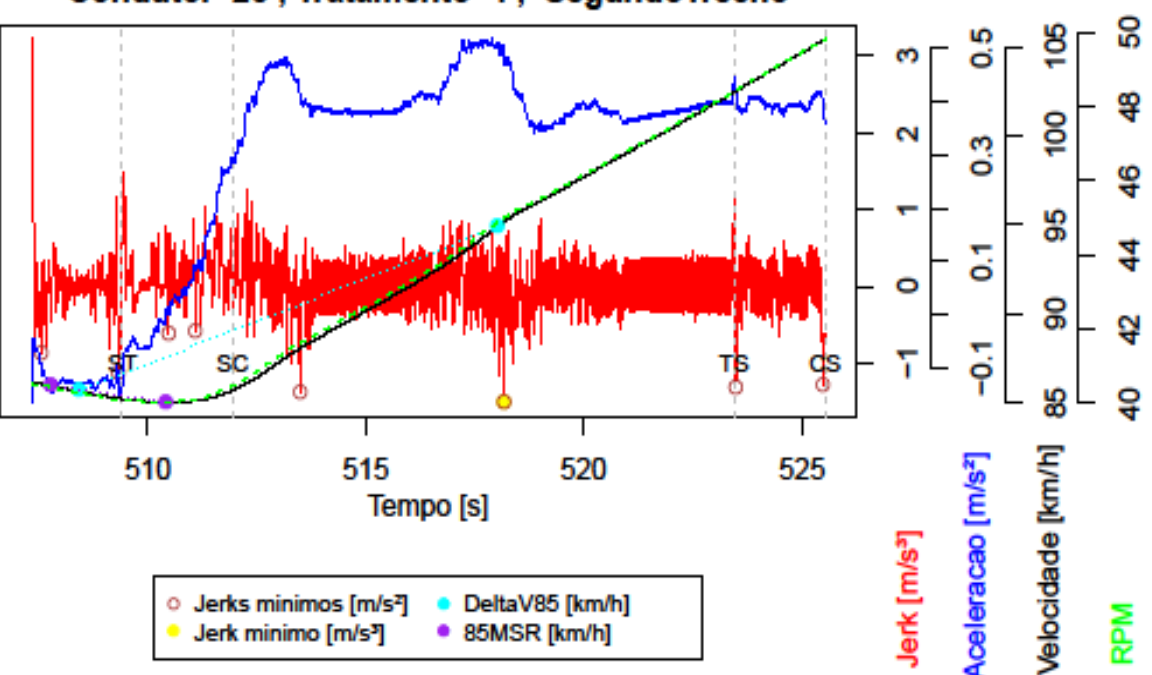


Condutor 25 , Tratamento 5 , SegundoTrecho

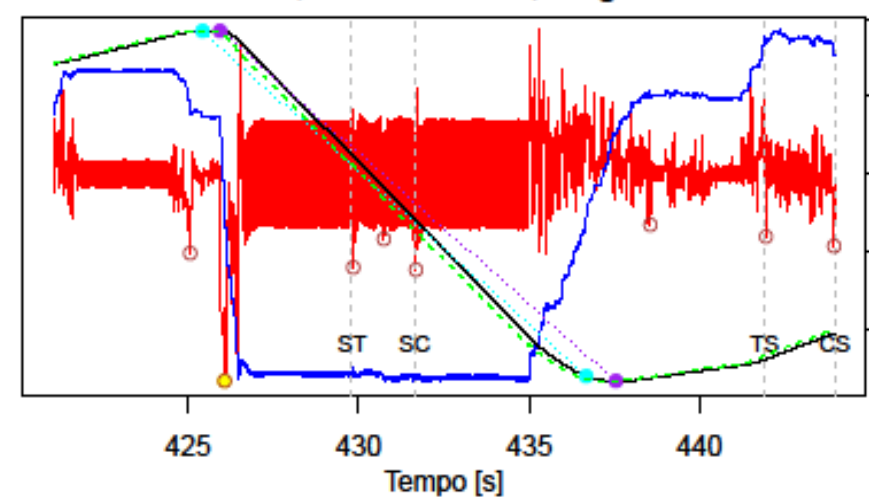

Jerks minimos [m/s $]$ DeltaV85 $[\mathrm{km} / \mathrm{h}]$ Jerk minimo $\left[\mathrm{m} / \mathrm{s}^{\mathrm{J}}\right]$ • $85 \mathrm{MSR}[\mathrm{km} / \mathrm{h}]$

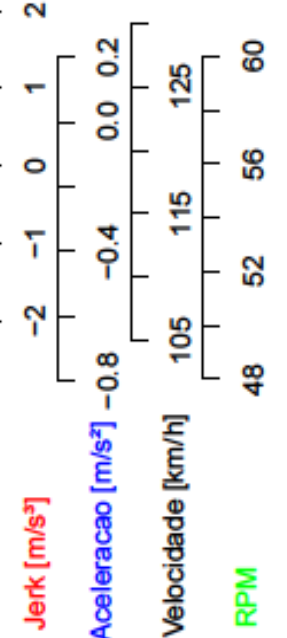

Condutor 25 , Tratamento 6 , SegundoTrecho

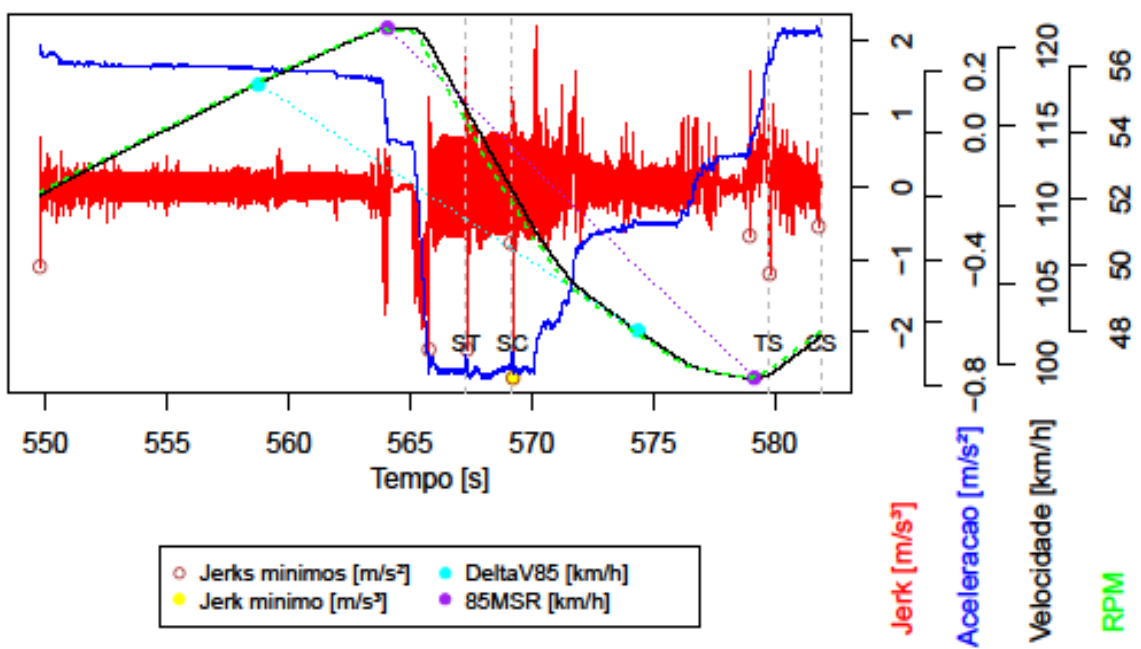

Condutor 25, Tratamento 7 , SegundoTrecho

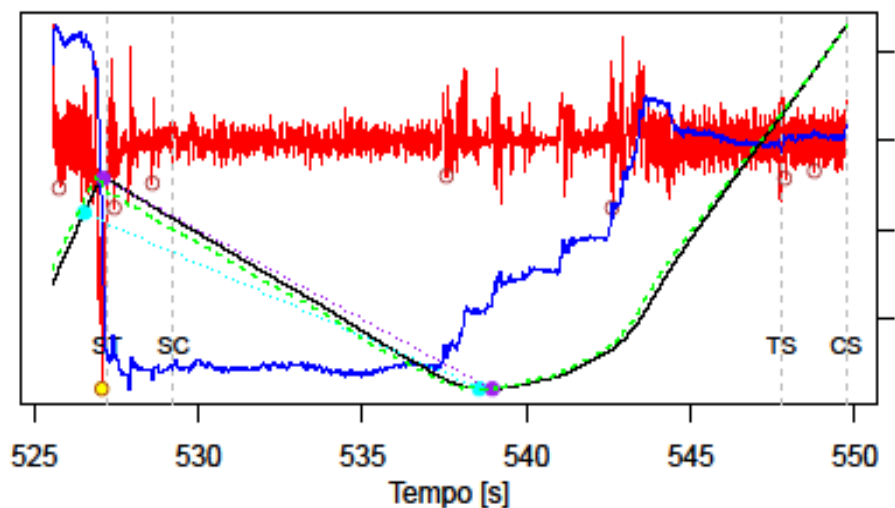

Jerks minimos $\left[\mathrm{m} / \mathrm{s}^{2}\right]$ DeltaV85 $[\mathrm{km} / \mathrm{h}]$ Jerk minimo [m/s $\left./ \mathrm{s}^{\mathrm{s}}\right]$. $85 \mathrm{MSR}[\mathrm{km} / \mathrm{h}]$

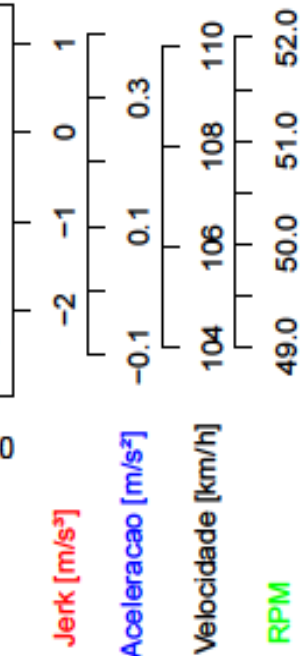

Condutor 25, Tratamento 8 , SegundoTrecho

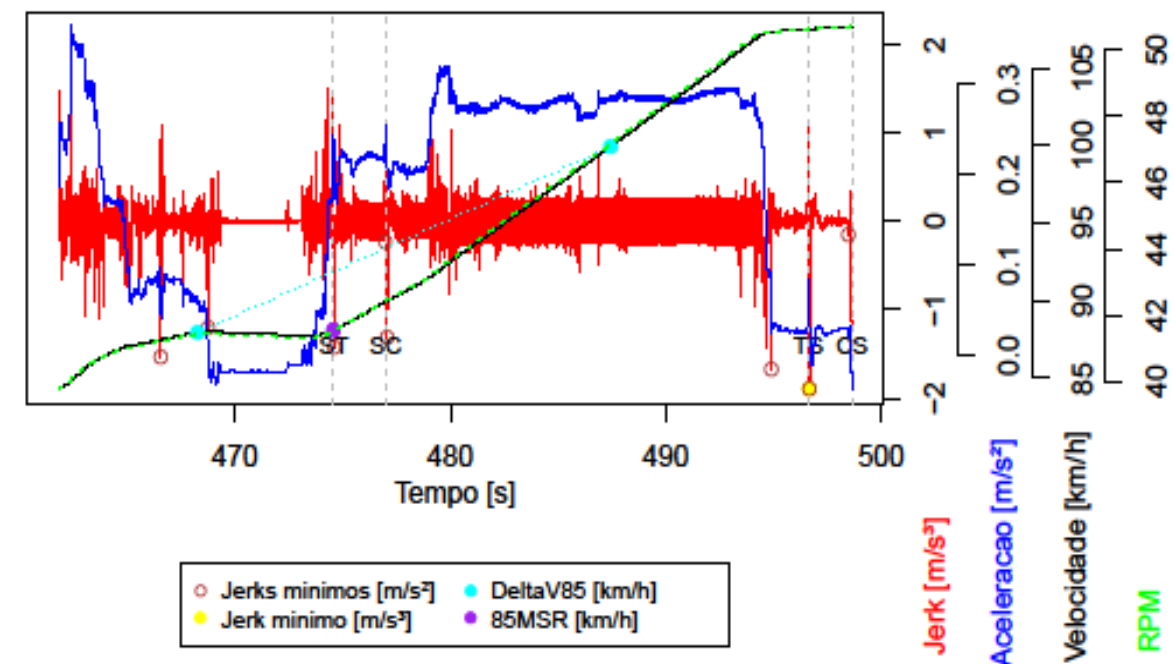



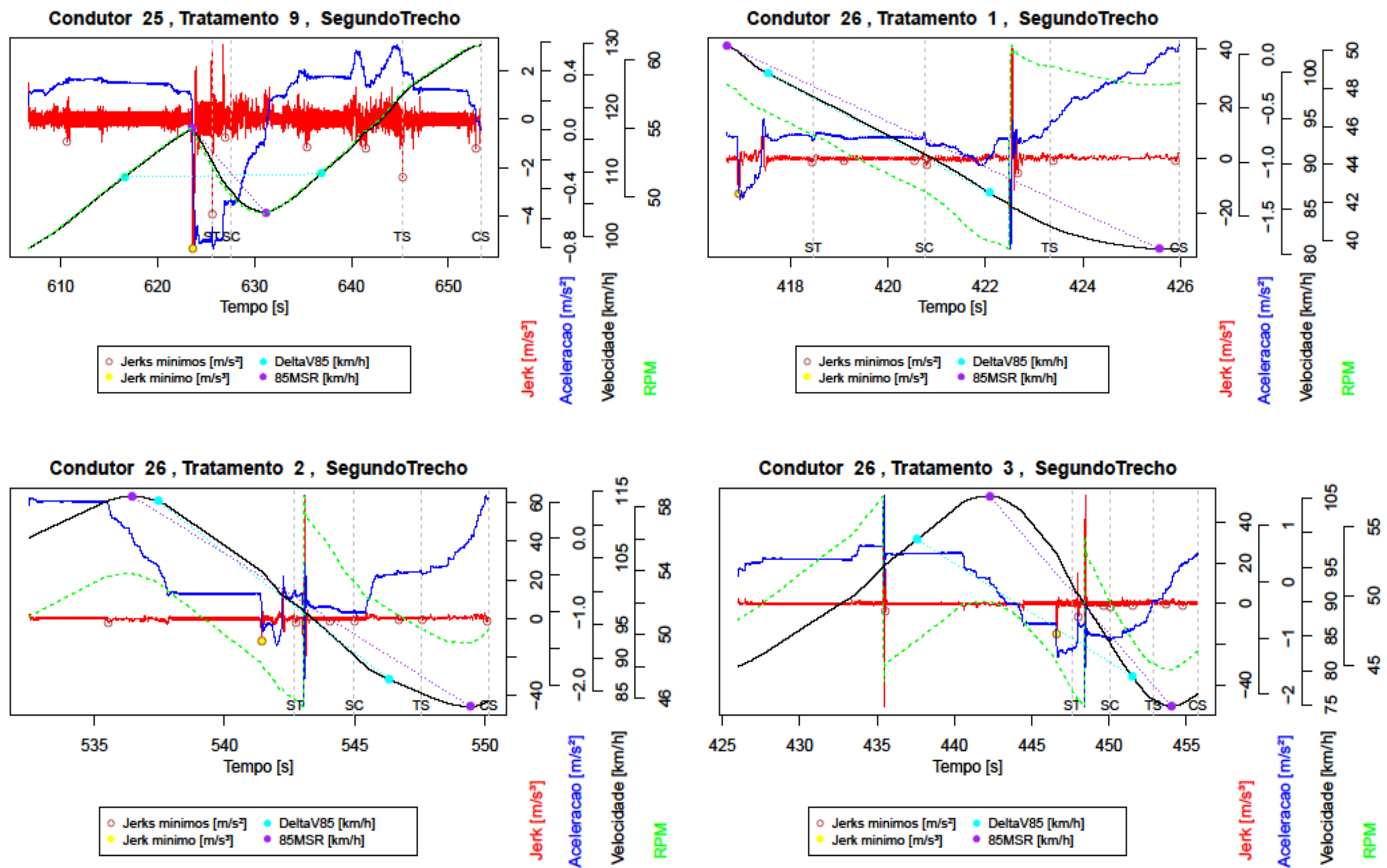

Jerks minimos $[\mathrm{m} / \mathrm{s}]]$ DeltaV85 $[\mathrm{km} / \mathrm{h}]$

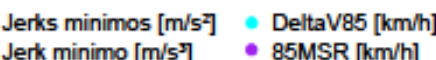


Condutor 26, Tratamento 4 , SegundoTrecho

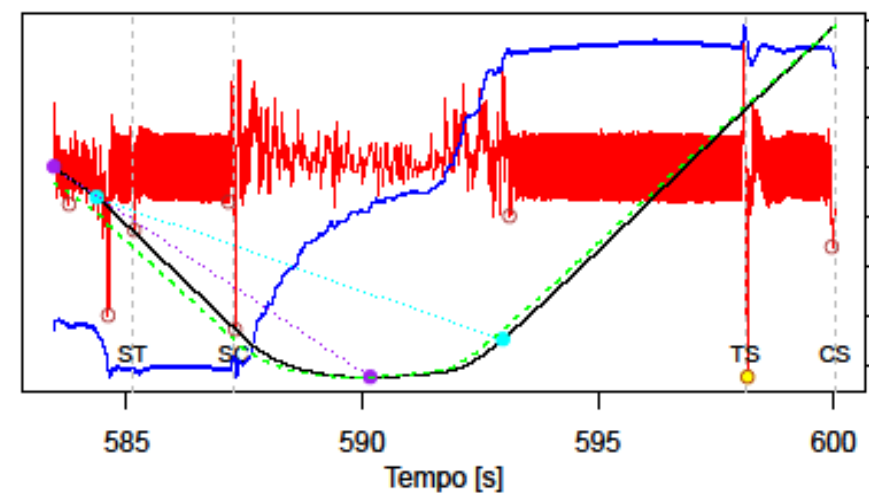

Jerks minimos $\left[\mathrm{m} / \mathrm{s}^{\mathrm{s}}\right] \quad$ DeltaV85 $[\mathrm{km} / \mathrm{h}]$ Jerk minimo $\left[\mathrm{m} / \mathrm{s}^{\mathrm{s}}\right]$ ๑ $85 \mathrm{MSR}[\mathrm{km} / \mathrm{h}]$

Condutor 26, Tratamento 6 , SegundoTrecho

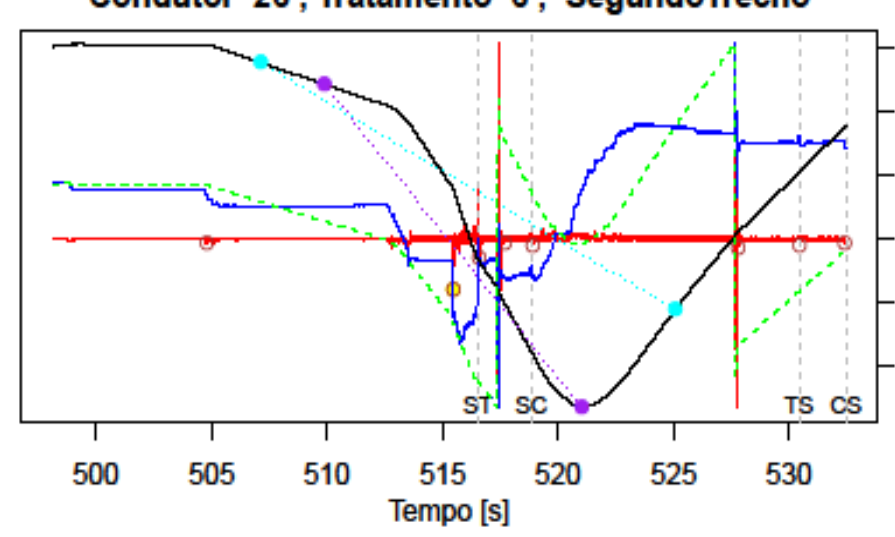

Jerks minimos $[\mathrm{m} / \mathrm{s}]$ - DeltaV85 $[\mathrm{km} / \mathrm{h}]$ Jerk minimo [m/s $\left./ \mathrm{s}^{\mathrm{s}}\right]$. $85 \mathrm{MSR}[\mathrm{km} / \mathrm{h}]$

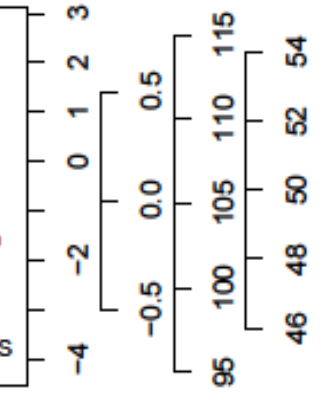

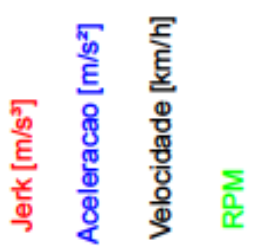

Condutor 26 , Tratamento 5 , SegundoTrecho

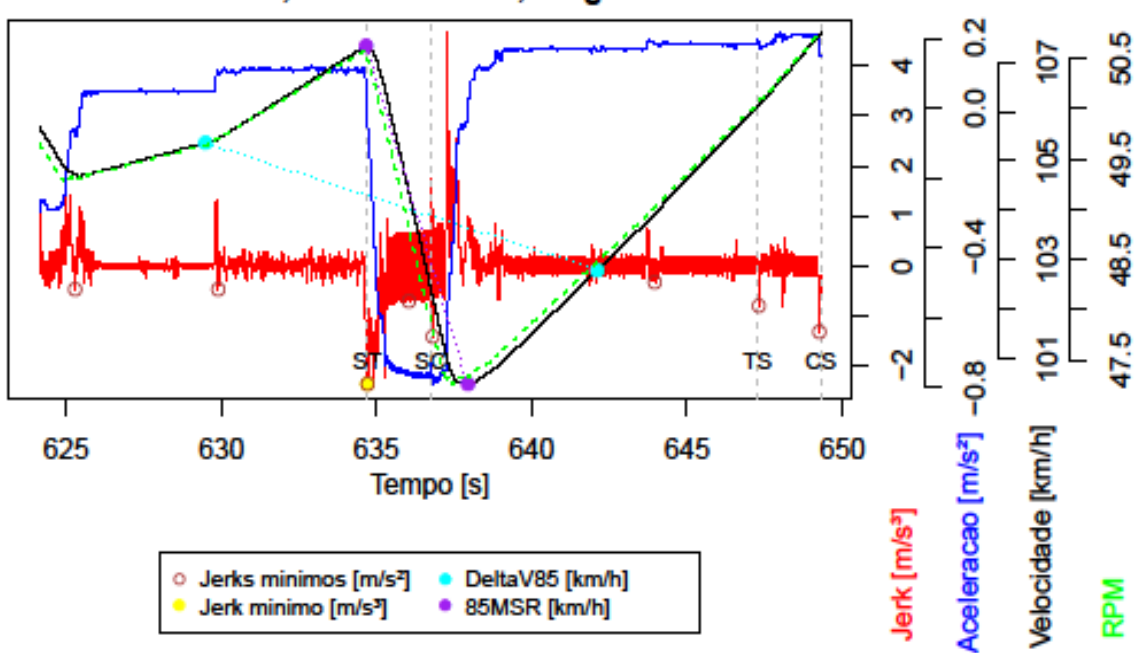

Condutor 26 , Tratamento 7 , SegundoTrecho

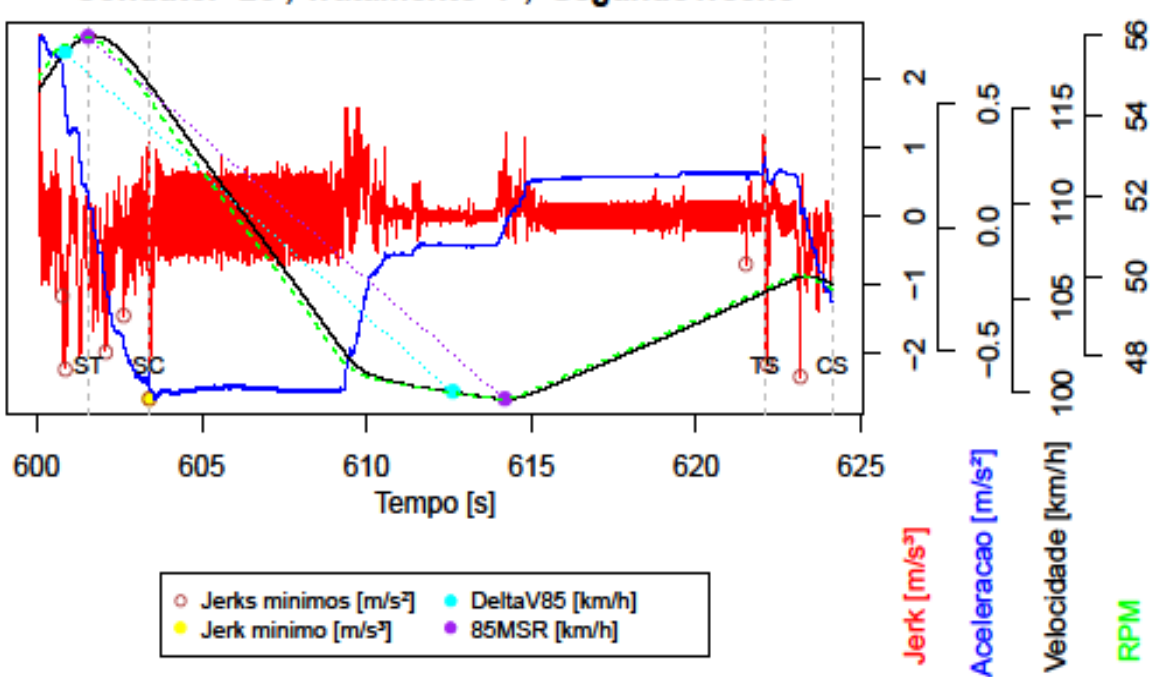


Condutor 26, Tratamento 8 , SegundoTrecho

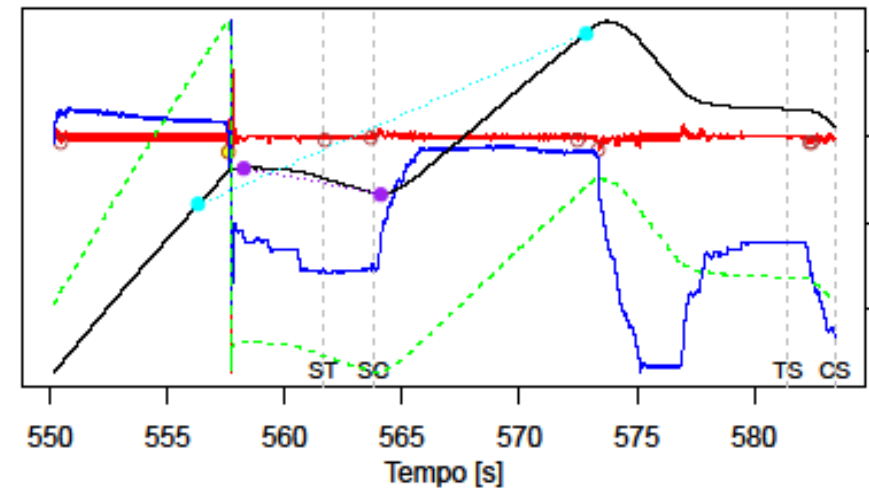

Jerks minimos $[\mathrm{m} / \mathrm{s}$ ] DeltaV85 $[\mathrm{km} / \mathrm{h}]$ Jerk minimo $\left[\mathrm{m} / \mathrm{s}^{\ni}\right] \bullet 85 \mathrm{MSR}[\mathrm{km} / \mathrm{h}]$

Condutor 27 , Tratamento 1 , SegundoTrecho

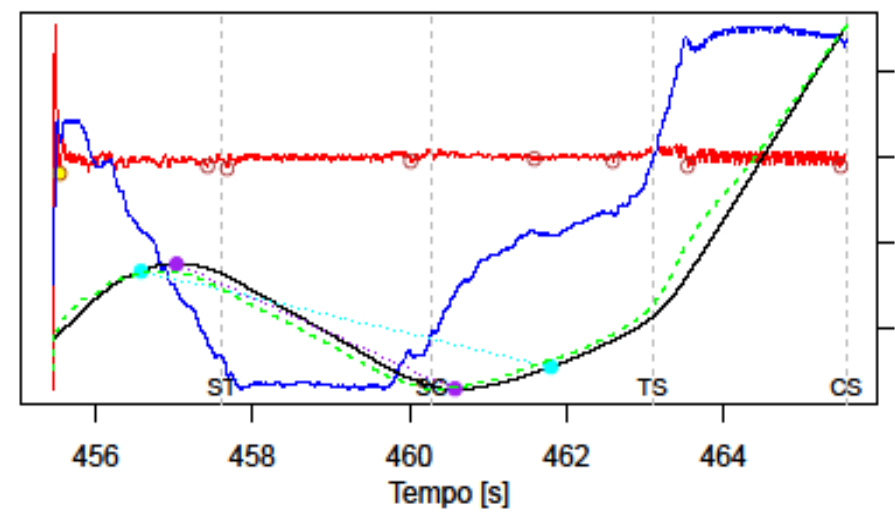

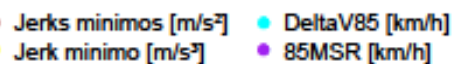

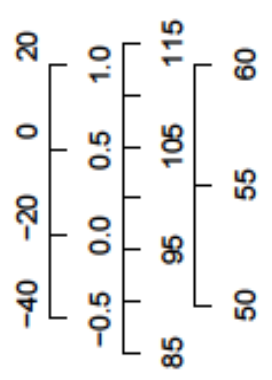

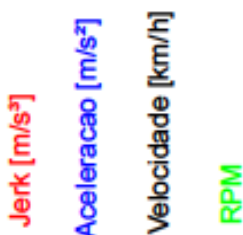

Condutor 26 , Tratamento 9 , SegundoTrecho

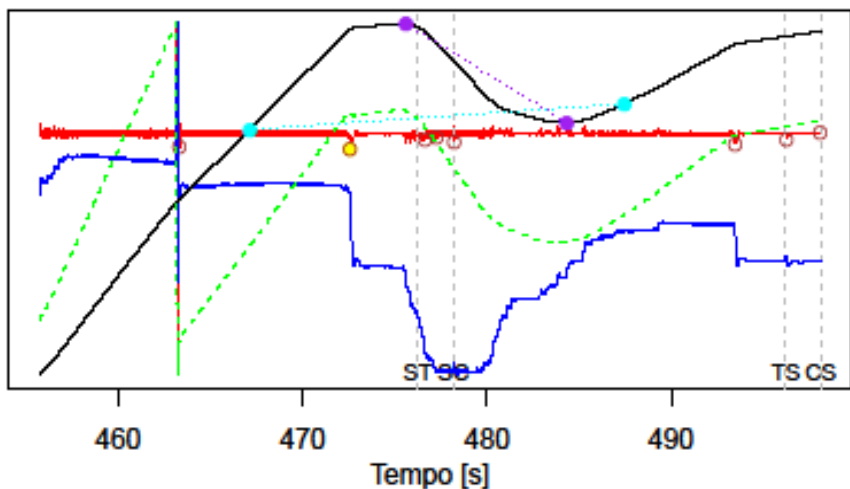

Jerks minimos $[\mathrm{m} / \mathrm{s}$ 》] - DeltaV85 $[\mathrm{km} / \mathrm{h}]$ Jerk minimo $\left[\mathrm{m} / \mathrm{s}^{\mathrm{y}}\right] \quad-85 \mathrm{MSR}[\mathrm{km} / \mathrm{h}]$

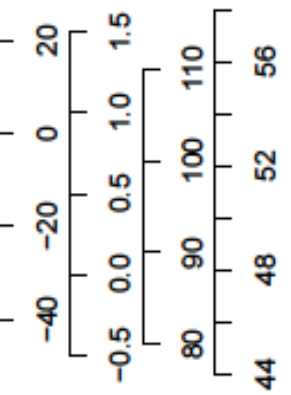

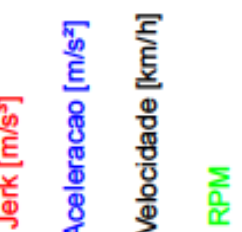

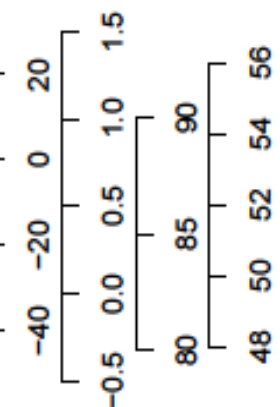

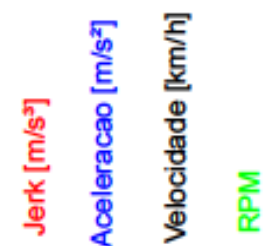

Condutor 27 , Tratamento 2 , SegundoTrecho

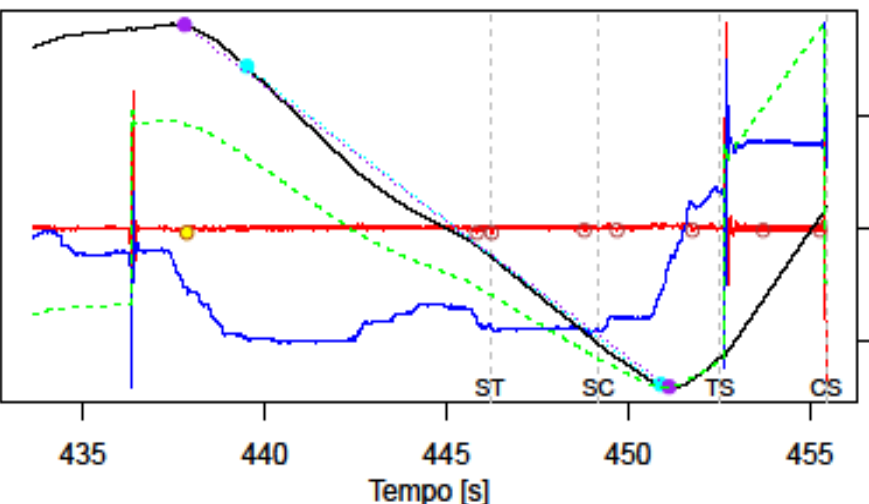

은

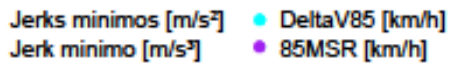

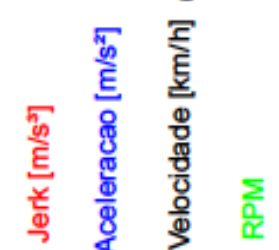


Condutor 27 , Tratamento 3 , SegundoTrecho

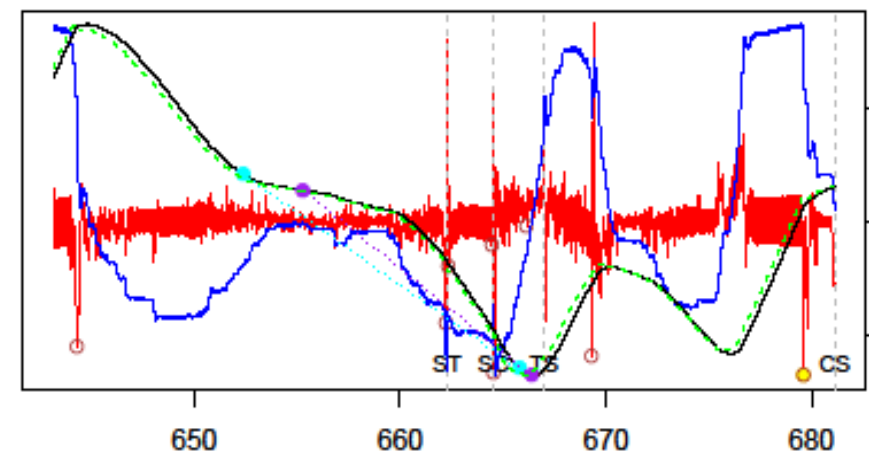

Jerks minimos [m/s $]$ - DeltaV85 $[\mathrm{km} / \mathrm{h}]$ Jerk minimo $\left[\mathrm{m} / \mathrm{s}^{\mathrm{s}}\right]$ • $85 \mathrm{MSR}[\mathrm{km} / \mathrm{h}]$
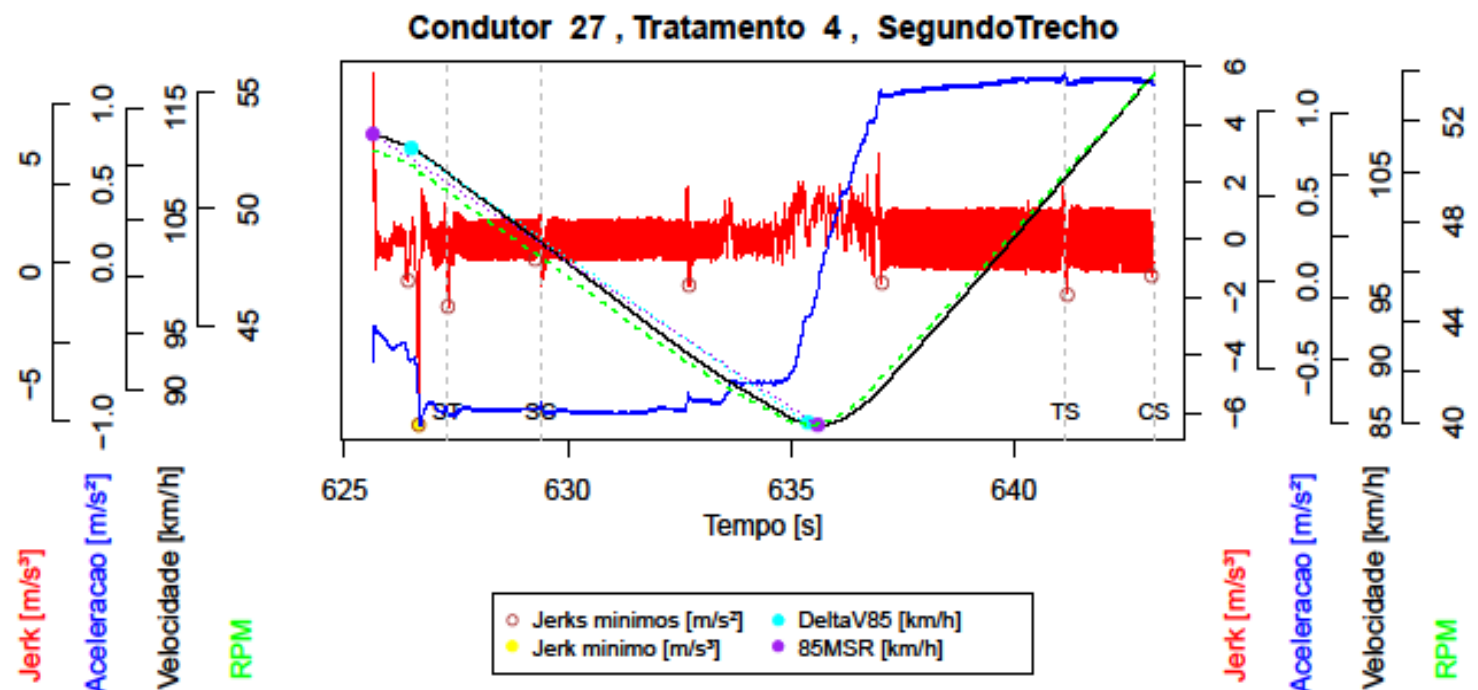

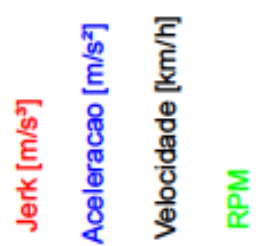

Jerks minimos $[\mathrm{m} / \mathrm{s}]$-DeltaV85 $[\mathrm{km} / \mathrm{h}]$ Jerk minimo $\left[\mathrm{m} / \mathrm{s}^{\mathrm{s}}\right]$ - $85 \mathrm{MSR}[\mathrm{km} / \mathrm{h}]$

\section{Condutor 27 , Tratamento 5 , SegundoTrecho}

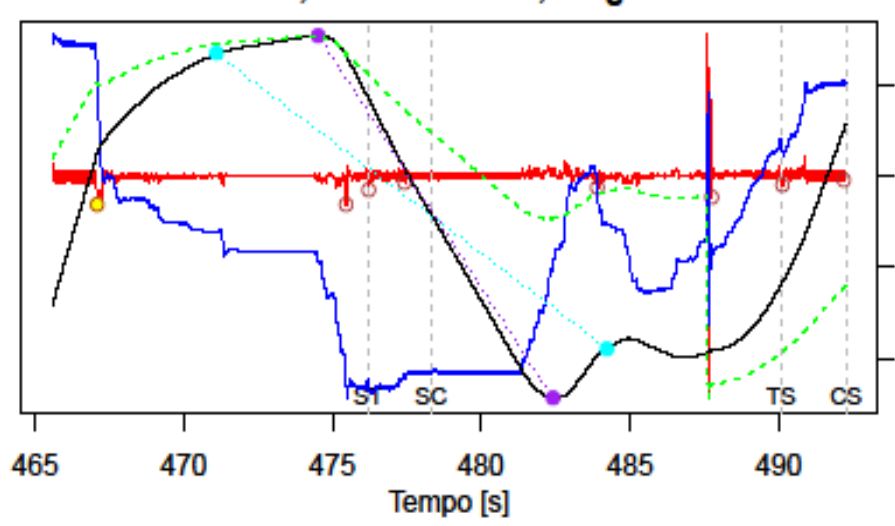

Jerks minimos $[\mathrm{m} / \mathrm{s}$ ] $\quad$ DeltaV85 $[\mathrm{km} / \mathrm{h}]$ Jerk minimo [m/s" $\bullet 85 \mathrm{MSR}[\mathrm{km} / \mathrm{h}]$

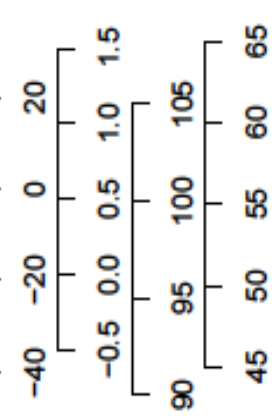

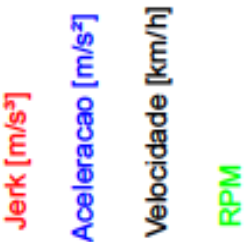

Condutor 27 , Tratamento 6 , SegundoTrecho

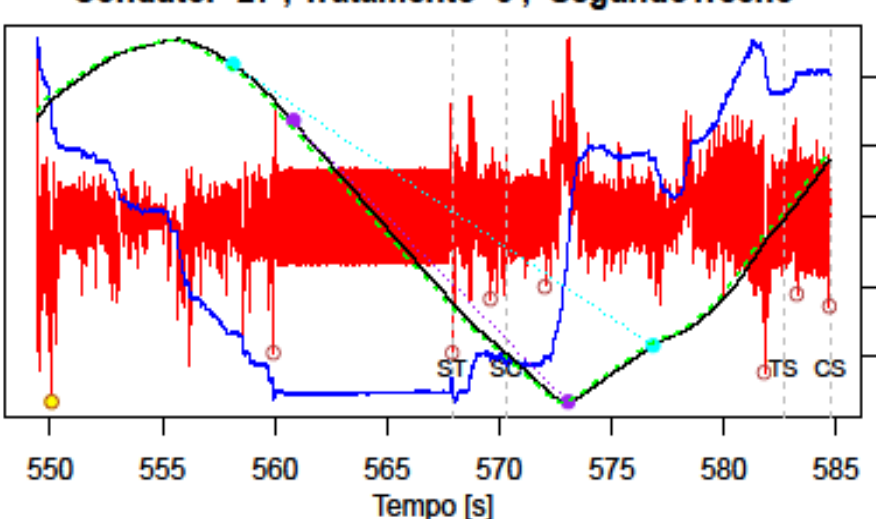

Jerks minimos $\left[\mathrm{m} / \mathrm{s}^{\mathrm{l}}\right]$ : DeltaV85 $[\mathrm{km} / \mathrm{h}]$

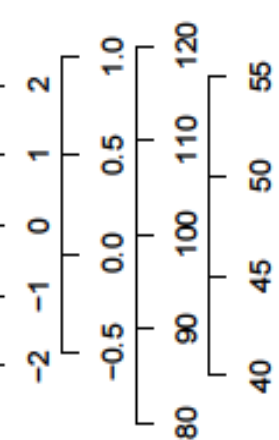

ᄂ 요 


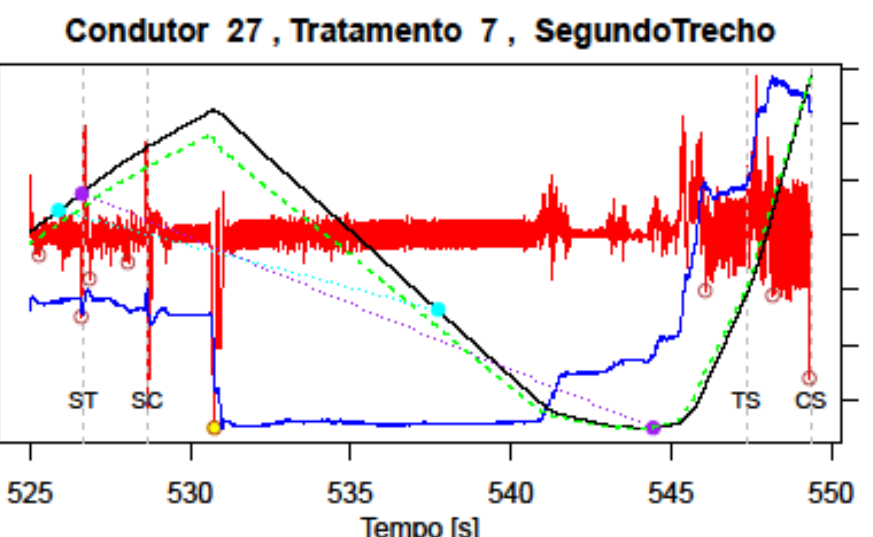

Jerks minimos $\left[\mathrm{m} / \mathrm{s}^{\mathrm{2}}\right]$ - DeltaV85 $[\mathrm{km} / \mathrm{h}]$ Jerk minimo $\left[\mathrm{m} / \mathrm{s}^{\mathrm{\vartheta}}\right]$ - $85 \mathrm{MSR}[\mathrm{km} / \mathrm{h}]$

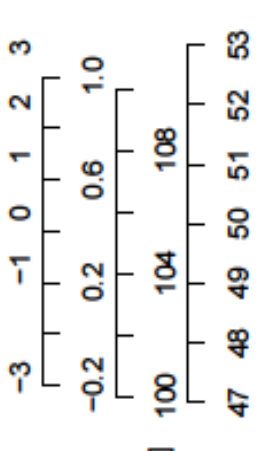

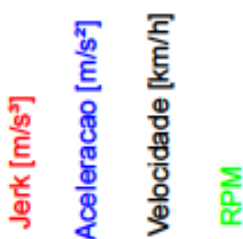

Condutor 27 , Tratamento 8 , SegundoTrecho

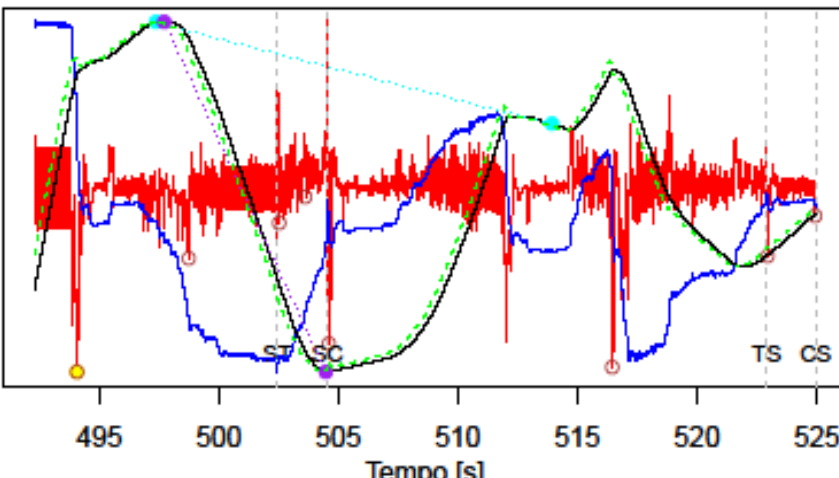

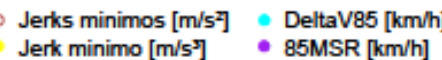

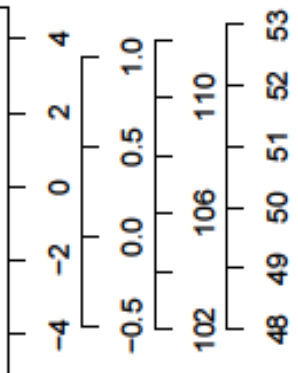

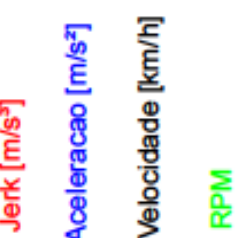

\section{Condutor 27 , Tratamento 9 , SegundoTrecho}

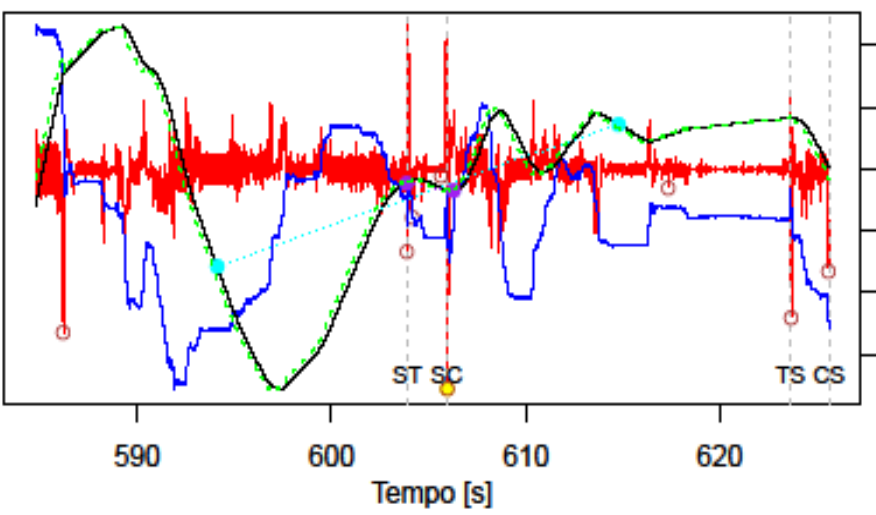

Jerks minimos $\left[\mathrm{m} / \mathrm{s}^{2}\right]$ DeltaV85 $[\mathrm{km} / \mathrm{h}]$ Jerk minimo $\left[\mathrm{m} / \mathrm{s}^{\mathrm{s}}\right]$ — $85 \mathrm{MSR}[\mathrm{km} / \mathrm{h}]$

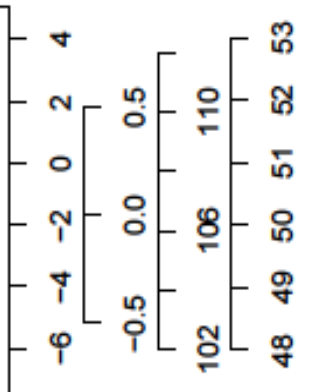

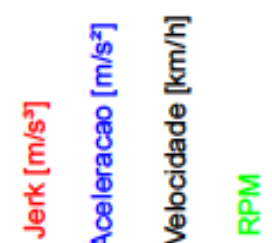

Condutor 28 , Tratamento 1 , SegundoTrecho

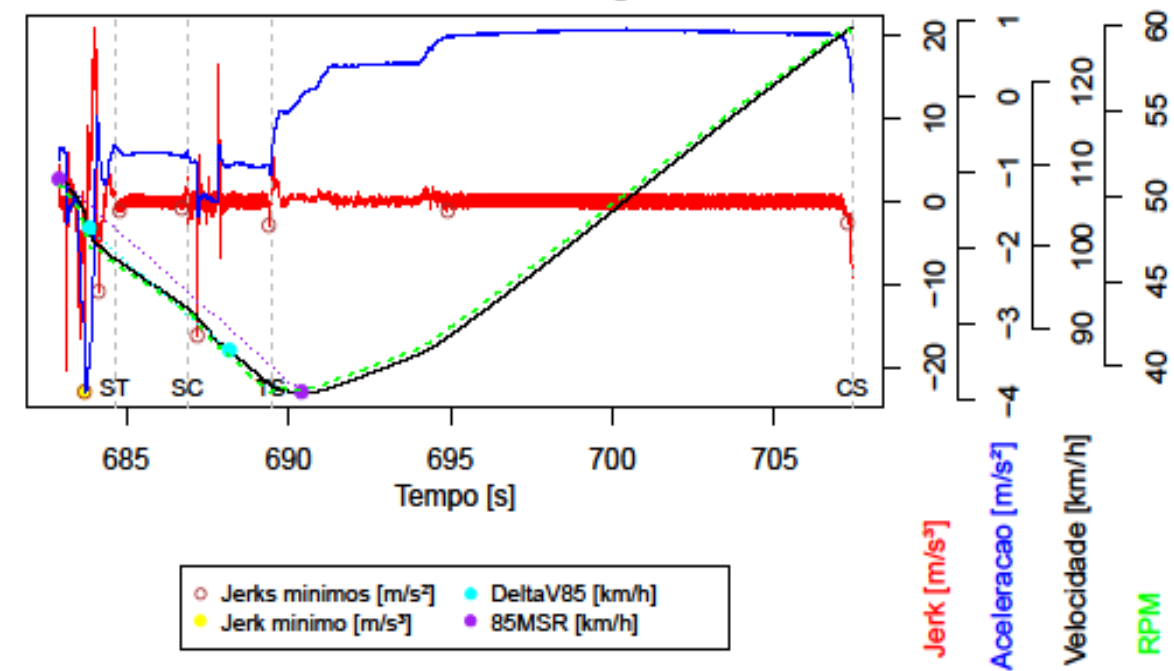



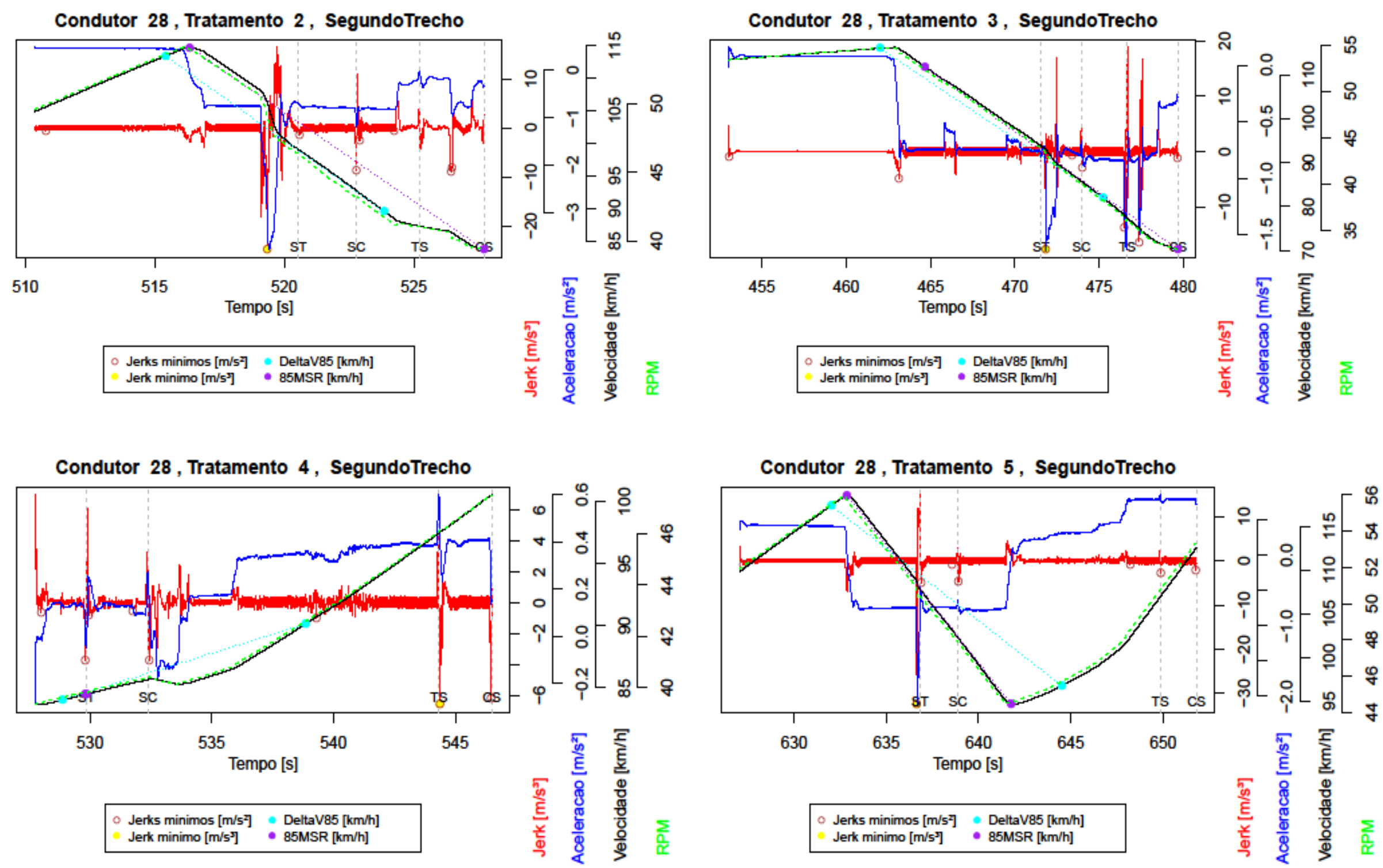

Jerks minimos $[\mathrm{m} / \mathrm{s}]$ - DeltaV85 $[\mathrm{km} / \mathrm{h}]$

Jerks minimos [m/s $]$ - DeltaV85 $[\mathrm{km} / \mathrm{h}]$ 
Condutor 28 , Tratamento 6 , SegundoTrecho

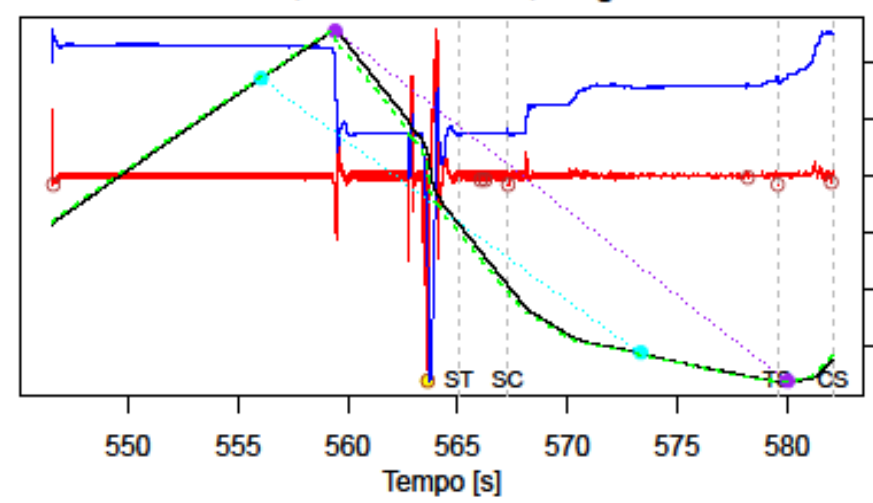

Jerks minimos $[\mathrm{m} / \mathrm{s}]$ - DeltaV85 $[\mathrm{km} / \mathrm{h}]$ Jerk minimo $\left[\mathrm{m} / \mathrm{s}^{\mathrm{s}}\right]$ - $85 \mathrm{MSR}[\mathrm{km} / \mathrm{h}]$

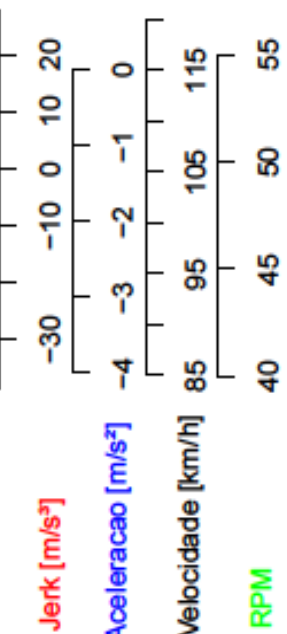

Condutor 28 , Tratamento 7 , SegundoTrecho

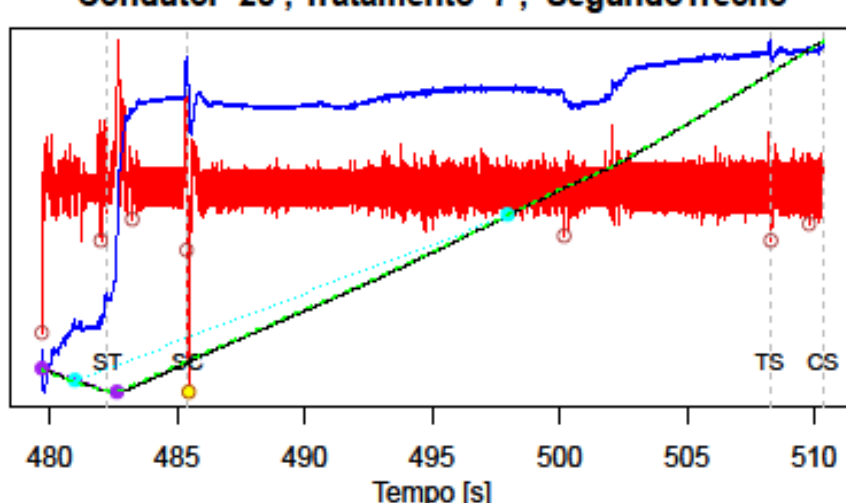

Jerks minimos [m/s $]$ DeltaV85 $[\mathrm{km} / \mathrm{h}]$ Jerk minimo $\left[\mathrm{m} / \mathrm{s}^{⿰}\right]$ - $85 \mathrm{MSR}[\mathrm{km} / \mathrm{h}]$

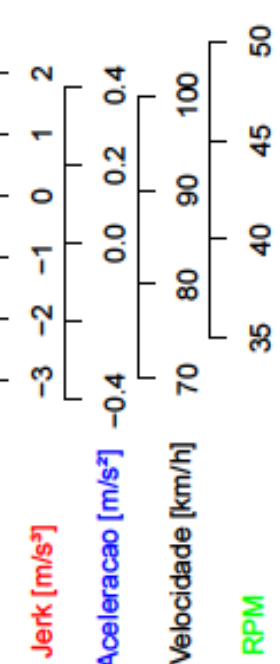

Condutor 28 , Tratamento 8 , SegundoTrecho

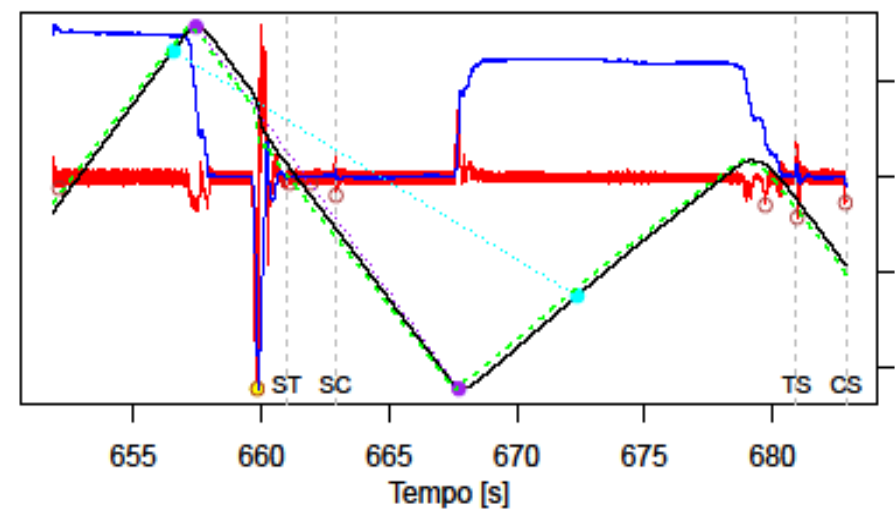

Jerks minimos [m/s'] DeltaV85 $[\mathrm{km} / \mathrm{h}]$ Jerk minimo $\left[\mathrm{m} / \mathrm{s}^{\mathrm{s}}\right]$ - $85 \mathrm{MSR}[\mathrm{km} / \mathrm{h}]$

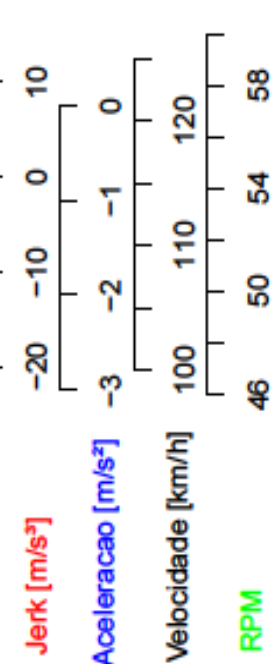

Condutor 28 , Tratamento 9 , SegundoTrecho

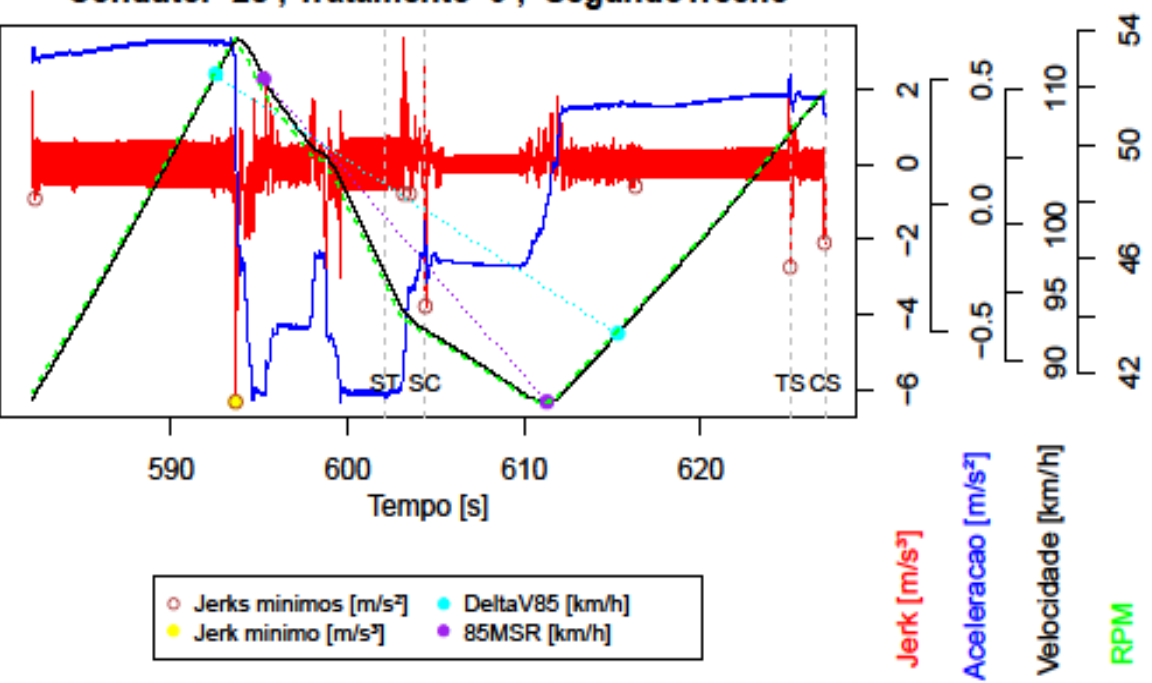



ANEXO

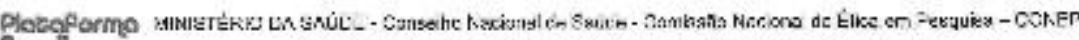
Grasil

TOLHA DE ROSTO PARA PEEOUBSA EA VOLVENDO SERES HUTANOS

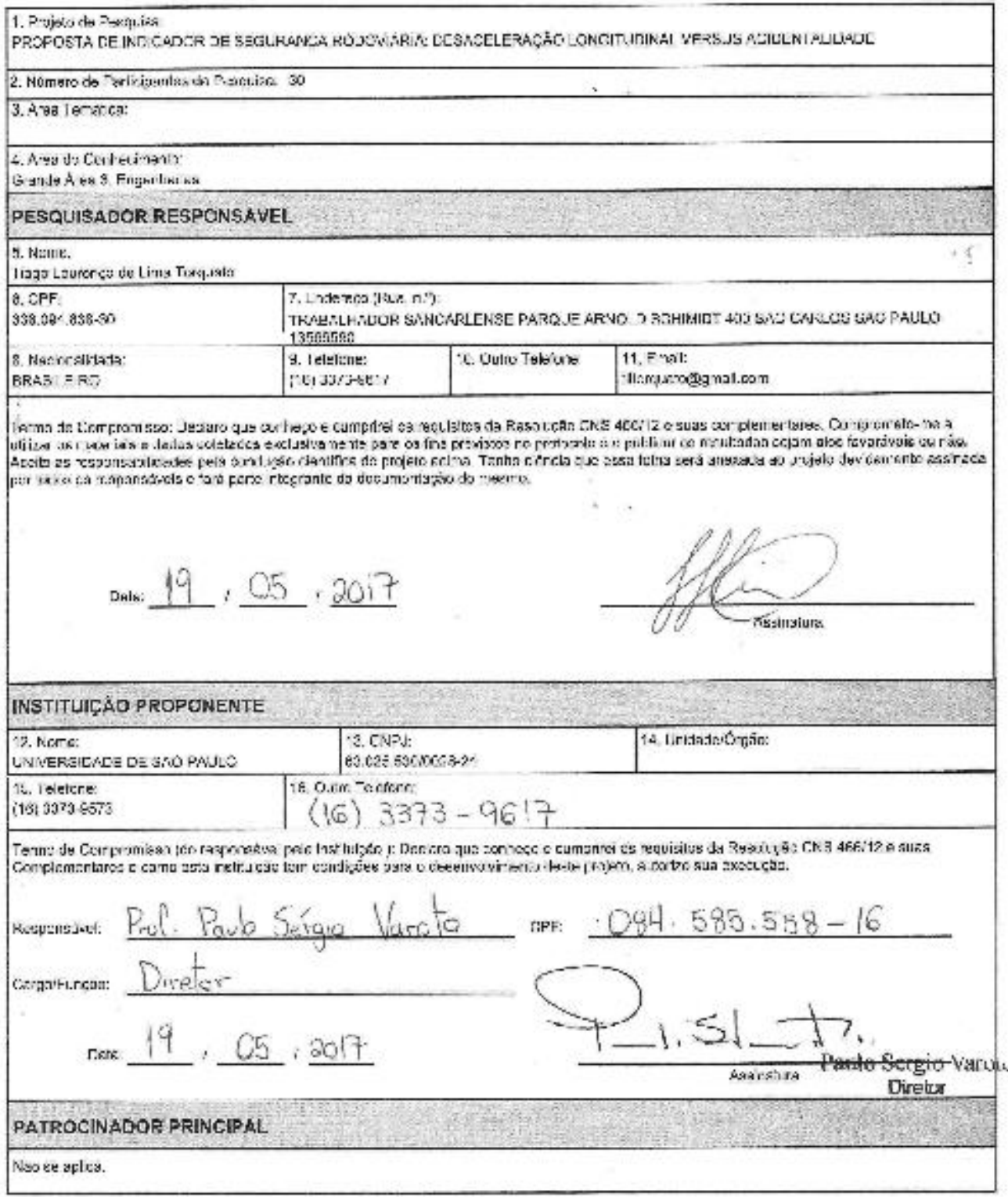




\section{$E E S[\cdot U S P$}

Fwath at: Fryenharia dia Sac Csnos

Det:anarienco de Engentiants of rongports?

\section{AUTORIZAÇĀO PARA RECRUTAMENTO DE AMOSTRA.}

O al Jno TIAGO LOURENÇO DE LIMA TORQUATO, matricuisdo ñ curso de doutorado do Programa de Pós-graduaçâo em Engenharia de Tranøportes da Escrble de Fngenharia de Săo Carlos/USP, mairiculado com núrna o USP 9058283, está autorizado a recrLtar uma amostra de ate 30 alunos de pós-graduaçăo e funclonárlos da Escola de Engenharia de Sâo CarlosilusP para particparam da pesquisa PROPOSTA DE INDICADOR DE SEGURANĊA RODOVIARIA: Desaceleraçăo Longitudinal Vergus Acidentalidado. As pessoas recrutacą dirigirăo por um canáro virtual do simulador de dirsçáa esiático do LabSim - Lajoratório de Simulaçăo - do depatamerto de Ençenharia de Transportes da EESCIUSP.

Respontával: Poulo SÉrgio VAROTO

CPF:

CargolFunção: DiketOR DA GSOLA DU ENGENHAGIA DU SÃo CARLOS/USP

Data:

Local:

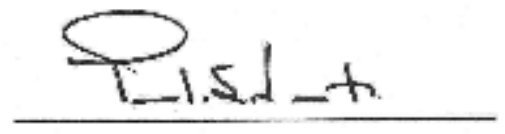

Assinatura 
UFSCAR - UNIVERSIDADE

FEDERAL DE SÃO CARLOS

Platoforma Brasil

\section{PARECER CONSUBSTANCIADO DO CEP}

\section{DADOS DO PROJETO DE PESQUISA}

Título da Pesquisa: PROPOSTA DE INDICADOR DE SEGURANÇA RODOVIÁRIA: DESACELERAÇĀO LONGITUDINAL VERSUS ACIDENTALIDADE

Pesquisador: Tiago Lourenço de Lima Torquato

Area Temática:

Versão: 2

CAAE: 68947017.7.0000.5504

Instituiçäo Proponente:UNIVERSIDADE DE SAO PAULO

Patrocinador Principal: Financiamento Próprio

\section{DADOS DO PARECER}

Número do Parecer: 2.184 .786

Apresentaçäo do Projeto:

Estudo com 3 etapas, sendo a relativa a apreciação deste Comitê aquela que se pauta em experimento controlado junto a condutores reais em ambiente de direção simulada. Intenciona-se como participantes pessoas maiores de idade com carteira nacional de habilitação, podendo ser aluno de pós-graduaçäo e funcionários de uma universidade elencada ao estudo, com experiència de direçäo em rodovias.

Objetivo da Pesquisa:

O objetivo principal é de propor um indicador que correlacione desacelerações.

obtidas da condução, com as interações entre as características geométricas de trechos em tangente e de trechos em curva.

Como objetivos secundários apresenta: (1) calibrar um modelo de desaceleração baseado em simulação virtual de conduçäo;(2) comparar o modelo obtido com os registros de acidentes em vias rurais.

Avaliaçäo dos Riscos e Benefícios:

Como riscos os pesquisadores apontam a possibilidade de surgir, durante a simulaçäo, enjoo, dor

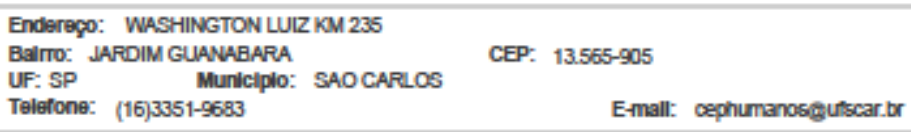

Pagre or de w 


\section{UFSCAR - UNIVERSIDADE S Platoforma}

Conthuschlo do Parecer: 2.184 .795

de cabeça, tontura, dentre outros sintomas e, afirma que na vigència destes desconfortos há a opção para a suspensāo imediata da simulação Além disso, afirmam na coleta de dados, caso haja constrangimento com alguma questäo, está garantido o direito de recusar-se a responder. Pactuam sigilo e confidencialidade das informaçōes.

Em termos de beneficios trazem a contribuiçäo com o avanço do conhecimento científico com contribuiçöes à sociedade.

Comentários e Consideraçōes sobre a Pesquisa:

A coleta de dados perpasse: informaçōes demográficas sobre o participante, preenchimento de questionário; imersão em cenário simulado em um cockpit.

Considerações sobre os Termos de apresentaçäo obrigatória:

Todos os termos de apresentaçäo obrigatória seguem as recomendaçōes deste Comitê.

Recomendações:

-

Conclusões ou Pendências e Lista de Inadequações:

Näo há pendências.

Considerações Finais a critério do CEP:

Recomendo aprovação. Proposta atende as recomendações éticas para estudos com seres humanos.

Este parecer foi elaborado baseado nos documentos abaixo relacionados:

\begin{tabular}{|c|c|c|c|c|}
\hline Tipo Documento & Arquivo & Postagem & Autor & Situaçăo \\
\hline $\begin{array}{l}\text { Informaçóes Básicas } \\
\text { do Projeto }\end{array}$ & $\begin{array}{l}\text { PB_INFORMAÇOES_BASICAS_DO_P } \\
\text { ROJETO 736048.pdf }\end{array}$ & $\begin{array}{c}21 / 06 / 2017 \\
14: 17: 39\end{array}$ & & Aceito \\
\hline $\begin{array}{l}\text { Declaração de } \\
\text { Instituiçâo e } \\
\text { Infraestnutura }\end{array}$ & Autorizacaolnstituicao_TLLT.PDF & $\begin{array}{l}21 / 08 / 2017 \\
14: 17: 15\end{array}$ & $\begin{array}{l}\text { Tiago Lourenço de } \\
\text { Lima Torquato }\end{array}$ & Aceito \\
\hline $\begin{array}{l}\text { Projeto Deta hado / } \\
\text { Brochura } \\
\text { Investioador }\end{array}$ & Brochura.pdf & $\begin{array}{c}23 / 05 / 2017 \\
16: 55: 09\end{array}$ & $\begin{array}{l}\text { Tiago Lourenço de } \\
\text { Lima Torquato }\end{array}$ & Aceito \\
\hline $\begin{array}{l}\text { TCLE / Termos de } \\
\text { Assentimento / } \\
\text { Justificativa de } \\
\text { Ausência. }\end{array}$ & TCLE_TLLT.doc & $\begin{array}{c}23 / 05 / 2017 \\
16: 53: 32\end{array}$ & $\begin{array}{l}\text { Tiago Lourenço de } \\
\text { Lima Torquato }\end{array}$ & Aceito \\
\hline
\end{tabular}

Enderego: WASHINGTON LUIZ KM 235

BalrT: JARDIM GUANABARA

CEP: $13.565-905$

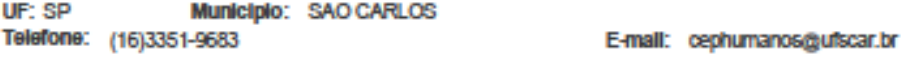


UFSCAR - UNIVERSIDADE FEDERAL DE SÃo CARLOS Platoforma ufxion r Grari

Contunuachlo do Parecer. 2.194.785

\begin{tabular}{|l|l|c|c|c|}
\hline Folha de Rosto & FolhaDeRostoTLLT.PDF & $\begin{array}{c}23 / 05 / 2017 \\
16-52: 18\end{array}$ & $\begin{array}{l}\text { Tiago Lourenço de } \\
\text { Lima Torouato }\end{array}$ & Aceito \\
\hline
\end{tabular}

Situaçäo do Parecer:

Aprovado

Necessita Apreciaçäo da CONEP:

Não

SAO CARLOS, 24 de Julho de 2017

Assinado por:

Priscilla Hortense

(Coordenador)

Endereģ: WASHINGTON LUIZ KM 235

Balmo: JARDIM GUANABARA

UF: SP MUNiciplo: SAOCARLOS

Teiefone: (16)3351-9683
CEP: $13.565-905$

E-mall: cephumanosgutscar.br 


\section{UNIVERSIDADE DE SÃO PAULO \\ DEPARTAMENTO DE ENGENHARIA DE TRANSPORTES \\ PROGRAMA DE PÓS-GRADUAC̣ÃO EM ENGENHARIA DE TRANSPORTES}

TERMO DE CONSENTTMENTO LIVRE E. ESCL.ARECTDO

(Resolução 466/2012 do CNS)

\section{PROPOSTA DE INDICADOR DE SEGURANÇA RODOVIÁRIA: DESACELERAÇÃo LONGITUDINAL VERSUS ACIDENTALIDADE}

Os acidentes de trânsito são grandes causadores de fatalidades no Brasil e no mundo. As curvas horizontais são trechos responsáveis por significativa parcela desse fenômeno, principalmente quando registram saídas de pista. Na tentativa de amenizar esse problema, o presente estudo tem como objetivo principal propor um indicador que correlacione desacelerações, obtidas da condução, com as interações entre as características geométricas de trechos em tangente e de trechos em curva.

Para tanto, far-se-á necessánio calibrar um modelo de desaceleração para esses elementos e comparar com registros de acidentes em vias rurais. O plano de trabalho envolve, fundamentalmente, o desenvolvimento de um experimento em simulador de direção estático. $O$ propósito da experiência é levantar, em ambiente controlado, as combinações de características que propiciem performances piores dos condutores, a partir de dados registrados em cenário virtual.

Pretende-se com essa pesquisa dar suporte cientifico a estratégias futuras que visem aumentar o poder de negociação entre os condutores e as curvas, a partir de sistemas embarcados, e auxiliar os gestores na identificação continua de pontos de risco. Com isso, espera-se melhorar a consistência das velocidades e, assim, diminuir a chance de inesperadas saidas de pista e acidentes mais graves.

O Sr./Sra. está sendo convidado a participar como voluntário nesta pesquisa, a fim de contribuir com a lacuna de conhecimento existente acerca da negociação entre condutores e trechos em curva, e ajudar as pessoas quando enfrentarem este tipo de situação. Você foi selecionado, ao acaso, dentro da Escola de Engenharia de São Carlos (EESC/USP) por ser maior de 18 anos, portador de Carteira Nacional de Habilitação válida e ter experiência em rodovias. Para isso, sua colaboração nesta pesquisa consistirá na participação em uma simulação virtual de direção, na qual o $\mathrm{Sr}$./Sra.: 01 - responderá um questionánio de caracterização da amostra; 02 - conduzirá em um cenánio virtual de treinamento, por aproximadamente, 10 minutos; 03 - conduzirá em um cenário virtual de interesse da pesquisa, por aproximadamente, 20 minutos; e 04 - responderá um questionánio de caracterização da experiência em imersão na simulação.

O experimento leva menos de 1 hora e, normalmente, não acarreta riscos para a saúde do voluntánio. Entretanto, em alguns casos poderá surgir, durante a simulação, enjoo, dor de cabeça, tontura, etc. Caso algum desses desconfortos oconram, o voluntánio deverá optar pela suspensão imediata da simulação.

Seus dados pessoais serão solicitados apenas para caracterização da amostra, em NENHUM momento serão divulgados. Qualquer dado que possa identificá-lo será omitido na divulgação dos resultados da pesquisa e o material será armazenado em local seguro. As informações obtidas serão tratadas com 
confidencialidade e utilizadas exclusivamente para a realização desta pesquisa. Caso haja constrangimento com alguma questão, você tem o direito de recusar-se a responder.

Sua participação na pesquisa não é obrigatória, e a sua recusa não implicará em nenhum prejuizo na sua relação com o pesquisador ou com a instituição. Você poderá cancelar sua concordância com este termo de consentimento a qualquer momento, sem nenhum tipo de prejuizo, bastando apenas não concluir o preenchimento do mesmo. Todas as despesas com o transporte e a alimentação decorrentes da sua participação na pesquisa, quando for o caso, serão ressarcidas no dia da coleta. Você terá direito a indenização por qualquer tipo de dano resultante da sua participação na pesquisa.

Como beneficios indiretos da sua participação, os dados obtidos nessa pesquisa poderão servir para ajudar imensamente outras pessoas na medida em que, poderemos compreender melhor o comportamento do condutor nas curvas horizontais e embasar a definição de parâmetros para futuros indicadores de segurança, a fim de evitar acidentes e salvar vidas.

Se você tiver qualquer problema ou dúvida durante a sua participação na pesquisa poderá comunicarse pelo telefone (16) 3373-9617 ou vir no Departamento de Transportes da EESC/USP, Av. Trabalhador Sãocarlense 400 , de $2^{\mathrm{a}}$. a $6^{\mathrm{a}}$. das $8 \mathrm{~h}$ às $12 \mathrm{~h}$ ou das $14 \mathrm{~h}$ às $16 \mathrm{~h}$ e procurar o pesquisador Tiago Lourenço de Lima Torquato. Você receberá uma via deste termo, rubricada em todas as páginas por você e pelo pesquisador, onde consta o telefone e o endereço do pesquisador principal. Você poderá tirar suas dúvidas sobre o projeto e sua participação agora ou a qualquer momento.

Declaro que entendi os objetivos, riscos e beneficios de minha participação na pesquisa e concordo em participar. $O$ pesquisador me informou que o projeto foi aprovado pelo Comitê de Ética em Pesquisa em 24/07/2017 que funciona na Universidade Federal de São Carlos, localizada na rodovia Washington Luiz kn 235. Fone (16) 3351-9683. Endereço eletrônico: cephumanos@ufscar.br

Endereço para contato (24 horas por dia e sete dias por semana):

Pesquisador Responsável: Tiago Lourenco de Lima Torquato

Endereço: Av. Trabalhador Sãocarlense 400

Contato telefonico:_(16) 3373-9617 e-mail: t_lltorquato $($ gmail.com

Local e data:

Nome do Pesquisador

Nome do Participante
Assinatura do Pesquisador

Assinatura do Participante 


\section{Questionário de Caracterização do Condutor}

Prezado participante

Inicialmente gostariamos de agradecer sua participação no experimento de Avaliação do Comportamento de Condutores em Ambientes Simulados. Por meio deste, pedimos o seu consentimento para usar os resultados do trabalho em publicações futuras. Ressaltamos que seus dados pessoais nunca serão divulgados, sendo apenas utilizados para caracterização dos grupos de amostra.

Segue abaixo questões que serão utilizadas para o prosseguimento de nossos estudos:

1) O que te motivou a participar do experimento?

2) Numa semana da sua rotina habitual, quantos dias você dirige por semana?

( ) Nenhum dia ( ) 1 a 3 dias ( ) 4 a 6 dias () Todos os dias

3) Num dia da sua rotina habitual, quantas vezes por dia você dinige? ( ) Não dirijo ( ) 1 ou 2 vezes ( ) 3 a 5 vezes ( ) Mais de 6 vezes

4) Num dia da sua rotina habitual, quanto tempo por dia você dinige? ( ) Não dinjo ( ) Até 30 min ( ) Até 2 horas ( ) Mais de 2 horas

5) Você se considera um condutor.

( ) Experiente ( ) Inexperiente

6) Quais caracteristicas melhor descrevem o tipo de condutor que você é?
( ) Inseguro
( ) Cauteloso
( ) Confiante
( ) Agressivo

7) Você já levou multas de trânsito?

( ) Não

( ) $\operatorname{Sim}$

- Considerando as multas cometidas nos últimos 12 meses, quais foram:

( ) Infrações leves. Quantas?

( ) Infraçôes médias. Quantas?

( ) Infrações graves. Quantas?

( ) Infrações gravissimas. Quantas?

8) Como condutor você já se envolveu em acidentes de trânsito?
( ) Não
( ) Sim, em batidas leves. Quantas?
( ) $\mathrm{Sim}$ em acidentes com vítimas. Quantos? 
9) Já participou de outras simulações com cockpit e manopla de comandos do tipo Racing wheels?
( ) Sim
( ) Não

10) Você habitualmente joga no celular, computador ou consoles?
( ) $\mathrm{Sim}$
( ) Não

- Se joga, com que frequência?
( ) Diariamente
( ) Algumas vezes por semana
( ) Algumas vezes por mês
( ) Raramente

- Você se entretém com jogos de corrida ou carros? Com que frequência?

( ) Diariamente

( ) Algumas vezes por semana

( ) Algumas vezes por mês

( ) Raramente

Idade:

Categoria da Habilitação:

Tempo de Habilitação:

Experiência em trecho urbano:

Experiência em pista dupla:

Experiência em pista simples:

Data

Assinatura 
Questionário de Caracterização de Imersão no Simulador

Condutor:

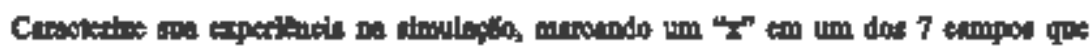
melhor traduz a sua sensação durante o experimento. Por favor, considere toda a escala quando assinalar as respostas, inclusive os niveis intermediários. Responda as questões na ordem apresentada, sem pular ou alterar uma resposta após assinalá-la.

COM RELAÇÃO À SUA EXPERIÊNCIA NA SIMULAÇÃO

1. Quanto você conseguiu controlar o veículo simulado?

\begin{tabular}{|l|l|l|l|l|l|l|}
\hline $\begin{array}{l}\text { Nenhum } \\
\text { controle }\end{array}$ & & $\begin{array}{c}\text { Algum } \\
\text { controle }\end{array}$ & & & Controle total \\
\hline
\end{tabular}

2. Qual o nivel de realidade sentida, em função das respostas do simulador, para suas ações?

\begin{tabular}{|l|l|l|c|l|l|c|}
\hline Não respondeu & & $\begin{array}{c}\text { Resposta } \\
\text { moderada }\end{array}$ & & & $\begin{array}{c}\text { Respondeu } \\
\text { completamente }\end{array}$ \\
\hline
\end{tabular}

3. Qual o nivel de naturalidade com o qual você interagiu com o simulador?

\begin{tabular}{|c|l|l|l|l|l|c|}
\hline $\begin{array}{c}\text { Extremamente } \\
\text { artificial }\end{array}$ & & Médio & & & $\begin{array}{c}\text { Completamente } \\
\text { natural }\end{array}$ \\
\hline
\end{tabular}

4. Em que nivel o aspecto visual (apenas) do simulador conseguiu te envolver no ambiente?

\begin{tabular}{|l|l|l|c|l|l|l|}
\hline Nenhum & & $\begin{array}{c}\text { Envolvimento } \\
\text { mediano }\end{array}$ & & & Completamente \\
\hline
\end{tabular}

5. Quão natural foi o seu controle dos mecanismos de direção do simulador?

\begin{tabular}{|c|l|l|l|l|l|c|}
\hline $\begin{array}{c}\text { Extremamente } \\
\text { artificial }\end{array}$ & & & Médio & & & $\begin{array}{c}\text { Completamente } \\
\text { natural }\end{array}$ \\
\hline
\end{tabular}

6. Qual o nivel de conviç̧ão que você daria para os objetos presentes na simulação?

\begin{tabular}{|c|l|l|l|l|l|l|}
\hline Nenhuma & & & $\begin{array}{c}\text { Convicção } \\
\text { mediana }\end{array}$ & & & $\begin{array}{c}\text { Completamente } \\
\text { convincente }\end{array}$ \\
\hline
\end{tabular}

7. Qual o nivel de coerência que você daria ao comparar o ambiente simulado com uma experiência de direção real?

\begin{tabular}{|l|l|l|l|l|l|l|}
\hline $\begin{array}{l}\text { Nenhuma } \\
\text { coerência }\end{array}$ & & Base coerente & & & $\begin{array}{c}\text { Completamente } \\
\text { idêntico }\end{array}$ \\
\hline
\end{tabular}


8. Quantas vezes você foi capaz de prever o que aconteceria logo após executar alguma ação no simulador? (Rotacionar o volante, acionar os freios...)

\begin{tabular}{|l|l|l|l|l|l|}
\hline Nenhuma vez & & & Algumas vezes & & \\
\hline
\end{tabular}

9. Quanto você conseguiu monitorar e explorar visualmente o ambiente e tomar decisões baseadas no entorno?

\begin{tabular}{|c|l|l|c|l|l|l|}
\hline $\begin{array}{c}\text { Nenhum } \\
\text { monitoramento }\end{array}$ & $\begin{array}{c}\text { Algum } \\
\text { monitoramento }\end{array}$ & & & $\begin{array}{c}\text { Monitoramento } \\
\text { constante }\end{array}$ \\
\hline
\end{tabular}

10. Quantos detalhes que você foi capaz de identificar nos objetos ao observá-los?

\begin{tabular}{|c|l|l|l|l|l|l|}
\hline $\begin{array}{c}\text { Nenhum } \\
\text { detalhe }\end{array}$ & & $\begin{array}{c}\text { Alguns } \\
\text { detalhes }\end{array}$ & & & $\begin{array}{c}\text { Muitos } \\
\text { detalhes }\end{array}$ \\
\hline
\end{tabular}

11. Considerando um mesmo objeto a diferentes distâncias, você percebeu diferença no nivel de detalhamento?

\begin{tabular}{|l|l|l|c|l|l|c|}
\hline $\begin{array}{c}\text { Nenhuma } \\
\text { diferença }\end{array}$ & & $\begin{array}{c}\text { Alguma } \\
\text { diferença }\end{array}$ & & & $\begin{array}{c}\text { Muita } \\
\text { diferença }\end{array}$ \\
\hline
\end{tabular}

12. Quão envolvido com o ambiente virtual você esteve?

\begin{tabular}{|c|l|l|l|l|l|l|}
\hline $\begin{array}{c}\text { Nenhum } \\
\text { envolvimento }\end{array}$ & $\begin{array}{c}\text { Alguma } \\
\text { relação }\end{array}$ & $\begin{array}{c}\text { Completamente } \\
\text { absolvido }\end{array}$ \\
\hline
\end{tabular}

13. Quanto tempo de atraso você encontrou entre uma ação tomada e a resposta do simulador?

\begin{tabular}{|c|l|l|c|l|l|c|}
\hline Nenhum atraso & & $\begin{array}{c}\text { Atrasos } \\
\text { toleráveis }\end{array}$ & & & $\begin{array}{c}\text { Respostas } \\
\text { lentas }\end{array}$ \\
\hline
\end{tabular}

14. Quanto tempo você demorou para se adaptar ao simulador?

\begin{tabular}{|c|c|c|c|c|c|c|}
\hline $\begin{array}{c}\text { Menos de 1 } \\
\text { minuto }\end{array}$ & $\begin{array}{c}\text { Menos } \\
\text { de 5 } \\
\text { minutos }\end{array}$ & $\begin{array}{c}\text { Ao fim } \\
\text { do } \\
\text { cenário } \\
\text { teste }\end{array}$ & $\begin{array}{c}\text { Apenas na } 1^{\mathbf{2}} \\
\text { volta }\end{array}$ & $\begin{array}{c}\text { Ao } \\
\text { fim } \\
\text { da } 1^{\circ} \\
\text { volta }\end{array}$ & $\begin{array}{c}\text { Apenas } \\
\text { na } 2^{\mathbf{2}} \\
\text { volta }\end{array}$ & Não me adaptei \\
\hline
\end{tabular}

15. No fim do experimento, como você classificaria seu nível de aptidão para dirigir no simulador?

\begin{tabular}{|c|l|l|l|l|l|c|}
\hline Não consigo & $\begin{array}{c}\text { Razoavelmente } \\
\text { experiente }\end{array}$ & & $\begin{array}{c}\text { Bastante } \\
\text { competente }\end{array}$ \\
\hline
\end{tabular}


16. Quanto à qualidade da resolução do vídeo, esse te distraiu ou não permitiu que você realizasse a tarefa?

\begin{tabular}{|l|l|l|c|l|l|l|}
\hline Não interferiu & & & $\begin{array}{c}\text { Interferiu de } \\
\text { alguma forma }\end{array}$ & & & $\begin{array}{c}\text { Não consegui } \\
\text { realizar tarefas }\end{array}$ \\
\hline
\end{tabular}

17. Quanto aos mecanismos de direção do cockpit, esses interferiram, ou não permitiram, que você conseguisse realizar alguma tarefa?

\begin{tabular}{|c|c|c|c|c|c|c|}
\hline Não interferiu & & $\begin{array}{c}\text { Interferiu de } \\
\text { alguma forma }\end{array}$ & & $\begin{array}{c}\text { Não consegui } \\
\text { comandar }\end{array}$ \\
\hline
\end{tabular}

18. Quanto você conseguiu se concentrar efetivamente na direção, ao invés de desviar a atenção para os mecanismos de direção?

\begin{tabular}{|c|c|c|c|c|c|c|}
\hline $\begin{array}{c}\text { Desviei muito } \\
\text { a atenção }\end{array}$ & Algumas vezzes & & & $\begin{array}{c}\text { Totalmente } \\
\text { concentrado }\end{array}$ \\
\hline
\end{tabular}

19. Em que nivel o aspecto auditivo (apenas) conseguiu te envolver no ambiente?

\begin{tabular}{|l|l|l|l|l|l|l|}
\hline Nenhum & & & $\begin{array}{c}\text { Algum } \\
\text { envolvimento }\end{array}$ & & & Completamente \\
\hline
\end{tabular}

20. Quão bem você conseguiu identificar os sons?

\begin{tabular}{|c|l|l|c|l|l|c|}
\hline $\begin{array}{c}\text { Nắ } \\
\text { identifiquei }\end{array}$ & & $\begin{array}{c}\text { Identifiquei } \\
\text { alguns }\end{array}$ & & & $\begin{array}{c}\text { Identifiquei } \\
\text { claramente }\end{array}$ \\
\hline
\end{tabular}

21. Quão bem você conseguiu identificar as origens dos sons?

\begin{tabular}{|c|c|c|c|c|c|c|}
\hline $\begin{array}{c}\text { Nầ } \\
\text { identifiquei }\end{array}$ & $\begin{array}{c}\text { Identifiquei } \\
\text { alguns }\end{array}$ & & $\begin{array}{c}\text { Identifiquei } \\
\text { todos }\end{array}$ \\
\hline
\end{tabular}


Procedimentos:
1. Saudações
2. TCLE
3. Primeiro questionário
4. Treinamento (Régis)
5. Calibração do Smart-Eye
6. Trecho definitivo segundo ordem abaixo
7. Segundo questionário
8. Agradecimento

\section{Recomendações:}

1. Sem conversa durante a realização da tarefa.

2. GRAVAR o arquivo do VTD

3. GRAVAR o arquivo do Smart-Eye

4. Exportar arquivo do Smart-Eye com Gaze

Informações aos condutores:

1. Pedais $\rightarrow$ Somente freio e acelerador

2. Troca de marchas na borboleta atrás do volante (Marcha mais direita e marcha menos esquerda)

3. A duração das simulações durará 10 minutos no treinamento e 15 minutos no cenário final

4. Se houver qualquer incomodo, por favor avisar, a simulação será pausada ou cancelada.

5. Dirija como se estivesse em um cenário como o que é apresentado na tela, da maneira mais natural possível, como se estivesse viajando em uma rodovia.

\begin{tabular}{|c|c|c|c|c|c|}
\hline \multicolumn{2}{|c|}{ Primeira rodada } & \multicolumn{2}{|c|}{ Segunda rodada } & \multicolumn{2}{|c|}{ Terceira rodada } \\
\hline 0.30 & 5 & 0.22 & 1 & 0.05 & 3 \\
\hline 0.31 & 7 & 0.25 & 3 & 0.12 & 4 \\
\hline 0.39 & 4 & 0.31 & 6 & 0.14 & 9 \\
\hline 0.44 & 6 & 0.31 & 4 & 0.25 & 8 \\
\hline 0.47 & 3 & 0.54 & 8 & 0.26 & 2 \\
\hline 0.51 & 1 & 0.63 & 7 & 0.34 & 7 \\
\hline 0.55 & 2 & 0.76 & 5 & 0.46 & 5 \\
\hline 0.67 & 8 & 0.76 & 9 & 0.65 & 6 \\
\hline 0.89 & 9 & 0.97 & 2 & 0.71 & 1 \\
\hline
\end{tabular}

